\title{
NUCLEAR REACTORS \\ and \\ EARTHQUAKES
}

428 Pgs.

Issuance Date: August 1963

Prepared by Lockheed Aircraft Corporation and Holmes \& Narver, Inc., for the Division of Reactor Development

UNITED STATES ATOMIC ENERGY COMMISSION Division of Reactor Development Washington, D. C.

This document is FUPLICLY RELEASABLE Nikineur 


\section{DISCLAIMER}

This report was prepared as an account of work sponsored by an agency of the United States Government. Neither the United States Government nor any agency Thereof, nor any of their employees, makes any warranty, express or implied, or assumes any legal liability or responsibility for the accuracy, completeness, or usefulness of any information, apparatus, product, or process disclosed, or represents that its use would not infringe privately owned rights. Reference herein to any specific commercial product, process, or service by trade name, trademark, manufacturer, or otherwise does not necessarily constitute or imply its endorsement, recommendation, or favoring by the United States Government or any agency thereof. The views and opinions of authors expressed herein do not necessarily state or reflect those of the United States Government or any agency thereof. 


\section{DISCLAIMER}

Portions of this document may be illegible in electronic image products. Images are produced from the best available original document. 


\section{INTRODUCTION}

This report has been prepared for the U. S. Atomic Energy Commission by personnel of Lockheed Aircraft Corporation and Holmes \& Narver. Inc. It is intended to supply pertinent seismological information to engineers in the nuclear reactor field. Included are historical data on occurrence, intensity, and wave shapes. Includedarso are some techniques for evaluating the response of structures to such events. A brief discussion of certain reactor types and modes of operation is included to provide architectural. structural, and mechanical engineers with an insight into the design requirements of the industry.

Although infrequent. earthquake effects on reactors should not be separated from the general problem of reactor safety. Seismology and geology should enter the earliest site-selection considerations. A criterion of possible earthquake damage should be determined prior to final design. and the effects of earth motion should be evaluated for all components of the plant. This would involve consideration of such items as: an increased possibility of structural failure in the reactor and a possible need for an added degree of containment; control and safety circuitry under vibratory stresses; need for seismoscopes to initiate protective action automatically; regular inspections to assure that plant modifications have not increased seismic vulnerability and special inspections after earthquakes to assess damage; increased susceptibility to failure of components during seismic motion due to aging, fatigue, or irradiation damage. The cost of decreasing the earthquake sensitivity of the plant would have to be balanced against the consequences of its failure. In a properly designed plant, however, it is to be expected that an earthquake will not be a unique and overriding hazard in itself, but it will add to the possibility of mechanical or structural failure, which could lead to more severe consequences.

The authors of this report are T. H. Thomas. G. Yasui, and R. H. Graham of Lockheed Aircraft Corporation and R. A. Williamson, R. E. Lowe, and Warren Hoak of Holmes \& Narver. Inc. B. J. Garrick of Holmes \& Narver. Inc., reviewed the material on reactor safety. The approach to earthquake-resistant structural engineering was guided by G. W. Housner of the California Institute of Technology. C. F. Richter of the California Institute of Technology furnished the domestic and world-wide maps of earthquake incidence. R. B. McCalley. U. S. Atomic Energy Commission. Washington. D. C.. contributed the analytical approach outlined in Appendix E.

The authors would like also to express their appreciation to J. Schlocker of the U. S. Geological Survey at Menlo Park. Calif., for his critical review and many suggestions regarding Chapter 1. Contributions have been made in the areas of seismoscopy by Dean S. Carder and William K. Cloud of the U. S. Coast and Geodetic Survey. In the area of industrial earthquake damage, contributions have been made by Karl Steinbrugge of the Earthquake Engineering Research Institute. George Coltrin of the Pacific Gas and Electric Company. and H. C. Vander Heyden of the Southern California Gas Company. 
Many other individuals and organizations, governmental and industrial, in the fields of seismology, structural engineering. and reactor development have generously assisted whenever contacted.

The accumulation of drafts, assembly of peripheral information, and much of the rewriting of the final manuscript have been by $\mathrm{T}$. H. Thomas. Technical monitors and reviewers for the Division of Reactor Development, U. S. Atomic Energy Commission, have been S. A. Szawlewicz, R. B. McCalley, and R. R. Newton.

Final editing for publication has been performed at the AEC's Division of Technical Information Extension, Oak Ridge, by Mrs. Anne M. Goulden and Miss Ruth N. Bean.

RICHARD H. GRAHAM Lockheed Aircraft Corporation 


\title{
CONTENTS
}

\author{
INTRODUCTION
}

CHAPTER 1 GENERAL EARTHQUAKE CONSIDERATIONS $\cdot \quad . \quad \cdot$

1.1 Characteristics of Strong-motion Earthquakes

A. Faults

B. Tsunami

C. Propagation of Seismic Waves

D. Earthquake Intensity

E. Energy Release and Magnitude

F. Relations Involving Intensity, Acceleration, Magnitude, and Distance

G. Effect of Local Geology

1.2 Seismicity of North America

A. Seismic Zones

B. Important Earthquakes

C. Location of Past Strong Earthquakes

D. Zones of Assessed Seismicity

E. Probability of Occurrence of Earthquakes.

1.3 Response of Structures to Earthquake Ground Motion

A. Single-degree-of -freedom Structure

B. Multidegree-of -freedom Structure . • . . . . . . . 26

C. Earthquake Spectra

D. Spectrum Intensities

E. Vibrational Energy of Structures

F. Effect of Damping

G. Limit-stress Design

H. Building Vibration Records

I. Influence of Foundation Conditions

References

CHAPTER 2 EARTHQUAKE GEOGRAPHY AND REGIONALIZATION

2.1 Acknowledgment

2.2 Earthquake Geography: General Description

A. Scope .

B. Tectonics

2.3 Earthquake Geography: Details .
A. Circum-Pacific Belt
B. Alpide Belt .
C. Eastern Asia Non-Alpide Areas
D. Oceanic Seismic Belts
E. Rift Zones 


\section{CONTENTS (Continued)}

F. Stable Masses .

G. Minor Seismic Areas . . . . . . . . . . . . . $\quad$. 62

H. Summary of Seismicity . . . . . . . . . . . 62

2.4 Seismic Regionalization: General . . . . . . . . . . 63

A. Forms of Presentation . . . . . . . . . . 63

B. Factors Pertinent to Regionalization . . . . . . . . 64

2.5 Seismic Regionalization: Application . . . . . . . . . . . 65

A. Union of Soviet Socialist Republics . . . . . . . . . . 65

B. Los Angeles Basin . . . . . . . . . . . . 65

C. California . . . . . . . . . . . . . . 67

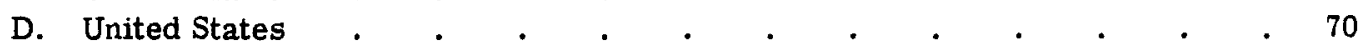

References

CHAPTER 3 BASIC REACTOR TYPES AND POTENTIAL DAMAGES DUE TO EARTHQUAKES

3.1 Description of Reactor Plants

3.2 Specific Types of Reactors
A. Pressurized-water Reactor
B. Boiling-water Reactor
C. Sodium-graphite Reactor
D. Gas-cooled Reactor
E. Fast Reactor
F. Aqueous Homogeneous Reactor.

3.3 Potential Seismic Damages to Reactor Plants

A. Critical Areas of Reactor Systems . . . . . . . . . 111

B. Direct Mechanical Damages . . . . . . . . . . 113

C. Nuclear Damage . . . . . . . . . . . . . . . 113

D. Indirect Damage .

E. Interaction Between Major Plant Components .114

3.4 Relative Susceptibility of Specific Reactor Systems . . . . . . . 116

A. Stationary Medium Power Plant No. 1 . . . . . . . . 116

B. Shippingport Pressurized-water Reactor . . . . . . . 116

C. Experimental Boiling-water Reactor . . . . . . . . . 116

D. Sodium Reactor Experiment . . . . . . . . . 117

E. Gas-cooled Reactor No. 2 . . . . . . . . . . . . . 117

F. Experimental Breeder Reactor No. 2 . . . . . . . . . 118

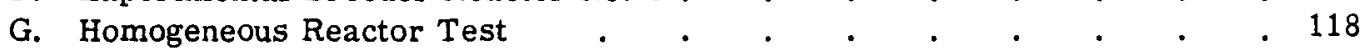

References

CHAPTER 4 GENERAL STRUCTURAL DESIGN CONSIDERATIONS $\quad$. . . . . 123

4.1 General Objectives of the Design . . . . . . . . . . . 123

4.2 Damage Minimization vs. Economic Considerations . . . . . . . 123

4.3 Adequacy of Seismic Provisions in Building Codes . . . . . . . . 123

4.4 Structural Features Contributing to Seismic Resistance . . . . . . . 124
A. Bracing System.
B. Low Mass
C. Ductility
D. Adequate Construction Methods .
E. Adequate Foundations .
F. Damping
G. Structural Symmetry .
H. Separation of Adjacent Structures 


\section{CONTENTS (Continued)}

I. Details Allowing Structural Movement Without Damage to Nonstructural Elements

4.5 Structural Features Contributing to Seismic Damage _ . . . . . 125

4.6 Static Method of Design . . . . . . . . . . . . . . . . 126

A. Lateral Forces on Main Structure . . . . . . . . . . . 126

B. Lateral Forces on Parts of the Structure . . . . . . . . 126

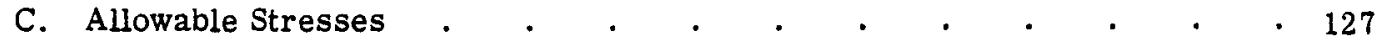

D. General Methods for Design of Structural Elements . . . . $\quad 127$

4.7 Design of Foundations

A. Overstressing of the Soil . . . . . . . . . . . . . . . $\quad . \quad 127$

B. Consolidation and Differential Settlement . $\quad . \quad$. $\quad . \quad$. $\quad . \quad$. 127

4.8 Relative Motion Between Structures and Parts of Structures . . . . $\quad$. 128

A. Separation Joints . . . . . . . . . . . . . . 128

B. Flexible Couplings . . . . . . . . . . . . . 128

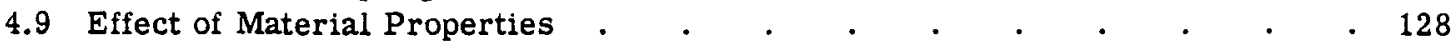

A. Ductility . . . . . . . . . . . . . . . 128

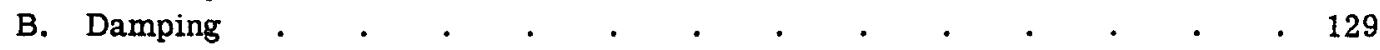

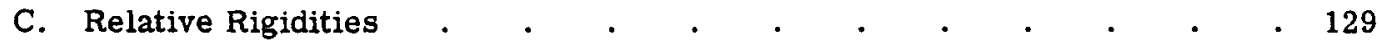

4.10 Specific Design Details Important to Earthquake Resistance . . . . . 130

A. Structural-steel Details . . . . . . . . . . . 130

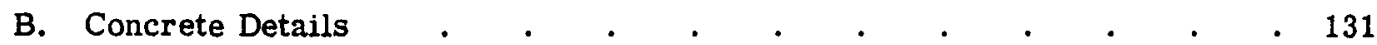

C. Foundations . . . . . . . . . . . . . . . . 133

D. Structural Separation . . . . . . . . . . . . . 133

E. Other Provisions for Relative Motion . . . . . . . . . . 133

4.11 Typical Building-code Requirements in Earthquake Regions . . . . . 133

A. Scope . . . . . . . . . . . . ., 133

B. Working Stresses Used in Seismic Desıgn . . . . . . . . . $\quad 135$

C. Preparation of Plans and Construction Inspection . . . . . . $\quad . \quad 135$

D. Earthquake Design Loads . . . . . . . . . . . 135

E. Overturning Moments . . . . . . . . . . . . . . 138

F. Distribution of Horizontal Shear . . . . . . . . . . . . 138

G. Deflections . . . . . . . . . . . . . . . 138

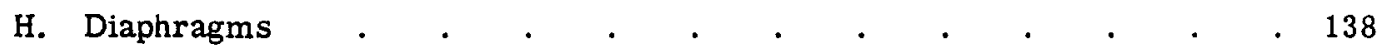

I. Masonry Shear Walls . . . . . . . . . . . 141

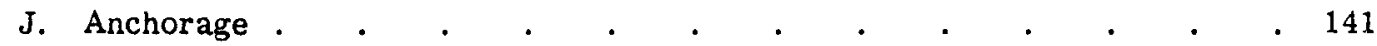

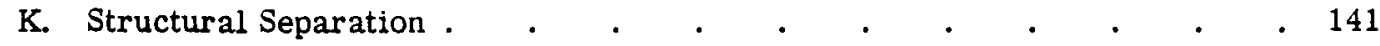

L. Foundation Ties . . . . . . . . . . . . . . . 141

4.12 Relation of Building Codes to Reactor Design . . . . . . . . . . $\quad$. 142

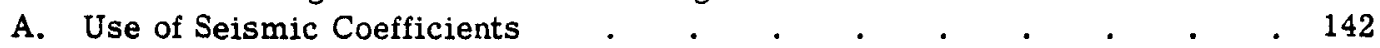

B. Seismic Zoning Provisions . . . . . . . . . . . . . 142

C. Detailed Seismic Provisions of Codes . . . . . . . . . 144

References OF STRUCTURES

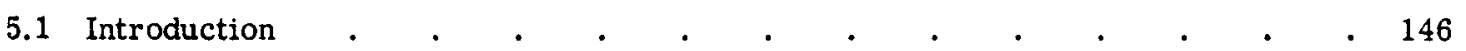

5.2 Considerations in Using the Spectrum Method . . . . . . . . 147

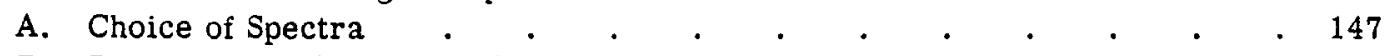

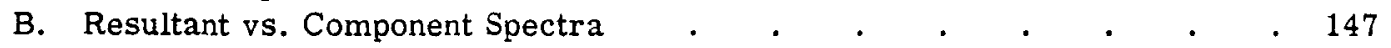

C. Damping Factors

D. Structures and Equivalent Models

5.3 Rigid-body Structures

Example 1. 


\section{CONTENTS (Continued)}

5.4 Structures with One Degree of Freedom . $\quad . \quad$. $\quad . \quad \cdot \quad \cdot \quad \cdot \quad$. 153

Example 2 .

5.5 Structures with Two Degrees of Freedom .

A. Periods of Vibration and Mode Shapes

B. Maximum Response

C. Example 3 .

5.6 Elastic Flexural Members.

A. Equations for Flexural Members

B. Example 4 .

5.7 Limit-design Approach

A. Energy Considerations

B. Ductility

C. Plastic Strain Reversal

D. Instability

E. Safety Factor

F. Procedure.

G. Example 5 .

5.8 Special Considerations in Designing Seismic-resistant Nuclear-reactor Structures

A. Seismic -resistance Requirements

B. Static, Dynamic, and Limit-design Methods . . . . . . . 177

C. Vessels and Shells

D. Shielding Structures

E. Exhaust Stacks

F. Auxiliary Structures

G. Equipment and Piping .

References

CHAPTER 6 DYNAMIC PRESSURE ON FLUID CONTAINERS $\quad . \quad$. $\quad . \quad$. $\quad$. 183

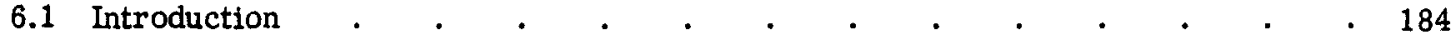

6.2 General Approach . . . . . . . . . . . . . . . . . . 185

6.3 Formulas for Tanks Supported on the Ground . . . . . . . . 185

6.4 Tanks Supported on the Ground $(\mathrm{h} / \mathrm{l}$ or $\mathrm{h} / \mathrm{R} \leq 1.5) \quad$. . . . . . . 187

Example 1. . . . . . . . . . . . . . 188

6.5 Procedure for Slender Tanks Supported on the Ground ( $h / l$ or $h / R>1.5)$. . 191

Example 2 . . . . . . . . . . . . . . 192

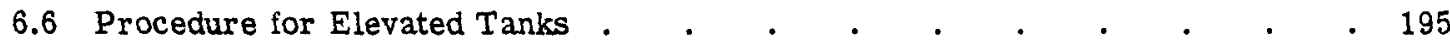

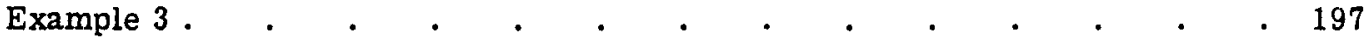

6.7 Special Considerations in Designing Seismic-resistant Fluid

Containers. . . . . . . . • • . • . . 201

6.8 Curves for Tanks Supported on the Ground . . . . . . . . . 203

References . . . . . . . . . . . . . . 209

CHAPTER 7 REACTOR HAZARDS AND THEIR DEPENDENCE ON

EARTHQUAKES . . . . . . . . . . . . 210

7.1 General Considerations for Reactor Safety . . . . . . . . 210

7.2 Earthquakes as Causes of Reactor Failures . . . . . . . . . . 212

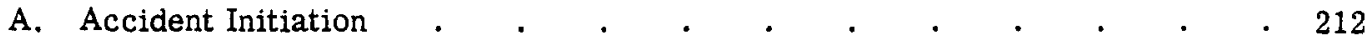

B. Power Increase . . . . . . . . . . . . . . 212

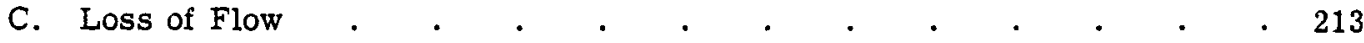

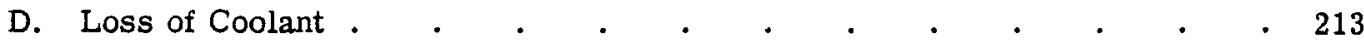




\section{CONTENTS (Continued)}

7.3 Energy Sources and Release Mechanisms

A. Nuclear Energy Sources

B. Stored Energy

C. Chemical Energy Sources

D. Contamination Release

7.4 Typical Maximum Credible Accidents

A Shippingport Pressurized-water Rea

B. Stationary Medium Power Plant No. 1. . . . . . . . . . 222

C. Experimental Boiling-water Reactor . . . . . . . . . 222

D. Experimental Breeder Reactor No. 2 . . . . . . . . . 223

E. Organic-moderated Reactor Experiment . . . . . . . . . 225

F. NASA Engineering Test Reactor . . . . . . . . . 225

7.5 Earthquakes and Power-distribution Networks . . . . . . . . 227

7.6 Seismology and the New Reactor Project . . . . . . . . . . . 228

7.7 Operating Practices Pertinent to Earthquakes . . . . . . . . . . 229

A. Continued Operation During an Earthquake . . . . . . . 230

B. Programmed Shutdown . . . . . . . . . . . 231

References

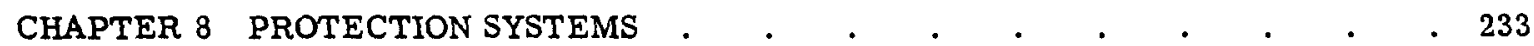

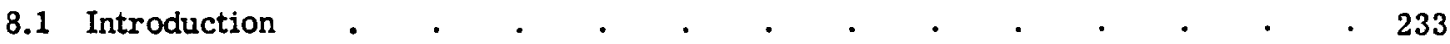

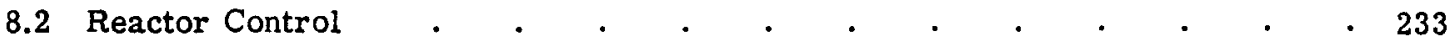

A. Inherent Mechanisms . . . . . . . . . . . . . . 233

B. Contrived Mechanisms . $\quad . \quad$. $\quad . \quad$. $\quad . \quad$. $\quad . \quad$. 234

8.3 Seismic Sensitivity of Control-rod Types . . . . . . . . . . . 235

A. Freely Falling Rods . . . . . . . . . . . . 235

B. Friction Damped Rods . . . . . . . . . . . . 235

C. Mechanically Driven Rods . . . . . . . . . . . . . 236

D. Controlled Drop Rods . . . . . . . . . . . . 237

E. Control-rod Whip During an Earthquake . . . . . . . 237

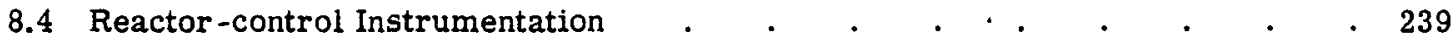

A. Startup . . . . . . . . . . . . . . . . . $\quad . \quad 239$

B. Intermediate Power Range . . . . . . . . . . . . 240

C. Full Power .

D. Seismic Sensitivity

8.5 Seismometers

8.6 Current Earthquake-protection Systems . . . . . . . . . . . 242

A. Aerojet-General Nucleonics . . . . . . . . . . . 242

B. General Electric Company, Vallecitos Atomic Laboratory . . . . 242

C. Atomics International . . . . . . . . . . . . . 243

D. American-Standard, Advanced Technology Laboratories . . . . 243

E. University of California Lawrence Radiation Laboratory . . . . 243

F. Hanford Production Reactors . . . . . . . . . . 243

G. Savannah River Production Reactors . . . . . . . . . 244

8.7 Recommended Earthquake Instrumentation . . . . . . . . . . . 244

References . . . . . . . . . . . . . . 245

APPENDIX A SEISMIC CONSIDERATIONS PERTINENT TO THE STATIONARY

MEDIUM POWER PLANT NO. 1 .

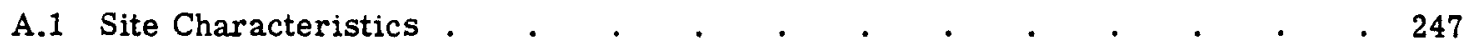

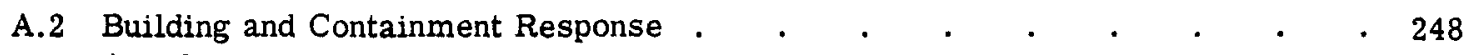

A. Containment Vessel . $. \quad . \quad . \quad . \quad . \quad . \quad . \quad . \quad . \quad . \quad 248$ 


\section{CONTENTS (Continued)}

B. Primary System . . . . . . . . . . . . 251

C. Primary Shielding . . . . . . . . . . . . 252

D. Turbine and Generator Support . . . . . . . . . . 253

E. Operations Building Framing . . . . . . . . . . . 253

F. Significance of Overstress . . . . . . . . . . . . . . 254

G. Static Resistance of Equipment Items . . . . . . . . . . 254

A.3 Reactor System . . . . . . . . . . . . . . . . . 254

A. Control Rods . . . . . . . . . . . . . . . 255

B. Loss of Power During Earthquakes . . . . . . . . 255

C. Loss of Heat Sink During Earthquakes . . . . . . . . . 255

D. Transient Load Demand During Earthquakes . . . . . . . 255

E. Nuclear Perturbations . . . . . . . . . . . 255

F. Energy Release . . . . . . . . . . . . . 255

A.4 Standard Operating Procedure with Respect to Earthquakes . . . . 256

A.5 Structural Calculations . . . . . . . . . . . . . 256

APPENDIX B SEISMIC CONSIDERATIONS PERTINENT TO THE EXPERIMENTAL BOILING-WATER REACTOR . . . . . . . . . . . 303

B.1 Site Characteristics . . . . . . . . . . . . 303

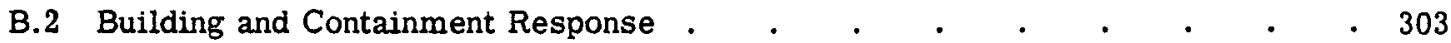

A. Containment Vessel . . . . . . . . . . . . . . 304

B. Equipment and Supports . . . . . . . . . . . . 306

C. Piping Stresses . . . . . . . . . . . . . . . 307

D. Service Building . . . . . . . . . . . . 308

E. Significance of Overstress . . . . . . . . . . . . . 309

F. Static Resistance of Equipment Items . . . . . . . . . . $\quad$. 309

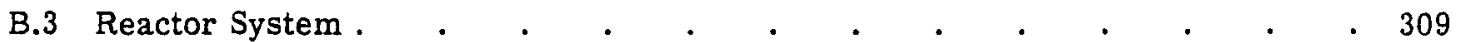

A. Nuclear Perturbations . . . . . . . . . . . . . . 309

B. Control Rods . . . . . . . . . . . . . 310

C. Core Structure . . . . . . . . . . . . . . . . 310

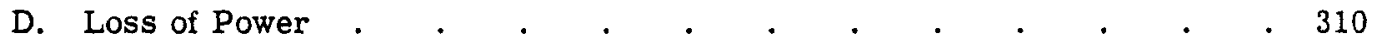

E. Failure of Steam System . . . . . . . . . . . . . . 310

F. Transient Load Demand . . . . . . . . . . . . 310

G. Energy Release . . . . . . . . . . . . . 311

H. Emergency Shutdown and Cooling System . . . . . . . 311

I. Fuel-transfer System .

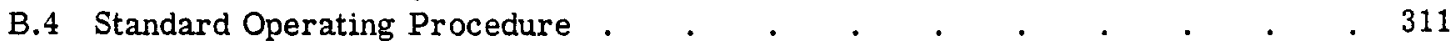

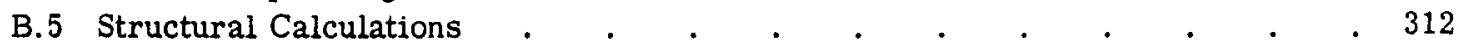

References

APPENDIX C EARTHQUAKE EXPERIENCE IN UTILITIES AND INDUSTRIAL PIANTS.

C.1 Introduction

C.2 Steam-Electric Power Stations
A. Plant 1
B. Plants 2 and 3
C. Plant 4
D. Plants 5 and 6

C.3 Oil Refineries

References. 


\section{CONTENTS (Continued)}

APPENDIX D EARTHQUAKE EXPERIENCE IN EXISTING REACTOR PLANTS

D.1 Introduction . . . . . . . . . . . .

D.2 Aerojet-General Nucleonics $\quad$. $\quad$. $\quad$. $\quad . \quad$. $\quad . \quad$. . . . 351

D.3 General Electric Company, Vallecitos Atomic Laboratory _ . . . . 351

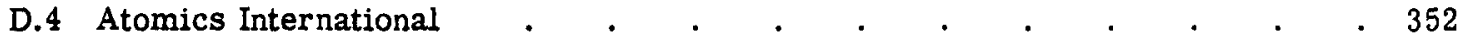

D.5 American-Standard, Advanced Technology Laboratories . . . . . . 352

D.6 Hanford Works . $. \quad . \quad . \quad . \quad . \quad . \quad . \quad . \quad . \quad . \quad . \quad .352$

D.7 Savannah River Production Reactors . . . . . . . . . . . . . 352

References . . . . . . . . . . 352

APPENDIX E MATRIX FORMAT FOR ANALYSIS OF TRANSIENT RESPONSE OF LINEAR UNDAMPED SYSTEMS . . . . . . . . . . 353

E.1 General . . . . . . . . . . . . . . 353

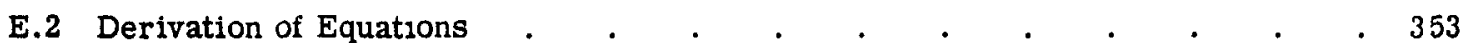

E.3 Calculation of Nondominant Frequencies and Modes . . . . . . . . 356

E.4 Simple Numerical Example . . . . . . . . . . . . . . . 359

References . . . . . . . . . . . . . . 366

APPENDIX F DYNAMIC ANALYSIS OF FLUIDS IN CONTAINERS SUBJECTED TO ACCELERATION . . . . . . . . . . . . . 367

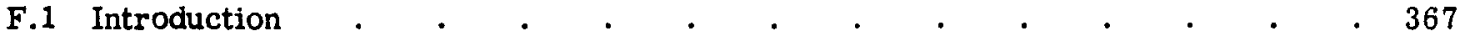

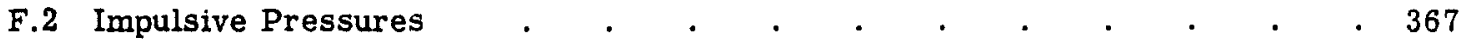

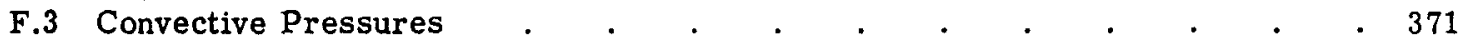

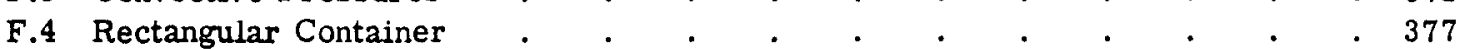

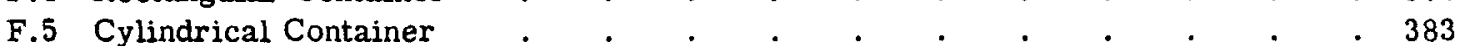

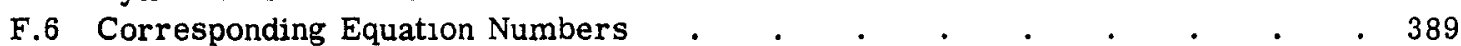

References . . . . . . . . . . . . . 390

APPENDIX G MISCELLANEOUS DERIVATIONS . . . . . . . . . . 391

G.1 Behavior of a Single-degree-of-freedom System _ . . . . . . . . 391

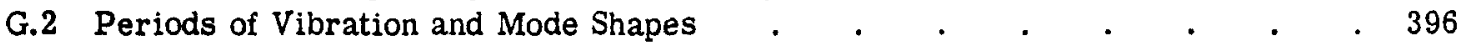

G.3 Derivation of Frequency Equation for a System with Two Degrees of
Freedom . . . . . . . . . 399

G.4 Derivation of Participation Factor for a System with Two Degrees of 401

References . . . . . . . . . . . . . . . . . . 401

$\begin{array}{lll}\text { APPENDIX H } & \text { SEISMIC CONSIDERATIONS PERTINENT TO THE ORNL } \\ \text { PROPOSED GAS-COOLED REACTOR NO. } 2 & \cdot . & .\end{array}$

H.1 Introduction . . . . . . . . . . . . . . . 403

H.2 Graphite Core . . . . . . . . . . . . . . . . 403

A. Restraint by Garter Rings . . . . . . . . . . 403

B. Restraint by Shear Keys . . . . . . . . . . . . 404

C. Horizontal Shear Transfer . . . . . . . . . . . . 404

D. Uplift . . . . . . . . . . . . . . . . 404

E. Miscellaneous . . . . . . . . . . . . . . . 405

F. Radiation Effects on Graphite (General) . . . . . . . 405

H.3 Pressure Vessel and Thermal Support Sleeve . . . . . . . . 407

A. Pressure-vessel Stresses . . . . . . . . . 408

B. Support-sleeve Stresses . . . . . . . . . . . . . 408 


\section{CONTENTS (Continued)}

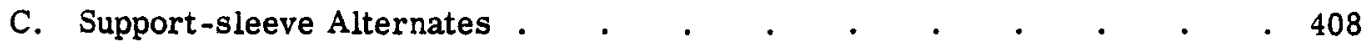

D. System Deflections . . . . . . . . . . . . 409

H.4 Primary System: Deflection-induced Leakage . . . . . . . . . . 409

H.5 Fuel-element and Control-rod Malfunction . . . . . . . . . 409

A. Fuel-element Jamming . . . . . . . . . . . . . . 409

B. Control-rod Malfunction . . . . . . . . . . . . 409

C. Control-rod Suspension . . . . . . . . . . . . . . 409

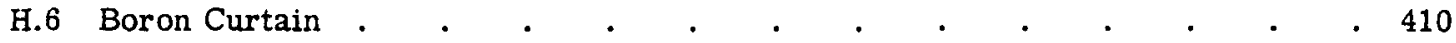

H.7 Fuel Transfer to Pond . . . . . . . . . . . . . . . 410

H.8 Top Biological Shield in Seismic Integrity . . . . . . . . . . . . 410

References . . . . . . . . . . . . . . . 410

INDEX

411 


\section{Chapter 1}

\section{GENERAL EARTHQUAKE CONSIDERATIONS}

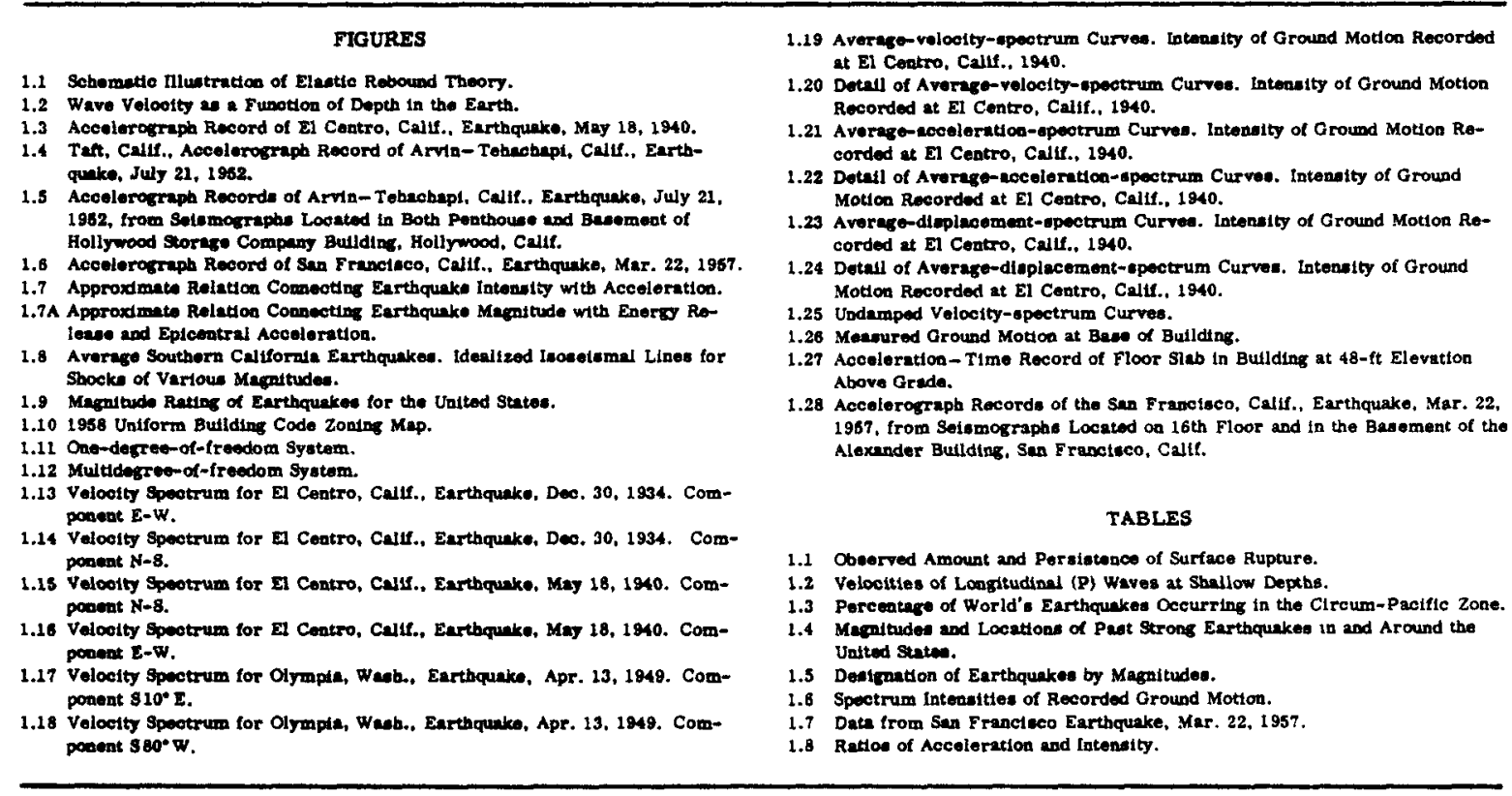

\subsection{CHARACTERISTICS OF STRONG-MOTION EARTHQUAKES}

In the past half century, which represents the era of modern seismology, it has been observed that most earthquakes occurring in this period originated in either the crust or the mantle of the earth at depths varying from a few to several hundred miles. ${ }^{1.1,1.2}$ These are so-called tectonic earthquakes because their origin can be correlated with deformation such as ruptures or faults. Other types of earthquakes, such as those associated with volcanic activity, landslides, and collapse of caverns, are not as well understood as the tectonic type but are of less practical interest since their occurrence is relatively infrequent, representing a minor fraction of the observed seismic activity of the earth.

Geophysical observations, particularly records of earthquakes, suggest this picture of the interior of the earth. The crust is a relatively thin, brittle outer shell, varying from a thickness of a few miles ( 7 to 11 miles average) under oceans to an average of 21 miles under continental masses. Under some mountain ranges the depth may be nearly 40 miles. The crust lies on the mantle, which extends to a depth of 1800 miles and con- 
stitutes more than $80 \%$ of the earth's volume. The mantle, in turn, surrounds the core. The average density of each layer, according to the American Geological Data Sheet Committee (1958 A6-19), is as follows: crust, $2.84 \mathrm{~g} / \mathrm{cm}^{3}$; mantle, $4.93 \mathrm{~g} / \mathrm{cm}^{3}$; and core, $10.93 \mathrm{~g} / \mathrm{cm}^{3}$.

There is disagreement concerning the physical state (solid vs. liquid) of the two inner regions, but the present trend of opinion is certainly toward a solid mantle and a liquid core. ${ }^{1.3}$ The doubt comes from the present lack of knowledge concerning properties of solids and liquids at the high pressures and temperatures that exist in the interior of the earth. Nevertheless, isostatic balance of high mountains and low valleys, disclosed by gravity measurements, indicates that the mantle is more or less plastic beyond a depth of about 60 miles below sea level. Rigid properties of the mantle, however, are indicated by deep-focus earthquakes arising from ruptures at depths as great as 435 miles below sea level. Further evidence is provided by the ability of the mantle to transmit, throughout its thickness, transverse seismic waves, which appear as shear displacements at right angles to the direction of propagation. Experimental evidence exists for the belief that material with little or no strength, but with high viscosity, can be ruptured and sheared. ${ }^{1.4}$ In contrast, the core does not transmit transverse seismic waves and is therefore considered to be fluid.

The crust and the rigid upper part of the mantle are in a continual state of deformation owing possibly to contraction from cooling, fluid drag from convection currents in the plastic part of the mantle and in the core, or from other unidentified forces of a thermal nature such as radioactive decay. As a result of these forces, strains that slowly accumulate in the crust and mantle are suddenly relieved by rupturing (faulting) at specific points, mostly in the heterogeneous outer regions of the crust and mantle. From this rupturing large amounts of stored energy are released. The portion of this energy transmitted as vibrations, particularly in the crust, gives rise to the commotion known as an earthquake.

The tectonic viewpoint is strongly supported by specific examples such as the 1906 San Francisco earthquake. Records for 50 years prior to the event reveal that triangulation monuments in the area changed position measurably, suggesting slow movement of adjacent crustal blocks along the San Andreas fault. After the earthquake, which resulted in horizontal displacements along the fault as great as $21 \mathrm{ft}, \mathrm{H}$. F. Reid ${ }^{1.2}$ proposed in his elastic rebound theory that strains in the tightly locked fault, as the result of the observed relative motion of the adjacent crustal blocks, gradually accumulated until the strength of the rock was exceeded, as shown schematically in Fig. 1.1. This resulted in a sudden slip, or elastic rebound, along a plane of weakness.

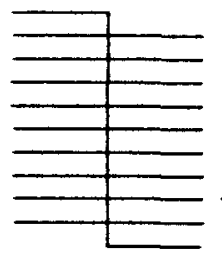

(A)

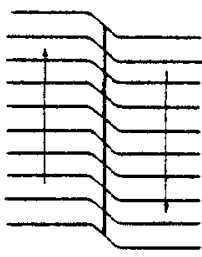

(B)

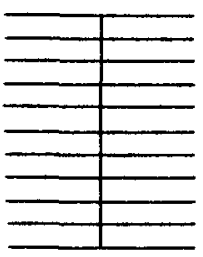

(C)
Fig. 1.1 - Schematic illustration of elastic rebound theory. A, unstrained blocks. B, strain condition preceding earthquake. C, configuration just after earthquake. (Data from Ref. 1.2.)

The numerous aftershocks usually accompanying earthquakes may be accounted for by this theory since it is plausible that the rebound motion either stops short of equilibrium displacement or continues beyond, leaving residual strain energy sufficient to cause later shocks of lesser magnitude along the weakened fault. Similarly, foreshocks, which often precede large earthquakes, are assumed to increase the accumulated stress at the focus, setting the stage for the main shock. 


\section{A. Faults}

The rough plane of weakness between adjacent crustal blocks is commonly referred to as a fault. A fault trace is the line of intersection of this plane with the earth's surface. The strike of a fault is the orientation with respect to longitude (angle from north) of the line of intersection of the fault plane and a horizontal plane. The dip of a fault is the acute angle between the fault plane and a horizontal plane. It is measured in the plane perpendicular to the strike. The focus or hypocenter of an earthquake is the point at which fracture first occurs on the fault. The epicenter is a point on the earth's surface directly above the focus, so that if the fault plane is inclined the epicenter will not be on the fault trace. For purposes of this document the term center is defined as the location of the center of the slipped area of the fault.

Sudden slippage on faults is the origin of the large majority of earthquakes. Volcanism accounts for most of the rest. According to C. F. Richter, conclusive surface evidence of faulting has been associated with earthquakes in only about 20 instances throughout the world. ${ }^{1.2}$ Despite the lack of surface evidence, the relative directions of slip on the two faces of a subsurface fault can be deduced from seismographs, and these observations indicate that destructive earthquakes in the western United States are caused by fault slipping.

Most earthquakes, including those most destructive, are shallow shocks originating in the upper 20 miles of the earth's crust. This is attributed to the brittle and heterogeneous nature of the material in this zone, which does not permit large deformations without rupture. The initial fracture usually starts at a depth of about 10 miles, and the slip zone rarely reaches the surface. In small earthquakes the slippage is confined to a local zone, which may be regarded as a point source, and the resulting ground motion is limited to a relatively small theoretically circular area. In large earthquakes the initial slippage, originating at a point source, is propagated along the fault plane, resulting in a larger and generally elongated area of strong ground motion.

Earthquakes may occur at depths greater than 20 miles. Gutenberg and Richter ${ }^{1.1}$ classify shallow and intermediate shocks as those originating at depths less than 40 miles and 200 miles, respectively, and deep shocks as those originating below 200 miles. Frequency of occurrence decreases with depth; intermediate and deep shocks are rarely destructive.

Surface rupturing along a fault trace may extend as much as several hundred miles as observed in the San Francisco shock ${ }^{1.2}$ of 1906 . Generally the amount and extent of surface rupture is directly proportional to the intensity of the earthquake, inasmuch as both are related to the slippage that takes place along faults at depths of several miles or more. At these depths the crustal rocks are more consolidated, less fractured, and less altered compared to rocks at or near the surface. In a region where a thick surface blanket of poorly to moderately consolidated sediments exist, such as in a wide, deeply alluviated valley, the slippage of deeply buried crustal blocks may be accommodated in the surficial blanket by widespread but minor rupturing, by folding or wrinkling, or by readjustment in the packing of grains. Thus no well-defined surface rupture may be found for destructive shocks in such areas. Examples are the earthquakes at Santa Barbara, Calif. (1925) and at Long Beach, Calif. (1933).

Destructive earthquakes in the western United States have originated from faults showing surface rupture that varies from predominately horizontal to predominately vertical. Both horizontal and vertical components are seen along some faults.

The observed amount and persistence of surface rupture associated with several strong earthquakes ${ }^{1.5}$ are shown in Table 1.1 .

Surface rupturing associated with strong earthquakes may be very complex. It may take the form of wide zones of small fissures in which individual offsets vary from an inch to a few feet. The zones may follow known faults or may have a straight or arcuate alignment unrelated to known faults. Fissures within the zones may have an echelon 
arrangement or have different trends, and the displacements on them may be in diverse directions. Examples of this type are described in considerable detail for the Fukui, Japan, earthquake ${ }^{1.6}$ of 1948 and the Kern County, Calif., earthquakes ${ }^{1.7}$ of 1952.

Precise resurveying of bench marks and triangulation points is exceedingly useful in revealing earth movements in connection with faulting and earthquakes. They generally show a more consistent and simpler pattern of movement than that shcwn by complex surface ruptures. ${ }^{1.6,1.7}$

Table 1.1 - OBSERVED AMOUNT AND PERSISTENCE OF SURFACE RUPTURE

\begin{tabular}{|c|c|c|c|c|}
\hline \multirow[b]{2}{*}{ Earthquake } & \multirow[b]{2}{*}{ Date } & \multicolumn{2}{|c|}{$\begin{array}{l}\text { Maximum observed offset } \\
\text { along fault trace, } \mathrm{ft}\end{array}$} & \multirow{2}{*}{$\begin{array}{l}\text { Length of } \\
\text { rupture, miles }\end{array}$} \\
\hline & & Horizontal & Vertical & \\
\hline Nagano, Japan & 1847 & & 9 & 5 \\
\hline \multicolumn{5}{|l|}{ Owens Valley, } \\
\hline Calif. & 1872 & 20 & 23 & 40 \\
\hline Japan & 1891 & 13 & 19 & 60 \\
\hline Assam & & & 35 & 12 \\
\hline \multicolumn{5}{|l|}{ Yakutat Bay, } \\
\hline Alaska & 1899 & & 47 & \\
\hline Formosa & 1906 & 8 & 6 & 30 \\
\hline $\begin{array}{l}\text { San Francisco, } \\
\text { Calif. }\end{array}$ & 1906 & 21 & 3 & 270 \\
\hline Pleasant Valley, & & & & \\
\hline $\begin{array}{l}\text { Nev. } \\
\text { Hawke's Bay, }\end{array}$ & 1915 & & 15 & 22 \\
\hline New Zealand & 1931 & 6 & 9 & \\
\hline E1 Centro, Calif. & 1940 & 15 & Small & 45 \\
\hline
\end{tabular}

B. Tsunami

Tsunami, often miscalled tidal waves, are large sea waves associated with earthquakes. They are assumed to be produced by shallow-focus earthquakes under the ocean bottom although some have been associated with seisms of inland origin. Waves can be very massive and appear suddenly with no associated meteorological activity.

These waves, when traversing the open sea, measure several miles from crest to crest and move at velocities of 400 to $500 \mathrm{miles} / \mathrm{hr}$. They create no hazard for ships in their path but can cause severe damage as they pile up in shallow water and enter bays, fjords, and narrow estuaries. A tsunami with a wave height of $210 \mathrm{ft}$ reached Cape Lopatka on the Kamchatka Peninsula in 1737.

Tsunami are potential sources of damage to tidewater nuclear power plants, as well as other coastal installations. A tsunami warning net, including Hawaii and the western coast of the United States, is in operation. Although intense weather systems create microseismic activity, tsunami appear out of the sea usually unannounced by local phenomena, other than seismographic evidence of a distant earthquake. Sometimes the sea withdraws from the coast prior to arrival of the wave; although this is not a reliable precursor. The seismograph stations in the warning net announce detection of severe local earthquakes. Tide gauge stations watch for abnormal fluctuations. If such occur, a tsunami warning is broadcast to coastal regions that are potentially afflicted. This technque allows sufficient warning time to prevent loss of life in distant areas; although property damage may be severe since tsunami travel for thousands of miles without appreciable attenuation. 
The Pacific Ocean is estimated ${ }^{1.8}$ to have one or two tsunami per year, but usually these are quite small.

\section{Propagation of Seismic Waves}

Seismic waves travel at varying speeds. These speeds depend on the properties of the transmitting medium. In soft alluvium the velocity of seismic waves may be as low as $0.3 \mathrm{mile} / \mathrm{sec}$, and in very firm alluvium the velocity may reach values of 0.9 to 1.2 miles/sec. Where velocities are stated in miles per second, statute miles are implied rather than nautical miles.

The seismic disturbance is propagated from the fault in two principal wave types: longitudinal, or $\mathrm{P}$ waves (dilatational), and transverse, or $\mathrm{S}$ waves (shear). The velocity of $S$ waves is less than that of the $P$ waves. Longitudinal waves have the compressionrarefaction vibration characteristics of sound waves, with frequencies that are sometimes audible. ${ }^{1.9}$

Transverse waves have shear strain characteristics, vibrating the soil particles in a plane normal to the direction of propagation. The theoretical velocities of these two types of waves, based on the idealized assumption of an infinite, homogeneous elastic medium, are given by the following expressions: 1.10

$$
\begin{aligned}
& v_{p}=\sqrt{\frac{(1-\sigma) E}{(1+\sigma)(1-2 \sigma) \rho}} \\
& v_{s}=\sqrt{\frac{E}{2(1+\sigma) \rho}}
\end{aligned}
$$

In Eqs. 1.1 and 1.2, $v_{p}$ and $v_{s}$ are the velocities of the $P$ and $S$ waves, respectively. For the particular medium, $E$ is the modulus of elasticity, $\sigma$ is Poisson's ratio, and $\rho$ is the mass density.

The velocity of these two types of waves in rock varies with depth below the earth's surface as shown in Fig. 1.2. The core, with the possible exception of the inner portion, does not transmit $S$ waves. For this reason the plot of the $S$ waves is shown as terminating at the interface between mantle and core. The velocities of $P$ waves through various materials are shown in Table 1.2.

Those $\mathrm{P}$ and $\mathrm{S}$ waves reaching the surface near the epicenter generate two other wave types, called Rayleigh waves $(R)$ and Love waves (L), which travel along the surface. The $R$ wave produces an elliptical surface motion in a vertical plane containing the source and the point of observation; whereas the $L$ wave is a shear type (transverse) wave vibrating in a horizontal plane. Surface reflection of $P$ and $S$ waves can also occur. $P$ and $S$ waves after one reflection are called PP and SS; and after two reflections they are called PPP and SSS. Reflection of $P$ waves in the form of $S$ waves is also possible. The resulting wave is designated PS, and, if it has a reverse history, it is designated SP. Differences in arrival times of the various wave types form the basis for locating epicenters.

The amplitudes of $S$ waves are usually much greater than those of the $P$ waves. The amplitudes of seismic waves in general decrease rapidly with the distance traveled while the periods increase. In the epicentral regions the shorter period wave components decay with distance much more rapidly than the longer period components. Thus, 50 miles from the fault, the 0.2 - to $0.3-\mathrm{sec}$ period components will have decayed two to three times as much as the 1-sec or longer period components. Because of this the seismic waves arriving at distant points have predominately longer periods than those occurring near the epicenter.

The interest of the structural designer is in the strong motion occurring near the epicenter, say within 100 miles. Typical records of strong-motion accelerations are shown in Figs. 1.3 to 1.6. These accelerograms, recorded by the U. S. Coast and Geo- 


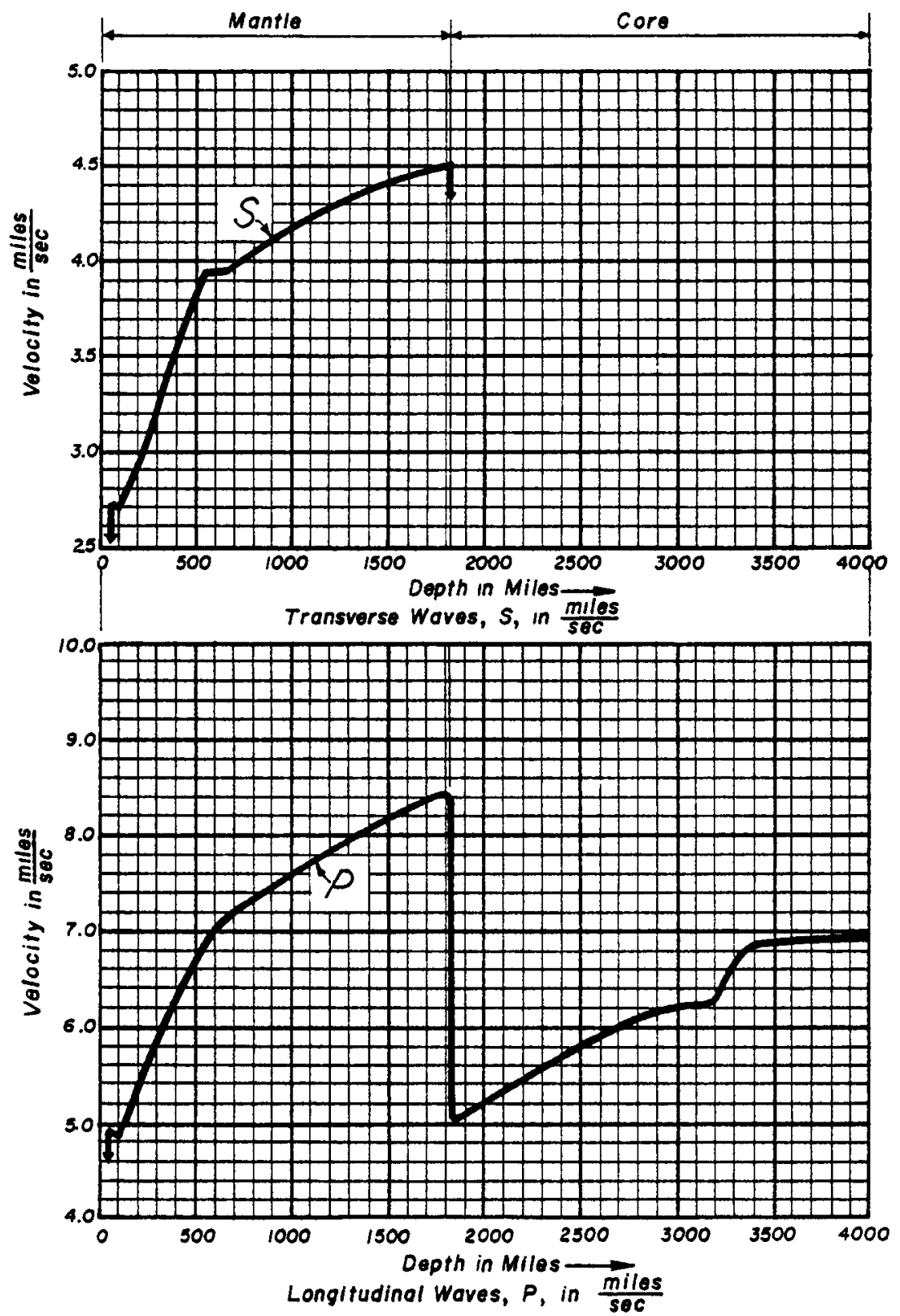

Fig. 1.2-Wave velocity as a function of depth in the earth. (Data from Ref. 1.2.)

detic Survey, are typical of records taken in the epicentral region by special strongmotion seismometers with characteristics suitable for recording the short-period highacceleration ground motion in this region. These instruments do not operate continuously but are started on the receipt of a threshold impulse. In a typical earthquake the strongest motions are recorded within a few seconds after the recelpt of this impulse, which serves to illustrate the extremely short period available for emergency action following the onset of an earthquake. In this epicentral region the amplitudes of the $S$ waves are much larger than those of the forerunning $P$ waves, and the distances involved are too small for large separation of $\mathrm{P}$ and $\mathrm{S}$ waves to occur. 
These facts may be important in the consideration of a reactor protection device to be activated by the earthquake motion. Such a device, if designed to operate on the forerunning $P$ waves of a major earthquake, would also be operated by the $S$ waves of the

Table 1.2 - VELOCITIES OF LONGITUDINAL (P) WAVES AT SHALLOW DEPTHS

\begin{tabular}{lc||lc}
\hline \multicolumn{1}{c||}{ Material } & $\begin{array}{c}\text { Velocity, } \\
\text { miles/sec }\end{array}$ & Material & $\begin{array}{c}\text { Velocity, } \\
\text { miles/sec }\end{array}$ \\
\hline Sand & $0.1-1.2$ & Salt & 2.8 \\
Loess and & & Sandstone & $0.9-2.7$ \\
$\quad$ artificial fill & $0.2-0.4$ & Limestone & $1.1-4.0$ \\
Alluvium & $0.3-1.2$ & Granite & $2.5-3.5$ \\
Clay & $0.6-1.7$ & Quartzite & 3.8 \\
\hline
\end{tabular}

numerous small earthquakes which occur frequently. To avoid this difficulty, the device would need to be triggered by the $S$ waves of large earthquakes. This would require that a system of such devices be used, surrounding the installation to be protected, at a distance sufficient to provide the necessary warning time. A detailed discussion of protective systems is presented in Chap. 8.

The El Centro 1940 record (Fig. 1.3) is representative of the record obtained near the epicenters of large magnitude earthquakes. Accelerations in past U. S. earthquakes may have exceeded the maximum value $(0.33 \mathrm{~g})$ of this shock; however, this is the largest acceleration recorded in the United States to date.

Figures 1.4 and 1.5 (Arvin-Tehachapi, 1952) are shown for comparison of a close-in record of a large earthquake with a more distant record. The record of Fig. 1.4 was obtained at Taft, Calif., about 30 miles from the center of the slipped area of the fault. Figure 1.5 represents a record of the same earthquake obtained at Hollywood, Calif., about 70 miles from the center.

Figure 1.6 (San Francisco, 1957) is representative of a close-in record of a small earthquake.

\section{Earthquake Intensity}

Earthquake intensity is a measure of the violence of the ground motion at a given point on the surface of the ground. A number of empirical scales have been developed for describing the violence of ground motion in a particular locality. These assess the intensity of the shock at a given point in only a qualitative way since they are not based on recorded ground motions but only on the observed effects of the ground motion.

In spite of this limitation, two such scales have proved fairly useful. The older of these, the Rossi-Forel scale, expresses intensity in general terms which are not well suited to take advantage of the voluminous and more detailed reporting of the present day. For these conditions the more recently developed Mercalli scale has distinct advantages. A modification of the Mercalli scale was developed in 1931 by $\mathrm{H}$. O. Wood of the Seismological Laboratory of the California Institute of Technology and Frank Neumann of the U. S. Coast and Geodetic Survey. This scale is in current use by the U. S. Coast and Geodetic Survey in evaluating U. S. earthquakes. Both the Rossi-Forel scale and an abridged form of the Modified-Mercalli scale are shown ${ }^{1.11}$ in Fig. 1.7, columns 1 and 2 . Intensities established by these scales can be only approximately correlated with seismographic data. 

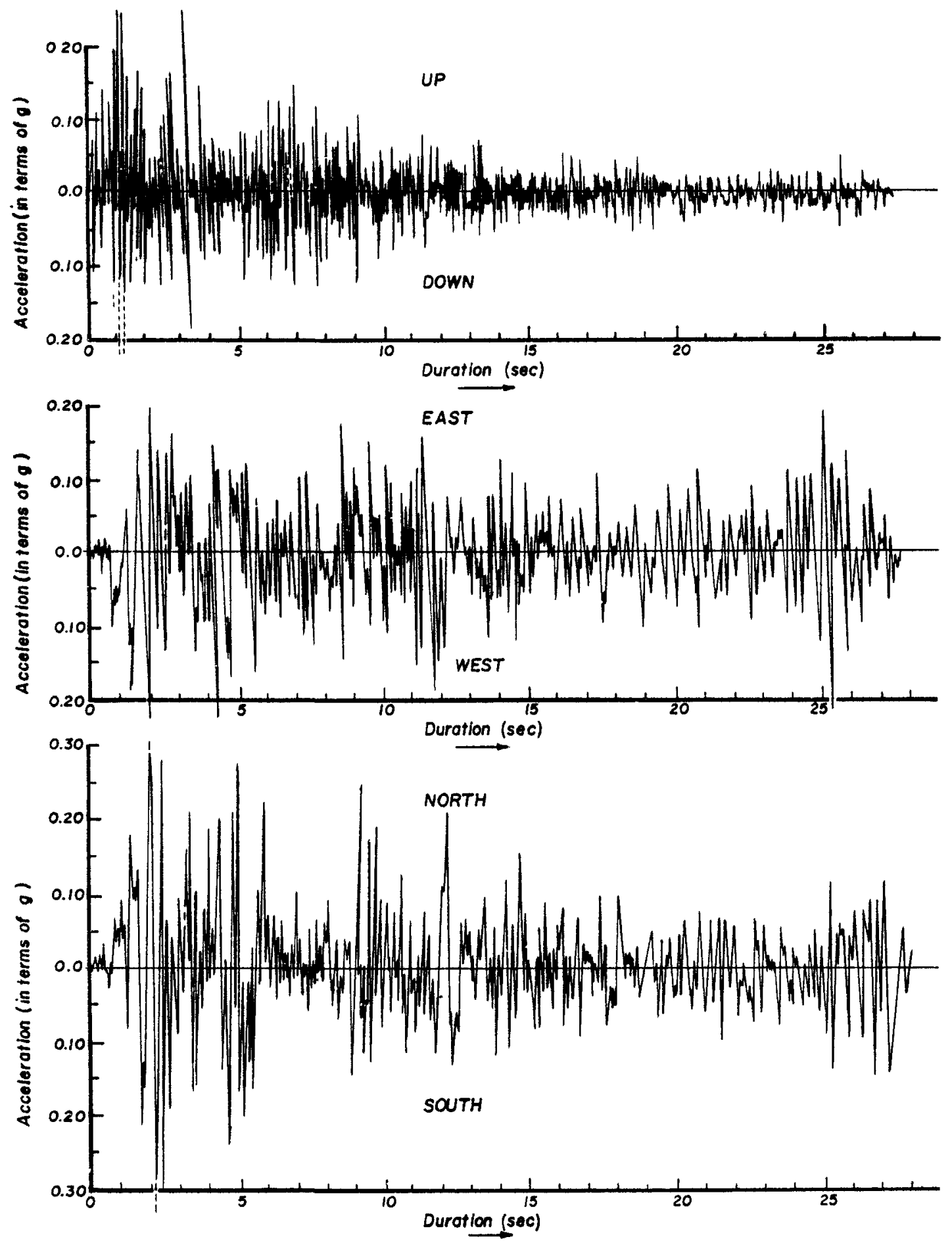

Fig. 1.3-Accelerograph record of El Centro, Calıf., earthquake, May 18, 1940. Earthquake recorded approximately 30 miles from center of slipped fault. Magnitude, $M=7 \pm$. (Data from U. S. Coast and Geodetic Survey.) 

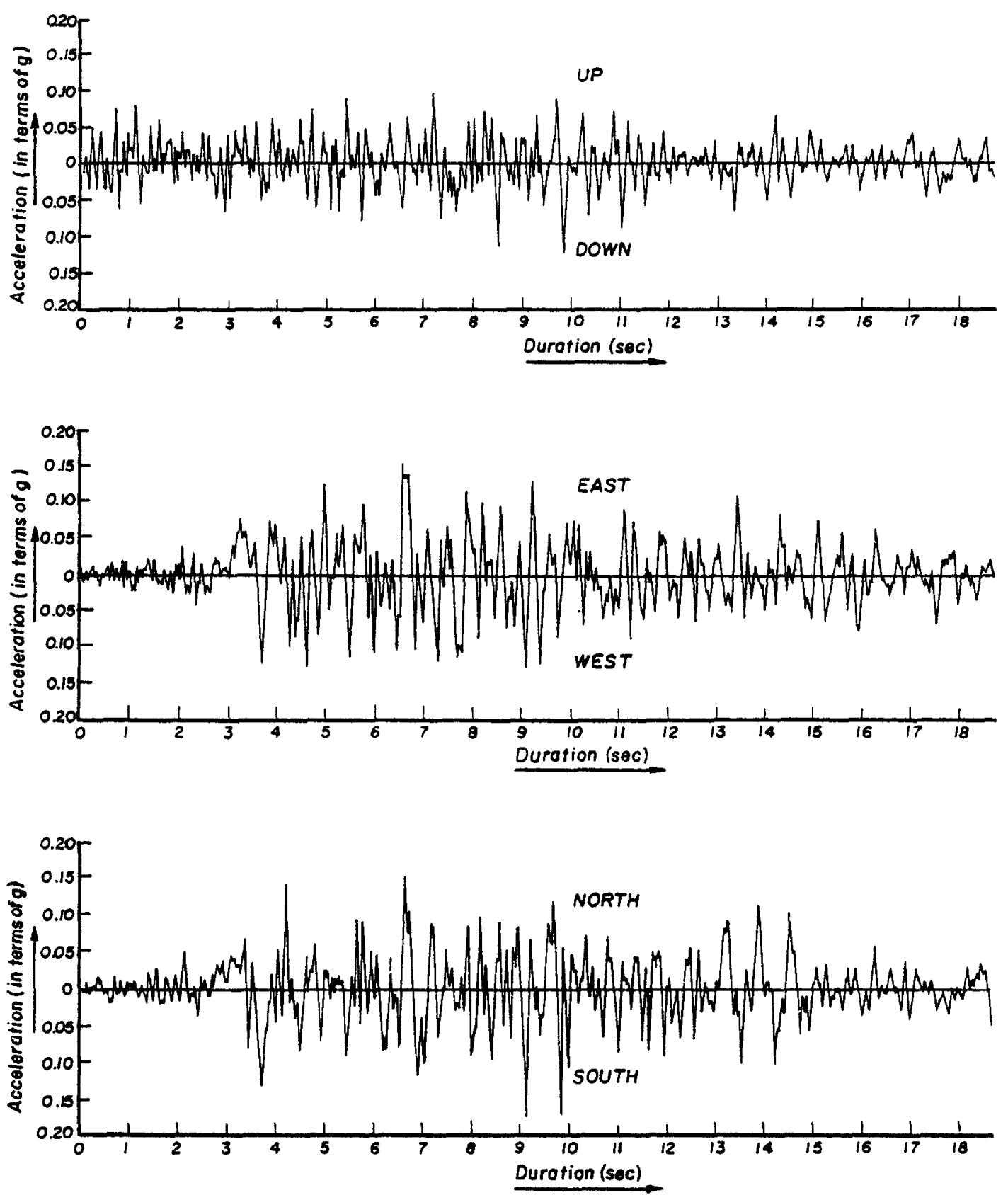

Fig. 1.4-Taft, Calif., accelerograph record of Arvin - Tehachapi, Calif., earthquake, July 21, 1952. Earthquake recorded approximately 30 miles from center of fault. Magnitude, $M=7.7$. (Data from U. S. Coast and Geodetic Survey.)

E. Energy Release and Magnitude

The energy release of the greatest shocks has been estimated as being roughly equivalent to the total energy of 10,000 twenty-kiloton atomic bombs; whereas the smallest shocks release only about $10^{-14}$ times as much energy as the largest earthquakes. ${ }^{1.2}$ 

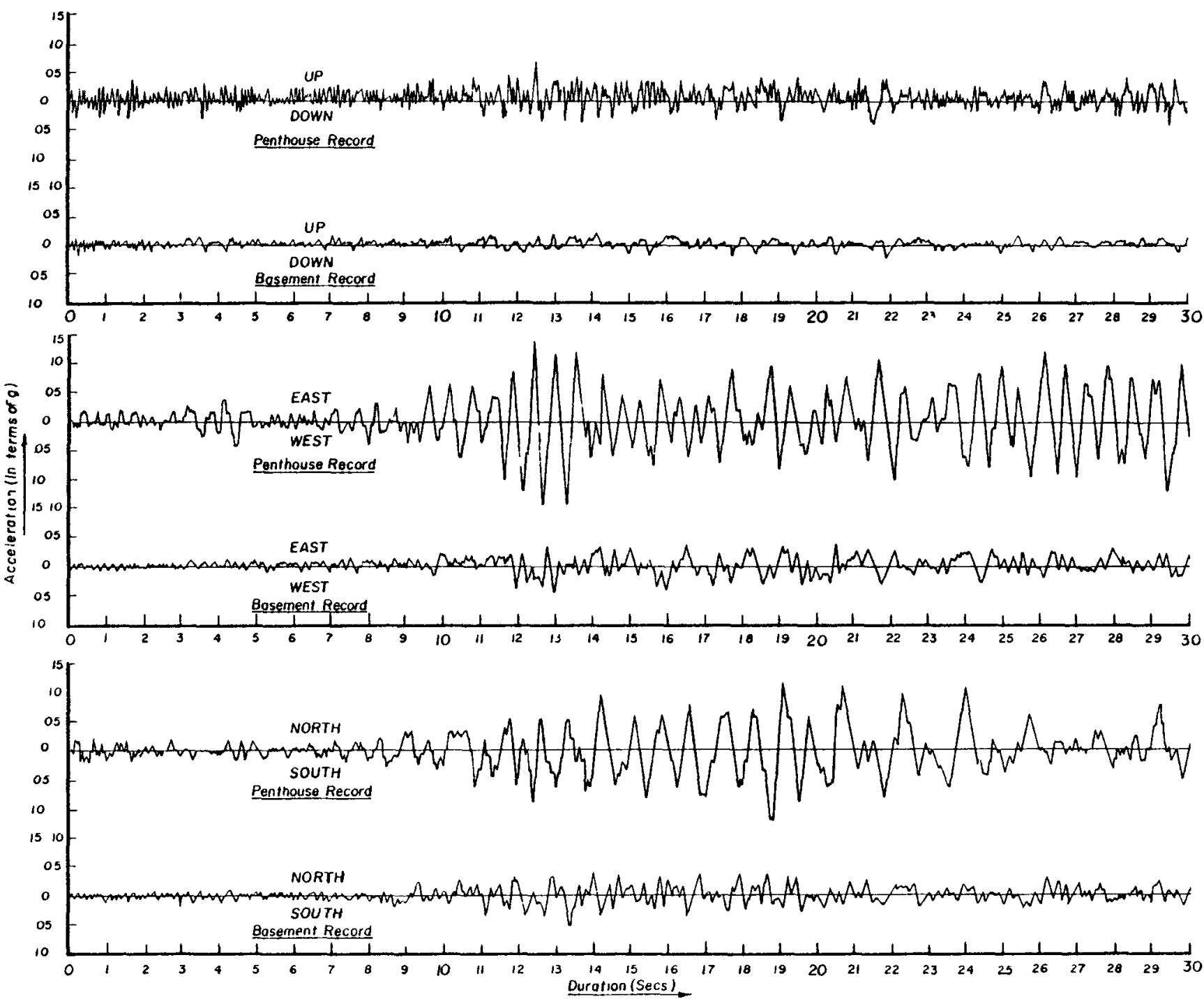

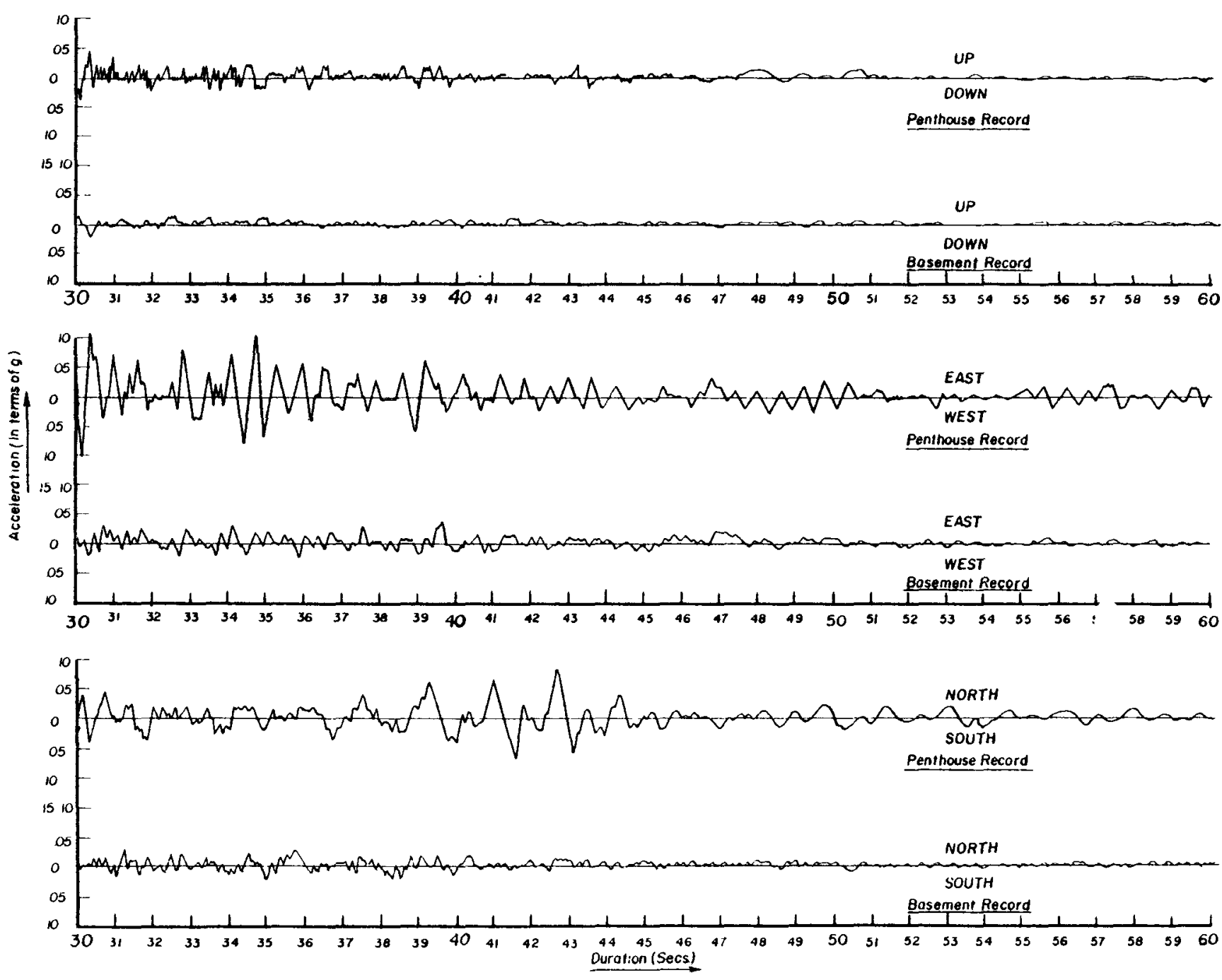

Fig. 1.5-Accelerograph records of Arvin-Tehachapi, Calif., earthquake, July 21, 1952, from selsmographs located in both penthouse and basement of Hollywood Storage Company Building, Hollywood, Calif. Located approximately 70 miles 

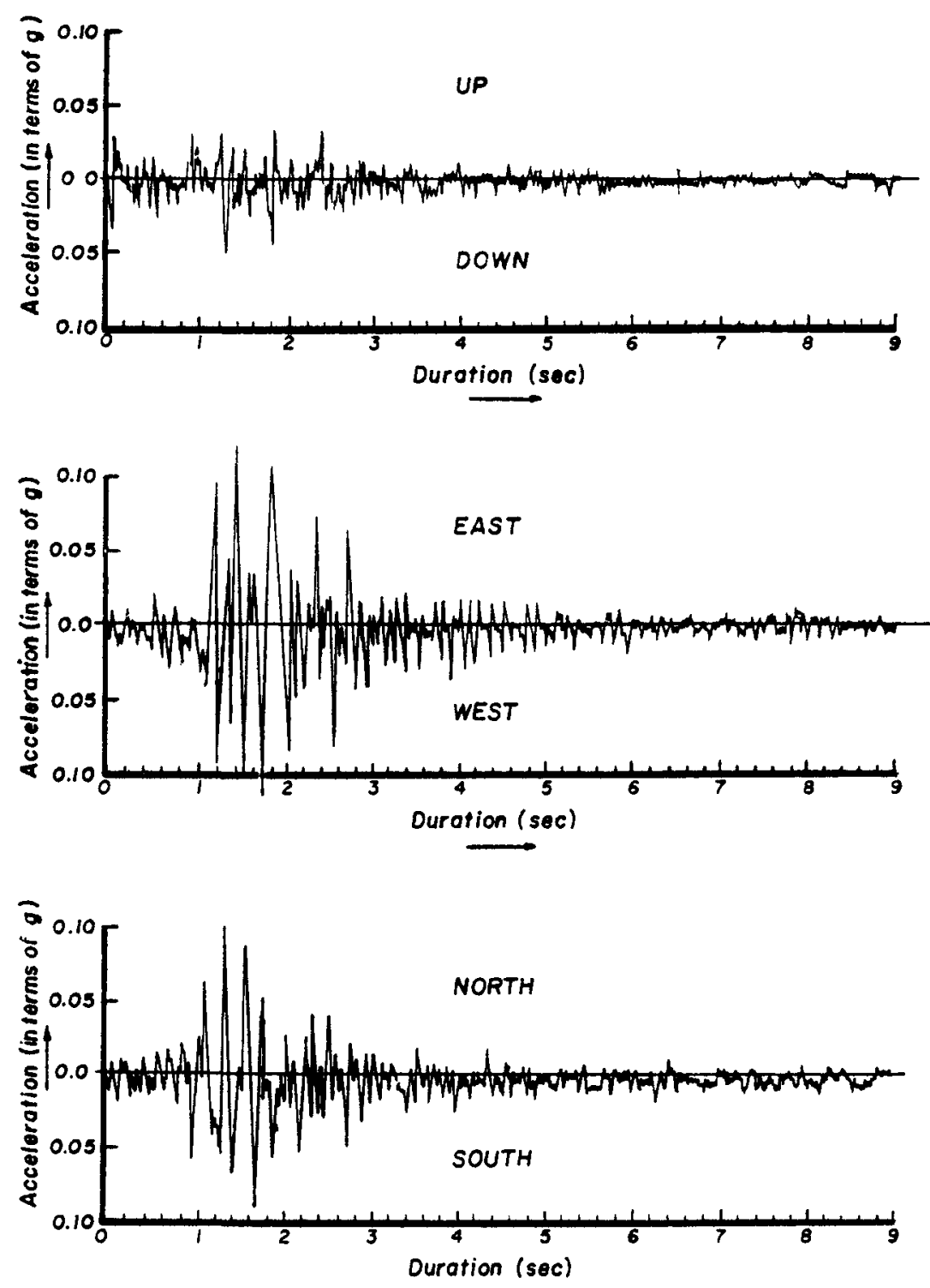

Fig. 1.6-Accelerograph record of San Francisco, Calif., earthquake, Mar. 22, 1957. Earthquake recorded at Golden Gate Park, approximately 7 miles from center of fault. Magnitude, $M=5.3$. (Data from U. S. Coast and Geodetic Survey.)

At the present time accurate calculation of energy release is not possible. However, as early as 1935 Richter devised an arbitrary magnitude scale based on the maximum amplitude of the record of a standard seismometer at a distance of $100 \mathrm{~km}$ from the epicenter.

In 1956 a rough approximation relating earthquake magnitude, $\mathrm{M}$, to the energy, $\mathrm{E}$, released as seismic waves was given by Gutenberg and Richter ${ }^{1.12}$ in the form

$\log E=9.4+2.14 \mathrm{M}-0.054 \mathrm{M}^{2}$ 


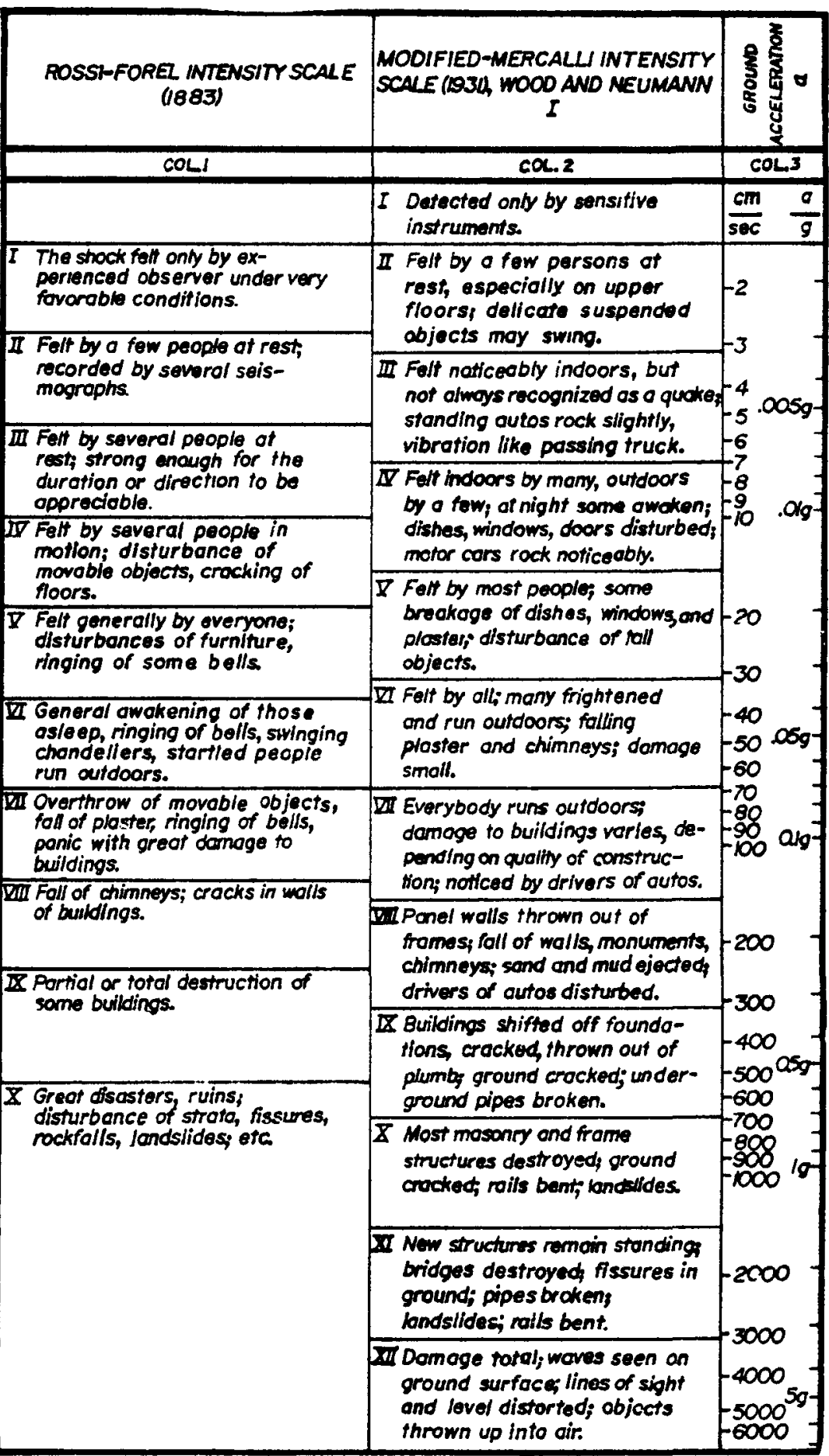

Fig. 1.7-Approximate relation connecting earthquake intensity with acceleration. (Data from Refs. 1.11 to 1.13.) 
where $E$ is the energy in ergs. This relation is shown in Fig. 1.7A, columns 1 and 2. The relative energy release of shocks having magnitudes 5,6 , and 7 would be 1,35 , and 980 , respectively.

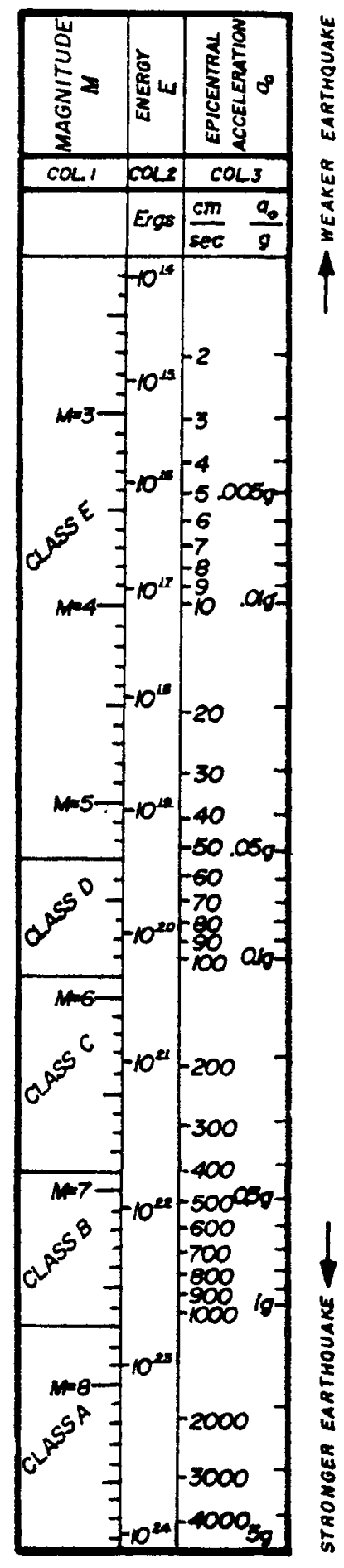

Fig. 1.7A-Approximate relation connecting earthquake magnitude with energy release and epicentral acceleration. (Data from Refs. 1.11 to 1.13.$)$ 


\section{F. Relations Involving Intensity, Acceleration, Magnitude, and Distance}

The relation between intensity and maximum ground acceleration and that between magnitude and acceleration at the epicenter are too complicated to be stated in exact terms. However, it is possible to express these relations in a very rough way, as shown by Gutenberg and Richter. ${ }^{1.13}$ Estimates of the acceleration, a, may be computed for the location where the Modified-Mercalli intensity, I, is known by the equation

$$
I=3 \log a+1.5
$$

where $\mathrm{a}$ is the acceleration in centimeters per second per second. Hershberger, in a recent analysis of 108 strong-motion records obtained from 60 earthquakes, ${ }^{1.14}$ suggests an equation of the same form as Eq. 1.4 but with different coefficients, as shown below:

$$
I=7 / 3 \log a+2.1
$$

Acceleration, $a_{0}$, at the epicenter, may be roughly estimated from the magnitude, $M$, of the earthquake by the equation

$$
M=2.2+1.8 \log a_{0}
$$

This equation assumes a point source of energy release. The relations given by Eqs. 1.4 and 1.5 are shown graphically in Figs. 1.7 and $1.7 \mathrm{~A}$.

It is also possible to show approximately the variation in Mercalli intensity with distance from the epicenter. Isoseismal lines of constant Modified-Mercalli intensity for shocks of magnitudes $5,6,7$, and 8 for average southern California conditions ${ }^{1.2}$ are shown in Fig. 1.8.

Propagation from a point source is assumed, which gives circular isoseismals and overestimates the acceleration and intensity in the epicentral regions of large-magnitude shocks. In reality the isoseismals are very irregular in shape. The pattern shown would be elongated in the case of a shallow shock involving a long fault break. The shape is also affected by ground conditions and underlying geology, as well as by the strike, dip, and depth of faulting. For these reasons large variations from the circular pattern shown must be expected. There is some evidence that the radii of the isoseismals may, for some earthquakes, be as much as $40 \%$ larger than indicated in Fig. 1.8.

The variation of maximum ground acceleration with hypocentral distance can be approximated, with large scatter, by applying the inverse-square law of radiation. This relation was stated by Gutenberg and Richter ${ }^{1.13}$ essentially as follows:

The maximum ground acceleration, a, varies inversely as $R^{2}$ and directly as the product $h \sqrt{E}$, where $R$ is the distance from the station to the center of the slipped area of the fault, $h$ is the depth to the center, and $E$ is the energy release. This relation assumes that the hypocenter coincides with the center of the slipped area of the fault.

\section{G. Effect of Local Geology}

Local geological conditions are important when considering the locations of buildings and structures. There is a general rule that firm ground is preferable to soft ground. However, the present state of knowledge does not permit an accurate assessment of the relative ground-motion intensities to be expected at different sites. Measurements of very small ground motions which have been made both in the United States and in Japan indicate that intensity is strongly correlated with the depth and softness of the alluvium on which the measurements are made. Measurements of strong ground motions which have been made in the United States indicate that greater depth and softness of alluvium can also decrease the intensity. Perhaps the only definite statement that can be made 
$M=$ MAGNITUDE OF OUAKE MEASURED IN STEPS ON A MAGNTUOE SCALE. IT REFERS TO THE QUAKE AS A WHOLE, ANO IS CONSTANT FOA EACH SHOCK.

I= DESTRUCTIVENESS OF QUAKE MEASURED IN STEPS ON THE MOOIFIEDMERCALLI SCALE. IT STANOS FOR. SEISMIC INTENSITY, AND REFERS TO VIOLENCE OF SHAKING AT ANY GIVEN POINT.

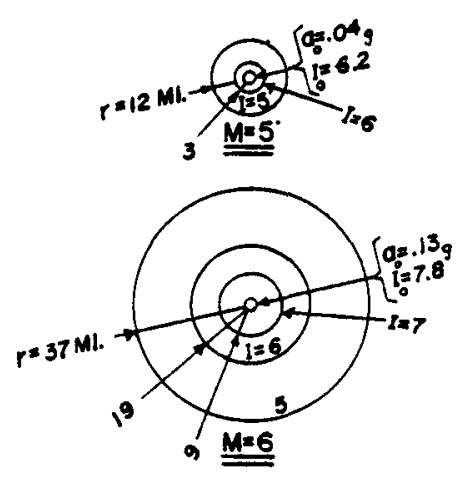

IJ VALUE OF I NEAR QUAKE CENTER.

g= ACCELERATION NEAR CENTER STATED IN TERMS OF ACCELERATION OF GRAVITY, $g$.

$r=$ (MILES), RADIUS OF ISOSEISMALS. THESE ISOSEISMALS ARE QUITE IRREGULAR IN SHAPE, BUT FOR PURPOSES OFILUUSTRATION THEY ARE ASSUMED CIRCULAR.

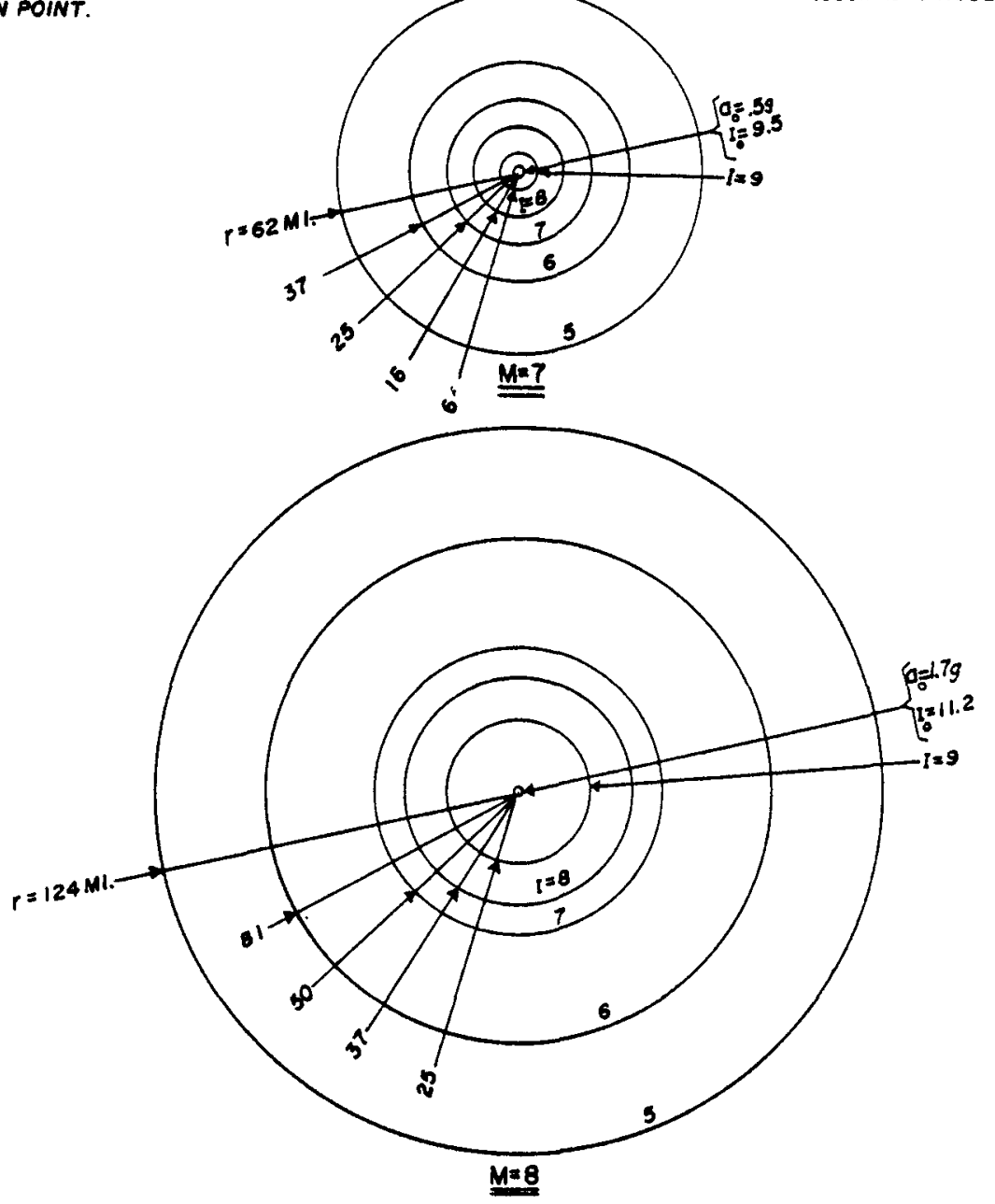

Fig. 1.8-Average southern California earthquakes. Idealized isoseismal lines for shocks of various magnitudes. (Data from Ref. 1.2.)

about the influence of local geology on strong ground motions is that seismic waves are affected by the elastic and inelastic properties of the materials through which they pass and by the size, shape, and orientation of the various strata and lenses of these materials. The influence of the material properties may be such as to increase or decrease the amplitudes of various frequency components in the ground motion. 
Observation would indicate that for strong ground motion the softness of ground may decrease the amplitudes of seismic waves whose frequencies lie above 3 to 4 cycles/sec and may under certain circumstances increase the amplitudes of waves that are in the range of $1 \mathrm{cycle} / \mathrm{sec}$ or greater. The possibility of selective frequency effects requires that the dynamic properties of the structures be considered when assessing the effect of local geology.

In view of the complexity of the problem of wave propagation in heterogeneous media, it is advisable to rely on local observations and measurements when selecting a site. In this connection it should be noted that observations of damage incurred during past earthquakes may give valuable information and that differential soil consolidation under the foundations of a building may be a problem in soft soils.

\subsection{SEISMICITY OF NORTH AMERICA}

The seismicity of North America discussed in the following paragraphs is limited to the area of the United States and adjacent areas that may be associated by faults with the United States (Fig. 1.9).

\section{A. Seismic Zones}

The worldwide distribution of earthquakes was thoroughly investigated in the early part of the twentieth century by the Compte de Monessus de Ballore of France. He noted that earthquake activity is associated with the gradient of the earth's crust, tending to a maximum where extremes of height and depth occur adjacent to one another. On this basis he estahlished two great-circle zones of seismic activity. One, called the Mediterranean-Transasiatic circle, included about 54\% of the world's known earthquakes, and the other, called the Circum-Pacific zone, ${ }^{1.15}$ included about $40 \%$.

The existence of these two rings of earthquake activity has since been substantiated by instrumental data, but there has been a reversal of emphasis. As a result of instrumental tabulation in accord with the Gutenberg-Richter magnitude scale of energy release and depth, the Circum-Pacific zone now seems to be the more active of the two. The evidence is shown in Table 1.3 for the Circum-Pacific zone. ${ }^{1.1,1.15}$

Appraisal of the seismicity of many regions is difficult because the lapse of time between great earthquakes may be greater than the existing periods of records. The seismic history and records of parts of China extend back as far as 3000 years; those of much of Europe, about 2000 years; those of the Americas, about 400 years. Those areas of the world known through reasonably complete instrumental records. however, have histories of about 45 years or less. Therefore present-day estimates regarding the relative seismicity of these two zones must be considered as tentative. In North America the CircumPacific zone includes the western United States, where numerous shallow shocks occur. Paradoxically 1600 miles east of the Circum-Pacific zone, in the Mississippi Valley, with no great gradient of the earth's crust, there occurred three earthquakes near New Madrid, Mo., in 1811 to 1812 , which shook down chimneys 325 miles away. It should be noted that 325 miles away from the 1906 San Francisco earthquake no tremor was felt. ${ }^{1.15}$ Each of the three New Madrid earthquakes and the 1866 Charleston, S. C., earthquake were felt over an area of 2,000,000 sq miles. No other shock in the United States is known to have affected more than one-fourth this area. ${ }^{1.16,1.17}$ These experiences emphasize that historically stable areas do not always remain so. The characteristic general mobility of the earth's crust supports the view that an earthquake may occur in any location. However, it is unlikely that future earthquakes will exceed in magnitude those which have occurred in the past.

This viewpoint is based on the theory that the maximum strain that can accumulate in the rock structure without rupture places an upper limit on the energy which can be released by an earthquake. Numerous earthquakes have occurred with energy releases approaching this limit. 


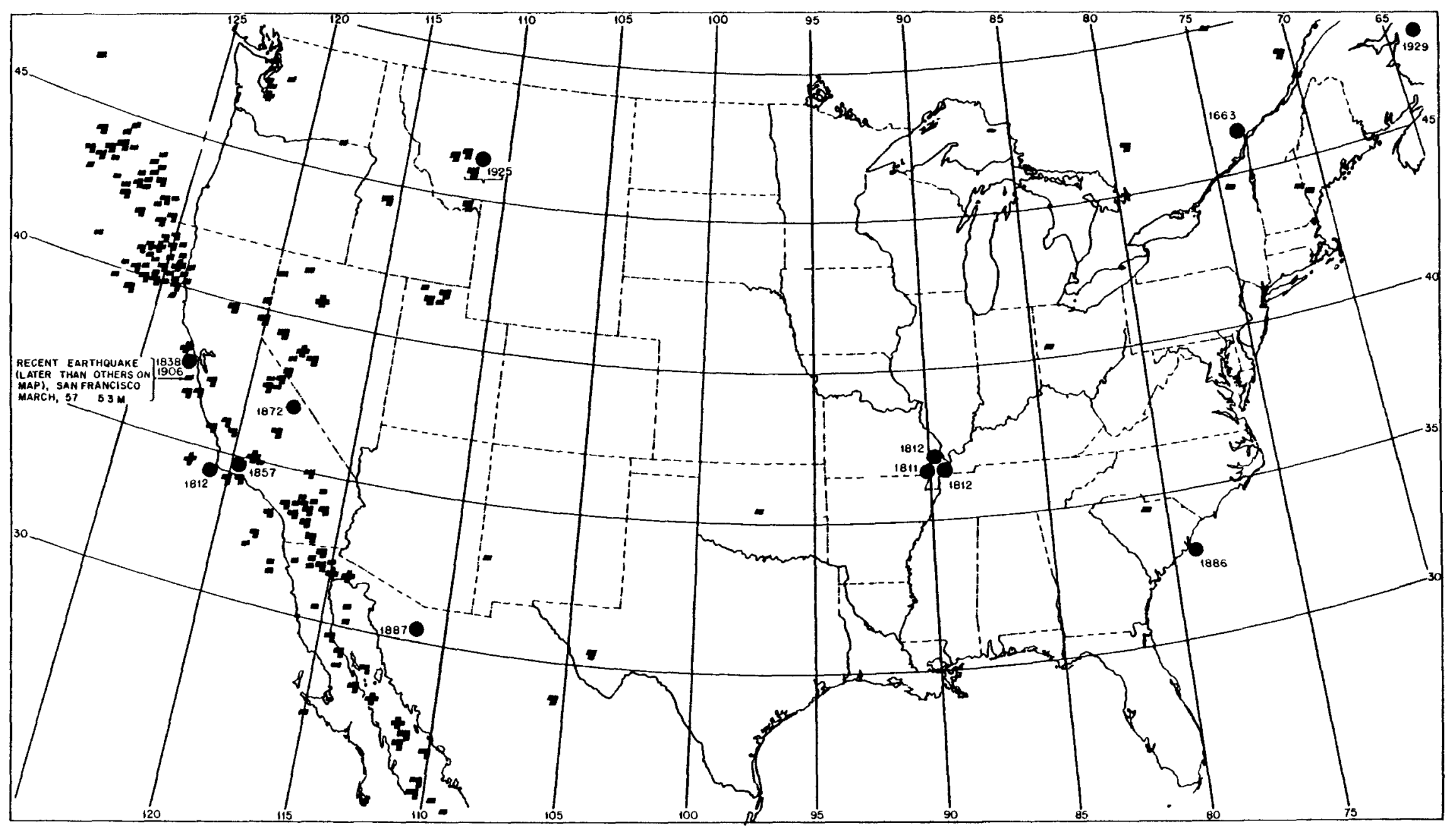

Fig. 1.9--Magnitude rating of edrthquakes for the United States.

UNAUTHENTICATED MAGNITUDES: Unauthenticated magnitude based on Modified-Mercallı intensity of $\mathrm{I}=\mathrm{X}+$, from Earthquake History of U. S. A., Serial No. 609, U. S. Coast and Geodetic Survey, Washıngton, D, C.

O. Magnitude $A$ and $B: M=7$ through $M=8.3$.

INS TRUMENTALLY AUTHENTICATED MAGNITUDES: 1925-1952 authenticated shocks, from 1900-1952 data based on Seismicity of the Larth, by Gutenberg and Richter, pp. 223 and 343.

7. magnitude $\mathrm{A}$ and $\mathrm{B}: \mathrm{M}=7$ through $\mathrm{M}=8.3 . \quad 7$, magnitude $\mathrm{C}: \mathrm{M}=5.9$ through $\mathrm{M}=6.9 . \quad$., magnitude $\mathrm{D}: \mathrm{M}=5.3$ through $\mathrm{M}=5.8$. 
As shown in Fig. 1.9, a large number of earthquakes have occurred off the coast of northern California and Oregon. South of this area major seismic activity occurs along the full length of California; one such zone following the coast ranges, with a second zone located along the eastern flanks of the southern Sierra Nevada range. Central California and Oregon are almost free of epicenters. However, there are no parts of California where earthquakes have not been felt. In fact, by comparison, all other western states are oniy moderately seismic.

Table 1.3-PERCENTAGE OF WORLD'S EARTHQUAKES OCCURRING IN THE CIRCUM-PACIFIC ZONE

\begin{tabular}{lc}
\hline \multicolumn{1}{c}{ Depth of shock } & $\begin{array}{c}\text { Percentage of world's earthquakes } \\
\text { occurring in Circum-Pacific zone }\end{array}$ \\
\hline Shallow, up to 37 miles deep & 80 \\
Intermediate, 38 to 190 miles deep & 90 \\
Deep, deeper than 190 miles & 99 \\
\hline
\end{tabular}

In accord with the intensity scale and based on earthquakes that have occurred within state borders, the seismicity of the western United States may be evaluated by comparing these states with California, which is assigned a rating ${ }^{1.15}$ of 10 :

$\begin{array}{lrll}\text { California } & 10.00 & \text { Oregon } & 0.27 \\ \text { Nevada } & 1.17 & \text { Idaho } & 0.25 \\ \text { Utah } & 1.14 & \text { Arizona } & 0.20 \\ \text { Washington } & 1.08 & \text { Wyoming } & 0.13 \\ \text { Montana } & 0.57 & \text { Colorado } & 0.06 \\ \text { New Mexico } & 0.33 & & \end{array}$

In this tabulation small shocks of intensity of 4 or less were given a weighted value of 1 , intensities 5 and 6 were given a weighted value of 5 , and larger shocks above intensity of 6 were given a weighted value of 25 . The sum of these weighted values for each state was divided by the area of the state. California was then arbitrarily assigned a seismicity of 10 , and the other states were assigned values proportional to the above quotients.

The middle and eastern United States rarely experience destructive earthquakes. However, there are four isolated areas where shocks of magnitude 7 or more occur. These areas are in the vicinities of New Madrid, Mo.; the St. Lawrence River; Charleston, S. C.; and western Ohio. In historical times the north-central United States and the area of the United States bordering the Gulf of Mexico have never experienced a destructive earthquake.

\section{B. Important Earthquakes}

The more important earthquakes in and around the United States are tabulated in Table 1.4. All magnitudes listed are greater than 6.9. Recent quakes are also listed according to the Modified-Mercalli intensity; and earlier quakes, by Rossi-Forel intensity. In the case of the very earliest quakes, where the Rossi-Forel intensity is the only available rating, no attempt is made to assign a magnitude rating. However, those early quakes which were reported as having a Rossi-Forel intensity greater than IX are arbitrarily included as important earthquakes.

The approximate relation between the Modified-Mercalli and the Rossi-Forel intensity scales is shown in Fig. 1.7. Figure 1.7A also indicates the relation between magnitude by classification and magnitude by numerical limits, which is repeated in Table 1.5 in more convenient form. 
Table 1.4-MAGNITUDES AND LOCATIONS OF PAST STRONG EARTHQUAKES IN AND AROUND THE UNTED STATES

\begin{tabular}{|c|c|c|c|c|c|c|c|}
\hline Date & District & $\begin{array}{l}\text { North } \\
\text { latitude }\end{array}$ & $\begin{array}{c}\text { West } \\
\text { longitude }\end{array}$ & $\begin{array}{l}\text { Extent of } \\
\text { tremor, } \\
\text { sq miles }\end{array}$ & Intensity* & Magnitude & Refs. \\
\hline $2 / 5 / 1663$ & St. Lawrence Valley & 46.5 & 72.5 & 750,000 & $\mathrm{x}$ & & 1.16 \\
\hline \multicolumn{8}{|l|}{1800} \\
\hline $12 / 16 / 11$ & New Madrid, Mo. & 36.6 & 89.6 & $2,000,000$ & $\mathrm{x}$ & $8.0+$ & $1.1,1.16$ \\
\hline $1 / 23 / 12$ & New Madrid, Mo. & 36.6 & 89.6 & $2,000,000$ & $\mathrm{x}$ & $8.0+$ & $1.1,1.16$ \\
\hline $2 / 7 / 12$ & New Madrid, Mo. & 36.6 & 89.6 & $2,000,000$ & $\mathrm{X}$ & $8.0+$ & $1.1,1.16$ \\
\hline $12 / 21 / 12$ & Santa Barbara, Calif. & 34.2 & 119.1 & & $\mathrm{X}$ & & 1.17 \\
\hline $6, / 28 / 38$ & San Francisco, Calif. & 38.0 & 123.0 & & $\mathrm{x}$ & & 1.17 \\
\hline $1 / 9 / 57$ & Fort Tejon, Calif. & 34.9 & 118.9 & & $\mathrm{X}$ & & 1.17 \\
\hline $3 / 26 / 72$ & Lone Pine, Calif. & 37.0 & 119.0 & 125,000 & $\mathrm{X}$ & & 1.17 \\
\hline $8 / 31 / 86$ & Charleston, S. C. & 32.9 & 80.0 & $2,000,000$ & $\mathrm{X}$ & & 1.16 \\
\hline $5 / 3 / 87$ & Sonora, Mexico & 31.0 & 109.0 & & $\mathrm{x}$ & & 1.16 \\
\hline \multicolumn{8}{|l|}{1900} \\
\hline $4 / 18 / 06$ & San Francisco, Calif. & 38.0 & 123.0 & 375,000 & $\mathrm{x}$ & 8.3 & $1.1,1.17$ \\
\hline $10 / 16 / 07$ & Lower Calif., Mexico & 28.0 & 112.5 & & & 7.5 & 1.1 \\
\hline $10 / 2 / 15$ & Pleasant Valley, Nev. & 40.5 & 117.5 & 500,000 & $\mathrm{x}$ & 7.8 & $1.1,1.17$ \\
\hline $11 / 21 / 15$ & Lower Calif., Mexico & 32.0 & 115.0 & & & 7.1 & 1.1 \\
\hline $1 / 31 / 22$ & $\begin{array}{l}\text { Pacific Ocean off } \\
\text { Calif. }\end{array}$ & 41.0 & 125.5 & & & 7.3 & 1.1 \\
\hline $1 / 22 / 23$ & $\begin{array}{l}\text { Pacific Ocean off } \\
\text { Calif. }\end{array}$ & 40.5 & 124.5 & & & 7.2 & 1.1 \\
\hline $3 / 1 / 25$ & St. Lawrence Valley & 48.3 & 70.8 & & & 7.0 & 1.1 \\
\hline $6 / 27 / 25$ & Helena, Mont. & 46.0 & 111.2 & 310,000 & $\mathrm{X}$ & & 1.16 \\
\hline $11 / 4 / 27$ & $\begin{array}{l}\text { Pacific Ocean off } \\
\text { Calif. }\end{array}$ & 34.5 & 121.5 & & & 7.3 & 1.1 \\
\hline $11 / 8 / 29$ & $\begin{array}{l}\text { Atlantic Ocean off } \\
\text { Newfoundland }\end{array}$ & 44.5 & 55.0 & & $\mathrm{x}$ & & 1.16 \\
\hline $12 / 20 / 32$ & Ione, Nev. & 38.8 & 118.0 & 500,000 & $\mathrm{x}$ & 7.2 & $1.1,1.17$ \\
\hline $12 / 31 / 34$ & Gulf of Calif., Mexico & 32.0 & 114.8 & & & 7.2 & 1.1 \\
\hline $1 / 27 / 45$ & Gulf of Calif., Mexico & 27.0 & 111.0 & & & 7.0 & 1.1 \\
\hline $4 / 13 / 49$ & Seattle, Wash. & 47.3 & 122.0 & 150,000 & (VIII) & 7.1 & $\begin{array}{c}1.1,1.18 \\
1.19\end{array}$ \\
\hline $7 / 21 / 52$ & Tehachapi, Calif. & 35.0 & 119.0 & 160,000 & (XI) & 7.7 & $1.1,1.20$ \\
\hline $12 / 16 / 54$ & Dixie Valley, Nev. & 38.0 & 118.0 & 200,000 & $(\mathrm{X})$ & 7.1 & $1.15,1.21$ \\
\hline
\end{tabular}

* The values in parentheses a re based on the Modified-Mercalli scale. All other values are based on the Rossi-Forel scale.

Table 1.5-DESIGNATION OF EARTHQUAKES BY MAGNTTUDES

\begin{tabular}{llllll}
\hline Classification rating & Class $\mathrm{A}$ & Class B & Class C & Class D & Class E \\
\hline Numerical rating & $8.8-7.8$ & $7.7-7.0$ & $6.9-6.0$ & $5.9-5.3$ & Below 5.3 \\
\hline
\end{tabular}


C. Location of Past Strong Earthquakes

The more important earthquakes in and around the United States are shown in Fig. 1.9. Magnitudes shown are greater than 5.2. Locations are also shown for those historic quakes of undisputed violence but unauthenticated magnitude because such quakes must be included to present a reasonably accurate picture. Quakes having a rating of X or more on either the Rossi-Forel or the Modified-Mercalli scale are included and are arbitrarily assumed to have a magnitude greater than 6.9 , which classifies them as class A or B earthquakes.

\section{Zones of Assessed Se1smicity}

Discrepancies between apparent epicenters located instrumentally and those found from macroseismic data have hindered the mapping of seismic zones in the United States. Grossly inaccurate estimates of the distribution of seismic intensity have resulted from concentration of population or construction in a small part of the shaken area. People are influenced by the behavior of buildings they are in or near during a quake; for example, it is plausible that a man standing on a featureless plain might give a better account of an earthquake than one in a city. ${ }^{1.22}$ Furthermore, the effect of local geology is not always sufficiently considered; for this reason, higher intensity in an alluviated valley may lead to a false epicenter. Finally, in the most destructive earthquake zone (of intensity seven or greater), no distinction has been made between areas which suffer frequent earthquakes of qualifying intensity and those areas which have experienced only two in modern times; e.g., New Madrid or Charleston.

In the United States, mapping of seismic zones is strongly influenced by population centers since the bulk of data comes from local reports. In some areas data are compiled from postcard questionnaires distributed by postmen along their mail routes following an earthquake. These reflect the errors common to all eyewitness testimony. especially when observations have been made under conditions of mental stress.

A large percentage of the mass of seismic data is obtained from newspapers. Such reports are often affected by exaggeration in an attempt to creale sensational news or by suppression in an attempt to munımize the situation. ${ }^{1.16}$

The seismic probability map of Fig. 1.10 is widely known. It was originally proposed in 1947 by the U. S. Coast and Geodetic Survey and was later adopted by the International Conference of Building Officials as a part of the Uniform Building Code. ${ }^{123}$ The zones shown are roughly related to the Modified-Mercalli intensity as follows:1.24

Zone 0 includes areas having extremely small probability of earthquake darnage and where the incensity of recorded earthquakes has generally not been greater than IV.

Zone 1 designates areas where earthquake damage has been minor, with intensities limited to V or VI, and normally below the threshold of structural damage.

Zone 2 includes areas of intensities VII to VIII, frequently subject to moderate structural damage. However, in this zone greater damage corresponding to intensity $\mathrm{LX}$ or higher might be expected at infrequent intervals.

Zone 3 delineates areas where major destructive earthquakes have occurred in the past and might reasonably be expected at any future time.

Other proposed seismic-probability maps show varying characteristics, such as more detailed zoning, use of Mercalli numbers, and discrimination between zones of equal seismicity based on trequency of occurrence.

Because of the imperfect statistics that comprise the data, seismic-probability maps must always have definite limitations. The boundary between any two zones, indicated as a well-defined line, actually is casually related to geological provinces and is largely arbitrary.

The relative seismicity of a site, even when evaluated from a seismic-probability map for a local area, may vary with orientation of the area with respect to the epicenter 


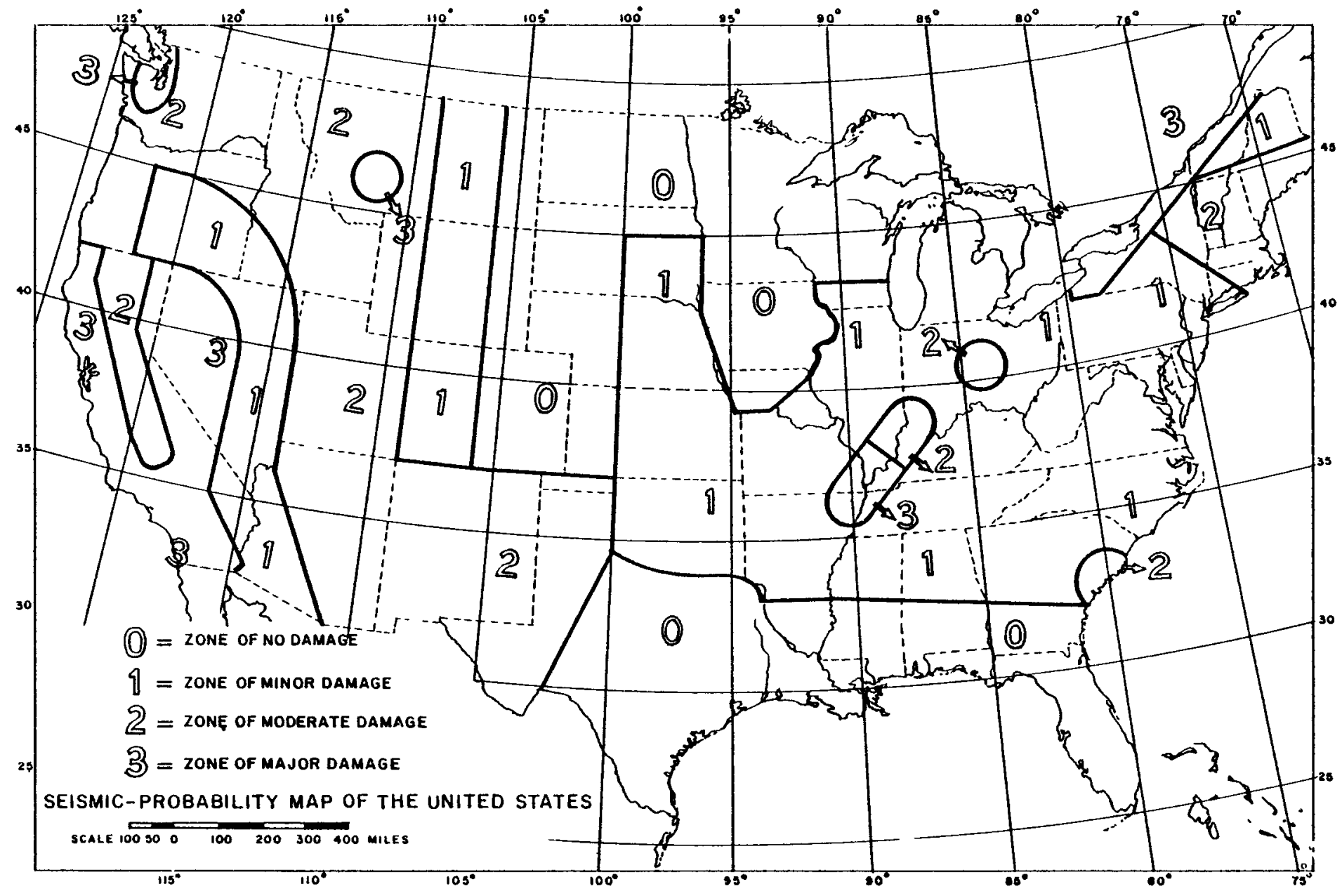

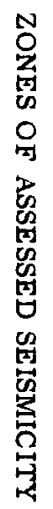


due to the unpredictable irregularity of the isoseismals. More knowledge is required before it will be possible to predict with confidence the effect of local geology on the ground motion without strong reliance on local observations of behavior in past earthquakes.

E. Probability of Occurrence of Earthquakes

For the United States as a whole, earthquakes occur so infrequently and in such widely separated zones that any estimate of probability and frequency, based on uniform distribution with respect to tıme or location, lacks real meaning. However, in the western United States and particularly in California, the frequency and regularity of shccks have resulted in data from which statistical predictions can be made.

Housner ${ }^{1.18}$ has made a quantitative probability study of the occurrence of California earthquakes based on 43 years of records during which 80 earthquakes of magnitude 5.2 or greater are considered. He gives an expression for the expected number, EN, of California earthquakes during a period of $\mathrm{Y}$ years, having a magnitude greater than $\mathrm{M}$. With $\mathrm{x}=8.7-\mathbf{M}$, this expression is as follows:

$$
\mathrm{EN}=\frac{\mathrm{Y}}{370}\left(8 \mathrm{x}^{2}-4.69 \mathrm{x}^{3}+7.52 \mathrm{x}^{4}\right)
$$

It is worthwhile noting that this equation establishes $M=8.7$ as the probable upper limit of magnitude for earthquakes. If the number of years, $Y$, is held at 200 , and the magnitude, $M$, is allowed to vary, then the following tabulation results:

\begin{tabular}{l|l|l|l|l|l|l|l|l|l|l|l|l|l|l}
$\mathrm{EN}$ & 198 & 146 & 138 & 106 & 74 & 51 & 34 & 21 & 13 & 7.8 & 4.1 & 2.2 & 1.0 & 0.34 \\
\hline $\mathrm{M}$ & 6.0 & 6.2 & 6.25 & 6.4 & 6.6 & 6.8 & 7.0 & 7.2 & 7.4 & 7.6 & 7.8 & 8.0 & 8.2 & 8.4
\end{tabular}

The probability of occurrence of a strong earthquake for an average California city was estimated by using the preceding data with the following approximations and assumptions:

(1) Only those earthquakes of magnitude 6 or greater are considered.

(2) The average area subjected to ground motion, equaling or exceeding that corresponding to a 0.2 damped spectrum intensity of 3.0 or greater, is $2000 \mathrm{sq}$ miles. (See Sec. 1.3D.)

(3) The probability of occurrence of earthquakes is constant throughout the state.

(4) The area of the state is $150,000 \mathrm{sq}$ miles.

The probability that the 2000-sq mile area will cover a given point, obtained by dividing this area by the total area of the state, was 0.0133 . In the 200-year period, the number of earthquakes exceeding magnitude 6, from the preceding tabulation, is 198.

Accordingly the expected number of times the 2000-sq mile area will cover a spec1fied location in 200 years is obtained by multiplying the value from the tabulation (198) by 0.0133 , which gives 2.6. This means that a Californa city may expect a ground motion with intensity equal to that experienced in the Long Beach 1933 quake with a frequency that would average about once every 77 years.

\subsection{RESPONSE OF STRUCTURES TO EARTHQUAKE GROUND MOTION}

During an earthquake the base of a structure is moved by the ground both horizontally and vertically, and accelerograms recorded in the basements of buildings show that the two horizontal components are approximately of equal intensity in both directions. The vertical component is usually less intense than the horizontal and is characterized by an accentuation of higher frequency components as compared to the horizontal motion. The vertical component has been observed to excite vertical oscillations in tall buildings, but 
these produce stresses that are only a fraction of the gravity load stresses, and hence only in very special circumstances is an analysis of vertical oscillations pertinent.

A building of moderate plan dimensions founded on reasonably firm soil will have its base moved with the ground; i.e., there will be negligible interplay between the ground and the building, and the basement of the building will move with essentially the same motion as a point on the ground adjacent to the building. ${ }^{1.25,1.26}$ Thus the horizontal components of acceleration recorded in the basement of a building or on the surface of the ground may be considered an accurate representation of the motion of the bases of structures located in that vicinity, unless the structure has unusual proportions, has unusual foundations, or is founded on particularly soft ground.

During an earthquake a structure is excited into oscillations whose magnitudes determine the maximum stresses and strains. ${ }^{1.27}$ Thus the behavior of structures during earthquakes is essentially a problem in vibrations. ${ }^{1.28-1.31}$

A. Single-degree-of-freedom Structure

The simplest vibrating structure is one having a single degree of freedom, and this structure also elucidates the vibratory behavior of more complex multidegree-of-freedom systems. Consider a one-degree-of-freedom structure, as shown in Fig. 1.11, having a mass, $\mathrm{m}$; a spring constant, $\mathrm{k}$, for lateral deflection; damping, $\mathrm{c}$; base motion, $\mathrm{z}$; and displacement, y, relative to the base. As shown in Sec. G.1, the equation of motion is

$$
m\left[\frac{d^{2}}{d t^{2}}(y+z)\right]=-k y-c \frac{d y}{d t}
$$

or

$$
m \ddot{y}+c \dot{y}+k y=-m \ddot{z}
$$

The relative motion, $y$, is thus the same as for a structure resting on an immovable base and subjected to a horizontal force ( $-\mathrm{mz})$.

The solution of Eq. 1.7, if the mass starts from rest, is

$$
y=-\frac{T}{2 \pi} \int_{0}^{t} \ddot{z}(\tau) e^{-n(t-\tau)} \sin \frac{2 \pi}{T}(t-\tau) d \tau
$$

where $\mathrm{y}=$ displacement relative to the base

$\mathrm{T}=$ damped period of vibration $=2 \pi / \omega$

$T_{0}=$ undamped period of vibration $=2 \pi / \omega_{0}$

$\mathrm{t}=$ time at which $\mathrm{y}$ is evaluated

$\tau=$ time at which increment of force is acting (see Sec. G.1, Fig. G.2)

$\ddot{z}=$ base acceleration

$\eta=\mathrm{c} / 2 \mathrm{~m}=$ damping factor

$\omega=$ damped circular frequency of vibration

It should also be noted that the undamped period, $T_{0}=2 \pi / \omega_{0}$, where $\omega_{0}$ is the undamped circular frequency of vibration.

Equation 1.8 glves the displacement of the mass, $\mathrm{m}$, when subjected to arbitrary horizontal base acceleration.

The behavior of the system is made clear by introducing the following notation:

$$
\begin{aligned}
& \int_{0}^{t} \ddot{z} e^{-n(t-\tau)} \cos \omega \tau d \tau=A(t) \\
& \int_{0}^{t} \ddot{z} e^{-\eta(t-\tau)} \sin \omega \tau d \tau=B(t)
\end{aligned}
$$




$$
\frac{1}{2}\left(A^{2}+B^{2}\right)\left(1+\frac{\eta^{2}}{\omega^{2}}\right)=\epsilon(t)
$$

In what follows $A(t), B(t)$, and $\epsilon(t)$ will be written $A, B$, and $\epsilon$, and it must be remembered that these are functions of time, t. For damping sufficiently small so that $\sqrt{1+\left(\eta^{2} / \omega_{0}^{2}\right)} \cong 1$, the damped period, $T$, is essentially equal to the undamped period, $T_{0}$, and the motion of the system is described by the following equations:

$$
\begin{aligned}
& y=-\frac{T}{2 \pi} \sqrt{2 \epsilon} \sin (\omega t-\alpha) \\
& \dot{y}=-\sqrt{2 \epsilon} \cos (\omega t-\beta) \\
& \ddot{y}+\ddot{z}=\frac{2 \pi}{T} \sqrt{2 \epsilon} \sin (\omega t-\gamma)
\end{aligned}
$$

where $\mathrm{T}$ is the period of vibration and $\alpha, \beta$, and $\gamma$ are phase factors involving $\mathrm{A}$ and $\mathrm{B}$.

The potential energy of the system is

$$
V=m \epsilon \sin ^{2}(\omega t-\alpha)
$$

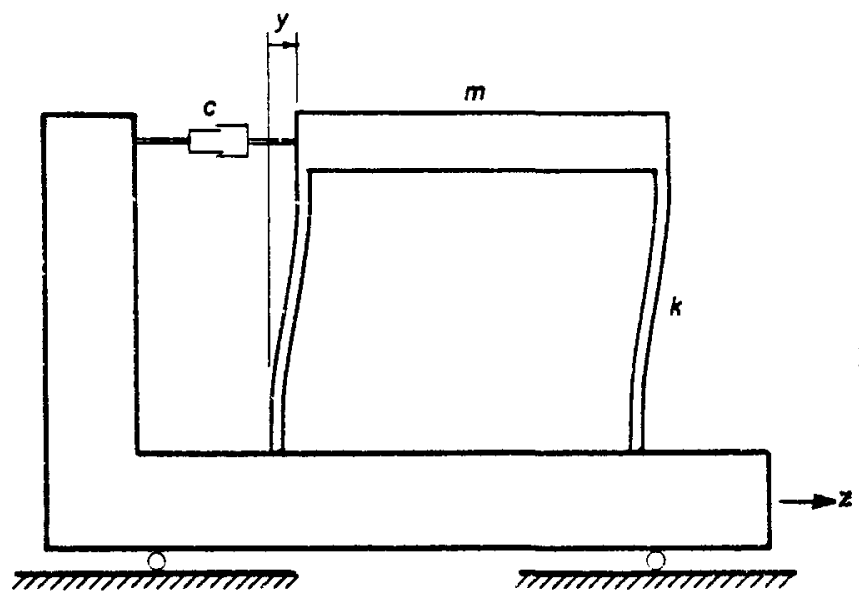

Fig. 1.11-One-degree-of-freedom system.

The relative kinetic energy is defined as $0.5 \mathrm{my}^{2}$, and it is given by

$$
\begin{aligned}
& \mathrm{KE}=\mathrm{m} \epsilon \cos ^{2}(\omega \mathrm{t}-\beta) \\
& \mathrm{V}+\mathrm{KE}=\mathrm{m} \epsilon[1+\sin (\beta-\alpha) \sin (2 \omega t-\alpha-\beta)]
\end{aligned}
$$

The ground motion recorded during strong earthquakes exhibits the characteristics of random functions ${ }^{1.32}$ for which $\epsilon, \alpha, \beta$, and $\gamma$ are slowly varying functions of time, and the excursions of $y, \dot{y}$, and $\ddot{y}$ closely approximate sinusoldal half-waves. For moderate amounts of damping, the factor $(\beta-\alpha)$ may be set equal to zero, and the maximum total energy attained by the system during the earthquake may be written

$$
m \vec{\epsilon}=1 / 2 m\left(A^{2}+B^{2}\right)_{\max }
$$


where $\vec{\epsilon}$ is the maximum eslergy per unit mass attained by the structure. The maximum relative displacement, relative velocity, and absolute acceleration attained by the mass, $m$, during the earthquake may be written as

$$
\begin{aligned}
& \mathrm{y}_{\max .}=\frac{T}{2 \pi} \sqrt{2 \bar{\epsilon}}=\frac{T}{2 \pi} \dot{y}_{\max } \\
& \dot{y}_{\max .}=\sqrt{2 \bar{\epsilon}} \\
& (\ddot{y}+\ddot{z})_{\max .}=\frac{2 \pi}{T} \sqrt{2 \bar{\epsilon}}=\frac{2 \pi}{T} \dot{y}_{\max }
\end{aligned}
$$

The maximum shear force developed in the structure is

$$
F_{\max .}=k y_{\max .}=k \frac{T}{2 \pi} \dot{y}_{\max .}=k \sqrt{\frac{m}{k}} \dot{y}_{\max .}=\sqrt{m k} \dot{y}_{\max }
$$

The maximum inertia force acting on the mass, $\mathrm{m}$, is

$$
m(\ddot{y}+\ddot{z})_{\max .}=m \frac{2 \pi}{T} \dot{y}_{\max .}=m \sqrt{\frac{k}{m}} \dot{y}_{\max .}=\sqrt{m k} \dot{y}_{\max }
$$

which, of course, agrees with Eq. 1.20. The maximum response of the structure is thus characterized by the value $\dot{y}_{\text {max. }}$, which, for moderate damping, may be written

$$
\dot{y}_{\max .}=\left[\int_{0}^{t} \ddot{z} e^{-n(t-\tau)} \sin \omega(t-\tau) d \tau\right]_{\max }
$$

Analyses of earthquake records show that the response of an undamped structure builds up roughly proportional to the square root of the duration of the earthquake ground motion, whereas the response of a damped structure builds up until the energy loss balances the energy input. Thus the response of a structure with zero or small damping may reach relatively high values, but the response is markedly reduced by the introduction of small amounts of damping.

A one-mass system, with two degrees of freedom, which can vibrate in both horizontal directions will respond to both horizontal components of ground motion, and the resultant motion is given by the superposition of the two component responses. In this case it should be noted, however, that the maximum responses in the two perpendicular directions do not necessarily occur at the same instant.

B. Multidegree-of-freedom Structure

For actual structures it is not always possible to determine the physical properties precisely. In particular, the precise nature of damping is not readily established. Experiments show, however, that, where moderate amounts of damping are involved, good results are obtained by considering the damping to be viscous in nature and the motion to be described by normal modes of vibration. The following discussion is limited to structures whose free vibrations can be resolved into normal modes of vibration that are orthogonal. Consider a general elastic structure undergoing small vibrations in the $\mathrm{X}-\mathrm{z}$ plane (Fig. 1.12). The undamped free vibrations of such a structure can be written

$$
y=\sum_{n} C_{n} \phi_{n}(x) \sin \omega_{n} t
$$

where $\mathrm{y}=$ displacement at point $\mathrm{x}$

$\phi_{\mathrm{n}}(\mathrm{x})=$ shape of $\mathrm{n}$ th mode of vibration (dimensionless)

$\omega_{\mathrm{n}}=$ circular frequency of $\mathrm{n}$ th mode

$\mathrm{C}_{\mathrm{n}}=$ amplitude coefficient of $\mathrm{n}$ th mode 


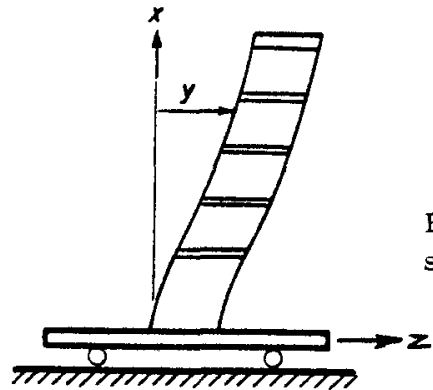

Fig. 1.12-Multidegree-of-freedom system.

As was shown in Eq. 1.7 for the simple oscillator, the response, y, to base acceleration, $\ddot{z}$, is the same as the response to a lateral force, $-m \ddot{z}$, acting on each element of mass, $m$. The effect of $\ddot{z}$ acting for a time dt is to produce an increment of velocity at each point of the structure:

$$
\mathrm{v}_{0}=-\ddot{z} \mathrm{dt}
$$

Since $\dot{y}=\sum_{n} C_{n} \omega_{n} \phi_{n}(x) \cos \omega_{n} t$

there is required

$$
\sum_{n} C_{n} \omega_{n} \phi_{n}(x)=-\ddot{z} d t
$$

and, from the orthogonality of the $\phi_{n}(x)$ values,

$$
C_{n}=\frac{\int \phi_{n} d m}{\omega_{n} \int \phi_{n}^{2} d m}(-\ddot{z}) d t=\frac{K_{n}}{\omega_{n}}(-\ddot{z}) d t
$$

where $K_{n}=\frac{\int \phi_{n} d m}{\int \phi_{n}^{2} \cdot d m}$

and where the integrals are to be evaluated over the mass of the structure. The consequent free vibrations are thus

$$
y=\sum_{d_{n}} K_{n} \frac{\phi_{n}(x)}{\omega_{n}} \sin \omega_{n} t(-\ddot{z}) d t
$$

As in the case of the simple oscillator, the response to a continuous $\ddot{z}$ is

$$
y=-\sum_{n} K_{v} \frac{\phi_{n}(x)}{\omega_{n}} \int_{0}^{t} \ddot{z}(\tau) \sin \omega_{n}(t-\tau) d \tau
$$

If there is damping in the structure, the response is

$$
\begin{aligned}
& y=-\sum_{n} K_{n} \phi_{n}(x)\left[\frac{1}{\omega_{n}} \int_{0}^{t} \ddot{z}(\tau) e^{-n(t-\tau)} \sin \omega_{n}(t-\tau) d \tau\right] \\
& y=-\sum_{n} K_{n} \phi_{n}(x)\left[\frac{\sqrt{2 \epsilon_{n}}}{\omega_{n}} \sin \left(\omega_{n} t-\alpha_{n}\right)\right]
\end{aligned}
$$

Comparing the upper of the two Eqs. 1.30 with Eq. 1.8, it is seen that the factor in the brackets is the same as the equation for the response of the single-degree-of-freedom 
structure. It thus follows that the response of a multidegree-of-freedom structure can be determined if the mode shapes are known and if the response of single oscillators of appropriate periods and damping can be computed.

The computation of the complete response of a multidegree-of-freedom structure is extremely laborious and is best done by means of computing machines..$^{1.33-1.35}$

By analogy with Eqs. 1.19, the maximum response may be written

$$
y_{\max }=\sum_{n}\left|K_{n} \phi_{n}(x)\right| \frac{T_{n}}{2 \pi} \sqrt{2 \bar{\epsilon}_{n}}
$$

where the absolute value of each mode is added.

The analysis of structures more complicated than those covered by the preceding equations can be carried out in a similar fashion, and results similar to Eqs. 1.30 and 1.31 will be obtained. In such analyses particular attention should be paid to the possibility of torsional oscillations.

Equations similar to Eq. 1.31 can be derived for the maximum shears and bending moments in a structure. From Eqs. 1.30 it is seen that the true response will, in general, be less than that given by Eq. 1.31 since each term of Eq. 1.30 contains a trigonometric expression which varies between positive and negative values and in addition the amplitude functions $\epsilon_{\mathrm{n}}$ vary with time. Thus there is only a small probability that all the terms will reach their peak values and be additive at the same time. Studies have snown that for earthquake ground motions, if only two modes of vibration are involved, Eq. 1.31 overestimates the true maximum by approximately $10 \%$; and similar results are obtained if three modes are involved and one of them predominates. However, if three or four modes are involved and they are all approximately the same peak value, Eq. 1.31 may appreciably overestimate the true maximum value. For such cases it has been proposed ${ }^{1.36}$ to use the following expression as an estimate of the true maximum:

$$
y_{\max }=\left\{\sum_{n}\left[K_{n} \phi_{n}(x) \frac{T_{n}}{2 \pi} \sqrt{2 \vec{\epsilon}_{n}}\right]^{2}\right\}^{1 / 2}
$$

Equation 1.31 and corresponding equations for quantities such as shear force or bending moment give the envelopes of maximum response. At each point the equation gives the maximum possible value.

\section{Earthquake Spectra}

In most cases it will not be feasible to make computations of the complete response of a structure. To be meaningful for design purposes, such computations would have to be made for several different recorded earthquake accelerations and for several different values of important structural parameters. To achieve a workable method of analysis, it is customary to utilize the so-called response spectra. ${ }^{1.37}$ The response spectrum for a given earthquake is a plot showing the variation in the maximum response of a singledegree-of-freedom oscillator vs. the natural true period of vibration when subjected to the base acceleration represented by the accelerogram of a given earthquake. The term maximum response as used here refers to the peak values of acceleration, velocity, and displacement of the oscillator.

The spectrum concept can be explained by outlining the steps involved in developing a spectrum curve. To establish a single point on the curve requires considering the effect of the earthquake acceleration on a hypothetical oscillator with a given fraction of critical damping and perıod of vibration. The variation in response vs. time is established, and the maximum value is plotted as an ordinate. The process is repeated for other assumed values of period in sufficient detail to establish the complete curve. Other curves corresponding to different fractions of critical damping are obtained in similar fashion. Thus 
each point establishing the curve requires a complete dynamic-response analysis, and the determination of a complete spectrum may involve hundreds of such analyses.

The velocity-response spectrum, $\mathrm{S}$, is a plot of $\mathrm{y}_{\max }$ of Eq. 1.19. The value of $\dot{y}_{\max }$. is a function of the natural period $T$ and of the fraction of critical damping, $\zeta$. Figures 1.13 to 1.18 show computed velocity spectra for various percentages of critical damping plotted against the period of vibration. The fraction of critical damping is $\zeta=\eta \sqrt{\mathrm{m} / \mathrm{k}}$, and the percentage of critical damping is $100 \zeta$. These spectra are obtained by means of a special electric-analog computer. ${ }^{1.33}$ Spectra for a large number of earthquakes have been computed by Housner and his co-workers. ${ }^{1.34}$

The velocity spectra for earthquake ground motions have certain well-defined characteristics. These may be summarized as follows:

(1) The zero-damping curve is marked by abrupt oscillations which indicate that the response is very sensitive to small differences in periods of vibration. The introduction of a moderate amount of damping makes the response much less sensitive to small period changes.

(2) The introduction of small amounts of damping produces a large reduction in the maximum response, particularly for short periods of vibration.

(3) For ground motion recorded relatively close to the epicenter, the spectra show differences between earthquakes of large magnitude and those of relatively small magnitude. As compared to large-magnitude spectra, the small-magnitude spectra are peaked more in the short-period region, and the effect of damping is not so pronounced.

(4) The higher frequency seismic waves damp out more quickly with distance from the epicenter than do the longer period waves. It has been observed that the spectrum values for periods below $0.5 \mathrm{sec}$ decrease with distance at a stronger rate than the values for periods above $1 \mathrm{sec}$.

(5) Spectrum curves for large-magnitude earthquakes at moderate distances from the epicenters have similar shapes.

The accelerograms for moderate distances from the epicenters of large-magnitude

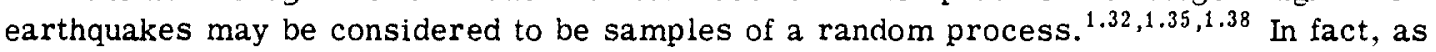
regards response of damped structures, it appears that they may be reasonably treated as a stationary random process and even the mathematics of stationary Gaussian processes apply reasonably well. $1.39-1.41$

If the normalized velocity spectra of both components of the four strong-motion ground accelerations: El Centro, Calif., Dec. 30, 1934; El Centro, Calif., May 18, 1940; Olympia, Wash., Apr. 13, 1949; and Taft, Calif., July 21, 1952, are averaged, there is obtained a set of relatively smooth curves shown in Fig. 1.19. These are the so-called average-velocity-spectrum curves for large-magnitude earthquakes at moderate distances from the epicenter. The scale of this average velocity spectrum is such that the damped curves agree with the average of the two components of the El Centro 1940 record, which is the most intense ground motion recorded to date.

It should be noted that the average spectrum curves are smooth; whereas an actual curve for low damping exhibits strong, random fluctuations. Figure 1.20 shows detail of average-velocity-spectrum curves.

Each ground shock may be viewed as a sample from a population of random functions. There is thus a finite probability that the period of a structure with zero damping may coincide with a peak or a valley of the spectrum curve. If the structure were subjected to a number of shocks of a given intensity. the average maximum velocities attained during each shock, when averaged, would correspond to the average-velocity-spectrum curve. From Figs. 1.13 to 1.18 , it can be seen that the fluctuations about the average spectrum curves may be comparatively large for zero damping and comparatively small for moderate damping. It should be noted that in practice a structure with zero damping is never encountered. 


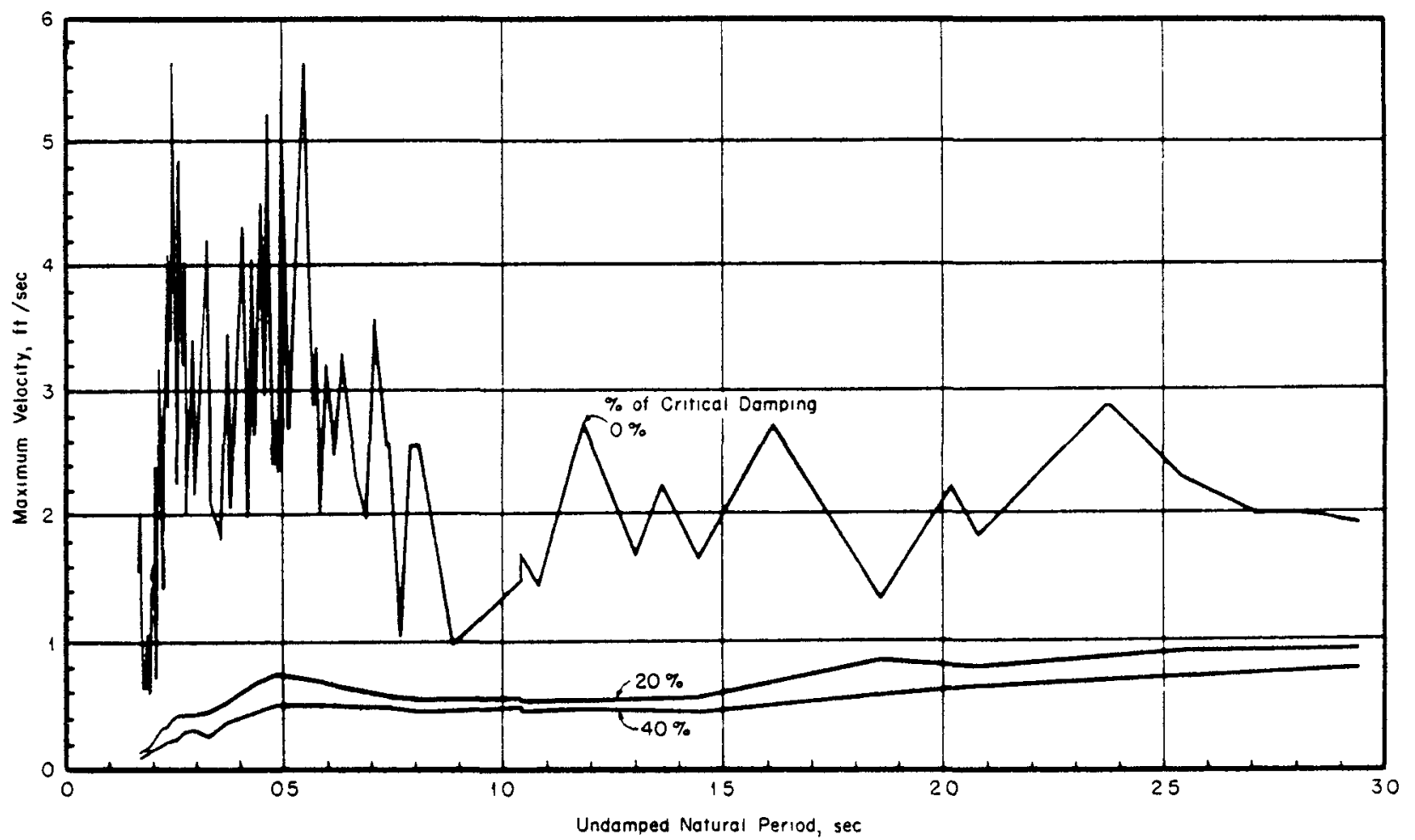

Fig. 1.13-Velocity spectrum for El Centro, Calif., earthquake, Dec. 30, 1934. Component E-W.

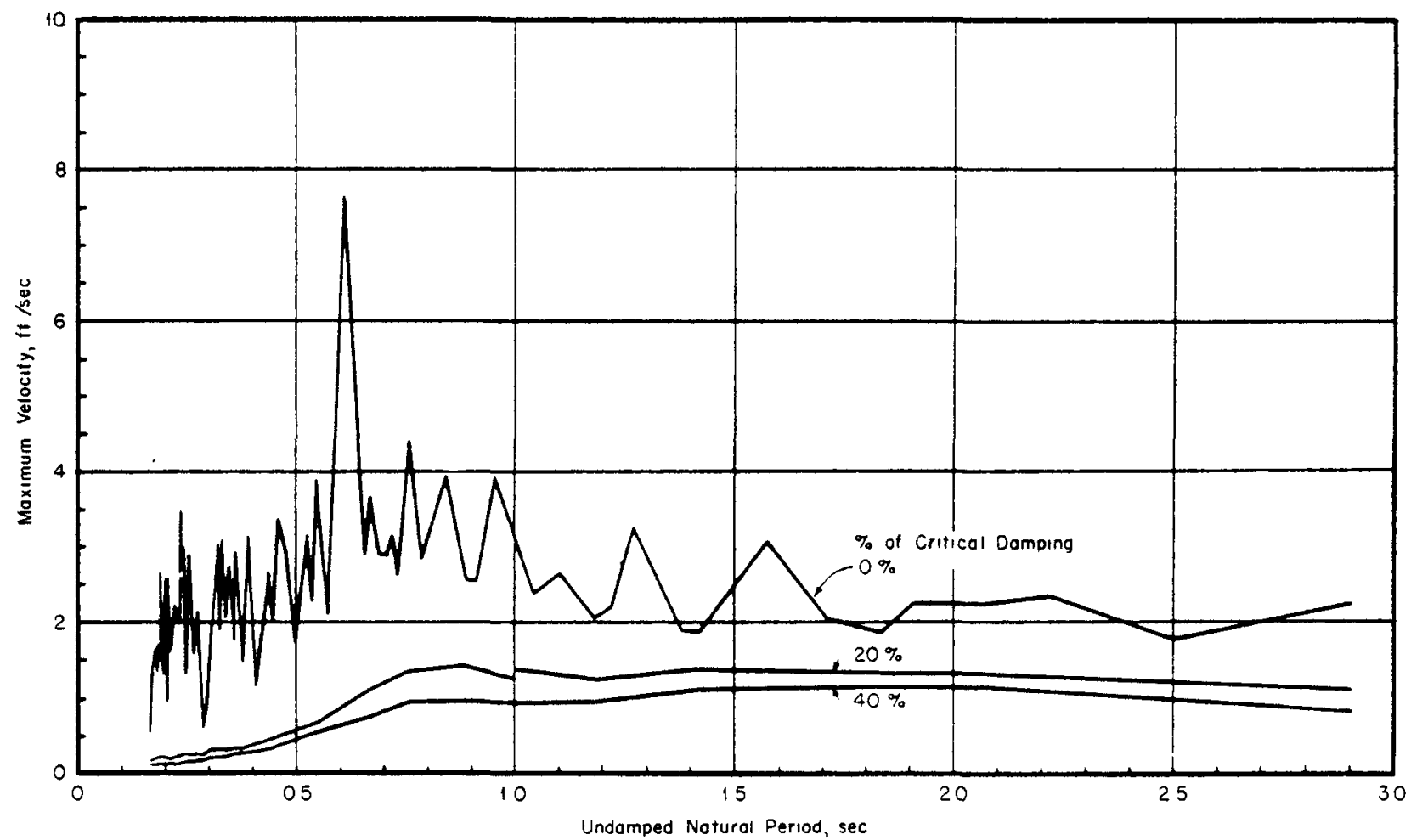

Fig. 1.14-Velocity spectrum for El Centro, Callf., earthquake, Dec. 30, 1934. Component N-S. 


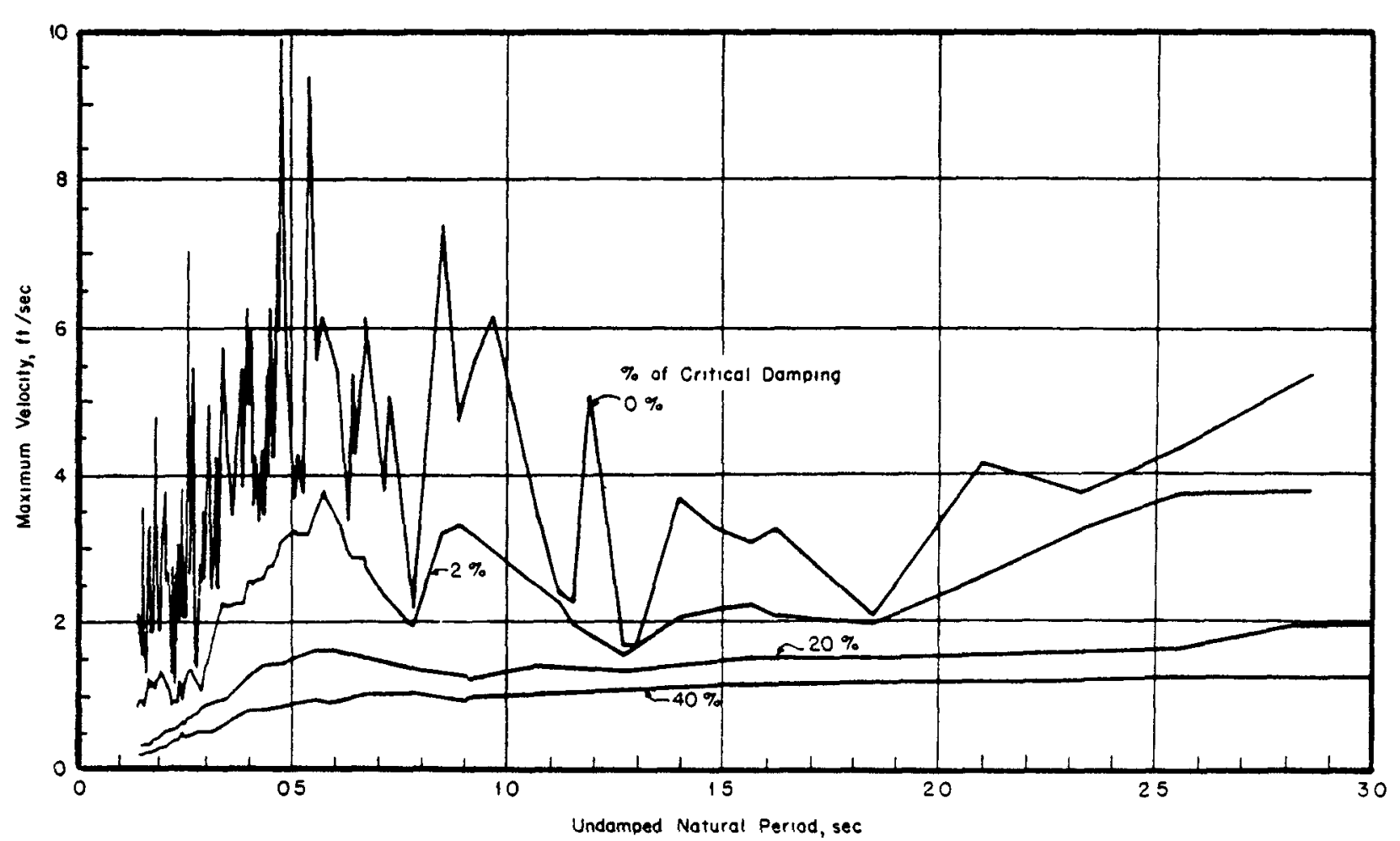

Fig. 1.15 - Velocity spectrum for El Centro, Calıf., earthquake, May 18, 1940. Component $Y^{-S}$.

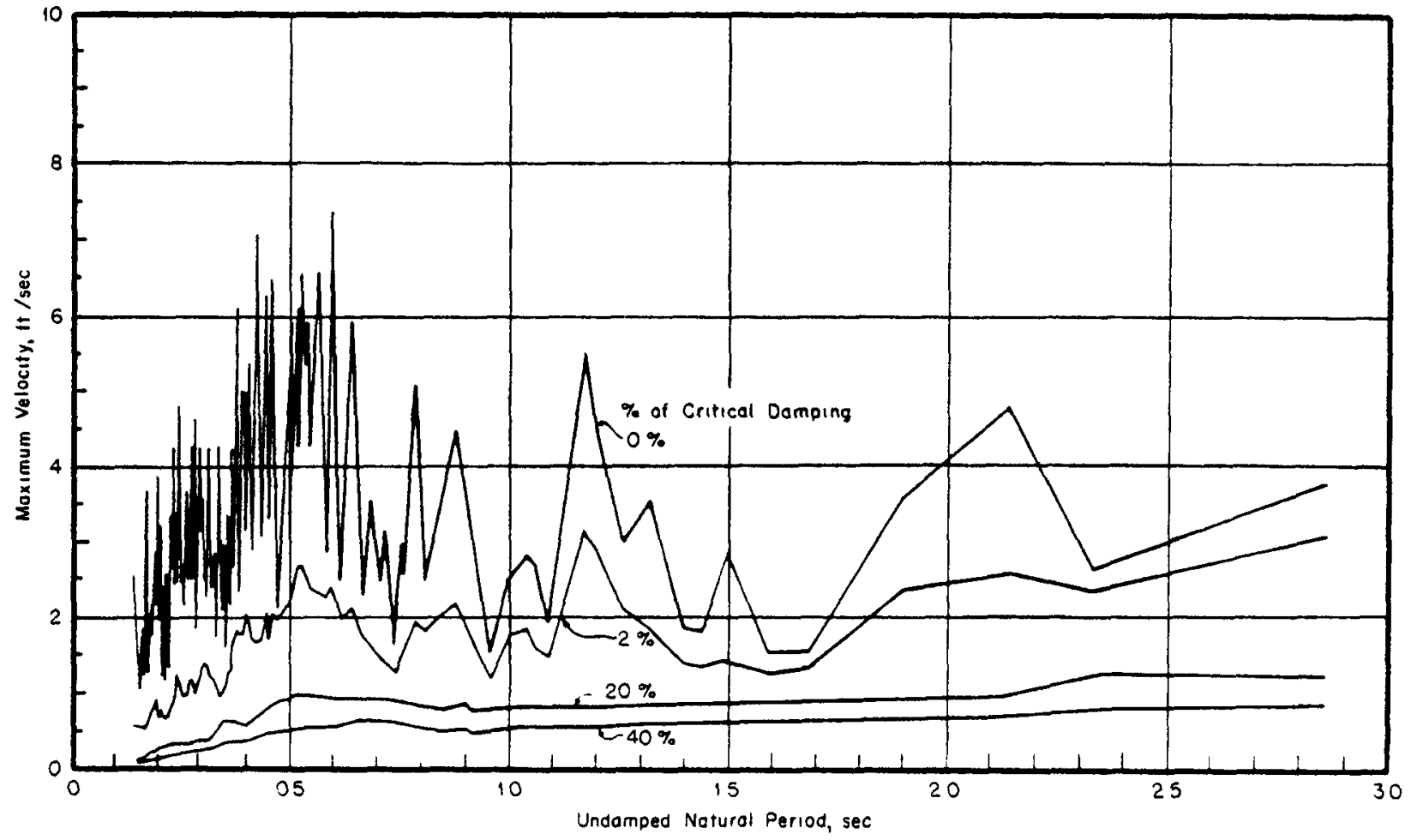

Fig. 1.16-Velocity spectrum for El Centro, Calif., earthquake, May 18, 1940. Component E-W. 


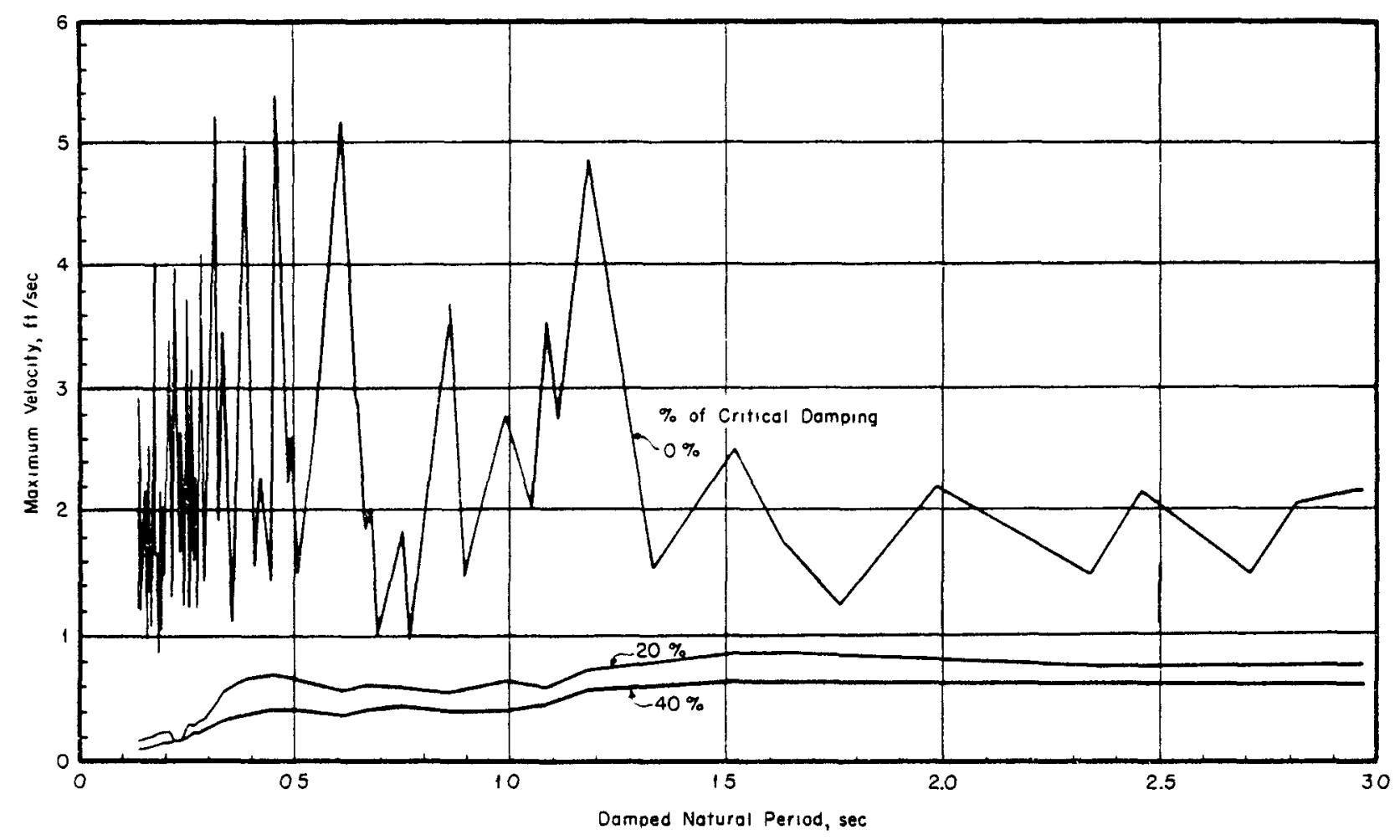

Fig. 1.17-Velocity spectrum for Olympia, Wash., earthquake, Apr. 13, 1949. Component S $10^{\circ} \mathrm{E}$.

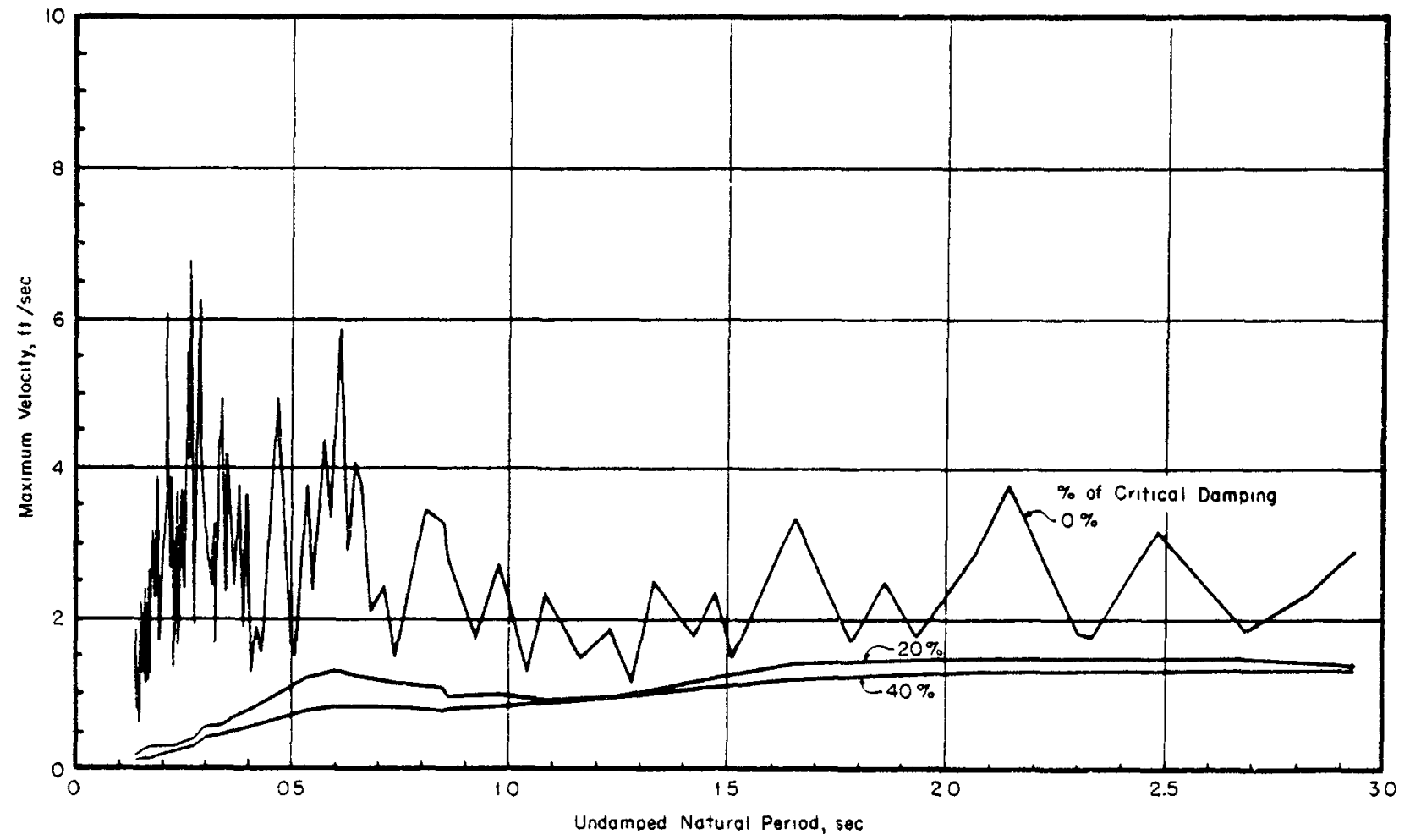

Fig. 1.18 - Veiocity spectrum for Olympia, Wash., earthquake, Apr. 13, 1949. Component S $80^{\circ} \mathrm{W}$. 


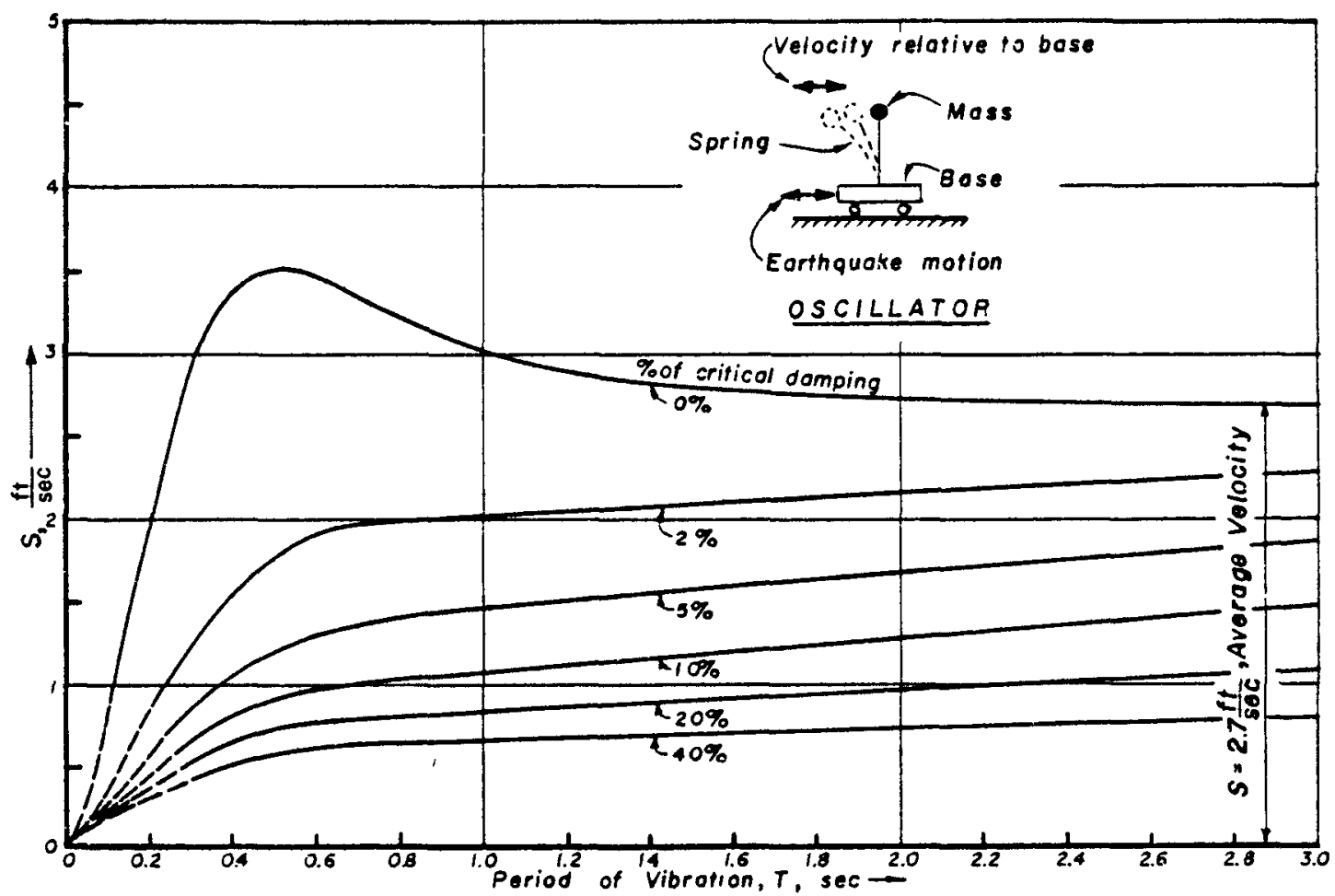

Fig. 1.19-Average-velocity-spectrum curves. Intensity of ground motion recorded at El Centro, Calif., 1940.

The average acceleration and displacement spectra a.s computed from Eq. 1.19 are shown in Figs. 1.21 to 1.24. It should be noted that at zero period the acceleration spectra approach the maximum ground acceleration recorded during the earthquake. In the case of the average acceleration spectrum, the zero-period value shown is that of the maximum acceleration recorded for the El Centro 1940 earthquake and is not the average maximum value. The quantities $S_{2}, S$, and $S_{d}$, designate, respectively, the accelerations, velocity, and displacement spectra.

From the spectrum curves it is possible to read off the maximum response of a single-degree-of-freedom system, and the maximum response of a mode of vibration of a more complex system can also be determined. The average spectrum curves give the average maximum response to be expected if the system is subjected to ground motions of the stated intensity.

The shape of the spectrum curves is affected by the distance from the epicenter. The foregoing spectra were all for points moderately close to the epicenter of a strong earthquake, that is, within approximately $\mathbf{4 5}$ miles. At greater distances from such earthquakes, the short-period end of the spectrum is relatively depressed showing that the higher frequency waves are more attenuated with distance than are the lower frequency waves. On the other hand, at points relatively close to the epicenter of a small earthquake, within approximately 20 miles, the short-period end of the spectrum is relatively accentuated. This is illustrated in Fig. 1.25 where smoothed zero-damped curves for three cases are shown. Curves A and B are spectra of the Tehachapi earthquake of July 21, 1952. Curve $A$ is obtained from the record at Taft, Calif.. about 25 miles from the epicenter, and is typical for locations moderately close to the epicenter of a strong earthquake. Curve $B$ is based on a record of the same earthquake obtained at the Holly wood Storage Company Building, about 70 miles from the epicenter, and is representative 


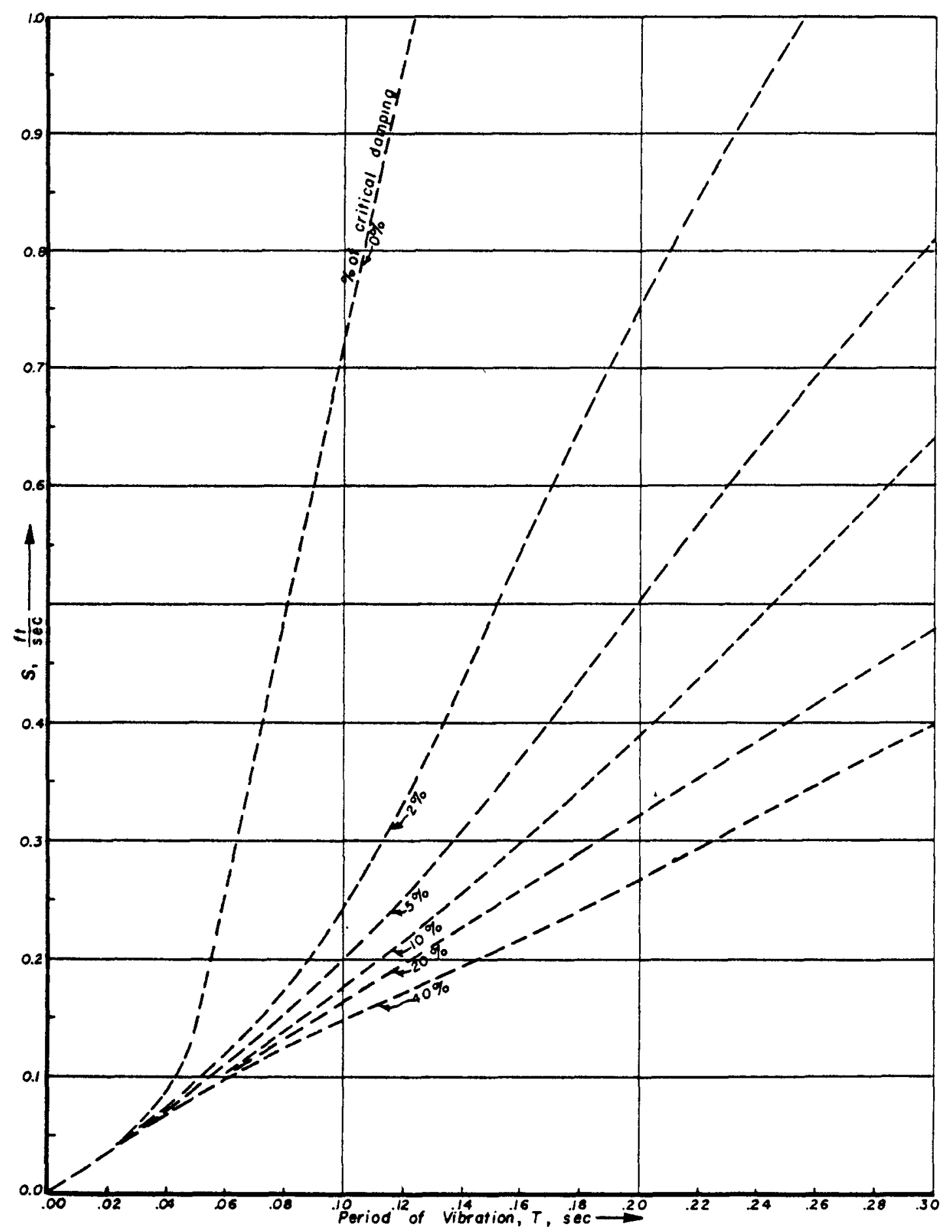

Fig. 1.20-Detail of average-velocity-spectrum curves. Intensity of ground motion recorded at El Centro, Calif., 1940. 


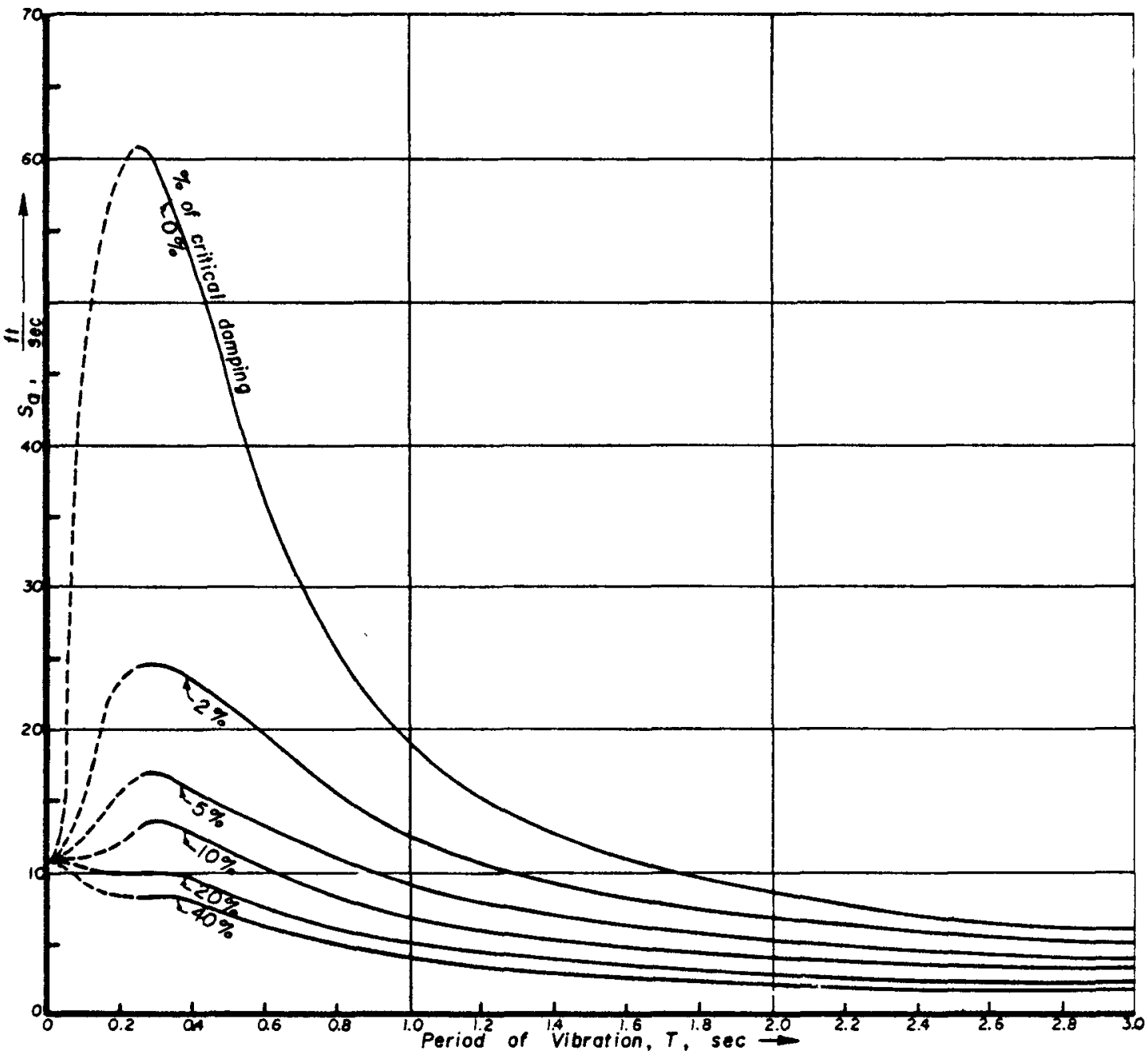

Fig. 1.21 - Average-acceleration-spectrum curves. Intensity of ground motion recorded at El Centro, Calif., 1940. (The zero-period value shown is that of the maximum acceleration recorded for the El Centro 1940 earthquake and is not the average maximum value.)

of a spectrum for points more remote from the epicenter of a strong earthquake. Curve $C$ is the spectrum of the relatively small San Francisco earthquake of Mar. 22, 1957, based on records at a location about 10 miles from the epicenter. This curve is typical of a spectrum for locations relatively close to the epicenter of a small earthquake. The Tehachapi and San Francisco earthquakes had magnitudes of 7.7 and 5.3, respectively.

\section{Spectrum Intensities}

The maximum response of a structure to earthquake ground motion is indicated by the velocity-spectrum curves, and therefore the area under one of the curves is a measure of intensity of the ground motion. ${ }^{1.18,1.42,1.43}$ The spectrum intensity (SI) is defined as the area under the velocity-spectrum curve of the appropriate damping ratio $\zeta$.

$$
\mathrm{SI}_{5}=\int_{0.1}^{2.5} \mathrm{~S}(\mathrm{~T}, \zeta) \mathrm{dT}
$$

It is a measure of the effect of the ground motion on structures having periods of vibration lying between 0.1 and $2.5 \mathrm{sec}$. This range essentially covers the periods of struc- 


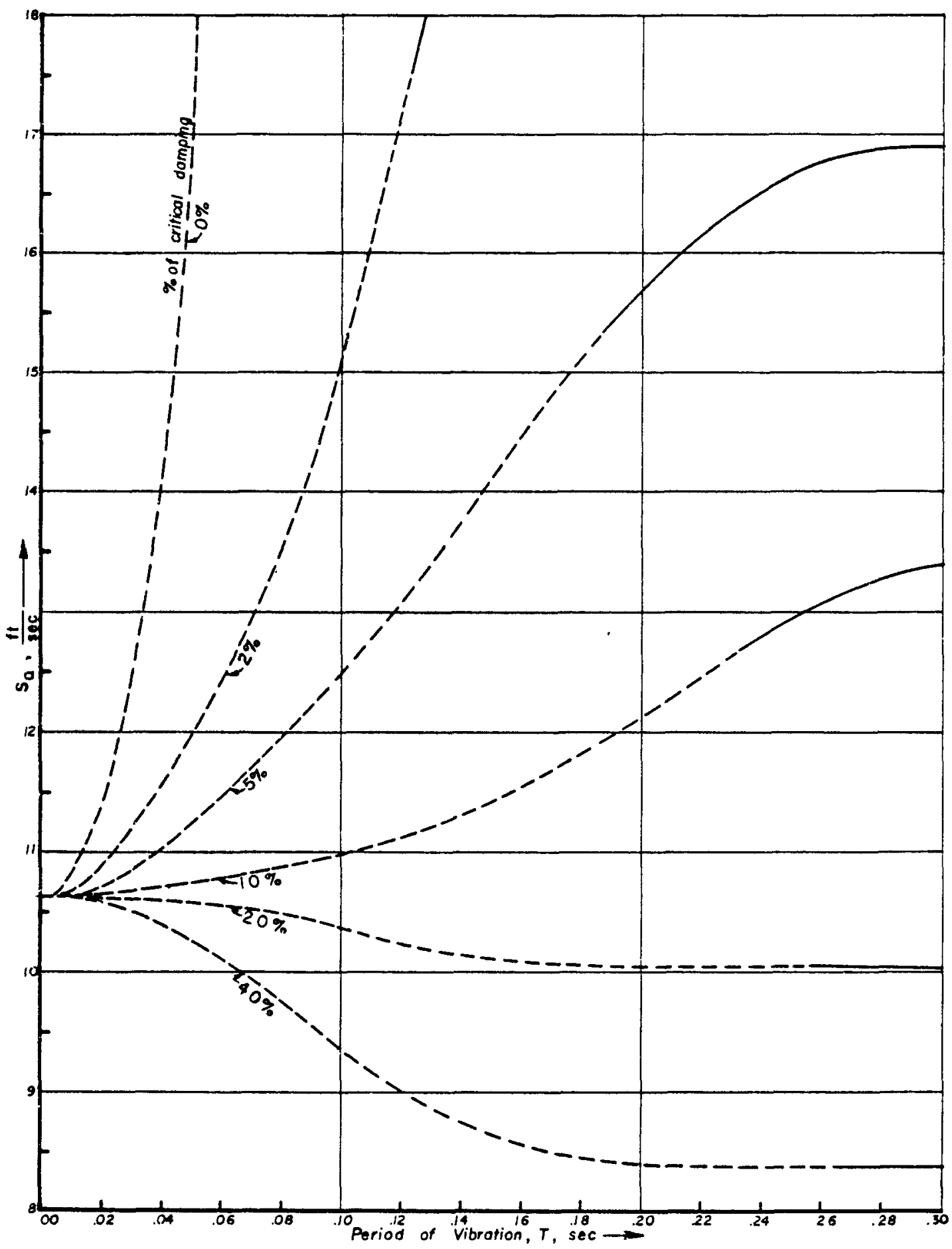

Fig. 1.22-Detail of average-acceleration-spectrum curves. Intensity of ground motion recorded at El Centro, Calif., 1940. (The zero-period value shown is that of the maximum acceleration recorded for the El Centro 1940 earthquake and is not the average maximum value.) 


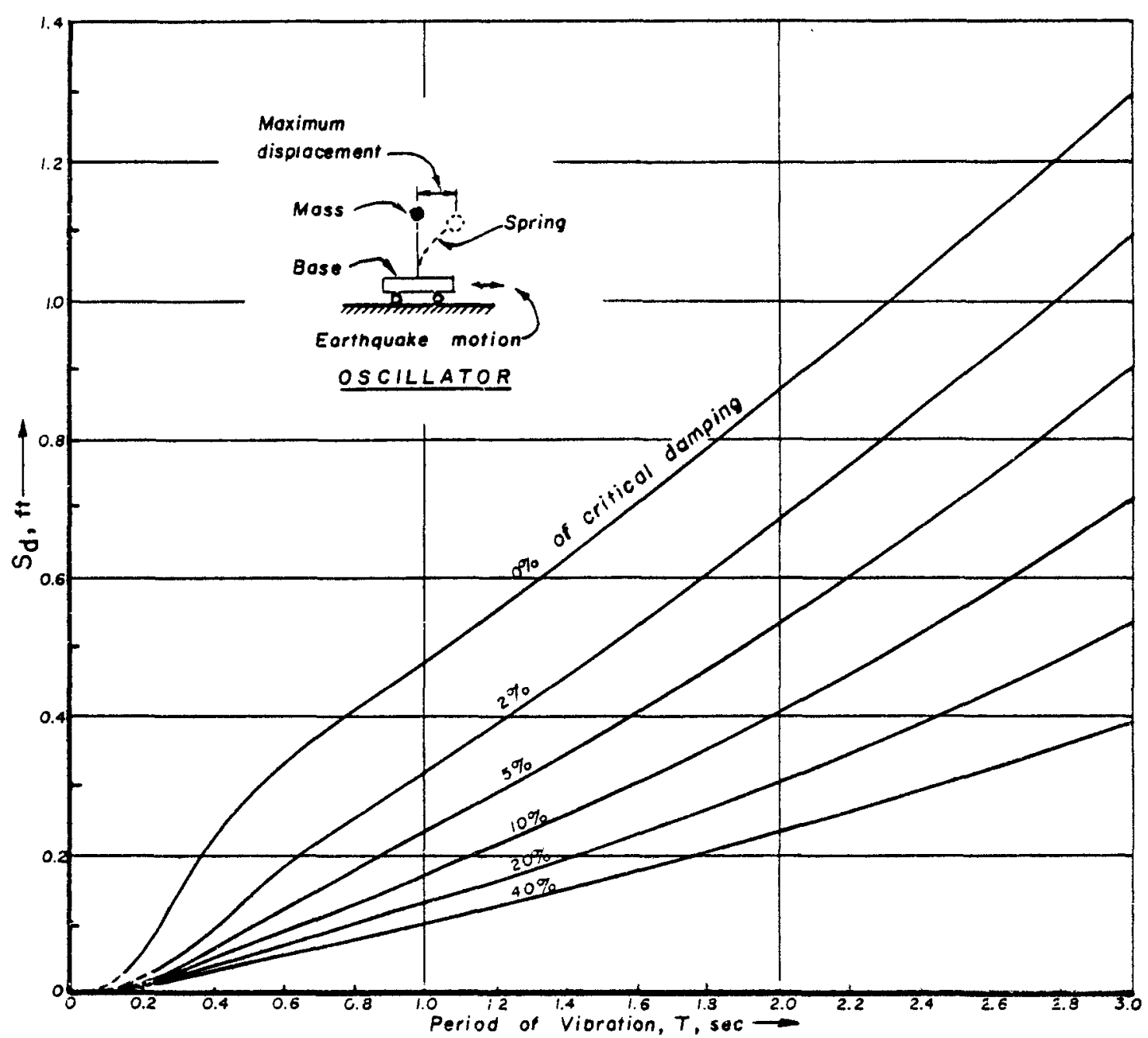

Fig. 1.23-Average-displacement-spectrum curves. Intensity of ground motion recorded at $\mathrm{El}$ Centro, Calit., 1940.

tures located in the earthquake regions of the United States. It should be noted that the spectrum intensity is an objective measure of the maximum stresses tnat would be induced in elastic structures if they were supjected to the recorded ground motion. On the other hand, the Modified-Mercalli intensity is a subjective measure of the degree of damage actually produced by the ground motion.

Table 1.6 presents the zero-damped spectrum intensities for both components of a number of recorded strong ground motions. The average of the two components is listed, and, for comparison, the average for the two componencs of the $20 \%$ critically damped spectrum intensity is also given. Table 1.6 also lists magnitudes and maximum accelerations. The quantity $r$ is the estimated horizontal distance to the center of the fault in miles, and $\mathrm{a}_{\mathrm{g}}$ is the maximum ground acceleration expressed as a fraction of gravity. Magnitudes are those repcrted by the Seismological Laboratory of the California Institute of Technology.

It should be noted that eartnquake No. 4 (July 21, 1952) was produced by more or less vertical slipping on the fault ratier than the more usual horizontal slipping and the rnotion was not as intense at Taft as might have been expected from a magnitude 7.7 snock. Rec- 


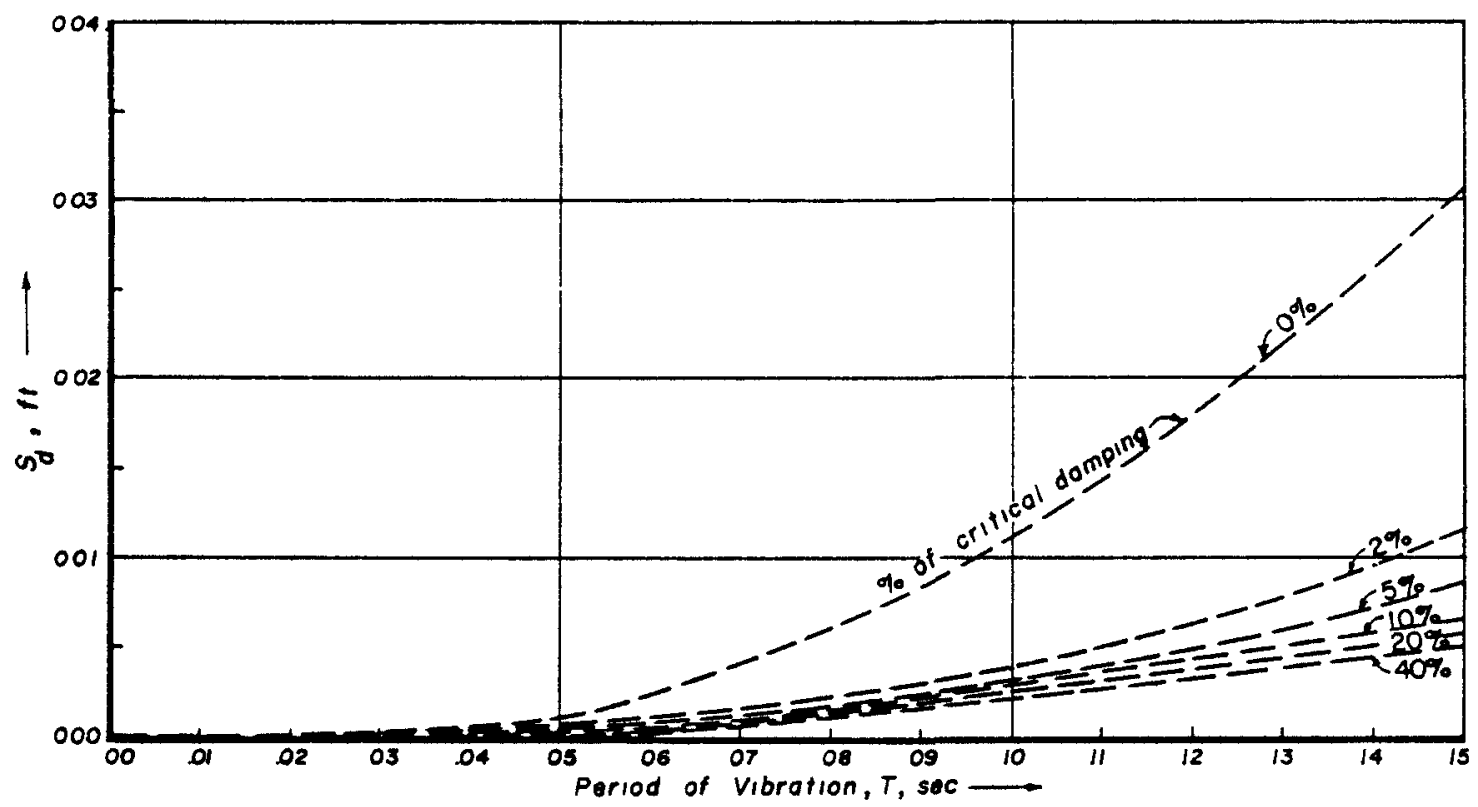

Fig. 1.24-Detall of average-displacement-spectrum curves. Intensity of ground motion recorded at El Centro, Calif., 1940.

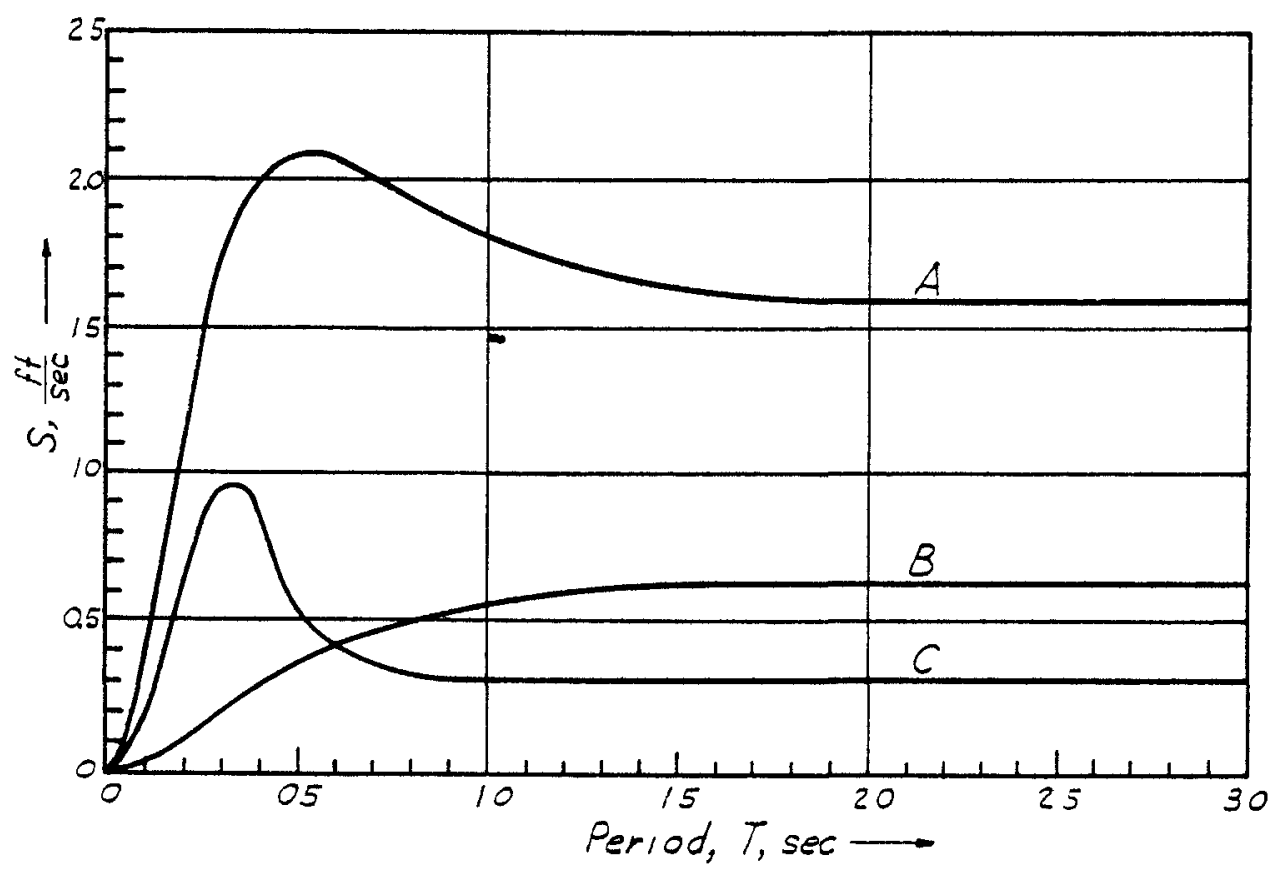

Fig. 1.25 - Undamped velocity-spectrum curves A, approximately 25 miles from center of large earthquake. B, approxımately 70 miles from center of large earthquake. C, approximately 10 miles from center of small earthquake. 
ords No. 9 (Seattle) $)^{1.34}$ and No. 19 (San Francisco, Southern Pacific Building) $)^{1.43}$ were obtained on unusual foundation conditions and therefore are not directly comparable to the other records.

It will be noted in Table 1.6 that the ratios between the zero-damped spectrum intensities are not the same as the ratios between the $20 \%$ critically damped intensities. The explanation for this is that the damped intensities are measures of only that portion of the record having the greatest accelerations, and the duration of the ground motion does not influence this intensity. On the other hand, the zero-damped intensity is in a sense a measure of both the magnitude of the accelerations and the duration of the ground motion. The average spectrum curves presented were scaled so that the damped intensities agreed with the average of the El Centro 1940 earthquakes, and in scaling to other shocks the $20 \%$ damped spectrum intensities should be used unless it is desired to investigate the behavior of an undamped structure.

It is found that the 0.2 damped intensities are approximately related to the undamped intensities by the following empirical equation: ${ }^{1.27}$

$$
\mathrm{SI}_{0.2}=0.444\left(\mathrm{SI}_{0}\right)-0.0124\left(\mathrm{SI}_{0}\right)^{2}
$$

It is found that the maximum accelerations of various earthquakes (see Table 1.6) are approximately related (with considerable scatter) to the damped intensities by the following empirical equation: ${ }^{1.27}$

$$
\begin{aligned}
& a_{g}=\frac{S I_{0.2}}{10} \\
& a_{g}=\text { maximum recorded acceleration as a fraction of gravity }
\end{aligned}
$$

The energy release, E, of an earthquake (in ergs) is approximately stated in terms of earthquake magnitude by Eq. 1.3. The undamped spectrum intensity is also a measure of the energy released, and reasonably good agreement is obtained by taking ${ }^{1.43}$

$$
\begin{aligned}
& \mathrm{E}=1.9 \times 10^{18}\left(\mathrm{SI}_{0}\right)^{2}\left(\frac{\mathrm{h}^{2}+\mathrm{r}^{2}}{\mathrm{~h}_{\circ}^{2}}\right)^{2} \\
& \mathrm{~h}=\text { depth to center of slipped area of fault (miles) } \\
& \mathrm{h}_{\circ}=15 \text { miles } \\
& \mathrm{r}=\text { horizontal distance to center of slipped area (miles) } \\
& \mathrm{SI}_{0}=\text { undamped spectrum intensity measured at distance } \mathrm{r}
\end{aligned}
$$

So $M$ may be calculated from the equation

$$
0.054 \mathrm{M}^{2}-2.14 \mathrm{M}+8.88+2 \log \left(\mathrm{SI}_{0} \frac{\mathrm{h}^{2}+\mathrm{r}^{2}}{\mathrm{~h}_{\circ}^{2}}\right)=0
$$

obtained by substituting Eq. $1.35 \mathrm{a}$ in Eq. 1.3. This empirical equation gives good agreement with the magnitudes calculated by the seismologists. ${ }^{1.43}$

It should be noted that the foregoing expressions do not take into account the details of local geology or the size of the slipped fault area, and hence considerable scatter can be expected if the expressions are checked against observations. The effect of local geology is discussed in Secs. $1.1 \mathrm{G}$ and $1.3 \mathrm{I}$, and reference may be made to publications describing efforts to take into account the size of the slipped area. ${ }^{1.44}$

\section{E. Vibrational Energy of Structures}

An undamped multidegree-of-freedom structure will have forced vibrations as given by Eq. 1.29. The relative kinetic energy and the potential energy at time $t$ are 


$$
\begin{aligned}
& X E=\int 1 / 2 \dot{y}^{2} d m \\
& V=-\int 1 / 2 y(\ddot{y}+\ddot{z}) d m
\end{aligned}
$$

The total energy, $U$, in the structure is

$$
\mathrm{U}=\mathrm{KE}+\mathrm{V}=1 / 2 \sum_{\mathrm{n}} \mathrm{K}_{\mathrm{n}}^{2} \int \phi_{\mathrm{n}}^{2} \mathrm{dm}\left[\left(\int_{0}^{\mathrm{t}} \ddot{z} \sin \omega \tau \mathrm{d} \tau\right)^{2}+\left(\int_{0}^{\mathrm{t}} \ddot{z} \cos \omega \tau \mathrm{d} \tau\right)^{2}\right]
$$

\begin{tabular}{|c|c|c|c|c|c|c|c|c|c|}
\hline No. & Date and location & $\begin{array}{c}\mathrm{r} \\
\text { miles }\end{array}$ & $\begin{array}{c}\mathrm{h} \text {, } \\
\text { miles }\end{array}$ & Magnitude & Component & $\mathrm{SI}_{0}$ & $\begin{array}{c}\mathrm{SI}_{0} \\
\text { (av.) }\end{array}$ & $\begin{array}{l}\mathrm{SI}_{0 . z} \\
\text { (av.) }\end{array}$ & $\begin{array}{l}a_{g}, \\
\% g\end{array}$ \\
\hline \multirow[t]{2}{*}{1} & May 18,1940 & 30 & 15 & 6.7 & $\mathrm{~N}-\mathrm{S}$ & 8.94 & 8.35 & 2.71 & 33 \\
\hline & El Centro, Calif. & & & & $E-W$ & 7.77 & & & 23 \\
\hline \multirow[t]{2}{*}{2} & Dec. 30,1934 & 35 & 15 & 6.5 & $N-S$ & 5.93 & 5.88 & 2.09 & 26 \\
\hline & El Centro, Calif. & & & & $E-W$ & 5.83 & & & 20 \\
\hline \multirow[t]{2}{*}{3} & Apr. 13,1949 & 45 & 45 & 7.1 & $\mathrm{~S} 80^{\circ} \mathrm{W}$ & 6.05 & 5.82 & 2.21 & 31 \\
\hline & Olympia, Wash. & & & & $\mathrm{S} 10^{\circ} \mathrm{E}$ & 5.59 & & & 18 \\
\hline \multirow[t]{2}{*}{4} & July $21,1952^{*}$ & 40 & 15 & 7.7 & $\mathrm{~S} 69^{\circ} \mathrm{E}$ & 4.84 & 4.69 & 1.91 & 18 \\
\hline & Taft, Calif. & & & & $\mathrm{N} 21^{\circ} \mathrm{E}$ & 4.53 & & & 17 \\
\hline \multirow[t]{2}{*}{5} & Mar. 10,1933 & 28 & 15 & 6.3 & $\mathrm{~S} 82^{\circ} \mathrm{E}$ & 4.9 & 4.62 & 1.70 & 19 \\
\hline & Vernon, Calif. & & & & $\mathrm{N} 08^{\circ} \mathrm{E}$ & 4.35 & & & 13 \\
\hline \multirow[t]{2}{*}{6} & June 30,1941 & 15 & 19 & 5.9 & $\mathrm{~S} 45^{\circ} \mathrm{E}$ & 3.43 & 3.29 & 1.80 & 24 \\
\hline & Santa Barbara, Calif. & & & & $\mathrm{N} 45^{\circ} \mathrm{E}$ & 3.15 & & & 23 \\
\hline \multirow[t]{2}{*}{7} & October 3,1941 & 50 & 15 & 6.4 & $\mathrm{~N} 45^{\circ} \mathrm{E}$ & 3.2 & 2.99 & 1.41 & 13 \\
\hline & Ferndale, Calif. & & & & $\mathrm{S} 45^{\circ} \mathrm{E}$ & 2.78 & & & 12 \\
\hline \multirow[t]{2}{*}{8} & May 10,1933 & 33 & 15 & 6.25 & $\mathrm{~N} 51^{\circ} \mathrm{W}$ & 3.21 & 2.94 & 0.82 & 6.5 \\
\hline & Los Angeles Subway Terminal & & & & $\mathrm{N} 39^{\circ} \mathrm{E}$ & 2.67 & & & 4 \\
\hline \multirow[t]{2}{*}{9} & Apr. $13,1949 \dagger$ & 55 & 45 & 7.1 & $\mathrm{~N} 88^{\circ} \mathrm{W}$ & 2.81 & 2.63 & 1.10 & 7.5 \\
\hline & Seattle, Wash. & & & & $\mathrm{S} 02^{\circ} \mathrm{W}$ & 2.46 & & & 5.8 \\
\hline \multirow[t]{2}{*}{10} & Mar. 9, 1949 & 10 & 15 & 5.3 & $\mathrm{~S} 01^{\circ} \mathrm{W}$ & 2.44 & 2.36 & 1.27 & 23 \\
\hline & Hollister, Calif. & & & & $\mathrm{N} 89^{\circ} \mathrm{W}$ & 2.29 & & & 11 \\
\hline \multirow[t]{2}{*}{11} & Oct. 31,1935 & 15 & 25 & 6.0 & $E-W$ & 2.49 & 1.82 & 1.02 & 16 \\
\hline & Helena, Mont. & & & & $\mathrm{N}-\mathrm{S}$ & 1.16 & & & 14 \\
\hline \multirow[t]{2}{*}{12} & Sept. 11, 1938 & 35 & 10 & $5 . \overline{5}$ & $\mathrm{~N} 45^{\circ} \mathrm{E}$ & 1.64 & 1.45 & 0.64 & 8.2 \\
\hline & Ferndale, Calif. & & & & $\mathrm{S} 45^{\circ} \mathrm{E}$ & 1.27 & & & 16 \\
\hline \multirow[t]{2}{*}{13} & Oct. 2,1933 & 17 & 15 & 5.3 & $\mathrm{~S} 82^{\circ} \mathrm{E}$ & 1.65 & 1.32 & 0.69 & 12 \\
\hline & Vernon, Calif. & & & & $\mathrm{N} 08^{\circ} \mathrm{E}$ & 0.99 & & & 8.5 \\
\hline \multirow[t]{2}{*}{14} & Feb. 9, 1941 & 75 & 15 & 6.6 & $\mathrm{~N} 45^{\circ} \mathrm{E}$ & 1.31 & 1.10 & 0.40 & 7.5 \\
\hline & Ferndale, Calif. & & & & $\mathrm{S} 45^{\circ} \mathrm{E}$ & 0.88 & & & 4 \\
\hline \multirow[t]{2}{*}{15} & Oct. 2,1933 & 22 & 15 & 5.3 & $\mathrm{~N} 39^{\circ} \mathrm{E}$ & 1.14 & 0.96 & 0.45 & 6.5 \\
\hline & Los Angeles Survey Termınal & & & & $\mathrm{N} 51^{\circ} \mathrm{W}$ & 0.78 & & & 6 \\
\hline \multirow[t]{2}{*}{16} & Mar. 22,1957 & 7.8 & 7 & 5.3 & $\mathrm{~S} 80^{\circ} \mathrm{E}$ & 1.04 & 0.84 & 0.49 & 13 \\
\hline & $\begin{array}{l}\text { San Francisco, Golden Gate } \\
\text { Park }\end{array}$ & & & & $\mathrm{N} 10^{\circ} \mathrm{E}$ & 0.64 & & & 9.5 \\
\hline \multirow[t]{2}{*}{17} & Mar. 22,1957 & 9.8 & 7 & 5.3 & $\operatorname{S} 09^{\circ} \mathrm{E}$ & 1.29 & 1.12 & 0.58 & 10 \\
\hline & San Francisco, State Building & & & & $\mathrm{S} 81^{\circ} \mathrm{W}$ & 0.95 & & & 6 \\
\hline \multirow[t]{2}{*}{18} & Mar. 22,1957 & 10.8 & 7 & 5.3 & $\mathrm{~N} 81^{\circ} \mathrm{E}$ & 0.50 & 0.48 & 0.28 & 5 \\
\hline & $\begin{array}{l}\text { San Francisco, Alexander } \\
\text { Building }\end{array}$ & & & & $\mathrm{N} 09^{\circ} \mathrm{W}$ & 0.45 & & & 5 \\
\hline \multirow[t]{2}{*}{19} & Mar. $22,1957 \dagger$ & 11.4 & 7 & 5.3 & $\mathrm{~N} 45^{\circ} \mathrm{E}$ & 1.32 & 1.22 & 0.48 & 5 \\
\hline & $\begin{array}{l}\text { San Francisco, Southern } \\
\text { Pacific Bullding }\end{array}$ & & & & $\mathrm{N} 45^{\circ} \mathrm{W}$ & 1.12 & & & 46 \\
\hline \multirow[t]{2}{*}{20} & Mar. 22,1957 & 17.2 & 7 & 5.3 & $\mathrm{~N} 26^{\circ} \mathrm{E}$ & 0.46 & 0.38 & 0.20 & 5 \\
\hline & Oakland, Calıf. & & & & $\mathrm{S} 64^{\circ} \mathrm{E}$ & 0.29 & & & 4 \\
\hline
\end{tabular}

Table 1.6 - SPECTRUM INTENSITIES OF RECORDED GROUND MOTION

*Slipping of fault mainiy vertical.

†Records obtained under unusual foundation conditions. 
The maximum value of the expression within the brackets is $S_{n}^{2}$, the square of the velocity spectrum value for zero damping. The upper bound for the total energy is thus

$$
\overline{\mathrm{U}}=1 / 2 \sum_{n}\left(K_{n}^{2} S_{n}^{2} \int \phi_{n}^{2} d m\right)
$$

The average value over a number of earthquakes of the same intensity is

$$
\overline{\mathrm{U}}_{\mathrm{av} .}=1 / 2 \sum_{\mathrm{n}} \mathrm{K}_{\mathrm{n}}^{2}\left(\mathrm{~S}_{\mathrm{n}}^{2}\right)_{\mathrm{av} .} \int \phi_{\mathrm{n}}^{2} \mathrm{dm}
$$

If the velocity spectrum is a horizontal line, $\left(S_{n}^{2}\right)_{2 v}$. is independent of the period of vibration, ${ }^{1.37}$ and the equation may be written

$$
\bar{U}_{\mathrm{av} .}=1 / 2\left(S_{n}^{2}\right)_{a v .} \sum_{n} K_{n}^{2} \int \phi_{n}^{2} d m
$$

From the orthogonality of the modes

$$
\sum_{n} K_{n} \phi_{n}=1
$$

Squaring and integrating over the mass of the structure gives

$$
\sum_{\mathrm{n}} \mathrm{K}_{\mathrm{n}}^{2} \int \phi_{\mathrm{n}}^{2} \mathrm{dm}=\int \mathrm{dm}=\mathrm{m}
$$

Thus Eq. 1.41 may be written

$$
\overline{\mathrm{U}}_{\mathrm{av} .}=1 / 2 \mathrm{~m}\left(\mathrm{~S}_{\mathrm{n}}^{2}\right)
$$

where $\mathrm{m}=$ total mass of structure.

In general, $\overline{\mathrm{U}}_{\mathrm{av}}$. can be computed from Eq. 1.41, but, if the pertinent modes have periods above approximately $0.3 \mathrm{sec}$, Eq. 1.45 will also give a reasonable estimate. If the modes have approximately $0.5 \%$ critical damping, the spectrum curve is very nearly horizontal in the range $0.3<\mathrm{T}<3$.

If Eq. 1.45 is applicable, it is seen that $\overline{\mathrm{U}}_{\mathrm{av}}$. depends only on the mass, $\mathrm{m}$, and the spectrum value $\left(\mathrm{S}^{2}\right)_{\mathrm{av}}$ and is independent of mass distribution, stiffness of the structure, or framing configuration. This is an important consideration in the determination of structural behavior.

\section{F. Effect of Damping}

It is seen from the spectrum curves that structures with low damping will be subjected to relatively high stresses in the event of strong ground motion. Bare steel structures, particularly such as are welded rather than riveted, have very low damping, ranging from perhaps $1 / 2$ to $3 \%$ of critical damping. Monolithic concrete structures also have relatively low damping of the order of $7 \%$ critical. It will, in general, be found that design of such structures, with the requirement that the stresses remain within the elastic limit, results in relatively large members. As seen from the spectrum curves, damping is very effective in reducing the maximum stresses experienced by a structure.

\section{G. Limit-stress Design}

The spectrum curves show that lightly damped and even moderately damped structures will be subjected to relatively large forces in the event of strong ground motion. In fact, these are larger than the design forces specitied by building codes in seismic regions. However, building codes do not aim at preventing overstress in structures but rather are intended to prevent serious damage. Evidences of overstressing have been observed ${ }^{1.45}$ in structures designed according to the building codes, and lateral forces 
equal to those specified by building codes have been measured even during moderate ground motion. $1.25,1.43$

Most structures have considerable capacity for energy dissipation when they are overstressed. In buildings the walls and partitions dissipate energy through cracking and rubbing, and steel frames can absorb energy by plastic defcrmation, etc.

An exact analysis of the vibrations of overstressed (nonlinear) structures is very difficult, and the results of such analyses are not yet in a form to be used for design. ${ }^{1.46,1.47}$ An approximate method has been proposed ${ }^{1.48}$ which is based on Eq. 1.45 or 1.41 , and can be expressed as follows:

$$
\mathrm{U}=\mathrm{D}+\mathrm{V}
$$

$U$ represents the total energy input into the structure up to the time that the last nonlinear overstress occurs; $D$ is the energy dissipated by the structure; and $V$ is the elastic strain energy in the structure at the time that the last overstress occurred. If it is taken that

$$
U=1 / 2 m s^{2}
$$

as in Eq. 1.45 (that is, if it is assumed that the maximum input energy into the overstressed structure is the same as the maximum input for an equivalent elastic undamped structure), then

$$
D=1 / 2 m S^{2}-V
$$

and this equation specifies the amount of energy that must be absorbed if the structure is to remain standing. For ground motion of approximately the intensity of the El Centro 1940 records (Fig. 1.19), the equation becomes

$$
\mathrm{D}=\mathrm{cW}-\mathrm{V}
$$

where $W$ is the weight of the structure and $c=1 / 16 \mathrm{ft}-\mathrm{lb} /$ pound of weight for a structure with approximately $2 \%$ damping.

Equation 1.48 is valid when $T$ is about $0.3 \mathrm{sec}$ or greater and gives reasonably good agreement with field observations of plastically deformed structures. ${ }^{1.48}$ If the equation is used for design, an appropriate factor of safety must be incorporated. Although the equation can be applied easily to simple structures, its usefulness when applied to complex structures is limited because of the difficulty of determining the specific points where plastic deformation will occur.

The importance of plastic energy absorption is illustrated by considering a steel bar of $1-s q$ in. cross-sectional area and 1 in. length. If the elastic limit of the steel is 33,000 psi, the strain energy absorbed at this stress is

$$
\mathrm{V}=\frac{1}{2} \frac{33,000}{30 \times 10^{6}} \frac{33,000}{12}=1.5 \mathrm{ft}-\mathrm{lb} / \mathrm{cu} \mathrm{in.}
$$

If the bar is stretched plastically to a strain of $0.02 \mathrm{in} . / \mathrm{in}$. , the energy absorbed plastically (assuming perfect plasticity) is

$$
D=33,000(0.02-0.0011) 1 / 12=50 \mathrm{ft}-\mathrm{lb} / \mathrm{cu} \text { in. }
$$

Thus it is seen that with suitable design it is possible for a structure to absorb a large amount of energy plastically while retaining an adequate factor of safety against collapse. For example, an elevated water $\operatorname{tank}^{1.48}$ with rod bracing, which would require design for 
a $40 \% \mathrm{~g}$ Iateral acceleration to remain elastic during ground motion of the El Centro 1940 intensity, could be designed for $12 \% \mathrm{~g}$ with allowance for plastic deformation and still have a factor of safety of approximately two. A plastic design must, of course, be done very carefully to ensure that rupture or brittle fracture does not occur. The total energy absorbed in failing members by oscillatory plastic strains is not well established at the present time so that such designs should be made on a conservative basis.

\section{H. Building Vibration Records}

As yet, structural response has not been measured during strong earthquake ground motion, but measurements have been recorded for moderately strong ground motion. Three examples of such records are given in the next three paragraphs.

A quarry blast ${ }^{1.49}$ involving $370,000 \mathrm{lb}$ of buried explosives at a distance of $370 \mathrm{yd}$ from a building produced the horizontal acceleration shown in Fig. 1.26 in the basement of the building. The concrete second floor of the building, supported on braced steel columns, experienced the horizontal accelerations shown in Fig. 1.27. The first two modes of vibration of the building had periods of 0.35 and $0.28 \mathrm{sec}$, respectively; the first of which was strongly excited. The maximum ground acceleration was $0.075 \mathrm{~g}$, and the maximum recorded building acceleration was $0.105 \mathrm{~g}$. From the spectrum of the ground motion, the maximum computed building acceleration was $0.10 \mathrm{~g}$.

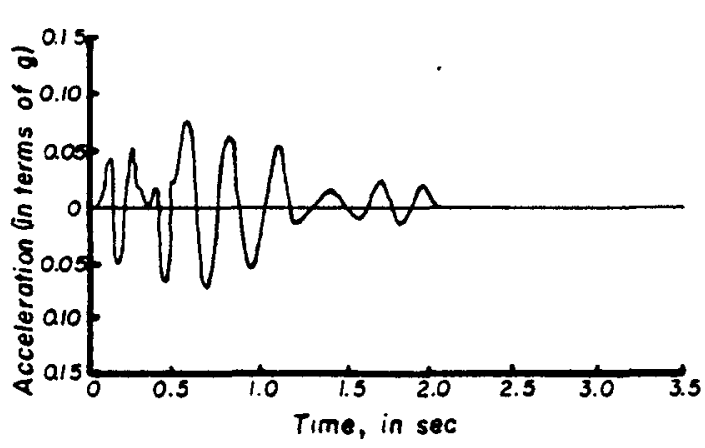

Fig. 1.26-Measured ground motion at base of the building.

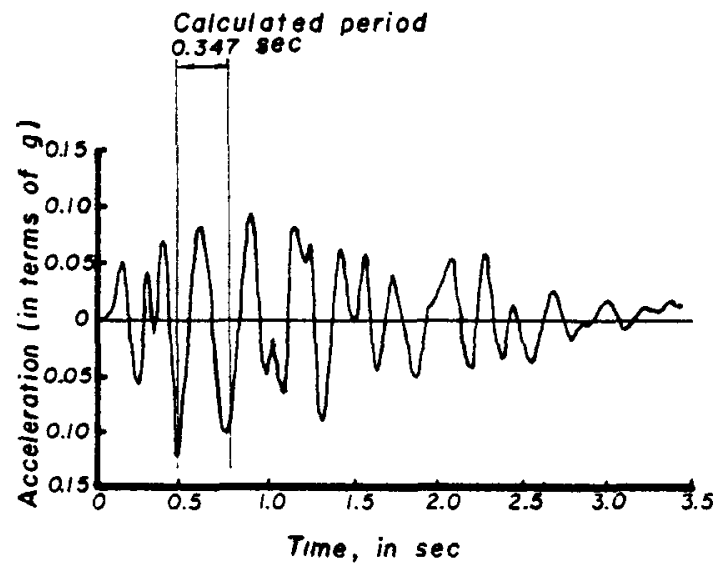

Fig. 1.27-Acceleration-time record of floor slab in building at $48-\mathrm{ft}$ elevation above grade.

As another example, the Hollywood Storage Company Building was approximately 70 miles south of the center of the Arvin-Tehachapi earthquake of July 21, 1952, and the ground motion recorded in the basement of the building is shown in Fig. 1.5. The building is a monolithic reinforced-concrete structure $141 \mathrm{ft}$ high, with a basement. It is rectangular in plan, measuring $217 \mathrm{ft}$ in the east-west direction and $51 \mathrm{ft}$ in the north-south direction. Prior to the earthquake the measured periods of wind-induced vibration were $0.49 \mathrm{sec}$ in the east-west direction and $1.2 \mathrm{sec}$ in the north-south direction. The periods in these two directions were 0.54 and $0.87 \mathrm{sec}$, respectively, as deduced from the measured building vibrations during the earthquake. The acceleration measured on the roof of the building is also shown in Fig. 1.5. The maximum roof acceleration in the north-south direction was $13 \% \mathrm{~g}$, which was composed of approximately $12 \% \mathrm{~g}$ from the first mode and $1 \% \mathrm{~g}$ from the second mode. In the east-west direction, the maximum roof acceleration was $14 \% \mathrm{~g}$ of which approximately $11 \% \mathrm{~g}$ came from the first mode and $3 \% \mathrm{~g}$ from the 
second mode. Because of the long distance from the epicenter, the spectra of this ground motion were relatively low in the short-period end. The undamped spectrum intensity for this ground motion was 1.4. The motions shown in Fig. 1.5 were recorded by the U. S. Coast and Geodetic Survey.

The Alexander Building was approximately 11 miles from the epicenter of the San Francisco earthquake of Mar. 22, 1957, and the ground motion recorded in the basement and on the roof of the building was as shown in Fig. 1.28. The building is a relatively slender 15 -story steel-frame structure ${ }^{1.50}$ with masonry walls. The periods in both directions were approximately $1.3,0.4$, and $0.25 \mathrm{sec}$ for the first three modes. Because the building was close to the epicenter of a small earthquake, the short-period end of the spectrum was relatively high, and the second and third modes of the building were strongly excited. The maximum ground acceleration was $5 \% \mathrm{~g}$ and the maximum roof acceleration was $12 \% \mathrm{~g}$. The building was excited into short-perıod vertical oscillations, as shown in Fig. 1.28. The motions shown in Fig. 1.28 were recorded by the U. S. Coast and Geodetic Survey. Analysis by Hudson shows good agreement between computed and measured response of this structure. ${ }^{1.40}$

\section{Influence of Foundation Conditions}

The precise influence of foundation conditions is not yet well understood. Two different factors are involved: the influence of local geology on the intensity of the ground motion, and the influence of the ground conditions on the behavior of the structure. The first of these is a matter of geology, and the second is a matter of engineering.

With respect to the influence of local geology on ground motion intensity, it is known that, if a plane stress wave travels through a medium of high modulus of elasticity into a medium of low modulus of elasticity, the displacements and accelerations are essentially doubled. Therefore it may be expected that, if seismic waves travel up through base rock and pass into surface alluvium, there would result at least a doubling of the intensity if the alluvium behaves elastically. On the other hand, if the alluvium is overstressed by the seismic waves, there will be energy absorption with a corresponding diminution of intensity. If the seismic waves travel from rock into an alluvium formed of layers and lenses with different properties, it appears at present to be impossible to predict the effect on the intensity of ground motion.

Observarions made after earthquakes often report heavier damage in alluvial valleys than on rocky nills. Similar reports are also sometımes made in comparing damage on firm vs. soft alluvium. Measurements of very weak ground motions ${ }^{1.51}$ have shown negligible influence for periods around 0.1 and $10 \mathrm{sec}$. However, for some locations, measurements have shown marked amplifications for periods between 0.1 and $10 \mathrm{sec}$. For the weak ground motions measured, it was found that some geological conditions amplified the ground motion as much as 5 to 1 compared with measurements on rock.

On the other hand, there have also been reports of more damage on rock than on alluvium. Strong-motion measurements at Olympia and Seattle during the earthquake of Apr. 13, 1949, showed the following influence of ground. ${ }^{1.34}$ The two instruments were approximately the same distance from the epicenter, with the Olympia instrument on firm alluvium and the Seattle instrument on water-logged fill. The Seattle record indicated less intense ground motion than the Olympia record, the undamped spectrum intensities being in the ratio of 2.6 to 5.8 .

During the San Francisco earthquake of Mar. 22, 1957, the data given in Table 1.7 were obtained. ${ }^{1.43}$

When correction ${ }^{1.43}$ is made for the different distances from the epicenter, the ratios of acceleration and intensity obtained are as given in Table 1.8. From this it appears that the local ground condition at the Alexander Building had small influence; whereas at the State Building it had appreciable influence. These data incicate that the effect of ground 

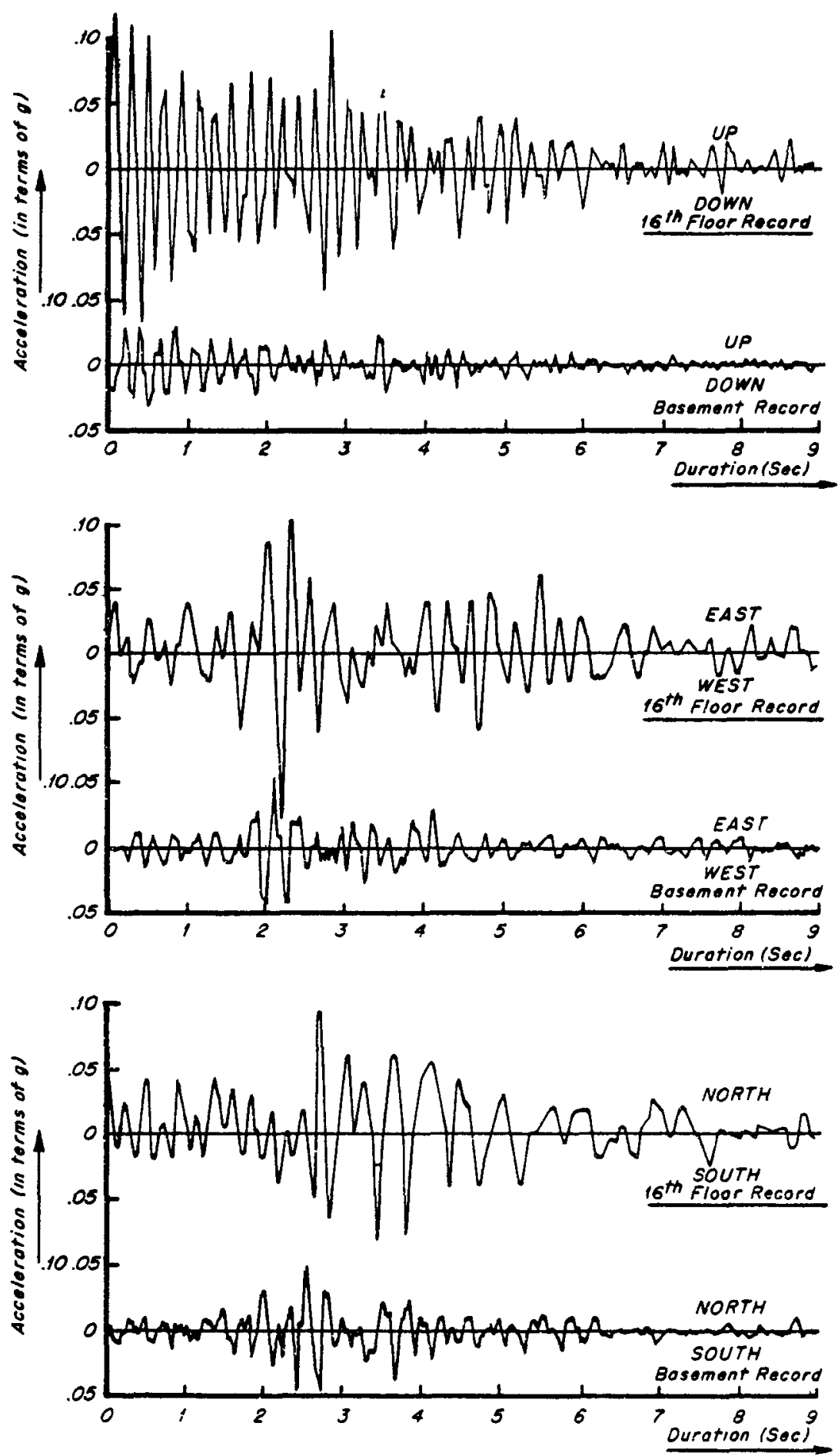

Fig. 1.28-Accelerograph records of the San Francisco, Calif., earthquake, Mar. 22, 1957, from se1smographs located on the 16th floor and in the basement of the Alexander Building, San Francisco, Calıf. Located approximately 10 miles from center of fault. (Data from U. S. Coast and Geodetic Survey.) 
is not simply a matter of depth and softness of alluvium. At present there are not sufficient instrumental data from strong earthquakes to establish the precise influence of local geology on strong earthquake ground motions.

Table 1.7-DATA FROM SAN FRANCISCO EARTHQUAKE, MAR. 22, 1957

\begin{tabular}{lclcc}
\hline \multicolumn{1}{c}{ Station } & $\begin{array}{c}\text { Epicentral } \\
\text { distance, } \\
\text { miles }\end{array}$ & Type of ground & $\begin{array}{c}\text { Maximum } \\
\text { acceleration, g }\end{array}$ & $\begin{array}{c}\text { Spectrum } \\
\text { intensity }\end{array}$ \\
\hline Golden Gate Park & 7.8 & Rock & 0.13 & 0.84 \\
State Building & 9.8 & $\sim 100 \mathrm{ft}$ of alluvium & 0.105 & 1.12 \\
Alexander Building & 10.8 & $\sim 120 \mathrm{ft}$ of alluvium & 0.05 & 0.48 \\
\hline
\end{tabular}

The influence of local geology on the behavior of structures is somewhat better understood. A soft alluvium that may consolidate unevenly during an earthquake and thus permit differential settlement of the foundation of the structure is a serious hazard. A differential settlement of a fraction of an inch may produce very large stresses and lead to failure during the earthquake. Such failures have been observed, but usually it is difficult to establish whether or not foundation settlement has occurred; thus very little data on this subject have been gathered. A soft alluvium may also promote rocking of the structure during an earthquake and cause overstressing of the soil with consequent deleterious effect on the structure.

A well-designed building of typical proportions founded on moderately firm soil can be treated as if supported on a firm base. However, if the soil is sufficiently soft, the base of the building may move laterally relative to the soil. This was demonstrated in the record obtained in the Southern Pacific Building in San Francisco during the earthquake of Mar. 22, 1957. This structure is founded on piles in very soft alluvium, and the acceleration recorded in the basement showed that the base of the building had oscillated

Table 1.8-RATIOS OF ACCELERATION AND INTENSITY

\begin{tabular}{lll}
\hline \multicolumn{1}{c}{ Station } & Maximum acceleration & Spectrum intensity \\
\hline Golden Gate Park & 1.0 & 1.0 \\
State Building & 1.3 & 2.0 \\
Alexander Building & 0.75 & 1.1 \\
\hline
\end{tabular}

laterally. The spectrum curves showed pronounced peaks that coincided with the measured periods of vibration of the building. ${ }^{1.43}$ Thus in this case the softness of the ground introduced another degree of freedom in the structure. There is nothing inherently bad in this extra degree of freedom. It may, in fact, be advantageous for a heavy stiff structure, but the soil must then be treated as part of the structure, and the design should be such as to avoid undesirable permanent displacements.

Numerous studies of the influence of ground have been made by Japanese investi gators and are reported in the bulletin of the Earthquake Research Institute of Tokyo University. These are of particular interest when considering the influence of very soft soils. 


\section{REFERENCES}

1.1 B. Gutenberg and C. F. Richter, Seismicity of the Earth and Associated Phenomena, Princeton University Press, Princeton, N. J., 1954.

1.2 H. Benioff and B. Gutenberg, General Introduction to Seismology, Earthquakes in Kern County, California, During 1952, Bulletin 171, State of California, Department of Natural Resources, Division of Mines, San Francisco, 1955.

1.3 L. U. DeSitter, Structural Geology, McGraw-Hill Book Company, Inc., New York, 1956, 555 pp.

1.4 B. Gutenberg and C. F. Richter, Evidence from Deep-focus Earthquakes, Internal Constitution of the Earth, Part 7 of the Series Physics of the Earth, McGraw-Hill Book Company, Inc., New York, 1939, 413 pp.

1.5 G. D. Louderback, Characteristics of Active Faults in the Central Coast Ranges of California with Application to the Safety of Dams, Bull. Seismol. Soc. Am., 27(1): 1-27 (1937).

1.6 J. J. Collins and H. L. Foster, The Fukui Earthquake, Hokuriku Region, Japan, 28 June 1948 , Vol. I, Geology, Office of the Engineer, U. S. Far East Command, 81 pp.

1.7 C. A. Whitten, Measurements of Earth Movements in California, in Earthquakes in Kern County, California, During 1952, Bulletin 171, pp. 75-80, State of California, Department of Natural Resources, Division of Mines, San Francisco, 1955.

1.8 G. Eiby, About Earthquakes, Harper \& Brothers, New York, 1957. (L of C card 57-6137).

1.9 N. H. Heck, Earthquakes, Princeton University Press, Princeton, N. J., 1936.

$1.10 \mathrm{~K}$. E. Bullen, An Introduction to the Theory of Seismology, 2nd ed., Cambridge University Press, New York, 1953.

1.11 D. B. Gumensky, Earthquakes and Earthquake Resistant Design, in Abbetts' American Civil Engineering Practice, Vol. III, John Wiley \& Sons, Inc., New York, 1957.

1.12 B. Gutenberg and C. F. Richter, Earthquake Magnitude, Intensity, Energy, and Acceleration, Bull., Seismol. Soc. Am., 46: (1956).

1.13 B. Gutenberg and C. F. Richter, Earthquake Magnitude, Intensity, Energy, and Acceleration, Bull., Seismol. Soc. Am., 32: (July 1942).

1.14 John Hershberger, A Comparison of Earthquake Accelerations With Intensity Ratings, Bull. Seismol. Soc. Am., 46(4): (October 1956).

1.15 Perry Byerly, Seismicity of the Western United States, in Proceedings of the 1956 World Conference, Earthquake Engineering, Earthquake Engineering Research Institute, 1956.

1.16 N. H. Heck, Earthquake History of the United States, Part I, Continental United States and Alaska (Exclusive of California and Western Nevada). Serial No. 609, rev. 1947 ed., U. S. Department of Commerce, Coast and Geodetic Survey, Washington, D. C.

1.17 H. O. Wood and N. H. Heck, Earthquake History of the United States, Pt. II, Stronger Earthquakes of California and Western Nevada, Serial No. 609, rev. 1951 ed., U. S. Department of Commerce, Coast and Geodetic Survey, Washington, D. C.

1.18 G. W. Housner, Spectrum Intensities of Strong-motion Earthquakes, in Proceedings of the Symposium on Earthquake and Blast Effects on Structures, Los Angeles, Earthquake Engineering Research Institute and University of California, 1952.

1.19 L. M. Murphy and F. P. Ulrich, United States Earthquakes, 1949 , Serial No. 748 , U. S. Department of Commerce, Coast and Geodetic Survey, Washington, D. C.

1.20 L. M. Murphy and W. K. Cloud, United States Earthquakes, 1952, Serial No. 773, U. S. Department of Commerce, Coast and Geodetic Survey, Washington, D. C.

1.21 L. M. Murphy and W. K. Cloud, United States Earthquakes, 1954, Serial No. 793, U. S. Department of Commerce, Coast and Geodetic Survey, Washington, D. C.

1.22 V. L. Vanderhoof, The Major Earthquakes of California: An Historical Summary, Earthquakes in Kern County, California, During 1952, Bulletin 171, State of California, Department of Natural Resources, Division of Mines, San Francisco, 1955.

1.23 Uniform Building Code, 1958, Pacific Coast Building Officials Conference, 610 South Broadway, Los Angeles. 


\section{REFERENCES}

1.24 Modern Building Inspection, 2nd ed., Building Standards Monthly Publishing Company, 124 West Fourth Street, Los Angeles, 1951.

1.25 G.W. Housner, Interaction of Building and Ground During an Earthquake, Bull. Seismol. Soc. Am., 47: (1057).

1.26 R. G. Merritt and G. W. Housner, Effect of Foundation Compliance on Earthquake Stresses in Tall Buildings, Bull. Seismol. Soc. Am., 44: (1954).

1.27 G. W. Housner, Intensity of Ground Motion During Strong Earthquakes, Second Technical Report for Office of Naval Research, Californı Institute of Technology, Pasadena, Calif., August 1952.

1.28 L. S. Jacobsen and R. S. Ayre, Engineering Vibrations, McGraw-Hill Book Company, Inc., New York, 1958.

1.29 S. Timoshenko, Vibration Problems in Engineering, 3rd ed., D. Van Nostrand Co., Inc., New York, 1955.

1.30 J. P. Den Hartog, Mechanical Vibrations, 4th ed., McGraw-Hill Book Company, Inc., New York, 1956.

1.31 W. T. Thomson, Mechanical Vibrations, 2nd ed., Prentice-Hall, Inc., Englewood Cliffs, N. J., 1953.

1.32 G. W. Housner, Characteristics of Strong-motion Earthquakes, Bull., Seismol. Soc. Am., 37: (1947).

1.33 T. K. Caughey and D. E. Hudson, A Response Spectrum Analyzer for Transient Loading Studies, in Proceedings of the Society for Experimental Stress Analysis, Vol. XIII, No. 1, 1956.

1.34 G. W. Housner, R. R. Martel, and J. L. Alford, Spectrum Analysis of Strong Motion Earthquakes, Bull. Seismol. Soc. Am., 43: (1953).

1.35 A. C. Eringen, Response of Beams and Plates to Random Loads, J. Appl. Mechanics, 24(1): (March 1957).

1.36 L. E. Goodman, E. Rosenblueth, and N. M. Newmark, Aseismic Design of Firmly Founded Elastic Structures, Trans. Am. Soc. Civil Engrs., 117: (1952).

1.37 D. E. Hudson, Response Spectrum Techniques in Engineering Seismology, in Proceedings of the 1956 World Conference, Earthquake Engineering, Earthquake Engineering Research Institute, 1956.

1.38 G. N. Bycroft, White Noise Representation of Earthquakes, Proc. Am. Soc. Civil Engrs., EM-2 (April 1960).

1.39 H. S. Tsien, Engineering Cybernetics, Chap. 9, McGraw-Hill Book Company, Inc., New York, 1954.

1.40 E. Rosenblueth, Some Applications of Probability Theory in Aseismic Design, in Proceedings of the 1956 World Conference, Earthquake Engineering, Earthquake Engineering Research Institute, 1956.

1.41 B. H. Rasmussen, Earthquake Forces on Systems with Several Degrees of Freedom, Bull. Seismoi. Soc. Am., 42: (1952).

1.42 H. Benioff, Physical Evaluation of Seismic Destructiveness, Bull. Seismol. Soc. Am., 24: (1934).

1.43 D. E. Hudson and G. W. Housner, Analysis of Strong-motion Accelerometer Data from the San Francisco Earthquake of March 22, 1957, Bull. Seismol. Soc. Am., 47: (1957).

1.44 G. W. Housner, Properties of Strong Ground Motion Earthquakes, Bull. Seismol. Soc. Am., 45: (1955).

1.45 G. B. Oakeshott (Ed.), Earthquakes in Kern County, California, During 1952, Bulletin 171, Department of Natural Resources, Division of Mines, San Francisco, 1955.

1.46 G. V. Berg, Analysis of Structural Response to Earthquake Forces, Report IP-291, University of Michigan, College of Engineering Industry Program. May 1958.

1.47 R. Tanabashı, Nonlinear Vibrations of Structures Subjected to Destructıve Earthquakes, in Proceedings of the 1956 World Conference. Earthquake Engineering, Earthquake Engineering Research Institute, 1956. 
1.48 G. W. Housner, Limit Design of Structures to Resist Earthquakes, in Proceedings of the 1956 World Conference, Earthquake Engineering, Earthquake Engineering Research Institute, 1956.

1.49 D. E. Hudson and G. W. Housner, Structural Vibrations Produced by Ground Motion, Trans. Am. Soc. Civil Engrs., 122: (1957).

1.50 J. A. Blume, Period Determinations and Other Earthquake Studies of a Fifteen Story Building, in Proceedings of the 1956 World Conference, Earthquake Engineering, Earthquake Engineering Research Institute, 1956.

1.51 B. Gutenberg, Effect of Ground on Earthquake Motion, Bull. Seismol. Soc. Am., 47: (1957).

\section{ADDITIONAL REFERENCE MATERIAL}

Alford, J. P., and G. W. Housner, A Dynamic Test of a Four Story Reinforced Concrete Building, Bull. Seismol. Soc. Am., 43: (1953).

Ayre, R. S., Interconnection of Translational and Torsional Vibrations in Buildings, Bull. Seismol. Soc. Am., 28: (1938).

Ayre, R. S., Methods for Calculating the Earthquake Response of Shear Buildings, in Proceedings of the 1956 World Conference, Earthquake Engineering, Earthquake Engineering Research Institute, 1956.

Biot, M. A., Analytical and Experimental Methods in Engineering Seismology, Trans. Am. Soc. Civil Engrs., 108: (1943).

Bull. Earthquake Research Inst., Tokyo Univ., 1926-1960.

Butler, D., M. Muto, and K. Minami, The Fukui Earthquake, Hokuriku Region, Japan, 28 June 1948, Office of the Engineer, Design Branch, Engineering and Operation Division, U. S. Far East Command.

Byerly, Perry, Earthquake Origin and Propagation. in Proceedings of the Symposium on Earthquake and Blast Effects on Structures, Los Angeles, Earthquake Engineering Research Institute and University of California, 1952.

Carder, D. S., Observed Vibrations of Buildings, Bull. Seismol. Soc. Am., 26: (1936).

Casagrande, A., and W. L. Shannon, Strength of Soils under Dynamic Loads, Trans. Am. Soc. Civil Engrs., 114: (1949).

Clark, G. B., and R. D. Caudle, Geologic Structure Stability and Deep Protection Construction, Report AFSWC-TDR-61-93, November 1961.

Clough, R. W., On the Importance of Higher Modes of Vibration in the Earthquake Response of a Tall Building, Bull. Seismol. Soc. Am., 45: (1955).

Converse, F. J., Movements of Building Footings due to Earthquake Loads, in Proceedings of the International Conference on Soil Mechanics and Foundation Engineering, Vol. 1, Harvard University, Cambridge, Mass., 1936.

Duke, C. M., Bibliography on Effects of Soil Conditions on Earthquake Damage, Earthquake Engineering Research Institute, San Francisco, 1958.

Duke, C. M., Effects of Ground on Destructiveness of Large Earthquakes, Proc. Am. Soc. Civil Engrs., 84: SM-3. Pt. 1, Paper 1730 (1958), 23 pp.

Duke, C. M., and R. A. Brisbane, Earthquake Strain Measurements in a Reinforced Concrete Building, Bull. Seismol. Soc. Am., 45: (1955).

Evaldson, R. L., R. S. Ayre, and L. S. Jacobsen, Response of an Elastically Nonlinear System to Transient Disturbances, J. Franklin Inst., 24: (1949).

Freeman, J. R., Earthquake Damage and Earthquake Insurance, McGraw-Hill Book Company, Inc., New York, 1932.

Hisada, T., and N. Nakagawa, Vibration of Buildings in Japan, in Proceedings of the 1956 World Conference, Earthquake Engineering, Earthquake Engineering Research Institute, 1956.

Hollis, E. P., Bibliography of Engineering Seismology, Earthquake Engineering Research Institute, San Francisco, 1958.

Housner, G. W., and H. Outinen, The Effects of Torsional Oscillations on Earthquake Stresses, Bull. Seismol. Soc. Am., 48: (1958). 


\section{REFERENCES}

Housner, G. W., Behavior of Structures During Earthquakes, Proc. Am. Soc. Civil Engrs., EM-4 (October 1959).

Isada, N.. Design and Analysis of Tall, Tapered Reinforced Concrete Chimneys Subjected to Earthquakes, in Proceedings of the 1956 World Conference, Earthquake Engineering, Earthquake Engineering Research Institute, 1956.

Jacobsen, L. S., Approximate Solution of the Steady Forced Vibration of a System of One Degree of Freedom Under the Influence of Various Types of Damping, Bull. Seismol. Soc. Am., 20: (1930).

Jacobsen, L. S., Effect of a Flexible First Story in a Building Located on Vibrating Ground; Stephen Timoshenko, 60th Anniversary Volume, The Macmillan Company, New York, 1938.

Jacobsen, L. S., Dynamic Behavior of Simplified Structures up to the Point of Collapse, in Proceedings of the Symposium on Earthquake and Blast Effects on Structures, Los Angeles, Earthquake Engineering Research Institute and University of California, 1952.

Jacobsen, L. S., Motion of a Soll Subjected to a Simple Harmonic Ground Vibration, Bull. Seismol. Soc. Am., 20: (1930).

Jacobsen, L. S., and H. J. Jesperson, Steady Forced Vibrations of a Single Mass System with Symmetrical as well as Nonsymmetrical Nonlinear Restoring Elements, J. Franklin Inst., 220: (1935).

Kanai, K., and S. Yoshizawa, On the Damping of Vibration of Actual Buildings, Bull. Earthquake Res. Inst., Tokyo Univ., 30: (1952).

Kanai, K., R. Takahashi, and H. Kawasumi, Seismic Characteristics of Ground, in Proceedings of the 1956 World Conference, Earthquake Engineering, Earthquake Engineering Research Institute, 1956.

Kawasumi, H., and K. Kanai, Vibrations of Buildings in Japan, in Proceedings of the 1956 World Conference, Earthquake Engineering, Earthquake Engineering Research Institute, 1956.

Kimizi, I., On the Elastic Properties of Soil, Particularly in Relation to Its Water Content, Bull. Earthquake Res. Inst., Tokyo Univ., 18: (1940).

Martel, R. R., Effect of Foundation on Earthquake Motion, Civil Eng., 10: (1940).

Menekami, T., and S. Sakuma, Earthquake Motions on Various Formations of the Earth's Surface, Bull. Earthquake Res. Inst., Tokyo Univ., 26: (1948).

Murphy, M. J., G. N. Bycroft, and L. W. Harrison, Electrical Analog for Earthquake Shear Stresses in a Multistory Building, in Proceedings of the 1956 World Conference, Earthquake Engineering, Earthquake Engineering Research Institute, 1956.

Neumann, Frank, Some Generalized Concepts of Earthquake Motion, in Proceedings of the Symposium on Earthquake and Blast Effects on Structures, Los Angeles, Earthquake Engineering Research Institute and University of California, 1952.

Neumann, F., Earthquake Intensity and Related Ground Motion, University of Washington Press, Seattle, 1954.

Newmark, N. M., Computation of Dynamic Structural Response in the Range Approaching Failure, in Proceedings of the Symposium on Earthquake and Blast Effects on Structures, Los Angeles, Earthquake Engineering Research Institute and University of California, 1952.

Newmark, N. M., Methods of Analysis for Structures Subjected to Dynamic Loading, Report NP-3572, Directorate of Intelligence, Department of the Air Force, Nov. 17, 1949, Revised Dec. 18, 1950.

Pacific Fire Rating Bureau, 465 California Street, San Francisco, Recommendations, Earthquake-resistant Design of Buildings, Structures, and Tank Towers, 1950.

Penzien, J., Dynamic Response of Elastoplastic Frames, Paper 2545, Proc. Am. Soc. Civil Engrs., July 1960.

Proceedings of Second World Conference on Earthquake Engineering, Science Council of Japan, Tokyo, 1960 .

Rodriguez, M., Aseismic Design of Simple Plastic Steel Structures Founded on Firm Ground, in Proceedings of the 1956 World Conference, Earthquake Engineering, Earthquake Engineering Research Institute; 1956. 
Salvadori, M. G., Earthquake Stresses in Shear Buildings, Proc. Am. Soc. Civil Engrs., $\underline{79}$ : (March 1953).

Savarenskii, E. F., I. E. Gubin, and D. A. Kharin, Earthquakes in the USSR, Moscow, USAEC Translation AEC-tr - 5424, 1961.

Suyehiro, K., Engineering Seismology, Notes on American Lectures, Proc. Am. Soc. Civil Engrs., 58: (May 1932).

Tung, T. P., and N. M. Newmark, Shears in a Tall Building Subjected to Strong Motion Earthquakes, in Proceedings of the 1956 World Conference, Earthquake Engineering, Earthquake Engineering Research Institute, 1956.

U. S. Coast and Geodetic Survey, Earthquake Investigations in California 1934-35, Special Publication 201, Washington, D. C., 1936.

White, M. P., Friction in Buildings, Bull. Seismol. Soc. Am., 31: (1941).

White, M. P', A Method of Calculating the Dynamic Force on a Building During an Earthquake, Bull. Seismol. Soc. Am., 32: (1942).

White, M. P., and R. Byrne, Model Studies of the Vibration of Structures During Earthquakes, Based on Ground Accelerations instead of Ground Displacements, Bull. Seismol. Soc. Am., 29: (1939).

Williams, H. A., Dynamic Distortions in Structures Subjected to Sudden Earth Shock, Trans. Am. Soc. Civil Engrs., 102: (1937).

Zeevaert, L., and N. M. Newmark, Aseismic Design of Latino Americana Tower, in Proceedings of the 1956 World Conference, Earthquake Engineering, Earthquake Engineering Research Institute, 1956. 


\section{Chapter 2}

\section{EARTHQUAKE GEOGRAPHY AND REGIONALIZATION}

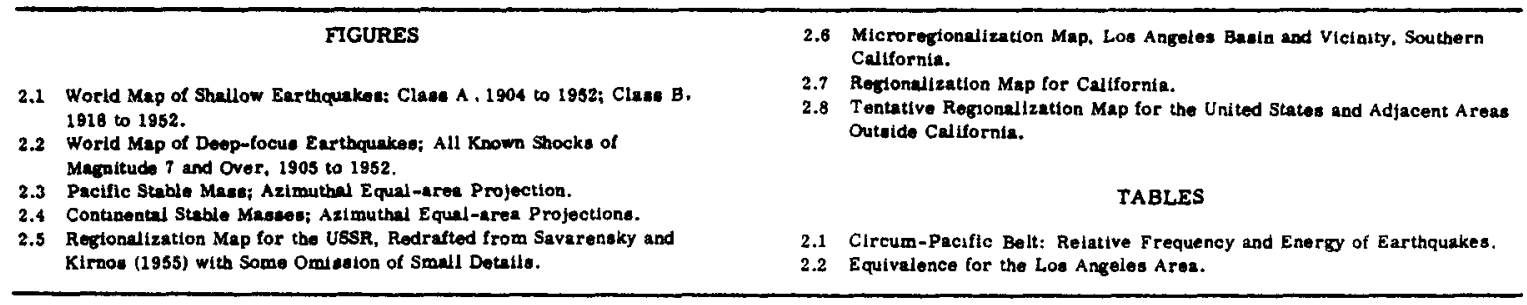

\subsection{ACKNOWLEDGMENT}

Proper and full acknowledgment must be given the distinguished work of $B$. Gutenberg and C. F. Richter of the Seismological Laboratory, California Institute of Technology. Their extensive studies of seismicity during the past 20 years have found comprehensive and definitive expression in the references comprising the foundation for this introduction to earthquake geography and regionalization.

The contribution of C. F. Richter in reviewing the material in this chapter is gratefully acknowledged.

\subsection{EARTHQUAKE GEOGRAPHY: GENERAL DESCRIPTION}

Inherent in the prediction of probable seismic intensity as related to engineering construction are the factors of (1) initial seismic energy release, (2) subsequent wave propagation or energy transport, and (3) the nature and violence of motion imparted to the foundation supporting the responding structure. The rigorous postulation of seismic damage to a given structure would be dependent upon comprehensive statistical and geophysical knowledge of these factors; however, such a state of technology is not likely of general attainment. Fortunately a rigorous approach is not a prerequisite to acceptable engineering studies, as previously indicated by the text of this report and as further supported by the material of this chapter.

The problems of energy release are those related to the statistical study of location, frequency, and magnitude of seismic disturbances, including the nature of the focal structure, or simply the problems of earthquake geography.

Prediction of probable seismic intensity as a function of both earthquake geography and local geology is the purpose of seismic zoning or seismic regionalization and is a field of study that is of interest to both the seismologist and the engineer. 
A. Scope

The worldwide distribution of earthquakes has been briefly mentioned in Sec. 1.2B. The greater majority of epicenters occur in a few narrow belts or zones, whereas certain wider areas show fairly general moderate activity. Those features of the earth's surface most pertinent to seismological study include

(1) The principal great-circle seismic belts

a. The Circum-Pacific belt-

b. The Alpide (Ballores' Transasiatic) belt

(2) The non-Alpide areas of eastern Asia

a. The Pamir-Baikal active zone of central Asia

b. The Chinese triangular active area

(3) The oceanic seismic belts

a. The Arctic belt

b. The Atlantic ridge

c. The Indian Ocean belt and branches

(4) Rift zones, including

a. The East African active rift

b. The Pacific stable area rifts

(5) The stable masses

a. Active continental margins and troughs adjacent to the stable masses, including the St. Lawrence rift zone

b. Stable-mass shatter zones

(6) Minor seismic areas, generally in regions of older mountain building

\section{B. Tectonics}

In the principal seismic zones, shallow earthquakes are associated with the conditions of two distinct environments: arc as opposed to block tectonics. The earthquakes of arcuate structures, dominant in most of the Circum-Pacific and Alpide belts, are . thought to be related to the thrust surfaces of the great mountain-building epochs. Where most clearly defined in the Circum-Pacific belt, these arcs are still active with earthquakes at all depths, and folding is thought to be still in progress. The similar arcs of the Alpide group are less active and show fewer of the characteristic features.

A group of typical phenomena and features normally identify the active Pacific arcuate structures. Most pronounced are the severe gradients; the topography of a typical transverse section ascends from a deep oceanic trench or foredeep along the outside margins to the heights of a principal mountain arc, complicated by an intervening series of anticlines that often appear as submarine ridges. The dynamic potential of the system finds evidence in pronounced isostatic anomalies, which, for certain conditions of structural environment, may find expression in active thrusting. Active or recently extinct volcanoes are characteristic of the principal mountain arc; farther inward in the system, another arc is marked by older volcanism, generally in a late stage or extinct. Shallow seismicity is most frequent between the foredeep and the principal mountain arc, whereas activity of intermediate depth extends from the mountain arcs to the interior. Well within the interior of the system are found the deep-focus disturbances.

Conversely the behavior in a block structure does not appear to be a direct expression of folding, but rather an indication of large-scale shearing adjustments subsequent to such activity. Characteristic of these adjustments are the development of long fault zones that often appear to be mechanically inconsistent with the apparent tectonic regime. Such faulting is geologically shallow, as evidenced by occasional surface rupture and the insignificant amount or absence of intermediate or deep seismicity.

The geographical location of faults associated with block tectonics can be determined in areas where the geology is well understood. Consequently the correlations of origin, 
path, and local geology for regionalization of such areas are susceptible to definitive treatment. In arcuate regions, however, the active surfaces are not simple sharp breaks but may, in the zone of shallow seismicity, extend horizontally over a wide belt. Probable epicentral location cannot then be precisely determined, and fine regionalization for arcuate areas may be more difficult than that for block structures.

Block faulting does not necessarily occur as a distinct alternate to the arcuate processes. In Japan particularly, the arc and block tectonics are enmeshed in a condition of unusual complexity. As examples, the strike-slip fault associated with the Mino-Owari earthquake of 1891 cleaves across Honshu transverse to the active arcuate structures; similarly the great transverse structural break known as the Fossa Magna partitions this principal island into a southwest and a northeast tectonic division. In Argentina shallow earthquakes of block tectonics, in the provinces of Mendoza and San Juan, lie directly above the hypocenters of deep shocks associated with Andean arcuate activity, where the surface expression of Andean arc tectonics is far to the west.

\subsection{EARTHQUAKE GEOGRAPHY: DETAILS}

A brief description of earthquake geography, such as the following, is of necessity overgeneralized, and many of the significant geological features pertinent to smaller areas are unfortunately rendered obscure. Reference should be made to the more exhaustive compilations available for detailed study of a particular locale. ${ }^{2.1,2.2}$

Figures 2.1 to 2.4 illustrate the discussion. The small scale of these figures again leads to overgeneralization. Obviously it is not possible to include finer geophysical detail in maps extending over such broad areas. They do, however, correctly indicate the general features of world seismicity and appear appropriate to the introductory treatment afforded by this chapter.

Explanatory statements should be made in regard to Figs. 2.1 and 2.2. From the engineering viewpoint light or moderate seismicity is not necessarily statistically significant with respect to large, damaging shocks. These figures were accordingly prepared to illustrate only major activity and should not be taken as necessarily representative of lighter seismicity. Further, only well-documented shocks over a relatively short period of time have been plotted; therefore these figures may not exactly represent the relative activity of some areas.

\section{A. Circum-Pacific Belt}

The geography of the Circum-Pacific belt is indicated by Figs. 2.1 to 2.3. The predominant position of this belt in any accounting of world seismicity was mentioned in Sec. $1.2 \mathrm{~A}$, where it was noted that, of all the world's earthquakes, $80 \%$ of the shallow, $90 \%$ of the intermediate, and more than $99 \%$ of the deep shocks are attributable to the CircumPacific belt. ${ }^{2.1}$ Accordingly in the following discussions the Circum-Pacific belt is given corresponding emphasis.

The location, structures, and relative seismicity by both frequency and energy release for regions of the Circum-Pacific belt are summarized in Table 2.1.

For convenience the regions have been identified with the principal geographical area; thus it must be understood that activity may extend beyond the indicated area. The Cali fornia region includes the Gulf of California to the south; Japan includes the Kurile Islands and the Kamchatka Peninsula. Location as given by coordinates should be taken as only indicative of the extent of seismicity for a given region and should not be applied rigorously. Regions of extended length are located at each end; regions which have obscure boundaries or which are areal in nature are located by a general coordinate.

Table 2.1 gives the type of structure for all regions except those for which the exact structural nature has not been determined. 


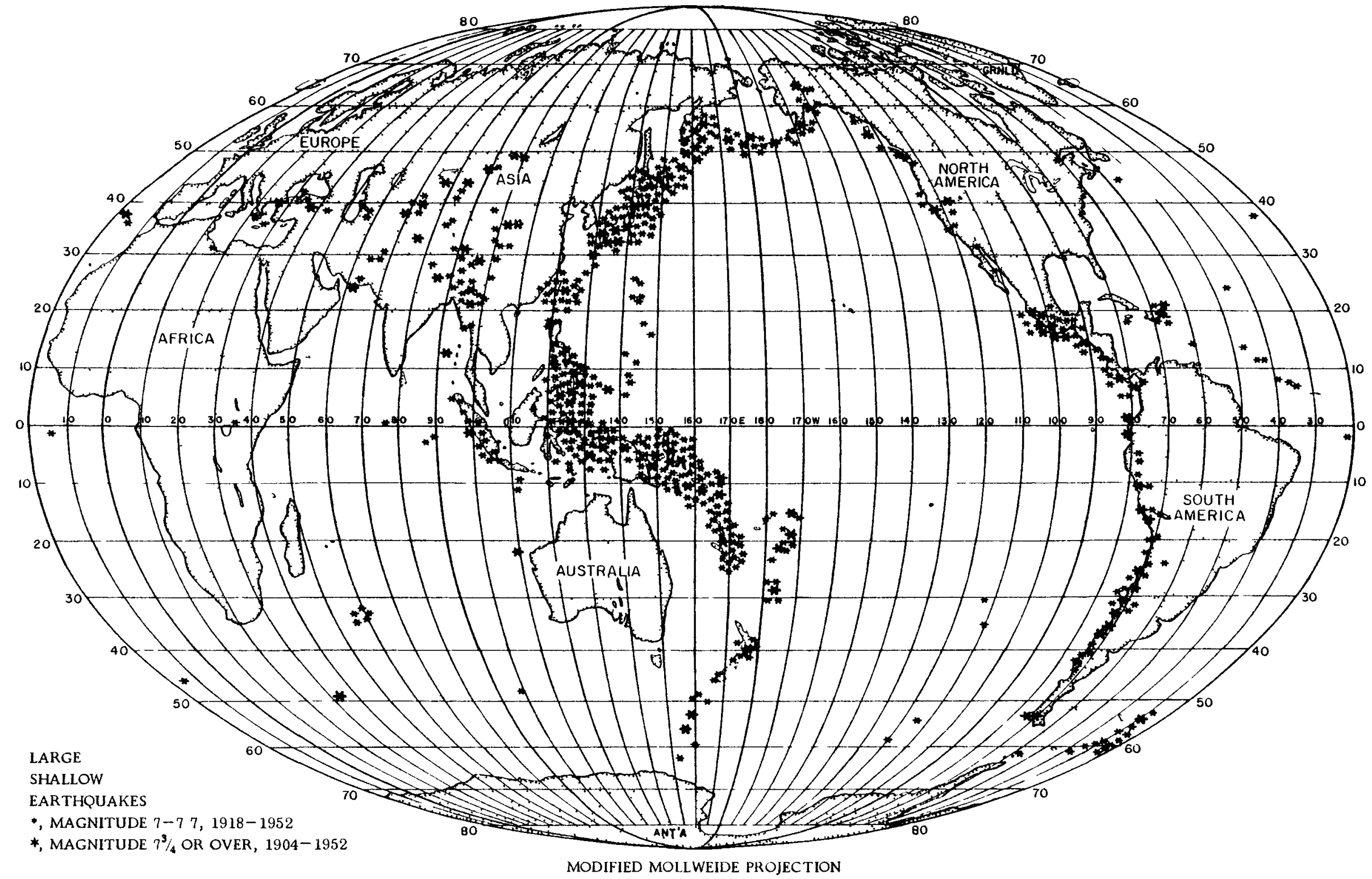

Fig 21 -World map of shallow earthquakes class A, 1904 to 1952, class B, 1918 to 1952 (Data from Ref 21) 


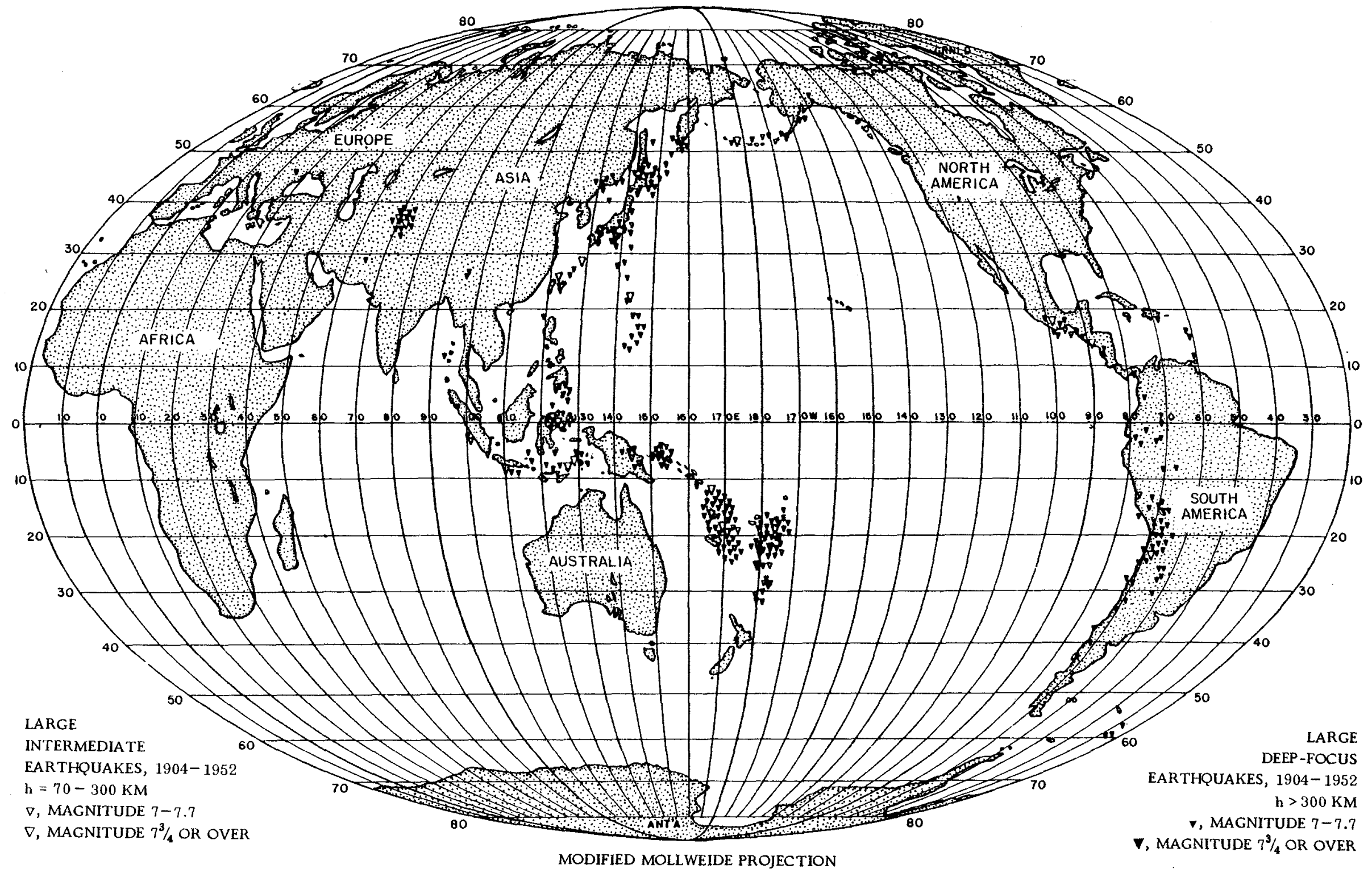

Fig. 2.2-World map of deep-focus earthquakes; all known shocks of magnitude 7 and over, 1905 to 1952. (Data from Ref. 2.1.) 


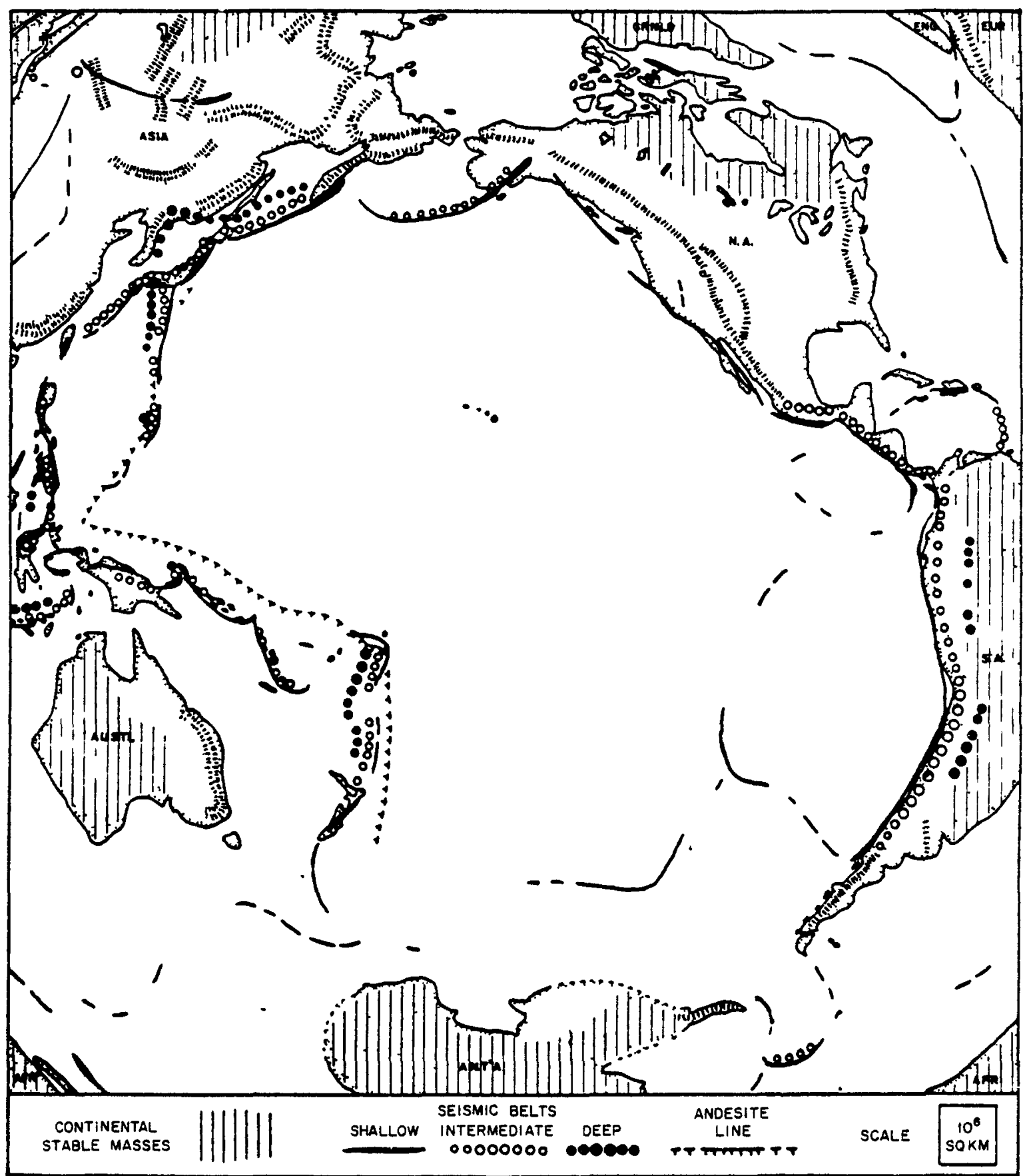

Fig. 2.3- Pacific stable mass, azimuthal equal-area projection (Data from Ref. 2 1.)

The statistical base period varies with earthquake depth and classification. With some qualifications Table 2.1 lists the class A shallow shocks for the period 1904 to 1945 , the class B shallow shocks for the period 1922 to 1945 , and the class C shallow shocks for the period 1932 to 1935. Intermediate - and deep-focus shocks are listed for about a 30 -year period. All data were derived from instrumental sources. It 15 obvious that, as 


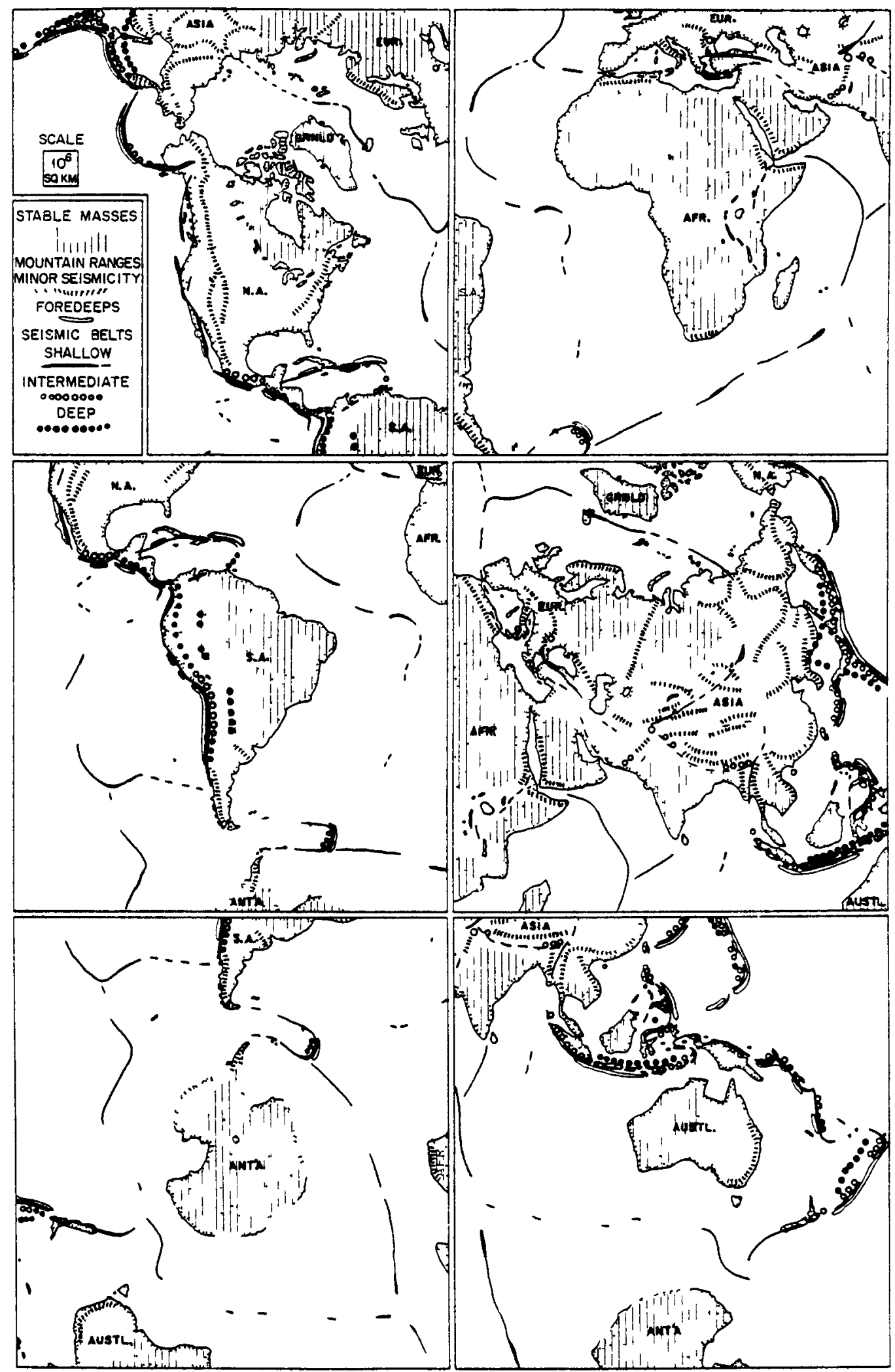

Fig 24 -Contmental stable masses, azımuthal equal-area projections (Data from Ref 2 I) 
the magnitudes to be considered increase, the statistical representation becomes less precise. Further, although moderate seismicity is well represented for engineering pur poses, some regions have exhibited broad fluctuations, and the representation for the short period of three years, although adjusted, may not be wholly correct for these regions.

Two indices of seismicity are presented in Table 2.1: (1) relative frequency, differentiating between the various depths and classifications of earthquakes, and (2) relative

Table 2.1-CIRCUM-PACIFIC BELT: RELATIVE FREQUENCY AND ENERGY OF EART HQUAKES*+

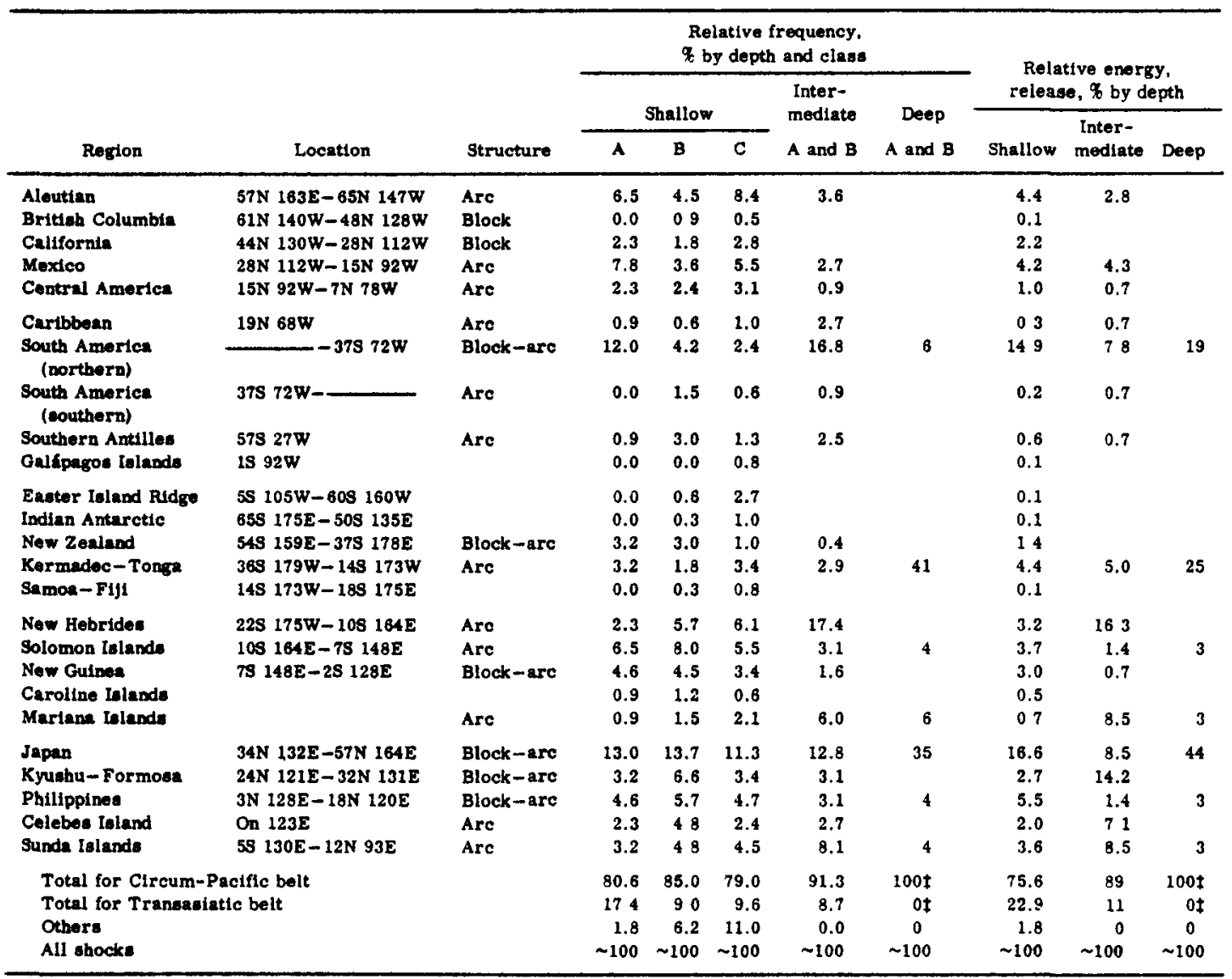

- Data are from Ret. 2.1.

tSee toxt for discusetion.

The Transadiatic deep-focue shock of 1954 under southern Spain does not appear in this data.

energy release, differentiating only by depth. Seismicity by relative frequency is more adaptable to engineering requirements; energy release tends to be heavily weighted by the very large shocks.

The Japan region, including the Kurıle Islands and the Kamchatka Peninsula, is that showing the highest general level of seismicity. The structures are arcuate, complicated not only by the dividing into the Formosa and the Marianas trends, but also by the super position of the well-developed block structure of the northern Honshu coastal region.

Further interest is afforded by the Fossa Magna, a large-scale graben of fissuring and volcanic activity reaching directly across Honshu from the Idzu Peninsula. Major disturbances emanate from all depths in frequent numbers. Gutenberg and Richter catalog more than a dozen class A shallow shocks from instrumental data. ${ }^{2.1}$ The destructive nature of this high seismicity upon a dense population has justifiably served to publicize 
these conditions and has resulted in a wealth of research activity in the seismological field and related fields.

The islands of the Philippines and Melanesia collectively account for $25.5 \%$ of shallow-focus, $40.4 \%$ of intermediate-focus, and $34 \%$ of deep-focus world seismicity on a relative-energy-release basis. The Philippines display a rich tectonic variety. An arcuate structure of strongly pronounced features and high seismic activity extends along the eastern margins of Mindanao and Samar Islands (3N 128E to $13 \mathrm{~N} 125 \mathrm{E}$ ) to front the Philippine Sea on the east. A less active arc of moderate activity follows the west coast of Luzon ( $14 \mathrm{~N} 122 \mathrm{E}$ to $18 \mathrm{~N} 120 \mathrm{E})$ to front the China Sea. These two areas are connected by a sweeping shear structure featuring a master strike-slip fault. Other structures of lower seismicity trend through the archipelago, some extending into northern Borneo. The Luzon arc continues north, becoming more obscure, and finally loses identity in a region of uncertain structure and low seismicity south of Formosa.

Central Mexico is among the regions of highest seismicity in the western hemisphere. The structures of Mexico and Central America (22N 107W to $7 \mathrm{~N} 78 \mathrm{~W}$ ) are those of a succession of active arcs which branch into the Caribbean loop. Three active volcanic lines are further evidence of the arcuate nature of the structures. One line extends across central Mexico in a roughly east-and-west manner from Colima to the vicinity of Veracruz; another begins in Guatemala and reaches southeastwardly through Central America; and that of the Caribbean branch assumes a north-and-south alignment at its easternmost extent. Although the shallow seismicity of Mexico is relatively the highest in the western hemisphere, the activity of the Caribbean is well below average for the Circum-Pacific belt; however, a number of locally destructive shocks have given the Caribbean an impression of high seismicity wholly undeserved.

Although the Andean zone of South America shows a relative energy release comparable with that of Japan, the Andean zone should not be accorded the same level of seismicity. South America has somewhat more frequent class A shocks than Japan; however, the latter has many times more class B earthquakes than South America and thus a higher seismicity from a risk standpoint. Especially pronounced in the southern part of the Andean zone ( $15 \mathrm{~S} 75 \mathrm{~W}$ to $45 \mathrm{~S} 74 \mathrm{~W}$ ) are strongly arcuate structures and features of the Pacific type. 'These features are less clearly defined in a long reach of Peru (5S $80 \mathrm{~W}$ to $15 \mathrm{~S} 75 \mathrm{~W}$ ) and are often completely obscured owing to a shear type structure with conspicuous recent fault scarps that are strongly suggestive of the strike-slip regions. A nearly continuous active volcanic line extends along the east coast of South America. This line is broken only through the area of Peruvian faulting. The high incidence of very large earthquakes relative to lesser activity has been noted; in addition, again excepting Peru, the focal depths of shallow shocks are, in general, greater than usual, frequently of the magnitude of 40 to $60 \mathrm{~km}$. Shocks at intermediate depths following a line of nearly extinct volcanoes are relatively common, and inland, east of the Andes, are found the deepfocus shocks expected with strongly active arcs, at typical depths of 600 to $650 \mathrm{~km}$.

\section{B. Alpide Belt}

Active arcs similar to those of the Pacific are characteristic of the Alpide Mediterranean-Transasiatic belt. Although these arcs are thought to be roughly of the same age as those of the Pacific, they are, in general, less active, suggesting that they have aged more rapidly. The Asiatic arcs are clearly defined; however, the Mediterranean seismicity assumes a more detalled expression that is not susceptible to a brief discussion. Consequently only a few remarks will be offered in the paragraph describing Mediterranean activity.

The Alpide belt trends successively along the Burma arc (roughly $17 \mathrm{~N} 97 \mathrm{E}$ to $28 \mathrm{~N}$ $97 \mathrm{E}$ ), the Himalayan arc (about $28 \mathrm{~N} 97 \mathrm{E}$ to $36 \mathrm{~N} 73 \mathrm{E}$ ), the Baluchistan structure (about $36 \mathrm{~N} 73 \mathrm{E}$ to $24 \mathrm{~N} 63 \mathrm{E}$ ), then extends northwestwardly through Iran in a broad, less clearly defined manner. 
The Himalayan is the most active and most clearly developed of the Asiatic arcs. Shallow activity is comparable with, or a little higher than, that of California. However, this activity must be considered to be well below that of the more active parts of the Pacific belt. A notable focus for activity of intermediate depth occurs in the Hindu Kush mountains beneath the angle formed by the Himalayan arc with the Baluchistan structures (about $36 \frac{1}{2} \mathrm{~N} 70 \frac{1}{2} \mathrm{E}$ ). About 70 shocks have been assigned to this focus since 1905 ; seven of these were large earthquakes and included some that were of destructive nature.

A comparison of the features of the landlocked Himalayan arc with the fully developed oceanfronting arc is of interest. The oceanic foredeep is represented by the extremely deep alluviated depression of the Ganges valley. As in the ocean arcs, a strong negative-gravity anomaly extends with some interruptions across the entire width of India in a belt well outside of the mountain arc. Again conforming, positive-gravity anomalies are indicated in the mountain-arc region. Intermediate shocks occur to the rear of the mountains, as would be expected of ocean structures, extending the full length of the range. Active volcanic lines are unknown, however, and deep-focus disturbances have not as yet been recorded.

From Iran the Alpide belt traverses Turkey and then the Aegean Sea and the Balkans in a broad swath curving northward. To the north, activity has been recorded in the Crimea, and the southern limits are well south of Crete. The belt returns south through Italy, then reaches across Sicily to Africa, and continues along the north coast into the Atlantic as far as the Azores; it is usually drawn as a loop that returns through Spain and France to the Alps.

\section{Eastern Asia Non-Alpide Areas}

The Pamir - Baikal active zone is a broad belt of activity extending from the Pamir region ( $36 \mathrm{~N} 73 \mathrm{E}$ ) to Lake Baikal (53N 108E). North of the belt is the stable area of north central Asia. South between the Pamir-Baikal zone and the Himalayan arc of the Alpide belt is the broad Chinese triangular actıve region. Seismicity of the Pamir-Baikal zone is apparently limited to shallow shocks; of these, tabulations include seven of great magnitude. The triangular active area is traversed by a series of structures showing varying degrees of seismicity, with intervening blocks remaining relatively undisturbed.

\section{Oceanic Seismic Belts}

The oceanic active belts, in general, follow narrow actıve ridges of young mountain ranges. Although active volcanic lines occur along these ridges, there is little other evidence to associate them with the arcuate structures of the Pacific. Only shallow disturbances are known, and the few available gravity observations have not indicated any coherent pattern of large negative-gravity anomalies. It has been hypothesized that these ridges, originally produced by folding, are being subjected to the shearing adjustments of block tectonics.

Notable oceanic belts include the Arctic, which extends from the mouth of the Lena River on the north coast of the USSR, across the north pole to Iceland. The belt extends south from Iceland as the Atlantic belt to Bouvet Island and then turns east as the Atlantic-Indian Swell. From Prince Edward Island the activity continues north in the Indian Ocean to end abruptly on the coast of Arabia.

\section{E. Rift Zones}

The rift zones as used here imply shallow shocks associated with interior fractures of the stable masses, the most active of which are those of the East Africa rifts (from about $12 \mathrm{~S} 32 \mathrm{E}$ to $18 \mathrm{~N} 41 \mathrm{E}$ ). The African activity is moderate; the complexity of the known rift structures is demonstrated by the seismicity, which follows no single line. This activity reaches through Ethiopia and north along the Red Sea; however, current knowledge 
fails to justify its extension through the Suez region into the active Jordan trough of Palestine.

Hawaiian shocks are considered to find ultimate origin in a rift system, for they undoubtedly occur along a fractured structure in the interior of the Pacific stable mass.

\section{F. Stable Masses}

The stable masses, illustrated by Fig. 2.4, are principally continental nuclei, continental shields, or oldlands, which have remained relatively undisturbed through most of their geological history. The Pacific basin, although differing structurally from the others, is most logically included in a cataloging of stable masses. It is obvious that only the more important stable areas can be listed; all sizes exist, becoming more numerous as smaller areas are considered.

The North American continent displays the Canadian shield; the South American continent encompasses the Brazilian stable mass east of the Andes Mountains. Sweeping across the Baltic, the Ural Mountains and northern Asia are a series of shields; collectively they are the Eurasian stable mass. Seismological evidence suggests that Africa is divided between two stable shields with the Congo River roughly intervening between the two. Arabia, southern India, and western Australia are of practically aseismic preCambrian continental nuclei. Antarctica is considered wholly stable, as supported by teleseismic observation. However, the presence of at least one active volcano strongly suggests possible minor seismic activity.

Aside from internal rifts such as in East Africa and at the Hawaiian Islands (as previously mentioned), plus the rift at the Samoan Islands, which represents an intra-Pacific rift similar to the Hawaiian rift, seismic activity associated with the stable masses is found to be confined to margins and troughs separating major and minor continental masses and to marginal shatter zones of the stable masses. Thus the St. Lawrence activity is marginal to the Canadian shield, and the shocks along the eastern margins of the Australian stable area are related to shatter-zone activity. The Mozambique Channel, which is between Africa and Madagascar, and Baffin Bay, which is between the Canadian shield and Greenland, are examples of troughs separating major and minor continental areas.

\section{G. Minor Seismic Areas}

Seismicity of significant magnitude is not limited to the principal areas previously discussed. One group of small regions exhibiting moderately frequent minor earthquakes are certain pre-Cretaceous mountain structures, including the Appalachian area of eastern North America, and geologically similar localities in eastern Australian, central Europe, and South Africa. Other disturbances, not so well geologically defined, include the Mississippi Valley earthquakes of 1811 and 1812 and the Charleston earthquake of 1886. These are discussed in Sec. 1.2A.

H. Summary of Seismicity

The Circum-Pacific belt is associated with $80 \%$ of all shallow shocks, about $90 \%$ of all intermediate shocks, and, taking into account rare exceptions, with all deep shocks. For comparison of shallow shocks, Japan, western Mexico, Melanesia, and the Philippines exhibit the highest seismicity; however, disturbances of South America have an unusually high proportion of great shocks.

All remaining intermediate and large shallow earthquakes are assignable to the Mediterranean and Transasiatic belts, where epicenters are found roughly aligned along mountain chains.

The principal ridges of the Atlantic, Arctic, and Indian oceans are associated with light-to-moderate seismic activity. 
The rift structures such as those of East Africa and the Hawaiian and Samoan Islands demonstrate moderate activity.

The stable masses of the continental nuclei and the Pacific basin appear to be relatively inactive; however, along the troughs and margins of these masses and also in areas of minor-to-moderate activity between these masses and the active belts, occasional large shocks have been recorded.

\subsection{SEISMIC REGIONALIZATION: GENERAL}

Seismic regionalization, the mapping of areas with respect to probable seismic activity, is of common interest to the seismologist, the insurance industry, and the engineer. Richter has introduced the term regionalization to describe zoning for engineering applications. ${ }^{2.3}$ The following material considers briefly each viewpoint, then propounds some of the qualifications and limitations to regionalization with regard to the engineer ing aspects. Finally, some engineering applications of regionalization are offered. The applications are accompanied by brief comments.

\section{A. Forms of Presentation}

Seismic zoning is most conveniently illustrated by the use of maps supplemented by explanatory or qualifying text. Such maps may be developed from the viewpoints of (1) the seismologist, as exemplified by the earthquake-geography maps; (2) the insurance statistician, ideally necessitating a rigorous synthesis of seismicity and local geology, to be applied with due regard to the character of community structures and services; and (3) the engineer, where integration of seismicity with local geology for regionalization is considerably simplified by the use of limiting assumptions to minimize variables.

Maps indicating the statistical distribution of seismic activity are generally not di rectly applicable to engmeering applications. Such maps are more properly concerned with the magnitude of disturbances as related to energy release and mechanism, whereas the engineer is concerned with the intensity of disturbances as related to the probable nature and violence of ground motion in the area of his studies.

Seismological maps do, however, provide the foundation for engineering regionalization. Seismological maps or data should be selected for this purpose with care; those reflecting a disproportionate weight of historical macroseismic data, or exhibiting large numbers of small earthquakes, will be distorted in areas of population concentration or in areas having established seismological stations.

Insurance mapping is directed to a determination of a final estimate of risk, as measured by the expected intensity of shaking, and must in consequence be based upon the statistical elements of seismic frequency and magnitude combined with the effect of local geology. In the application of these maps, one must consider the strength, or weakness, of existing or proposed structures, as well as the integrity of essential public services, including those of gas, water, and power.

Engineering regionalization is similar to zoning for insurance purposes, except that it is simpler because it considers only the expected maximum intensity as a basis for design or study.

The engineer's responsibility to his community requires a conservative approach. Thus it is appropriate, when seismic geography is being considered, to allow the boundary range of maximum recorded or expected activity to govern, in lieu of a possible lessthan-humane statistical abstract. Similarly, when the effect of deep alluvium under a structure is being evaluated, the engineer will assume the alluvium to multiply the magnitude and violence of seismic motion, unless very strong evidence exists to the contrary, even though it is known that under some conditions alluviums may not amplify seismic intensity (see Secs. 1.1G and 1.31). To some extent engineering regionalization is then seen to evolve through considered opinions with the attendant complications and possible conflict between recognized authorities. 


\section{B. Factors Pertinent to Regionalization}

Several qualifying factors pertinent to regionalization must be considered in a study of earthquake geography. Among these factors is the distortion that can result, as mentioned previously, from improper use of historical data or from undue emphasis on minor disturbances. Other qualifying factors are (1) the influence of local geology, (2) the location of structures with respect to local geology, and (3) the proper sequence of developing maps.

The possible distortions arising from the use of historical or macroseismic data have been discussed in Sec. 1.2D. Summarizing, earthquake geography as determined by unmodified historical or macroseismic data will reflect higher seismicity in areas of denser population or older culture. Such data may not be directly applicable where population and industry are expanding into areas that formerly were sparsely occupied.

Small or moderate disturbances tend to distort a review of seismicity in two ways. Data on small earthquakes will show an apparently high rate of activity around centers in which detection instruments are located and in a manner that is analogous to the relatively high seismicity indicated by historical data around older population centers. Further, the frequency of occurrence of small earthquakes varies with the incidence of large-scale earthquakes in a different way from area to area. Since large earthquakes are rare, it is often necessary to rely upon comparatively small shocks as a source of data for regionalization. Reliance upon such data could lead to serious error.

The influence of local geology has been presented in Secs. 1.iG and 1.31. Some of the principal effects will be iterated and their application to regionalization indicated here.

As seismic waves pass from a medium of high modulus of elasticity to one of low modulus of elasticity such as an alluvium, the amplitude of motion essentrally doubles. In addition to this doubling, there can be further amplification when seismic waves travel through an alluvium formed of layers and lenses that have different properties. With alluviated valleys it may be possible to consider compensating factors such as unusual depth, softness, or complexity of alluvium, which tend to attenuate the violence, provided that adequate seismological evidence justifies such an approach. Conversely, as waves pass from a fractured rock structure to a firm, consolidated alluvium, only moderate increases of intensity may occur.

When seismic waves pass through a variety of materials over appreciable distances, a selective frequency filtering can be impressed, so that in areas distant from the seismic epicenter the ground motion may be predominantly of the longer perıods. Although such long-period motions are significant in the response of taller buildings and towers, it is not convenient to include this characteristic in regionalization. Engineers concerned with these taller structures should apply regionalization maps only with regard to this qualification.

Business and industrial centers trend to locations on level ground. In areas exhibiting fine geological detail, such as rocky hills and alluviated valleys in close and complex juxtaposition, it follows that the more important buildings and the seismically susceptible older structures which represent these centers will occur in the more level alluviated areas. When drawing small-scale regionalization maps incapable of depicting such fine geological detail, the problems of generalization arise, and it is necessary to make a representative selection from among several levels of anticipated intensity. The choice of intensity level, of course, should be for the ground under the majority of existing or projected buildings and therefore will generally be for the higher expected intensities characteristic of alluvium.

Small-scale regionalization maps that represent vast areas usually obscure the de tail necessary for engineering applications. Further, many portions of these maps are of speculative nature, and these portions detract from the authenticity of representation for those areas where detail seismicity and geology are well known. Such maps achieve their most definitive status and attendant usefulness when constructed from previous microre- 
gionalization studies; however, even for this case they would serve best as indices and for illustrating general trends not possible with large-scale maps.

Development of regionalization for engineering purposes often implies the assumption that the strongest known earthquake of a given locality is representative of the maximum to be expected. The corollary to this assumption would be that our very brief quantitative seismic history is a representative sample for all times. Every major earthquake that occurs in a region where only minor seismicity has been previously known is seen to refute these gross assumptions.

The opposing point of view would be to maintain that any locality, over a sufficient period of time, would experience an earthquake approaching maximum possible intensity. An acceptable solution for engineering regionalization has been suggested as that of preparing a series of maps for a given area; each map would illustrate maximum expectable intensities for successively increasing intervals of time, e.g., several years, several decades, and then possibly a period of centuries.

Even with this approach it must be recalled that the truly great earthquakes are sporadic in time and locality and, further, that such earthquakes are not necessarily statistically represented by smaller shocks. The difficulty of postulating the probabilities of future great activity in areas where such activity has not been previously known is apparent and is seen to be a principal obstacle to satisfactory regionalization.

The discussion to this point has tacitly assumed continued integrity of the terrain, although landslides, gross soil settlement, or other expressions of ground failure may be of severe consequence to structures. In general, failures of this kind are not represented by regionalization maps since they would lend undue complications; instead, the possibility of such occurrences is more appropriate to investigations in connection with specific works of construction.

\subsection{SEISMIC REGIONALIZATION: APPLICATION}

A. Union of Soviet Socialist Republics

Seismic regionalization of the Union of Soviet Socialist Republics (illustrated by Fig. 2.5) has been accorded official sanction in that country, with mapping by division into areas identified with degrees of expectable intensity represented by a Modified-Mercalli scale. Earlier work was concerned with small-scale maps, subject to the limitations that were discussed in Sec. 2.4B, namely, the obscuring of geological and seismological detail essential to the knowledgeable engineering applications. Both seismological data and geological qualification of these early maps were subject to justifiable criticism: the seismological data were of a short-term historical nature that led to distortions as mentioned in Sec. $2.4 \mathrm{~B}$, and the effects of local geology received inadequate consideration.

In more recent work a strong effort is being made to render the seismological data more statistically representative by means of an active instrumental program. Work has also progressed on larger scale regionalization where it has been possible to account for local variations. Unfortunately in much of the Soviet Union the instrumental data are principally for smaller earthquakes that are not necessarily statistically representative of great shocks, and, further, the natural application of geological principles often leads to apparently illogical results; thus these phases are still of an argumentative nature.

B. Los Angeles Basin

The microregionalization of the Los Angeles basin by Richter, ${ }^{2.3}$ which is shown in Fig. 2.6, may be regarded as reasonably definite. For this area the expectable intensities are determined in principal measure by the nature of the ground. The location of active faults, although pertinent, are in the nature of secondary considerations. The problem of regionalization is thus the translation of geological features into terms of intensity. 


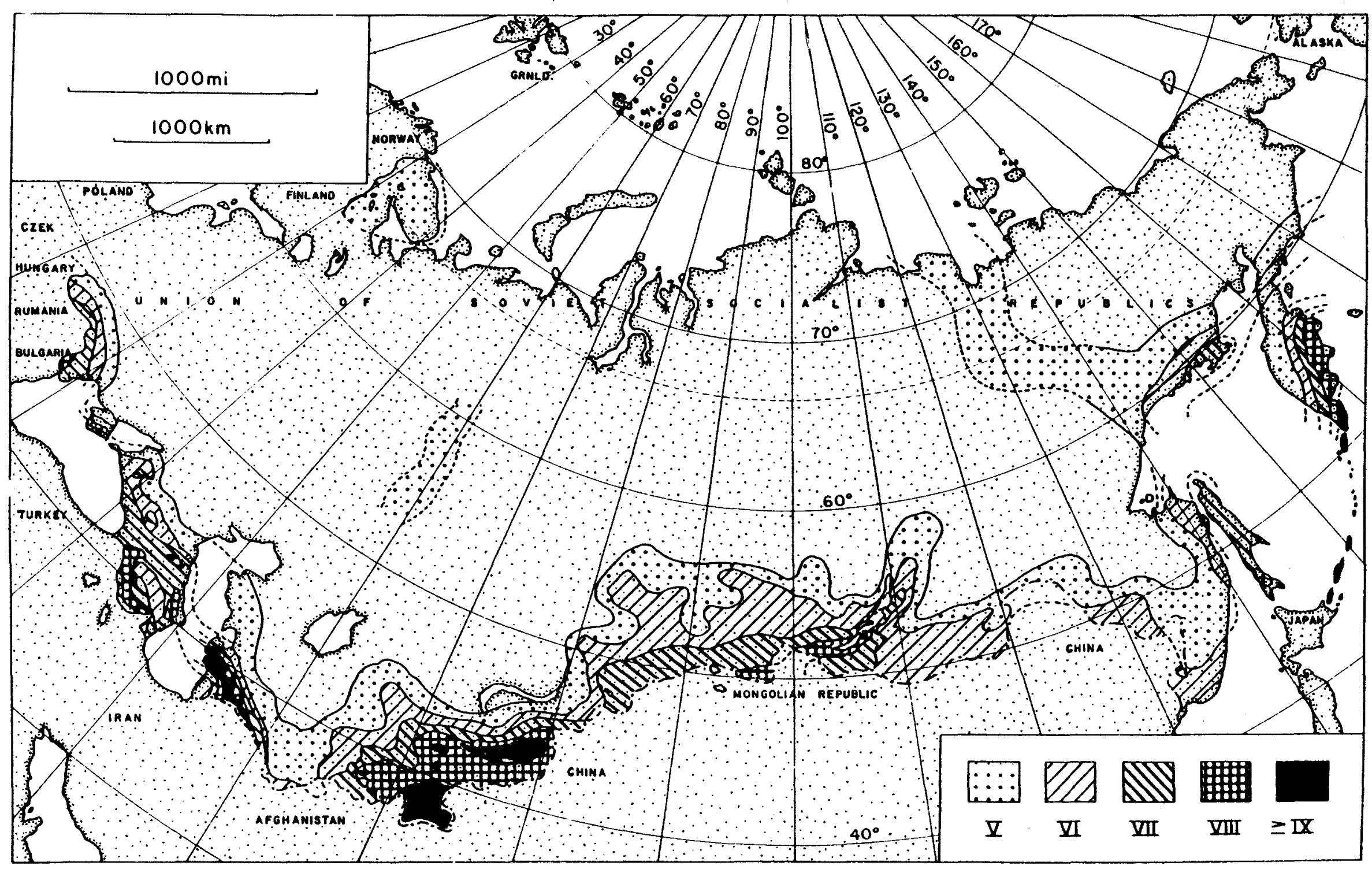

Fig. 2.5-Regionalization map for the USSR, redrafted from Savarensky and Kirnos (1955) with some omission of small details. (Data from Ref. 2.3.) 


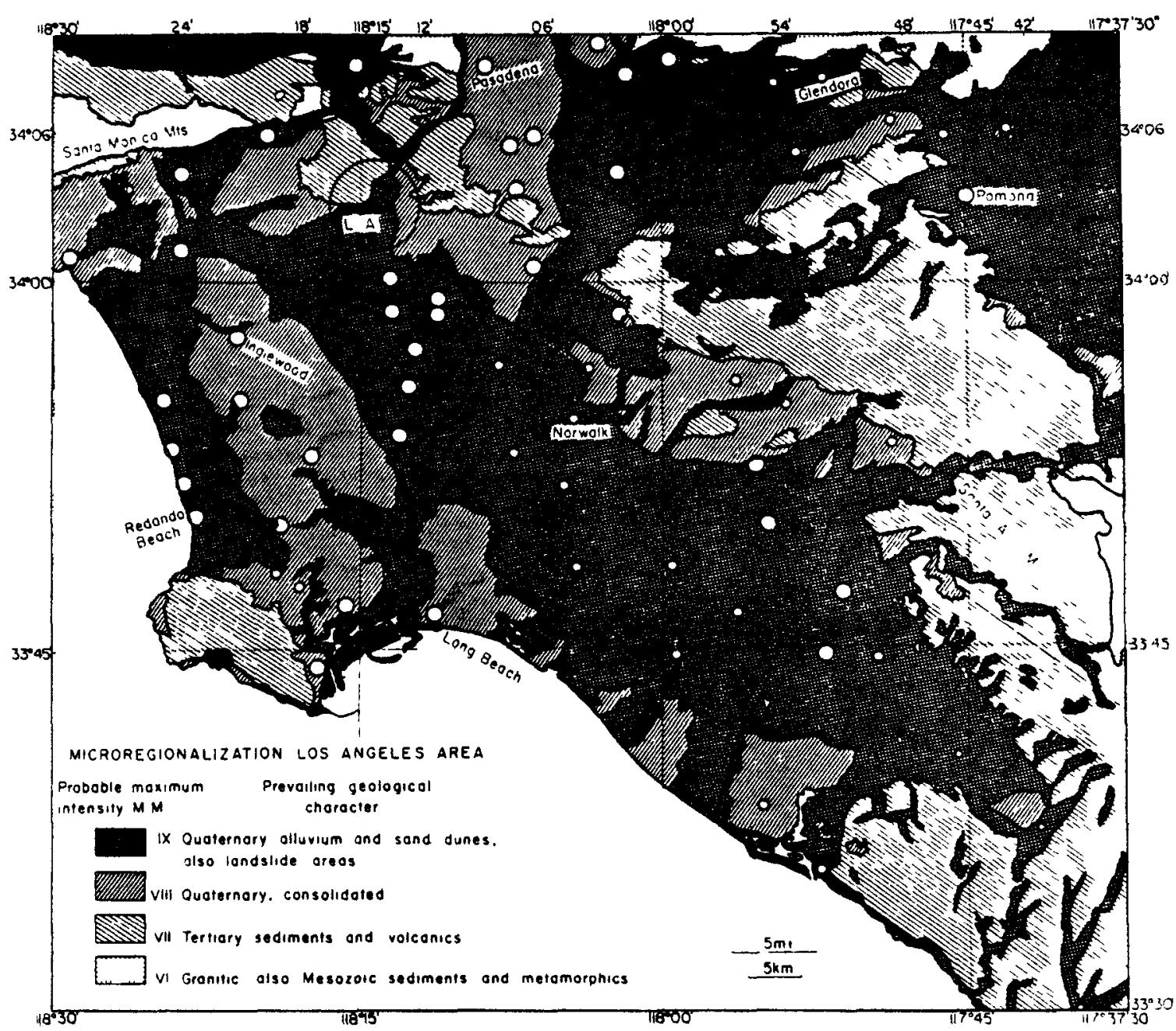

Fig. 2.6-Microregionalization map, Los Angeles basın and vicinity, Southern California. (Data from Ref. 2.3.)

A sound basis for this translation has been laid by work of the Selsmological Laboratory of the California Institute of Technology. This includes the comparative study of simultaneous operation of identical seismological instruments on both granite and soil of terrace classification. Further experimentation has extended and refined the results. This work has indicated the equivalence (Table 2.2) for the Los Angeles area. The intensity values given in Table 2.2 are believed to be satisfactory for the requirements of microregionalization.

Small terrace patches adjacent to rock have been assigned the next higher intensity in conformity with the arguments of Sec. 2.4B. Further, certain departures from the simple geological equivalence have been dictated by considerations of path effect with respect to the possible event of a great earthquake originating along the San Andreas fault to the north.

\section{California}

Regionalization for Californı by Richter, ${ }^{2.3}$ as shown in Fig. 2.7, is not of uniform reliability. This reflects the current variable status of detalled geological knowledge for 
Table 2.2-MICROREGIONALIZATION EQUIVALENCE OF LOCAL GEOLOGICAL STRUCTURE AND SEISMIC INTENSITY FOR THE LOS ANGELES AREA

\begin{tabular}{cl}
\hline $\begin{array}{c}\text { Modified-Mercalli } \\
\text { intensity }\end{array}$ & \multicolumn{1}{c}{ Formation } \\
\hline IX & $\begin{array}{l}\text { Quaternary alluvium and sand dunes } \\
\text { Quaternary terraces } \\
\text { VII }\end{array}$ \\
VI & $\begin{array}{l}\text { Tertiary } \\
\text { Mesozolc sediments and igneous rock } \\
\text { (the latter prevailingly granodiorites) }\end{array}$ \\
\hline
\end{tabular}

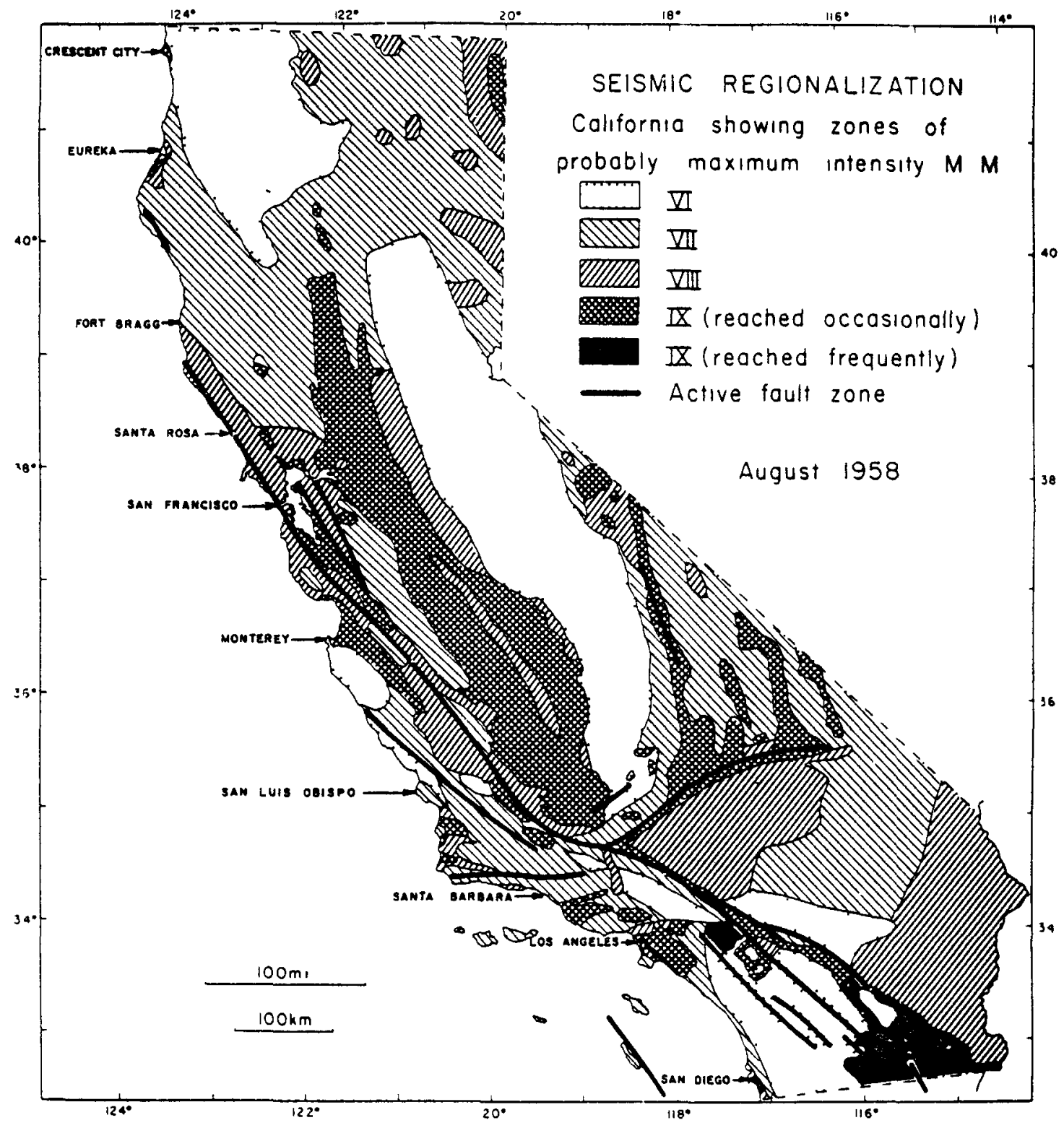

Fig. 2 7-Regionalization map for Cal.fornia. (Data from Ref. 2.3.) 


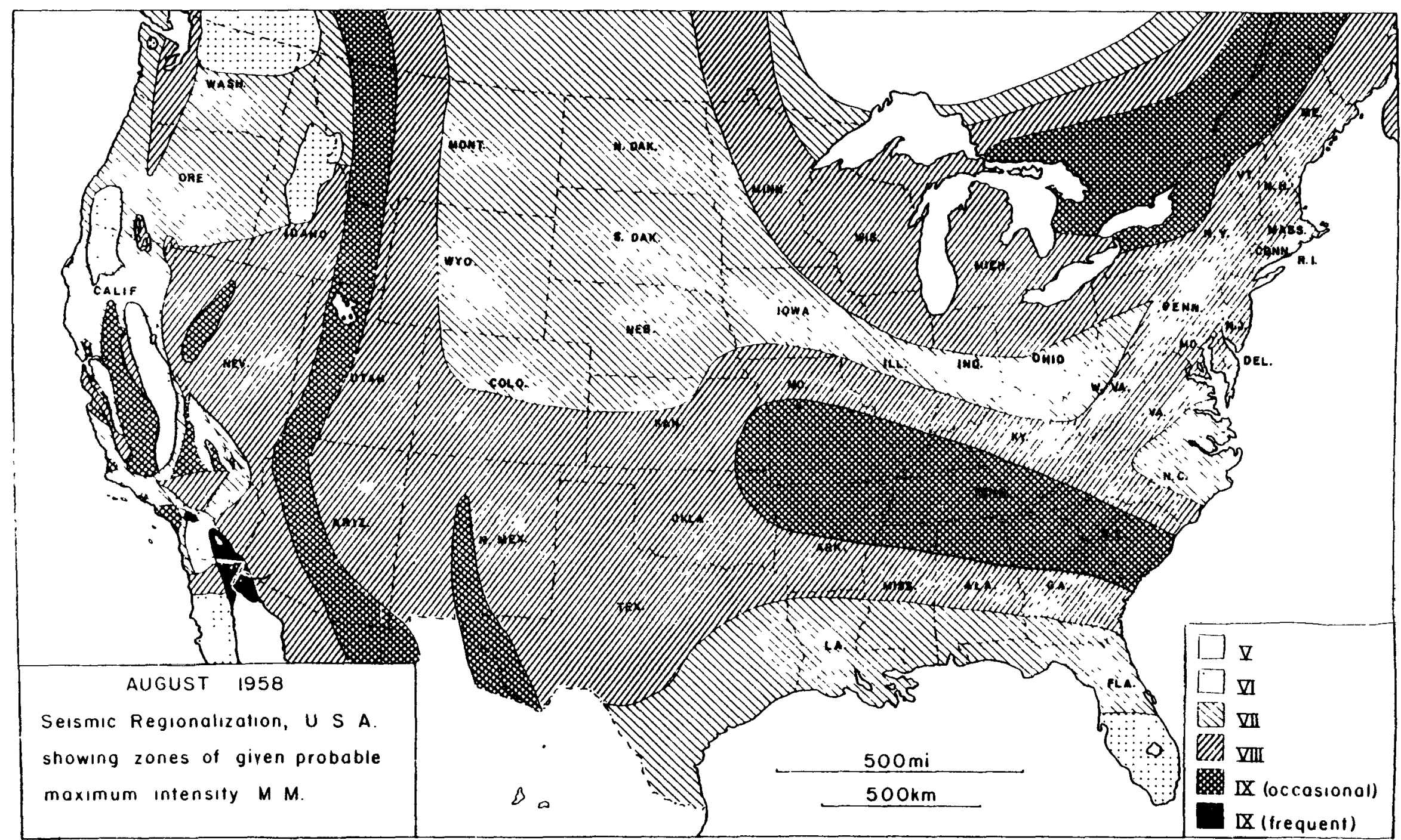

Fig. 2.8-Tentative regionahzation map for the United States and adjacent areas outside California. Lines between the areas of differing intensity are approximations only. (Data from Ref. 2.3.) 
this state. The map obviously does not have the engineering significance of microregionalization maps; the less definitive aspects of the generalizations identified with smaller scales are readily apparent.

The distribution of active faults is such that poorly consolidated ground of most areas will experience probable severe intensities. Thus, as in the Los Angeles basin, regionalization is primarily dependent upon the nature of the ground and secondarily upon location. The relation between intensity and geology is assumed to be that used for Los Angeles (Sec. 2.5B) with appropriate local adjustments for path.

The importance of geology is again emphasized. Geological maps are available in large-scale detail for most of the settled areas and for mining and oil districts, and therefore the resulting intensity determinations for these regions have good reliability. At the opposite extreme, large areas, principally those of the eastern desert or northern forests, have been mapped only on a small scale or at the reconnaissance level; intensity determinations in these regions are correspondingly uncertain.

The immediate zones of the San Andreas and other active faults represent an unusual risk to construction because of the effects of rending, tilting, and shattering by displacements at the surface. These effects are not conveniently represented by regionalization and would require special consideration in connection with specific works of construction.

D. United States

Richter ${ }^{2.3}$ tentatively proposes regionalization for the United States as shown by the map in Fig. 2.8. However, he cautions that this map is subject to the qualifications of any very small-scale treatment as briefly mentioned in Sec. 2.4B. It is subject even more so to the statistical limitations of a heterogeneous, sporadically seismic area as discussed in Sec. 2.4B. Richter further cautions that such maps are open to every sort of challenge and question.

The most uncertain areas, which Richter would be most ready to revise in the light of further evidence, include: ${ }^{2.3}$

(1) "The entirely hypothetical band of VIII extending northward into Canada along the west margin of the Canadian Shield."

(2) "Assignment of maximum IX to a belt including Charleston, South Carolina, and extending westward. Assignment of $\mathrm{IX}$ is appropriate to the western end of this belt, which includes the New Madrid region."

(3) "Neglect of the suggested active alignment extending from Lake Erie southwest across Ohio and Indiana to the New Madrid region."

\section{REFERENCES}

(The bibliographies of these references comprise an extensive selective listing of seismological and related literature.)

2.1 B. Gutenberg and C. F. Richter, Seismicity of the Earth and Associated Phenomena, Princeton University Press, Princeton, N. J., 1954.

2.2 C. F. Richter, Elementary Seismology, W. H. Freeman and Company, San Francisco, 1958.

2.3 C. F. Richter, Seismic Regionalization, Division of Geological Sciences, California Institute of Technology, Contribution No. 897, Bull. Seismol. Soc. Am., (1959). 


\section{Chapter 3}

\section{BASIC REACTOR TYPES AND POTENTIAL DAMAGES DUE TO EARTHQUAKES}

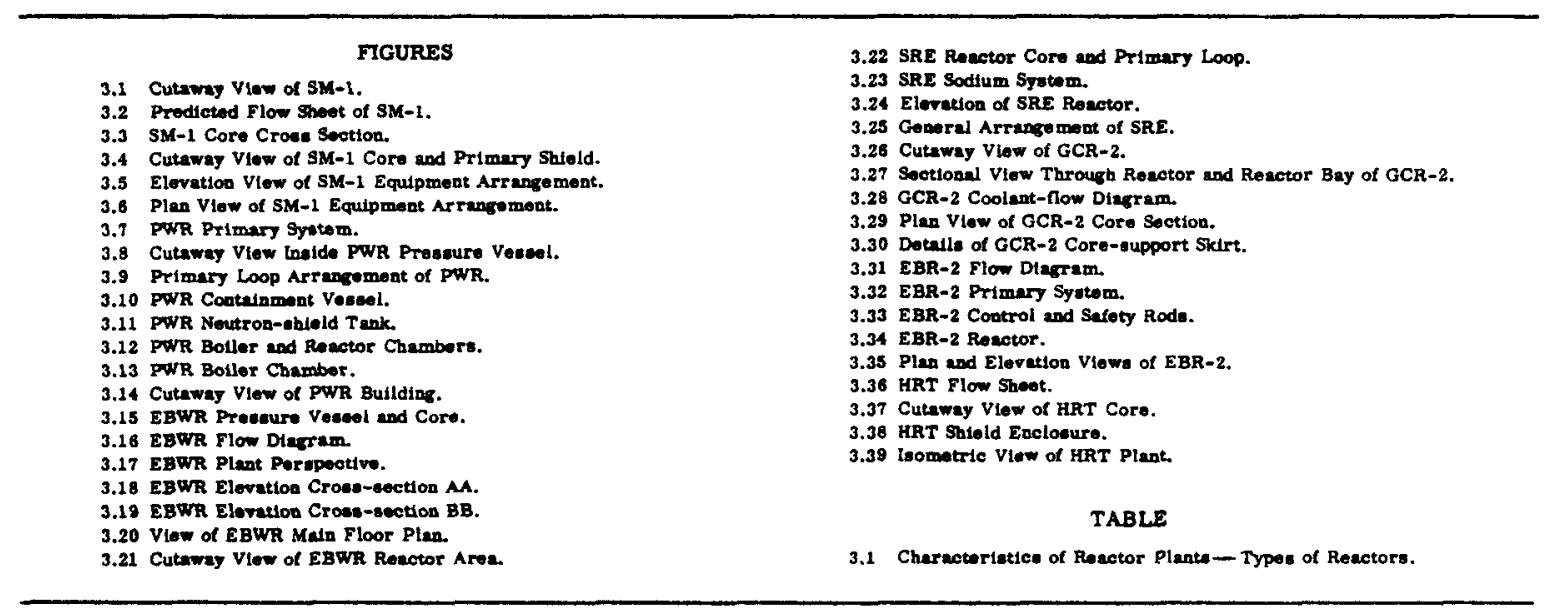

\subsection{DESCRIPTION OF REACTOR PLANTS}

In this chapter several types of nuclear-reactor power plants are described with respect to potential damages and hazards that may result from strong earthquakes. Information pertaining to safety, such as stored potential energy, emergency shutdown, and containment of fission products, is qualitatively presented for the information of the reader not familiar with nuclear power plants.

Power is produced in an analogous manner by both fossil-fuel and nuclear power stations; i.e., thermal energy is converted to mechanical energy and thence to electrical energy by means of steam or other heat-transfer media and turbogenerator machinery. The chief difference between the two plants lies in the heat-generating unit in which the conventional furnace is replaced by a nuclear reactor. The fission process occurring in the reactor core produces, in addition to the necessary thermal energy, biologically hazardous radiation and radivactive materials. Extensive shielding and other safeguards are therefore required. In some reactor systems chemically reactive materials are used, and therefore additional safety provisions are needed. Elaborate instrumentation is needed in all nuclear reactors to control the rapid fission process. In this description of various 
nuclear plants and how their safe operation might be affected by earthquakes, attention will be directed mainly to the reactor system itself. Besides the reactor a large nuclear power station may have a fuel-processing plant and a radioactive-waste-treatment plant. These may be regarded as hazardous chemical plants with respect to industrial safety practices, and there would be the added necessity of radiation protection. Their details will not be pursued in this study, but many of the safety considerations of the reactor system apply also to them.

\subsection{SPECIFIC TYPES OF REACTORS}

Large power reactors in particular are discussed because their sizeable inventory of fission products, fuel, and reactive materials constitute greater potential hazards to the populace than small research type low-power reactors. The basic types investigated are pressurized-water reactors, boiling-water reactors, sodium-graphite reactors, gascooled reactors, fast breeder reactors, and homogeneous reactors. Since detailed information on specific reactors is available in the literature, only brief descriptions of the types of nuclear reactors chosen will be given here.

Points of comparison to be noted for these reactors are the presence or absence of moderators; the types of material used as moderator, coolant, and fuel; the distribution of fuel in the core; the number of cycles or heat-exchange loops used; the types of material and design of the control rods; and the various hazards and safety features. Some of these data are conveniently summarized in Table 3.1.

\section{A. Pressurized-water Reactor}

A pressurized-water reactor (PWR) is characterized by its highly pressurized primary loop containing subcooled water that serves both as a moderator and a coolant. For large power reactors the pressure vessel containing the core must be very thick to withstand the high pressure. Since a PWR seeks to avoid boiling in its primary loop, steam if formed in a secondary loop. Conventional turbogenerator sets produce electrical power from the steam. Examples of PWR units are the Stationary Medium Power Plant No. 1 (SM-1) [formerly called the Army Package Power Reactor (APPR)] and the Shippingport Atomic Power Station.

The SM-1 (see Appendix A for seismic analysis) is rated at $10 \mathrm{Mw}(\mathrm{t})$ and operates at 1200 psia and $450^{\circ} \mathrm{F}$ (Fig. 3.1). In the steam generator, heat is transferred from the primary loop water to the secondary steam system, which is used to run the turbogenerator set (Fig. 3.2). Flat fuel plates containing highly enriched uranium dioxide $\left(\mathrm{UO}_{2}\right)$ and boron carbide $\left(B_{4} C\right)$ in stainless steel are sandwiched-between stainless -steel cladding. When some burnable poison in the form of $\mathrm{B}_{4} \mathrm{C}$ is added to the fuel plates, the time between fuel recharging is lengthened to 18 months. In principle, part of the initial excess reactivity is balanced by the poison; however, as the poison burns away, the liberated excess reactivity compensates for the depletion of fuel and the buildup of fission products and heavy isotopes. Forced circulation is employed to cool the fuel plates, and a pressurizer is used to keep the water below its boiling point. The active core, which is 22 by 20 by $20 \mathrm{in}$, has upper and lower grid plates to lock the fuel plates in place and to give lateral support to control rods (Figs. 3.3 and 3.4). These control rods are square tubes made with $\mathrm{B}_{4} \mathrm{C}$ and stainless steel.

During reactor operation the absorber section is displaced upward from the core. A scram signal releases the magnetic clutch to allow the rods to fall back into the core by means of gravity, which results in shutting down the reactor. The drive shaft for the control rods extends out through the side of the pressure vessel below the core level. Labyrinth seals allow a small, controlled amount of leakage from the shaft extension. The shaft seals, clutches, and drive motors are thus outside the primary vessel.

The pressure vessel is surrounded by combination blast and gamma shields of steel and water in a large tank. A spent-fuel transfer tube, located directly beside the cover 
Table 3.1-CHARACTERISTICS OF REACTOR POWER PLANTS-TYPES OF REACTORS

\begin{tabular}{|c|c|c|c|c|c|c|c|}
\hline \multirow[b]{2}{*}{ Reactor characteristics } & \multicolumn{7}{|c|}{ Reactor type } \\
\hline & $\begin{array}{l}\text { PWR } \\
\text { SM-1 }\end{array}$ & $\begin{array}{c}\text { PWR } \\
\text { Shippingport }\end{array}$ & $\begin{array}{l}\text { BWR } \\
\text { EBWR }\end{array}$ & $\begin{array}{l}\text { SGR } \\
\text { SRE }\end{array}$ & $\begin{array}{l}\text { Gas-cooled } \\
\text { ORNL GCR-2 }\end{array}$ & $\begin{array}{l}\text { Fast breeder } \\
\text { EBR-2 }\end{array}$ & $\begin{array}{l}\text { Homogeneous } \\
\text { HRT }\end{array}$ \\
\hline Rated power, Mw(t) & 10 & 505 (original 231) & $20 *$ & 20 & 687 & 62.5 & 5 \\
\hline Design-core pressure, psla & 1600 & 2500 & 800 & 18 & 300 & 120 & 2000 \\
\hline Test-core pressure, paia & 2400 & $\mathbf{3 7 5 0}$ & 1200 & & & & 2800 \\
\hline Coolant exit temp., $\boldsymbol{F}$ & 450 & 540 & 488 & 960 & 1000 & 900 & 570 \\
\hline Max. element surface temp., ${ }^{\top} \boldsymbol{F}$ & 554 & 740 & 645 & $10^{3}$ & 1200 & 950 & 570 \\
\hline \multirow{2}{*}{\multicolumn{8}{|c|}{$\begin{array}{l}\text { Max. element heat flux, } \\
\text { Btu/gr)(ga ft) }\end{array}$}} \\
\hline & $2.2 \times 10^{4}$ & $4.2 \times 10^{5}$ & $1.4 \times 10^{5}$ & $3.4 \times 10^{5}$ & $\sim 1 \times 10^{6}$ & $1 \times 10^{8}$ & \\
\hline Max. neut ron flux, nv & $1 \times 10^{14}$ & $2.5 \times 10^{14}$ & $2.4 \times 10^{13}$ & $5 \times 10^{13}$ & $5 \times 10^{12}$ & $25 \times 10^{18}$ (fast) & $7 \times 10^{13}$ \\
\hline Prompt-neutron lifetime, sec & $2 \times 10^{-5}$ & $5.6 \times 10^{-1}$ & $63 \times 10^{-6}$ & $5 \times 10^{-4}$ & & $8 \times 10^{-3}$ & $2 \times 10^{-4}$ \\
\hline \multicolumn{8}{|l|}{ Reactivity temp. coefficlent. } \\
\hline Average acram time, sec & 0.53 & 1.35 & 0.35 & 0.6 & & 0.38 & \\
\hline Refuel-cycle time, months & 18 & & & 13 & & $\mathbf{3}$ & \\
\hline Fuel burnup, $\%$ & 25 & & & 10 & & 4 & \\
\hline \multicolumn{8}{|l|}{ Approx. fission-produet inventory. 1} \\
\hline total curies & $8 \times 10^{1}$ & $2 \times 10^{4}$ & $2 \times 10^{4}$ & $2 \times 10^{4}$ & $6 \times 10^{10}$ & $5 \times 10^{8}$ & $4 \times 10^{7}$ \\
\hline Moderator material & $\mathrm{H}_{2} \mathrm{O}$ & $\mathrm{H}_{2} \mathrm{O}$ & $\mathrm{H}_{2} \mathrm{O}$ & Graphite & Graphite & None & $\mathrm{D}_{2} \mathrm{O}$ \\
\hline Primary coolant system & $\mathrm{H}_{2} \mathrm{O}$, forced & $\mathrm{H}_{2} \mathrm{O}$, forced & $\mathrm{H}_{2} \mathrm{O}$, bolling & $\mathrm{Na}$, forced & He, forced & $\mathrm{Na}$, forced & Fuel, forced \\
\hline Secondary loop syatem & $\mathrm{H}_{2} \mathrm{O}$-steam & $\mathrm{H}_{2} \mathrm{O}$-steam & None & $\mathrm{Na}$, forced & $\mathrm{H}_{2} \mathrm{O}$-steam & $\mathrm{Na}$, forced & $\mathrm{H}_{2} \mathrm{O}$-steam \\
\hline Fuel-element material & $\mathrm{UO}_{2}-\mathrm{B}, \mathrm{C}-\mathrm{S} . \mathrm{S}$ & U-2r & $\mathrm{U}-\mathrm{Zr} \mathbf{r}-\mathrm{Nb}$ & $\mathbf{u}$ & $\mathrm{UO}_{2}$ & U-fission & $\mathrm{UO}_{2} \mathrm{SO}_{4}-\mathrm{D}_{2} \mathrm{O}$ \\
\hline Fuel-element geometry & Flat plate & Flat plate & Flat plate & Rod & Rod & Pin & Llquild sphere \\
\hline Fuel-element cladding & 304 S S. & Zircaloy-2 & Zircaloy-2 & 304 S.S. & 304 S.S & s.s. & S.S. piping \\
\hline Fuel enrichment, o $U^{235}$ & 93 & 93 & 1.4 & 2.8 & 2 & $\sim 49$ & $\sim 90$ \\
\hline Fuel-bundle length, it & 3 & 6 & 6 & 6 & $\mathbf{3 . 3}$ & 1.2 & \\
\hline $\begin{array}{l}\text { Safely-rod material } \\
\text { Safety-rod geometry }\end{array}$ & $\begin{array}{l}\text { B, C-Fe } \\
\text { Square (3 in.) }\end{array}$ & $\begin{array}{l}\text { Hi-Zircaloy } \\
\text { Cructform (3.4 in.) }\end{array}$ & $\begin{array}{l}\text { Hf-B-Fe } \\
\text { Cructform }\end{array}$ & $\begin{array}{l}\text { B-Ni-Fe } \\
\text { Rod (2.3 in. dia.) }\end{array}$ & $\begin{array}{l}\text { As-S.S. } \\
\text { Rad }\end{array}$ & $\begin{array}{l}\mathbf{U} \text { (fuel) } \\
\text { Hexagonal } \\
\text { (1.908 in. } \\
\text { across } \\
\quad \text { flats) }\end{array}$ & None \\
\hline Safety-rod travel length, it & 2 & 6 & 4 & 6 & & 1.2 & \\
\hline Scram-system force & Gravity & Gravity & $\begin{array}{l}\text { Pressure gravity. } \\
\text { springt }\end{array}$ & Gravity & Gravity & Gravity, spring & Pressure, gravity \\
\hline \multicolumn{8}{|l|}{ Primary container: } \\
\hline Diameter, it & 4 & $\mathbf{9}$ & 7 & 11 & 50 & 26 & 5 \\
\hline Shape & Cylinder & Cylinder & Cylinder & Cyllnder & Sphere & Cylinder & Sphere \\
\hline Thickness, in. & 2.8 & 85 & 2.25 & 1.5 & 3.3 & 0.5 & 44 \\
\hline Height, ft & 135 & 33 & 23 & 19 & (Sphere) & $\sim 25$ & (Sphere) \\
\hline Material & Carbon steel & Carbon steel & Carbon steel & 304 S.S. & Steel & s s. & Steel \\
\hline Cladding & $1 / 4$-in. S.S & 1/4-in. S.S. & $1 / 1 /$-in. S.S. & None & None & None & ss. \\
\hline \multicolumn{8}{|l|}{ Secondary container: } \\
\hline Shape & Domed cylinder & Cylunders, sphere & Domed cylinder & Conventional & Conventional & Domed cylinder & Cubicie \\
\hline Thickmess, in. & $24-36$ & $\frac{1 / 2}{V}$ & $\sim 12$ & mill type & building & 1-in. steel & \\
\hline $\begin{array}{l}\text { Dameter, ft } \\
\text { Height, ft }\end{array}$ & $\begin{array}{l}36 \\
64\end{array}$ & $\begin{array}{l}\text { Varlous } \\
\text { Various }\end{array}$ & $\begin{array}{l}80 \\
119\end{array}$ & bunlding & & $\begin{array}{l}80 \\
139\end{array}$ & \\
\hline HRT dimensions & & 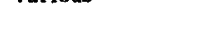 & 110 & & & ton & $25 \times 32 \times 54$ \\
\hline Material & Steel-concrete & Steel & Steel-concrete & & & Steel-concrete & Steel-concrete \\
\hline Design pressure, psig & 43 & $+53,-3$ & $+15,-0.5$ & & & $+24,-1$ & $+32,-1$ \\
\hline Leakage rate, vol.\%/day & & 015 & & $\sim 10$ & & 0125 at $24 \mathrm{psig}$ & 002 \\
\hline Net volume, cu ft & 37,000 & 473,000 & 400,000 & & & 450,000 & 25,000 \\
\hline
\end{tabular}




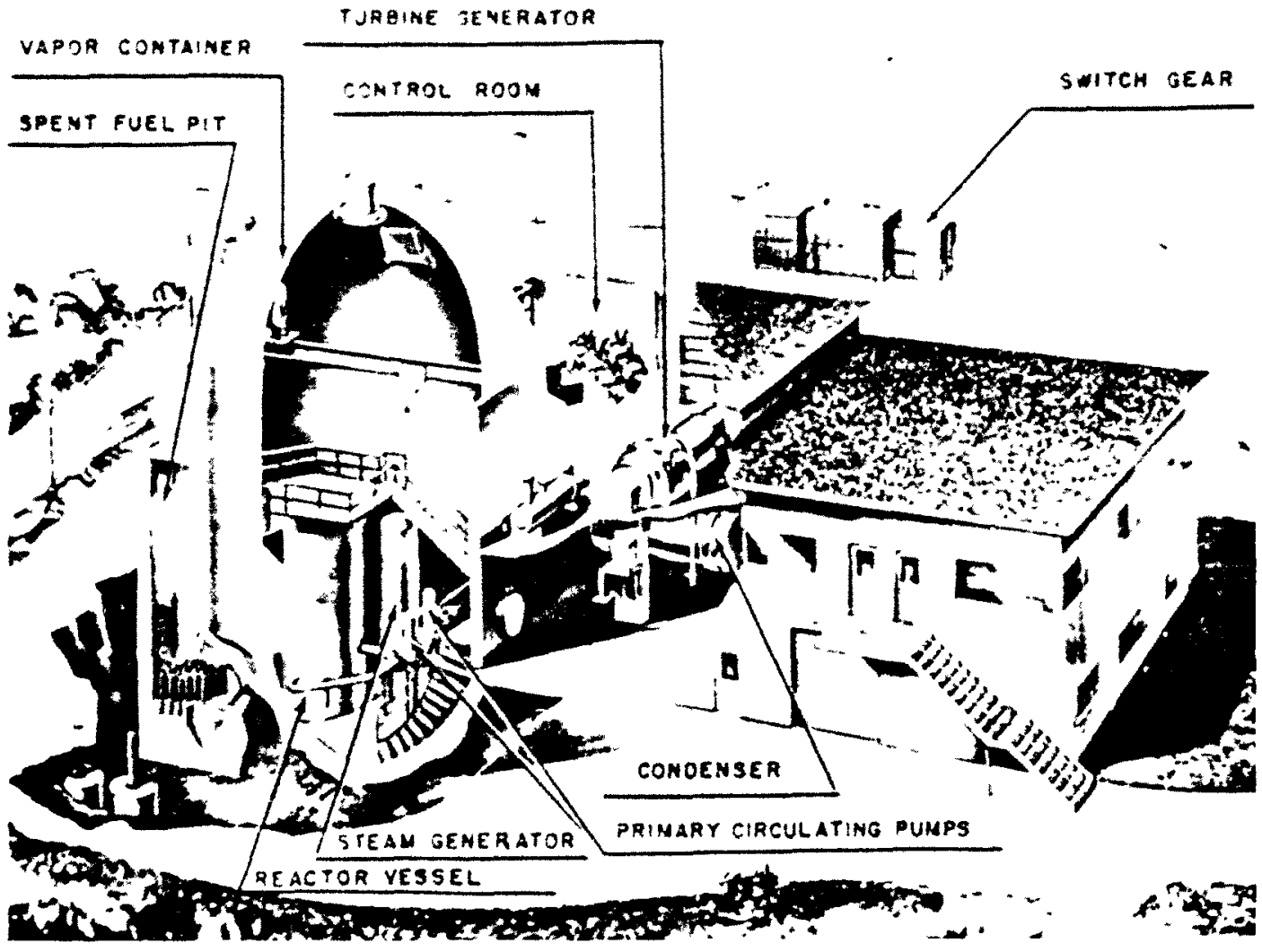

Fig. 3.1-Cutaway view of SM-1. (Alco Products, Inc.)

of the pressure vessel, leads to a pit outside the secondary container. A plug seals the transfer tube during reactor operation.

The secondary container which is $36 \mathrm{ft}$ in diameter and $64 \mathrm{ft}$ in height, is a cylindrically shaped vessel with hemispherical heads, is fabricated from $1 / 2$ - and $7 / 8$-in. -thick steel, and is lined on the inside with a 2 -ft-thick layer of concrete (Figs. 3.5 and 3.6). The concrete shell is, in turn, lined with Nc. 18 gauge, type 304 stainless steel. During reactor operation personnel are not permitted in the secondary containment shell. Access manholes are gasketed and bolted to $2 \frac{1}{2}$-in. -thick steel covers. At the top of the vapor container two emergency spray nozzles are installed to reduce the temperature and pressure rise that may result from accidental rupture of the primary components. The source of this emergency water is the Fort Belvoir water supply, which normally is disconnected from the spray system. The reactor, the pressurizer, the primary coolant pumps, and the steam generator constitute the major components in the containment vessel. This vessel was hydrostatically tested at $75 \mathrm{psig}$. In addition to an auxiliary power line from the outside, a battery set furnishes emergency power to the system.

The Shippingport Pressurized-water Reactor, located at Shippingport, Pa., is a fullscale power reactor of the PWR class (Fig. 3.7). The core, which has a heat-generation rate of $505 \mathrm{Mw}$, is cooled by water at $540^{\circ} \mathrm{F}$ at 2000 psia. The core is composed of plate type seed elements of fully enriched uranium-zirconium alloy and of tubular blanket elements composed of natural $\mathrm{UO}_{2}$ pellets.

The pressure vessel is $8 \frac{1}{2}$ in. thick, $9 \mathrm{ft}$ in inside diameter, and $33 \mathrm{ft}$ high. Its shell is made of carbon steel clad on the inside with stainless steel. Four separate coolant loops (one stand-by) are provided to remove the heat. Cruciform-shaped control rods 


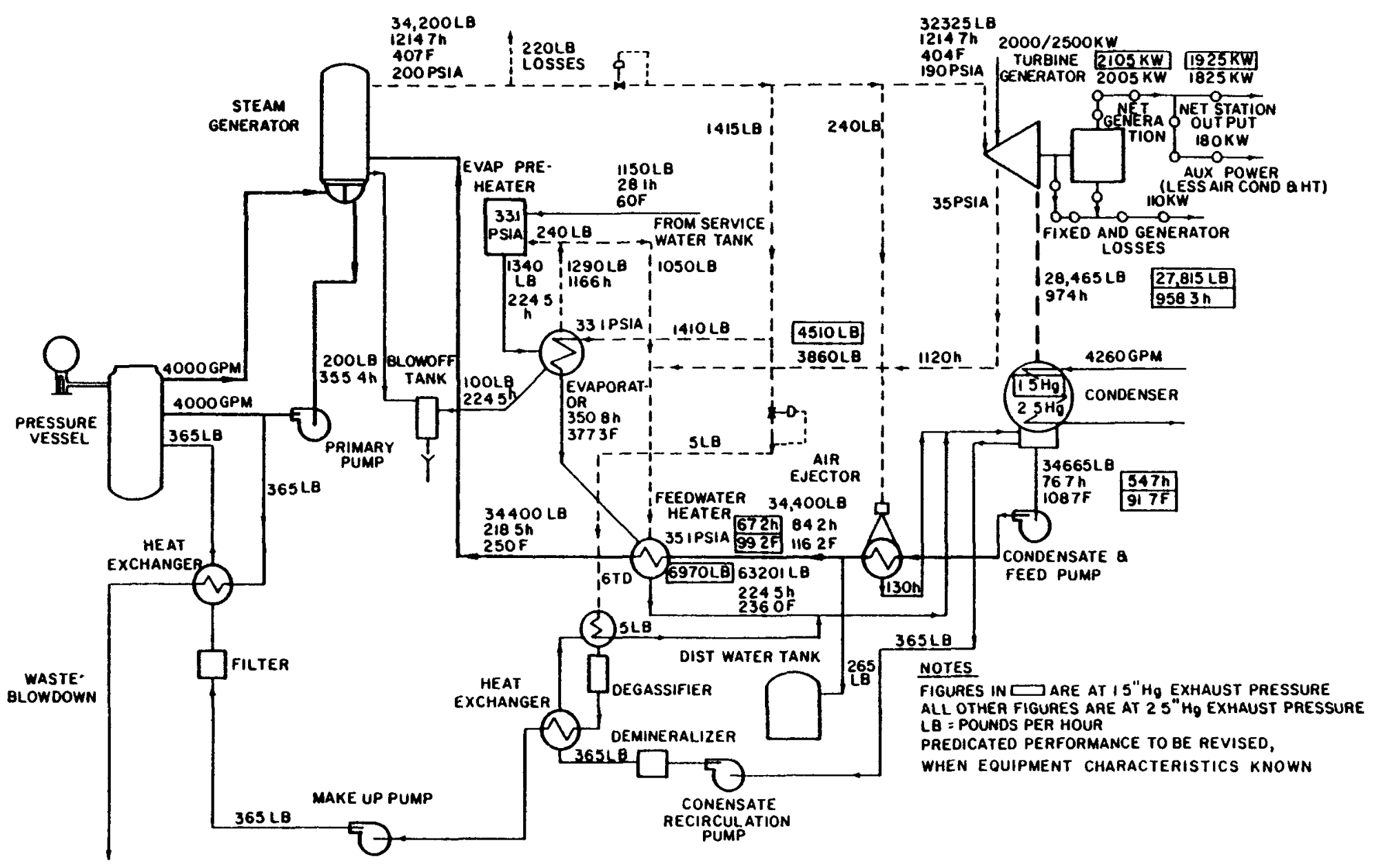

NET STATION HEAT RATE@ $25^{\prime \prime} \mathrm{H}_{0}=\frac{341 \times 10^{6}}{1825}=18,685$ BTU/NET KWH

NET STATION HEAT RATE @ $15 " \mathrm{Hg}_{0}=\frac{341 \times 10^{6}}{1925}=17,715$ BTU/NET $\mathrm{KWH}$

Fig. 3.2-Predicted flowsheet of SM-1. (Alco Products, Inc.) 


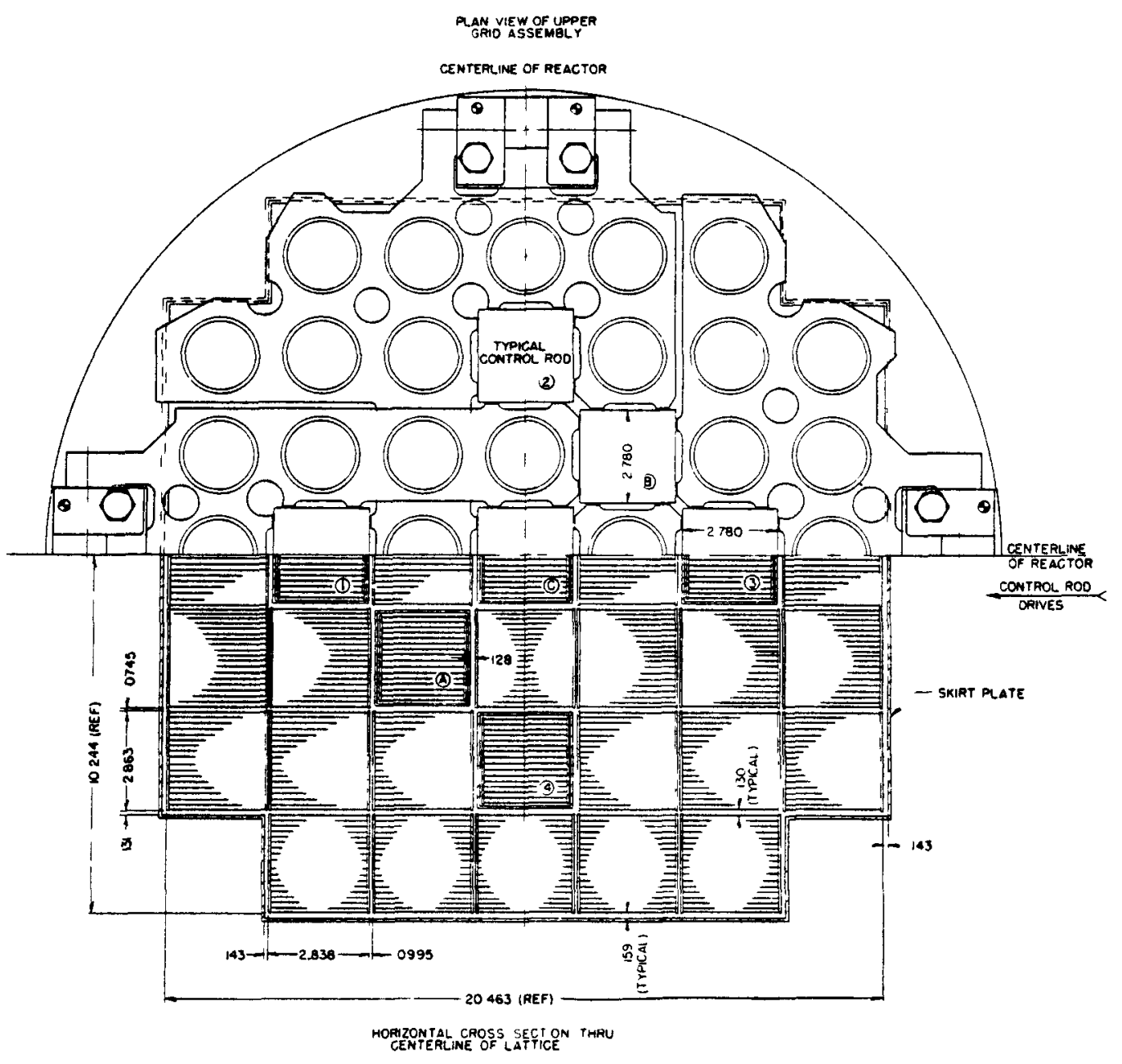

Fig. $3.3-$ SM-1 core cross section. (Alco Products, Ine)

are driven oy top-entering-drive mechanisms. The rods fall in by gravity in the event of an emergency scram (Fig. 3.8). The pressure vessel is shielded by $3 \mathrm{ft}$ of water and $5 \mathrm{ft}$ of concrete. Fuel transfer is performed underwater in the fuel-handling bullding, where spent fuel can be stored in water canals.

Vaportight steel containers enclose all critical plant components to prevent the spread of radioactivity following a maximum credible accident (Figs. 3.9 to 3.14 ). The reactor vessel is enclosed in a 38 -ft-diameter spherical shell having an 18 -ft cylindrical dome on the top to house the control-rod-drive mechanısm. In addition, there are two cylinders $50 \mathrm{ft}$ in diameter and $97 \mathrm{ft}$ in length, each of which contains two of the primary coolant loops and their associated equipment. Between these containers and the turbogenerator is situated another cylinder, $50 \mathrm{ft}$ in diameter and $147 \mathrm{ft}$ in length, which contains the pressurizer and auxiliary equipment. These secondary containers are all interconnected by a system of 8 - and 12 -ft-diameter pipes. The net free volume is $473,000 \mathrm{cu} f t$. Maximum design pressure for the system is $53 \mathrm{psig}$. At this pressure a maximum leakage rate of $0.15 \%$ of the net volume per day 1 s anticipated. A water spray system is built in to reduce the pressure in the vapor container in the event an accident releases the potential energy of the primary loop. In case of an electrical power fallure, the plant is equipped with a manually started diesel-driven motor-generator set. 


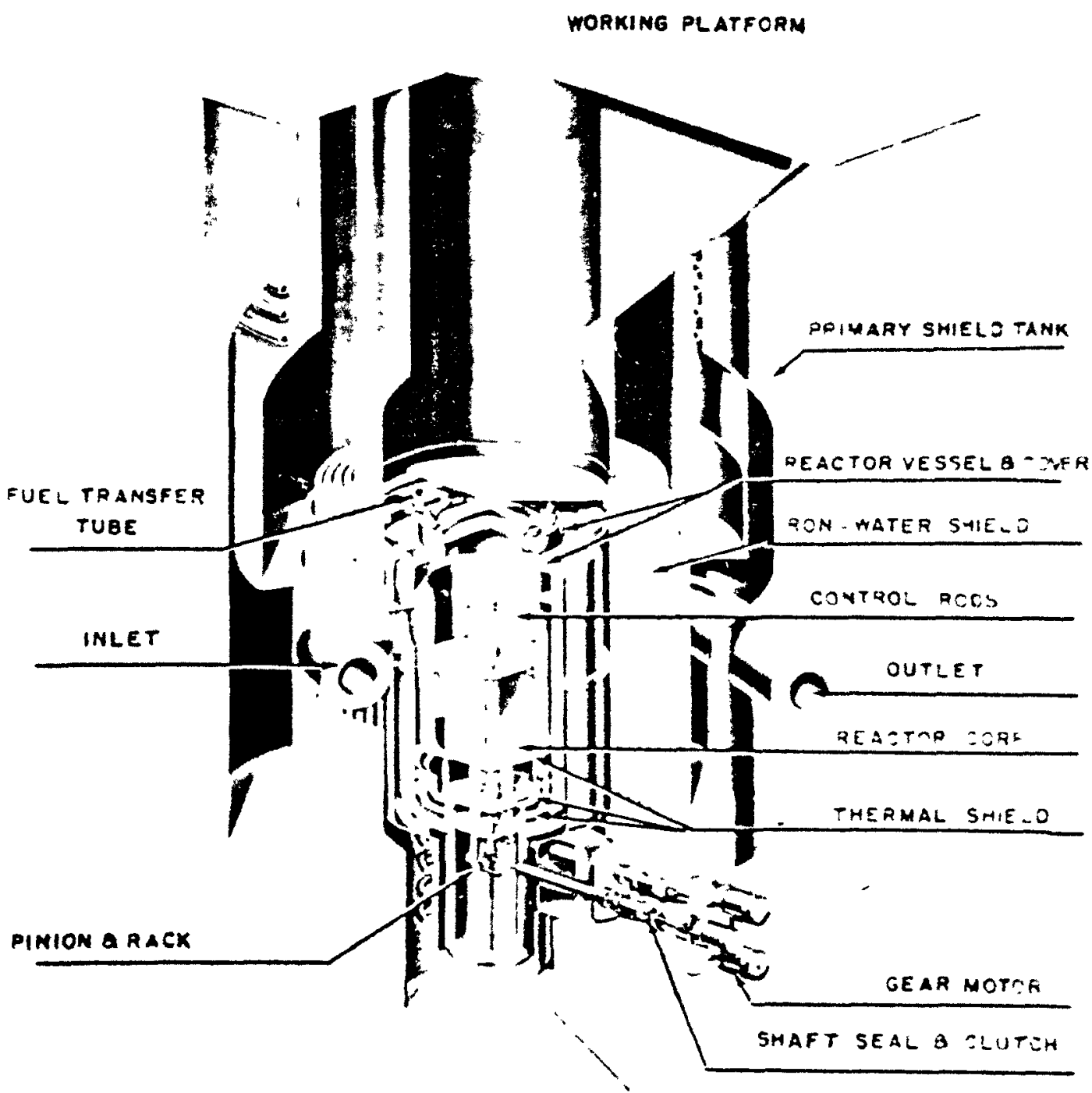

Fig. 3.4-Cutaway view of SM-1 core and primary shield. [Reprinted from Nucleonucs, 15 (8): facing p. $60(1957)$.] 


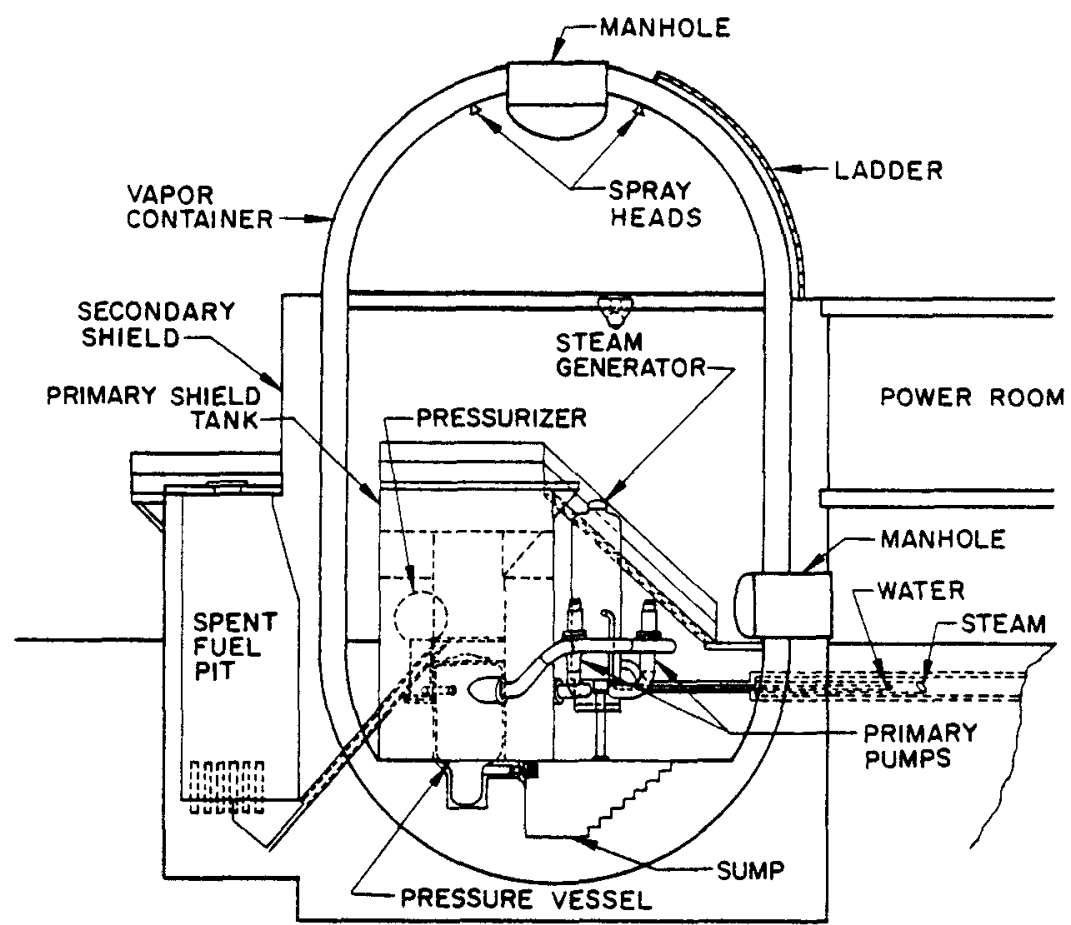

Fig. 3.5 - Elevation view of SM-1 equipment arrangement. (Alco Products, Inc.)

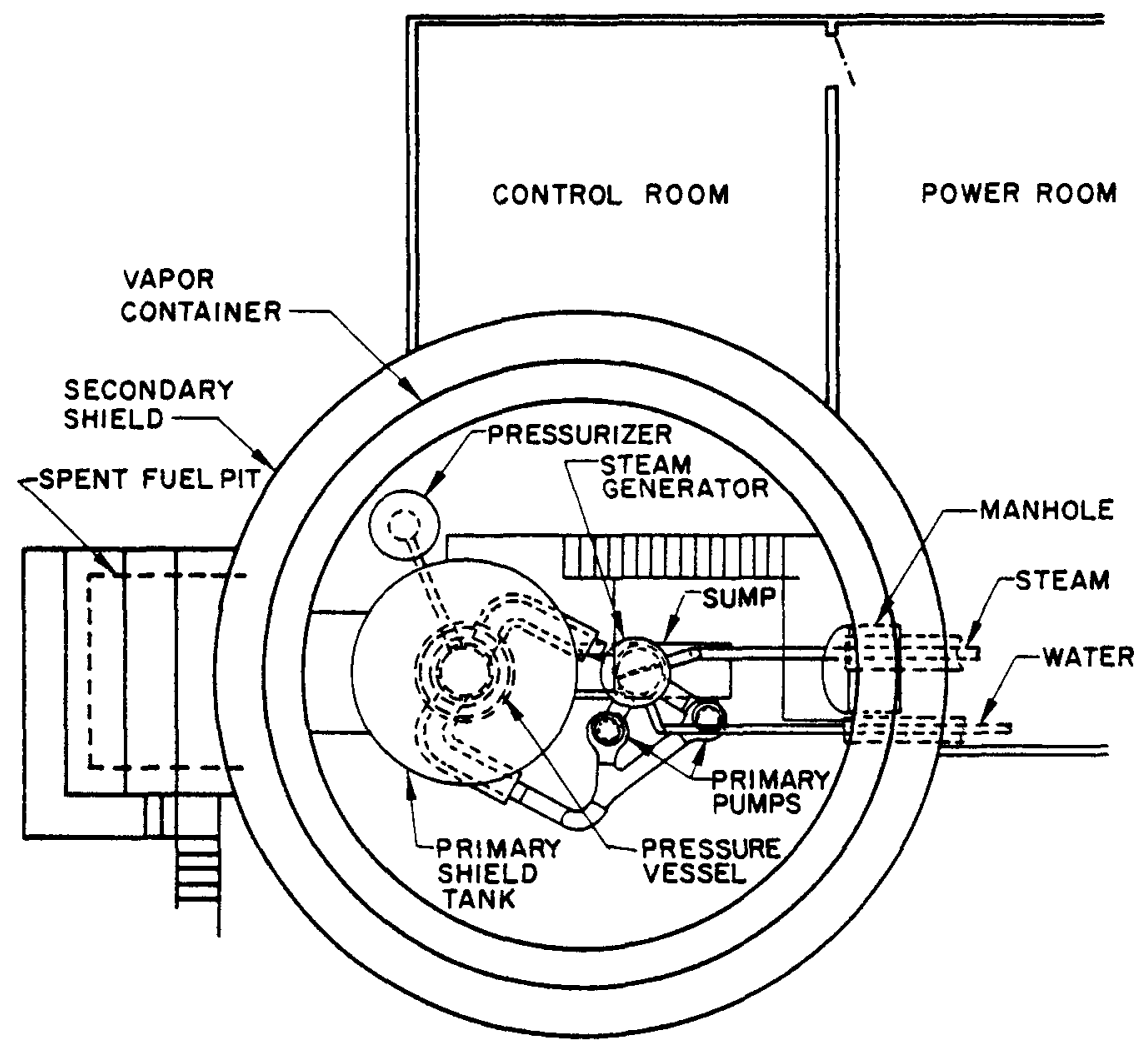

Fig. 3.6-Plan view of SM-1 equipment arrangement. (Alco Products, Inc.) 


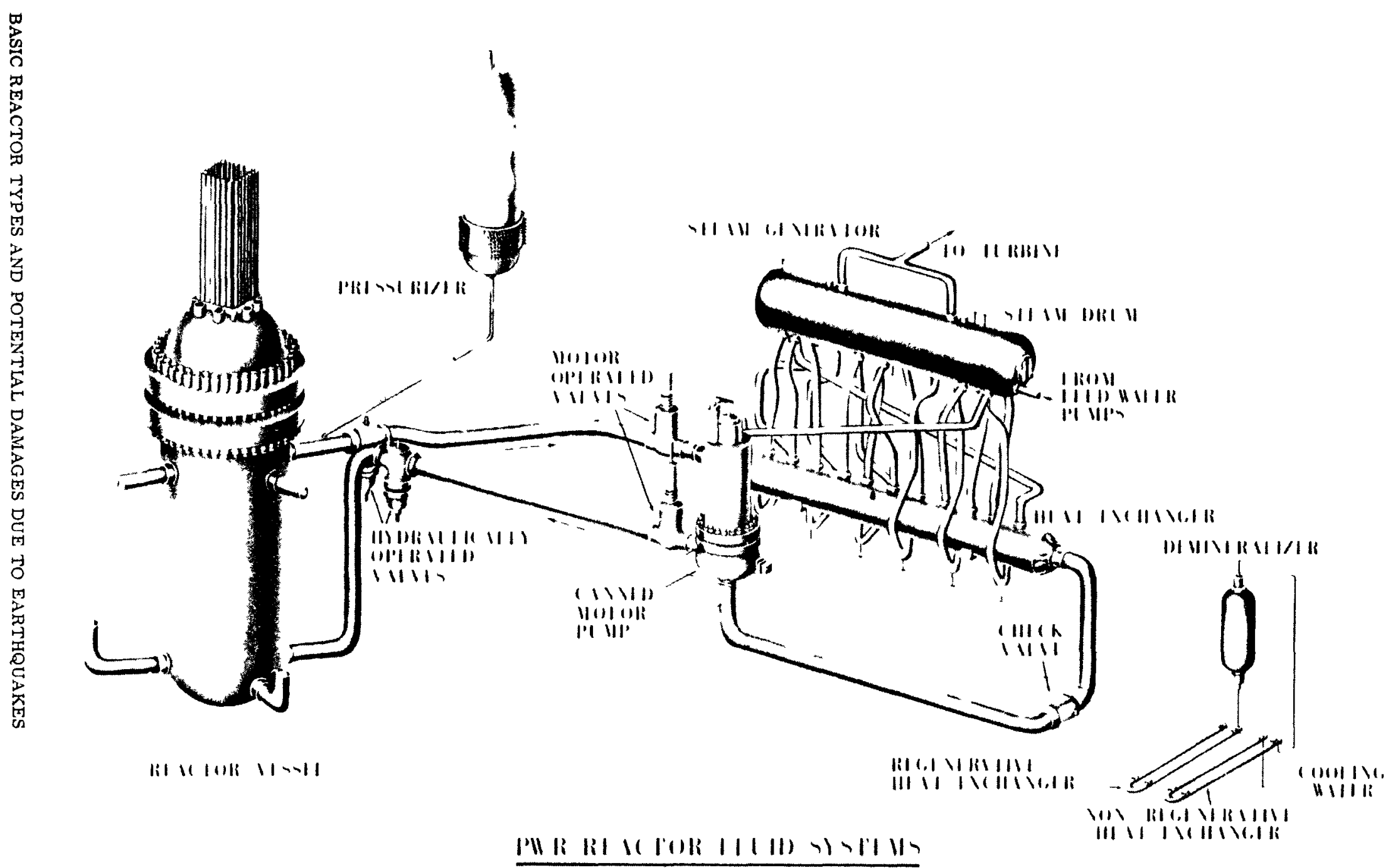




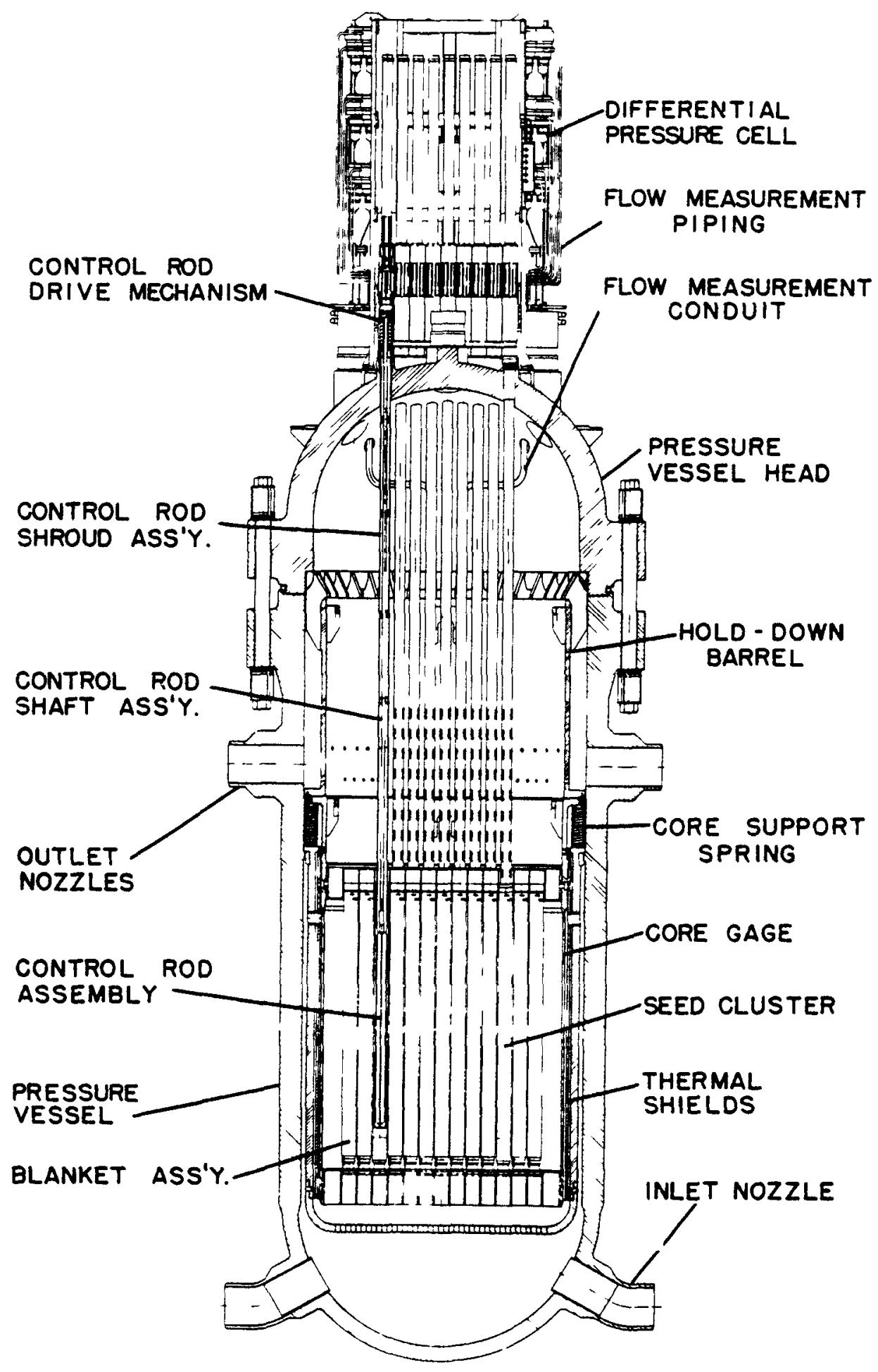

Fig. 3.8-Cutaway view insıde PWR pressure vessel. (Westinghouse Electric Corporation, Bettis Atomic Power Division) 


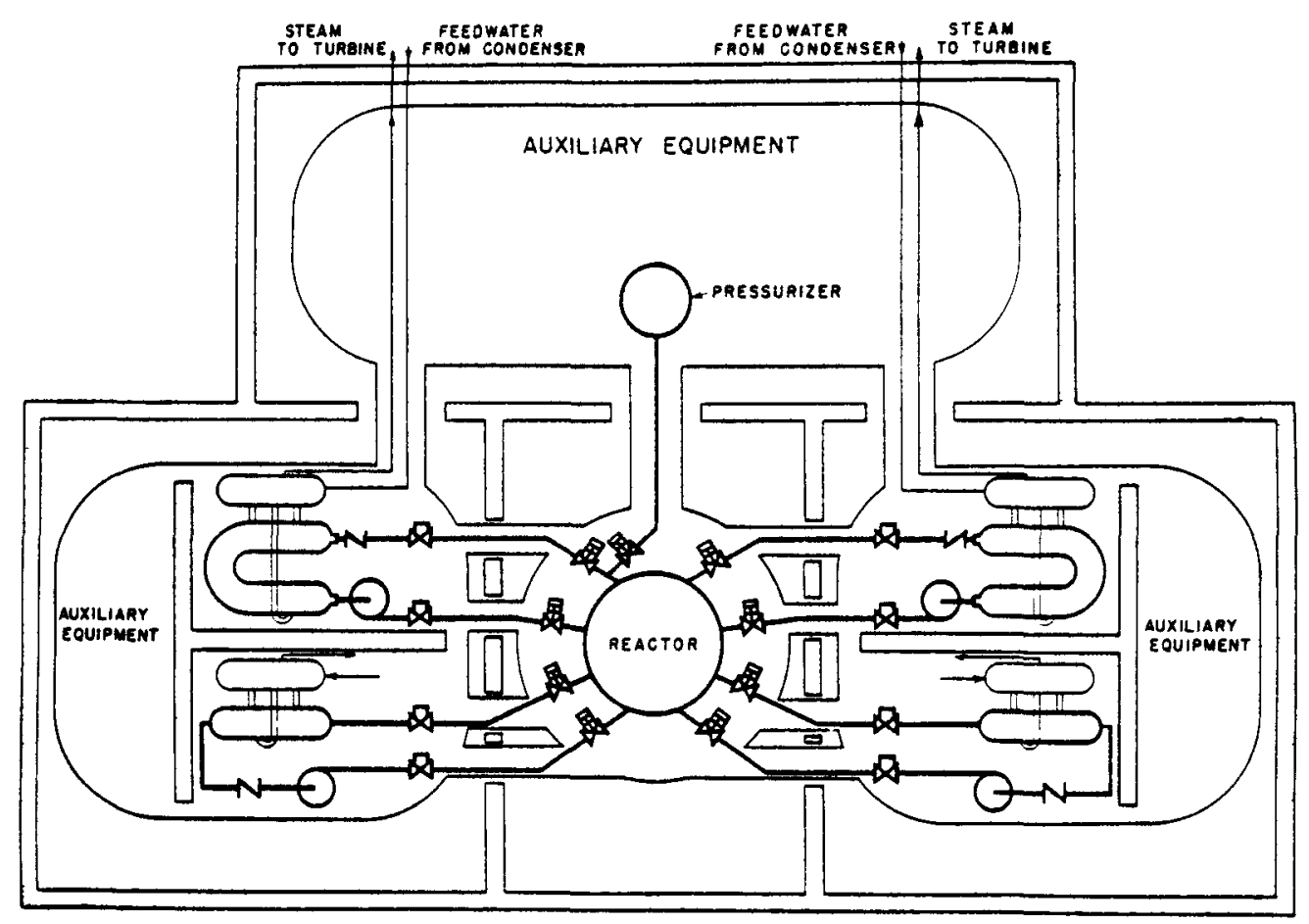

Fig. 3.9-Primary loop arrangement of PWR. (Westinghouse Electric Corporation, Bettis Atomic Power Division)
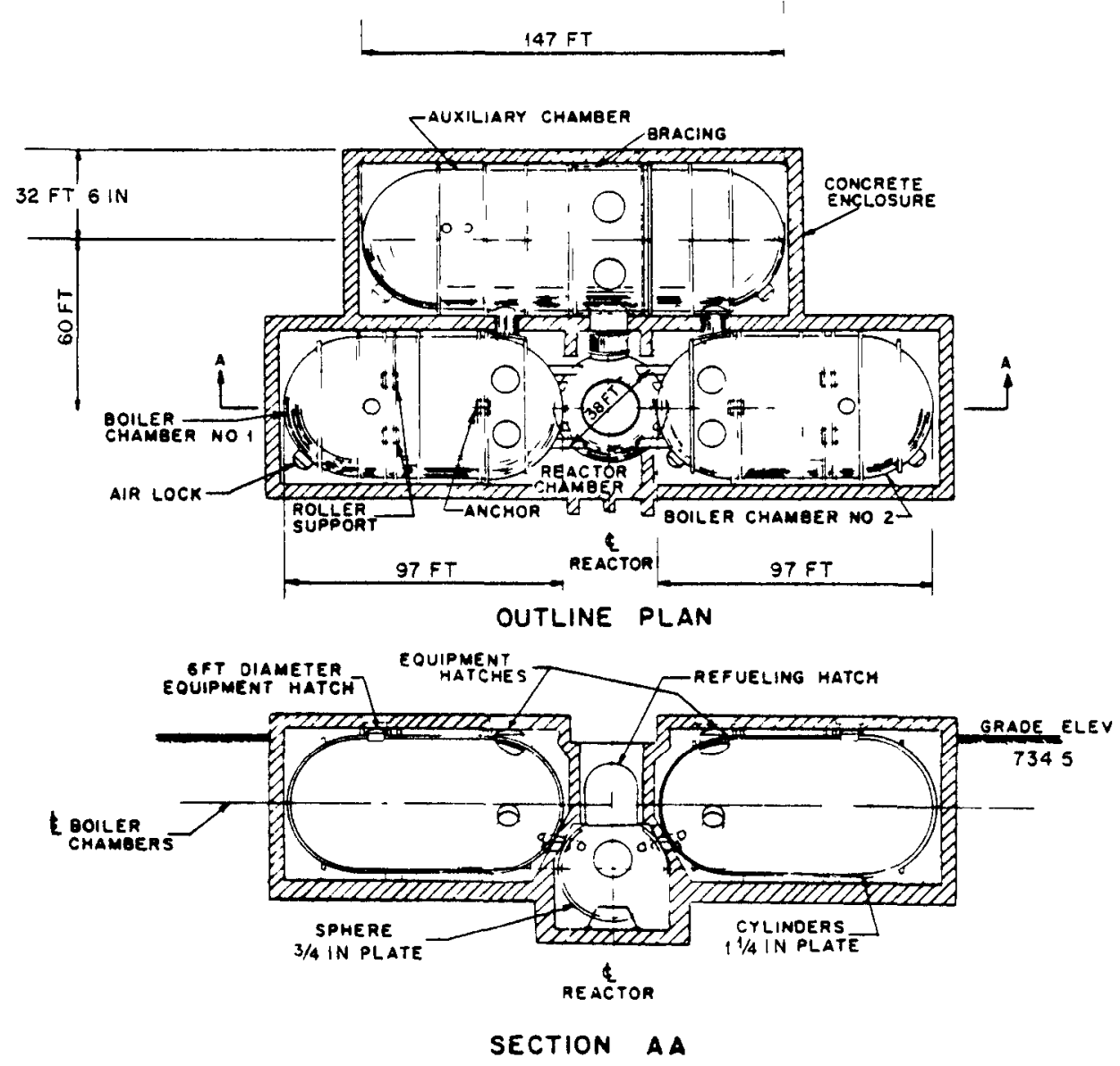

Fig. 3.10- PWR containment vessel. (Westinghouse Electric Corporation, Bettıs Atomic Power Division) 


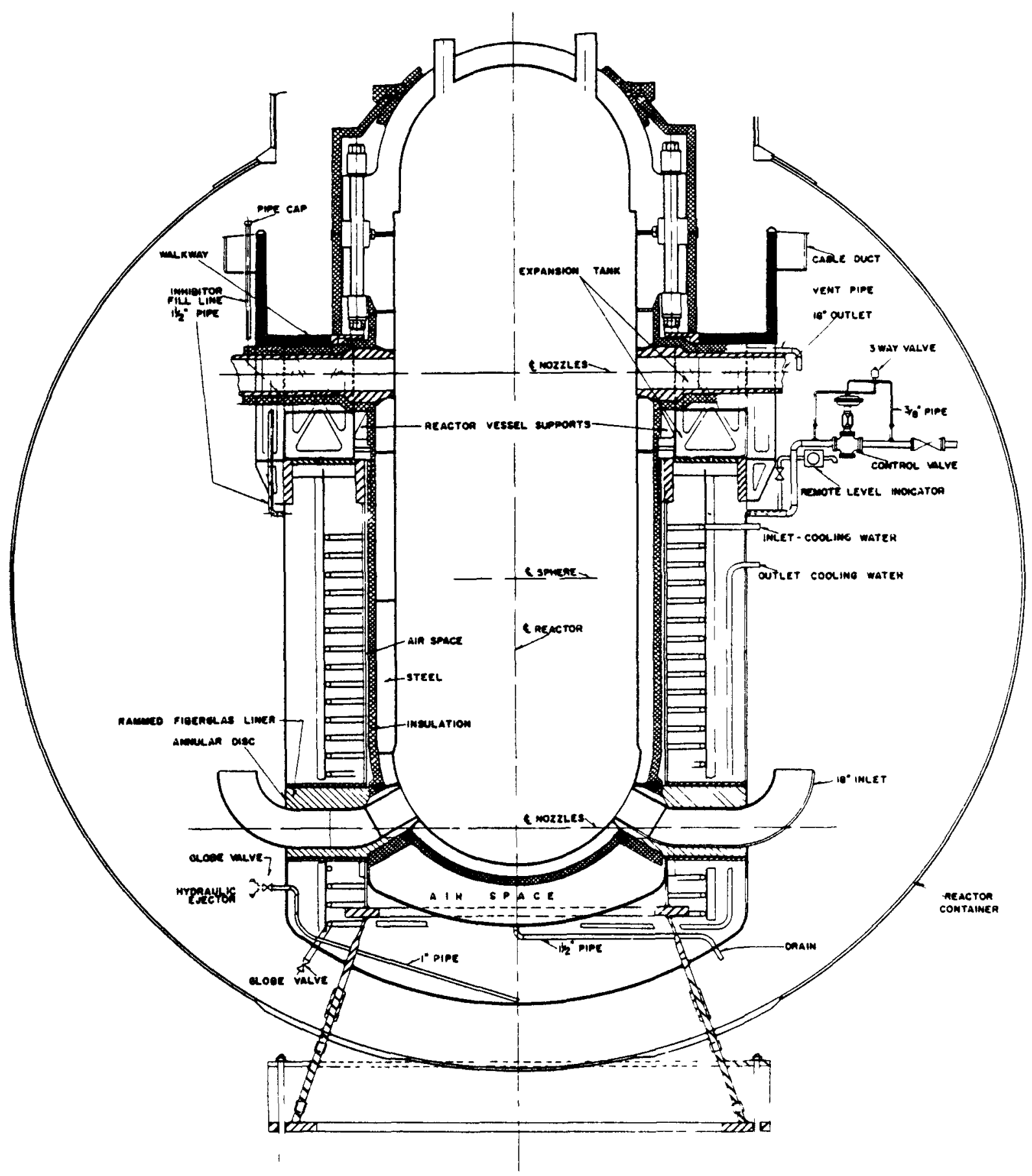

Fig. 3.11-PWR neutron-shield tank. (Westinghouse Electric Corporation, Bettis Atomic Power Division) 


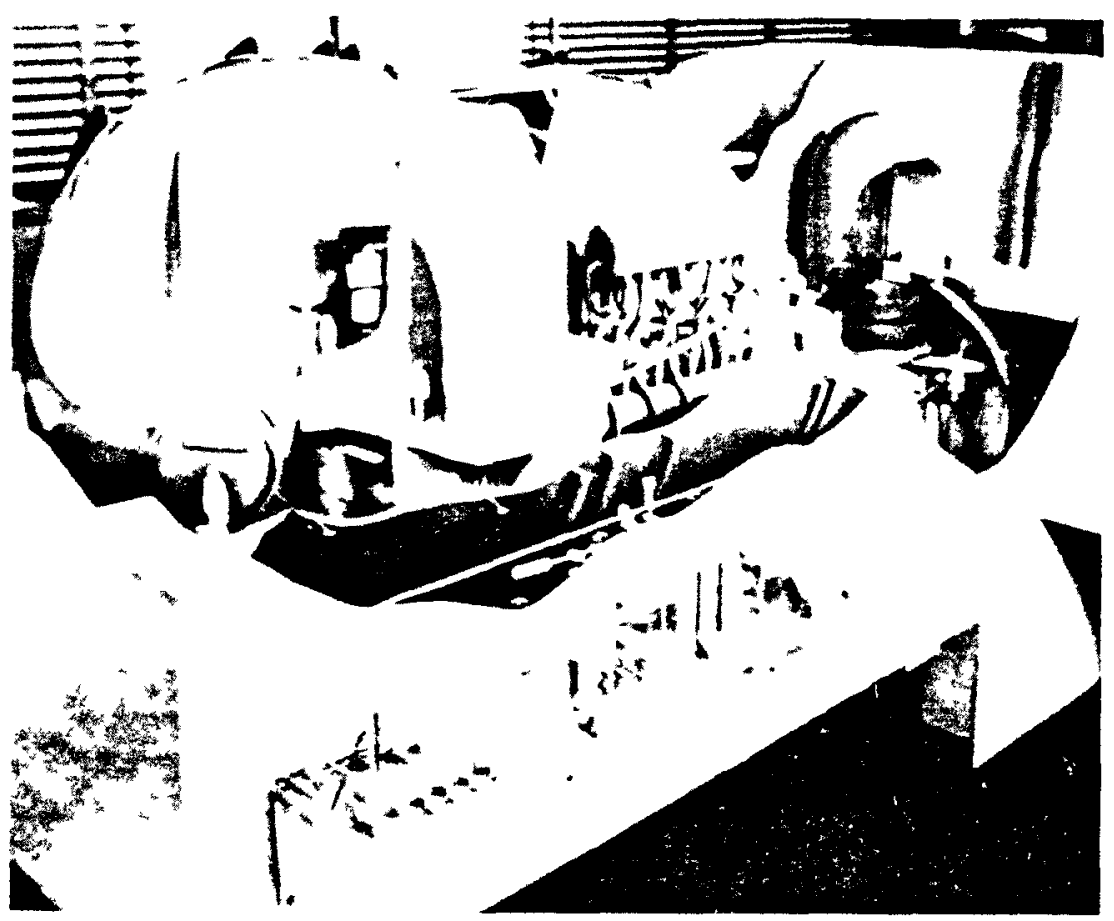

Fig. 3.12-PWR boller and reactor chambers. (Westinghouse Electric Corporation, Bettis Atomic Power Division)

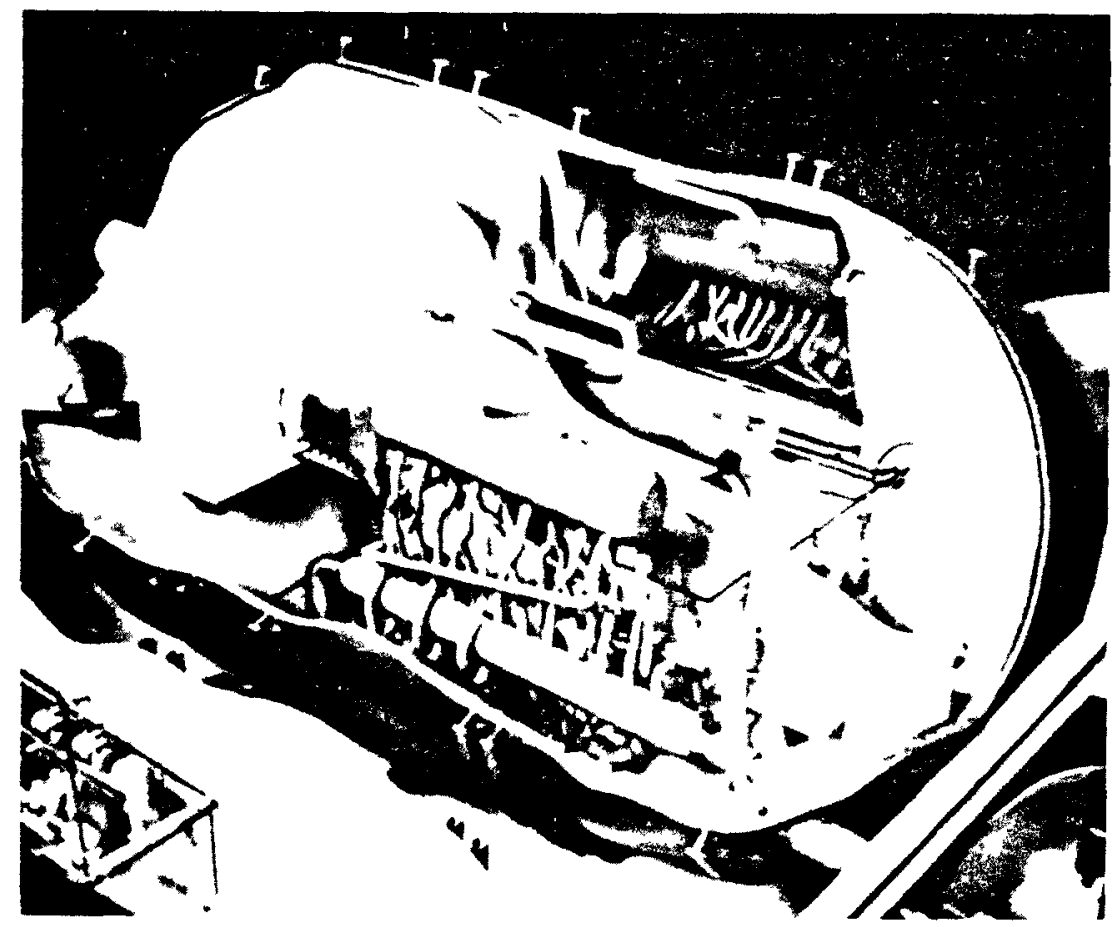

Fig. 3.13-PWR boller chamber. (Westinghouse Electric Corporation, Bettıs Atomic Power Division) 


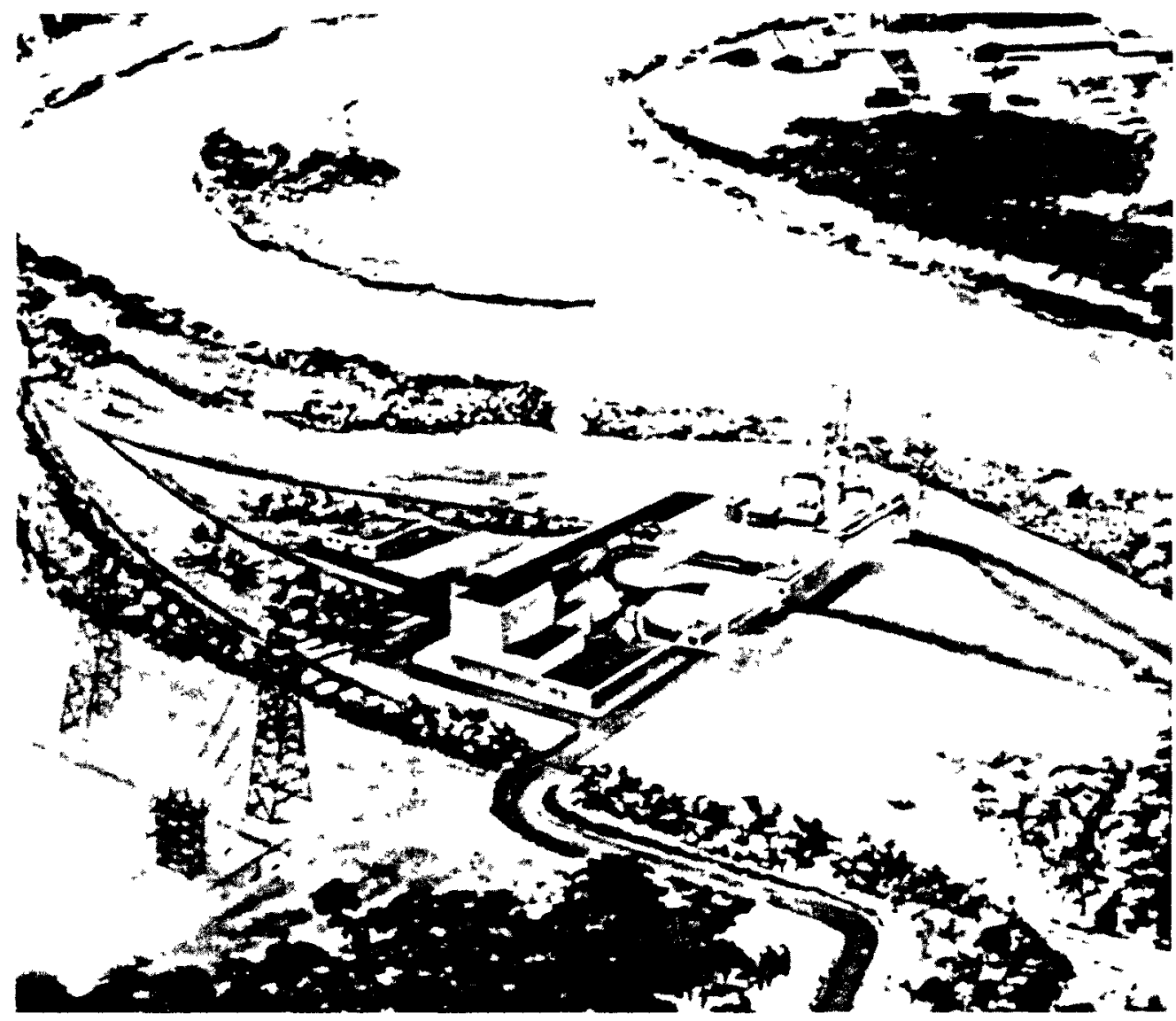

Fig. 3.14-Cutaway view of PWR building. (Westinghouse Electric Corporation, Bettis Atomic Power Division)

B. Boiling-water Reactor

In a boiling-water reactor (BWR) the water in the core is bolled to produce steam. Thus electrical power can be produced using a single heat-transfer loop in which the water serves as moderator, coolant, and working fluid. The Experimental Boiling Water Reactor (EBWR) (Argonne National Laboratory) has successfully demonstrated this principle. The full-scale Dresden (Commonwealth Edison) BWR also uses the direct-cycle method. Only the EBWR will be discussed here in detail.

In the EBWR (see Appendix B for seismic analysis) water is bolled in the core at 600 psig $\left(488^{\circ} \mathrm{F}\right)$, and the steam is used to transfer an original rated $20 \mathrm{Mw}(\mathrm{t})$ of energy out of the core, which is $4 \mathrm{ft}$ in diameter and $4 \mathrm{ft}$ in height [however, the core has been operated up to $100 \mathrm{Mw}(\mathrm{t})$ to demonstrate the capabilities of the system]. Plate type uraniumzirconium-nickel alloy fuel elements are clad with Zircaloy-2. The pressure vessel, a carbon steel cylinder internally clad with stainless steel, is $7 \mathrm{ft}$ in inside diameter and $23 \mathrm{ft}$ in height. The wall thickness is $2 \frac{1}{4}$ in. (Figs. 3.15 and 3.16 ).

A cylindrical steel shell, which is $80 \mathrm{ft}$ in diameter and $119 \mathrm{ft}$ in height, with a hemispherical dome, serves as the secondary container. It is capable of withstanding 15 psig. Most of the shell is lined with concrete. A 15,000-gal tank, located in the ceiling dome, holds the emergency water supply for a spray system. The steam turbine generator and condenser are located within the secondary shell (Figs. 3.17 to 3.20 ). 


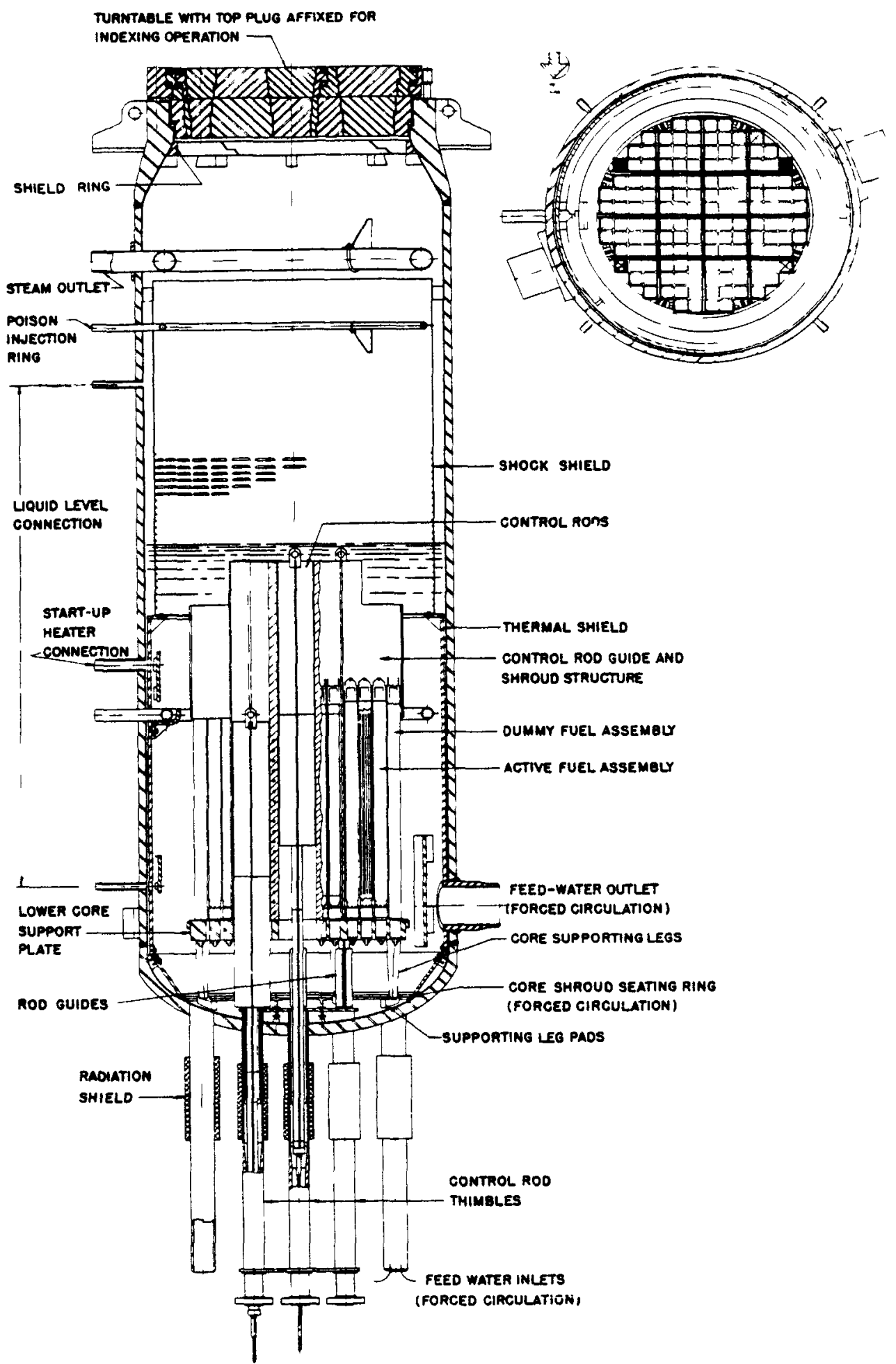

Fig. 3.15-EBWR pressure vessel and core. (Argonne National Laboratory) 


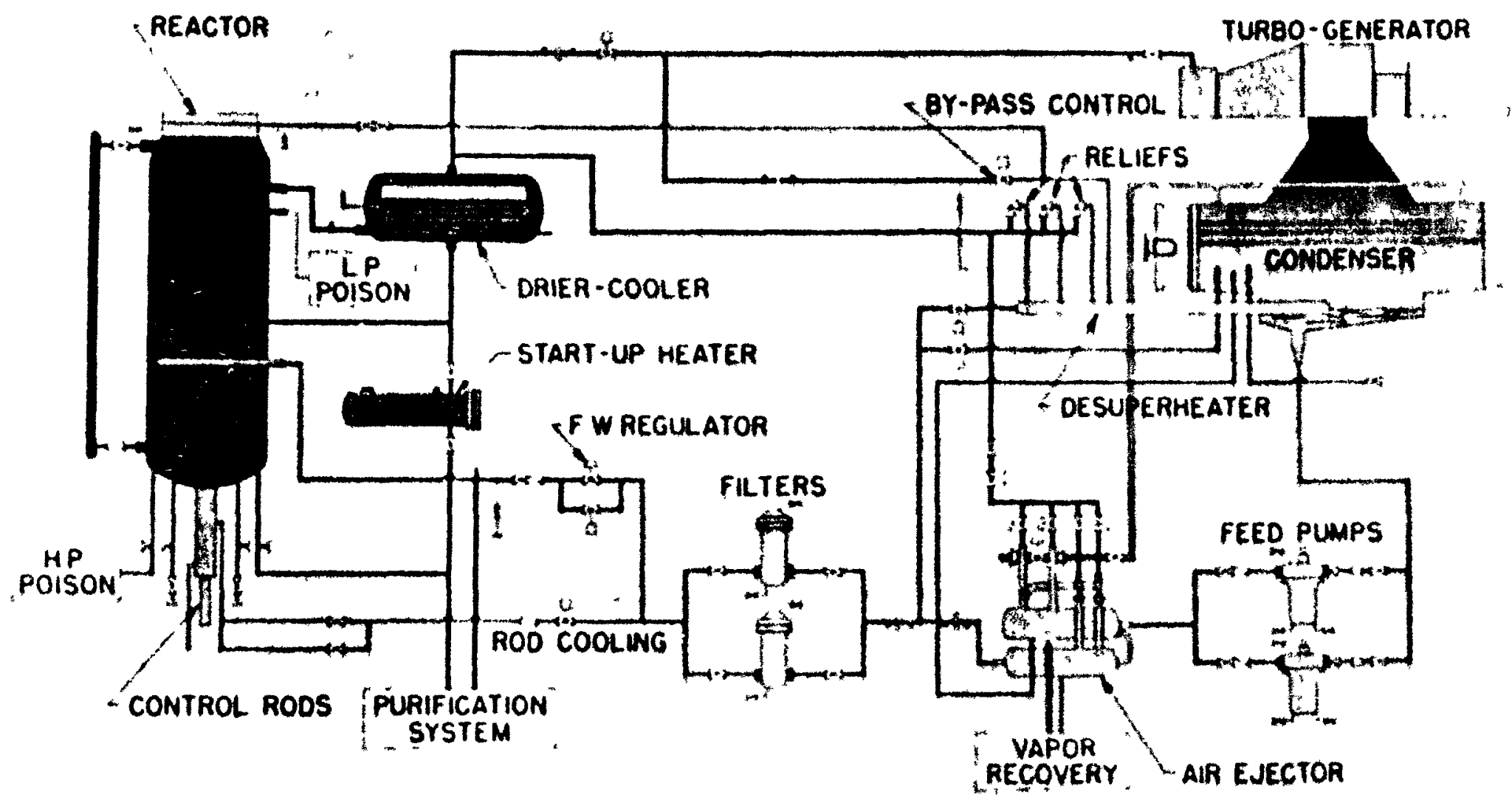




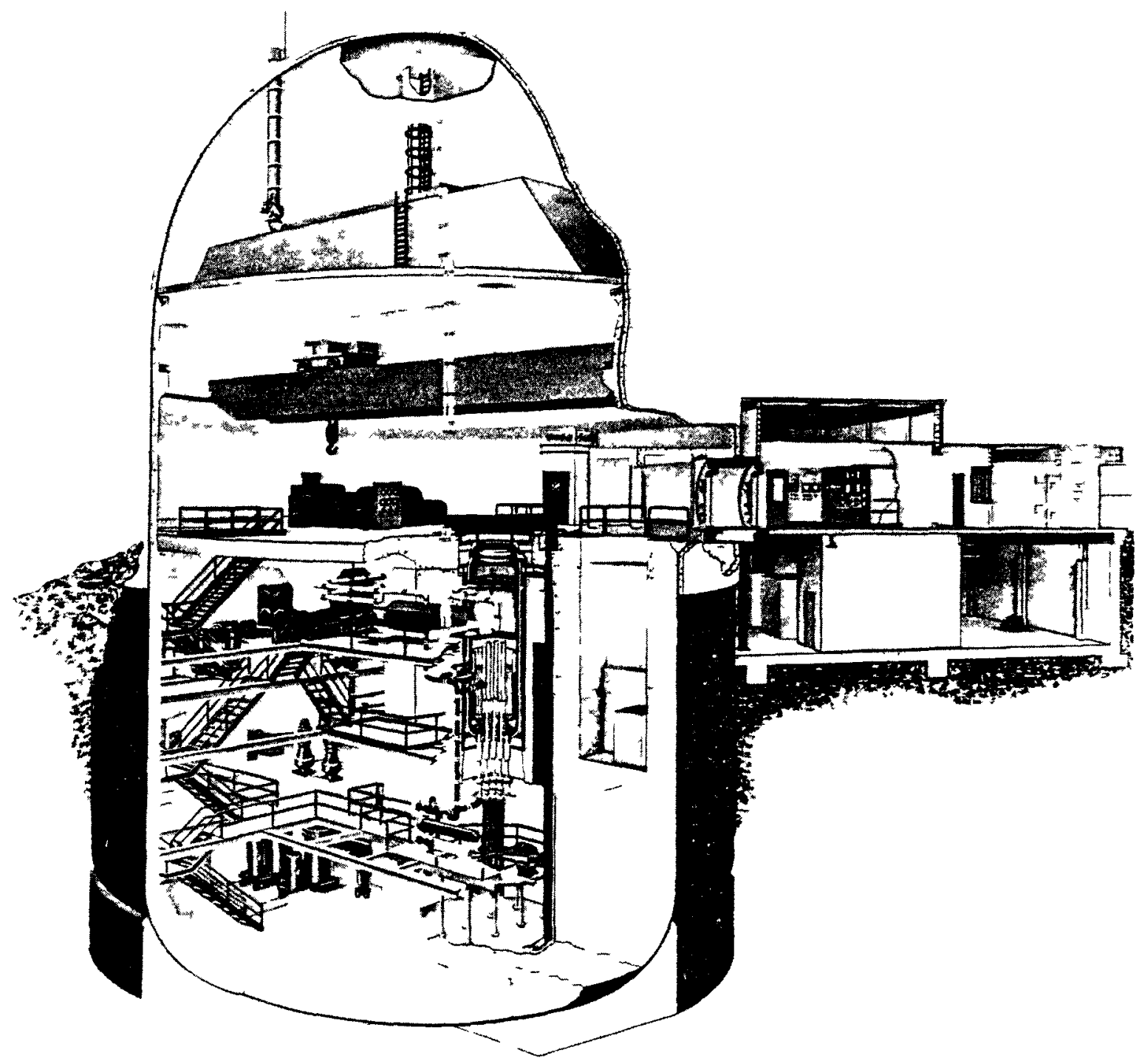

Fig. 3.17-EBWR plant perspective. (Argonne National Laboratory)

Cruclform -shaped control rods of hafnium and boron steel are operated by mechanisms located below the reactor vessel. For quick scram (emergency shutdown) the fallsafe mechanism permits the rods to fall into the core by gravity. This is alded by an initial spring force and system pressure. An auxiliary shutdown system is provided by a low - and high-pressure boric acid system. Blast shields are located around the reactor to absorb most of the energy that may be released in case of a detonation from a potential metal-water reaction (F1g. 3.21). Numerous other safety provisions are also incorporated.

Replacement of spent fuel is accomplished by transferring the depleted fuel elements to a shrelded fuel-transfer coffin that moves on floor ralls. These elements are then stored underwater in racks designed to prevent an inadvertently critical assembly. 


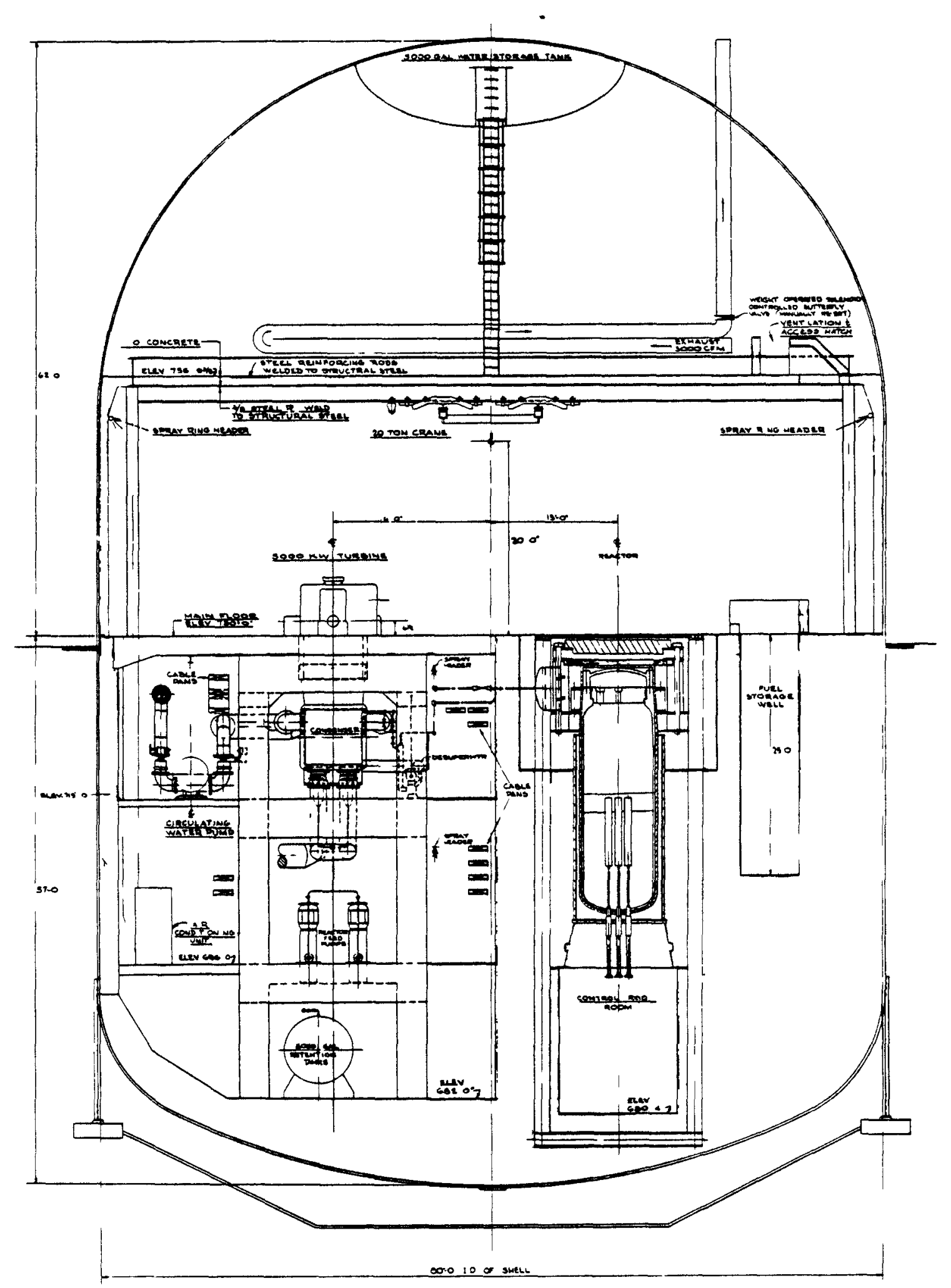

Fig. 3.18-EBWR elevation cross-section AA. (Argonne National Laboratory) 


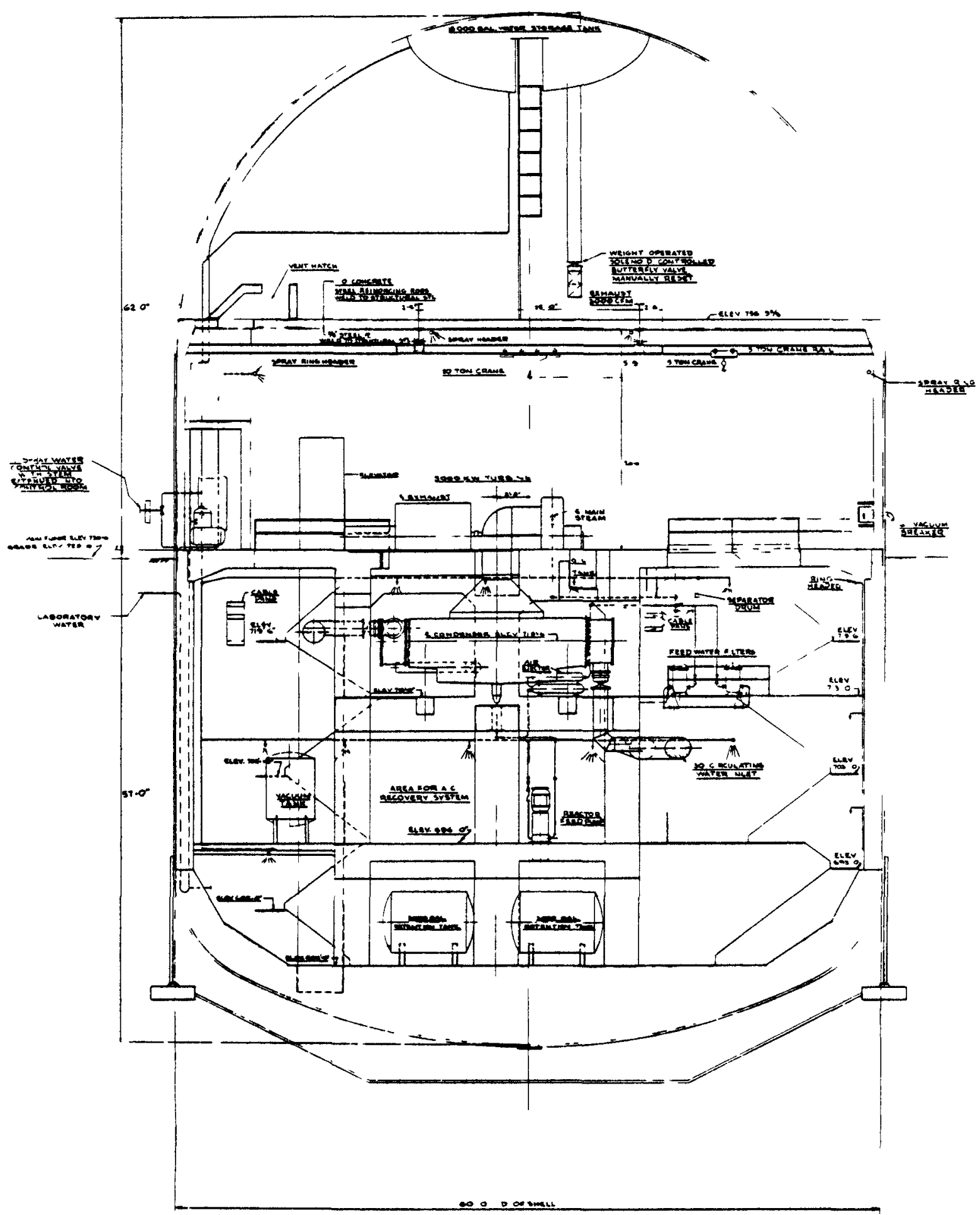

Fig. 3.19-EBWR elevation cross-section BB. (Argonne National Laboratory) 


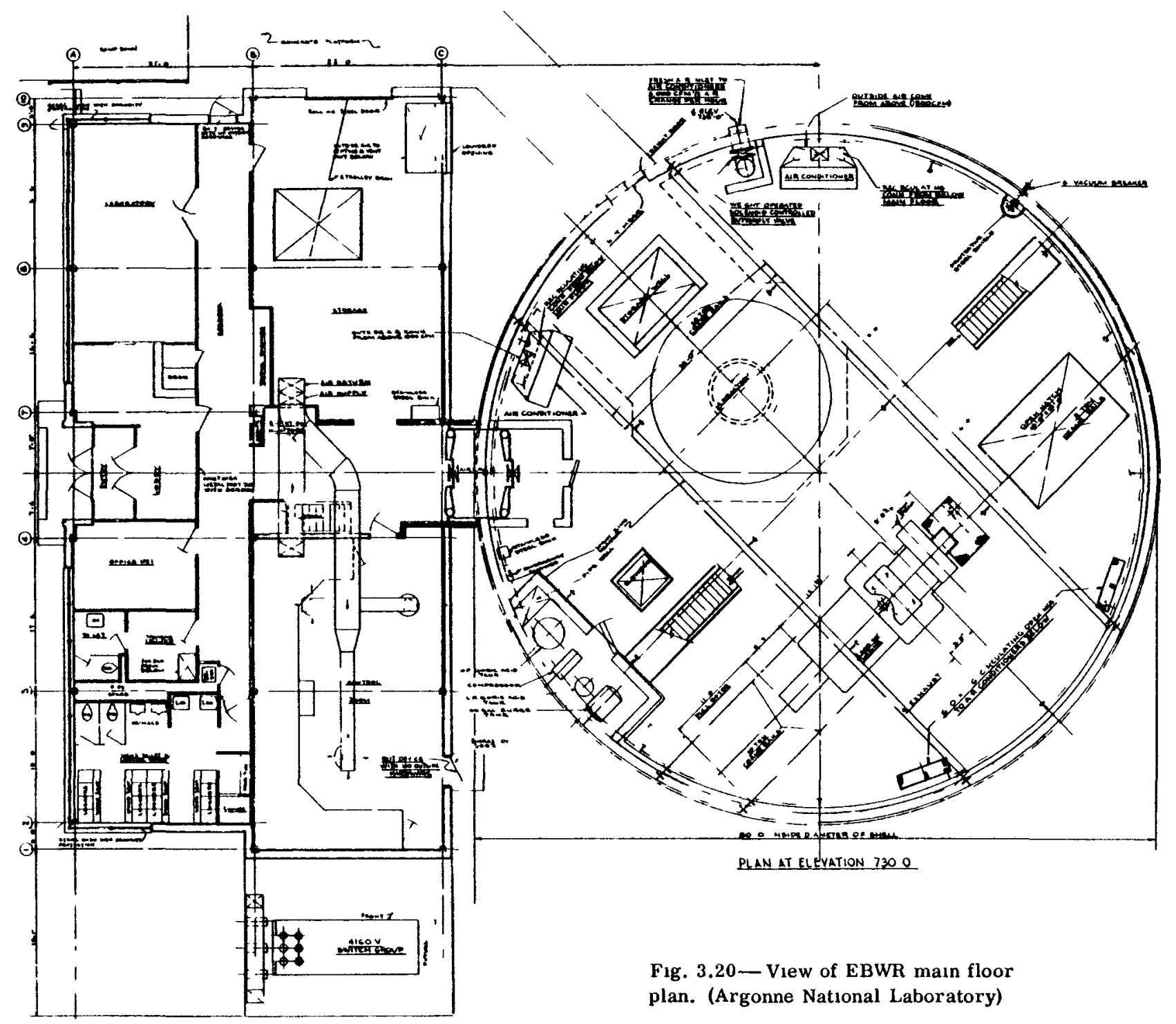

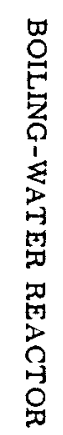

Fig. 3.20-View of EBWR main floor plan. (Argonne National Laboratory) 


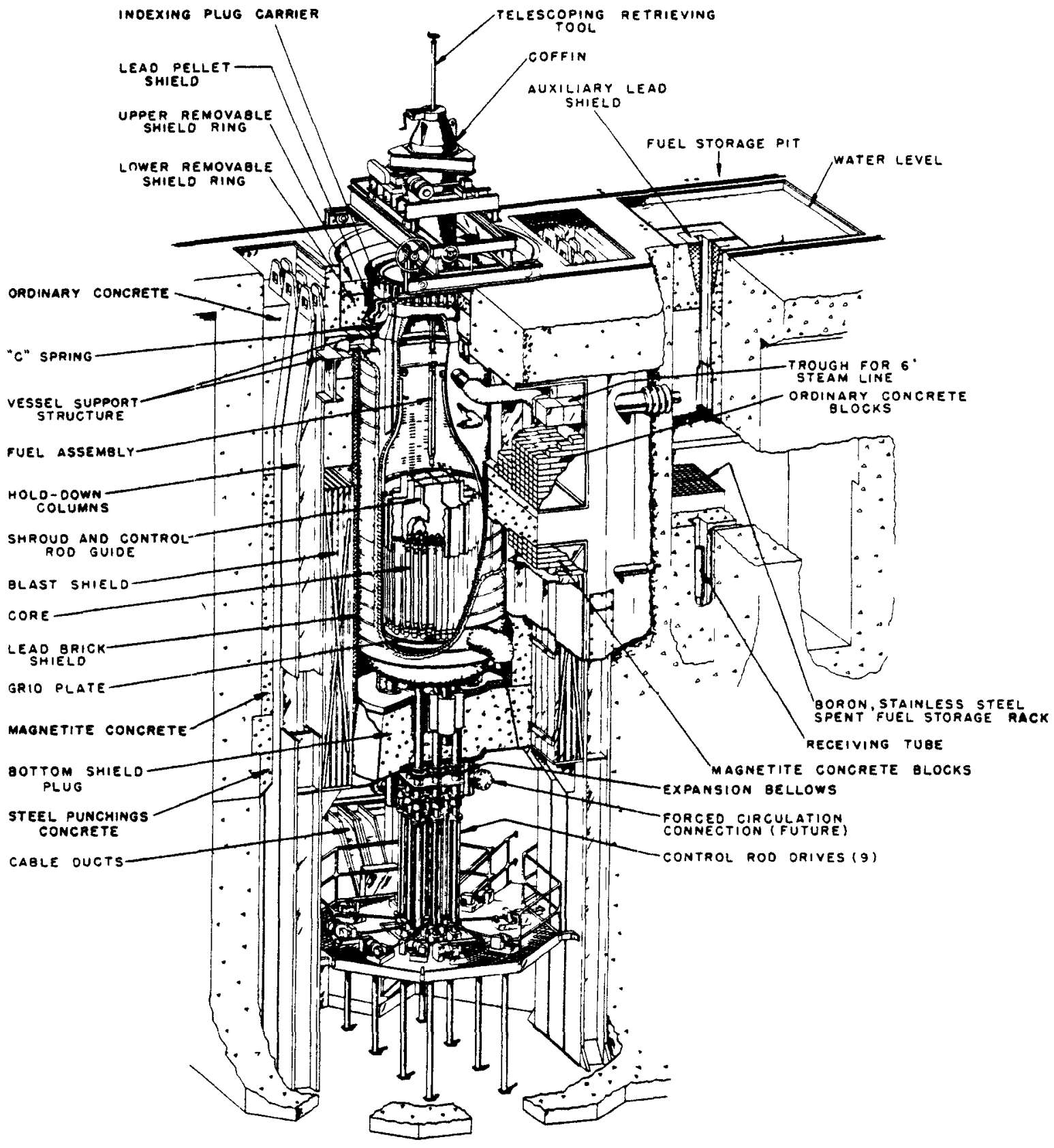

Fig. 3.21 - Cutaway view of EBWR reactor area. (Argonne National Laboratory) 
C. Sodium-graphite Reactor

The sodium - graphite reactor (SGR) concept is being studied for commercial power plant application since the economics of nuclear power reactors indicate the desirability of high-temperature operation at low pressure coupled with good heat-transfer character istics in the core fuel elements. The Sodium Reactor Experiment (SRE), sponsored by the U. S. Atomic Energy Commission (AEC) and conducted by the Atomics International Division of North American Aviation, Inc., proposes to explore the use of sodium-cooled graphite-moderated nuclear reactors that combine the features listed.

The SRE, a $20-\mathrm{Mw}(\mathrm{t})$ reactor, operates at nearly atmospheric pressure with the primary sodium coolant heated to $960^{\circ} \mathrm{F}$. The graphite moderator is canned in 0.035 -in.-thick zirconium to prevent disintegration by sodium. Heat is transferred from the primary sodium loop to an intermediate sodium loop and then to a steam-generating water loop (Figs. 3.22 and 3.23).

Each fuel rod consists of a 6 -ft-long stainless-steel cladding filled with metallic uranium slugs that are $3 / 4$ in. in diameter and 6 in. in length. Sodium-potassium alloy $(\mathrm{NaK})$ bonding provides good thermal contact between the fuel and the stainless-steel cladding. A small space filled with helium allows thermal expansion and venting of fission-product gases at the top of the fuel-rod tubes. Seven fuel rods are arranged in a cluster. Control and safety rods, together with the complicated drive mechanism, are enclosed in long, thin stainless-steel thimbles that enter from the top cover. The main core tank of stainless steel, which is $1 \frac{1}{2}$ in. thick, $11 \mathrm{ft}$ in diameter, and $19 \mathrm{ft}$ in height, is placed within an outer tank that serves as a sodium catch tank if the core tank should leak. This assembly rests in a concrete well. A heavy concrete cover rests on the surrounding foundation and is sealed with a low-temperature melting alloy (Cerrobend). Removable plugs in the cover are sealed with $O$ rings. The core tank is shown in Fig. 3.24 .

A fuel-handling coffin system allows remote handling of spent fuel without leakage of radioactive gas to the building (Fig. 3.25). Helium and nitrogen gases are used as an inertgas blanket. Stored spent-fuel elements are cooled by a toluene coolant system.

The outer building that houses the SRE is not constructed to be gastight; one estimate gives a leakage rate of $10 \%$ of its volume per day.

\section{Gas-cooled Reactor}

Many of the problems of corrosion and phase changes associated with liquid metals and water at high temperatures are avoided by using inert gas as a coolant for the nuclear reactor core. Ideally, the coolant gas could be used in a direct cycle to power a gas turbine. However, gases have poor heat-transfer characteristics and require significant pumping power. These disadvantages can be minimized by resorting to high system pressure. Another problem that becomes acute at high temperatures is the retention of fission products in fuel elements.

In general, graphite appears to be the economically optimum moderator for large central-station power plants utilizing gaseous coolants. Proposed plant designs vary fundamentally in the choice of a coolant, in the degree of fuel enrichment, and in fuelelement materials. The exact parameters of the thermodynamic cycle and design details differ widely. The basic problem regarding aseismic design, however, is common to all U. S. design studies to date and hinges on the vibrational resistance of (1) a large stack of graphite bars, (2) a very large pressure vessel, (3) a complex of massive gas -heated steam generators, and (4) mechanisms providing for relative motion between these primary components during differential heating.

There is some possibility that future designs will be based on a heavy-water moderator. This will shift the seismic design problem from one dealing with a structure of brittle pieces to one in which an extremely large volume of liquid must be constrained against position shifts. 


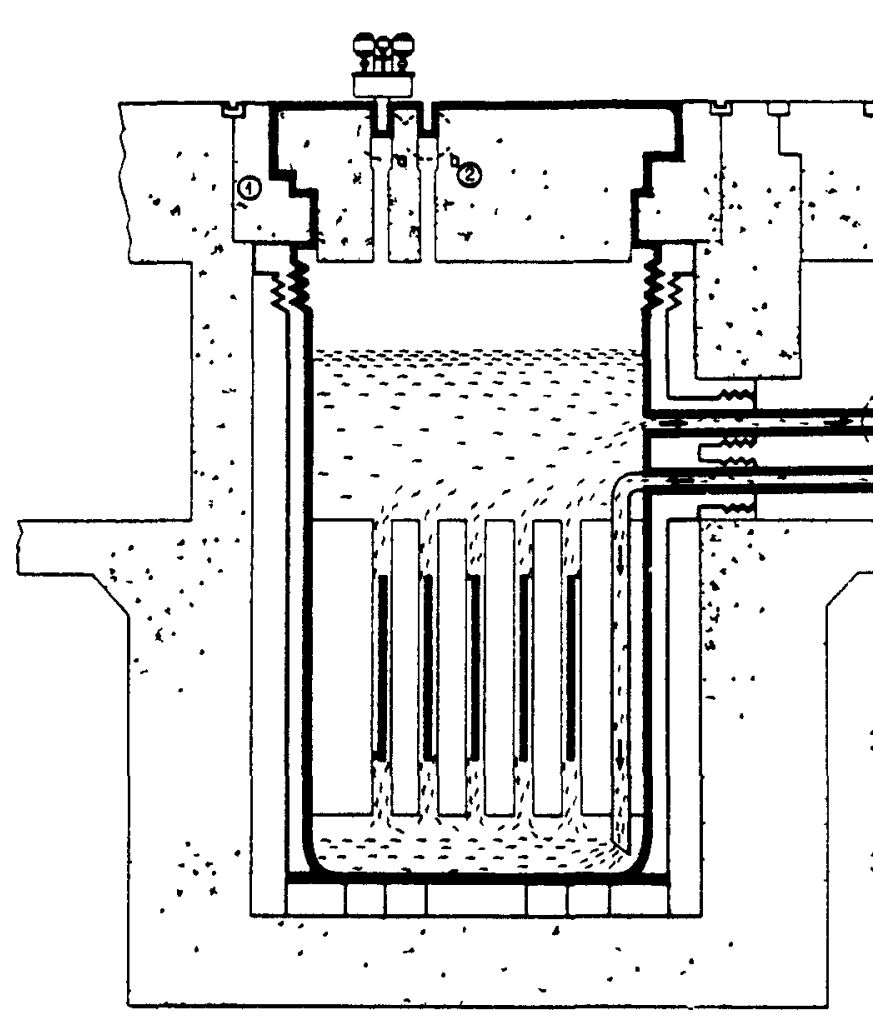

1. FROZEN METAL SEALS (LEAD TIN ALLOY) USED FOR REACTOR SHIELD

2. O-RING SEALS USED FOR:

a. CONTROL AND SAFETY THIMBLES

b. FUEL PLUGS

3. FROZEN SODIUM SEALS USED IN COOLING SYSTEM FOR:

a. VALVES

b. PUMPS

Fig. 3.22-SRE reactor core and primary loop. (Atomics International)

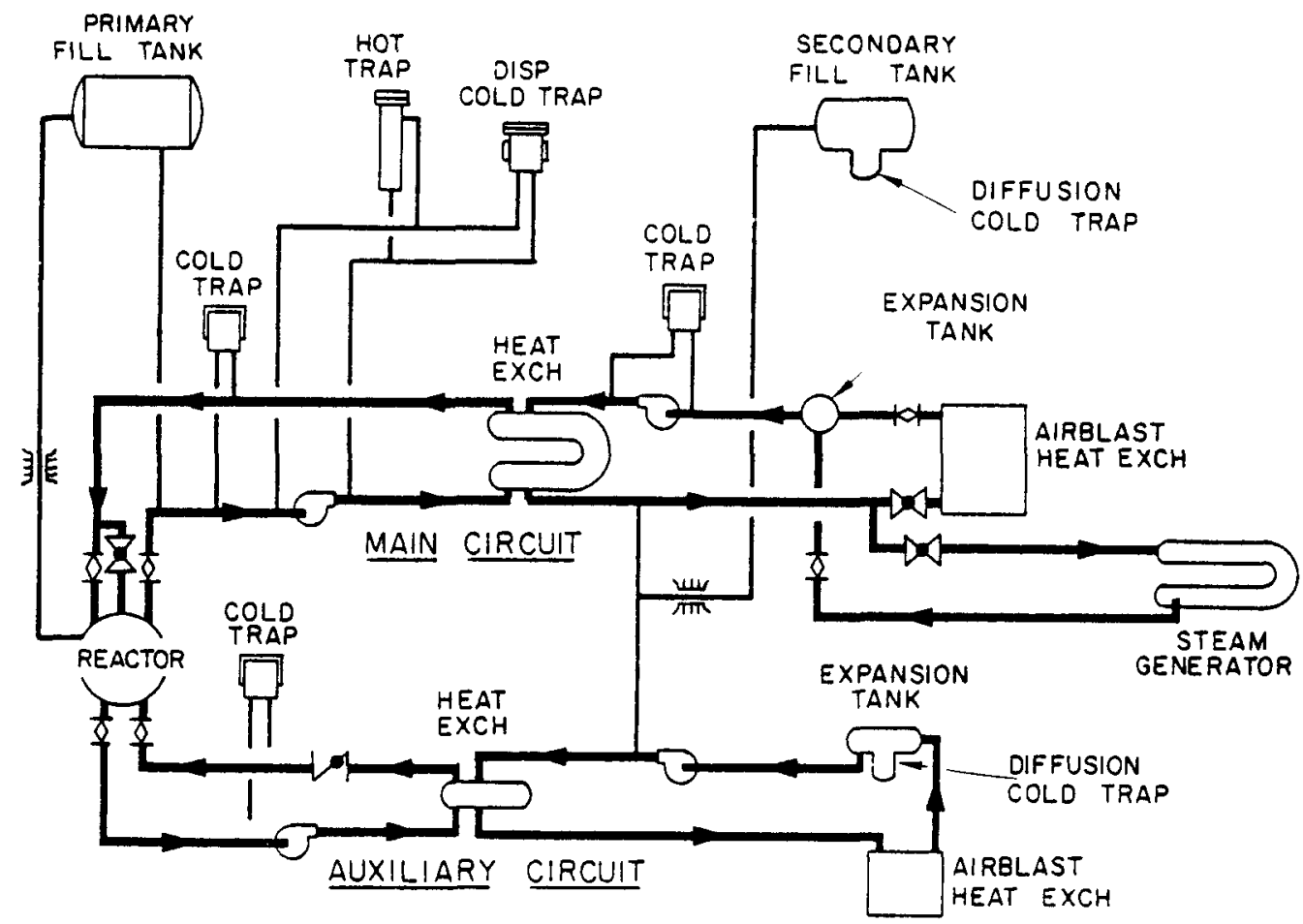

Fig. 3.23-SRE sodium system. (Atomics International through American Society of Mechanical Engineers) 


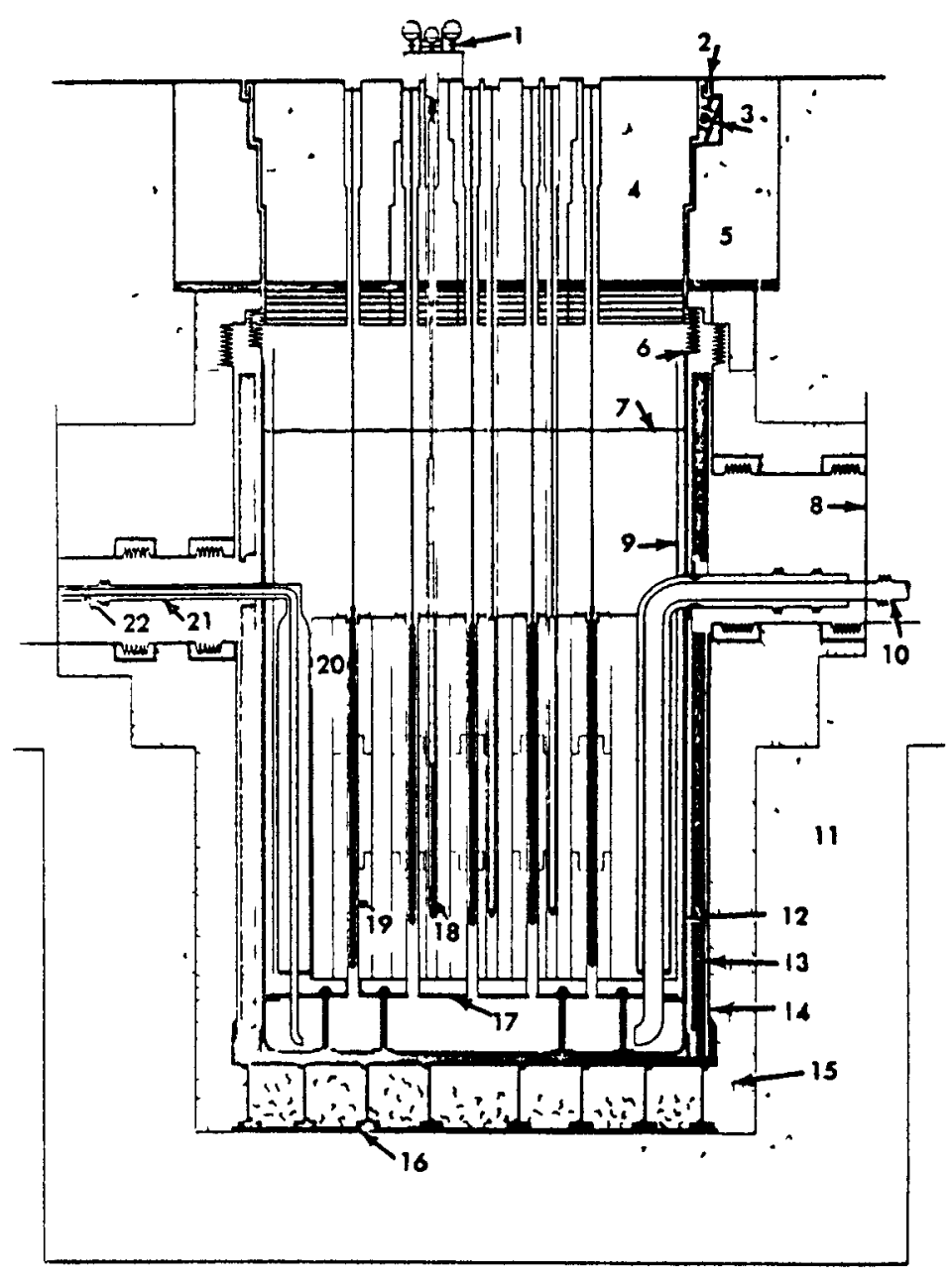

1. Control olement drivo

2. Soal

3. Roiler

4 Rotatable shieid

5 Ring shield

6. Bellows

7 Sodium lovel

8 Diophrogm

- Inner liner

10 Main sodium Inlet line

11. Biological shield

12 Core tank

13. Thermal shiald

14. Outer tank

15. Thermal insulation

16. Bearing plate

17 Grid plate

18. Control element

19 fual oloment

20. Moderator olemont

21. Guard pipe

22. Auxoliary sodium inlat line

Fig. 3.24-Elevation of SRE reactor. (Atomics International)

-One of the AEC-sponsored studies of the gas-cooled power reactor concept, the Gascooled Reactor No. 2 (GCR-2) at Oak Ridge National Laboratory (ORNL), is taken as an example (see Appendix $\mathrm{H}$ for seismic analysis) This design employs slightly enriched uranium oxide fuel canned in stainless steel, with graphite as the moderator and helium as the coolant. An indirect cycle is utilized to transfer heat from the gas to water in large heat exchangers to form high-pressure steam.

Figure 326 shows an overall view of the main reactor components, and Fig. $3.27 \mathrm{in}$ dicates the size of the components. This reactor, which operates at $300 \mathrm{ps} 1 \mathrm{a}$ and generates about $687 \mathrm{Mw}(\mathrm{t})$ of energy, is contained in a 50 -ft-diameter steel sphere with a $3 \frac{1}{4}-1 \mathrm{n}$ wall. Purified helium enters the core at $460^{\circ} \mathrm{F}$ and leaves at $1000^{\circ} \mathrm{F}$ through four main ducts, each $5 \mathrm{ft}$ in diameter In the four separate heat exchangers spaced around the re actor, $950 \mathrm{psig}$ steam at $950^{\circ} \mathrm{F}$ is formed and fed to two identical turbogenerator units, which, together, produce a net output of $225 \mathrm{Mw}$ (Fig. 3.28).

Within the core, which is $30 \mathrm{ft}$ in diameter and $20 \mathrm{ft}$ in height, (Fig. 3.29), are 1597 vertical fuel channels, varying from 3.05 to $3.45 \mathrm{nn}$. in diameter. These fuel channels hold fuel-element clusters composed of seven elements $0.8 \mathrm{in}$. in diameter and about $40 \mathrm{in}$. in length. Each element is loaded with 75 annular $\mathrm{UO}_{2}$ fuel slugs which are $0.75 \mathrm{in}$. in outside diameter, $0.32 \mathrm{in}$. in inside diameter, and $0.50 \mathrm{in}$. in height. Each cluster of elements 


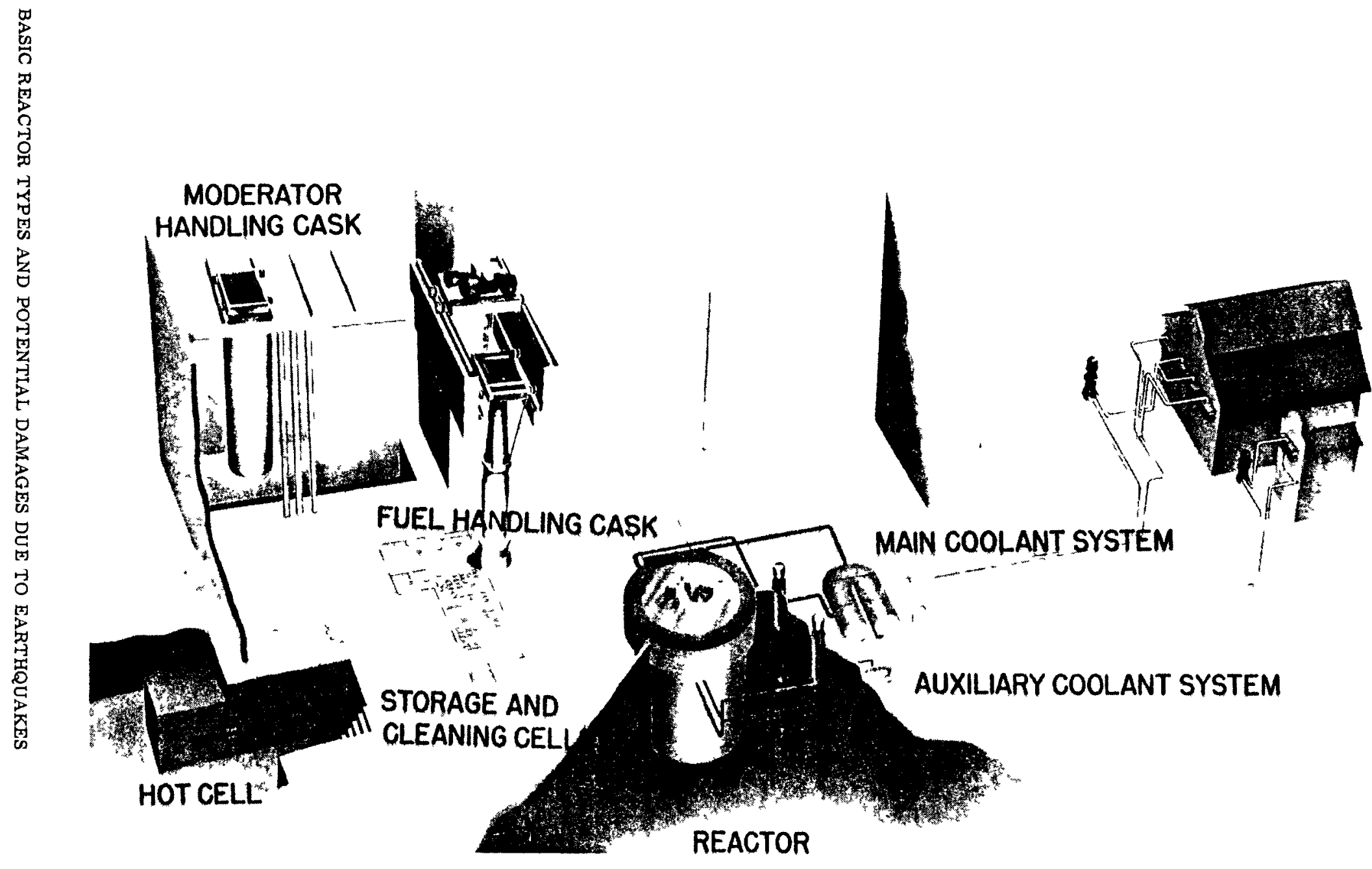

Fig. 3.25-General arrangement of SRE. (Atomics International through American Society of Mechanı- 


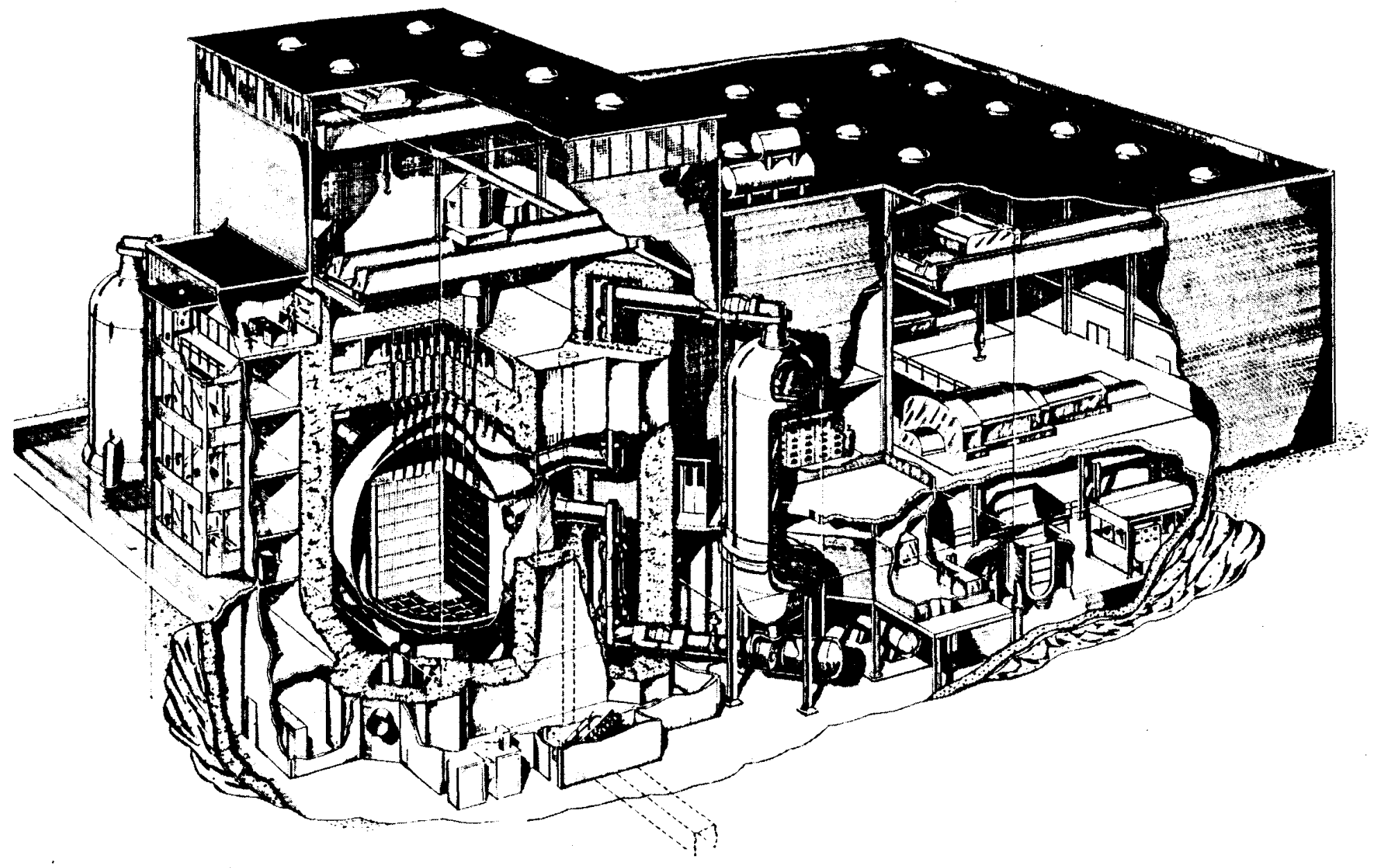




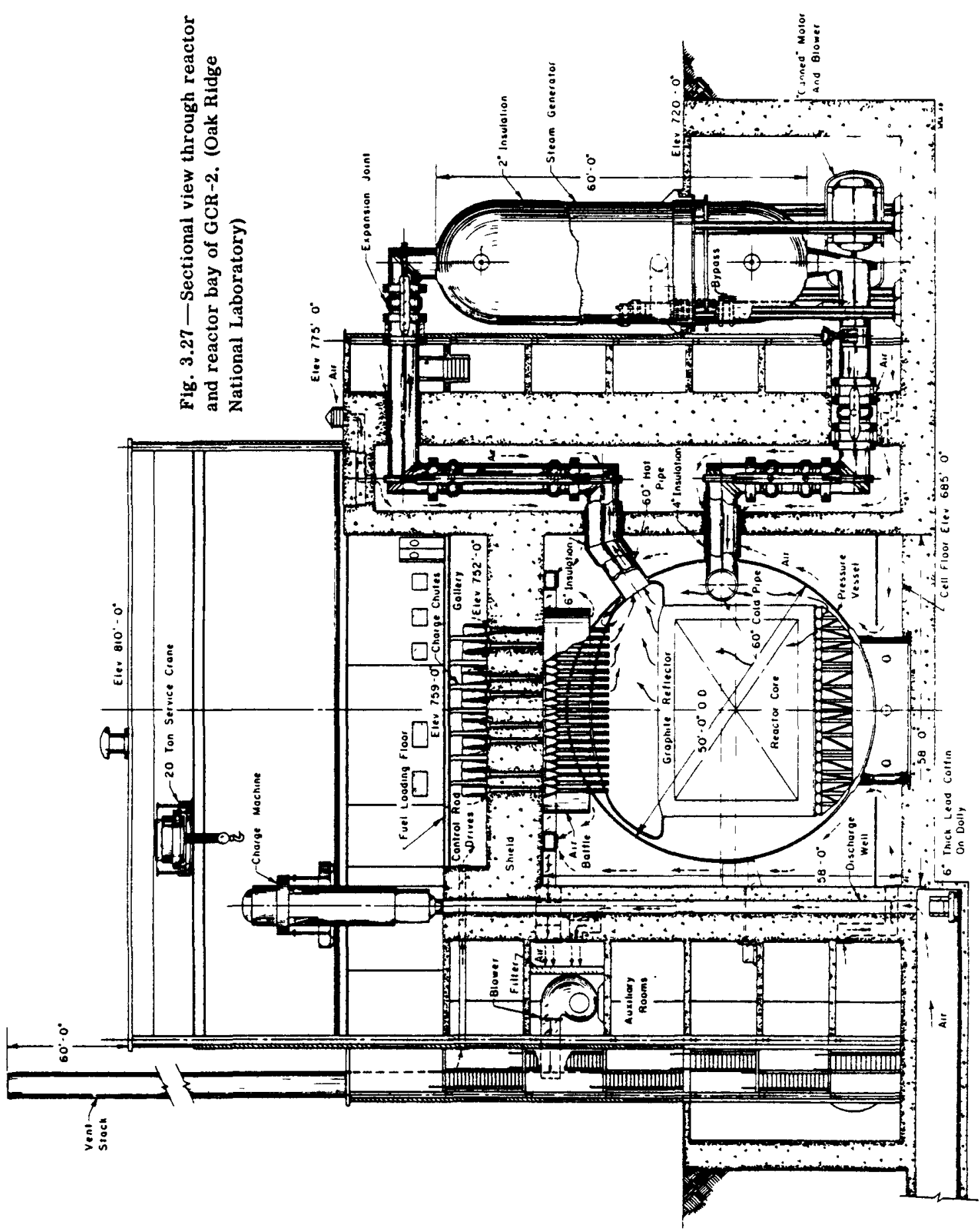




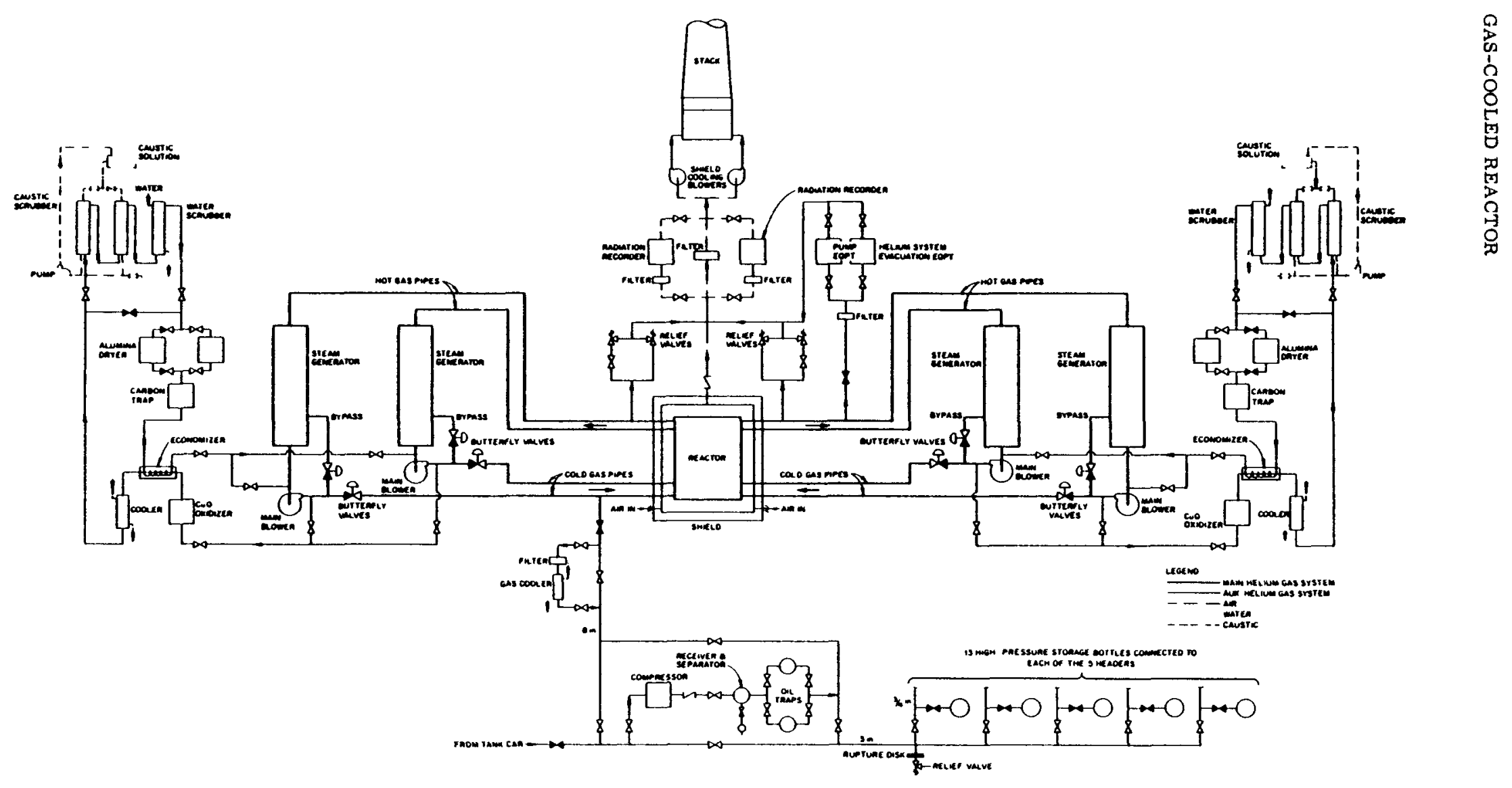

Fig. 3.28-GCR-2 coolant-flow diagram. (Oak Ridge National Laboratory) 


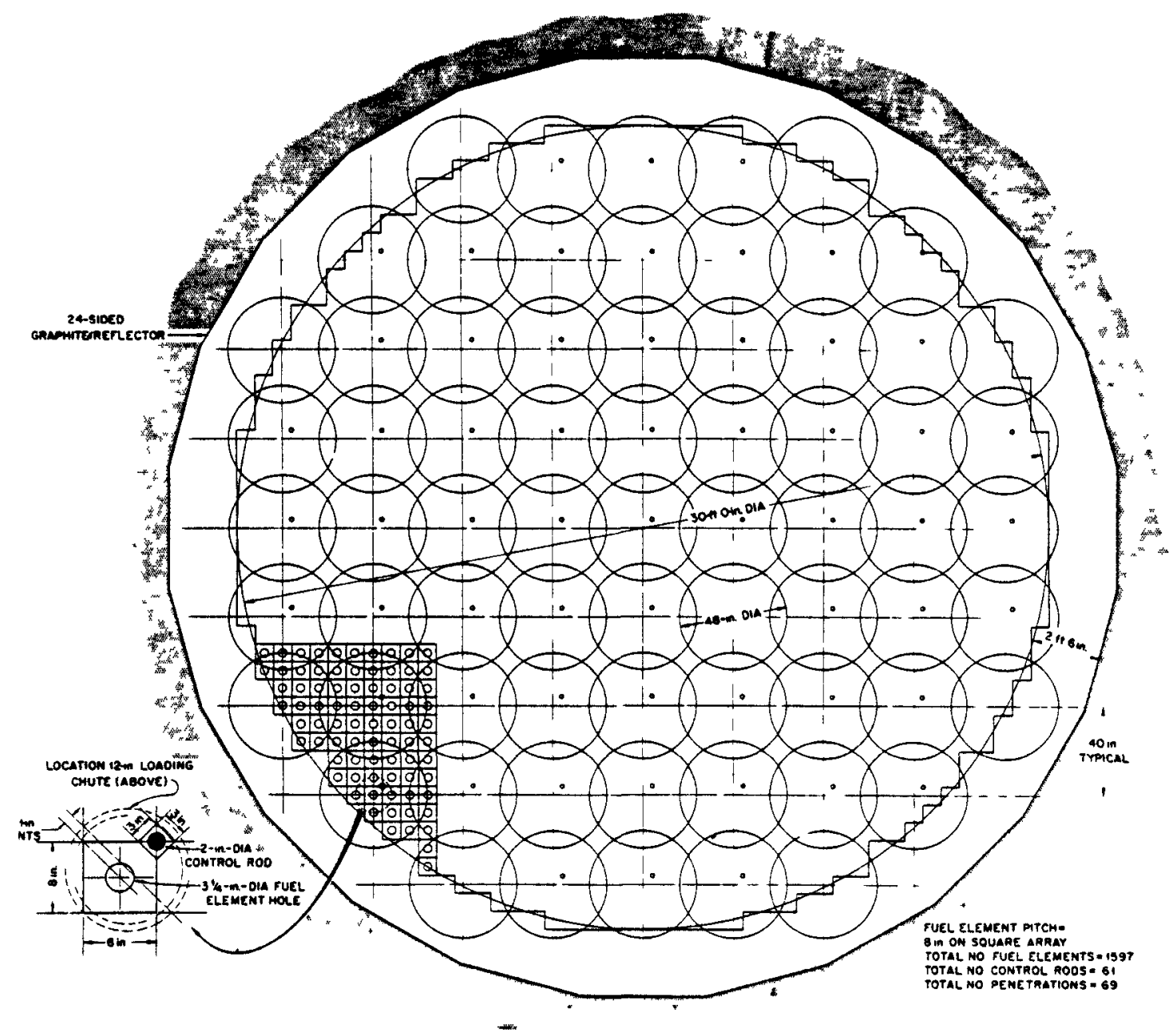

Fig. 3.29-Plan view of GCR-2 core section. (Oak Ridge National Laboratory)

is individually supported at the top by a horizontal bar that rests in a groove cut into the graphite wall of the fuel channel.

Since the core is composed of a vertical array of graphite blocks $8 \mathrm{in}$. square by 40 in. long with fuel-channel holes in the center, lateral support must be provided to hold the assembly together. Special tubular hoops bearing on flat steel plates (which, in turn, ring each layer of the graphite assembly) will permit thermal expansion while holding the assembly together. Each graphite piece has a pilot extension at its lower end which fits into a counterbored hole in the top of the blocks below.

For reactor control, silver rods encased in stainless steel and suspended from above by stainless-steel cables are employed to absorb neutrons. Sixty-one of these control rods, each $2 \mathrm{in}$. in diameter and $18 \mathrm{ft}$ in length, are positioned in 3-in.-square channels.

With enriched fuel $\left(2 \% \mathrm{U}^{235} \mathrm{in} \mathrm{U}^{238}\right)$ there will be $3.3 \times 10^{5} \mathrm{lb}$ of $\mathrm{UO}_{2}$. The total weight of the machined graphite is 1122 tons. The gross weight, including the pressure vessel, core support, graphite, and fuel, which must be borne by the base support of the 22 -ftdiameter by 2-1n -thick thermal sleeve, is in excess of 2000 tons. Figure 3.30 shows the details of the core support skirt.

Each of the four primary loops contains a vertical steam generator having a diameter of $20 \mathrm{ft}$, a wall thickness of $2.75 \mathrm{in}$., and a body length of $60 \mathrm{ft}$. With water in the finned 

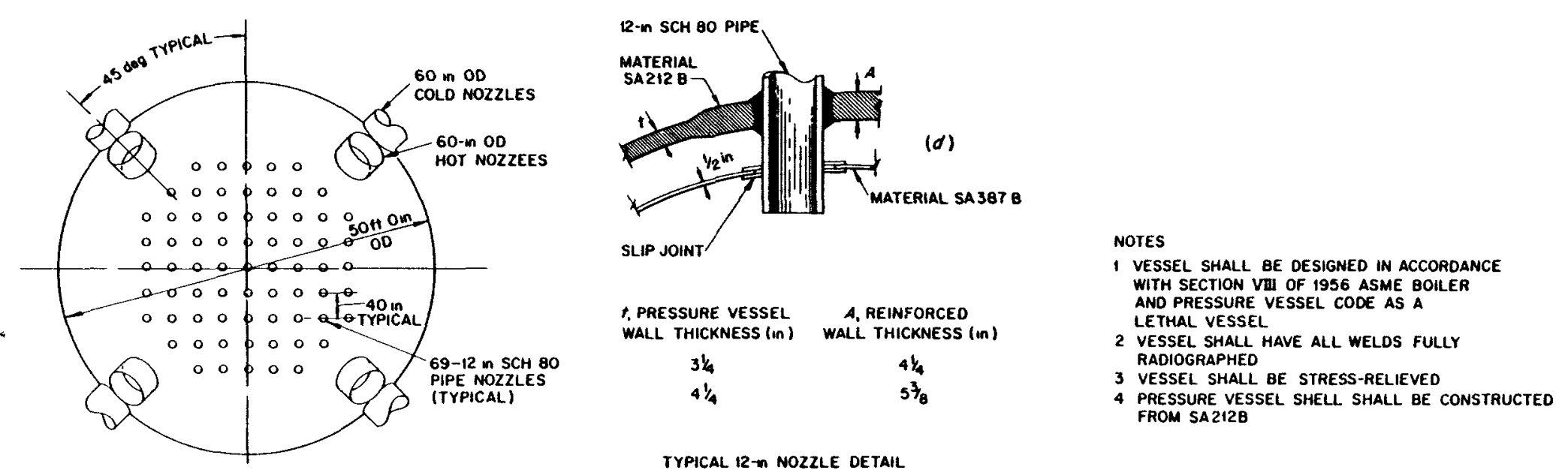

PLAN

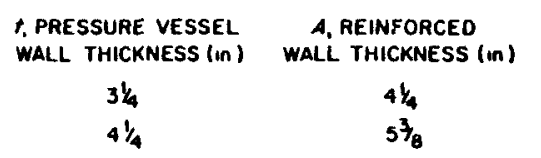

NOTES

VESSEL SHALL BE OESIONED IN ACCOROANCE

HAL VESSEL

FROM SA212B

TYPICAL 12-n NOZZLE DETAIL

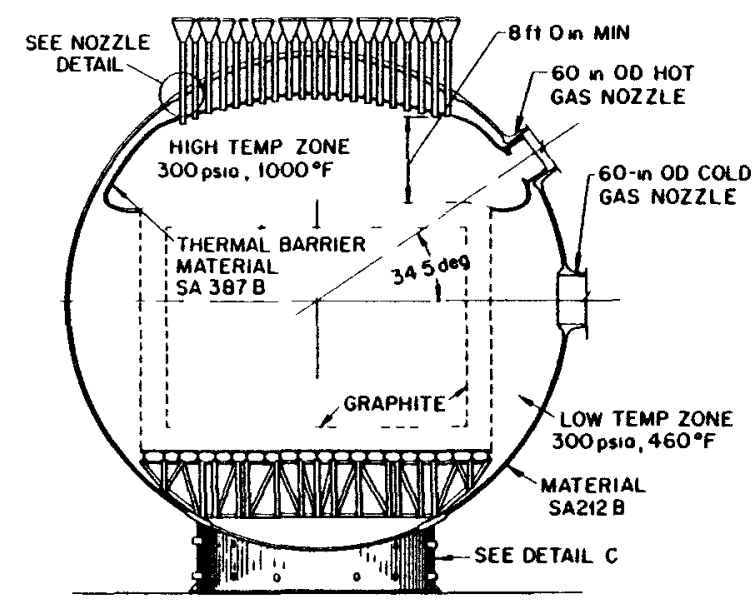

ELEVATION

(a)

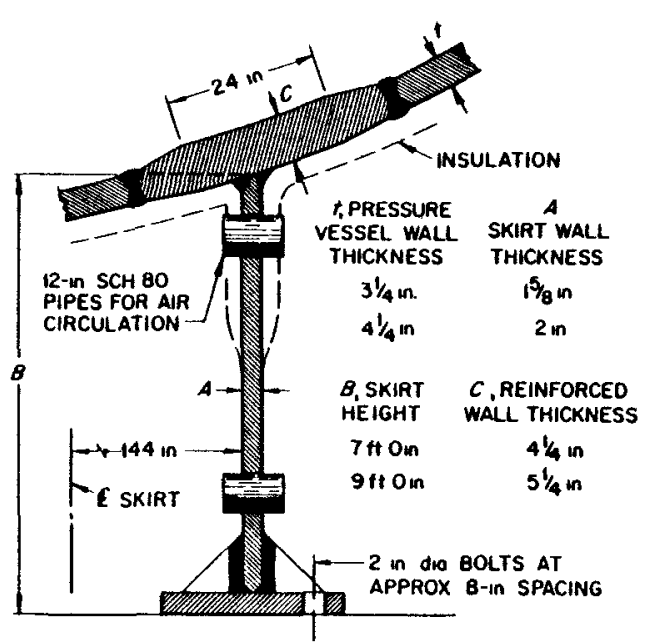

DETALL C

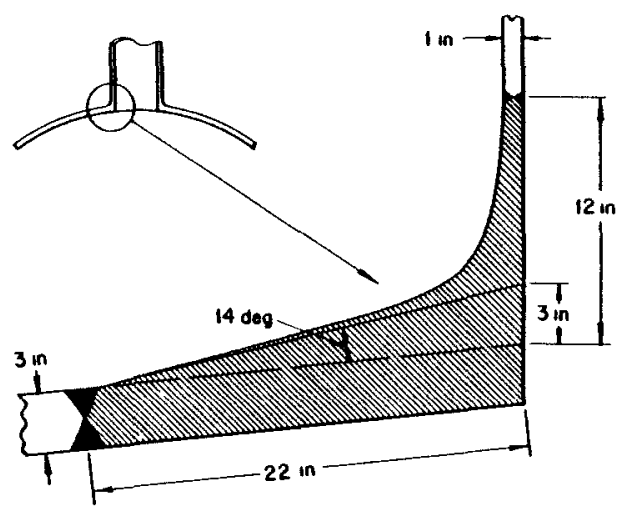

TYPICAL JUNCTION FORGING ACCEPTABLE FOR

Fig. 3.30-Details of GCR-2 core-support skirt. (Oak Ridge National Laboratory) 
tubes and helium on the shell side, three zones (the economizer, the boiler, and the superheater sections) are included in the once-through design.

It is believed that the helium leak rate can be kept below $1 \%$ per day in the primary circuit. A canned motor-blower design is used to prevent leakage of the coolant through the shaft seal. Stainless-steel bellows expansion joints take up differential thermal expansion in the connecting piping. Each loop has a single butterfly control valve between the blower and the reactor. Thus it is necessary to shut down the reactor if a major leak occurs in any one loop or if a primary circuit component requires removal from the line.

Fuel loading and discharging is accomplished from the top of the reactor by machines that can load or unload 25 fuel elements through a single port. Handling of the irradiated fuel is carried out by remote control after the reactor is completely shut down and the pressure in the core is reduced to atmospheric. The spent fuel removed from the core is lowered down a well to a transfer carriage. The carriage conveys the fuel elements through a tunnel to the storage pond.

Through the intermittent sampling of gas from each fuel channel, the release of radioactive fission products from defective fuel elements is noted on recorders, and a helium purification system is provided. Only the biological shield cooling air is discharged to the atmosphere, and filters and a tall stack are provided for this purpose.

\section{E. Fast Reactor}

All the reactors thus far described utilize slow - or thermal-energy neutrons for the fissioning process. In a fast reactor high-energy neutrons are used directly. One of the major advantages of the fast-reactor concept is the conversion of $U^{238}$ to plutonium for maximum exploitation of natural-uranium resources. The most efficient method for converting the abundant natural supply of $\mathrm{U}^{238}$ to fissionable $\mathrm{Pu}^{239}$ is the utilization of reactors in which most fissions are initiated by fast neutrons, for which losses due to nonfission-producing absorption of neutrons by reactor materials are low. This permits a breeding gain greater than unity and produces more fissionable material than is consumed. At the same time such a reactor may provide energy for power production.

From a control standpoint, fast reactors differ from thermal reactors in several important respects:

(1) The prompt-neutron lifetime and thermal relaxation time of the fast system are very much shorter than those of thermal reactors.

(2) The nature of the reactivity coefficients differs considerably between the systems. Positive and negative components combine in the fast reactor to give net coefficients which may be small and which may vary in size with the rate of reactivity changes. They depend strongly on the core design and fabrication details. ${ }^{3.1}$

(3) Few materials have sufficiently high cross sections for use as control rods in fast reactors. Alternate methods, as used in the Experimental Breeder Reactor (EBR), employ movable fuel rods or movable reflector pieces.

(4) Since most materials have low cross sections for high-energy neutrons, a fast reactor may be operated at power for long periods with excess reactivity below that required for prompt criticality. Therefore inadvertent prompt criticality is unlikely. ${ }^{3.2}$

Since moderators are not used, the fast reactor core is smaller than that of thermal reactors. Consequently very high power densities can be achieved in such reactors, and rapid heat removal is necessary. Sodium and $\mathrm{NaK}$ have been used as coolants because of their excellent heat-transfer characteristics.

The Experimental Breeder Reactor No. 2 (EBR-2), which has a heat-generation rate of $62.5 \mathrm{Mw}(\mathrm{t})$, seeks to demonstrate the engineering feasibility of fast reactors for central-station power application and it is taken as an example for this study. As shown in Fig. 3.31, heat generated in the reactor core is transferred by forced circulation of the sodium coolant in the primary tank to the secondary sodium loop in the main heat ex- 


\subsection{F AQUEOUS HOMOGENEOUS REACTOR}

changer. The heat in this secondary sodium is used to generate superheated steam that drives the 20-Mw(e) turbogenerator set.

The reactor proper is composed of the enriched core and the breeding blanket around it. Control and safety rely on the displacement of fuel with an effective void of nonfuel material. The core is quite small, with an equivalent diameter of $19 \mathrm{in}$. and a height of $14 \mathrm{in.}$, and yields a very high power density at the rated power level of $53 \mathrm{Mw}$.

The primary sodium pool, as shown in Fig. 3.32, is contained in a large sealed tank that contains such equipment as the heat exchangers, fuel storage system, neutron shield, and sodium pumps, as well as the reactor. A double-walled construction is used for the tank to minimize the probability of coolant loss by primary tank failure. The temperature of the inlet sodium to the reactor is $700^{\circ} \mathrm{F}$, and the exit temperature is $900^{\circ} \mathrm{F}$. Topentering control-rod-drive mechanisms and the fuel-handling mechanism are mounted on the cover (Fig. 3.33).

The reactor is enclosed by a fast-neutron shield made from canned graphite. Fuelelement pins, which are $0.144 \mathrm{in}$. in diameter and $14 \mathrm{in.}$. in length, are made from enriched uranium and simulated fission-product elements. They are clad in stainless steel with sodium to give good thermal contact between the fuel and cladding. A helical winding around certain pins serves to keep the pins separated from one another. This assures rigid geometry while providing a good coolant flow path. An isometric view of the reactor is shown in Fig. 3.34.

Blast shields are built around the primary tank. A gastight containment vessel of steel and concrete is built to contain the fission products in the event of a maximum credible accident (Fig. 3.35). The shell of 1 -in. steel plate is $80 \mathrm{ft}$ in diameter and $147 \mathrm{ft}$ in height ( $48 \mathrm{ft}$ below grade). It is designed for an internal pressure of $24 \mathrm{psig}$ but tested at 30 psig. The leakage rate at $20 \mathrm{psig}$ is not to exceed $1000 \mathrm{cu}$ ft per day. There is a minimum of $14 \mathrm{in}$. of concrete lining the steel shell except for the top portion of the reactor building. The top closure is protected by 6 -in. -thick high-temperature insulation.

The ventilation openings of 16-in.-diameter pipe are provided with fast-acting valves to permit rapid shutoff in the event of an accident. There are a large number of other openings in the shell, such as the secondary sodium-system pipes, air locks, and electrical lines.

\section{F. Aqueous Homogeneous Reactor}

The aqueous homogeneous reactor concept is another of the many systems that have been investigated in the United States. The Homogeneous Reactor Test (HRT) discussed in this section is an example of this type, although it is no longer in operation. A uranyl sulfate $-\mathrm{D}_{2} \mathrm{O}$ solution in a spherical zirconium core is surrounded by a breeding blanket of thorium oxide $-\mathrm{D}_{2} \mathrm{O}$ slurry. This aqueous system operates at high pressure (2000 psia) and transfers the fission heat by circulation of the fuel solution through a secondary heat exchanger to form steam. A schematic flow sheet is shown in Fig. 3.36. Since the fuel solution has a sufficiently high negative temperature coefficient of reactivity, the system is self-regulating, and no control rods are used.

A primary pressure vessel surrounds the core and blanket. It is a steel sphere $5 \mathrm{ft}$ in diameter and 4.4 in. in thickness (Fig. 3.37). A dump tank for shutdown storage is provided. Because of the very high level of radioactivity associated with the fuel solution in the primary system, stringent requirements are set up to achieve leaktightness, and a secondary gastight container encloses the bulk of the equipment (Fig. 3.38). This vapor container is a seal-welded rectangular shell 25 by 54 by $30 \mathrm{ft}$ made of welded steel plate $3 / 4$ in. thick, and it is designed for 30 psig. This will contain the pressure rise associated with the maximum credible accident involving primary loop rupture, metal - water reaction, and hydrogen burning. Missile protection is provided by a 77-in. -OD stainless-steel spherical blast shield with a $1 \frac{1}{2}$ in. wall. The maximum allowable leakage rate for the 


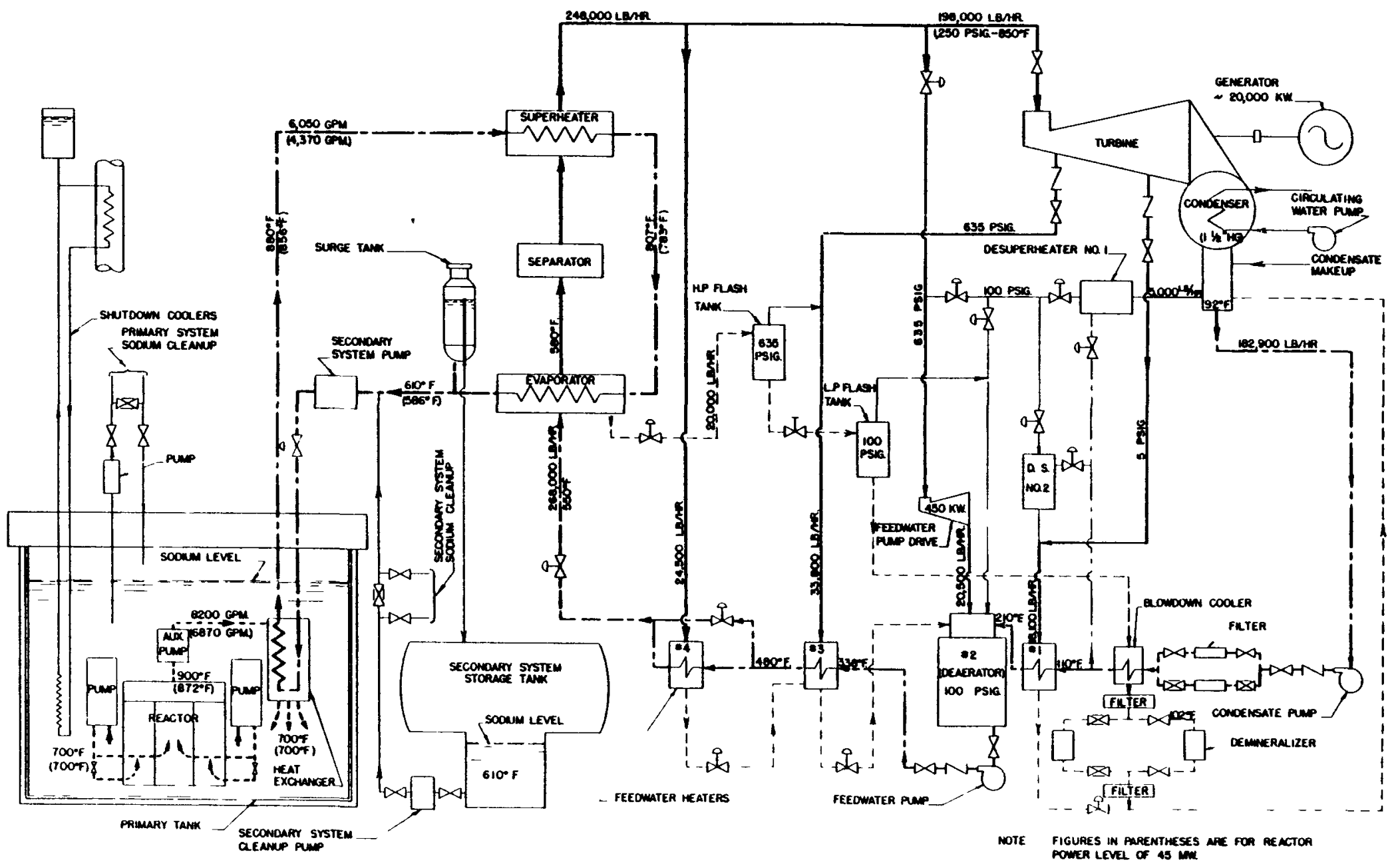

Fig. 3.31-EBR-2 flow diagram. (Argonne National Laboratory) 


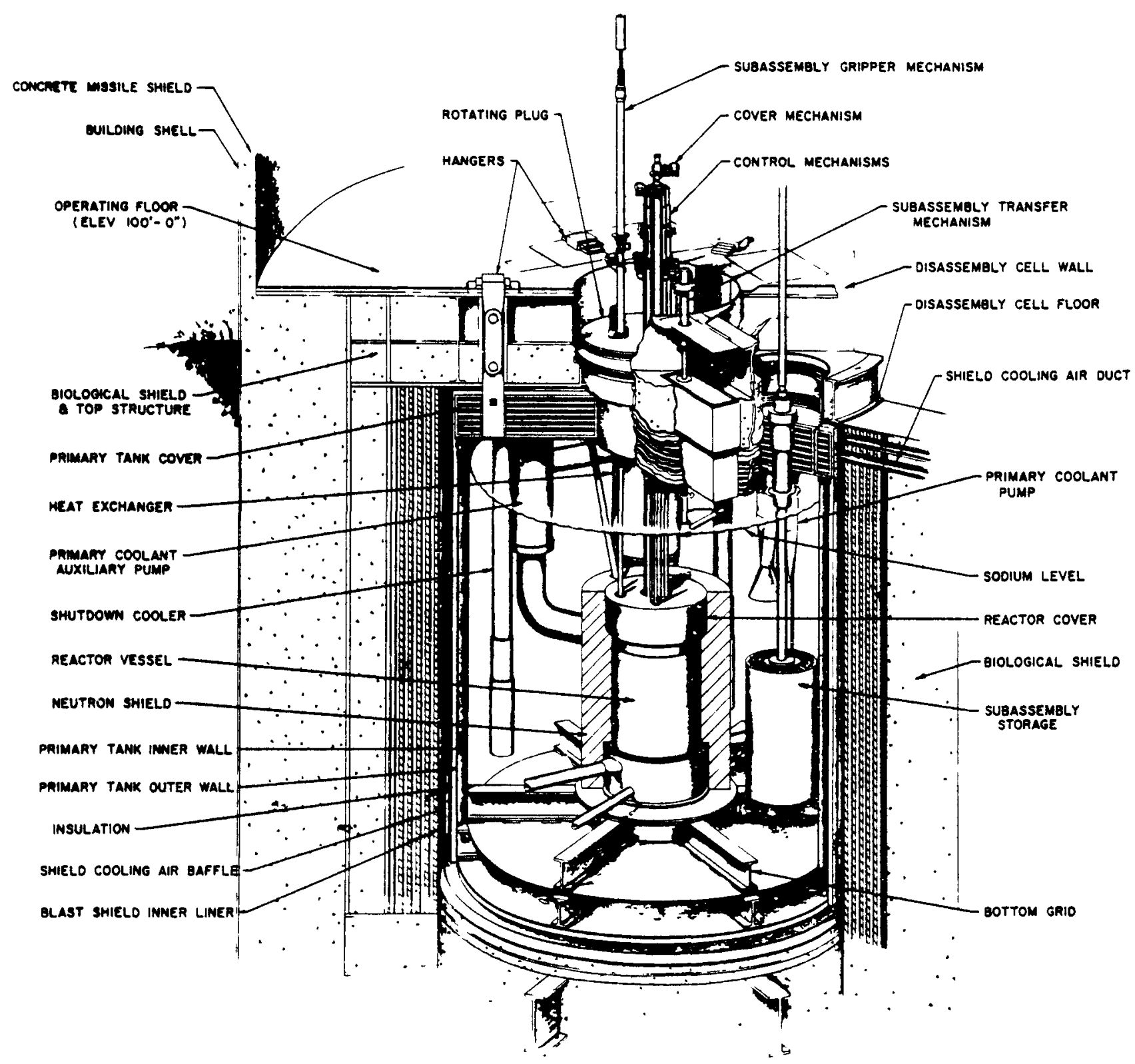

Fig. 3.32-EBR-2 primary system. (Argonne National Laboratory) 


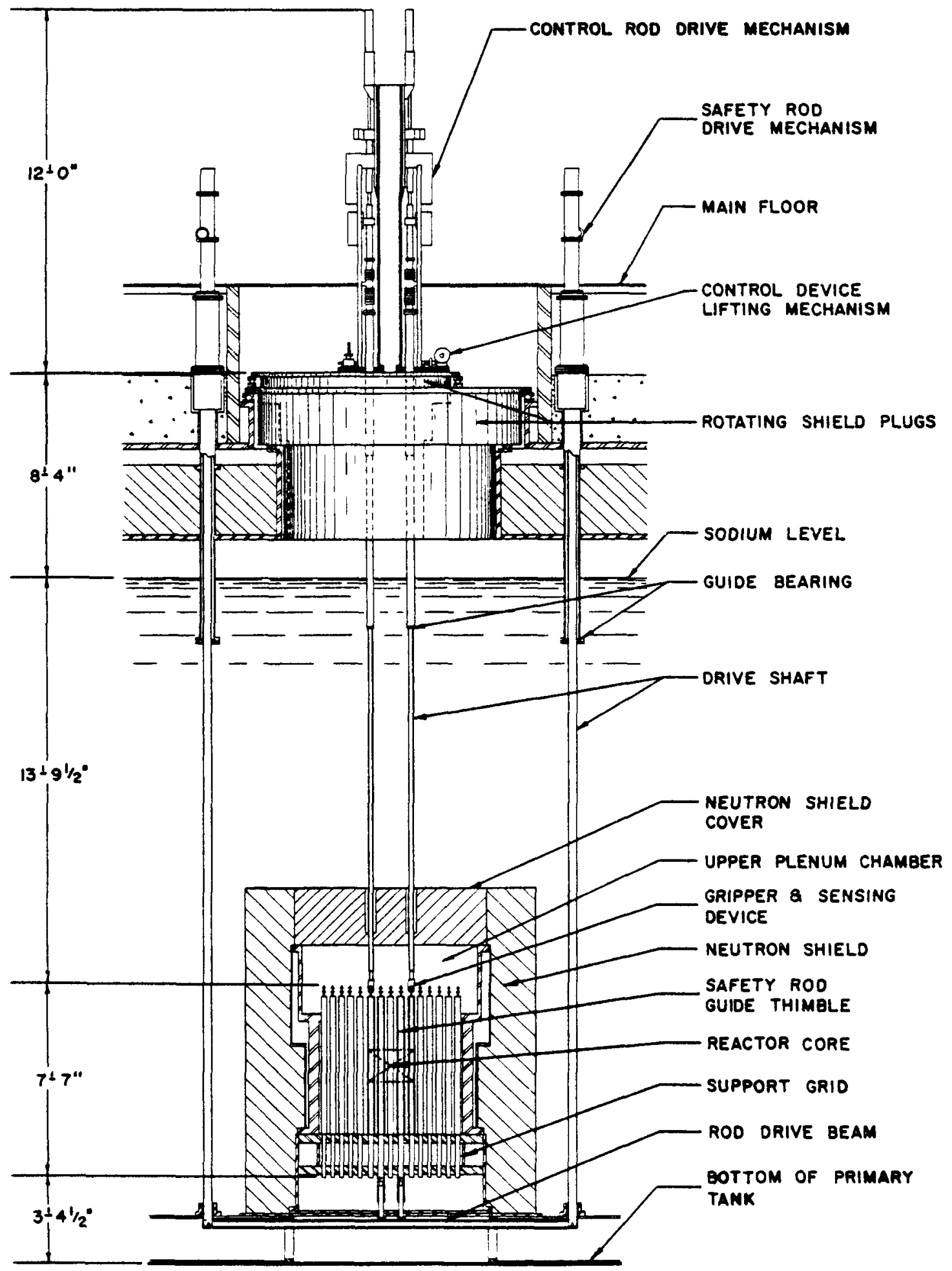

Fig. 3.33-EBR-2 control and safety rods. (Argonne National Laboratory) 


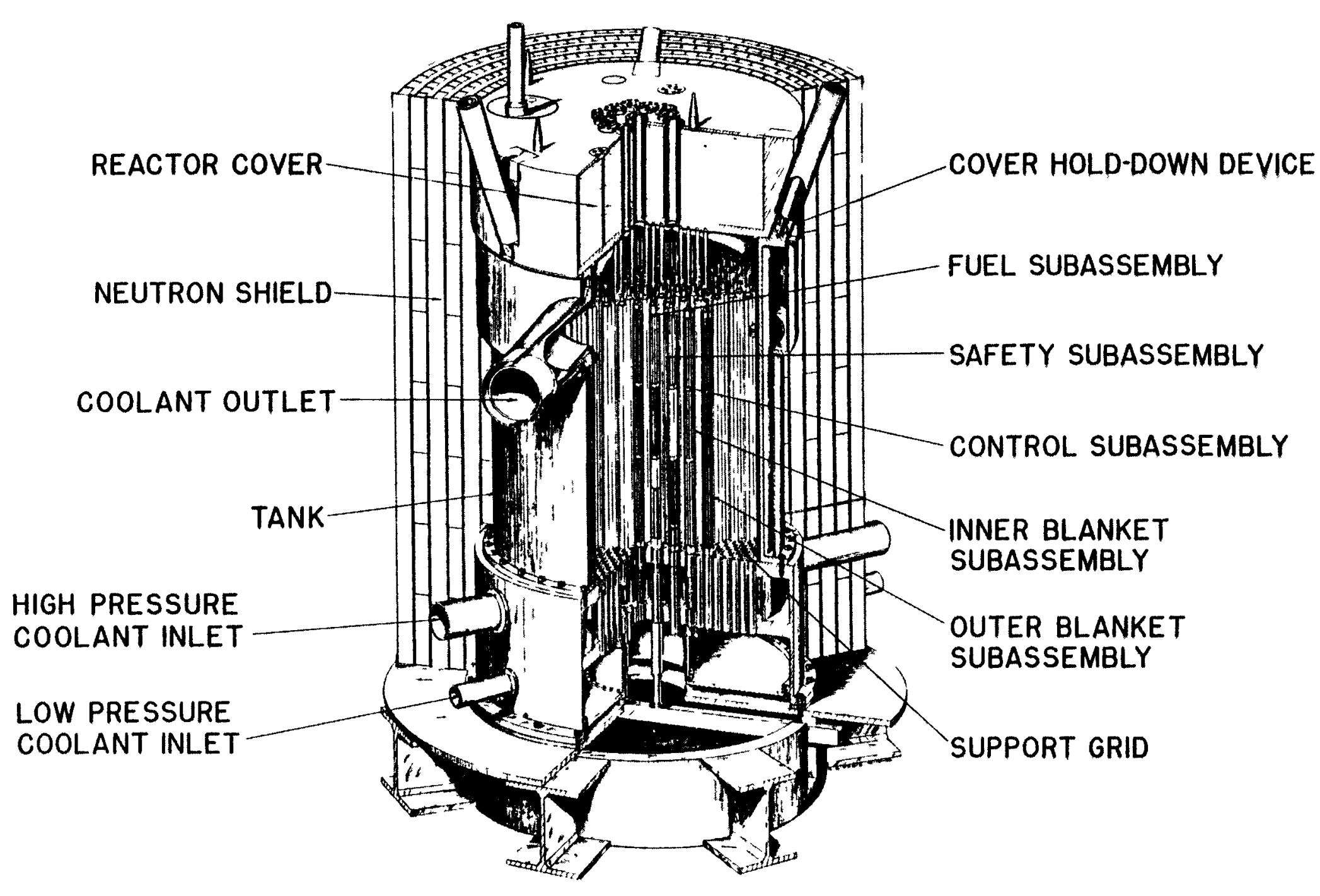




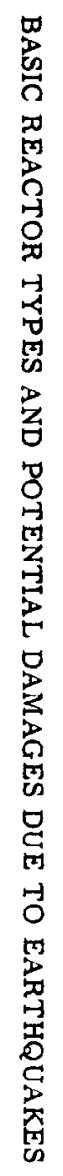

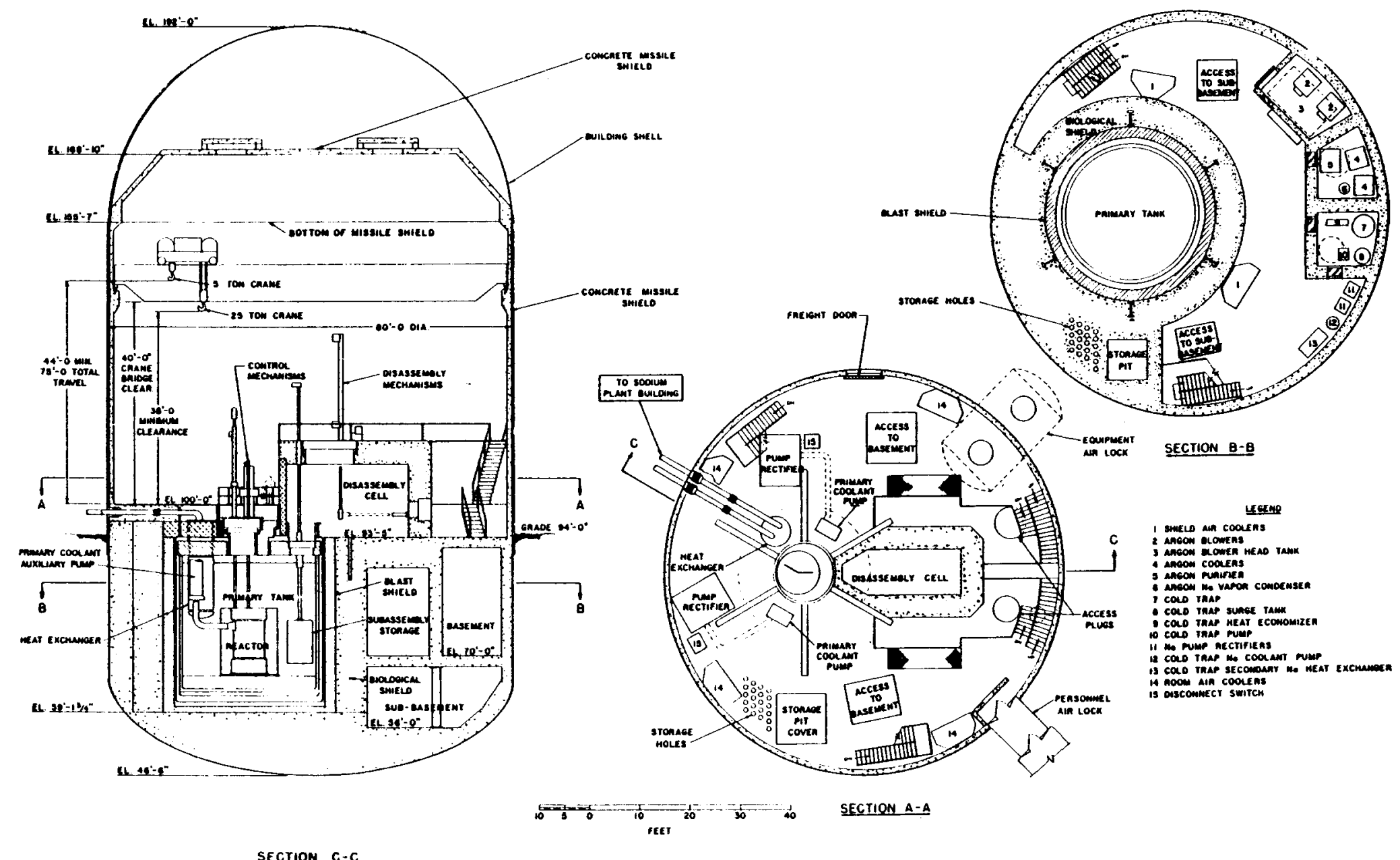

Fig. 3.35- Plan and elevation views of EBR-2. (Argonne National Laboratory) 


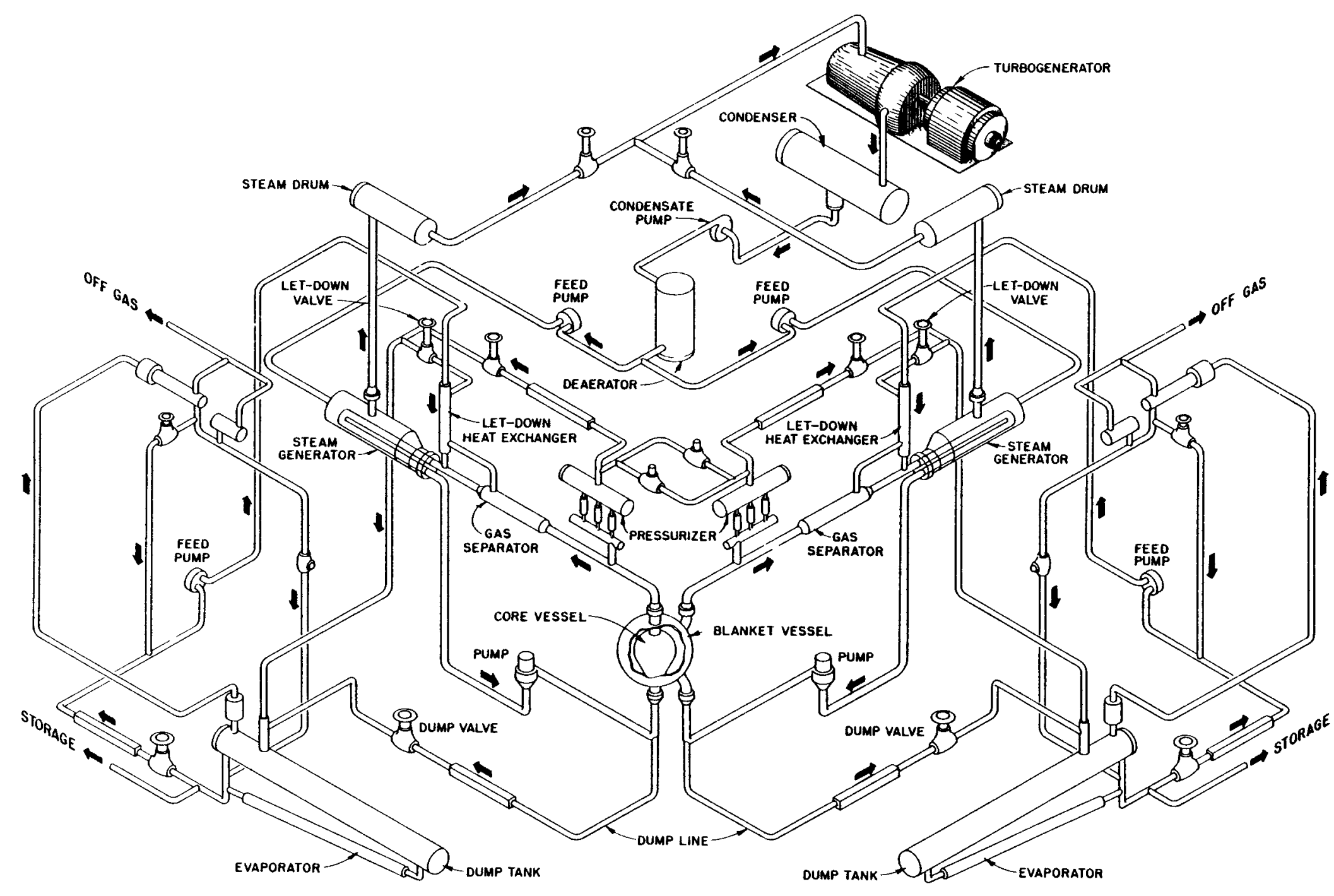




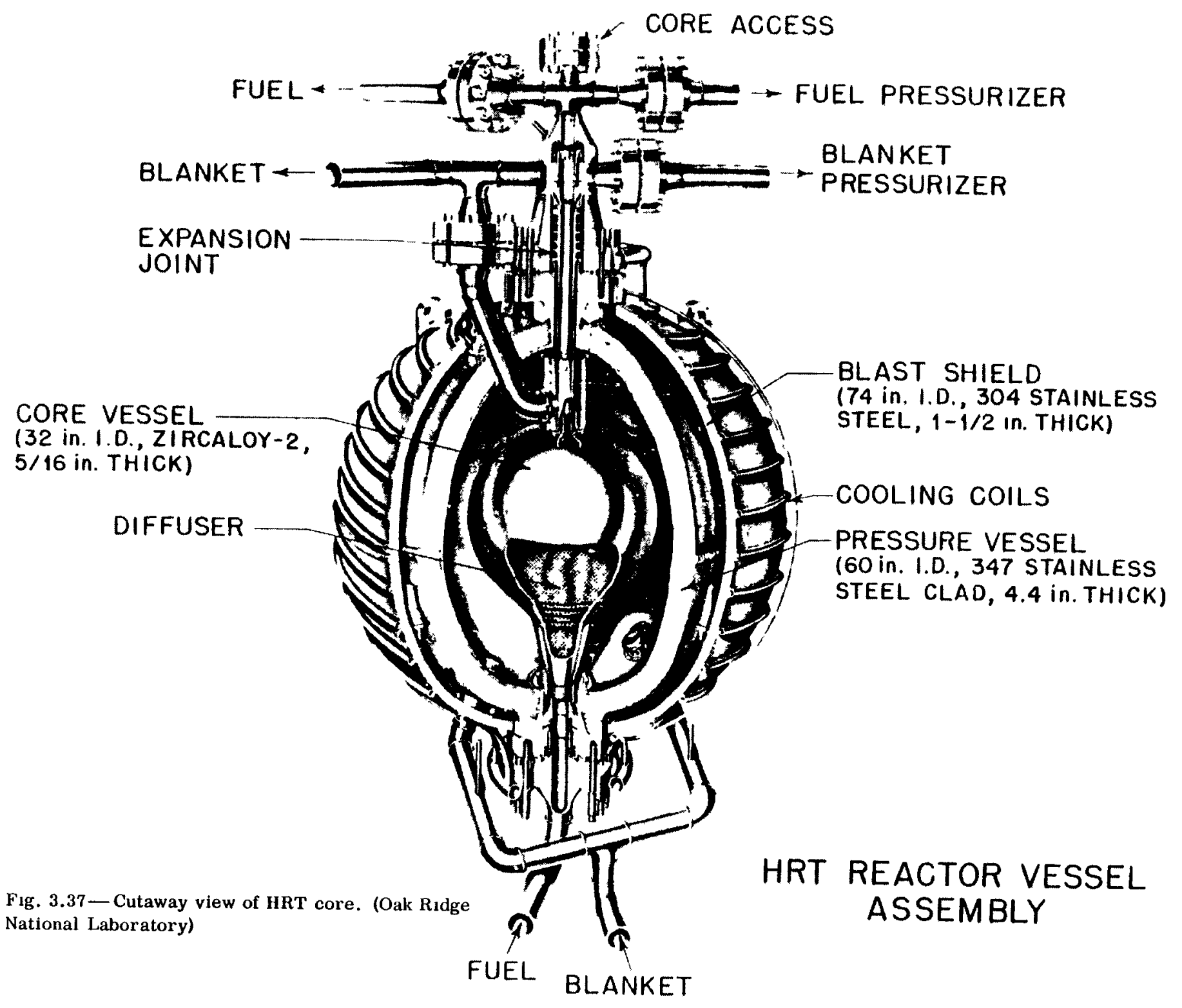



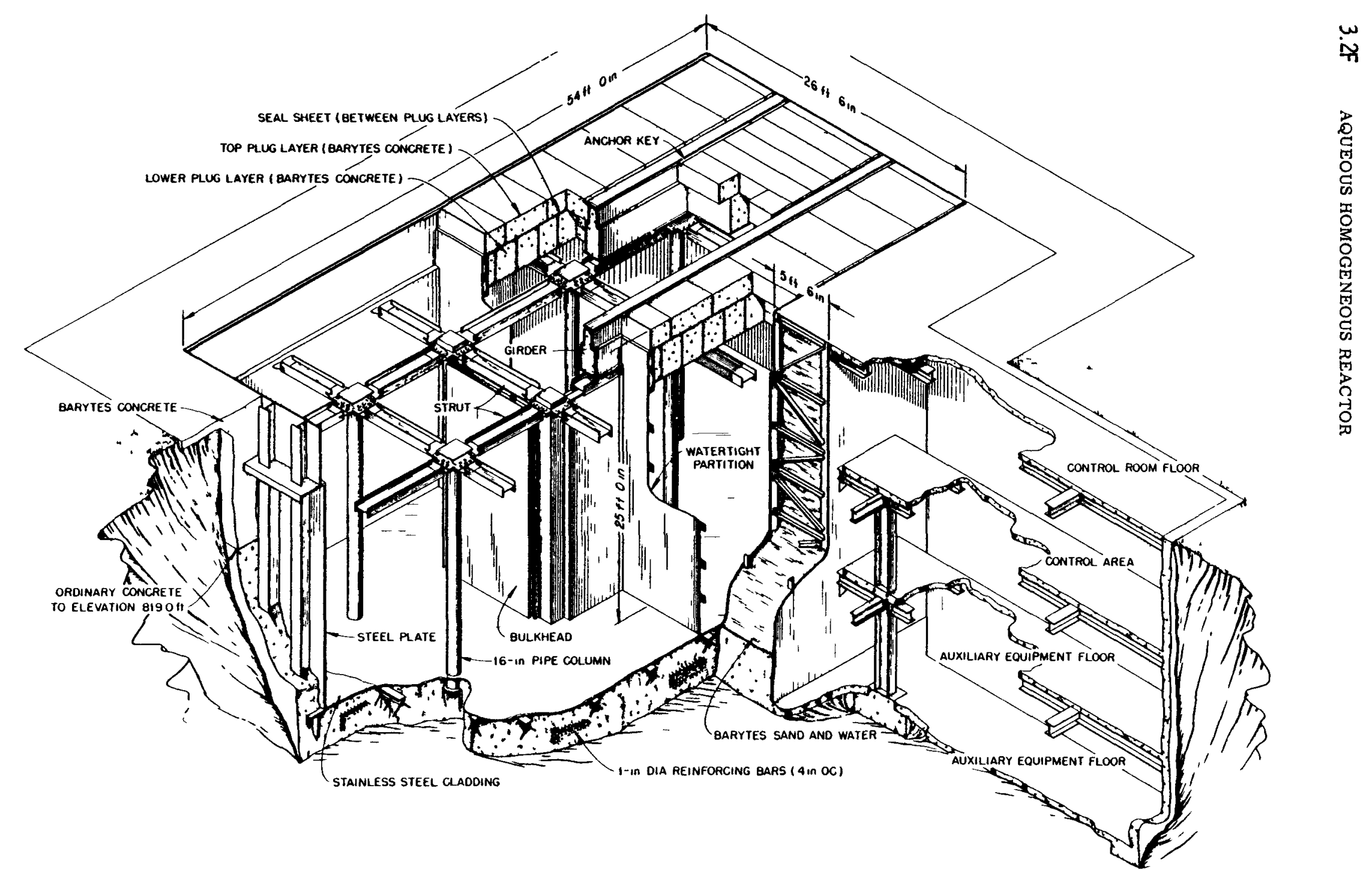

Fig. 3.38- HRT shıeld enclosure. (Oak Ridge National Laboratory) 
HRT secondary vessel is $100 \mathrm{~cm}^{3} / \mathrm{min}$. A cutaway view of the HRT plant is shown in Fig. 3.39.

Emergency cooling water is available from a cooling tower that can supply wate: by gravity feed when necessary.

\subsection{POTENTIAL SEISMIC DAMAGES TO REACTOR PLANTS}

This section briefly covers possible areas of structural damages and nuclear pertur bations that might result from strong earthquake motions. The general subject of reactor hazards and safeguards is discussed in Chap. 7, and seismic disturbances and earthquakeresistant engineering practices are discussed in Chaps. 1 and 4 to 6.

The extent of damage incurred by a structure is, in general, dependent on (1) stresses imposed by seismic shocks (together with other significant forces), (2) the aseismic properties of the structure, and (3) the plant activities at the time of selsmic disturbances.

A. Critical Areas of Reactor Systems

A prime concern of nuclear reactor safety is to prevent the release of fission products to the environment. This aspect of safety distinguishes nuclear power plants from conventional plants in which maximum hazards are relatively localized. The following is a list of certain reactor plant components which may be sensitive to mechanical damage during strong earthquakes and which may involve major reactor safety problems:

(1) Reactor primary system

a. Reactor core

1. Supporting members

2. Fuel elements or subassemblies

3. Positioning members

4. Control and safety rods

b. Reactor pressure vessel

c. Primary coolant loop

1. Heat exchanger

2. Pressurizer

3. Piping, valves, pumps, etc.

(2) Secondary system

a. Heat exchanger

b. Turbogenerator

c. Condenser

d. Cooling water system

(3) Auxiliary systems

a. Inert-gas blanket system

b. Emergency water system

c. Power system

d. Instrumentation

e. Coolant purification system

f. Ventilation system

(4) Fuel handling and storage system

(5) Secondary containment vessel or building

a. Shell

b. Foundation

The principal hazards associated with damage in some of these areas are discussed in Chap. 7. 

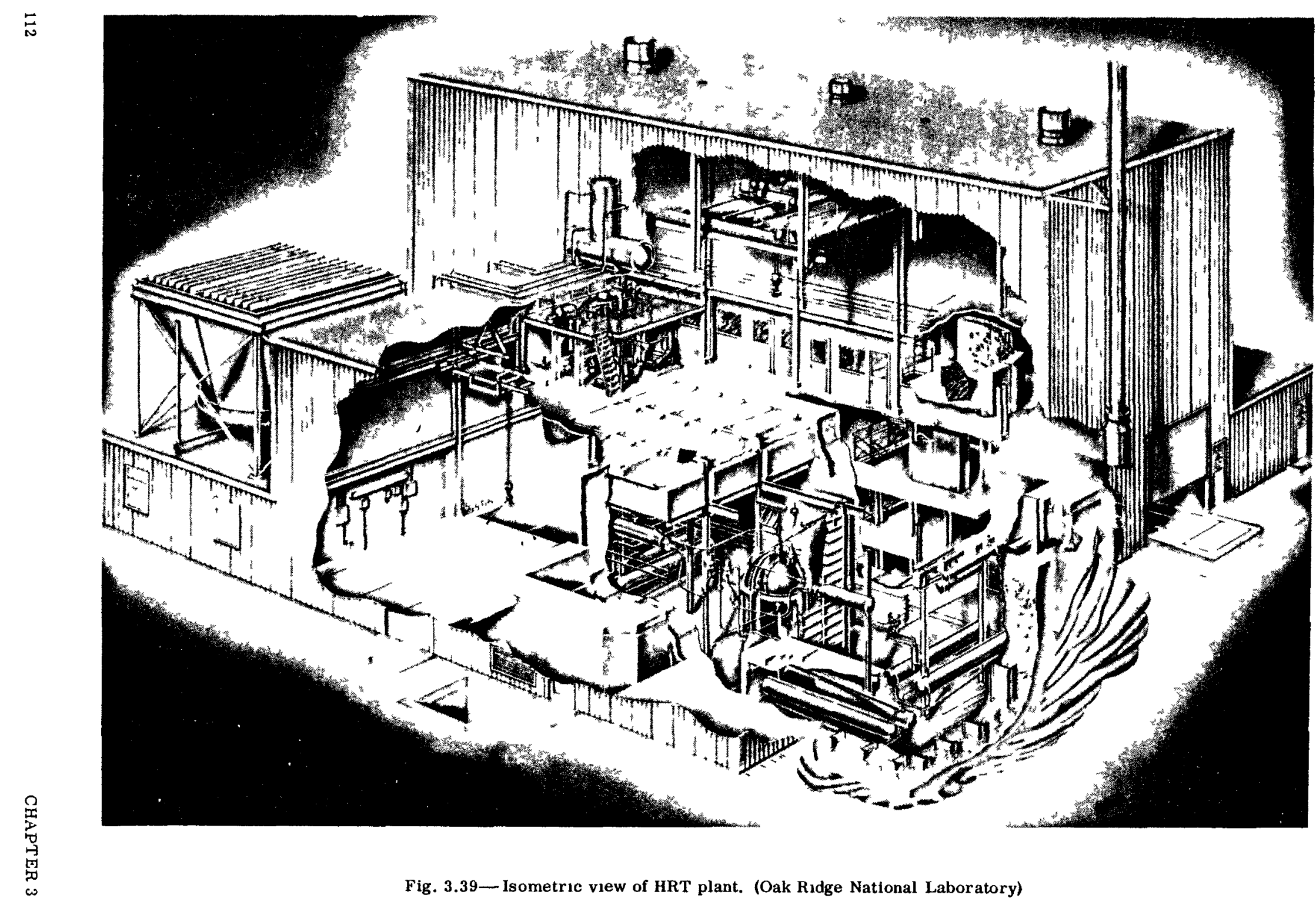

Fig. 3.39- Isometrıc view of HRT plant. (Oak Rıdge National Laboratory) 


\section{B. Direct Mechanical Damages}

Damages to structures overstressed because of the direct transmission of ground motion to the structures are referred to as "direct mechanical damages." Such failures can be categorized approximately as follows:

(1) Failure of isolated structural units due to bending, buckling, or shear stresses created by their movements. In particular, long thin structures, such as control rods, fuel subassemblies, vent stacks, and water towers, may be subject to distortion or breakage.

(2) Failure of lines or members joined to structural units which undergo large differ ential motions. For example, the coolant pipe joining the reactor pressure vessel to heat exchangers may be overstressed during earthquakes.

(3) Failure at the base of structural units. For example, tie bolts and anchor bolts may be stretched beyond their elastic limits to fail completely. The concrete of the base may crack or break off.

(4) Failure caused by dynamic loads, such as liquid movements, since oscillations of liquids with a free surface may magnify stresses resulting from earthquakes.

(5) Failure of structures due to seismic shocks imposed on materials that have been weakened by such causes as chemical attack, radiation embrittlement, stress-corrosion cracking, thermal shocks, or previous overstressing from earthquakes.

\section{Nuclear Damage}

Seismic shocks might conceivably lead to dangerous power fluctuations through resonance-instability mechanisms and delay in insertion of negative reactivity represented by control rods. If extreme power surges should occur in a nuclear reactor, the generated heat can lead to serious damages. The possible high temperatures and short time constants involved may result in thermal shock failure, partial meltdown of the core, and a pressure increase sufficient to rupture the primary loop. Stored-energy release from vaporization of the liquid coolant, possible metal-water reactions, and hydrogen detonations may follow.

At the high-power densities desired in commercial power reactors, the boiling-water reactor may experience resonance instability. ${ }^{3.3}$ Briefly, the phenomenon of resonance instability, although not clearly understood, is believed to be due to a feedback mechanism between the reactivity and power of a reactor when a certain phase relation is satisfied. In boiling-water thermal reactors, changes in moderator density (i.e., variations in the water and steam fractions) result in a changing power coefficient. Should the amount of water and steam in the core fluctuate at some critical frequency, the alternate increase and decrease of reactivity may lead to diverging power oscillations at this condition of resonance. Fast reactors may also experience resonance, but they are difficult to analyze because the effective reactivity coefficient depends strongly on the actual physical design. In the EBR-1, for instance, iuel-element bowing has been hypothesized as the primary cause of instability. Therefore the subject of deformation during seisms requires careful examination in this type of reactor.

With respect to earthquake-induced variations in the moderator density of the EBWR, if one assumes at startup a pressure of 96 psia and a maximum vertical acceleration of $0.1 \mathrm{~g}$, the variation of voids due to earthquake accelerations is a fraction of $1 \%$ locally. At higher initial pressures the variations due to earthquakes become relatively less noticeable since void fractions are functions of the total pressure. These variations appear to be small enough so that seismic shocks are not likely to induce instability from this cause, except possibly at some very high power density.

Experimental techniques using pile oscillators have been developed to predict with reasonable certainty the threshold levels at which instability will occur. Sinusoidal reactivity oscillations are introduced at low power levels, and the resulting reactivity transients are observed as the transit time around the loop is varied by throttling the 
coolant flow rate. This method delineates the safe operating limits for a given reactor system (and the effect of any reactivity changes potentially due to seisms) before significant power levels are approached.

With regard to control-rod delay, emergency cases may arise in which a slight delay in initial insertion of the rods may cause a dangerous overshoot of the power rise. A combination of lateral and vertical forces imposed by earthquakes may delay the scram operation. Reactors may be particularly vulnerable to damage from seismic shocks during startup. These points are more fully discussed in Chaps. 5 and 7.

\section{Indirect Damage}

Possible indirect damages to the reactor plant from earthquakes include the effects of falling objects, fire, and operator panic.

For reactors with an unencumbered top surface on the biological shield (bottom entry of control rods), little harm is anticipated from falling structural components. Heavy missile shields above the reactor proper tend to further protect the plant. In reactors with unprotected rod-drive mechanisms, such as the swimming-pool type, the components are extremely sensitive to damage from falling objects. Superstructure design of such plants in highly seismic areas should eliminate or protect easily severed items.

An overhead water reservoir, such as that used in the EBWR, may be subject to hydrodynamic forces from either impulsive shocks or waves. However, the stress at the rim of the EBWR overhead tank is not significant because of the large rim-base area.

Attention should be given to all heavy masses in elevated positions, for example, the overhead crane system, which might be a sensitive area during lateral earthquake movements. Possible toppling of external structures, such as exhaust stacks, and damage to reactor containment shells should also be considered in seismic design.

\section{E. Interaction Between Major Plant Components}

In a typical earthquake a well-designed foundation in strong soil or poured on bedrock will exactly duplicate the motion of the ground imposed on it by the passing earth waves. There will be no decoupling, defined as relative motion between the ground and that part of the structure extending below ground level, which would be evidenced by fissures or cracks between the foundation and the earth after an earthquake.

Such foundations should be of sufficient thickness and have the necessary reinforcement to withstand the shear and bending forces imposed on it by the seismic waves in passing, as described in Chap. 1. These forces include dynamic reactions of the biological shield, heat exchangers, pressure vessel, and other massive equipment supported by the foundaticn.

The biological shield is preferably a monolithic structure firmly anchored to the foundation. If this structure is rigid (high spring rate with good damping) and tied to the foundation with reinforcing steel, there should be a low probability of damage even in a disastrous earthquake. In this connection, shields constructed of mortared concrete blocks with no reinforcement or tie strips should be avoided since such structures, often used as temporary shields for experimental purposes, are susceptible to damage from lateral accelerations. The installation of free-surface liquid reservoirs, highly elastic and poorly damped structures, heavy-wheeled machines, or tall heavy equipment with poor lateral bracing should not be permitted on top of the biological shield. Such equipment, in addition to having a high probability of failure in its own right, may also impose undue stresses on the shield due to forces arising from the amplification of the earthquake velocities and displacements.

In the reactor proper the prime consideration is that the reactor structure be sufficiently rigid so as not to distort and jam control rods or damage fuel elements. Those graphite-moderated reactor cores which consist of large stacks of small blocks of graphite with low surface coefficients of friction should be keyed and braced to prevent shifting 
of layers. Furthermore, the reactor, control-rod drive, and the pressure vessel must comprise a sufficiently rigid assembly so that the relative motions one might expect in a violent earthquake do not exceed allowable limits.

In small enriched reactors the strength and rigidity of the reactor structure, as dictated by other considerations, is usually sufficient for earthquake resistance if mounting details are adequate. In large reactors, however, the sheer mass of the assembly (often exceeding 1000 tons), coupled with design details that allow freedom for radial and axial thermal expansion, and the relatively weak mechanical properties of some moderators (such as graphite) pose unusual problems in seismic restraint. Two-dimensional keying of adjacent core components, plus the use of circumferential support rings are methods that have been employed to maintain core integrity under seisms.

The support and lateral restraint of the pressure vessel for large reactors, where this vessel is subject to considerable temperature cycling, also poses unusual problems in seismic areas. It is often desirable to support the vessel on low-friction devices, such as roller or ball-thrust bearings, to avoid excessive thermal stresses. This leaves the vessel free to expand radially from the vertical centerline and axially in either direction from the plane of support, with suitable expansion bends or flexible joints in the connecting piping or ductwork to accommodate this movement. In this situation some means of lateral restraint during earthquakes must be provided, and, at the same time, free radial adjustment for thermal expansion must be permitted. A solution to this appears to be a system in which the lateral support is provided by a series of tongue-and-groove guides arranged radially around the pressure vessel. The tangential clearance between the tongue and groove (see Chap. 4, Fig. 4.3) is sufficient to provide only for the small thermal expansion of the tongue relative to the groove; whereas the tongue is free to move radially relative to the groove to accommodate the much larger thermal expansion across the vessel diameter. Thus, in any direction in the horizontal plane, translation of the vessel relative to the restraining member is limited to the clearance between the tongue and groove; whereas unlimited uniform radial expansion is permitted by sliding of the tongue relative to the groove. In the utilization of this or similar seismic-restraint schemes, connecting piping, ductwork, control-rod drives, fuel-charging machines, etc., should be designed to allow for possible seismic-induced displacement as well as for the normal movements from thermal expansion. The vertical component of earthquake motions rarely exceeds $0.1 \mathrm{~g}$; thus provisions for seismic restraint along this axis need not ordinarily be considered.

In the design of the overall reactor complex, interconnected components should, if possible, be mounted solidly on a unit foundation of adequate earthquake-resistant design. This would include all components interconnected by ductwork or piping carrying radioactive fluids, fluids that might become radioactive in the event of an accident, or other fluids vital to reactor safety, such as primary coolant and hydraule supplies for operating control rods. Expansion bends and flexible couplings should be designed to handle not only motion due to relative thermal expansion but also the maximum predictable motion (described in Chap. 1) which might arise in an earthquake.

In very large reactor plants it is sometimes necessary to mount the components on separate foundations. For instance, the reactor and biological shield may be mounted separately from the heat exchangers and power-conversion equipment. Since the maximum separation of foundations is small in comparison to the length of earth waves, it is unlikely that the foundations will be displaced relative to one another sufficiently to damage interconnections among components due to differential foundation displacements alone. It is also improbable that oscillations of structures attached to independent foundations will exert forces on the foundation to produce more than minor relative displacement. Earthquake-induced misalignment of large reactor-plant units on separate foundations are therefore expected to result mainly from the sum of three effects: (1) the slight dif ferences in the accelerating wave form, (2) the differential deformation in response to 
earth motion as dictated by the mass and spring-constant relations of the structures supported on these foundations, and (3) the possibility of differential foundation settling. Of these, the second effect is probably the most important. Interconnections between units on separate bases are often made at points well above the foundation top surface, for example, from the top of the reactor vessel to the tops of the heat exchangers. Relative motions of the bases can be amplified by the whipping of these tall components since the structures, having different periods and damping coefficients, will respond with different frequencies and amplitudes to identical excitation. Seismic forces are also likely to accelerate settling of foundations in soils which have not been compacted with exact uniformity. In addition, the interconnections themselves will oscillate, stressing points of connection.

\subsection{RELATIVE SUSCEPTIBILITY OF SPECIFIC REACTOR SYSTEMS}

In general, reactor plants are ruggedly constructed, and adequate safety factors are included; therefore, damage from strong earthquakes seems unlikely. However, each plant must be analyzed separately to determine the effects of an earthquake so that it can be accounted for in the design.

An estimate of damage susceptibility in the event of strong earthquakes is given in Sec. 3.4A for various reactor power plants. The discussion is qualitative and is only intended to suggest possible points of damage. In most cases the plants examined are located in relatively nonseismic areas; thus their original design criteria do not include critical earthquake effects. If similar plants were to be built in a seismically active zone, the points noted should be reviewed.

A. Stationary Medium Power Plant No. 1

This relatively small power plant appears to be compact and sturdy. Supporting structures for the vertical steam generator and the pressurizer as designed should withstand strong earthquakes, although some improvements would be advisable. Analysis indicates an insignificant stress in the thermal shield from hydrodynamic forces exerted by the shield water during severe earthquakes; however, the outer bottom rim of the shield tank should be anchored. The water supply for the spray system on the vapor container is dependent on a source outside the plant, and temporary connections are made in an emergency. A strong earthquake may break the supply line, or a heavy demand elsewhere may limit the spray-water flow rate.

Factors favorable to seismic resistance are (1) the relatively small and compact design, (2) the extremely rugged concrete-lined containment vessel, (3) the demonstrated ability of tre plant to follow abrupt changes in the electrical load, and (4) the springloaded vertical positioning of the fuel subassemblies.

\section{B. Shippingport Pressurized-water Reactor}

Differential movements among the four secondary steel containment shells under a very strong earthquake should be considered. Differential settling due to slight differences in soil structure could occur and magnify the displacement. It is conceivable that the primary coolant pipes could be broken. Similar damage to the secondary loop might be expected. However, such failures are considered very unlikely, even with the present design.

C. Experimental Boiling-water Reactor

This system seems, in general, to be structurally adequate with respect to seismic shocks. However, the vacuum tank support, the steam dryer support, and the general construction of the service building merit reconsideration if the plant site is seismically active. Liquid forces are not structurally significant. The question of possible power in- 
stability is difficult to answer. It is believed that extremely high-power densities must be achieved in the core before nuclear perturbations from seismic effects become significant (see Sec. $3.3 \mathrm{C}$ ).

\section{Sodium Reactor Experiment}

This reactor, being located in a relatively active seismic zone, has been designed to withstand the equivalent of the $1940 \mathrm{El}$ Centro earthquake. In addition, it is equipped with a commercial earthquake scram switch that is set to trip at a nominal Modified-Mercalli intensity of VIII. Some of the specific measures taken to prevent seismic damage have been described as follows: ${ }^{3.4}$

The entire core assembly is carried on cylindrical support rings which are anchored to the concrete foundation which, in turn, rests upon solid sandstone bedrock. The outer tank is doweled to the outer support ring for lateral restraint at the base. The core tank is similarly keyed to the base of the outer tank, with radial lugs maintaining separation between the core tank and the rmal shield. Thus the bases of the core tank, outer tank, and thermal shield are interlocked, preventing differential lateral displacement of the bases. The moderator cans are supported laterally at the bottom by seating into the grid plate and at the top by core clamps.

The SRE safety rod consists of a column of poison rings supported by a pull-tube which, in the cocked position, is held out of the core by an electromagnet. Loss of current to the magnet results in a scram. The complete assembly is contained in a thimble. Analytical studies of deflection and stresses in the rod due to vibrations set up by an earthquake loading (using the acceleration spectrum of the El Centro earthquake of April 18, 1940) indicate that in no case would the safety rod fail to function properly. In this connection, it should be noted that the poison column is fle:ible and is designed to accommodate a relative horizontal displacement of up to one inch between the top shield and the core to differential thermal expansion.

The SRE plant represents an unusual approach to containment in that the reactor core and primary loop are housed in a massive sealed concrete pit located below grade and sheltered by a conventional mill type building that offers limited containment at low pressure differential. Commercial buldings of this type usually cannot withstand more than a 1-psi external load without failure. Comparable reactor systems usually employ an outer metal shell capable of confining the maximum credible accident involving pressure differentials as high as 35 psi. Leakage rates of fission products from conventional mill type buildings can be $10 \%$ /day/inch of water pressure or more, compared to measured rates of less than $0.5 \%$ per day from metal shells at design pressure. However, it is believed that such mill type construction is amenable to improved erection and sealing techniques that would significantly reduce leakage rates.

E. Gas-cooled Reactor No. 2

Since the ORNL graphite-moderated gas-cooled power reactor is a large reactor, care must be taken in the aseismic design of the structure.

The cylindrical skirt supporting the entire weight of the pressure vessel, including graphite, fuel, and core support (amounting to over 2000 tons), must be able to withstand lateral earthquake forces in addition to the vertical load. This skirt has a radius of $12 \mathrm{ft}$ and a height of $7 \mathrm{ft}$ and it can be adequately designed to resist seismic loads. As previously mentioned, large high-temperature cores and pressure vessels must allow for thermal expansion without permitting large lateral movement from earthquake forces. Radial spokes, having sufficient clearance for thermal expansion, prevent large shifting motion in the GCR-2 core. A point of concern in the primary system is the coolant-piping bellowsexpansion joint. The relatively thin walls of the bellows under high pressure and temper ature are subjected to a major fraction of their allowable stress; thus additional loads im posed by seismic oscillations should be carefully examined in the design of the joint. 
Seismic design should assure that sufficient clearance is provided to accommodate radial core expansion and to permit safety rods to fall into their slots and coolant flow to enter the fuel channels without postshock interference.

Differential motion between the tall heat exchanger and the pressure vessel should be minimized by bracing the heat exchanger to the heavy biological shield or to the heavy concrete foundation. Heavy movable machinery, such as cranes and charging machines, should be examined with regard to seismically imposed stresses.

For this reactor it is considered uneconomical to construct an outer containment shell because of the size of the core and pressure vessel. Integrity of the fuel cladding and of the pressure vessel are relied upon to prevent general fission-product release, with considerable emphasis being placed on the detection of fission-product activity in the coolant stream. Therefore seismic design should give special consideration to these items.

F. Experimental Breeder Reactor No. 2

A partial core meltdown occurred in EBR-1 during an experiment in which reactor power was being oscillated drastically. It has been hypothesized that the fuel rods, which were rather loosely suspended in the sodium coolant, bowed inward due to the radial temperature gradient through the core. This bowing, although slight, increased the reactivity that fluctuated in phase with the power oscillations and led to the meltdown. In the EBR-2 core design, invariant geometry is sought by continuous spacing of adjacent fuel elements relative to one another over their entire length, plus close-fitting grids for lateral and vertical positioning. Hence, seismic-induced deflections of rods, which could produce effects similar to those caused by thermal bowing, are prevented. Transfer function studies of the EBR indicate that earthquake vibrations are not likely to contribute deflections in phase with power oscillations.

The method of suspending the core tank by its top in the EBR-2 desig 11 allows some lateral movement of the tank during strong earthquakes. The 5-in. clearance between the walls of the inner tank and the outer fixed tank is more than adequate to prevent inter action. Even for strong shocks the maximum stress in the tank wall due to deflection is well below the allowable stress. Since the reactor is firmly attached to the inner tank, it, too; will move; however, neither mechanical damage nor power-level disturbance is expected from shaking. The safety-rod mechanism is also considered to be seismically adequate. An earthquake coefficient of 0.2 was used for this zone 2 site. ${ }^{3.5}$

\section{G. Homogeneous Reactor Test}

The small size of the main components and the flexible piping arrangement of the HRT plant suggest that, with adequate bracing to the cell walls, most components would not be damaged during earthquakes. Owing to the location of the plant, earthquake sensitivity was not considered in the original hazards evaluation.

Although stringent requirements were mec with in regard to (1) shock resistance (in the case of $\mathrm{D}_{2}-\mathrm{O}_{2}$ explosions following zirconium - water reactions), (2) vibration from the diaphragm pumps, and (3) containment of explosions due to brittle fracture failure, several points should be examined for possible damage during an earthquake for any future systems of this type.

Both the inner and outer dump-tank systems are comprised of tanks freely suspended from crossarms located on vertical structural members. Horizontal stops should be installed to prevent excessive swaying of the dump tanks. During severe earthquakes the forces associated with the large masses attached to the vertical members may create sufficient stress to overload the anchor-bolt system. Stretching of the tie bolts may cause a break at the seal of the metal floor lining.

Whereas three walls are heavily reinforced and backfilled with earth, the north wall of the containment structure is of lesser strength; a fact which resulted in the reduc- 
tion of the rated capacity of the containment vessel from 50 to 32 si after hydrostatic testing was completed. Although no heavy equipment is mounte, on this wall, it is penetrated at hundreds of points by piping, conduit, instrument leads, etc. The void space between the steel bulkheads comprising the wall is filled with barytes, sand, and water for biological protection to the operating crew in the control gallery. Although this mixture has neither strength nor rigidity, it has a tremendous mass ( 500 tons). The forces imposed on the wall by combined seismic activity and internal pressure may be sufficient to breach the wall, despite the considerable inertia to be overcome.

\section{REFERENCES}

3.1 R. O. Brittan, Some Problems in the Safety of Fast Reactors, USAEC Report ANL-5577, Argonne National Laboratory, May 1956.

3.2 Fast Breeder Power Reactors - Their Problems and Prospects, Nucleonics, 15(4): 62-66 (1957).

3.3 Nucleonics, $15(7):$ (1957).

3.4 R. K. Holbrook, Atomics International, personal communication, 1958.

3.5 R. O. Brittan, Argonne National Laboratory, personal communication, 1958.

\section{ADDITIONAL REFERENCE MATERIAL}

Stationary Medium Power Plant No. 1

Army Package Power Reactor, USAEC Report AECD-3731, Alco Products, Inc., October 1955. Hazards Summary Report for the Army Package Power Reactor, USAEC Report APAE-2, Alco Products, Inc., July 1955.

Design Analysis for the Army Package Power Reactor, USAEC Report APAE-10, Vols. I and II. Alco Products, Inc., August 1956.

Initial Operation and Testing of the Army Package Power Reactor-1, USAEC Report APAE-18, Alco Products, Inc., August 1957.

Reactors on the Line, Nucleonics, 15(8): facing p. 60(1957).

\section{Shippingport Pressurized-water Reactor}

Simpson, J. W., Description of the Pressurized Water Reactor (PWR) Power Plant at Shippingport, Pa. Part A: Nuclear Power Generation, in Proceedings of the International Confer $\in$ nce on the Peaceful Uses of Atomic Energy, Geneva, 1955, Vol. 3, pp. 211-226, United Nations, New York, 1956.

Mandil, I. H., and N. J. Palladino, Description of the Pressurized Water Reactor (PWR) Power Plant at Shippingport, Pa. Part C: Core Design, in Proceedings of the International Conference on the Peaceful Uses of Atomic Energy, Geneva, 1955, Vol. 3, pp. 231-242, United Nations, New York, 1956.

Description of the Shippingport Atomic Power Station, USAEC Report WAPD-PWR-970, Westinghouse Electric Corporation, June 1957.

PWR Hazards Summary Report, USAEC Report WAPD-SC-541, Westinghouse Electric Corporation, September 1957.

Rome, R. M., and T. R. Moffett, PWR Plant Container Sizing Criteria, USAEC Report WAPDSC-549, Stone and Webster Engineering Corporation and Westinghouse Electric Corporation, June 1957.

Lustman, B., Zirconium-Water Reaction Data and Application to the PWR Loss-of-Coolant Accident, USAEC Report WAPD-SC-543, Westinghouse Electric Corporation, May 1957. 


\section{REFERENCES}

Jones, D. H., and N. J. Galper, PWR Reactivity Accidents, USAEC Report WAPD-SC-542, Westinghouse Electric Corporation, October 1957.

Mason, H., Selection and Application of Materials for PWR Reactor Plant, USAEC Report WAPD-PWR-971, Westinghouse Electric Corporation, July 1957.

Rickover, H. J., The Significance of Shippingport, Nucleonics, 16(4): 53-72(1958).

$$
\text { Experimental Boiling-water Reactor }
$$

The Experimental Boiling Water Reactor (EBWR), USAEC Report ANL-5607, Argonne National Laboratory, May 1957.

West, J. M., J. R. Dietrich, A. S. Jameson, G. A. Anderson, J. M. Harrer, and H. F. Brush, Hazards Summary Report on the Experimental Boiling Water Reactor, USAEC Report ANL5781, Argonne National Laboratory, November 1957.

Heineman, A. H., and L. W. Fromm, Containment for the EBWR, in Proceedings of the Second International Conference on the Peaceful Uses of Atomic Energy, Geneva, 1958, Vol. 11, pp. 139-152, United Nations, New York, 1958.

Roundup, Nucleonics, 16(1): 17-28(1958).

DeShong, J. A., Jr., Upping EBWR's Power, Nucleonics, 16(6): 68-72(1958).

Harrer, J., A. S. Jameson, and J. M. West, The Engineering Design of a Prototype Boiling Water Reactor, in Proceedings of the International Conference on the Peaceful Uses of Atomic Energy, Geneva, 1955, Vol. 3, pp. 250-262, United Nations, New York, 1956.

Reactor News, Nucleonics, 16(4): 25(1958).

\section{Sodium Reactor Experiment}

Eggen, D. T., A. M., Stelle, and M. Heisler, Design and Development of the Coolant System for the Sodium Reactor Experiment, in Proceedings of the Nuclear Engineering and Science Conference, Philadelphia, 1957, Vol. 2, p. 483.

Nucleonics, 15(12): (1957).

Parkins, W. E., The Sodium Reactor Experiment, in Proceedings of the International Conference on the Peaceful Uses of Atomic Energy, Geneva, 1955, Vol. 3, pp. 295-321, United Nations, New York, 1956.

Gerber, R. C., Safety Evaluation of Sodium Graphite Reactors, USAEC Report NAA-SR-1626, North American Aviation, Inc., May 1956.

$$
\text { Gas-cooled Reactors }
$$

ORNL GCR-2:

The ORNL Gas-cooled Reactor, USAEC Report ORNL-2500, Parts 1 to 4, Oak Ridge National Laboratory, April 1958.

The ORNL Gas-cooled Reactor Materıals and Hazards, USAEC Report ORNL-2505(Rev.), Oak Ridge National Laboratory, May 1958.

\section{Kaiser GCR:}

Preliminary Design, 55,000 KW Prototype Natural Uranium, Gas Cooled, Graphite Moderated Nuclear Power Plant, USAEC Report IDO-2021(Rev.1), Henry J. Kaiser Company, April 1958.

Feasibility Study Optimum Natural Uranium, Gas Cooled, Graphite Moderated Nuclear Power Plant, USAEC Report IDO-2022(Rev.1), Henry J. Kaiser Company, April 1958. 
Feasibility Study, 44,000 KW Prototype Partially Enriched Uranium, Gas Cooled, Graphite Moderated Nuclear Power Plant, USAEC Report IDO-2023(Rev.1), Henry J. Kaiser Company, April 1958.

Feasibility Study, Optimum Partially Enriched Uranium, Gas Cooled, Graphite Moderated Nuclear Power Plant, USAEC Report IDO-2024(Rev.1), Henry J. Kaiser Company, April 1958.

Other Reactors

HW-5427, March 1958.

Hinton, C., The Graphite-moderated, Gas-cooled Pile and Its Place in Power Production, in Proceedings of the International Conference on the Peaceful Uses of Atomic Energy, Geneva, 1955, Vol. 3, pp. 322-329, United Nations, New York, 1956.

J. Brit. Nuclear Energy Conf., 2(2): (1957).

J. Brit. Nuclear Energy Conf., 2(3): (1957).

Nuclear Power, 1(6): (1956).

Nuclear Power, 1(7): (1956).

Nuclear Power, 1(8): (1956).

Nuclear Power, 1 (18): $397(1957)$.

Nuclear Power, 2(19): 450-454(1957).

Nuclear Power, $3(24): 3(1958)$.

Nuclear Power, 3 (29): 408-409(1958).

Calder Hall, Nucleonics, 14(12): S10-S25(1956).

Nucleonics, 16(8): 118-121(1958).

Experimental Breeder Reactor No. 2

Koch, L. J., H. O. Monson, D. Okrent, M. Levenson, W. R. Simmons, J. R. Humphreys, J. Haugsnes, V. C. Jankus, and W. B. Loewenstein, Experimental Breeder Reactor II, Hazard Summary Report (EBR-2), USAEC Report ANL-5719, Argonne National Laboratory, May 1957.

Abstracts of Papers from Fast Reactor Information Meeting, USAEC Report TID-7548, pp. 20 21, Argonne National Laboratory, Los Alamos Scientific Laboratory, and Power Reactor Development Company, 1957.

Roundup, Nucleonics, 16(1): 17-23(1958).

Barnes, A. H., L. J. Koch, H. O. Monson, and F. A. Smith, The Engineering Design of EBR-II, A Prototype Fast Neutron Reactor Power Plant, in Proceedings of the International Conference on the Peaceful Uses of Atomic Energy, Geneva, 1955, Vol. 3, pp. 330-344, United Nations, New York, 1956.

Kasten, P. R., Operational Safety of the Homogeneous Reactor Test, USAEC Report ORNL2088, Oak Ridge National Laboratory, July 1956.

Miller, E. C., HRT Reactor Hazards, USAEC Report ORNL-2089, Oak Ridge National Laboratory, March 1957.

Beall, S. E., Containment Problems in Aqueous Homogeneous Reactor Systems, USAEC Report CRNL-2091, Oak Ridge National Laboratory, August 1956.

Bohlmann, E. G., and G. M. Adamson, Stress-Corrosion Cracking Problems in the Homogeneous Reactor Test, in Proceedings of the Nuclear Engineering and Science Conference, Philadelphia, 1957, Vol. 2, p. 36. 


\section{REFERENCES}

Rosenthal, M. W., Hazard to NRT Containment Cell from Zirconium - Water Reaction or $\mathrm{D}_{2} \mathrm{O}$ Explosion, USAEC Report CF-56-8-156, Oak Ridge National Laboratory, August 1956.

Beall, S. E., and J. A. Swartout, The Homogeneous Reactor Test, in Proceedings of the International Conference on the Peaceful Uses of Atomic Energy, Geneva, 1955, Vol. 3, pp.263-282, United Nations, New York, 1956.

$$
\text { Reactors, General }
$$

Baron, S., Eight Reactor Types: A Thermodynamic Comparison, Nucleonics, 16(6): 64-67 (1958).

Weil, J. W., Void-induced Power Distortion in Boiling-water Reactors, Nucleonics, 16(6): 90 94(1958).

Reactor Projects, Nucleonics, 16(9): 72-82, 94-124(1958).

Power Reactor Control, Nucleonics, 16(5): 61(1958).

Experimental Power and Test Reactors, Technical and Pictorial Summary, USAEC Report TID4562, Division of Reactor Development, November 1956. 


\section{Chapter 4}

\section{GENERAL STRUCTURAL DESIGN CONSIDERATIONS}

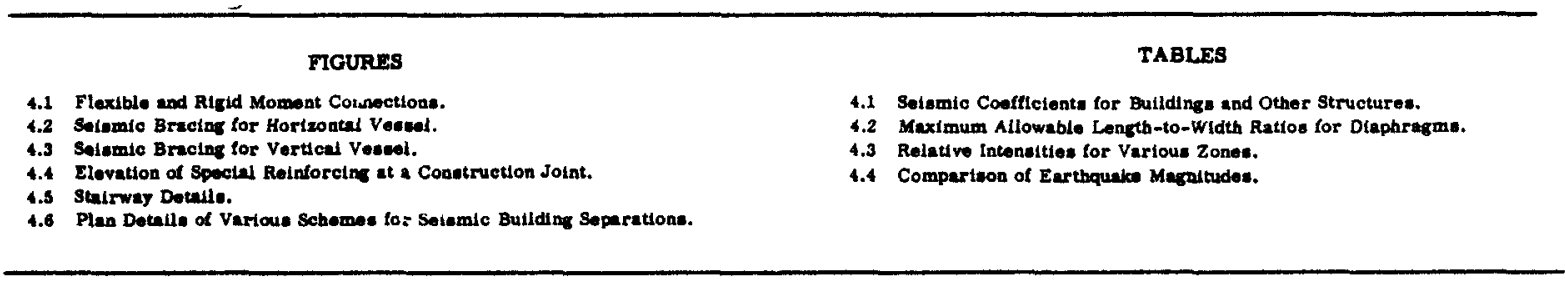

\subsection{GENERAL OBJECTIVES OF THE DESIGN}

Discussion of seismic effects in this chapter is necessarily limited by the present state of knowledge in regard to structural behavior. For the most part, this emphasizes the performance of multistory commercial, apartment, and light-manufacturing buildings rather than that of structures more closely related to the nuclear reactor field, such as those found in industrial and process installations. However, there is no great disadvantage resulting from this approach since the basic principles involved in earthquakeresistant design apply in general to structures in all these categories.

It is not intended to present material readily found elsewhere relative to the stress analysis of structural elements under seismic forces. ${ }^{4.1,4.2}$ Instead, emphasis is placed on evaluation of the seismic forces based on the dynamic characteristics of both the structure and the earthquake.

\subsection{DAMAGE MINIMIZATION VS. ECONOMIC CONSIDERATIONS}

The added cost of providing seismic resistance in accordance with California building codes, for example, is nominal for small structures but becomes more appreciable for taller structures. The increase in the cost of a conventional 12 -story building that is designed to resist a static horizontal force equal to $10 \%$ of its weight has been estimated ${ }^{4.3}$ at about 4 to $6 \%$. Part of this economic penalty may be recoverable in the form of a lower rate for earthquake insurance. The cost of altering an existing structure to comply with code seismic requirements may be a large percentage of its original cost. The cost of designing an earthquake-resistant structure is increased considerably, largely owing to the increase in the amount of work required of the structural engineer. ${ }^{4.3}$

\subsection{ADEQUACY OF SEISMIC PROVISIONS IN BUILDING CODES}

The design of a structure in accordance with the seismic provisions of current building codes will not necessarily ensure against earthquake damage, since the re is evidence that the horizontal forces specified by these codes may sometimes be too low to provide 
necessary protection against the larger earthquakes. ${ }^{4.4,4.5}$ The consequences of deficiency in seismic resistance depend on the energy-absorbing characteristics of the structure and on the effects of sources of reserve strength which have not been considered in its design. The forces that are specified in the codes are adequate to provide survival with minimum structural damage for buildings which have a large amount of damping (i.e., a large energy-absorbing capacity from yielding and fracture of nonstructural elements) or which have a large amount of reserve strength.

However, the currently specified forces may not be adequate for structures that have poor damping characteristics (particularly if these structures are designed for the same forces as those for structures having greater damping) because, in a major earthquake, these structures must depend on yielding of the primary structures for energy absorption. The avoldance of earthquake damage to this type of structure may require the use of horizontal forces in design that are several times greater than the specified code values. This could be justified economically in exceptional cases only.

Many of the structures typical of electric power plants, both nuclear and conventional, as well as those typical of refinery installations, have these low damping characteristics. This condition may require a nominal desıgn resistance much greater than that resulting from code requirements in order to maintain elastic response to a major earthquake. Where some permanent deformation is acceptable, a safe, economical design can sometimes be obtained by using methods that account for strain into the plastic range (see Sec. 5.7G).

\subsection{STRUCTURAL FEATURES CONTRIBUTING TO SEISMIC RESISTANCE}

Some of the general requirements for satisfactory performance under earthquake conditions are enumerated and discussed in the following paragraphs.

\section{A. Bracing System}

A positive means for resisting the seismic forces and tying the structure together is an obvious necessity. In some cases the walls, roof, and floor of the structure itself can be designed to perform this function.

Experience has shown that (1) the bracing system for this purpose requires special care in design and detailing in order to be adequate, (2) bracing systems designed for wind are often inadequate, and (3) ornamentation, facings, cornices, and other nonstructural elements constitute a major hazard unless adequately secured to seism-resisting elements.

\section{B. Low Mass}

With other things being equal, the greater the mass of the structure the greater is the seismic force. Lightweight construction materials minimize seismic forces but do not necessarily result in minimum cost.

C. Ductility

Brittle materials should be avoided in primary seism-resisting elements. Some overstressing that is due to the action of a major earthquake is probable in many structures designed under the seismic provisions of conventional codes. Under these conditions ductility is necessary for survival.

\section{Adequate Construction Methods}

The importance of good workmanship, inspection, and supervision is demonstrated in every major earthquake affecting urban areas. This is shown largely by the damage incurred, even in well-designed structures, when these qualities are lacking. The impor- 
tance of these features is further substantiated by the fact that some exceptionally wellconstructed buildings have survived major shocks with minor damage, even though they were not specifically designed for earthquake resistance.

\section{E. Adequate Foundations}

Differential movement of foundations that is due to seismic motions is an important cause of structural damage, especially to heavy, rigid structures that cannot accommodate these movements. Adequate design must minimize the possibility of relative displacements between the various parts of the foundation and between the foundation and superstructure.

F. Damping

The damping characteristics of the structure have a major effect on its response to seismic motion because the presence of a small amount of damping significantly reduces the earthquake stresses. In this connection, reinforced concrete has a higher degree of damping than structural steel. However, damping in itself is not a complete index of the antiseismic value of a material.

G. Structural Symmetry

Past experience has shown that buildings which are unsymmetrical in plan have greater susceptibility to earthquake damage than symmetrical structures. Structures that are $L$ shaped in plan, for example, frequently suffer damage at the junction of the two wings.

Structural dissymmetry can also be found in buildings which are symmetrical in plan but which have eccentric bracing systems. Such a condition can exist, for example, in buildings having a flexible front wall with large openings and an essentially nonflexible solid rear wall. The effect of dissymmetry is to induce torsional oscillations of the structure. Buildings with structural dissymmetries of these types need not be disqualified for use in seismic areas because such buildings can be made resistant to earthquakes by cur rent seismic-design methods.

H. Separation of Adjacent Structures

To permit free horizontal deflection of adjacent structures under seismic forces requires an adequate separation, since, in general, the oscillations of buildings do not occur in phase. The hammering effect that results from insufficient clearance has, in the past, resulted in severe damage.

I. Details Allowing Structural Movement Without Damage to Nonstructural Elements

Damage to such items as piping, glass, plaster, light fixtures, and partitions may constitute a major financial loss even though the damage to structural elements is minor. Special care in detailing is required to minimize this type of damage. However, in some cases nonstructural damage cannot be completely eliminated without interfering with functional requirements.

\subsection{STRUCTURAL FEATURES CONTRIBUTING TO SEISMIC DAMAGE}

The conditions maximizing seismic damage are obvious from the foregoing discussion. A structure completely lacking in bracing, with walls not positively anchored to floors and roof, constructed of unreinforced masonry using lime mortar, would be a poor earthquake risk. Its chances for survival would be significantly decreased by poor construction, differential displacement of foundations, structural dissymmetry, and insuffi- 
cient separation from adjacent buildings. Paint and plaster repairs, often undertaken in lieu of structural rehabilitation after damage from an earthquake, leave a structure vulnerable to further damage and possible collapse in the event of a second strong shock.

\subsection{STATIC METHOD OF DESIGN}

The dynamic problem of seismically induced structural vibrations is usually treated as a static problem in which the structure is designed to resist certain static horizontal forces. ${ }^{4.6}$ These forces are intended to induce static stresses roughly corresponding to the maximum dynamic stresses caused by the earthquake. It is not possible for a simple equivalent static method of design to cover adequately all different types of structures; for this reason the forces specified by building codes may not be the correct static loads. Therefore they must be considered as approximations, to be revised as more knowledge is accumulated.

\section{A. Lateral Forces on Main Structure}

The main structural system is designed to withstand horizontal forces that are proportional to the weight of the structure. The weight, $W$, of each mass element in the structure is assumed to apply a horizontal force, F, to the system in accordance with the equation

$$
\mathrm{F}=\mathrm{CW}
$$

where $C$ is the specified seismic coefficient.

The value of $C$ reflects the opinion and judgment, regarding the seismicity of various regions, of those concerned with the writing of building codes. According to some codes, $\mathrm{C}$ is specified to vary with height, and it has a different value at each floor level. This modification is intended to provide static loads that approximate dynamic forces of vibration. Under other codes, $C$. varies with the bearing value of the soil and the type of footing. The function of the structure also influences the value of $\mathrm{C}$, high values being used for school buildings and important parts of power plants and low values for frame dwellings. $C$ also varies with the type of structure; for example, higher values are often used in the case of towers, stacks, and tanks.

The value of $\mathrm{W}$ in Eq. 4.1 includes the dead-load weight of the structure, plus a percentage of the vertical live load which varies under different codes from 0 to 100 . Most codes agree that $100 \%$ of the vertical live load is appropriate in the case of floors carrying storage loads.

Regardless of the percentage of the live load used in determining the seismic forces, it is usually required that members carrying dead and live loads be designed to carry seismic forces in combination with the live load. Wind loads and seismic loads are not considered to act simultaneously.

\section{B. Lateral Forces on Parts of the Structure}

Components of the structure are also designed for a static horizontal force as defined by Eq. 4.1. However, the value of $C$ assigned may differ from those values used for the main structural system. The value is higher for components whose failure would be particularly hazardous to life and limb and for which the cost of providing extra internal strength is minor. For example, $C$ values for walls are generally higher than those for the main system, and $C$ values for parapet walls are even higher. 


\section{Allowable Stresses}

It is customary to permit an increase in the basic allowable stresses under seismic conditions. Usually the allowable stresses, under the combined condition of vertical loads and seismic forces, are specified to be one-third greater than the basic allowable stresses.

D. General Methods for Design of Structural Elements

In the static-design approach, the tributary horizontal loads at each level are distributed to the main resisting elements on the basis of relative rigidities. The floors and roof are usually utilized as horizontal beams, or diaphragms, to distribute horizontal shears into the vertical frames, trusses, or shear walls. In the case of concrete floors and steel columns, the diaphragm can usually be considered infinitely rigid, and under this assumption each column carries a part of the total shear which is proportional to its relative rigidity.

Special consideration is given to the situation occurring where the center of mass does not coincide with the center of rigidity of the vertical elements. In this case the resisting elements are designed on the basis of an elastic analysis and take into account the torque about the center of rigidity.

Flexible diaphragms, formed of wood sheathing, plywood, rod bracing, or metal decking, are not considered capable of distributing shears to the vertical elements in the same fashion as a rigid diaphragm. For this reason, when such diaphragms are used, shears are often proportioned to the vertical elements on the basis of the mass tributary to each.

Diaphragms are checked for bending and shear stresses as horizontal beams. Nailing controls the strength of wood sheathing and of plywood diaphragms. The analysis of metal diaphragms is based on test results and is usually controlled by weld size, pattern, and spacing. Rod bracing systems are analyzed approximately as trusses, with the rods in tension acting as diagonal web members, and the floor or roof members acting as chords or posts of the trusses. The shears and moments in rigid-frame bents are calculated by standard methods of rigid-frame analysis, such as those based on moment distribution or slope deflection. ${ }^{4.7-4.9}$

When shear walls are used in lieu of rigid frames, the portions of these walls between wall openings are considered to act as piers, fixed at either top or bottom, or at both these locations. Bending and shear deflections are accounted for in establishing relative rigidities of the various piers. From these the shears carried by each pier are computed, the unit shear stress and other stresses in the piers are checked, and vertical reinforcing steel is provided for the bending moments. ${ }^{4.1,4.2}$

\subsection{DESIGN OF FOUNDATIONS}

A. Overstressing of the Soil

The foundation system is proportioned to resist all or most of the overturning moment developed by the static horizontal forces applied to the structure above. Some reduction in moment is permitted on the basis that the allowable dynamic soil pressure exceeds the allowable static pressure.

\section{B. Consolidation and Differential Settlement}

Earthquake vibrations may cause consolidation of loose soils, and the resulting settlement of building foundations is rarely uniform. In the case of rigid structures supported on individual spread footings bearing on such material, differential settlements can result in extensive damage to the superstructure. Either the stabilization of the soil prior to construction or the use of piles, piers, or caissons bearing on a firm stratum is a solution to this problem. 


\subsection{RELATIVE MOTION BETWEEN STRUCTURES AND PARTS OF STRUCTURES}

Relative motion between adjacent structures or between parts of the same structure is a matter of considerable importance as regards seismic damage. Two main types of damage are possible: type 1 is the damage due to impact of structures or parts separated by a gap insufficient to accommodate the differential motions involved, and type 2 is the damage due to the failure of elements joining the vibrating structures or parts, where the failure is caused by the differential movement.

Often the simplest way to prevent or minimize type 1 damage is to provide sufficient clearance so that free motion of the vibrating parts will result. When the clearance cannot be increased sufficiently, a possible alternative approach is to tie the structures together to form an integrated system. However, the large forces to be transmitted through this system may make such an approach impractical. When this happens the only other alternative, in general, would be to accept whatever impact damage might occur to each structure due to improper clearance.

Type 2 damage can also be minimized by tying the structures together with a bracing system, to act as a unit, if the magnitudes of the forces permit a reasonable design of this nature. Very often, however, provisions allowing independent relative motion of each structure without damage to connecting elements will be found to be more acceptable. This is accomplished by incorporating flexibility into the connecting elements so that the necessary differential deflection can be accommodated without overstress.

\section{A. Separation Joints}

In past earthquakes the mutual hammering received by buildings in close proximity has caused sufficient damage to justify the inclusion of provisions in many building codes which require a certain minimum structural separation. The amount of separation required increases with the height of the structure. In recent years proposals have been made, ${ }^{4.10}$ and codé provisions have been adopted, ${ }^{4.11}$ which limit the amount of deflection permitted in each story of a building.

Junctures between distinct parts of buildings, such as the intersection of a wing of a building with the main portion, are often designed with frangible joints that allow relative movement. When this is done, each part of the building must be considered as a separate structure that has its own independent bracing system.

\section{B. Flexible Couplings}

Certain types of structures commonly found in industrial installations are tied together at or near their tops by connecting elements such as piping, ducts, conveyors, chutes, etc. As previously described, the alternatives are (1) to design a structurally integrated system to transmit the seismic forces involved or (2) to provide flexible couplings to reduce these forces to negligible values. The first alternative may not be feasible for large, heavy, or complex structures.

The motion to be provided for in the flexible coupling is produced partly by the deflections of the structures themselves and partly by the rocking or settling of the foundations. In the case of structures which are relatively rigid but which are founded on compressible soil, considerable reduction in the amount of relative motion between the structures and the soil can possibly be attained by the use of a common footing instead of two separate footings.

\subsection{EFFECT OF MATERIAL PROPERTIES}

A. Ductility

Ductile materials are highly desirable for earthquake-resistant designs. Brittle materials should not be used to resist seismic forces; in this category are unreinforced 
concrete and all unreinforced-masonry materials, such as concrete block, brick, and tile. When properly reinforced with steel, concrete is fairly ductile in flexure and is much used in earthquake-resistant construction. With proper design and rigid control of workmanship, both concrete block with reinforcing in concrete-filled cells ${ }^{4.12}$ and reinforced grouted brick ${ }^{4.2}$ can also develop considerable seismic resistance.

The low tensile, shear, and bond strengths of reinforced concrete and masonry materials must be recognized, particularly since these can lead to brittle types of failure. There is a better balance between strengths in flexure, tension, compression, and shear in structural steel, and its high ductility is favorable.

B. Damping

The amount of damping in the structure significantiy affects response; values as small as $2 \%$ critical damping can cause marked reductions in seismic stresses. The internal damping available in elastic steel structures is less than that of reinforcedconcrete or -masonry structures. Damping is largely associated with inelastic action, which occurs to a minimum degree in a welded steel structure, to a greater degree in reinforced concrete, and to a still greater degree in reinforced masonry. However, the plastic yielding of a steel structure can be equivalent in its effect to a high damping capacity.

\section{Relative Rigidities}

Relative rigidities are important in determining the distribution of seismic shears between resisting elements. The moduli of both elasticity and shear have a bearing on the relative rigidities. In the case of steel, these moduli have relatively constant, predictable values in the usual range of working stresses. In general, shear deflections are important only in short-span, deep beams. However, since steel beams are rarely of such proportions, only the modulus of elasticity is of primary interest.

In the case of reinforced-concrete and -masonry materials, the moduli of both elasticity and shear vary with load intensity and duration and with the ultimate strength of the material. In seismic design, shear deflections become an important percentage of the total deflection in the case of shear walls and piers constructed of these materials. Because of this, both the shear modulus and the elasticity modulus are significant. The accuracy with which the division of load between resisting elements can be estimated is reduced when these elements are composed of different materials, with some elements having moduli that are not accurately known. Under these circumstances, overlapping assumptions may have to be made, using upper and lower limits, to be certain that the design is adequate. For example, the distribution of lateral force between a steel rigid frame and an interconnected reinforced-concrete shear wall is difficult to establish owing to the uncertainties involved in calculating the rigidity of the shear wall. Because of this, the shear wall would have to be designed on the assumption that its rigidity was relatively high, and the frame would have to be designed on the assumption that the rigidity of the shear wall was relatively lower.

The effect of overstress should be considered when combining materials of different rigidities. In the event of overload, a relatively rigid but brittle structural element may fail while acting in combination with a second, more flexible but ductile element, thereby transferring its load to the second element.

The question of relative rigidities also becomes important in the support of relatively rigid parts of the structure by flexible bracing elements. The limitations placed on the amount of horizontal deflection per story to reduce cracks in masonry walls, glass, and plaster show that this problem ${ }^{4.10,4.11,4.13}$ is recognized. 


\subsection{SPECIFIC DESIGN DETAILS IMPORTANT TO EARTHQUAKE RESISTANCE}

A. Structural-steel Details

Consideration must be given to the possibility of stress reversal under seismic conditions. Beam flanges, which are normally in tension, may require lateral bracing because of the compression.

Use of nonrigid connections of steel beams, such as the ordinary web clip angle or the top and seat angle types (parts $a$ or $b$ of- Fig. 4.1), should be avoided where definite seismic moments must be provided for. Rigid types of connections should be used; some examples are the split-beam type (part $c$ of Fig. 4.1) or its welded equivalent; riveted, bolted, or welded brackets; and knee braces.

Certain deficiencies in the seismic behavior of rod-braced tower type structures have been noticed. ${ }^{4.14}$ These include stretching of rods and anchor bolts, and torn gusset plates. Joint failure due to shearing of cotter keys, which allows the clevis pins to drop out, has also been observed.

For bracing rods, forged clevises are preferable to those of the bent plate type. As ordinarily designed, the bent-plate clevis tends to fail through the bolt hole without de-

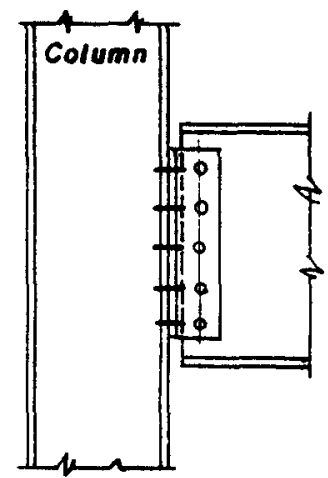

(a) Flexible

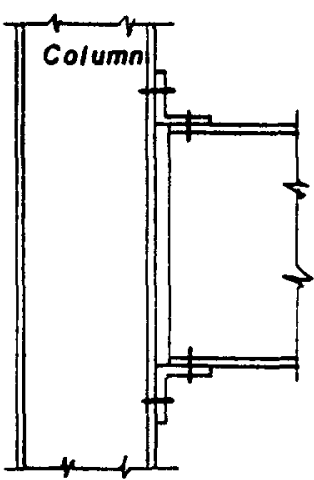

(b) Flexible

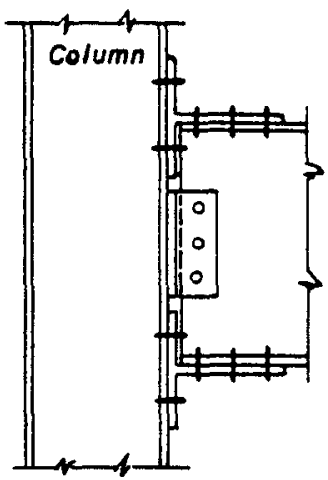

(c) Rigid

Fig. 4.1-Flexible and rigid moment connections.

veloping the strength of the rod. Fabrication error through the use of undersized dies in threading of rods has been known to cause failure from stripping of threads. ${ }^{4.15}$ Upset rods have more energy-dissipation capacity through inelastic stretch than do standard rods, and they are to be preferred in certain structures, such as tank towers, where over stress under seismic forces is likely.

Antiseismic details that permit temperature movement are often required in pressurevessel installations and similar applications. Of the several ways of accomplishing this, two are shown in Figs. 4.2 and 4.3.

A bracing scheme for a suspended cylindrical vessel is indicated schematically in Fig. 4.2. Thermal movement in the $x$ direction is permitted at end $B$; seismic motion in this direction is prevented by bracing member $A E$. Members AC and BD prevent seismic motion in direction $\mathrm{y}$; member $\mathrm{BD}$ being pivoted to accommodate the thermal movement at $\mathrm{B}$.

The system shown in Fig. 4.3 for seismic support of a vertıcal cylindrical vessel provides for radial and vertical thermal movement by means of the large expansion gap. Translation of the vessel in a horizontal plane is limited by the small clearance gap provided between the contact surfaces of the lugs on the vessel walls and those on the supporting structure. 


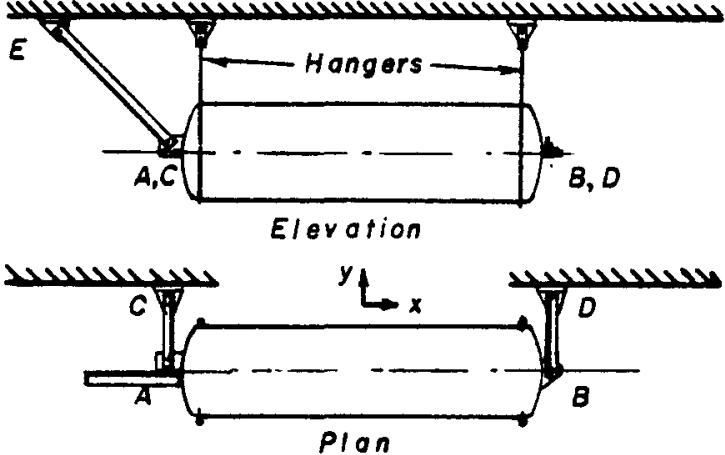

Fig. 4.2- Seismic bracing for horizontal vessel.

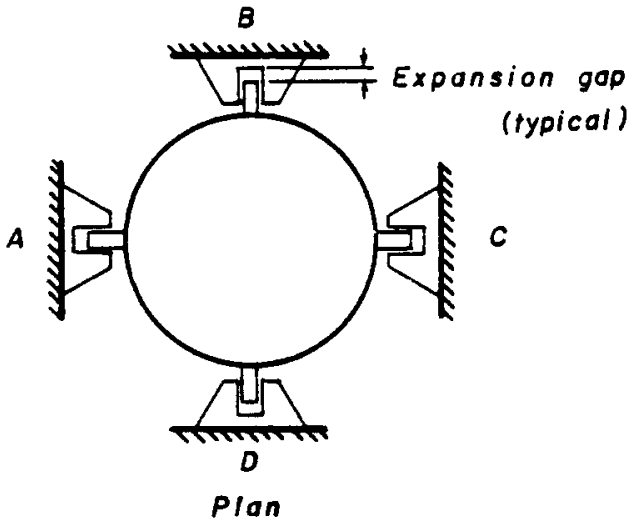

Fig. 4.3-Seismic bracing for vertical vessel.

\section{B. Concrete Details}

In antiseismic construction with reinforced concrete, care is required to ensure that potentially weak points, which may not be serious in ordinary circumstances, do not develop trouble under seismic loadings.

Continuity of the main reinforcing steel is desirable to allow for reversals in the sign of the bending moments. Part of the top steel in beams should extend the full length of the span, and a portion of the bottom steel should be made continuous with that from adjoining spans. Haunches utilizing diagonal bars can be used advantageously to strengthen beam-to-column intersections.

In general, it is preferable to design multistory flat-slab buildings as shear-wall structures, since it is difficult to transmit large bending moments from the slab into the columns. Bars placed in the bottom surface of flat-slab capitals are helpful in preventing cracking where seismic bending moments must be developed.

In floors and roof slabs used as diaphragms, it is customary to provide for tensile stresses by means of flange steel concentrated at the edges of the slab. Shrinkage reinforcement in the slab, as well as the main reinforcing, is made continuous with the wall reinforcing by means of dowels between slab and wall, with the intent of minimizing slab cracks. Tensile stresses due to the bending moments in shear walls are also provided for by steel concentrated at the vertical edges of the wall.

Recently, shear failures in certain types of reinforced-concrete members have resulted in corrective code revisions ${ }^{4.16}$ that should be observed. These revisions apply to continuous or restrained beams joined to a slab in such a way that T-beam action cannot be developed. These revisions also provide that web reinforcing, designed for at least two-thirds of the total shear at a given section, be used in regions of negative moment.

Occasionally seismic shears at a given cross section, combined with those due to other loads, result in maximum positive and negative shears with intensities sufficient to require web reinforcing. Under these conditions vertical stirrups should be used, since they are effective regardless of the sign of the shear, whereas inclined bars are entirely effective only for shear with a sign such as to induce tension in the bars.

Under the combined effect of compression and flexure, a common mode of failure for tied columns is by buckling of the main steel and spalling of the concrete cover near the floor level. A reduced spacing of ties should be used at these locations. Columns with spiral reinforcing have greater reserve strength and are less vulnerable to this type of failure. 
Se1smic damage at construction joints has been frequently noted. Such damage may be minimized by the use of those methods of joint preparation which result in a high bond strength. Diagonal bars are sometımes used where shearing forces are high (Fig. 4.4).

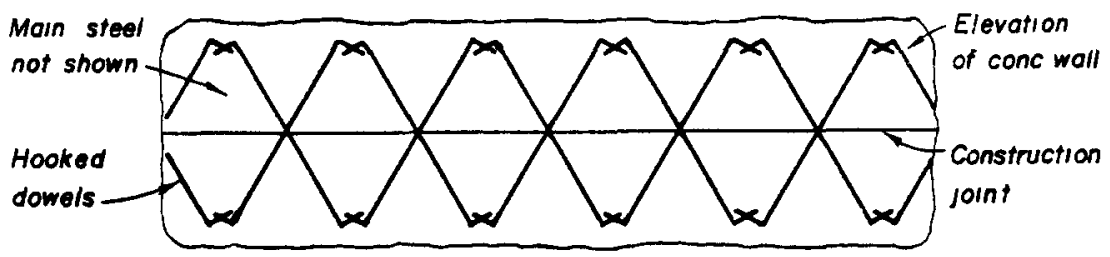

Fig. 4.4-Elevation of special reinforcing at a construction joint.

Concrete staurways often suffer seismic damage due to differential displacement of the connected floors. This can be avoided by providing open joints in each floor at the stairway to eliminate the bracing effect or by providing an adequate load path for the forces by using stair walls extending the full height of the stairs (F1g. 4.5).

Earthquake experience with tilt-up and precast construction is very limited. Potential sources of weakness are the jounts between units. In the case of tilt-up walls, the use of

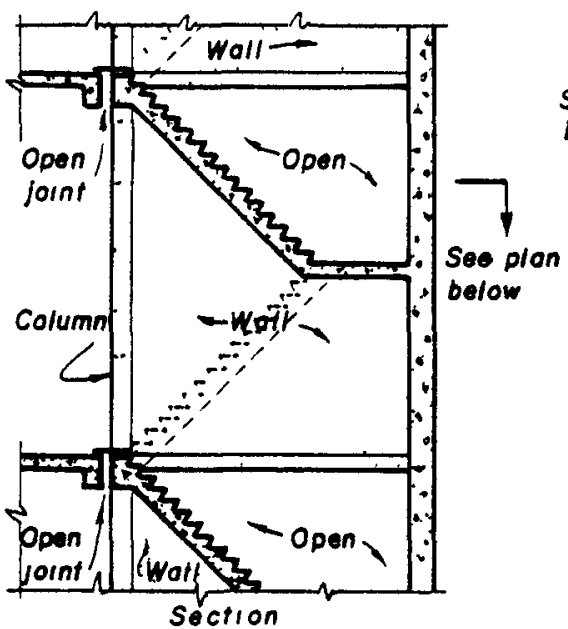

(a) Separation Joint for Rolioving Shears, Using Open Starr Well.

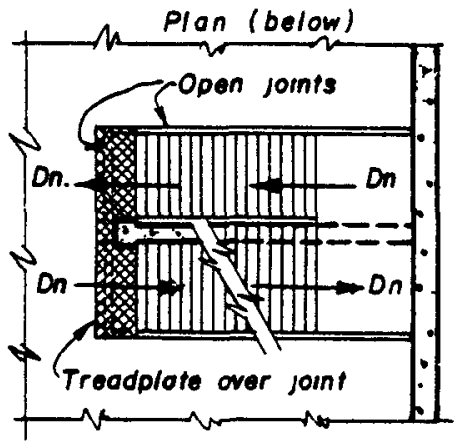

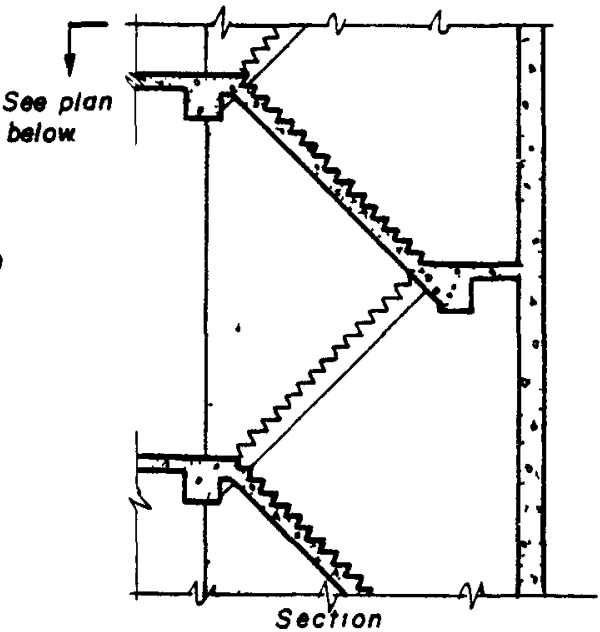

(b) Stair Walls for Tronsmitting Shears

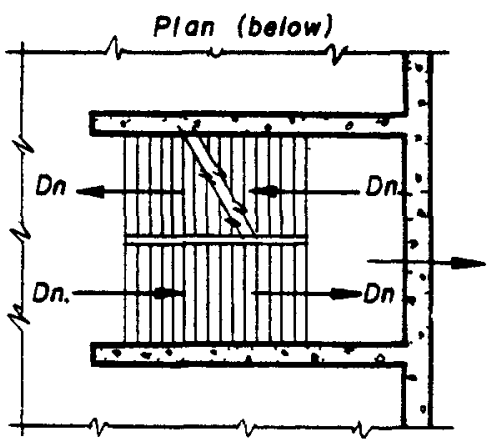

Fig. 4.5-Stairway details. 
either poured-in-place concrete or gunite with wall bars lapped across the joint is considered the most acceptable. ${ }^{4.17}$ The equivalent of a continuous tie is required at top and bottom. In some cases, load transfer across joints may have to be made using such mechanical tying elements as reinforcing bars, bolts, welds, and keys.

\section{Foundations}

Pile foundations, and foundations on soil with a low bearing value, should be tied together in a way to prevent relative movement of the various parts of the foundation with respect to each other. An interconnecting grid may be used, each member being designed for an axial load equal to a percentage of the vertical load carried by the heavier of the footings connected. Alternatively, an interconnecting reinforced-concrete slab, providing restraint in all horizontal directions, may be used for this purpose.

\section{Structural Separation}

The clearance between adjacent structures or parts of the same structure which are dissimilar in mass or stiffness should provide for maximum amplitudes of the motion of each structure or part. Frangible crumple joints, which should be continuous through walls and roof, are often used to cover this gap.

The practice in the use of structural separations varies with types of construction. Such separations are used most often in reinforced-concrete and -masonry structures at junctions between distinct parts of the buildings and at other locations where large and possibly indeterminate forces would have to be provided for if integrated construction were used.

Separations are used less frequently in steel buildings, where smaller seismic forces are involved. Those placed in long steel structures for relieving temperature stresses usually function also as seismic separations.

Structural separations are seldom used in wood-frame buildings, since, in this case, integrated construction can usually be economically designed to transmit the relatively small seismic forces generated in the structure. Typical separation details for these types of construction are shown in Fig. 4.6.

\section{E. Other Provisions for Relative Motion}

Damage to partitions can be largely eliminated by locating them away from columns and by providing a detail at the top which will permit relative motion between the partition and the floor above. ${ }^{4.18}$ Breakage of glass windows can be minimized by providing extra clearance at the edges to allow for frame distortion. ${ }^{4.19}$

In piping installations the expansion loops and bellows joints used to accommodate temperature movement are often adaptable to handling the relative seismic deflections between adjacent equipment items.

\subsection{TYPICAL BUILDING-CODE LEQUIREMENTS IN EARTHQUAKE REGIONS}

A. Scope

Current methods of seismic design are governed largely by the earthquake provisions in California building codes. To illustrate some of the main requirements, the seismic provisions of four such codes have been selected for discussion. These are:

Code 1, San Francisco City and County Builaing Code,,${ }^{4.20} 1958$

Code 2, Los Angeles City Building Code, ${ }^{4.21} 1957$

Code 3, California Administrative Code, Title 21, Public Works, ${ }^{4.11} 1958$

Code 4, Uniform Building Code of the Pacific Coast Building Officials Conference, ${ }^{4.22}$ 1958 


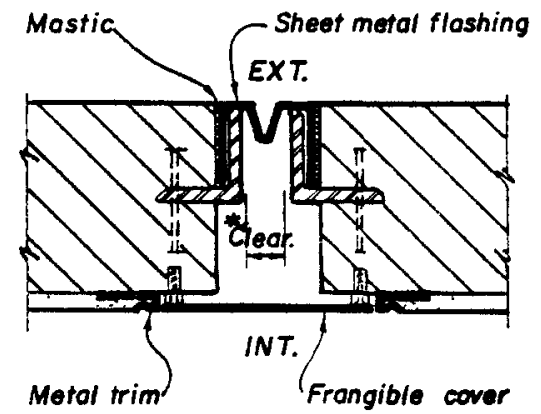

(a)BRICK WALLS; IMPORTANT WORK

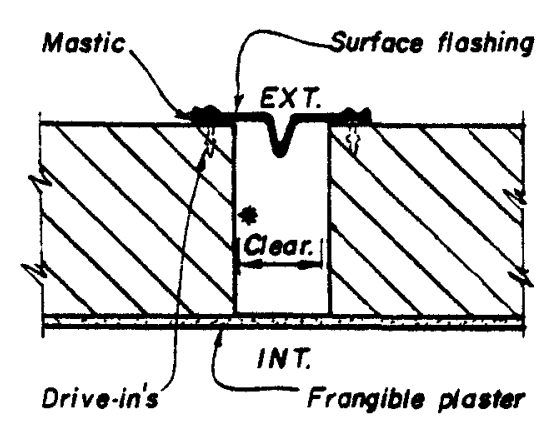

(c) BRICK OR BLOCK WALLS; MIN. WONK

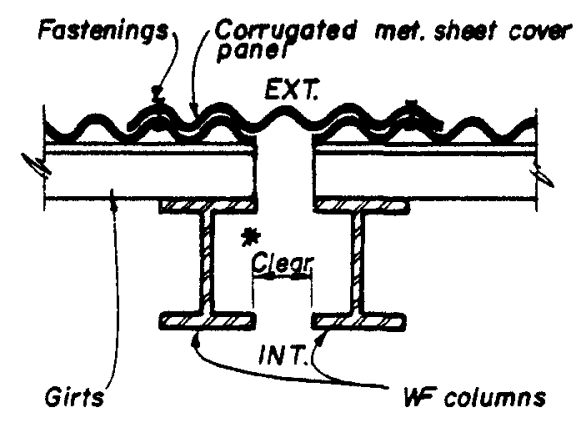

(e) METAL SIDING; INOUSTRIAL WORK
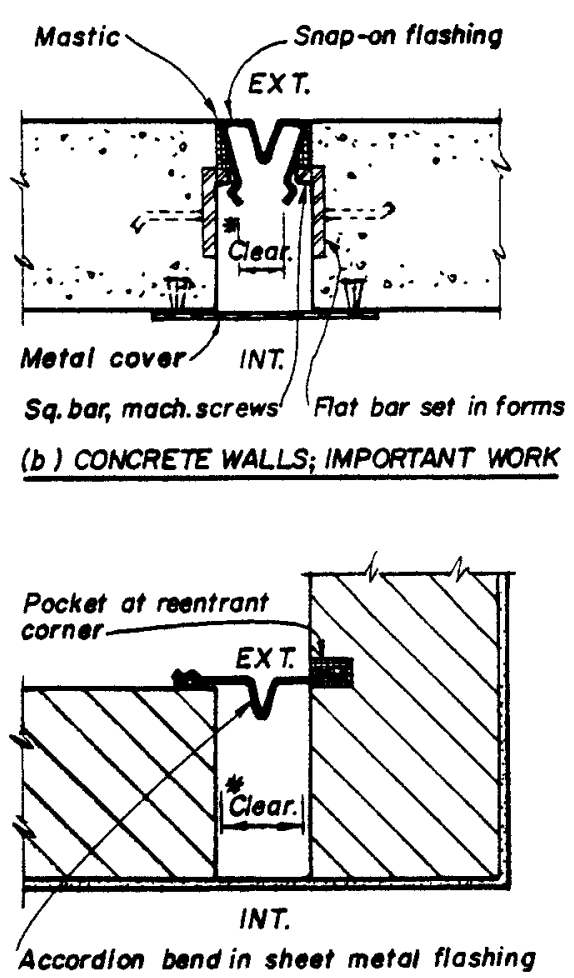

(d) ERKCK OR BLOCK WALLS; MIN. WORK

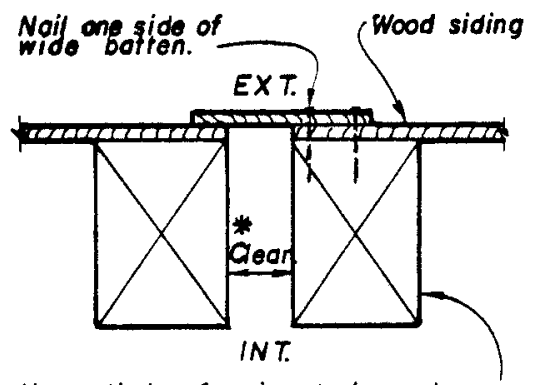

Heavy timber froming; timber columns

(f) WOOD SHEATHING; INOUSTRIAL WORK

"Clearance is required by Southern California building codes to be at least
$1^{\prime \prime}$ plus $1 / 2$ " for each ten feet of the building height above twenty feet.

Fig. 4.6-Plan details of various schemes for seismic building separations.

The seismic provisions specified in codes are usually considered by the code author ity to be of a general nature, and, in the interest of fulfilling their intent, the building official is permitted to supplement these provisions with interpretations and special rulings.

In this section no attempt is made to discuss the minute details of seismic-code requirements; instead, pertinent provisions are presented in general terms accompanied by brief explanatory comments. For explicit requirements the codes cited should be consulted. 


\section{B. Working Stresses Used in Seismic Design}

These codes permit working stresses under the combined action of vertical loads and seismic forces which are $1 \frac{1}{3}$ times the working stresses normally allowed under the action of the vertical loads only. Wind forces must be considered, but not in combination with seismic forces.

To allow for the vertical component of acceleration, Code 3 states essentially that in calculating any effect of dead loads in relieving seismic stresses, not more than $75 \%$ of the dead-load stress may be used.

In the case of soil-bearing values for foundations, all codes give due consideration to combined vertical and short-time lateral loading. The usual increase for combined loading is $33 \frac{1}{3} \%$, but Code 1 approves an increase in soil-bearing value not to exceed $66 \% 3 \%$.

C. Preparation of Plans and Construction Inspection

Deficiencies in joints and connections constitute a major cause of seismic damage. This is often identified with inadequate detailing of structural drawings, and because of this, codes generally require all features of the structural framing, which are involved in resisting seismic forces, to be detailed on the working drawings.

The deficiencies referred to are also often attributable to poor construction practices. This has resulted in improved inspection requirements, and in some cases, reductions in allowable stresses are specified when inspection is not continuous.

D. Earthquake Design Loads

In order to specify earthquake design loads, California codes agree in general on the formula

$$
F=C\left(W_{D}+k W_{L}\right)
$$

This formula and its implementation require the following notation:

$$
\begin{aligned}
F= & \text { lateral force of the earthquake (horizontal force induced by seismic ground } \\
& \text { motion) } \\
W_{D}= & \text { total weight of portion considered (vertical dead load, including machinery } \\
& \text { and other fixed loads) } \\
W_{L}= & \text { total live load on portion considered } \\
K= & \text { coefficient dependent on nature of live load } \\
\mathrm{C}= & \text { coefficient dependent on type of structure or part of structure } \\
\mathrm{Z}= & \text { multiplier (relative intensity) of } 1,0.5 \text {, or } 0.25 \text { used for the seismic zones of } \\
& \text { the Code } 4 \text { Seismic -probability Map reproduced in this report as Fig. } 1.10 ; \\
& \text { see also Sec. } 4.12 B \\
\mathrm{~N}= & \text { number of stories above the story under consideration }
\end{aligned}
$$

A comparative tabulation of the coefficients $C$ and $k$ in Eq. 4.2 is given in Table 4.1. The tabulated values of $k$ give a reduction in the amount of live load permissible for computation of the mass contributing to the horizontal seismic force, $F$. In the design of members stressed by floor live loads and seismic forces, the design live load must be assumed to act simultaneously with the seismic forces. These provisions are stated in Code 2 and generally accepted by the other building codes.

It will be noted from this table that Codes 2,3 , and 4 agree on a coefficient $C$, for the entire building or structure, which varies with height in accordance with $\mathrm{N}$, the number of floors. Code 1, which was not evaluated in the table in this regard, goes further and takes into account the dynamics of the problem using seismic coefficients based in part on the earthquake spectrum. In this code the $C$ value for the entire building or structure is made 
a function of the fundamental period of vibration $T$, in seconds, for the direction of motion under consideration. Buildings and structures other than buildings are handled by separate formulas. For buildings, Code 1 gives

$$
\mathrm{C}=\frac{0.02}{\mathrm{~T}}
$$

where $0.035<\mathrm{C}<0.075$.

A semiempirical formula is provided for estimating $T$ and is based on the geometry of the building; under certain conditions this code permits $T$ to be estimated on the basis of technical data.

The use of a moment-resisting structural frame is credited in a provision stating that, under certain conditions, the lateral-force-resisting capacity of such a frame may be deleted from the total required seismic force to determine the required resistance of the other lateral-force-resisting elements.

For structures other than buildings, Code 1 gives

$$
\mathrm{C}=\frac{0.035}{\mathrm{~T}}
$$

where $0.04<\mathrm{C}<0.10$. In this case, $\mathrm{T}$ can either be calculated or substantiated by technical data. In tower-supported structures, such as elevated tanks, 0.10 is the minimum allowable value for $C$.

In Code 1 the horizontal force that is acting at each floor level of a building is obtained on the assumption that the deflection curve is linear with height, which leads to the following expression:

$$
F_{x}=\frac{V W_{x} h_{x}}{\Sigma W h}
$$

Notation used in this formula is as follows:

$F_{x}=$ lateral force applied at any level $\mathrm{x}$

$\mathrm{V}=$ seismic shear at the base, computed from $\mathrm{V}=\mathrm{CW}$, where $\mathrm{C}$ is obtained from Eq. 4.3

$\mathrm{W}_{\mathrm{x}}=$ weight at level $\mathrm{x}$ (dead load plus a portion of the live load) from Table 4.1

$\mathrm{h}_{\mathrm{x}}=$ height in feet of level $\mathrm{x}$ above the base

$\Sigma W_{h}=$ summation of the $W_{x} h_{x}$ values for the full height $h$

Buildings with setbacks receive special treatment under Code 1. The conditions just described still apply, except that in determining the period $T$, the coefficient $k$, and the base shear $\mathrm{V}$, the height used is an average value derived by dividing the area of the elevation of the building, as projected on a plane parallel to the direction considered, by the base width. A tower having a plan area that is less than $25 \%$ of the plan area of the lower level of the building may be designed separately for its own height, width, and weight. In such a case the resulting total horizontal shear from the tower is to be applied at the top of the lower part of the building. The lower part of the building is otherwise considered separately for its own height, width, and weight.

The preceding rules and regulations are the minimum requirements of Code 1 for computation of earthquake forces. If the construction is on marshy or filled ground, whether carried on piles or not, these requirements are increased $25 \%$ unless the footings under the columns are so interconnected as to prevent horizontal displacement. Inter connection consists of a contınuous reinforced-concrete foundation slab or grillage, a system of struts or ties, a reinforced-concrete floor slab, or some other equivalent means 
Table 4.1-SEISMIC COEFFICIENTS FOR BUILDINGS AND OTHER STRUCTURES

(For Use Only in the Equation $\mathrm{F}=\mathrm{C}\left(\mathrm{W}_{\mathrm{D}}+\mathrm{kW} \mathrm{W}\right)$; See Text for Definitions of Terms)

\begin{tabular}{|c|c|c|c|c|}
\hline & \multicolumn{4}{|c|}{$\begin{array}{l}\text { Coefficient } C \text { as stated in } \\
\text { the indicated building code }\end{array}$} \\
\hline & $\begin{array}{c}\text { Code } \\
1\end{array}$ & $\begin{array}{c}\text { Code } \\
2\end{array}$ & $\begin{array}{c}\text { Code } \\
3\end{array}$ & $\begin{array}{c}\text { Code } \\
4\end{array}$ \\
\hline \multicolumn{5}{|l|}{$\begin{array}{l}\text { Entire building or other structures } \\
\text { when the force is from any direction } \\
\text { horizontally: }\end{array}$} \\
\hline $\begin{array}{l}\text { Any type of building or structure } \\
\text { except tanks, towers, and chimneys }\end{array}$ & See text & $0.60 /(N+4.5)$ & $0.60 /(N+4.5)$ & $0.60 \mathrm{Z} /(\mathrm{N}+4.5)$ \\
\hline $\begin{array}{l}\text { Tanks, towers, and chimneys when not } \\
\text { connected to a building }\end{array}$ & See text & 0.20 & 0.12 & $0.10 \mathrm{Z}$ \\
\hline $\begin{array}{l}\text { Anchorage of tanks, towers, and chimneys } \\
\text { when not connected to a building }\end{array}$ & & & 0.20 & \\
\hline \multicolumn{5}{|l|}{$\begin{array}{l}\text { Parts of a building or other structures } \\
\text { when the direction of force is normal } \\
\text { to the wall surface: }\end{array}$} \\
\hline Parapets and other cantilever walls & 0.50 & 1.00 & 1.00 & $1.00 \mathrm{Z}$ \\
\hline Exterior walls, not cantilevered & $0.20 *$ & 0.20 & 0.20 & $0.20 \mathrm{Z}$ \\
\hline Interior walls, not cantilevered & $0.10+$ & 0.20 & 0.20 & $0.20 \mathrm{Z}$ \\
\hline \multicolumn{5}{|l|}{$\begin{array}{l}\text { Parts of a building or other structures } \\
\text { when the force is from any direction } \\
\text { horizontally: }\end{array}$} \\
\hline Ornamentation or appendages & 0.50 & 1.00 & 1.00 & $1.00 \mathrm{Z}$ \\
\hline Wharves & & 0.05 & & \\
\hline \multirow{4}{*}{$\begin{array}{l}\text { Tanks, towers, chimneys, and penthouses } \\
\text { that are connected to or integral with a } \\
\text { building }\end{array}$} & 0.20 & 0.20 & 0.20 & $0.20 \mathrm{Z}$ \\
\hline & \multicolumn{4}{|c|}{$\begin{array}{l}\text { Coefficient } k \text { as stated in } \\
\text { the indicated building code }\end{array}$} \\
\hline & Code & Code & Code & Code \\
\hline & 1 & 2 & 3 & 4 \\
\hline \multicolumn{5}{|l|}{$\begin{array}{l}\text { Parts of a building or other structures } \\
\text { when the force is from any direction } \\
\text { horizontally: }\end{array}$} \\
\hline Roofs of buildings & 0.00 & 0.00 & 0.00 & 0.00 \\
\hline Floors other than storage floors & 0.25 & 0.00 & 0.00 & 0.00 \\
\hline Storage floors & 0.50 & 0.50 & 0.50 & 0.50 \\
\hline Taniks & & & 1.00 & 1.00 \\
\hline $\begin{array}{l}\text { Other structures; instead of coefficient } \\
k \text {, use the normal operating live load } \\
\text { for } k W_{L}\end{array}$ & 1.00 & & & \\
\hline
\end{tabular}

* $W_{D}$ may not be less than that calculated on basis of $15 \mathrm{lb} / \mathrm{sq} \mathrm{ft}$ of wall area.

$+W_{1}$ may not be less than that calculated on basis of $15 \mathrm{lb} / \mathrm{sq} \mathrm{ft}$ of wall area. 


\subsection{E OVERTURNING MOMENTS}

of tying the footings together. All codes have similar foundation tie requirements. Code 4 also requires ties if the soil has a safe bearing value of less than $2000 \mathrm{lb} / \mathrm{sq} \mathrm{ft}$.

E. Overturning Moments

All the codes require that the dead-load moment of stability (righting moment) be at least $1 \frac{1}{2}$ times as great as the overturning moment. As presented in some codes, this rule is written for wind loads, but in each code, by inference at least, it applies to all lateral forces including seismic forces. There is considerable variation in the way the rule is applied. For example, Code 2 excludes righting moments induced by special loading such as vats, tanks, and bins; on the other hand, Code 1 requires that the loads used in calculating both righting and overturning moments be identical.

Code 1 requires that provision for overturning moment and direct stress shall be made for the specified earthquake forces in the top 10 stories of buildings or the top $120 \mathrm{ft}$ of height of other structures and that the moments and direct stresses shall be assumed to remain constant from these levels to the foundations.

F. Distribution of Horizontal Shear

It is a typical requirement that the total horizontal shear at any horizontal plane is required to be distributed to the various resisting elements in proportion to their rigidities, giving due consideration to the distortion of the horizontal distributing elements. ${ }^{4.11}$ Proper provisions should be made for torsional movements unless the center of rigidity of the resisting structural units is coincident with the center of gravity of the vertical loads in the building or other structure. ${ }^{4.21}$

\section{G. Deflections}

Traditionally, building codes place few limitations on deflections that are due to lateral forces. However, in recent years the emphasis on more open structures, on economy through lighter design, and on more generous use of fenestration has resulted in flexible buildings. Such buildings increase the probability of costly nonstructural damage and injury from falling plaster, glass breakage, and other damage to the finish. Code 3 contains provisions intended to limit excessive seismic deflections by requiring that consideration be given to the secondary stresses induced by deflections of a building or its parts when these deflections might create unsafe conditions.

Code 3 limits the amount of deflection of shear walls and similar elements resisting horizontal forces to $1 / 16$ in. per foot of height. Comparable restrictions apply to glazed openings unless special details are used to permit relative movement between glass and frame.

\section{H. Diaphragms}

The main seismic-load-resisting system may be steel, concrete, or wood frame; it may consist of a system of vertical and lateral trussing; or it may consist only of walls, floors, and roofs which are then designed structurally as lateral-load-resisting elements called diaphragms. Diaphragms may be classified as horizontal (floors and roofs), or vertical (walls). In this report the term shear wall is used synonymously with the term vertical diaphragm. The use of floors and roofs as diaphragms is probably a distinctive feature of California practice.

There are many types of diaphragms; the general limitations of each variety vary considerably. Rules governing the use of diaphragms are based mainly on test data. This is especially true in the case of steel decking, where acceptance of new types usually requires load testing and a determination of deflection characteristics to substantiate the validity of any design method used. 
In the case of plywood and diagonal sheathing, rational analysis alone is acceptable as Iong as the shears comply with the allowable code values (which have been based on test results).

No attempt will be made here to detail the requirements for design of all the differ ent kinds of diaphragms. Instead, only the general methods and limits of resistance will be noted for a few of the types most usually found in practice. For actual design pur poses the codes themselves should be consulted and so should various trade publications such as those listed in the bibliography.

Diaphragm flexibility is controlled by limiting the length-to-width ratios and by limiting maximum stresses. Only stress limitations are specified in Code 2. Table 4.2 gives a typical sampling of code restrictions on length-to-width ratios. These ratios are often of basic interest in a building layout.

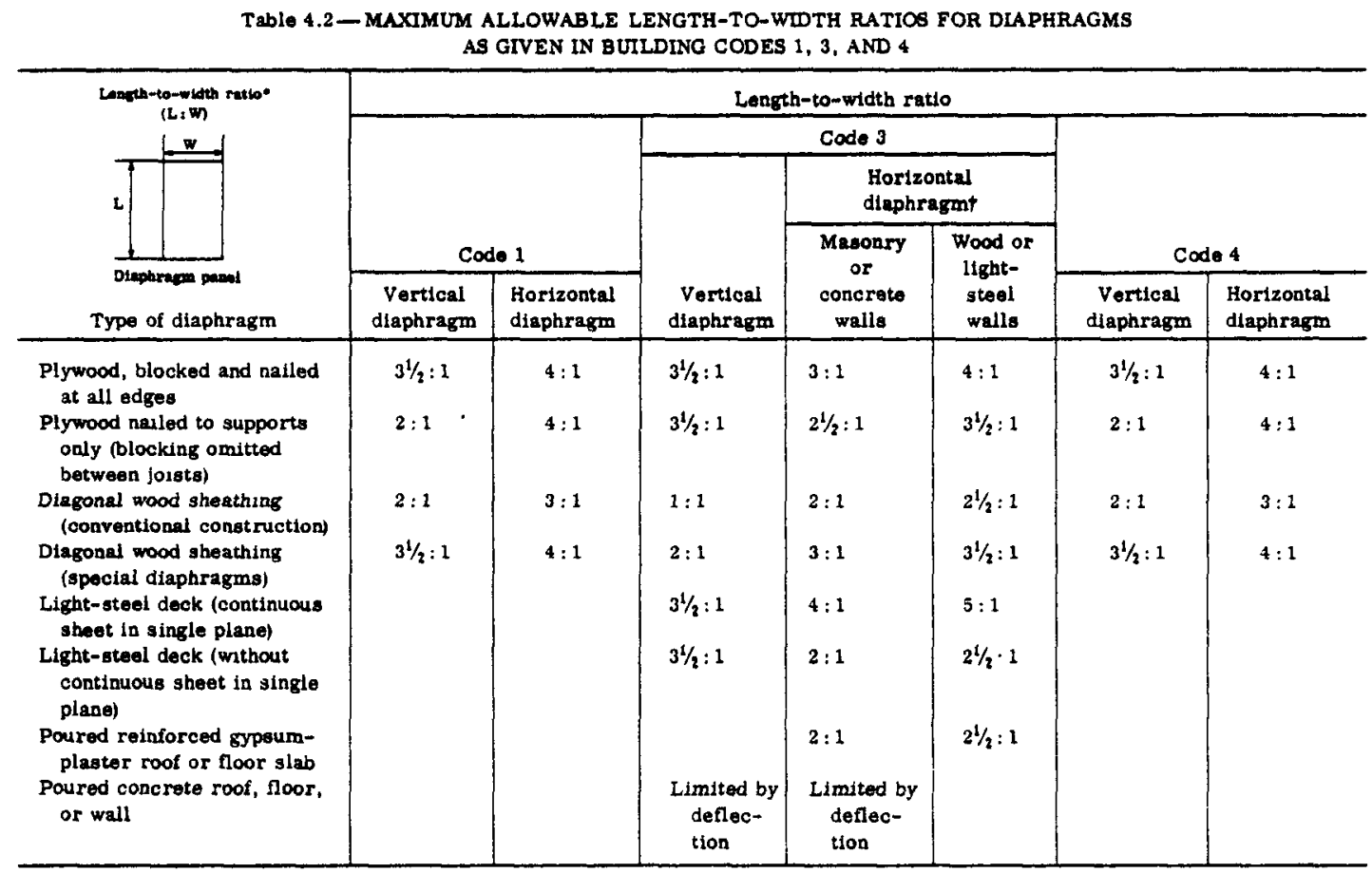

* $L$ = length (horizontal diaphragm); $L=$ height (vertical diaphragm).

† Ratio varies with type of supporting wall.

It is customary to utilize walls or parts of walls as shear-resisting elements to transmit lateral forces from higher levels to the ground. Code provisions sometimes limit the spacing of these elements when flexible diaphragms are used. For example, Code 3 specifies the use, under certain conditions, of one such element in each 150-ft length of wall. This rule applies where horizontal wood diaphragms or rod bracing systems are used to brace buildings with continuous steel or reinforced-concrete framing. This rule also applies to buildings with continuous, reinforced grouted masonry walls. When the framing is wood, the spacing is reduced to $100 \mathrm{ft}$, and additional resisting elements are required. These additional elements must be normal to those previously mentioned and must be spaced so as to divide the diaphragm above into bays having length-to-width ratios that comply with the requirements of Table 4.2 . The spacing requirements of Codes 1,2 , and 4 are less restrictive. 
Wood and plywood diaphragms are designed as beams so that the web (sheathing boards or plywood) will carry shear and the flanges (plates or other framing members) at the edges will resist the bending moment.

Connections and anchorages capable of resisting the design forces are required between the diaphragms and the resisting elements. Openings and edge conditions, which materially affect strength, require complete detailing to show that the shearing stresses will be developed.

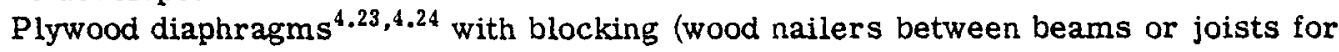
fastening the panel edges) detailed according to code can be assumed to resist seismic shears ranging from a lower limit of $124 \mathrm{lb} / \mathrm{ft}$ for $1 / 4$-in. -thick plywood (in accordance with Code 2) up to $820 \mathrm{lb} / \mathrm{ft}$ for $1 / 2$-in. -thick plywood (in accordance with Code 4). Under certain conditions the upper limit can be raised still higher.

Code 1 states that, when blocking is omitted from plywood diaphragms and the panels are arranged so that the load is applied perpendicular to the unblocked edges and to the continuous panel joints, resistance to shear is reduced depending on the nail spacing, to values ranging from $2 / 3$ to $\frac{1}{2}$ of the above figures.

Each of the codes in effect classifies diagonally sheathed diaphragms as conventional (meeting minimum structural requirements only) or special (incorporating special engineering features to increase shear resistance). In addition, Code 2 defines a 2 -in. plank diaphragm, permitting allowable stresses higher than those for conventional, and lower than those for special, as a diagonally sheathed diaphragm.

Diagonally sheathed wood diaphragms in conventional construction are fundamentally 1 - by 6 -in. or 1 - by 8 -in. boards which are laid at $45^{\circ}$ to the studs, joists, or rafters and which are nailed to them and to the boundary members with a specified number of nails through each board at each bearing. Boundary members at edges of such diaphragms must be designed to resist direct tensile or compressive chord stresses and must be adequately tied together at corners. These are minimum structural requirements. Shears up to 300 $\mathrm{lb} / \mathrm{ft}$ depending on the panel ratio, are permissible for this kind of diaphragm under all four codes.

The special diagonally sheathed wood diaphragms must conform to these same minimum structural requirements. In addition, the component of the axial stress in the boards acting normal to a boundary member must be accounted for in the design of the boundary member itself and in its attachments. Such special diagonally sheathed diaphragms, and comparable double diagonally sheathed diaphragms, may be used to resist shears due to wind or seismic loads up to $500 \mathrm{lb} / \mathrm{ft}$ according to Code 4 and up to $600 \mathrm{lb} / \mathrm{ft}$ according to the three other codes.

The use of steel-deck diaphragms, with welded seams at the edges of each sheet, is permitted by all four codes. Codes 1,2 , and 4 rely on official full-scale acceptance tests, ${ }^{4.25,4.26}$ on the basis that the important structural properties of a steel-deck diaphragm (especially its load-deflection characteristics) may not be in many cases satisfactorily determined by a rational analysis. This results in the granting of definite maximum allowable shears for a diaphragm of a particular cross-sectional configuration when certain welding details and other features are fully specified.

These individual rulings are not presented in the code itself; but they are retained in the files of the code authority. This information is available to the designer upon request.

Code 3 also utilizes rulings based on tests. However, if test data are lacking, structural analysis according to certain assumptions which show that the shears and deflections are below certain limits may be accepted. These shears vary with the configuration of the panel. Allowable shears for welds are also specified.

Poured gypsum decks (reinforced) are accepted as diaphragms on a test basis ${ }^{4.27}$ similar to that prevailing in the case of light-steel deck diaphragms. When test data are lacking, Code 3 permits an analysis which is similar to that for reinforced concrete but which is modified to account for the lower structural properties of gypsum. Minimum thickness, reinforcement, and anchorage to boundary members are specified. 
Reinforced concrete is the most rigid of conventional diaphragms and has the most liberal panel-ratio limitations. The codes place restrictions on the spacing of lateral supports in terms of slab thickness. The codes also specify minimum slab thickness. Codes 1 and 3 restrict the allowable shear as a function of thickness and support spacing. Where precast construction is used, all codes specify requirements for the joints between the precast units. In other respects the design of reinforced-concrete diaphragms follows that for conventional reinfor ced-concrete construction. 4.16

\section{Masonry Shear Walls}

Masonry shear walls are usually constructed of reinforced brick or reinforced concrete. All codes require both vertical and horizontal steel at certain maximum spacings and in minimum amounts expressed as percentages of the wall cross-sectional area. A part of the horizontal steel is required to be concentrated in bond beams and footings and at tops of parapet walls. All reinforcing must be completely embedded in the grouting material.

Design methods specified are those used for reinforced concrete but are modified for the conditions and working stresses appropriate to masonry. Working stresses vary with the strength of the units and with the type of inspection provided and are lower than those used in the design of reinforced concrete.

Codes 1,2 , and 4 have no requirements prohibiting the use of unreinforced masonry, provided the stresses do not exceed specified values. However, the use of this material is rare in earthquake areas.

Code 3 completely disavows the use of unreinforced masonry, obviously on the basis of the poor performance of this material in strong earthquakes. This code also restricts the use of reinforced holiow masonry to nonbearing partitions unless all cells are filled.

The statements made in this section are also applicable to masonry walls other than shear walls.

J. Anchorage

All seismic codes require that concrete or masonry walls be positively anchored to all floors and roofs that provide lateral support. Such anchorage is required by Code 4 to be capable of resisting the calculated horizontal forces due to wind or earthquake with a minimum force of $200 \mathrm{lb}$ per lineal foot of wall.

K. Structural Separation

Typically the codes require that adjacent buildings be structurally separated (1) by a minimum distance that is specified arbitrarily in the particular code having jurisdiction and (2) in a manner that is satisfactory ${ }^{4.22}$ to the building official who issues the building permit. Typical separation details are discussed in Sec. 4.10D. However, if the building complex is properly designed to act integrally in resisting lateral forces, separation requirements are waived.

L. Foundation Ties

In the case of major structures supported on pile foundations, the codes require foundation ties under certain conditions. Codes 1, 2, and 4 apply this requirement to all pile foundations, whereas the Code 3 provision applies only to pile foundations involving poor soil conditions. In addition, Codes 1 and 4 require such ties for all isolated footings where the soil has a bearing value less than $2000 \mathrm{lb} / \mathrm{sq} \mathrm{ft}$.

The ties can be formed by an interconnecting grid network of reinforced-concrete struts or structural steel shapes encased in concrete. These are designed for an axial tension or compression equal to $10 \%$ of the vertical load carried by the heavier of the two footings connected. 


\subsection{RELATION OF BUILDING CODES TO REACTOR DESIGN}

As an alternative, a reinforced-concrete slab with specified minimum thickness and reinforcing may be used in lieu of the grid network.

\subsection{RELATION OF BUILDING CODES TO REACTOR DESIGN}

The stated purpose of codes is to "provide minimum standards to safeguard life or limb, health, property, and public welfare by regulating and controlling the design, construction, quality of materials, use and occupancy, location and maintenance of all buildings and structures within the city, and certain equipment specifically regulated herein." ${ }^{, 4.22}$ The lateral-force coefficients of codes are minimum standards and are not intended to prevent overstress. In the event of a strong earthquake, these coefficients will not always prevent overstress and especially not in structures with low damping and few uncounted sources of reserve strength. Furthermore, it must be remembered that building codes are frequently revised, and therefore the code provisions discussed in the foregoing sections merely represent the status at the time this chapter was written.

A. Use of Seismic Coefficients

Whether the code coefficients are acceptable or not depends (1) on an estimate of the consequences of possible damage due to the use of such coefficients and (2) on the cost increase incurred by provisions for larger seismic forces, if such provisions are required to hold damage within tolerable limits. In some cases the answer is immediately obvious; in other cases it may require the investigation of a complete chain of events that are triggered by structural damage, as well as the preparation of alternate designs and cost estimates.

In important cases it is not uncommon to use static lateral-force coefficients considerably higher than code values, where the installation must continue to function during and after a strong earthquake. For example, critical elements of conventional electric power generating plants in seismic areas are sometimes designed using a seismic coefficient of $0.20 \mathrm{~g}$.

For structures that are to be designed so that the stresses will remain within elastic limits during earthquakes of specified intensities, a dynamic analysis will give better design forces than those specified by building codes. It is very difficult, however, to make a dynamic analysis of a structure that is overstressed into the nonelastic range. Dynamic analysis can possibly be justified only in the case of very special structures. For ordinary structures, designs based on equivalent static lateral forces, as specified in building codes, are satisfactory if it is recognized that some damage may be incurred in the case of especially strong ground motion.

Refinement in choosing the proper seismic force should not be undertaken at the expense of providing complete load paths of consistent strength. The seismic resistance of a structure depends not only on the horizontal forces assumed in the design, but also on what is done with those forces. Seismic damage very often results from superficial treatment of the details needed to transmit the loads; it results less often from lack of precision in estimating the magnitude of the earthquake forces to be used in design.

B. Seismic Zoning Provisions

The inherent lack of precision in assessing seismicity of a site and the uncertain influence of local geology have previously been discussed in Secs. 1.1G, 1.2D, 1.3I, and 3.9. With these limitations in mind, it is believed that the seismic zoning map in Fig. 1.10 can be used as a rough guide in estimating relative seismicity, but with the restriction that no zone in the United States can be considered entirely immune from earthquakes. This restriction is not considered unreasonable, in view of the proven fact that historically stable areas do not necessarily remain so. Requirements for considering minimum seismic forces in areas where they are now ignored would have an important effect in improving 
the methods of supporting items of equipment, especially those housed within structures, which are often not even checked for wind loading. A minimum seismic requirement would in many cases result in design loads, even for masonry buildings, which are less than those due to wind.

It may be argued that, in view of the very violent earthquakes which have infrequently occurred in supposedly stable areas, minimum earthquake provisions would be no better than none at all. The answer here is that lack of earthquake provisions sometimes produces conditions and practices that result in no positive means whatever for resisting lateral forces in key parts of the installation. In these cases the use of minimum seismic requirements at least provides load paths that would otherwise be lacking. This is a marked improvement, even if damage occurs, since it increases the chance of survival from zero to some finite amount.

In the design of nuclear reactor projects to be located in seismically active areas, the services of a seismologist should be used in evaluating seismicity. However, where more definite information is not available, it is suggested that the relative intensity of earthquakes in damage Zones 1, 2, and 3 of Fig. 1.10 be as specified in Ref. 4.22 but that the intensity for Zone 0 be increased to that applying for Zone 1 . On this basis the relative intensities for the various zones would be as shown in Table 4.3.

\begin{tabular}{cc}
$\begin{array}{c}\text { Table } \\
4.3-\text { RELATIVE INTENSITIES } \\
\text { FOR VARIOUS ZONES }\end{array}$ \\
\hline $\begin{array}{cc}\text { Damage } \\
\text { zone }\end{array}$ & $\begin{array}{c}\text { Relative } \\
\text { intensity, } \mathrm{Z}\end{array}$ \\
\hline 0 & 0.25 \\
1 & 0.25 \\
2 & 0.5 \\
3 & 1 \\
\hline
\end{tabular}

The values in the second column of Table 4.3 are the multipliers, $Z$, previously described in Sec. 4.11D. They are used as indicated in Table 4.1 to obtain static seismic coefficients. They can also be used in connection with the spectra of Figs. 1.19 to 1.24, which apply to Zone 3 conditions, to approximate spectral values for other zones by assuming that the ordinates to the spectra curves are proportional to the $Z$ values.

The reduction of the relative intensity below that specified for a given damage zone, on the basis that the site is remote from known faults, may not be good practice. Such a reduction usually cannot be justified by the accuracy with which the relative intensities can be evaluated.

The average spectra of Figs. 1.19 to 1.24 are based largely on the records of the El Centro earthquake, 1940, which is the most intense ground motion (in the United States) for which accelerograms are available. These records are often considered to represent the strongest probable ground motion for Zone 3. The maximum horizontal acceleration of this earthquake was $0.33 \mathrm{~g}$.

The probability of occurrence of earthquakes vs. magnitude was also discussed in Sec. 1.2E, in which it was indicated that an upper limit to the magnitude of an earthquake appears to be $M=8.7$. A comparison of this maxumum magnitude with the magnitudes of the earthquakes at San Franc1sco, 1906, and El Centro, 1940, is shown in Table 4.4. The maximum intensity of ground motion associated with the maximum earthquake cannot be accurately established but is estimated by Housner to be from two to three times that of the El Centro earthquake, 1940. From this it follows that the ordinates to the spectra for such an earthquake might be two to three times those shown in Figs. 1.19 to 1.24.

It is probable that a structure designed to resist an earthquake of the El Centro 1940 intensity (maximum probable earthquake for Zone 3) with slight structural damage could 
also survive the ground motion of an earthquake of magnitude 8 without collapse, although major rehabilitation might be required. Only in rare instances would it be feasible to provide a resistance sufficient to withstand an earthquake of this magnitude with no damage.

\begin{tabular}{lcc} 
Table 4.4-COMPARISON OF EARTHQUAKE MAGNITUDES \\
\hline Earthquake & Magnitude & $\begin{array}{c}\text { Frequency per } \\
\text { 200 years }\end{array}$ \\
\hline Maximum & 8.7 & 0 \\
San Francisco, 1906 & 8.2 & 1 \\
El Centro, 1940 & 6.7 & 63 \\
\hline
\end{tabular}

C. Detailed Seismic Provisions of Codes

Many of the practices required by the detailed seismic provisions of building codes have been developed through experience, and, although they are often arbitrary, these provisions may provide answers in situations where a rational solution is impractical. For this reason they can be used as a guide in the seismic design of reactors.

Where code static seismic coefficients are used, the allowable stresses should not exceed those specified in the detailed provisions of the code. When a more refined approach is applied in cases where the properties of the structure can be accurately estimated, it is reasonable to increase allowable stresses above code values.

\section{REFERENCES}

4.1 Analysis of Small Reinforced Concrete Buildings for Earthquake Forces, Portland Cement Association, 33 West Grand Avenue, Chicago, 1955.

4.2 H. C. Plummer and J. A. Blume, Reinforced Brick Masonry and Lateral Force Design, 1st ed., Structural Clay Products Institute, Washington, D. C., 1953.

4.3 Recommendations - Earthquake Resistant Design of Buildings, Structures and Tank Towers, Pacific Fire Rating Bureau, San Francisco, revised 1950.

4.4 D. E. Hudson, J. L. Alford, and G. W. Housner, Measured Response of a Structure to an Explosive-generated Ground Shock, Bull. Seismol. Soc. Am. (1954).

4.5 G. W. Housner, Behavior of Structures in Earthquakes, Modern Designing with Steel, Vol. 3, No. 2, Kaiser Steel Corp., May 1957.

4.6 G. W. Housner, The Design of Structures To Resist Earthquakes: Earthquakes in Kern County, California, During 1952, Bull. 171, State of California, Department of Natural Resources, Division of Mines, San Francisco, 1955.

4.7 L. C. Maugh, Statistically Indeterminate Structures, John Wiley \& Sons, Inc., New York, 1946.

4.8 L. E. Grinter, Theory of Modern Steel Structures, Vol. II, revised ed., The Macmillan Company, New York, 1949.

4.9 H. Sutherland and H. L. Bowman, Structural Theory, 4th ed., John Wiley \& Sons, Inc., New York, 1950.

4.10 Horizontal Bracing Systems in Bulldings Having Masonry or Concrete Walls, Tech. Bull. No. 1, Structural Engineers Association of Southern Californı, 1950.

4.11 Californıa Administrative Code, Title 21, Public Works, State of California, Sacramento, Calif., 1958.

4.12 Concrete Masonry Design Manual, Concrete Masonry Association, 3250 West Sixth Street, Los Angeles, 1955. 
4.13 Good Practice in Engineering Design and Construction with Reinforced Concrete Masonry, Tech. Bull. No. 3, Structural Engineers Association of Southern California, 1950.

$4.14 \mathrm{~K}$. V. Steinbrugge and D. F. Moran, An Engineering Study of the Southern California Earthquake of July 21, 1952, and Its Aftershocks. Bull. Seismol. Soc. of Am., 44(2B): 2nd pt. (1954).

4.15 H. J. Degenkolb, Structural Observations of the Kern County Earthquake, Trans. Am. Soc. Civil Engrs., Paper No. 2777, (1955).

4.16 Building Code Requirements for Reinforced Concrete (ACI 318-56). J. Am. Concrete Inst., P. O. Box 4754, Redford Station, or 18263 West McNichols Road., Detroit 19, Mich.

4.17 Tilt-up Construction, Tech. Bull. No. 2, Structural Engineers Association of Southern California, 1950.

4.18 A. Zeevaert, The Latino Americana Building, in Proceedings of the Twenty-Sixth Annual Convention, Structural Engineers Association of California, Coronado, Calif., 1957.

4.19 F. S. Merritt, Earthquake Revealed Defects in Design, Eng. News-Record (1957).

4.20 San Francisco Building Code, 1958, City and County of San Francisco.

4.21 Los Angeles City Building Code, 1957, Uniform Building Code Association, Inc., 610 South Broadway, Los Angeles.

4.22 Uniform Building Code, 1958, Pacific Coast Building Officials Conference, 610 South Broadway, Los Angeles.

4.23 Technical Data on Plywood, Douglas Fir Plywood Association, Tacoma, Wash.

4.24 Fir Plywood Design Data, Douglas Fir Plywood Association, Tacoma, Wash.

4.25 S. B. Barnes, Report on H. H. Robertson Co. Steel Q-Floor Tested as a Diaphragm, H. H. Robertson Co., 2330 West Third Street, Los Angeles, 1949.

4.26 Fenestra Building Panels - Fenestra Diaphragm Design, Seismic, Wind, Bomb, Detroit Steel Products Co., 2250 East Grand Boulevard, Detroit, January 1955.

4.27 S. B. Barnes, Extracts from Report on Tests of Poured Gypsum as a Horizontal Diaphragm, Tests for United States Gypsum Co., 1888 S. W. Sixth Avenue, Portland Ore., February 1955.

\section{ADDITIONAL REFERENCE MATERIAL}

Proceedings of Second World Conference on Earthquake Engineering, Science Council of Japan, Tokyo, Japan, 1960. 


\section{Chapter 5}

\section{SEISMIC-RESPONSE CALCULATIONS FOR SIMPLE TYPES OF STRUCTURES}

\begin{tabular}{|c|c|}
\hline & \\
\hline & \\
\hline & \\
\hline & \\
\hline & 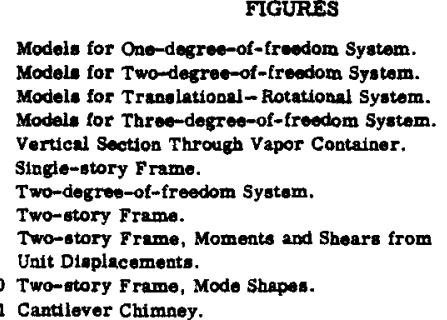 \\
\hline
\end{tabular}

\subsection{INTRODUCTION}

In this section simple structural types are classified according to the number of degrees of freedom of motion involved. Dynamic methods of analysis based on the earthquake spectrum are presented for each class of structure and demonstrated with simple numerical examples. In general, these approaches emphasize some of the special techniques appropriate in application to components whose integrity is vital to the prevention of a nuclear incident.

The determination of seismic effects on a structure using dynamic methods requires simplifying assumptions and idealization to formulate a problem that lies within the capability of known methods of solution. These simplifications, in effect, involve the substitution of a model for the structure, and the response determined is that of the model. The success of this idealization obviously depends on how well the physical properties of the model duplicate those of the actual structure; the simulation may not be adequately provided by a simple model if the actual structure is complex.

However, the fact that an earthquake may be considered as a random phenomenon es tablishes an upper limit to the accuracy attainable, regardless of differences in the behavior between model and structure. From this viewpoint a solution can often be considered adequate if the model and analysis chosen indicate only the main general features of the actual structural motion.

Many of the principal structures involved in reactor installations can be classified as simple types indicative of the kind of model used to represent their dynamic behavior.

These models may be systems having one or more degrees of freedom, appropriate to structures consisting mainly of masses concentrated at one or more definite levels; or 
they may be elastic bodies, appropriate to structures with essentially uniform mass distribution; or they may be a combination of the two. A very stiff structure firmly attached to the earth can be represented simply as a rigid body.

In the following sections, dynamic methods of analysis are presented for the rigidbody type, for lumped-mass systems with one and two degrees of freedom, and for elastic bodies. A simple numerical example is presented for each type to illustrate the method of analysis, with computations carried to slide-rule accuracy. Finally, the limit-design approach is applied to the inelastic response of a structure with one degree of freedom.

\subsection{CONSIDERATIONS IN USING THE SPECTRUM METHOD}

A. Choice of Spectra

For purposes of illustration the examples in this chapter are based on the spectra of Figs. 1.19 to 1.24 , which are considered to represent the maximum probable earthquake for zone 3 conditions. These spectra require modification so that they may apply to other zones, as discussed in Sec. 4.12B. For example, if the $S$ value for zone 3 (as obtained from Fig. 1.19) is $1 \mathrm{ft} / \mathrm{sec}$, the value appropriate to zone 2 would be $0.50 \mathrm{ft} / \mathrm{sec}$, and for zones 1 and 0 the $S$ value would be $0.25 \mathrm{ft} / \mathrm{sec}$.

\section{B. Resultant vs. Component Spectra}

It is customary to use records of horizontal acceleration components measured in directions $90^{\circ}$ apart to obtain two spectra, one for each component. The discussion of spectra and their implications in this report refers to a single component, and it must be kept in mind that a structure will at the same time be excited into vibrations by the perpendicular component. The maximum stress in a simple oscillator resulting from the twocomponent motion would have an upper limit of $\sqrt{2}$ times that produced by a single component. This limit would occur only in the improbable case in which the hypothetical single-mass oscillator used in deriving the spectra would reach its maximum response to each component accelerogram at the same instant. A more realistic value of this ratio probably would be about 1.2 .

In this report the smoothed average spectra of Figs. 1.19 to 1.24 have been used. These are component spectra. In assessing the importance of the error resulting from the use of component spectra, the following considerations are involved.

(1) It is impossible to predict the intensities of future earthquakes.

(2) There are statistical variations in spectra of the earthquakes of the same intensity.

(3) Variations in structural properties from those assumed can cause errors in response which might exceed $20 \%$. Typical yield stresses are usually higher than the minimum specified values normally used. These values are further increased by rapid strain rates occurring under dynamic loading conditions.

Based on these considerations, it may not be unreasonable to design for a single component of motion when the resulting error is accepted as being within the limits of accuracy attainable by computation. Although such a philosophy has been adopted in this report, it is recognized that there can be important cases where absolute safety is im perative, which may justify designing for the two-component spectra simultaneously.

\section{Damping Factors}

The spectrum method requires the assumption of the fraction of critical damping, $\zeta$, for each mode considered. At present there are very little data on which to base such an assumption.

Reasonable values of $100 \zeta$ (damping factor in per cent of critical) appear to be as shown in Table 5.1. 
TABLE 5.1 - DAMPING FACTORS

\begin{tabular}{ll}
\hline \multicolumn{1}{c}{ Type of structure } & $1005, \%$ critical \\
\hline Bare steel structures, ${ }^{*}$ welded & 0.5 to 2 \\
Bare steel structures, ${ }^{*}$ riveted & 2 to 3 \\
Concrete structures & 7 \\
Masonry structures & 15 to 40 \\
Fluid containers, ground supported & 0.5 \\
Fluid containers, elevated $\dagger$ & \\
\hline
\end{tabular}

*Bare signufies no fireproofing.

†See Sec. 6.6.

For simplicity it is recommended that $\zeta$ be assumed the same for each mode. An exception might be made in the case of elevated fluid containers, as discussed in Sec. 6.6.

D. Structures and Equivalent Models

Figures 5.1 to 5.4 are presented to demonstrate in some detail the concept of representing a simple lumped-mass structure by a dynamic model. The mass, $m$, in the model is equal to that in the actual structure. The $\mathrm{k}$ values shown in Figs. 5.1 to 5.4 represent the spring constant, or the spring force, produced by a unit displacement of the mass. For example, the flexural spring in (b) of Fig. 5.1 represents the columns of the actual structure in (a) of Fig. 5.1. Its spring constant, $k$, is numerically equal to the horizontal force, $\mathrm{H}$, that must be applied to the structure in (a) of Fig. 5.1 to give a unit horizontal deflection at the top of the columns.

As a second illustration, the guyed structure in (c) of Fig. 5.1 is equivalent to the model in (d) of Fig. 5.1. The structure consists of the mass, $m$; a flexural spring of constant, $k$, representing the tower; and a compression-tension spring of constant, $k^{\prime}$, representing the guys. The sum of these two spring constants represents the horizontal force, $\mathrm{H}$, required to produce a unit horizontal deflection at the top of the tower. A part of this force is contributed by the shear in the tower itself and is identified with the spring constant $\mathrm{k}$. The remainder is contributed by the horizontal component of the reaction developed in the guys and is identified with the spring constant $\mathrm{k}^{\prime}$.

The model in (e) of Fig. 5.1 is the equivalent of that in (d), and the model in (f) is the equivalent of that in (b). Thus the structures in (a) and (c) can also be represented by a mass with a compression-tension spring.

Similar considerations apply to the two mass systems in Fig. 5.2 , in which it is assumed that the horizontal shears in each story depend solely on the relative lateral displacement of immediately adjacent levels. The structure in (a) can be represented by the model in (b). The spring constant $k_{b}$ is the horizontal shear in the upper story of the structure in (a) which results when level b is displaced laterally a unit distance, with lateral translation prevented at level a. The spring constant $\mathrm{k}_{\mathrm{a}}$ is the horizontal shear in the lower story which results from a unit lateral displacement of level a, with lateral translation prevented at level $b$. The total horizontal force induced at level $a$ is the sum of $\mathrm{k}_{\mathrm{a}}$ and $\mathrm{k}_{\mathrm{b}}$.

The guyed structure in (c) is represented by the model in (d), where the guys are accounted for by springs with constants $k_{a}^{\prime}$ and $k_{b}^{\prime}$. The total horizontal force required at level $b$ to produce a unit translation at that point, with level a restrained, is the sum of $k_{b}^{\prime}$ and $k_{b}$. Similarly, when level $a$ is translated $a$ unit distance with level $b$ restrained, the total force developed at level $a$ is the sum of $k_{b}, k_{a}^{\prime}$, and $k_{a}$. A model equivalent to (d) is shown in (e).

In (a) of Fig. 5.3 is shown a more complex structure, in which, owing to one-fold structural dissymmetry, vibrations in direction $\mathrm{x}$ can be accompanied by rotation about vertical axis $z$. The structure, supporting masses $m_{a}$ and $m_{b}$, consists of three frames 


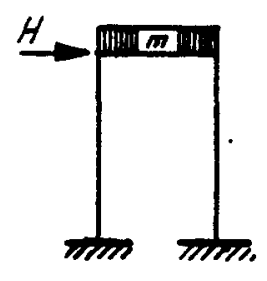

(a)

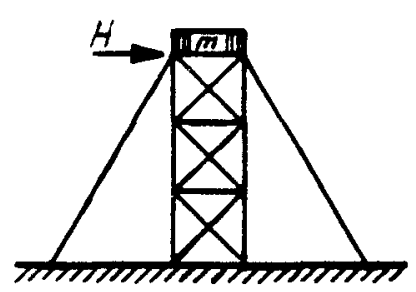

(c)

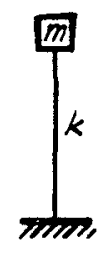

(b)

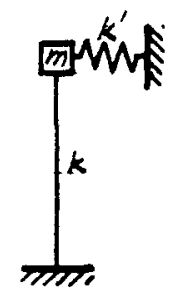

(d)

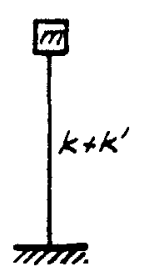

(e)

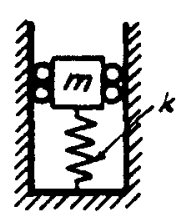

(f)

Fig. 5.1-Models for one-degree-of-freedom system.

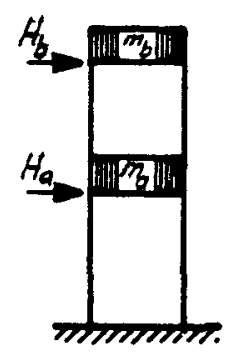

(a)

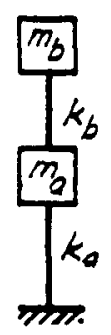

(b)

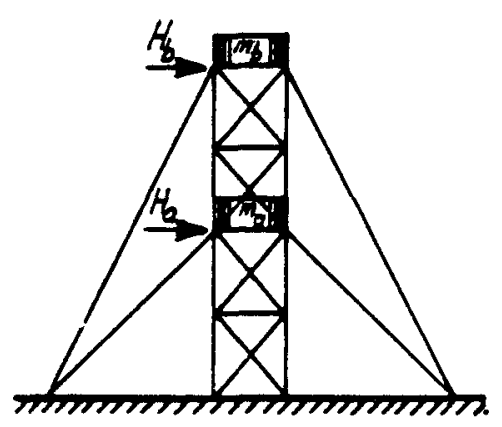

(c)

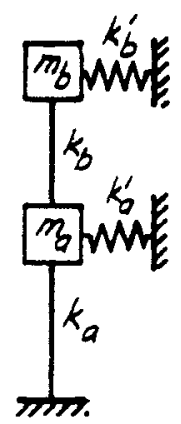

(d)

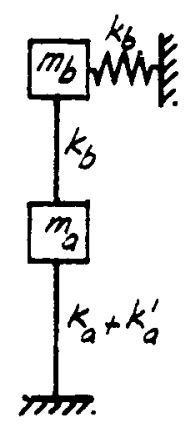

(e)

Fig. 5.2-Models for two-degree-of-freedom system. 

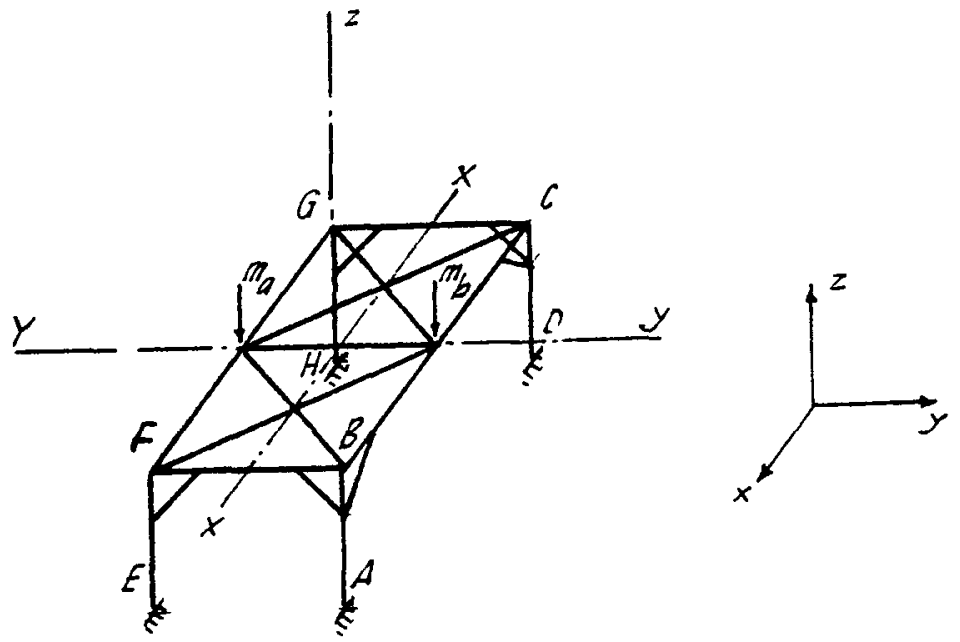

(a)

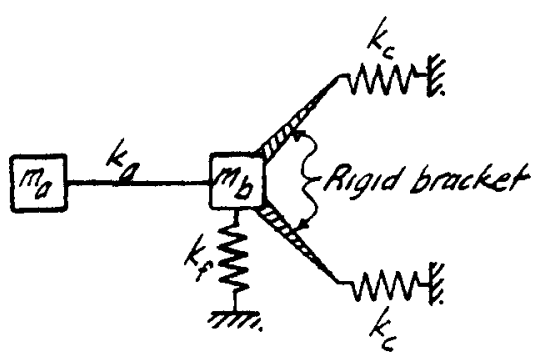

(b)

Fig. 5.3-Models for translational-rotational system.

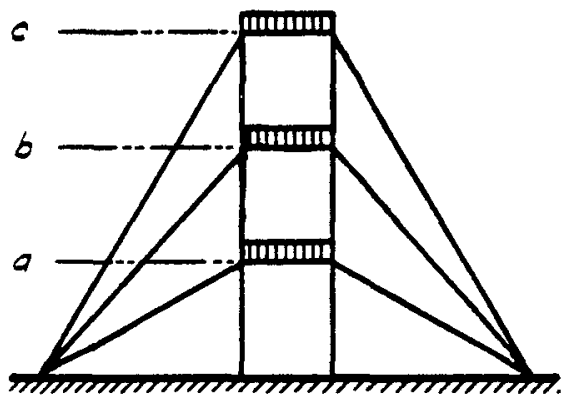

(a)

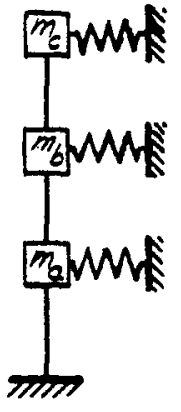

(b)

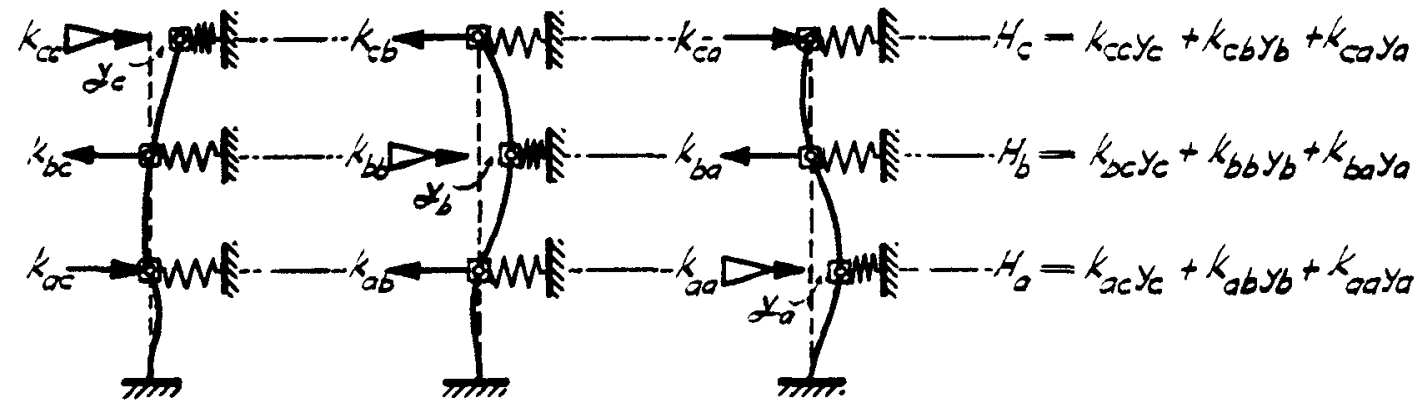

(c)

Fig. 5.4-Models for three-degree-of-freedom system. 
capable of resisting horizontal forces acting in their respective planes and connected to a trussed diaphragm in plane FC. One frame is located in plane AC, and the two side frames, of equal rigidity, are located in planes AF and DG. The frame in plane EG is assumed to have no lateral resistance. Consequently vibrations induced in direction $\mathrm{x}$ will be accompanied by rotation since the center of mass and the center of rigidity do not coincide.

In (b) of Fig. 5.3 is shown a dynamic model simulating the actual structure. Spring constants $k_{a}, k_{c}$, and $k_{f}$ are associated with the diaphragm, the two side frames, and the frame in plane $A C$, respectively.

In strongly coupled structures with two or more degrees of freedom, a unit displacement at any given level can cause significant horizontal forces at levels beyond those immediately adjacent to the displaced level. Under these circumstances the total force acting at each level is not simply a function of the tributary spring constants. A system of this type, with three degrees of freedom, is shown in Fig. 5.4. The double subscripts in (c) of Fig. 5.4 denote force per unit displacement; the first letter indicates the level at which the force is measured, and the second indicates the displaced level. Thus $k_{c c}$ is the force at level $c$ due to a unit displacement of level $c ; k_{c 2}$ is the force at level $c$ due to a unit displacement at level a. The total force at any given level, represented by the symbol $\mathrm{H}$ with a single subscript, is the sum of those contributed by the displacements at all levels including the given level.

\subsection{RIGID-BODY STRUCTURES}

As shown in Fig. 1.21, maximum accelerations for any degree of damping are obtained in oscillators with periods of vibration, $T$, in the range of 0.2 to 0.4 sec. It is also evident from Fig. 1.21 that, when $T$ is less than about $0.05 \mathrm{sec}$, a good approximation of the earthquake effect is obtained by assuming $T$ to be zero. This is equivalent to assuming a structure of infinite rigidity. Under these circumstances the maximum horizontal acceleration of the structure is the maximum horizontal acceleration of the ground; and, at any level, a horizontal shear is induced which is proportional to the weight of the structure above that level. This is the condition assumed in the usual static "\% $\mathrm{g}$ " type of analysis.

Typical of this type of structure are containment vessels and pressure vessels of low height-to-diameter ratio, which are directly attached to a rigid foundation. The following example, representing a small reactor-containment vessel, is included as an illustration of the static-analysis procedure.

\section{Example 1}

Determine the maximum shear, bending moment, and resulting stresses in the structure shown in Fig. 5.5 due to an earthquake having a maximum acceleration of $0.33 \mathrm{~g}$.

\section{Solution}

Values of moments and shears are given in Table 5.2.

Maximum stresses at top of footing

Assume that the concrete is reinforced and well bonded to the steel shell. Ignoring the $1 / 8$-in. liner plate, the transformed area in terms of concrete is

$$
\begin{aligned}
A_{T} & =A_{C}+n A_{S} \quad(n=10=\text { assumed ratio of modulus of elasticity of steel to concrete }) \\
A_{T} & =3.14(28)(2)+10(3.14)(30.1)(1 / 12)=176+78.8 \\
& =254.8 \mathrm{ft}^{2}=36.7 \times 10^{3} \text { in. }^{2} \\
I_{T} & =I_{C}+\mathrm{nI}_{S}
\end{aligned}
$$




\subsection{RIGID-BODY STRUCTURES}

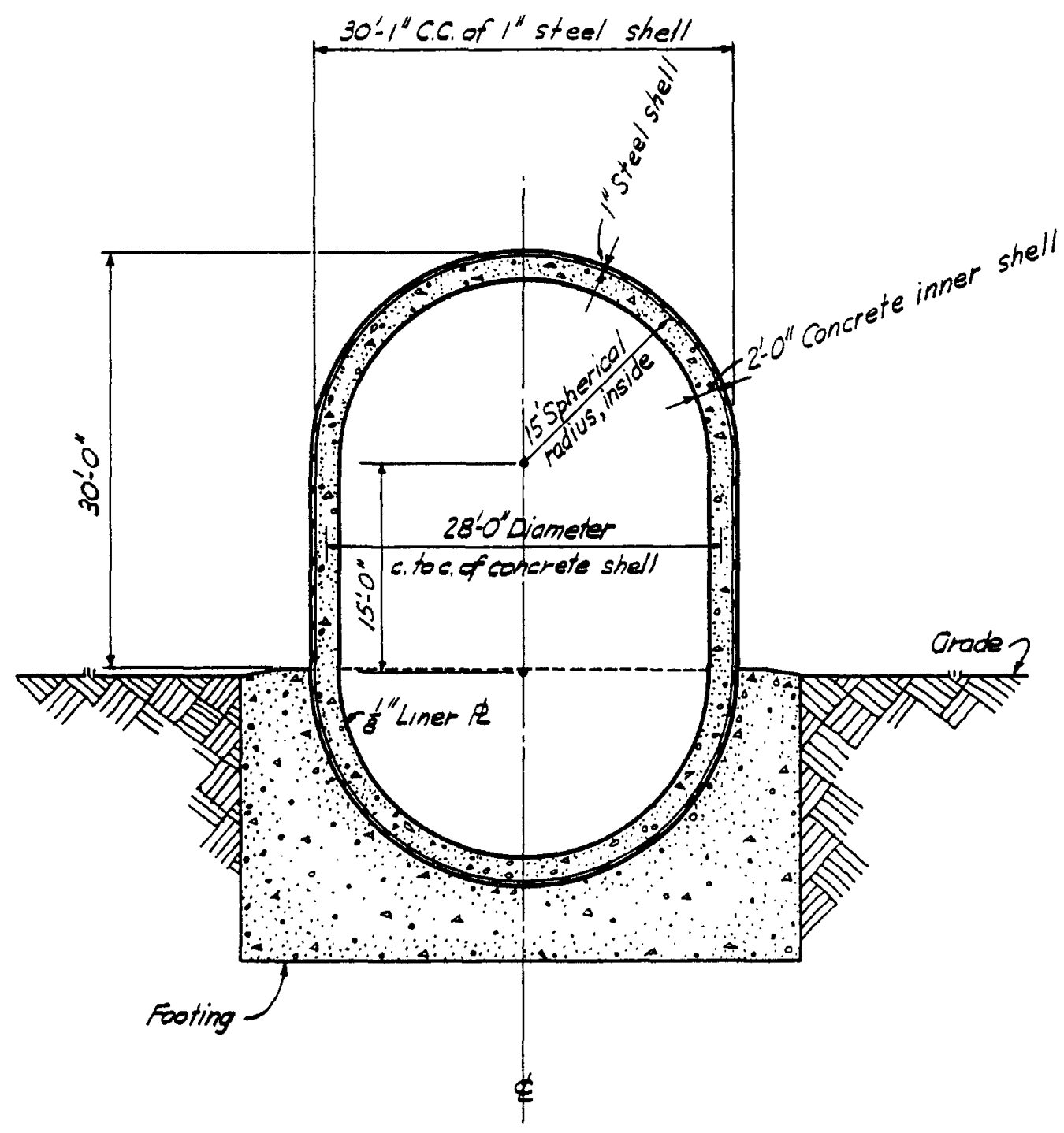

Fig. 5.5-Vertical section through vapor container.

TABLE 5.2- MOMENTS AND SHEARS*

\begin{tabular}{|c|c|c|c|c|}
\hline Element & Dead load, kipst & $\begin{array}{c}\text { Dead } \\
\text { load } \\
\times 0.33\end{array}$ & $\begin{array}{l}\text { Distance to } \\
\text { center of } \\
\text { gravity } \\
\text { from top of } \\
\text { footing, } f \mathrm{ft}\end{array}$ & $\begin{array}{l}\text { Moment } \\
\text { about } \\
\text { footing, } \\
\text { ft-kip }\end{array}$ \\
\hline Steel hemisphere & $0.49(3.14)(30.1)^{2}(0.5)(1 / 12)=58.1$ & 19.2 & 22.5 & 432 \\
\hline Steel cylinder & $0.49(3.14)(30.1)(15)(1 / 12)=57.9$ & 19.1 & 7.5 & 144 \\
\hline Concrete hemisphere & $0.15(3.14)(28)^{2}(0.5)(2) \quad=369$ & 121.7 & 22.08 & 2670 \\
\hline \multirow[t]{2}{*}{ Concrete cylinder } & $0.15(3.14)(28)(15)(2)$ & 131.0 & 7.5 & 982 \\
\hline & $\Sigma=882$ & 291.0 & & 4228 \\
\hline
\end{tabular}

*For reinforced-concrete notation, see Refs. 5.1 and 5.2 .

fOne kip equals $1000 \mathrm{lb}$.

\$Full fixity is assumed to occur at top of concrete footing.

sAssumes that the distance from the base of a thin hemisphere to the center of gravity is one-half the mean radius. 
For an annular ring,

$$
\begin{aligned}
& \text { Approximate } I=\frac{\text { area } \times d_{\text {mean }}^{2}}{8} \\
& \therefore I_{T}=\frac{176(28)^{2}}{8}+\frac{78.8(30.1)^{2}}{8}=17,250+8920 \\
& =26,170 \mathrm{ft}^{4}=542 \times 10^{6} \mathrm{in.}^{4} \\
& r^{2}=\frac{I_{T}}{A_{T}}=\frac{542 \times 10^{6}}{3.67 \times 10^{4}}=148 \times 10^{2} \text { in. }^{2} \quad(r=\text { radius of gyration }) \\
& \mathrm{e}=\frac{\mathrm{M}}{\mathrm{P}}=\frac{4228}{882}=4.79 \mathrm{ft}=57.5 \mathrm{in} .=\text { eccentricity of the load } \\
& f_{c_{\text {max. }}}=P\left(1+\frac{e c}{r^{2}}\right) \div A_{T} \quad(c=\text { distance to extreme fiber }) \\
& \therefore \mathrm{f}_{\mathrm{c}_{\text {max. }}}=882 \times 10^{3}\left(1+\frac{57.5 \times 180}{14,800}\right) \div 36.7 \times 10^{3} \\
& =24.0(1+0.70)=41 \mathrm{psi} \\
& f_{c_{\text {min. }}}=24.0(1-0.70)=24.0(0.30)=7.2 \mathrm{psi} \\
& f_{s_{\max }}=10(41)=410 \mathrm{psi} \\
& \mathrm{f}_{s_{\min }}=10(7.2)=72 \mathrm{psi}
\end{aligned}
$$

Stresses shown are compressive.

\section{Comment}

The fundamental period of this structure, based on the assumptions of the problem and computed from the Rayleigh approximation in Sec. G.2, is estimated to be about $0.02 \mathrm{sec}$. According to Fig. 1.22, this would give a maximum acceleration of $11 \mathrm{ft} / \mathrm{sec}^{2}$ or $0.34 \mathrm{~g}$ for a structure with $7 \%$ of critical damping, which exceeds the maximum acceleration of the earthquake by less than $1 \%$.

The seismic stresses are low, which is to be expected in structures having a large amount of reserve strength for other, more severe loading conditions.

The code coefficient of Ref. 5.3 would give a maximum acceleration of 0.10 or $0.133 \mathrm{~g}$, depending on whether the code authority would choose to classify the vapor container as a tank or as a building. The low seismic stresses indicate that, in this case, there would probably be no cost penalty in designing for the assumed seismic coefficient which is greater than the code value since other loadings would apparently govern.

\subsection{STRUCTURES WITH ONE DEGREE OF FREEDOM}

As shown in Eq. 1.19, the maximum velocity, $\dot{y}_{\text {max., }}$ of a one-degree-of-freedom system relative to the ground is given by

$$
\dot{\mathrm{y}}_{\max .}=\sqrt{2 \bar{\epsilon}}
$$

where $\bar{\epsilon}$ is the maximum energy per unit mass attained by the structure.

The term on the left-hand side of Eq. 5.1 has been show ${ }^{5.4}$ to be the ordinate, $S$, to the velocity spectrum corresponding to a given accelerogram, period of vibration, and amount of damping. 
Consequently Eq. 5.1 can be stated simply as

$\dot{\mathrm{y}}_{\max .}=\mathrm{S}$

The relation between $\dot{y}_{\max }$, and the maximum deflection, $y_{\max }$, relative to that of the ground, and absolute maximum acceleration, $a_{\max }$, is given by the following simple equations:

$$
\begin{aligned}
& a_{\max .}=\dot{y}_{\max .} \frac{2 \pi}{T}=S \frac{2 \pi}{T}=S \omega \\
& y_{\max .}=\dot{y}_{\max .} \frac{T}{2 \pi}=S \frac{T}{2 \pi}=\frac{S}{\omega}
\end{aligned}
$$

The period of vibration of the system (which must equal that of the actual structure it represents) is obtained from the following expressions:

$$
T=2 \pi \sqrt{\frac{\mathrm{m}}{\mathrm{k}}}
$$

or

$$
\begin{aligned}
& \mathrm{T}=2 \pi \sqrt{\frac{\mathrm{y}_{\mathrm{st}}}{\mathrm{g}}} \\
& \mathrm{m}=\text { mass }=\frac{\mathrm{W}}{\mathrm{g}}\left(\frac{\mathrm{lb} \mathrm{sec}}{\mathrm{ft}}\right) \\
& \mathrm{W}=\text { weight }(\mathrm{lb})
\end{aligned}
$$$$
\mathrm{g}=\text { acceleration due to gravity }=32.2 \mathrm{ft} / \mathrm{sec}^{2}
$$$$
\mathrm{k}=\text { spring constant }(\mathrm{lb} / \mathrm{ft})=\text { force }(\mathrm{lb}) \text { required to cause a } 1-\mathrm{ft} \text { deflection }=\frac{\mathrm{W}}{\mathrm{y}_{\mathrm{st}}}
$$

$\mathrm{y}_{\mathrm{st}}=$ static deflection of the spring which would be caused by a force equal to the weight of the mass

$$
\omega=\frac{2 \pi}{T}=\text { circular frequency (radians per second) }
$$

The procedure for determining the seismic response of a single-degree-of-freedom system consists of the following steps:

(1) Determine the period of vibration, $T$, of the system and estimate the fraction of critical damping, $\zeta$.

(2) From a spectrum curve, such as that in Fig. 1.19, for the values of $T$ and $\zeta$ in step 1 , read off the value of $S$. This equals the maximum velocity of the mass.

(3) Compute the maximum acceleration, $a_{\max }$, and the maximum deflection, $y_{\max }$, from Eqs. 5.3 and 5.4.

(4) Compute the maximum inertia force applied to the mass by multiplying $y_{\max }$. by the spring constant, $\mathrm{k}$; or, alternatively, multiply the maximum acceleration by the mass of the system. This is the maximum seismic force, $F$, on the structure. It should be noted that, when $S$ is in $\mathrm{ft} / \mathrm{sec}, \dot{y}_{\max }$. is also in $\mathrm{ft} / \mathrm{sec}, a_{\max }$. is in $\mathrm{ft} / \mathrm{sec}^{2}$, and $y_{\max }$. is in $\mathrm{ft}$.

The system can be used to represent such structures as one-story buldings and single-story platforms carrying equipment loads.

The following example illustrates the application of the procedure to a simple singlestory rigid-jounted frame. 
Example 2

Determine the maximum acceleration, deflection, horizontal force, and seismic bending moment in the steel rigid frame shown in Fig. 5.6, based on the earthquake spectrum in Fig. 1.19. For convenience, assume that the mass of the frame is accounted for in the 15 -kip uniform load supported by the girder. Assume hinged bases and $2 \%$ critical damping.

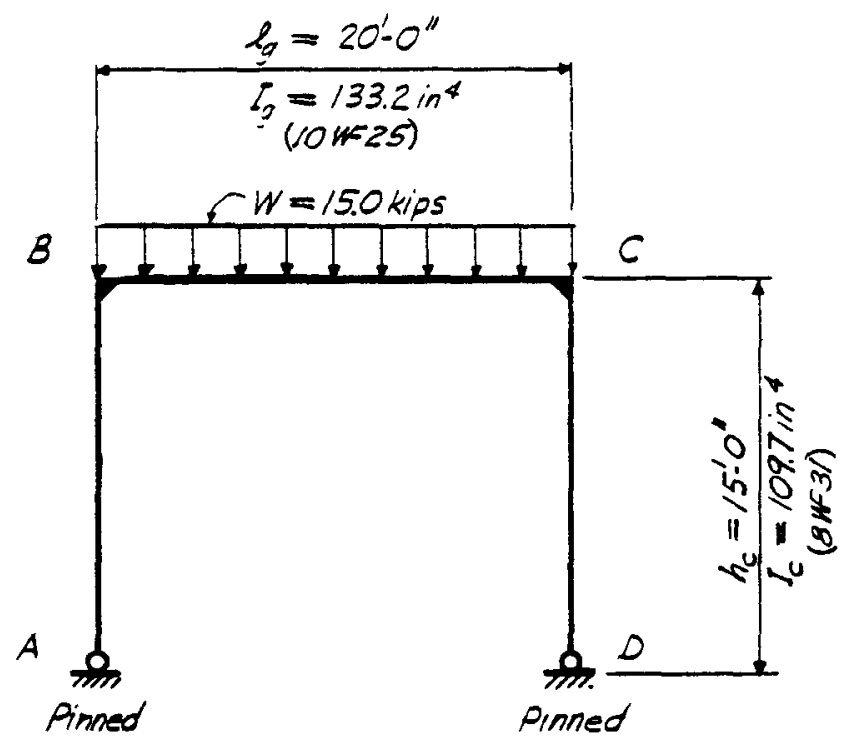

Fig. 5.6-Single-story frame.

\section{Solution}

From Eq. 5.6

$$
T=2 \pi \sqrt{\frac{y_{s t}}{g}}
$$

The static deflection from Ref. 5.5 , page 7 , is given by

$$
y_{s t}=\frac{W h_{c}^{3}}{6 E I_{c}}\left(1+\frac{I_{c} l_{g}}{2 I_{g} h_{c}}\right)
$$

where $\mathrm{W}=$ dead load (kips)

$\mathrm{E}=$ modulus of elasticity $\left(\mathrm{kips} / \mathrm{in.}^{2}\right)$

$\mathrm{h}_{\mathrm{c}}=$ height of columns (in.)

$l_{\mathrm{g}}=$ length of girder (in.)

$I_{c}=$ moment of inertia of column (in. ${ }^{4}$ )

$I_{g}=$ moment of inertia of girder (in. ${ }^{4}$ )

Substituting values

$$
\begin{aligned}
& y_{s t}=\frac{15.0(15)^{3}(1728)}{6\left(3 \times 10^{4}\right)(109.7)}\left[1+\frac{109.7(240)}{2(133.2)(180)}\right]=6.88 \mathrm{in} . \\
& T=6.28 \sqrt{\frac{6.88}{386}}=0.84 \mathrm{sec}
\end{aligned}
$$




\subsection{STRUCTURES WITH TWO DEGREES OF FREEDOM}

For $100 \zeta=2$ and $\mathrm{T}=0.84 \mathrm{sec}, \mathrm{S}=2.0 \mathrm{ft} / \mathrm{sec}$ (Fig. 1.19).

From Eqs. 5.3 and 5.4

$$
\begin{aligned}
& a_{\max .}=S \frac{2 \pi}{T}=2.0 \frac{6.28}{0.84}=15.0 \mathrm{ft} / \mathrm{sec}^{2} \\
& y_{\max .}=S \frac{T}{2 \pi}=2.0 \frac{0.84}{6.28}(12)=3.21 \mathrm{in} .
\end{aligned}
$$

The maximum seismic force is given by Eq. 1.20:

$$
\begin{aligned}
& F_{\text {max. }}=\mathrm{ky}_{\max .} ; \mathrm{k}=\frac{15.0}{6.88} \therefore \mathrm{F}_{\max .}=\frac{15.0}{6.88}(3.21)=7.0 \mathrm{kips} \\
& \text { Seismic moment } \mathrm{M}_{\mathrm{BA}}=\frac{7.0}{2}(15)=52.5 \mathrm{ft} \text {-kips }
\end{aligned}
$$

The maximum shear corresponds to a static coefficient of $0.47 \mathrm{~g}$, which is 3.5 times the $0.133 \mathrm{~g}$ required by Ref. 5.3 for a zone 3 location. This is a fairly typical comparison of the resistance required to maintain elastic response with that required by code coefficients (for a structure with low damping).

The analysis presented is usually considered to be satisfactory when the motion of the supported mass consists of translation with negligible tilting. The frame of Fig. 5.6 meets this requirement since the small axial deformations of the columns do not permit appreciable tilting. However, in some cases tilt may be significant and should be considered. An example of this type would be a tall rigid mass supported at the top of a single vertical column fixed at the base. Owing to the tilting motion, such a system acquires a second degree of freedom. Reference 5.6, page 204, derives periods of vibration and mode shapes for this case, and Appendix $E$ considers the earthquake response of a similar system.

\subsection{STRUCTURES WITH TWO DEGREES OF FREEDOM}

In a two-degree-of-freedom system, two modes of vibration are possible, as in Fig. 5.7, and an analysis of the response requires the determination of the mode shapes, periods of vibration, and spectrum values for each of the two modes.

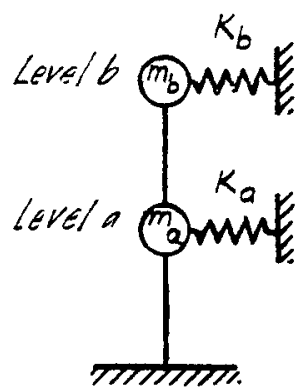

TWO MASS MODEL

(a)
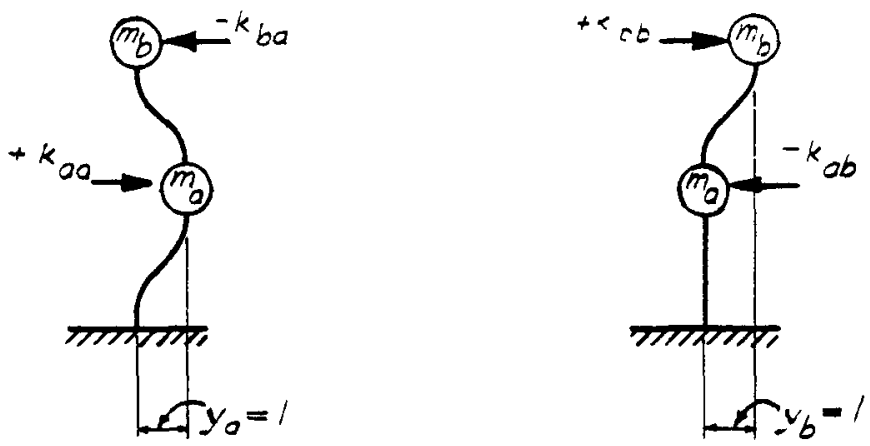

OEFIECTION PATTERNS ANO HORIZONTAL FORCES

(b)

$$
\text { signs } \rightarrow+k
$$

Fig. 5.7-Two-degree-of-freedom system. 
The maximum possible velocity, deflection, and acceleration of each mass are obtained by summing the contributions of each mode.

\section{A. Periods of Vibration and Mode Shapes}

The periods of vibration and the mode shapes may be found by the procedure outlined below for the two-mass system shown in Fig. 5.7.

(1) Deflect each of the two levels separately a unit horizontal distance, $y=1$, with the remaining level restrained against horizontal movement. Calculate the horizontal restraining forces, $\mathrm{k}$, which must be applied at each level to maintain the deflected shape of the structure.

(2) Determine the two natural frequencies, $\omega$, and the period of vibration, $T$, in terms of the $k$ values and the masses, $m$, at each level using Eqs. 5.7 and 5.8 .

(3) Determine the two mode shapes by substituting the $\omega$ values into either Eq. 5.9 or 5.10 .

The two natural vibration frequencies, $\omega_{n}$, in terms of the restraining forces, $k$, and the masses, $\mathrm{m}$, are determined from the following equation, derived in Sec. G.3:

$$
\omega_{\mathrm{n}}^{2}=\frac{1}{2}\left[\frac{k_{\mathrm{aa}}}{\mathrm{m}_{\mathrm{a}}}+\frac{\mathrm{k}_{\mathrm{bb}}}{\mathrm{m}_{\mathrm{b}}} \mp \sqrt{\left(\frac{\mathrm{k}_{\mathrm{aa}}}{\mathrm{m}_{\mathrm{a}}}-\frac{\mathrm{k}_{\mathrm{bb}}}{\mathrm{m}_{\mathrm{b}}}\right)^{2}+4 \frac{\mathrm{k}_{\mathrm{ab}}}{\mathrm{m}_{\mathrm{a}}} \frac{\mathrm{k}_{\mathrm{ba}}}{\mathrm{m}_{\mathrm{b}}}}\right]
$$

For the first mode $n=1$, and for the second mode $n=2$. The period of vibration, $T$, for each value of $\omega_{n}$ is given by

$$
\mathrm{T}_{\mathrm{n}}=\frac{2 \pi}{\omega_{\mathrm{n}}}
$$

The amplitude, $\phi_{\mathrm{an}}$, at level a, which determines the mode shape of the ireely vitrating system, is given by either of the following equations, derived in Sec. G.3:

$$
\begin{aligned}
& \phi_{a n}=\frac{-\left(k_{a b} / m_{a}\right)}{\left(k_{a 2} / m_{a}\right)-\omega_{a}^{2}} \\
& \phi_{a n}=\frac{-\left(k_{b b} / m_{b}\right)+\omega_{n}^{2}}{\left(k_{b a} / m_{b}\right)}
\end{aligned}
$$

The amplitude at level $\mathrm{b}$ is assumed to be unity $\left(\phi_{\mathrm{ba}}=1\right)$. The symbol $\mathrm{k}$ indicates the force per unit displacement; the first letter of the double subscript denotes the point at which $\mathrm{k}$ is measured and the second denotes the point which is deflected. Thus $\mathrm{k}_{\mathrm{a} a}$ denotes the force at level a due to $y_{a}=1$, and $k_{a b}$ denotes the force at level a due to $y_{b}=1$. By Maxwell's law, $k_{a b}=k_{b a}$. Values of $k$ used in Eqs. 5.9 and 5.10 are to be given positive signs when acting toward the right, so that, in general, $\mathrm{k}_{\mathrm{ab}}$ and $\mathrm{k}_{\mathrm{ba}}$ should be substituted in these equations with a negative sign when $k_{a a}$ and $k_{b b}$ are assumed to be positive (see Fig. 5.7).

\section{B. Maximum Response}

As shown in Sec. G.4, the maximum response of the structure of Fig. 5.7 is obtained for each of the two modes in terms of participation factors, K, given by Eqs. 5.15 and 5.16 . For the first mode

$$
\bar{y}_{b 1}=\frac{K_{1} S_{1}}{\omega_{1}}
$$




$$
\overline{\mathrm{Y}}_{\mathrm{a} 1}=\frac{\mathrm{K}_{1} \mathrm{~S}_{1}}{\omega_{1}} \phi_{\mathrm{a} 1}=\bar{y}_{\mathrm{b} 1} \cdot \phi_{\mathrm{a} 1}
$$

For the second mode

$$
\begin{aligned}
& \overline{\mathrm{y}}_{\mathrm{b} 2}=\frac{\mathrm{K}_{2} \mathrm{~S}_{2}}{\omega_{2}} \\
& \overline{\mathrm{y}}_{\mathrm{a} 2}=\frac{\mathrm{K}_{2} \mathrm{~S}_{2}}{\omega^{2}} \phi_{\mathrm{a} 2}=\overline{\mathrm{y}}_{\mathrm{b} 2} \cdot \phi_{\mathrm{a} 2}
\end{aligned}
$$

In the above equations

$$
\begin{aligned}
& \mathrm{K}_{1}=\frac{\mathrm{m}_{\mathrm{a}} \phi_{\mathrm{a} 1}+\mathrm{m}_{\mathrm{b}}}{\mathrm{m}_{\mathrm{a}} \phi_{\mathrm{a} 1}^{2}+\mathrm{m}_{\mathrm{b}}} \\
& \mathrm{K}_{2}=\frac{\mathrm{m}_{\mathrm{a}} \phi_{\mathrm{a} 2}+\mathrm{m}_{\mathrm{b}}}{\mathrm{m}_{\mathrm{a}} \phi_{\mathrm{a} 2}^{2}+\mathrm{m}_{\mathrm{b}}}
\end{aligned}
$$

For each mode the maximum inertia force, $F$, acting on each mass can be expressed in terms of the spring constants, $\mathrm{k}$, and the maximum deflections, $\bar{y}$, as follows:

$$
\begin{aligned}
& F_{b n}=k_{b b} \bar{y}_{b n}+k_{b a} \bar{y}_{a n} \\
& F_{a n}=k_{a b} \bar{y}_{b n}+k_{a a} \bar{y}_{a n}
\end{aligned}
$$

Alternatively, each of these forces can be calculated as the product of the mass, $\mathrm{m}$, times its maximum acceleration, $\omega_{\overline{\mathrm{y}}}^{2}$.

The following example applies the foregoing procedure to a simple two-story rigidjointed frame.

\section{Example 3}

Determine the maximum deflections, horizontal shears, and seismic bending moments in the frame shown in Fig. 5.8, based on the earthquake spectrum of Fig. 1.19. Assume hinged bases and $2 \%$ critical damping. For convenience the mass of the frame is assumed to be included in the concentrated masses acting on the girders.

\section{Solution}

The values of $\mathrm{k}$ are determined in Fig. 5.9 using a moment distribution procedure. From Fig. 5.9

$$
\begin{aligned}
& \mathrm{m}_{\mathrm{b}}=\frac{10,000}{32.2(12)}=25.9 \mathrm{lb} \mathrm{sec} \mathrm{in}^{-1} \\
& \mathrm{~m}_{\mathrm{a}}=\frac{15,000}{32.2(12)}=38.9 \mathrm{lb} \mathrm{sec} \mathrm{in}^{-1} \\
& \mathrm{k}_{\mathrm{aa}}=14,200 \mathrm{lb} / \mathrm{in} . \\
& \mathrm{k}_{\mathrm{bb}}=9,320 \mathrm{lb} / \mathrm{in} . \\
& \mathrm{k}_{\mathrm{ab}}=\mathrm{k}_{\mathrm{ba}}=-10,600 \mathrm{lb} / \mathrm{in} .
\end{aligned}
$$




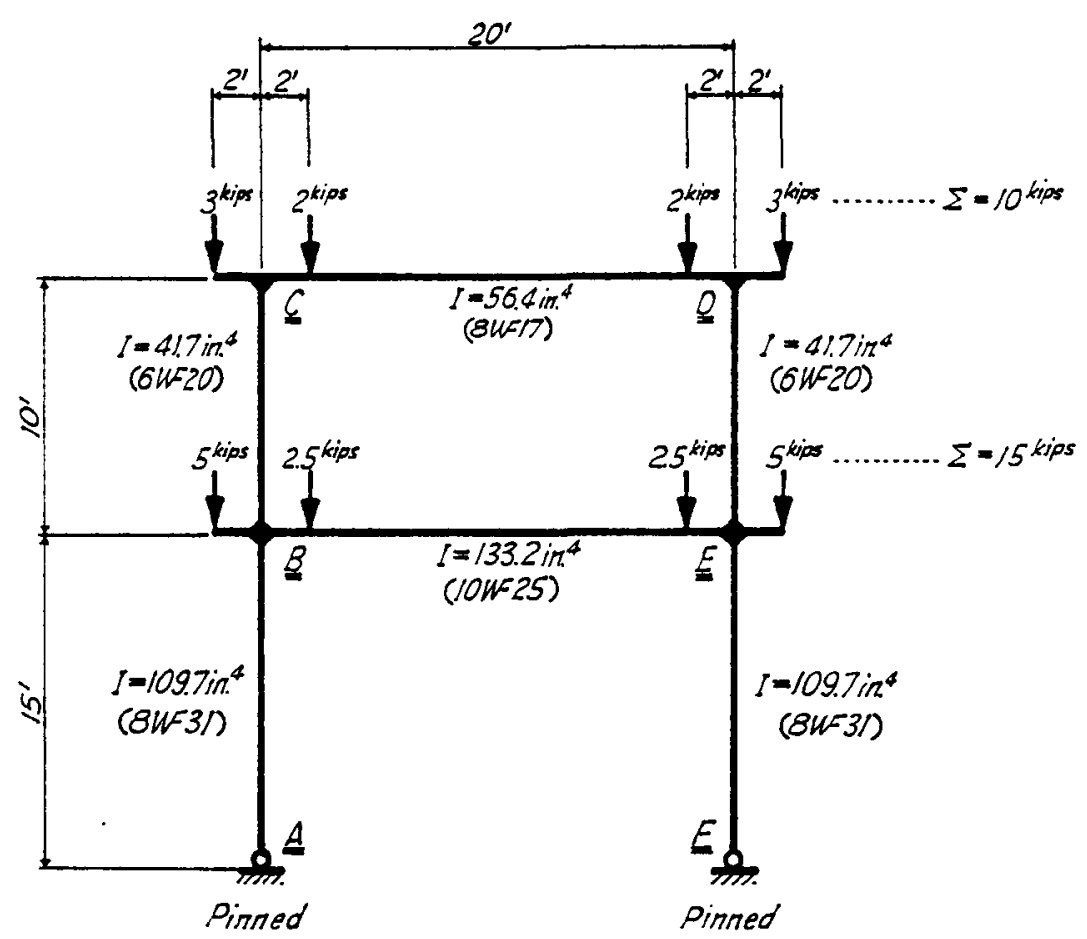

Fig. 5.8- Two-story frame.

Frequencies are given by Eq. 5.7

$$
\omega^{2}=\frac{1}{2}\left[\frac{k_{a a}}{m_{2}}+\frac{k_{b b}}{m_{b}} \mp \sqrt{\left(\frac{k_{a a}}{m_{a}}-\frac{k_{b b}}{m_{b}}\right)^{2}+4 \frac{k_{a b}}{m_{a}} \frac{k_{b a}}{m_{b}}}\right]
$$

Substituting values

$$
\begin{aligned}
& \omega^{2}=\frac{1}{2}\left[\frac{14,200}{38.9}+\frac{9320}{25.9} \mp \sqrt{\left(\frac{14,200}{38.9}-\frac{9320}{25.9}\right)^{2}+4 \frac{-10,600}{38.9} \frac{-10,600}{25.9}}\right] \\
& \omega^{2}=\frac{725^{\circ} \mp 668}{2} \quad \omega_{1}^{2}=28.5 \quad \omega_{2}^{2}=696.5 \\
& \omega_{1}=\sqrt{28.5}=5.34 \mathrm{rads} / \mathrm{sec} ; \mathrm{T}_{1}=2 \pi / \omega_{1}=1.18 \mathrm{sec} \\
& \omega_{2}=\sqrt{696.5}=26.4 \mathrm{rads} / \mathrm{sec} ; \mathrm{T}_{2}=2 \pi / \omega_{2}=0.24 \mathrm{sec}
\end{aligned}
$$

Mode shapes are given by Eq. 5.9

$$
\phi_{\mathrm{an}}=\frac{-\left(\mathrm{k}_{\mathrm{ab}} / \mathrm{m}_{\mathrm{a}}\right)}{\left(\mathrm{k}_{\mathrm{az}} / \mathrm{m}_{\mathrm{a}}\right)-\omega_{\mathrm{a}}^{2}}
$$

Substituting values when $\omega_{1}^{2}=28.5$

$$
\phi_{\mathbf{a} 1}=+0.81
$$

and, when $\omega_{2}^{2}=696.5$,

$$
\phi_{\mathrm{a} 2}=-0.82
$$




\subsection{EXAMPLE 3}

\section{CALCULATION OF SPRING CONSTANTS BY DISTRIBUTING FIXED END MOMENTS}

\section{SIGNS Positive and moment acts clackwise on the member}

STIFFNESS Stiffiness factor for a member equals $\frac{1}{2}$

MOMENTS Distribufion foctor for a moment of a joint equals $\frac{\frac{1}{2}}{\sum \frac{1}{l}}$

DEFLECTION Deflection at one end of a fixed member from a

fangent drown at the oftier end of the fired member:

$y=\frac{M l^{2}}{\sigma E I} \quad$ (or) $\quad M=\frac{\sigma E I y}{l^{2}}$

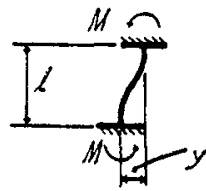

If follows that if ane end of the member is hinged then the deflection of the hinged end from the tangent to the member at the fixed end will be:

$y=\frac{M L^{2}}{3 E I}$ (or) $M=\frac{3 E I y}{L^{2}}$

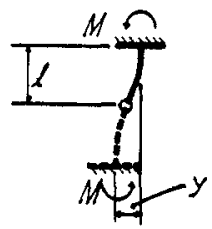
Elastic eurve of deflected frome
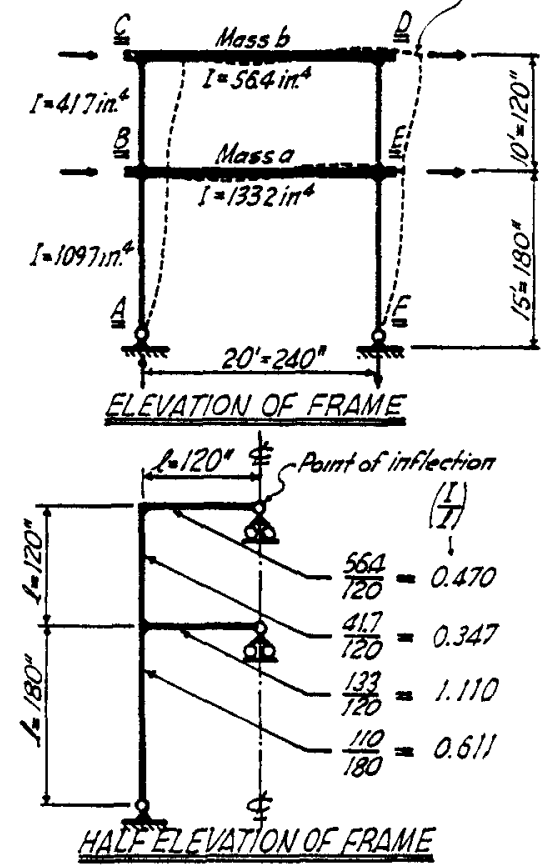

HINGED END The end moment required to produce unit rotation ot one end of a prismatic beom hoving the far end hinged is $\frac{3}{4}$ as great os of the far end wore fixed. The relative stiffness foctor when the far end is hinged accordingly becomes $75 \%$ of the stiffress factor ( $\frac{f}{q}$ value) which apolies when it is fixed. Hence for a member with the far end free to rotate, the $\frac{C}{Z}$ value is reduced $25 \%$ when distribution factors ore determined. Then there is no fixed-end moment or carry-over moment of the pinned end and the lobor of andysis is meduced. SYMMETRY Since thrs frame is symmetrical the points of inflection of the beams fall on the center line of the frame further simplifying the labor of andysis, becouse this allows a moment distribution to be contrived which involues only one half ar the frame.

FEM's At each end of each spon, compute the FEM due to the lood of that span with the jorits assumed fixed.

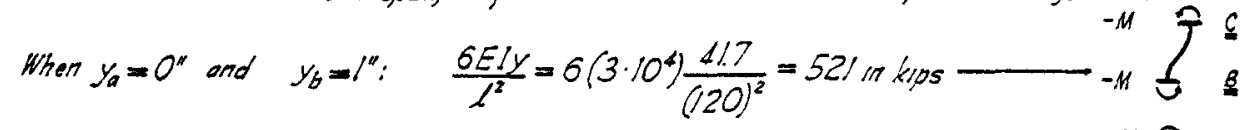

$$
\begin{aligned}
& \text { When } y_{0}=l^{\prime \prime} \text { and } y_{b}=0^{\prime \prime}: \quad \frac{6 E l y}{l^{2}}=5\left(3 \cdot 10^{4}\right) \frac{417}{(120)^{2}}=52 i \text { in kios } \ldots \\
& \frac{3 E l y}{\ell^{2}}=3\left(3 \cdot 10^{4}\right) \frac{110}{(180)^{2}}=305 \mathrm{mkips}-\mathrm{M} \widetilde{\sigma}_{\mathrm{S}}^{\mathrm{s}}
\end{aligned}
$$

Fig. 5.9-Two-story frame, moments and shears from unit displacements (Refs. 5.7 to 5.9). 
EXAMPLE $3 \quad 5.5 \mathrm{C}$ CALCULATION OF SPRING CONSTANTS BY OISTRIBUTINO FIXED END MOMENTS

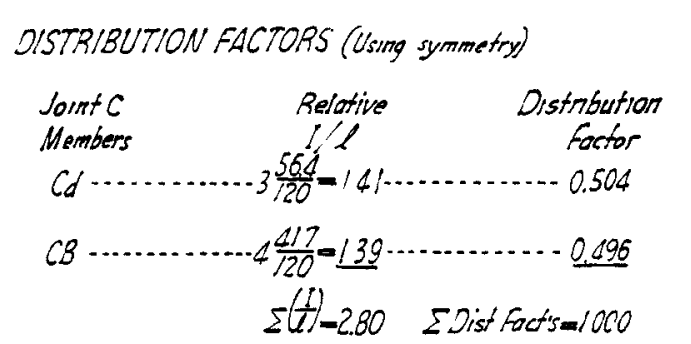

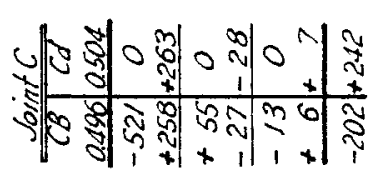

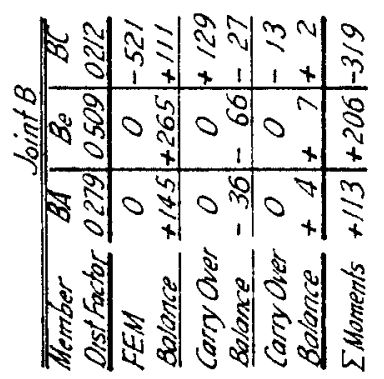

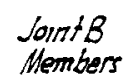

$B A \cdots$

Be ….........-3 $\frac{133}{120}=333$

$B C$

Oistibufion Factor $\Sigma\left(\frac{I}{I}\right)=655 \quad \Sigma$ Dist Facts $=1000$
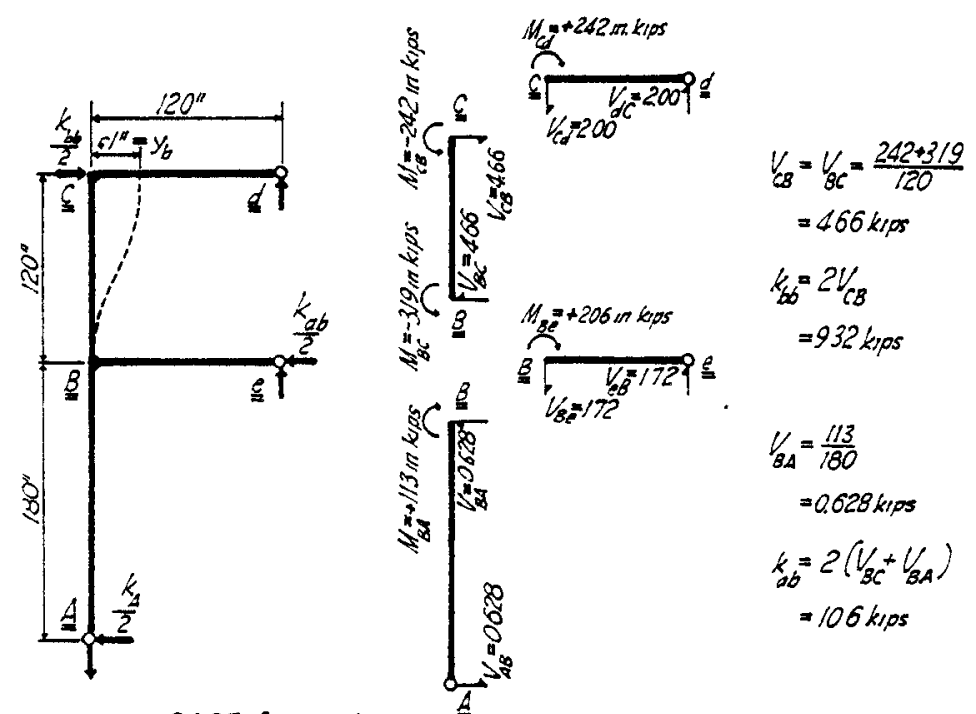

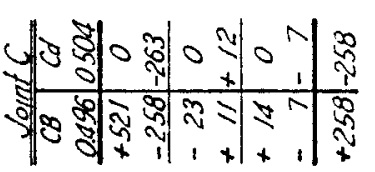

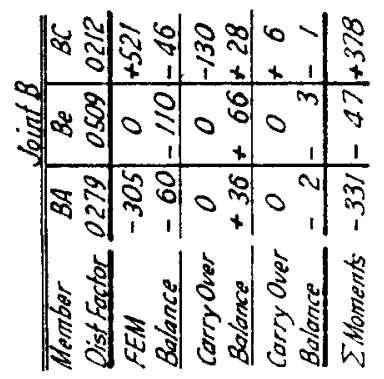

CASE $:: y_{s}=1 / \pi$

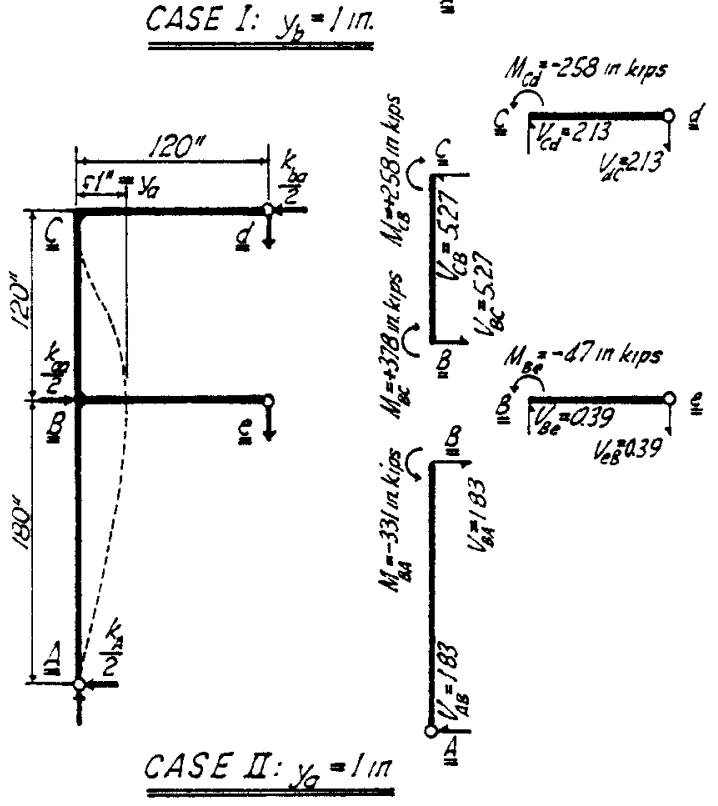

Fig. 5.9 - (Contrnued)

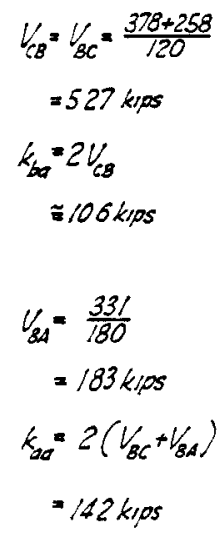


5.5C EXAMPLE 3

\section{Horizontal deflection}

First mode:

$\omega_{1}=5.34 \mathrm{rads} / \mathrm{sec}, \phi_{21}=+0.81, \mathrm{~T}_{1}=1.18 \mathrm{sec}$

$\mathrm{S}_{1}=2.0 \mathrm{ft} / \mathrm{sec}$ for $\zeta=0.02$ (Fig. 1.19)

Using Eqs. 5.11 and 5.12 , with $\mathrm{K}$ values from Eq. 5.15

$$
\begin{aligned}
\bar{y}_{b 1} & =\frac{m_{\mathrm{a}} \phi_{\mathrm{a} 1}+\mathrm{m}_{\mathrm{b}}}{\mathrm{m}_{\mathrm{a}} \phi_{\mathrm{a} 1}^{2}+\mathrm{m}_{\mathrm{b}}} \frac{\mathrm{S}_{1}}{\omega_{1}} \\
& =\frac{38.9(0.81)+25.9}{38.9(0.81)^{2}+25.9} \times \frac{2.0(12)}{5.34}=5.02 \mathrm{in} . \\
\overline{\mathrm{y}}_{\mathrm{a} 1} & =\mathrm{y}_{\mathrm{b} 1} \cdot \phi_{\mathrm{a} 1}=5.02(0.81)=4.06 \mathrm{in} .
\end{aligned}
$$

Second mode:

$$
\begin{aligned}
& \omega_{2}=26.4 \mathrm{rads} / \mathrm{sec}, \phi_{\mathrm{a} 2}=-0.82, \mathrm{~T}_{2}=0.24 \mathrm{sec} \\
& \left.\mathrm{S}_{2}=0.95 \mathrm{ft} / \mathrm{sec} \text { for } \zeta=0.02 \text { (Fig. } 1.19\right)
\end{aligned}
$$

Using Eqs. 5.13 and 5.14, with $\mathrm{K}$ values from Eq. 5.16

$$
\begin{aligned}
\overline{\mathrm{y}}_{b 2} & =\frac{38.9(-0.82)+25.9}{38.9(-0.82)^{2}+25.9} \times \frac{0.95(12)}{26.4} \\
& =(-0.115)(0.43) \cong-0.05 \mathrm{in} . \\
\bar{y}_{\mathrm{a} 2} & =\bar{y}_{\mathrm{b} 2} \phi_{\mathrm{ae}} \\
& =-0.05(-0.82) \cong 0.04 \mathrm{in} .
\end{aligned}
$$

Figure 5.10 shows schematically the two mode shapes.
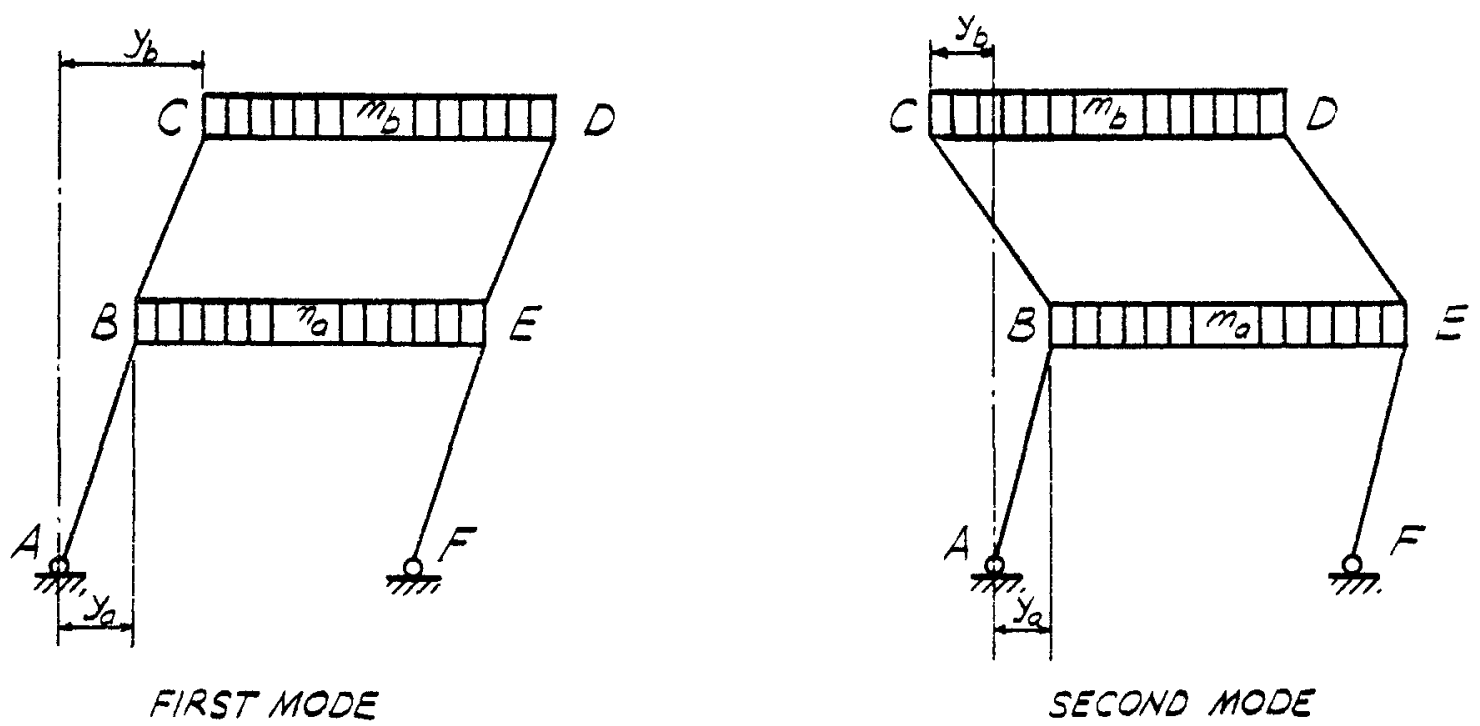

Fig. 5.10- Two-story frame, mode shapes. 
Horizontal shear

First mode:

Using Eqs. 5.17 and 5.18, $F=$ seismic force (inertia force acting on the accelerated

$$
\begin{aligned}
& F_{b}=9.32(5.02)-10.6(4.06)=3.80 \mathrm{kips} \\
& F_{a}=14.2(4.06)-10.6(5.02)=4.50 \mathrm{kips}
\end{aligned}
$$

Second mode:

$$
\begin{aligned}
& F_{b}= \pm 9.32(-0.05) \pm 10.6(0.04)= \pm 0.89 \mathrm{kip} \\
& F_{2}= \pm 14.2(0.04) \pm 10.6(-0.05)= \pm 1.10 \mathrm{kips} \\
& \text { Maximum } F_{b}=3.80+0.89=4.69 \mathrm{kips} \\
& \text { Maximum } F_{a}=4.50+1.10=5.60 \mathrm{kips}
\end{aligned}
$$

Maximum shear in second story $=4.69$ kips

Maximum shear at base $=3.80-0.89+4.50+1.10=8.51$ kips

\section{Seismic moments}

First mode:

$$
\begin{aligned}
& \mathrm{M}_{\mathrm{BA}}=-27.5(4.06)+9.43(5.02)=-64.5 \mathrm{ft}-\mathrm{kips} \\
& \mathrm{M}_{\mathrm{BC}}=31.4(4.06)-26.6(5.02)=-6.2 \mathrm{ft}-\mathrm{kips} \\
& \mathrm{M}_{\mathrm{BE}}=-(-64.5-6.2)=+70.7 \mathrm{ft}-\mathrm{kups} \\
& \mathrm{M}_{\mathrm{CB}}=-\mathrm{M}_{\mathrm{CD}}=-20.0(5.02)+21.3(4.06)=-13.9 \mathrm{ft}-\mathrm{kips}
\end{aligned}
$$

Second mode:

$$
\begin{aligned}
& \mathrm{M}_{\mathrm{BA}}=\mp 27.5(0.04) \pm 9.43(-0.05)=\mp 1.6 \mathrm{ft} \text {-kips } \\
& \mathrm{M}_{\mathrm{BC}}= \pm 31.4(0.04) \mp 26.6(-0.05)= \pm 2.6 \mathrm{ft}-\mathrm{kips} \\
& \mathrm{M}_{\mathrm{BE}}=\mp(2.6-1.6)=\mp 1.0 \mathrm{ft}-\mathrm{kips} \\
& \mathrm{M}_{\mathrm{CB}}=-\mathrm{M}_{\mathrm{CD}}=\mp 20.0(-0.05) \pm 21.3(0.04)= \pm 1.8 \mathrm{ft} \text {-kips }
\end{aligned}
$$

Maximum seismic moments:

$$
\begin{aligned}
& \mathrm{M}_{\mathrm{BA}}=-64.5-1.6=-66.1 \mathrm{ft}-\mathrm{kips} \\
& \mathrm{M}_{\mathrm{BC}}=-6.2-2.6=-8.8 \mathrm{ft}-\mathrm{kips} \\
& \mathrm{M}_{\mathrm{BE}}=70.7+1.0=71.7 \mathrm{ft}-\mathrm{kips} \\
& \mathrm{M}_{\mathrm{CB}}=-\mathrm{M}_{\mathrm{CD}}=-13.9-1.8=-15.7 \mathrm{ft}-\mathrm{kips}
\end{aligned}
$$

The maximum seismic moments shown correspond to a sidesway to the right in the primary mode. Since reversal of motion will occur, for design purposes signs should be assumed to be either positive or negative.

It is instructive to note that the maximum shears correspond to the use of a static seismic coefficient of $0.47 \mathrm{~g}$ in the upper story and $0.34 \mathrm{~g}$ in the lower story. Reference 5.3 for zone 3 conditions would require static seismic coefficients that are only about $30 \%$ as great $(0.133$ and $0.109 \mathrm{~g}$ for upper and lower stories, respectively). The design of this 
frame is such that there is negligible plastic deformation. It is evident that the frame is more costly than one designed using code coefficients. However, a lighter frame designed using code coefficients would depend for survival on energy absorption through inelastic response, resulting in a certain amount of structural damage.

\subsection{ELASTIC FLEXURAL MEMBERS}

The recent publication of tables for normal modes of vibration of beams having various end conditions ${ }^{5.10}$ permits the rapid determination of maximum seismic effects in flexural members of constant section.

Elastic bodies, such as flexural members, can vibrate laterally in an infinite number of natural frequencies. If the vibration is harmonic, then for each such frequency the deflection curve of the beam assumes a definite shape which is called the normal mode of vibration. The mathematical expressions defining the shapes of the normal modes are known as characteristic functions. For each type of flexural member with given end conditions, there are an infinite number of these functions.

The tables of Ref. 5.10 give the relative ordinates, $\phi$, to the deflection curve at selected points along the span and successive derivatives that are proportional to the slope, bending moment, and shear acting on the beam.

The discussion to follow presents the basic equations applicable to elastic flexural members and adapts them for use with the tables of Ref. 5.10.

A. Equations for Flexural Members

From Eq. 1.31 the maximum possible seismic deflection, $\bar{y}$, at any point on a structure, is obtained by summing the contributions of each mode as follows:

$$
\vec{y}=\sum_{n} K_{n} \phi_{n}(x) \frac{T_{n}}{2 \pi} \sqrt{2 \bar{\epsilon}_{n}}
$$

where $\bar{\epsilon}_{\mathrm{n}}$ is the maximum energy per unit mass attained by the structure.

As discussed in Sec. 5.4, the expression $\sqrt{2 \bar{\epsilon}_{n}}$ is the ordinate, $\mathrm{S}_{\mathrm{n}}$, to the velocity spectrum of the earthquake for a single-degree-of-freedom system of period $T_{n}$ and with the same damping as exists in the flexural member. Consequently Eq. 5.19 can be written

$$
\bar{y}=\sum_{n} K_{n} \phi_{n}(x) \frac{T_{n}}{2 \pi} S_{n}
$$

and for any mode, $n$,

$$
\bar{y}_{n}=K_{n} \phi_{n}(x) \frac{T_{n}}{2 \pi} S_{n}
$$

The bending moment, $\overrightarrow{\mathrm{M}}_{\mathrm{n}}$, and the shear, $\overline{\mathrm{V}}_{\mathrm{n}}$, at any point on a structure for a given mode, $\mathrm{n}$, are of primary interest. Differentiating Eq. 5.21 twice, multiplying both sides by $\mathrm{EI}$, and incorporating the term $\beta_{\mathrm{a}}^{2}$ gives the value of the maximum bending moment

$$
\overline{\mathrm{M}}_{\mathrm{n}}=\operatorname{EI} \frac{\mathrm{d}^{2} \overline{\mathrm{y}}_{\mathrm{n}}}{d \mathrm{x}^{2}}=\frac{\mathrm{K}_{\mathrm{n}} \mathrm{T}_{\mathrm{n}} S_{\mathrm{n}}}{2 \pi} \operatorname{EI} \beta_{\mathrm{n}}^{2}\left(\frac{1}{\beta_{\mathrm{n}}^{2}} \frac{\mathrm{d}^{2} \phi_{\mathrm{n}}}{d \mathrm{x}^{2}}\right)
$$

The term $\beta_{\mathrm{n}}^{2}$ (defined in Eq. 5.29) is introduced to provide notation for the term in parentheses, which is consistent with that of Ref. 5.10. Note that the $\beta_{\mathrm{n}}^{2}$ terms cancel.

$$
\bar{V}_{\mathrm{n}}=\operatorname{EI} \frac{\mathrm{d}^{3} \bar{y}_{\mathrm{n}}}{\mathrm{dx}^{3}}=\frac{\mathrm{K}_{\mathrm{n}} \mathrm{T}_{\mathrm{n}} \mathrm{S}_{\mathrm{n}}}{2 \pi}\left[\operatorname{EI} \beta_{\mathrm{n}}^{3}\left(\frac{1}{\beta_{\mathrm{n}}^{3}} \frac{\mathrm{d}^{3} \phi_{\mathrm{n}}}{\mathrm{dx^{3 }}}\right)\right]
$$


Using the notation of Ref. 5.10 , where the primes denote differentiation with respect to $\beta_{n} \mathbf{x}$, parenthetic terms in the above equations are defined as follows:

$$
\begin{aligned}
& \frac{1}{\beta_{\mathrm{n}}^{2}} \frac{\mathrm{d}^{2} \phi_{\mathrm{n}}}{\mathrm{d \textrm {x } ^ { 2 }}}=\phi_{\mathrm{n}}^{\prime \prime} \\
& \frac{1}{\beta_{\mathrm{n}}^{3}} \frac{\mathrm{d}^{3} \phi_{\mathrm{n}}}{\mathrm{dx^{3 }}}=\phi_{\mathrm{n}}^{\prime \prime}
\end{aligned}
$$

Tabulated values of $\phi_{\mathrm{n}}, \phi_{\mathrm{n}}^{\prime \prime}$, and $\phi_{\mathrm{n}}^{\prime \prime \prime}$ are given in Ref. 5.10 for various points along the span.

With this notation Eqs. 5.21 to 5.23 become

$$
\begin{aligned}
& \overline{\mathrm{Y}}_{\mathrm{n}}=\left(\frac{\mathrm{K}_{\mathrm{n}} \mathrm{T}_{\mathrm{n}} \mathrm{S}_{\mathrm{n}}}{2 \pi}\right) \phi_{\mathrm{n}} \\
& \overline{\mathrm{M}}_{\mathrm{n}}=\left(\frac{\mathrm{K}_{\mathrm{n}} \mathrm{T}_{\mathrm{n}} \mathrm{S}_{\mathrm{n}} \mathrm{EI} \beta_{\mathrm{n}}^{2}}{2 \pi}\right) \phi_{\mathrm{n}}^{\prime \prime} \\
& \overline{\mathrm{V}}_{\mathrm{n}}=\left(\frac{\mathrm{K}_{\mathrm{n}} \mathrm{T}_{\mathrm{n}} \mathrm{S}_{\mathrm{n}} \mathrm{EI} \beta_{\mathrm{n}}^{3}}{2 \pi}\right) \phi_{\mathrm{n}}^{\prime \prime \prime}
\end{aligned}
$$

The term $\beta_{n}$ depends on the end conditions and is related to the circular frequency of vibration, $\omega_{n}$, and the period of vibration, $T_{n}$, in the following way:

$$
\frac{2 \pi}{\omega_{n}}=T_{n}=\frac{2 \pi}{\left(\beta_{n} l\right)^{2}} \sqrt{\frac{m_{1} l^{4}}{E I}}
$$

where $m_{1}$ is the mass per unit length.

Equation 1.27 uses the value of $K_{\mathrm{u}}$ in a general form. In the special case of constant EI, alternative expressions are $\mathrm{e}^{5.11}$

$$
\mathrm{K}_{\mathrm{n}}=\frac{1}{l} \int_{0}^{l} \phi_{\mathrm{n}} \mathrm{dx}=\frac{1}{\beta_{\mathrm{n}}^{4} l} \frac{\mathrm{d}^{3} \phi_{\mathrm{n}}}{\mathrm{dx^{3 }}}
$$

Equation 5.30 applies only when the normalized modes, $\phi_{\mathfrak{n}}$, satisfy the orthogonality condition used in Refs. 5.10 and 5.11, which states that

$$
\int_{0}^{l} \phi_{\mathrm{n}}^{2} \mathrm{dx}=\ell
$$

This particular normalization is used in this document only in connection with the $\mathrm{K}_{\mathrm{n}}$ values defined in Sec. $5.6 \mathrm{~A}$.

The term $\mathrm{K}_{\mathrm{n}}$ is sometimes called the participation factor, ${ }^{5,12,5.13}$ having values for various end conditions and assuming constant $\mathrm{EI}$, as follows $\mathrm{s}^{5.11}$

\section{End conditions}

One end of beam clamped, the other end free

One end clamped, the other end supported

Both ends of beam clamped

One end free, the other end supported

Both ends of beam free.
$\underline{K_{n}}$

$$
\begin{aligned}
& 2 \alpha_{n} / \beta_{n} \lambda \\
& {\left[1 / \beta_{n} l\right]\left[(-1)^{n+1} \sqrt{\alpha_{n}^{2}+1}-\sqrt{\alpha_{n}^{2}-1}+2 \alpha_{n}\right]} \\
& {\left[2 \alpha_{n} / \beta_{n} l\right]\left[1-(-1)^{n}\right]} \\
& {\left[1 / \beta_{n} l\right]\left[(-1)^{n} \sqrt{\alpha_{n}^{2}+1}-\sqrt{\alpha_{n}^{2}-1}\right]} \\
& 0
\end{aligned}
$$


Tabulated values of $\alpha_{\mathrm{n}}$ and $\beta_{\mathrm{n}}$ for various end conditions are given in Ref. 5.10.

The term $\left(2 \pi / T_{n}\right)\left(S_{n} / g\right)$ is sometimes called the load factor, $D_{n}$. Equations 5.26 to 5.28 can be expressed in terms of $D_{n}$ in the following forms, which have previously appeared in the literature: $:^{5.12,5.13}$

$$
\begin{aligned}
& \bar{y}_{\mathrm{n}}=\frac{w l^{4} \phi_{\mathrm{n}} \mathrm{K}_{\mathrm{n}}}{\operatorname{EI}\left(\beta_{\mathrm{n}} l\right)^{4}} \mathrm{D}_{\mathrm{n}} \\
& \overline{\mathrm{M}}_{\mathrm{n}}=\frac{w \ell^{2} \phi_{n}^{n} \mathrm{~K}_{\mathrm{n}}}{\left(\beta_{\mathrm{n}} l^{2}\right.} \mathrm{D}_{\mathrm{n}} \\
& \overline{\mathrm{V}}_{\mathrm{n}}=\frac{w{ }^{\prime} \phi_{\mathrm{n}}^{m} \mathrm{~K}_{\mathrm{n}}}{\beta_{\mathrm{n} \ell}} D_{\mathrm{n}}
\end{aligned}
$$

where $w$ is the load per unit length $\left(w=m_{1} g\right)$.

The results obtained by Eqs. 5.31 to 5.33 are identical with those obtained using Eqs. 5.26 to 5.28. The maximum possible values of $y, M$, and $V$ are obtained by summing the absolute values of each mode.

The procedure for determining the seismic response of a constant section beam or other flexural member is as follows:

(1) For each mode, $n$, to be considered, evaluate the beam constants $\beta_{n}, \omega_{n}, T_{n}, K_{n}$, $\phi_{n}, \phi_{n}^{\prime \prime}$, and $\phi_{n}^{m}$. The factors $\beta_{n}$ and $K_{n}$ and the values $\phi_{n}^{n}$ and $\phi_{n}^{m}$ at selected points along the span are conveniently obtained from Ref. 5.10.

(2) For the $T_{n}$, damping values, and earthquake spectrum considered (such as that given in Fig. 1.19), determine the values of $\mathrm{S}_{\mathrm{n}}$.

(3) Evaluate for each mode the maximum deflection, moment, and shear using Eqs. 5.26 to 5.28 or, alternatively, Eqs. 5.31 to 5.33 .

(4) Combine results for each mode to get the maximum possible values.

Common types of structure to which the foregoing analysis can be adapted are cantilever elements such as chimneys and pressure vessels.

The following example illustrates the application of the procedure to a stack of uniform cross section.

\section{B. Example 4}

Determine the curves of maximum deflection, shear, and moment for the cantilever chimney shown in Fig. 5.11 using the spectrum of Fig. 1.19. Assume full fixity at the base and $5 \%$ critical damping. Calculations are to be made for the first three modes only.

\section{Solution}

Substituting the value $C_{n}$ from Sec. 6.1 for the expression $K_{n} T_{n} S_{n} / 2 \pi$ in Eqs. 5.26 to 5.28 gives the following expressions for use in calculating the chimney response:

$$
\begin{aligned}
& \mathrm{y}_{\mathrm{n}}=\mathrm{C}_{\mathrm{n}} \phi \\
& \mathrm{M}_{\mathrm{n}}=\mathrm{C}_{\mathrm{n}} \mathrm{EI} \beta_{\mathrm{n}}^{2} \phi_{\mathrm{n}}^{\prime \prime} \\
& \mathrm{V}_{\mathrm{n}}=\mathrm{C}_{\mathrm{n}} E I \beta_{\mathrm{n}}^{3} \phi_{\mathrm{n}}^{m}
\end{aligned}
$$

Also, from Sec. 5.6A

$$
\begin{aligned}
& \mathrm{T}_{\mathrm{n}}=\frac{2 \pi}{\left(\beta_{\mathrm{n}} l\right)^{2}} \sqrt{\frac{\mathrm{m}_{1} l^{4}}{\mathrm{EI}}} \\
& \mathrm{K}_{\mathrm{n}}=\frac{2 \alpha_{\mathrm{n}}}{\beta_{\mathrm{n} l}}
\end{aligned}
$$




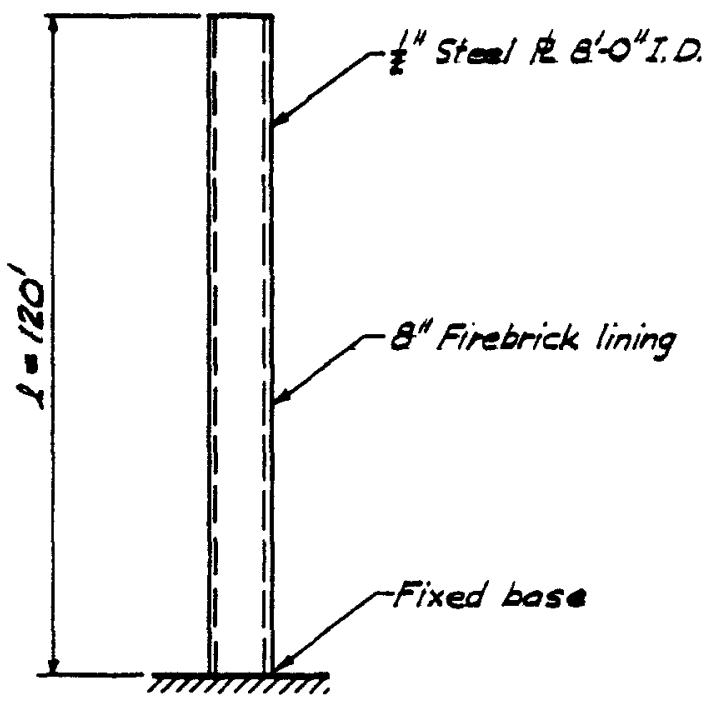

Fig. 5.11-Cantilever chimney.

Steel shell

$$
\begin{aligned}
& I_{s}=\frac{\pi\left[{\text { (outside diameter } \left.)^{4}-(\text { inside diameter })^{4}\right]}_{64}\right.}{I_{s}=1.76 \times 10^{5} \text { in. }^{4}, E_{s}=3.00 \times 10^{7} \mathrm{lb} \mathrm{in}^{-2}}
\end{aligned}
$$

Weight of steel is $3.40 \mathrm{lb}$ for 1 -in. $\times 1$-in. $\times 1$-ft-long volume.

$$
\mathrm{m}_{\mathrm{s}}=(3.14)(8.04)(0.500)(3.40)(1 / 12.0)(1 / 32.2)=0.111 \mathrm{lb} \mathrm{sec}^{2} \text { in. }^{-2}
$$

\section{Brick lining}

Weight of brick in a wall is $120 \mathrm{lb} \mathrm{ft}^{-3}$.

$$
\mathrm{m}_{\mathrm{b}}=(3.14)(7.33)(0.667)(120)(1 / 12.0)(1 / 12.0)(1 / 32.2)=0.400 \mathrm{lb} \mathrm{sec} \text { in. }^{-2}
$$

Total mass per inch of height

$$
\mathrm{m}_{1}=\mathrm{m}_{\mathrm{s}}+\mathrm{m}_{\mathrm{b}}=0.511 \mathrm{lb} \mathrm{sec}{ }^{2} \text { in. }{ }^{-2}
$$

Neglecting I of brick lining

$$
\begin{aligned}
E_{s} I_{s}= & \left(30 \times 10^{6}\right)\left(0.176 \times 10^{6}\right)=5.28 \times 10^{12} \mathrm{lb} \mathrm{in.}{ }^{2} \\
T_{n}\left(\beta_{n} l\right)^{2} & =2 \pi \sqrt{\frac{m_{1} l^{4}}{E I}}=6.28\left[\frac{0.511(120)^{4}\left(2.07 \times 10^{4}\right)}{5.28 \times 10^{12}}\right]^{1 / 2} \\
& =6.28(0.65)=4.08 \mathrm{sec}
\end{aligned}
$$

Beam constants for the first three modes are given in Table 5.3 .

\section{Comment}

Numbers in Figs. 5.12 to 5.14 are shown without regard to sign, even though some are negative, because the envelopes are obtained by absolute summation.

The shape of the moment envelope deviates considerably from the moment diagram obtained on the assumption of a uniform lateral loading that would produce the same base moment, the envelope moments tending to be higher by a considerable percentage in the 
TABLE 5.3-BEAM CONSTANTS*

\begin{tabular}{|c|c|c|c|c|c|c|c|c|c|}
\hline \multicolumn{2}{|c|}{$\begin{array}{c}\text { Beam } \\
\text { constants }\end{array}$} & \multicolumn{2}{|c|}{ First mode } & \multicolumn{3}{|c|}{ Second mode } & \multicolumn{3}{|c|}{ Third mode } \\
\hline \multicolumn{2}{|l|}{$\beta$} & \multicolumn{2}{|l|}{$1.31 \times 10^{-3}$} & \multicolumn{3}{|c|}{$3.25 \times 10^{-3}$} & \multicolumn{3}{|c|}{$5.46 \times 10^{-3}$} \\
\hline \multicolumn{2}{|l|}{$\beta^{2}$} & \multicolumn{2}{|l|}{$1.71 \times 10^{-8}$} & \multicolumn{3}{|c|}{$10.55 \times 10^{-6}$} & \multicolumn{3}{|c|}{$29.8 \times 10^{-6}$} \\
\hline \multicolumn{2}{|l|}{$\beta^{3}$} & \multicolumn{2}{|l|}{$2.23 \times 10^{-9}$} & \multicolumn{3}{|c|}{$34.3 \times 10^{-9}$} & \multicolumn{3}{|c|}{$163 \times 10^{-9}$} \\
\hline & \multicolumn{2}{|l|}{1.88} & \multicolumn{3}{|l|}{4.69} & \multicolumn{3}{|l|}{7.85} \\
\hline \multicolumn{2}{|c|}{$(\beta l)^{2}$} & \multicolumn{2}{|l|}{3.52} & \multicolumn{3}{|l|}{22.0} & \multicolumn{3}{|l|}{61.7} \\
\hline \multicolumn{2}{|c|}{$\alpha$} & \multicolumn{2}{|l|}{0.73} & \multicolumn{3}{|l|}{1.02} & \multicolumn{3}{|l|}{1.00} \\
\hline \multicolumn{2}{|c|}{$2 \alpha / \beta l=K$} & \multicolumn{2}{|l|}{0.78} & \multicolumn{3}{|l|}{0.44} & \multicolumn{3}{|l|}{0.25} \\
\hline & & $4.08 / 3.52$ & $1.16 \mathrm{sec}$ & $0.19 \mathrm{se}$ & & & $0.07 \mathrm{se}$ & & \\
\hline & & $1.5 \mathrm{ft} / \mathrm{sec}$ & $18.0 \mathrm{in} . / \mathrm{sec}$ & $0.45 \mathrm{ft} /$ & $e c=5.4$ & in./sec & $0.12 \mathrm{ft} /$ & $\mathrm{ecc} \simeq 1.4$ & in. $/$ sec \\
\hline TKS & $2 \pi=C$ & 2.59 in. & & $0.072 \mathrm{i}$ & & & $0.004 \mathrm{ir}$ & & \\
\hline CEI & & $23.4 \times 10^{6}$ & n. $-1 b$ & $4.01 \times$ & $j^{6}$ in. $-1 b$ & & $6.29 \times 1$ & $0^{5}$ in. - lb & \\
\hline CEI & & $30.5 \times 10^{3}$ & & $13.0 \times$ & $3^{3} \mathrm{lb}$ & & $3.44 \times 1$ & $0^{3} 1 \mathrm{~b}$ & \\
\hline$x / l$ & $\phi$ & $\phi^{\prime \prime}$ & $\phi^{\prime \prime \prime}$ & $\phi$ & $\phi^{\prime \prime}$ & $\phi^{m}$ & $\phi$ & $\phi^{\prime \prime}$ & $\phi^{\prime \prime \prime}$ \\
\hline 0.0 & 0.000 & 2.000 & -1.468 & 0.000 & 2.000 & -2.037 & 0.00 & 2.000 & -1.999 \\
\hline 0.1 & 0.034 & 1.725 & -1.466 & 0.185 & 1.048 & -2.007 & 0.456 & 0.457 & -1.869 \\
\hline 0.2 & 0.128 & 1.451 & $-1,452$ & 0.602 & 0.140 & -1.827 & 1.209 & -0.790 & -1.206 \\
\hline 0.3 & 0.273 & 1.182 & -1.415 & 1.052 & -0.634 & -1.436 & 1.512 & -1.315 & -0.091 \\
\hline 0.4 & 0.460 & 1.922 & $-1,347$ & 1.367 & -1.179 & -0.860 & 1.052 & -0.948 & 0.965 \\
\hline 0.5 & 0.679 & 0.679 & -1.241 & 1.427 & -1.427 & -0.193 & 0.039 & 0.039 & 1.414 \\
\hline 0.6 & 0.922 & 0.460 & -1.091 & 1.179 & -1.367 & 0.431 & -0.948 & 1.052 & 1.034 \\
\hline 0.7 & 1.182 & 0.273 & -0.894 & 0.634 & -1.052 & -0.867 & -1.315 & 1.512 & 0.090 \\
\hline 0.8 & 1.451 & 0.128 & -0.647 & -0.140 & -0.602 & 0.990 & -0.790 & 1.209 & -0.794 \\
\hline 0.9 & 1.725 & 0.034 & $-0,349$ & -1.048 & -0.185 & 0.715 & 0.457 & 0.456 & -0.959 \\
\hline 1.0 & 2.000 & 0.000 & 0.000 & -2.000 & 0.000 & 0.000 & 2.000 & 0.000 & 0.000 \\
\hline
\end{tabular}

*For values of $\beta \ell, \alpha, \phi, \phi^{*}$, and $\phi^{\prime \prime}$, see Ref. 5.10 .

$\dagger$ From Figs. 1.19 and 1.20.

upper portions of the chimney. The base moment in this case is equal to that computed on the basis of a total uniformly applied static horizontal load of $0.27 \mathrm{~g}$. In practice, moments in chimneys calculated by superposition of modes are sometimes reduced to account for the overestimate of higher mode effects. ${ }^{5.14}$

By way of comparison, some codes ${ }^{5.3}$ specify $0.10 \mathrm{~g}$ for stacks ${ }^{5.3}$ and others ${ }^{5.15}$ require $0.20 \mathrm{~g}$. A stack designed for $0.20 \mathrm{~g}$, using code allowable stresses, would probably survive an earthquake of the intensity assumed in this example without significant over stress, whereas a stack similarly designed for $0.10 \mathrm{~g}$ would be damaged.

\subsection{LIMIT-DESIGN APPROACH}

The earthquake effect on structures with low damping, as demonstrated in Fig. 1.21, is maximized when the period of vibration of the structure ranges from 0.2 to $0.5 \mathrm{sec}$. The accelerations involved can approach $1 \mathrm{~g}$ when elastic response is maintained, and providing for the resulting seismic forces in these circumstances may be very costly in the case of heavy structures. The use of code seismic coefficients under these conditions will result in cost savings but may also result in damage in the event of a major earthquake. For an important structure where some overstress will occur, it is desirable to be able to estimate the amount of plastic deformation and the reserve strength of the structure. The limit-design concept provides this capability for simple structures ${ }^{5.16}$ such as those laterally braced with tension members.

\section{A. Energy Considerations}

The energy input, $U$, of a given earthquake can be estimated in terms of the ordinate to the velocity spectrum, $\mathrm{S}$, and the mass, $\mathrm{m}$, of the structure by Eq. 1.47. This energy 


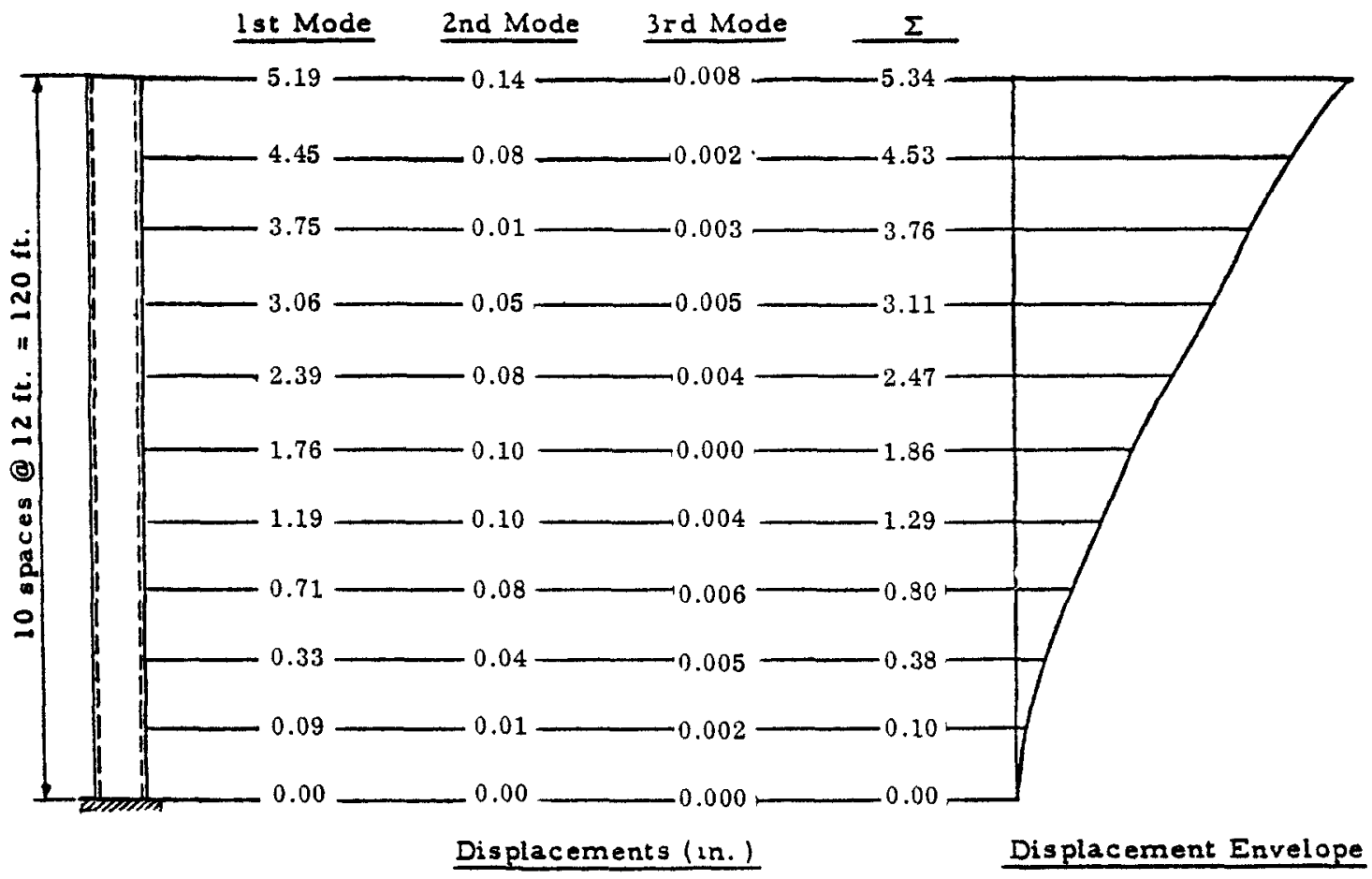

Fig. 5.12-Cantılever chimney, displacements.

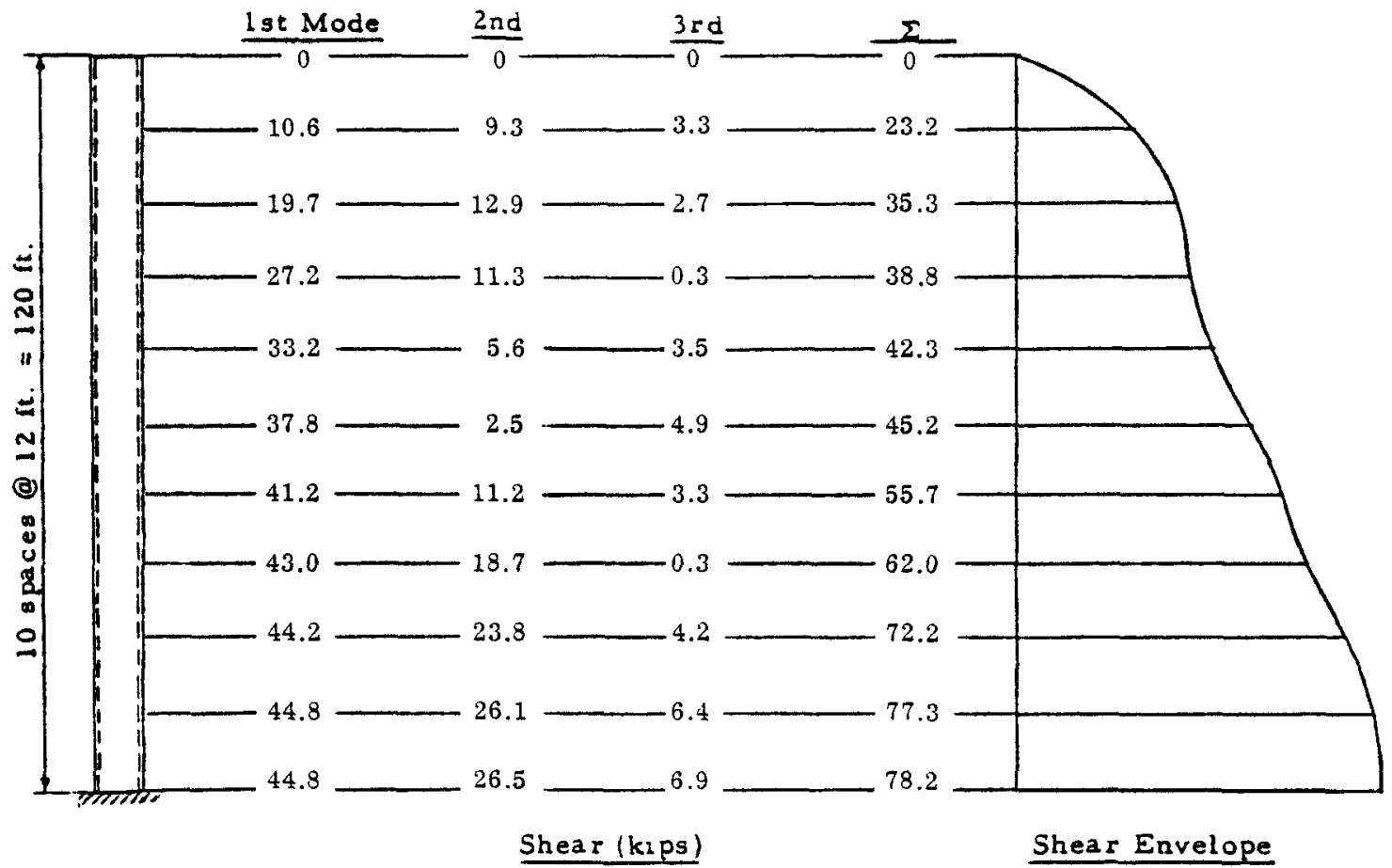

Fig. 5.13-Cantılever chımney, shears. 


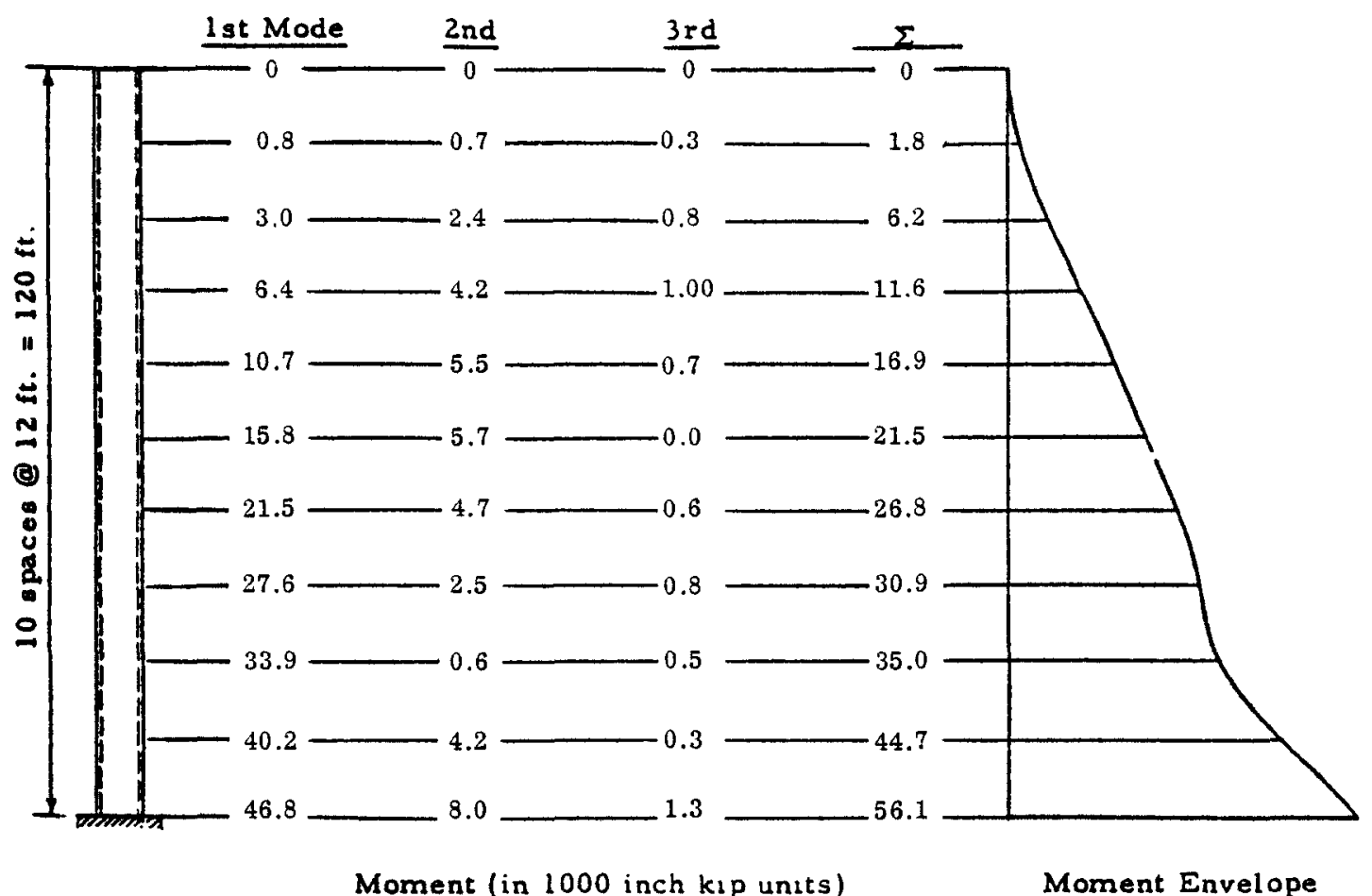

Fig. 5.14-Cantilever chimney, moments.

is stored as elastic strain energy, $\mathrm{V}$, as long as response is elastic; but, when plastic deformation occurs, a portion is dissipated as plastic strain energy, D.

The earthquake motion excites the system into a number of cycles of alternating motion, each excursion above a certain amplitude producing an increment of plastic deformation in the structure which dissipates a part of the energy input. The number of increments and the amount of deformation per increment cannot be determined by using the limit-design method given here. However, the total permanent deformation can be roughly estimated in certain cases.

In the case of a structure laterally braced with tension diagonals, the shear reversals in any given panel due to the excursions stress all the diagonals in the panel, regardless of the direction of slope. Each diagonal becomes effective as an energy dissipator whenever the stress becomes sufficient to cause inelastic stretch. This conclusion is supported by the observed fact that the permanent stretch observed in diagonal bracing rods of tank towers after a strong earthquake is not confined to those sloping in the same direction. ${ }^{5.17}$ Stretching of the rods of opposite slope is also usual, although the amounts of stretch in the two sets of rods are not necessarily equal. Similarly, general nonuniform stretching of anchor bolts has been observed in the case of tall cantilever fractionating columns after a major earthquake. ${ }^{5.17}$

Caution should be used in assuming the number of members that are regarded as being fully effective as energy dissipators. For example, in the limit design of a rodbraced structure four tiers high, with vertical columns supporting a mass at the top, it would be reasonable, in the present state of knowledge, to consider the energy absorption of only two tiers.

B. Ductility

The ductllity of a member can be measured by the ratio of the deflection or strain at impending collapse to the deflection or strain at yield. This ratio, $\mu$, is called the ductility 
factor. The value of $\mu$ for a structural-steel tension member may be very large, from 20 to 100. For a structural-steel flexural member secured against secondary types of failure, 4 may range from 8 to 40 or more. ${ }^{5.18,5.19}$ The ductility factor for reinforced-concrete members depends on the ratios of tensile and compressive steel and may be as high ${ }^{5.19}$ as 30. The ductility factor for compression members should preferably be assumed as unity. Caution should be used in assuming high $\mu$ values to avoid intolerably large deflections.

\section{Plastic Strain Reversal}

It is important to recognize and avoid situations involving alternating plasticity or reversal of plastic strains. This is the type of action that can be illustrated by the breaking of a piece of thin metal due to its repeated flexing in opposite directions.

Very little is known about the effect of such strain reversal on the energy-absorbing capacity of flexural members. $5.20,5.21$ In important structures where such members are to be used as energy absorbers, it is advisable to make certain that no cross section is subjected to plastic strain reversal.

D. Instability

The plastic strains in a structure subjected to a strong earthquake can cause horizontal oscillations of very large magnitude. This may be important in the case of a structure supporting a heavy elevated mass since the resulting eccentric moment caused by horizontal displacement of the mass decreases the seismic resistance of the supporting structure. This destabilizing effect may be accounted for by increasing the total energy input, $\mathrm{U}$, as demonstrated in Example 5.

\section{E. Safety Factor}

A safety factor is necessary in using limit design, applied in such a way that the plastic strain energy provided is some multiple of that required. That is,

$$
\mathrm{D}=\mathrm{c}(\mathrm{U}-\mathrm{V})
$$

where $c$ is the safety factor.

If $c$ is about 3 , the results are comparable to that provided by code requirements in many cases. The use of a safety factor resulting in a design that is considerably lighter than that obtained using code coefficients may be unwise.

Careful detailing is required when plastic strains are involved. All joints must be capable of developing the strength of the weakest member connected.

F. Procedure

In general, the following steps summarize the limit-design approach:

(1) Assume an allowable plastic deformation, which can be a value of the fiber strain in the members or a deflection of the structure. Decide on the number of energy absorbing members to be considered and the required safety factor. Select the appropriate percentage of critical damping.

(2) Calculate the elastic strain energy, $V$, and the energy, $D$, which can be dissipated in plastic deformation.

(3) Estimate a value for $S$ from a spectrum such as that in Fig. 1.19, based on the chosen percentage of critical damping and a roughly estimated period of vibration, $T$. A minimum limiting value of $S$ corresponding to $T=0.5 \mathrm{sec}$ is suggested.

(4) Compute the energy input, U, from Eq. 1.47 and the required energy dissipation from Eq. 5.34.

(5) From the preceding step, estimate the required member sizes. 
(6) Determine the maximum lateral deflection of the structure, allowing for instability effects.

(7) Revise member sizes if required by the results of step 6 .

This procedure is demonstrated in detail in the following example, and results are compared with those obtained by other methods.

\section{G. Example 5}

Size the steel diagonal bracing rods for the pressure-vessel-support structure shown in Fig. 5.15 under the assumptions stipulated below, and compare the results.

(1) Limit-design considerations using the spectrum of Fig. $1.19,2 \%$ critical damping, a safety factor of 3 , a yield stress of $33 \mathrm{ksi}$, an ultimate elongation of $2 \%$, and a modulus of elasticity of $3 \times 10^{7} \mathrm{psi}$

(2) Dynamic considerations using the spectrum of Fig. 1.19, an allowable stress of $33 \mathrm{ksi}$, and $2 \%$ critical damping

(3) A static seismic coefficient of $10 \% \mathrm{~g}$ using an allowable tensile stress of $26.7 \mathrm{ksi}$

Neglect leg deformations in estimating the period of vibration and energy-absorbing capacity. Assume that upset rods are to be used.

\section{Solution (a)}

Energy capacity of structure

From Fig. 5.16 elastic energy per cubic inch of rod = area under stress -strain curve.

$$
\begin{aligned}
& \therefore V=\frac{f_{y} \epsilon_{y}}{2} L \Sigma A=\frac{f_{y}^{2}}{2 E} L \Sigma A(i n .-l b) \\
& D=f_{y}\left(\epsilon_{m}-\epsilon_{y}\right) L \Sigma A=f_{y} \epsilon_{y}(\mu-1) L \Sigma A=\frac{f_{y}^{2}}{E}(\mu-1) L \Sigma A(i n .-l b) \\
& V+D=\frac{f_{y} \epsilon_{y}}{2}(2 \mu-1) L \Sigma A=\frac{f_{y}^{2}}{2 E}(2 \mu-1) L \Sigma A(\text { in. }-1 b) \\
& \frac{V}{D+V}=\frac{1}{2 \mu-1}
\end{aligned}
$$

where $\Sigma A$ is the cross-sectional area of four rods (in. ${ }^{2}$ ).

$$
\begin{aligned}
& \text { If } E=3 \times 10^{7} \text { psi and } f_{y}=33,000 \text { psi, } \epsilon_{y}=\frac{f_{y}}{E}=1.1 \times 10^{-3} \text { in. } / \text { in. } \\
& \text { Since } \epsilon_{m}=0.02 \text { in. } / \text { in. }, \mu=\epsilon_{m} / \epsilon_{y}=0.02 / 0.0011=18.2 ; \text { and, with } \mathrm{L}=340 \text { in., } \\
& D+V=\frac{33,000 \times 0.0011}{2}(2 \times 18.2-1)(340)(\Sigma \mathrm{A}) \\
& D+V=218,000 \Sigma \mathrm{A} \mathrm{in.}-\mathrm{lb}=18,200 \Sigma \mathrm{A} \mathrm{ft}-\mathrm{lb} \\
& \mathrm{V}=\frac{\mathrm{D}+\mathrm{V}}{2 \mu-1}=\frac{18,200 \Sigma \mathrm{A}}{35.4}=\quad 500 \Sigma \mathrm{A} \mathrm{ft}-\mathrm{lb} \\
& D=
\end{aligned}
$$



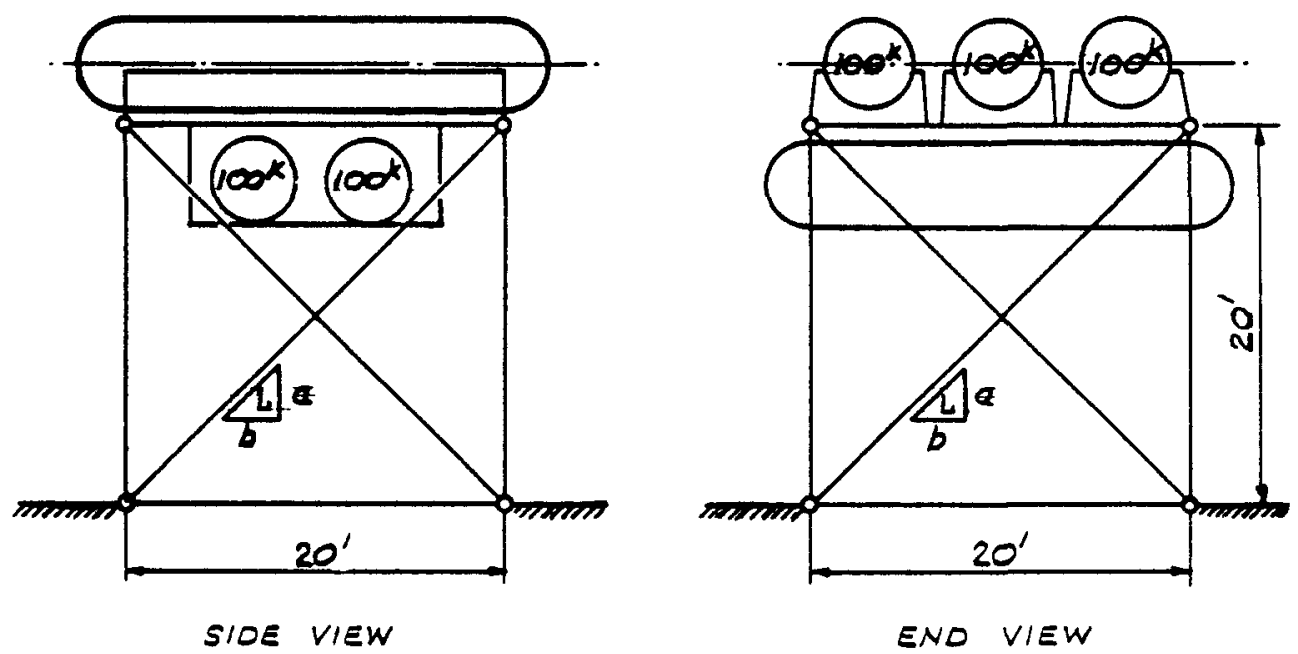

Fig. 5.15-Pressure-vessel-support structure.

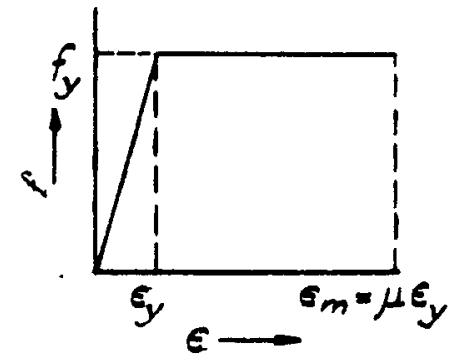

Fig. 5.16-Stress-strain curve.

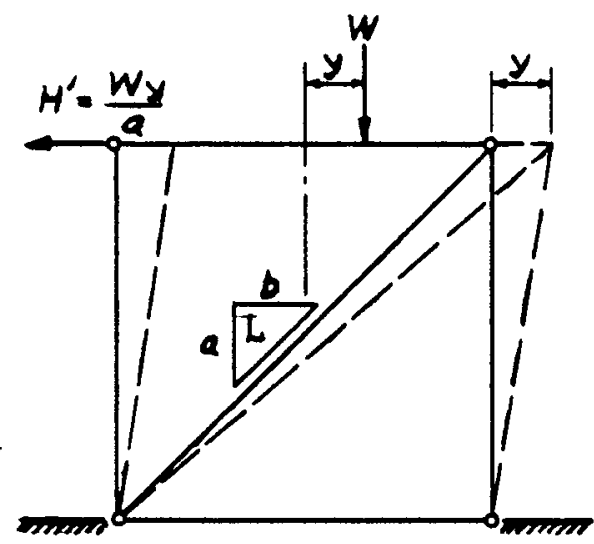

(a)

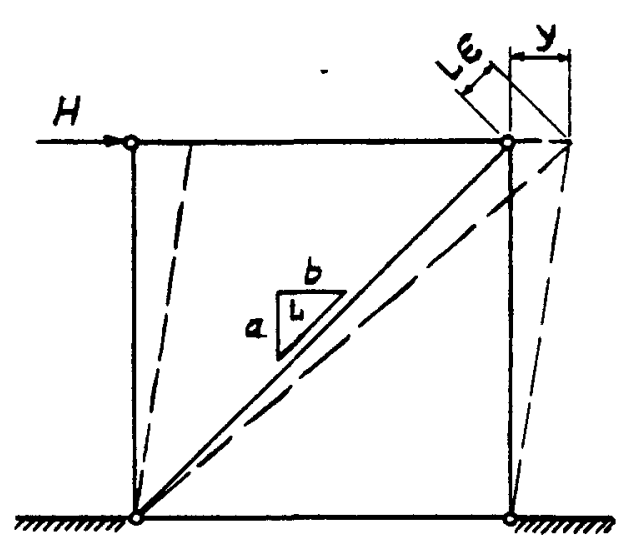

(b)

Fig. 5.17-Deformation of support structure. 


\section{$5.7 \mathrm{G}$}

EXAMPLE 5

Energy input

From Fig. 1.19, for $T$ between 1 and 2 sec and $2 \%$ critical damping, use $S=2.1$ as a good average. Since $T<1 \mathrm{sec}$, this slightly overestimates $S$, which is conservative

$\therefore$ Energy input $U=\frac{W^{2}}{2 g}=\frac{500(1000)(2.1)^{2}}{2(32.2)}=34,200 \mathrm{ft}-\mathrm{lb}$

Required rod size

Using a safety factor of 3 ,

$\mathrm{D}=3(\mathrm{U}-\mathrm{V})$

$17,700 \Sigma \mathrm{A}=3(34,200-500 \Sigma \mathrm{A})=102,600-1500 \Sigma \mathrm{A}$

$\Sigma \mathrm{A}=\frac{102,600}{19,200}=5.34 \mathrm{in.}^{2}$

$\mathrm{A}=0.25 \Sigma \mathrm{A}=1.33 \mathrm{in}^{2}$ per $\operatorname{rod}$

Use $13 / 8$-in.-diameter upset rods (area $A=1.485$ in. $^{2}$ ).

\section{Maximum horizontal deflection}

From (a) of Fig. 5.17, secondary horizontal shear, $\mathrm{H}^{\prime}$, due to vertical load, W, is given by

$$
H^{\prime}=\frac{W y}{a}
$$

Resultant increment of energy input is

$$
\mathrm{U}^{\prime}=\frac{\mathrm{Wy}}{2 \mathrm{a}}=\frac{500 \times 1000}{2 \times 20} \mathrm{y}^{2}=12,500 \mathrm{y}^{2} \mathrm{ft}-\mathrm{lb}
$$

From (b) of Fig. 5.17

$$
\begin{aligned}
& y=L \epsilon \frac{L}{b}=\frac{L^{2} \epsilon}{b}=\frac{L^{2}}{b} \epsilon_{y} \mu=\frac{(340)^{2}}{240}(0.0011 \mu)=0.529 \mu \text { (in.) } \\
& \mathrm{y}=0.044 \mu(\mathrm{ft}) \\
& \therefore \mathrm{U}^{\prime}=12,500(0.044 \mu)^{2}=24.2 \mu^{2} \\
& \mathrm{D}+\mathrm{V}=\frac{f_{y} \epsilon_{y}}{2}(2 \mu-1) L \Sigma \mathrm{A}=\frac{33,000 \times 0.0011}{2}(2 \mu-1)(340)(1.485) \\
& =36,700(2 \mu-1) \text { in. }-\mathrm{lb}=3060(2 \mu-1) \mathrm{ft}-\mathrm{lb} \\
& \mathrm{U}^{\prime}+\mathrm{U}=\mathrm{D}+\mathrm{V} \\
& 24.2 \mu^{2}+34,200=3060(2 \mu-1)
\end{aligned}
$$

Solving, $\mu=6.25 ; \mathrm{y}=0.044 \mu=0.275 \mathrm{ft}=3.3 \mathrm{in}$.

If $\mathrm{U}^{\prime}$ is neglected, $\mu=6.08$ and $\mathrm{y}=3.2 \mathrm{in}$; thus in this case the effect of the secondary horizontal shear due to the vertical load eccentricity is negligible. 
This shear is

$$
\frac{\mathrm{Wy}}{\mathrm{a}}=\frac{500 \times 0.275}{20}=6.87 \mathrm{kips}=\mathrm{H}^{\prime}
$$

Maximum shear $=$ horizontal component of two rod loads $=2 \times 1.485 \times 33 \times 0.707=$ 69.3 kips. Therefore the secondary shear is about $10 \%$ of the total.

This design is equivalent to a code design using a static coefficient of about $11 \%$. Rod size is adequate to withstand three shocks of the intensity corresponding to Fig. 1.19 without exceeding the $2 \%$ rod elongation by more than $3 \%$.

This conclusion implies that the structure is realigned and that rods are retensioned before undergoing a further shock of the same intensity.

\section{Solution (b)}

From (b) of Fig. 5.17, if a 1-kip horizontal load is applied at the to ${ }_{1}$

$$
\begin{aligned}
H & =0.500 \mathrm{kip}=500 \mathrm{lb} \\
y & =L \epsilon^{\prime} \frac{L}{b}=\frac{L^{2}}{b} \epsilon^{\prime}=\frac{L^{2}}{b} \frac{H L}{b} \frac{1}{A E}=\frac{L^{3} H}{b^{2} A E} \\
& =\frac{(340)^{3}(500)}{(240)^{2}(A)\left(3 \times 10^{7}\right)}=\frac{0.0113}{A} \mathrm{in} .
\end{aligned}
$$

$\mathrm{y}_{\mathrm{st}}=$ horizontal deflection due to a 500-kip horizontal load at the top

$$
\mathrm{y}_{\mathrm{st}}=\frac{500 \times 0.0113}{\mathrm{~A}}=\frac{5.65}{\mathrm{~A}} \mathrm{in} \text {. }
$$$$
\mathrm{T}=2 \pi \frac{\sqrt{\mathrm{y}_{\mathrm{st}}}}{\mathrm{g}}=2 \pi \frac{\sqrt{5.65}}{386 \mathrm{~A}}=\frac{6.28}{8.3 \sqrt{\mathrm{A}}}=\frac{0.756}{\sqrt{\mathrm{A}}}
$$

Try $3 \frac{1}{4}$-in.-diameter rod,

$$
\begin{aligned}
& A=8.30 \sqrt{\mathrm{A}}=2.88 \\
& T=\frac{0.756}{2.88}=0.26 \mathrm{sec} \\
& \therefore S_{a}=24.5 \mathrm{ft} / \mathrm{sec}^{2}
\end{aligned}
$$

From Fig. 1.21, for $\mathrm{T}=0.26$ and $2 \%$ critical damping,

$$
\frac{\mathrm{a}}{\mathrm{g}}=\frac{24.5}{32.2} \cong 0.76
$$

$\therefore$ Horizontal shear $=500 \times 0.76=380 \mathrm{kips}$

$$
\begin{aligned}
& \text { Rod load }=380 \times \frac{1.414}{2}=269 \mathrm{kips} \\
& \text { Stress }=\frac{269}{8.30}=32.4 \mathrm{ksi}<33 \mathrm{ksi}
\end{aligned}
$$

Use $3 \frac{1}{4}$-in.-diameter upset rods. 
Solution (c)

Horizontal shear $=0.10(5)(100)=50 \mathrm{kips}$

Load per $\mathrm{rod}=50^{\mathrm{k}}(1 / 2)(1.414)=35.3 \mathrm{kips}$

Required net area $=\frac{35.3}{26.7}=1.32$ in. $^{2}$

Use $13 / 8$-in. -diameter upset rods (area $A=1.485$ in. ${ }^{2}$ ).

Comparison of results

Assumption

(a) Limit-design method

(b) Spectrum method

(c) Use of static-load coefficient
Equivalent, \% g

11

76

10
Rod diameter, in.
$13 / 8$
$3 \frac{1}{4}$
$1 \%$

The penalty in attempting to maintain elastic response (assumption $b$ ) is evident. The resistance required is about 7.5 times greater than that required by assumptions a and c.

The economy in assumptions $a$ and $c$ is obtained at the expense of considerable permanent deformation in the structure, which, in some cases, might not be functionally acceptable.

\subsection{SPECIAL CONSIDERATIONS IN DESIGNING SEISMIC-RESISTANT NUCLEAR-REACTOR STRUCTURES}

A. Seismic-resistance Requirements

As previously stated in Sec. 4.12 , it is not uncommon to provide a higher degree of seismic resistance in critical elements of conventional electric-power generating plants than would be prescribed by earthquake provisions of building codes. Critical components, which include structures and equipment essential to continuous operation, are designed for seismic factors higher than code requirements. For noncritical components that are not absolutely vital to continuing operation, building-code requirements may be used in design.

The temporary shortage of electric power caused by earthquake damage to a conventional power plant is of limited significance compared to the potential threat to the public which might result from fission-product release possibly occasioned by severe earthquake damage to a nuclear reactor. For this reason, reactor structures (both buildings and equipment) whose failure could cause release of fission products might be considered to constitute a category of very critical components which could be termed "category 1" (see Sec. 3.3A). The components of this category should be designed so that the probability of failure approaches zero under the strongest probable earthquake ground motion. In general, the design of these structures should be such that the effect of this ground motion, combined with that from other simultaneous loadings, would cause a resuitant stress that lies below the yield point.

For estimating the strongest probable ground motion and seismicity, the discussion in Sec. 4.12 may serve as a guide in preliminary estimates of relative ground-motion intensities.

Structures in nuclear-power-reactor installations which are important to reactor operation but whose failure would not involve the release of fission products, also require special consideration, but to a lesser degree. In this category, which can be termed "category 2," a limited amount of damage and plastic yielding from the maximum probable ground motion can be considered acceptable. 
A noncritical category, which can be termed "category 3 ," comprises service and support structures not vital to reactor safety and operation. In this category, the use of seismic requirements in building codes is appropriate. When structures are designed in this way, some cracking and plastic yielding can be anticipated under strong ground motion, with significant damage perhaps occurring at maximum probable ground-motion intensities.

B. Static, Dynamic, and Limit-design Methods

Three approaches have been considered in aseismic-structural design: (1) use of static coefficients, (2) a method based on dynamics, and (3) a limit-design method. Each method is appropriate under certain conditions and should not be applied indiscriminately.

Static coefficients at present receive widespread usage, accomplishing results with the least amount of effort, and should be used for structures in the nuclear reactor field which are of lesser importance. In addition, use of static coefficients is the only appropriate alternative where it becomes impractical to estimate with confidence the structural properties required for a dynamic or limit-design analysis. This is true regardless of the importance of the structure. Thus static coefficients may find application in any of the three categories defined in Sec. 5.8A. It is recommended that the static coefficients be not less than the code values. ${ }^{5.3}$

As a prerequisite to the use of any method based on dynamics, the structure and coupling should be sufficiently simple to permit a realistic estimate of the properties needed for analysis. Otherwise, the result may be no better than that obtained using an estimated static coefficient. For structures meeting this requirement, use of the spectrum method of this report is appropriate when it is important that the response of the structure remain within the elastic range, as would be the case for structures in category 1 . The spectrum method may also be warranted when a negligible cost penalty results from designing so as to maintain elastic response under the higher calculated seismic loads sometimes resulting from spectrum analysis even though elastic response may not be mandatory.

In common with the spectrum method, the limit-design approach also requires reasonably accurate estimate of structural properties and is appropriate where some yielding is acceptable, as in the case of some structures in category 2, and where it is also desirable to have an assessment of the remaining reserve strength. Application of limit design to yielding flexural members is subject to more uncertainty than that involved in its application to yielding tension members.

Assignment of allowable stresses should reflect the accuracy with which the seismic loading is evaluated, the stresses being higher when the loading is more reaiistic. No general rule can be stated to cover this situation since considerations other than those of a seismic nature make this a matter that should be decided by the designer. However, in uncomplicated cases where the spectrum approach is used, an allowable stress in tension or flexure approaching the static yield point of the material may be considered. When limit design is applied, the static yield stress of the material is used, but the adequacy of the structure is measured by its energy-absorbing capacity, which is a function of the amount of plastic deformation considered to be acceptable.

C. Vessels and Shells

It has been indicated that vessels attached to a firm foundation could be expected to experience about the same acceleration as that of the ground itself. However, a vessel in an elevated position is a system having one or more degrees of freedom and will often experience an increase in seismic effects, as compared to those encountered when the same structure is directly anchored to a rigid foundation in firm ground. This is es- 
pecially true when the structural elements provided for resisting horizontal forces are relatively flexible members with low damping. Such bracing would have to be designed for very high seismic factors, about $50 \%$ or more, to entirely prevent plastic deformation in the event of a strong earthquake.

When a massive support structure is provided beneath the elevated vessel to carry the vessel, the weight of the reactor, biological shield, and other interior equipment, a very rigid load path can be effected which may be quite capable of functioning elastically under seismic forces. When this condition exists, the main problem resulting from the elevated position (aside from larger seismic forces) becomes possible soil overstress and tilting or differential settlement of the support structure due to the large seismic overturning moment.

Seismic-induced malfunction of the reactor may indirectly cause stresses in the vessel as a result of increased internal pressures which are additive to the stresses caused directly by seismic motion. It is probably unnecessarily conservative to combine maximum values of the internal pressure and seismic stresses since they would probably not coincide in time. The stresses from internal pressure would probably occur after the main earth shock had passed and could decay with time, due to heat losses. Furthermore, the aftershocks immediately following the main shock are usually much less severe than the main shock. It is improbable that an aftershock of intensity comparable to that of the main shock would occur within one or two days of the main shock. Under these conditions it is considered reasonable to combine with the maximum internal pressure only a fraction of the maximum seismic stress, perhaps $50 \%$.

The effect of seismic stresses in increasing leakage rates is unknown. It would probably vary with the stress intensity, and it might be negligible when these stresses are low, for example, in the range of 5000 psi or less in the case of structural steel.

D. Shielding Structures

Support considerations similar to those previously discussed for containment vessels apply to massive, heavily reinforced shielding structures of concrete. When supported directly on the ground, it is often permissible to consider such a structure as a rigid body. However, if any flexibility exists in the structure, seismic-induced flexural tension may be sufficient to require reinforcing steel in addition to that needed for thermal or other considerations.

Flexibility requirements for the alleviation of thermal stresses may result in an articulated construction that may be unfavorable from a seismic standpoint. For example, intersections of abutting shielding walls or intersections of shielding walls and the top shield may have to permit relative movement under temperature cycling, which would reduce the continuity normally characteristic of monolithic reinforced-concrete construction that is usually relied upon for load transfer under seismic conditions.

Laminated constructions, combining concrete with metal, may require that relative interlaminar slippage be considered unless special measures are taken to ensure bond capable of transferring the necessary shearing forces across the contact interface.

Similar constructions combining metal and wood may also be susceptible to such slippage. Shielding walls with a core constructed in blocks consisting of vertical wood and metal lamina sandwiched between metal facings have an indeterminate, but very low, seismic resistance unless special features are incorporated to permit shear transfer between lamination and between blocks. The resistance to loads applied normal to the plane of the wall, where the load is sufficiently intense to cause slippage, would be essentially that of the facings (which would probably be continuous plates spanning between wall boundaries) resulting in large deflections when the ratio of span to plate thickness is large. Since it is usually not feasible to prevent core slippage, this type of construction should be avoided if seismic integrity is a design consideration. 


\section{E. Exhaust Stacks}

The method presented in Sec. 5.6 is satisfactory for the design of cantilever stacks having a constant cross section anchored directly to a foundation on firm ground, but it may not be satisfactory when applied to stacks that taper in cross section or thickness. Tall cantilever stacks of either constant or variable section, mounted on a flexible supporting structure, are subject to amplification of seismic effects, as previously discussed in the case of vessels and shields, and definitely require special treatment. The subject of seismic effects on tall stacks has received considerable attention in recent technical literature (Refs. 5.14 and 5.22 to 5.24 ), much of it consisting of attempts to simplify the aseismic design of such structures.

Application of the spectrum curves to elevated stacks or those of variable section involves the determination of the shapes of at least the first three modes of vibration. An analytical method is theoretically possible for the case of an elevated stack of constant section, but numerical integration processes are generally required whenever the stack section varies. These routines can be performed by hand computation, but they are very time consuming and involve a tremendous amount of detail that is more efficiently handled by electronic computers.

In tall flexible chimneys it is typical to find that the calculated bending moments in the lower portion, based on a dynamic analysis, are less than those computed by considering the chimney as a rigid body subjected throughout its height to a uniform acceleration equal to the assumed maximum ground acceleration. Conversely, at sections in the middle region and above, the bending moments based on dynamics are typically greater than those corresponding to the rigid-body assumption. This agrees with the observed prevalence of failures in reinforced-concrete chimneys at levels above the third point in height. ${ }^{5.23}$

Chimney linings should receive special attention when continuous operation is mandatory after an earthquake. Solid brick linings supported on corbels at frequent intervals are preferable from an earthquake standpoint to perforated brick linings with a large corbel spacing. Linings of pneumatically applied, heat-resistant concrete, or metal linings of special alloy steel, can provide increased seismic resistance where their use is otherwise feasible.

\section{F. Auxiliary Structures}

Auxiliary structures include buildings whose structural integrity is relatively unimportant to the function of the reactor. In this category, for example, are administration buildings, warehouses, garages, and maintenance facilities. The building-code seismic requirements of Ref. 5.3 are considered to be appropriate for these structures. As has been emphasized previously, some damage could be expected, but a greater degree of protection for these structures would have little economic justification.

\section{G. Equipment and Piping}

The usual seismic problem with respect to equipment is the prevention of malfunction. Such malfunction may originate internally, owing to sensitivity to earthquake motion of the internal parts. It may originate from external causes, such as support failure.

The equipment item, with its supports, is usually a structure with small damping and a short period of vibration. Therefore the structure must be designed for an unusually high seismic factor, often $0.50 \mathrm{~g}$ or more, to maintain elastic response to strong earthquake motion. When it is extremely important that no overstressing be permitted and when the structure is simple enough that its periods of vibration and damping factors can be reliably estimated, the use of the earthquake spectrum is recommended in deter mining the earthquake effect. 
When the supporting element is a structure that responds as a rigid body, the points at which the equipment is attached are subjected to essentially the same acceleration as that of the ground itself. In this case it is often possible to approximate the seismic response of the equipment as that of a system having one degree of freedom, to which the procedure of Sec. 5.4 applies.

When the support structure is elastically coupled to the ground, the equipment and the support structure can frequently be idealized as a system with two degrees of freedom. Under these conditions the procedure of Sec. 5.4 can be used to estimate the response of the equipment.

An effort should be made to keep the structural system simple enough so that its response can be determined in a rational and straightforward manner. Obviously this cannot always be done. The designer must then estimate the proper seismic factor by more refined analysis, overlapping assumptions, study of simplified versions of the structure, judgment, or other means suited to the time available. For zone 3 conditions it does not seem advisable to use a coefficient of less than $0.2 \mathrm{~g}$ for equipment items of major importance. In this zone a coefficient of $0.1 \mathrm{~g}$ seems appropriate for equipment of a minor nature where the cost penalty in using $0.2 \mathrm{~g}$ would be significant and where failure would not jeopardize important functions or human life.

Since piping often joins numerous pieces of equipment, a very complex coupled structural system would result if the piping were rigid. Usually, however, problems of thermal expansion require flexibility in the piping, which largely reduces the coupling.

The need for flexibility in piping to accommodate thermal movement often tends to be incompatible with the requirement for restraint to resist seismic effects. In such cases this leads to the use of widely spaced lateral stays, limit stops instead of solid supports, or hydraulic snubbers which permit slow thermal movements but which act as solid supports under transient loads.

Under these conditions seismic resistance can often be obtained by (1) designing the equipment supports to carry the entire tributary horizontal seismic force and (2) providing sufficient flexibility in the piping to accommodate the differential movements involved without overstress.

Seismic stresses in runs of straight piping, due to lateral ground motion normal to the axis of the pipe, are rarely critical when it is possible to provide lateral support at each vertical support.

Long, laterally unsupported pipe loops in a vertical plane presents a more complex problem, requiring consideration of ground motion both normal and parallel to the plane of the piping, for which no generalizations are applicable. If functionally acceptable, simplification results when bracing can be provided near each elbow which approximates the condition occurring in a series of straight runs.

Laierally flexible equipment supports are sometimes used, apparencly for the purpose of eliminating the flexible joints in the piping which would normally be required to provide for thermal movement. Under these conditions seismic resistance is provided primarily by the piping itself, and it may be extremely difficult to evaluate in all but the simplest systems.

As in the case of building structures, it is reasonable, when considering seismic forces acting on piping systems, to permit an increase in allowable stresses used under nonseismic conditions. In those piping-system designs where thermal stresses predominate, with stresses due to pressure and dead load being fairly low, such an increase readily permits tolerating high seismic factors in many cases.

Use of the electronic computer to evaluate stresses in highly redundant piping systems is a recent development that often makes it practical to consider the entire piping system as a single structural entity. Programs that are capable of determining stresses due to static forces, such as dead load or wind, can perform the rigid-body type of analysis for seismic stresses in which the exciting force at any point in the system is propor- 
tional to the mass at that point. Pipe-stress programs, which have been extended to solve dynamic problems, may be capable of determining seismic stresses more precisely through the use of the spectrum technique. The cost of this added precision should be weighed against the anticipated benefits of the more refined analysis.

In addition to earthquake intensity, the seismic performance of buried pipe depends strongly on factors related to soil properties, bedding, pipe material, type, design, and workmanship of joints, and restraints such as penetrations into structures. The movement of buried pipe is essentially that of the surrounding soil, whether this occurs under normal service conditions or under earthquake ground motion. Examples of unfavorable environments are shallow depths of burial in unstable ground and poorly compacted fill over improperly bedded pipe. The use of ductile pipe materials, flexible couplings, and similar provisions for differential movement are needed for a high degree of integrity in buried pipe systems.

Cast-iron pipe and fittings are vulnerable to earthquake effects. Where the hazard from rupture is great, steel pipe and fittings should be used. The earthquake performance of threaded joints is also poor.

\section{REFERENCES}

5.1 Building Code Requirements for Reinforced Concrete (AC1 318-56), American Concrete Institute (P. O. Box 4754, Redford Station, or 18263 West McNichols Road), Detroit 19 , Mich., January 1953.

5.2 C. D. Williams and C. E. Cutts, Structural Design in Reinforced Concrete, The Ronald Press Company, New York, 1954.

5.3 Uniform Building Code, Pacific Coast Building Officials Conference, 610 South Broadway, Los Angeles 14, Calif., 1958.

5.4 D. E. Hudson, Response Spectrum Techniques in Engineering Seismology, in Proceedings of the World Conference on Earthquake Engineering, Earthquake Engineering Research Institute, 1956.

5.5 S. Timoshenko, Vibration Problems in Engineering, 3rd ed., D. Van Nostrand Company, Inc., Princeton, N. J., 1955.

5.6 S. Timoshenko, Vibration Problems in Engineering, 2nd ed., D. Van Nostrand Company, Inc., Princeton, N. J., 1937.

5.7 L. C. Maugh, Statically Indeterminate Structures, John Wiley \& Sons, Inc., New York, 1946.

5.8 L. E. Grinter, Theory of Modern Steel Structures, Vol. II, revised edition, The Macmillan Co., New York, 1949.

5.9 H. Sutherland and H. L. Bowman, Structural Theory, 4th ed., John Wiley \& Sons, Inc., New York, 1950.

5.10 Dana Young and Robert P. Felgar, Jr., Tables of Characteristic Functions Representing Normal Modes of Vibration of a Beam, Engineering Research Series No. 44, Bureau of Engineering Research, University of Texas Publication No. 4913, July 1, 1949.

5.11 Robert P. Felgar, Jr., rormulas for Integrals Containing Characteristic Functions of a Vibrating Beam, Circular No. 14, Bureau of Engineering Research, University of Texas, Austin 12, Texas.

5.12 J. A. Cheney, Structural Analysis by Dynamic Load Parameters, J. Am. Concrete Inst. (July 1956).

5.13 D. F. Moran and J. A. Cheney, Earthquake Response of Elevated Tanks and Vessels, Proc. Am. Soc. Civil Engrs., Paper 1563 (March 1958).

5.14 J. E. Rinne, Earthquake Design Criteria for Stack-like Structures, Proc. Am. Soc. Civil Engrs., Paper 1696 (July 1958).

5.15 Los Angeles City Building Code, Uniform Building Code Association, Inc., 610 South Broadway, Los Angeles 14, Calif., 1957. 
5.16 G. W. Housner, Limit Design of Structures to Resist Earthquakes, in Proceedings of the World Conference on Earthquake Engineering, Earthquake Engineering Research Institute, 1956.

5.17 K. V. Steinbrugge and D. F. Moran, An Engineering Study of the Southern California Earthquake of July 21, 1952, and Its Aftershocks, Bull. Seismol. Soc. Am., 44(2B): Part II (April 1954).

5.18 R. L. Sanks and J. F. Woolley, Proceedings of Structural Engineering Conference on Plastic Design in Structural Steel, Department of Civil Engineering, University of Utah, October 1957.

5.19 N. M. Newmark, An Engineering Approach to Blast-resistant Design, Trans. Am. Soc. Civil Engrs. (1956).

5.20 L. S. Beedle, B. Thurlimann, and R. L. Ketter, Plastic Design in Structural Steel, Lecture Notes, Summer Course, Lehigh University and American Institute of Steel Construction, September 1955.

5.21 K. E. Knudsen, C. H. Yang, B. G. Johnston, and L. S. Beedle, Plastic Strength and Deflec tions of Continuous Beams, Progress Report No. 9, Fritz Engineering Laboratory Report No. 86, Lehigh University.

5.22 ACI Committee 505, Proposed Standard Specifications for the Design and Construction of Reinforced Concrete Chimneys, J. Am. Concrete Inst. (January 1953).

5.23 G. W. Housner, Earthquake Resistant Design Based on Dynamic Properties of Earth- , quakes, J. Am. Concrete Inst. (July 1956).

5.24 N. M. Isada, Design and Analyses of Tall, Tapered Reinforced Concrete Chimneys Subjected to Earthquake, in Proceedings of the World Conference on Earthquake Engineering, Earthquake Engineering Research Institute, 1956.

5.25 Proceedings of Second World Conference on Earthquake Engineering, Science Council of Japan, Tokyo, 1960. 


\section{Chapter 6}

\section{DYNAMIC PRESSURE ON FLUID CONTAINERS}

\begin{tabular}{|c|c|c|}
\hline & FIGURES & $\begin{array}{l}\text { 6.10 Rectangular Tank, } h_{1} / h \text { vs. } l / h \text {, Including Bottom Pressure. } \\
\text { 6.11 Rectangular Tank, } l \theta_{h} / A_{1} \text { vs. } l / h \text {. }\end{array}$ \\
\hline 6.1 & Dynamic Model for Fluid Container Supported on the Ground. & 6.12 Cylindrical Tank, $\mathrm{w}_{1} / \mathrm{W}$ vs, $\mathrm{R} / \mathrm{h}$ \\
\hline 6.2 & Slender Ground-supported Water Tank. & 6 13 Cylindrical Tank, $h_{4} / h$ vs. R/h. Excluding Bottom Pressure. \\
\hline 6.3 & Dynamic Models for Elevated Fluid Container. & 6.14 Cylindrical Tank. $h_{1} / h$ vs. $R / h$. Including Bottom Pressure \\
\hline 6.4 & Elevated Water Tank. & 6.15 Cylindrical Tank, $R \theta_{h} / A_{1}$ vs. $R / h$. \\
\hline 6.5 & Elovated Water Tank Showing Mode Shapes and Inertia Forces. & \\
\hline 6.6 & Rectangular Tank, $w_{0} / w$ vs. $l / h$; Cylindrical Tank. $W_{0} / w$ vs. $R / h$. & TABLES \\
\hline 6.7 & Rectangular Tank. $h_{q} / \mathrm{h}$ vs. l/h: Cylindrical Tank, ho/h vs. R/h. & \\
\hline 6.8 & Rectangular Tank, $W_{1} / W$ vs. $\mathcal{L}$ h. & 6.1 Calculation of Convective Forces. \\
\hline 6.9 & Rectengular Tank, $h_{1} / \mathrm{h}$ vs $\mathrm{l} / \mathrm{h}$, Excluding Bottom Pressure. & 6.2 Curyes for Ground-supported Tanks. \\
\hline
\end{tabular}

\section{NOMENCLATURE*}

A $\quad$ Maximum displacement of $W_{1}$.

$\mathrm{d}_{\max }$. Maximum water-surface displacement.

EBP Excluding bottom pressure (excluding the effect of the dynamic fluid pressure on the tank bottom).

F Total seismic force $\left(F=F_{0}+F_{1}\right)$.

$F_{0}, F_{1} \quad$ Seismic forces on $W_{0}$ and $W_{1}$ (inertia forces due to acceleration).

g Acceleration of gravity.

$\mathrm{h} \quad$ Height of water surface above the bottom of the tank.

$\mathrm{h}_{0}, \mathrm{~h}_{0}^{\mu}, \mathrm{h}_{1}$ Vertical distance from the tank bottom to $\mathrm{W}_{0}, \mathrm{~W}_{0}^{n}$, and $\mathrm{W}_{1}$, respectively.

IBP Including bottom pressure (including the effect of the dynamic fluid pressure on the tank bottom).

k Spring constant.

$k_{1} \quad$ Spring constant for $W_{1}$.

$k_{0} \quad$ Spring constant for $W_{0}$.

$\ell \quad$ One-half length of rectangular tank wall.

$\mathrm{m} \quad$ Mass of vibrating body.

$\mathrm{M}_{0}, \mathrm{M}_{1} \quad$ Bending moment on a horizontal section of the tank just above the bottom, due to $\mathrm{P}_{0}$ and $\mathrm{P}_{1}$, respectively. Overturning moment on a horizontal plane just below the bottom, due to $\mathrm{P}_{0}$ and $\mathrm{P}_{1}$, respectively.

$\mathrm{M}_{0}^{\prime \prime} \quad$ Modified $\mathrm{M}_{0}$ value corresponding to equivalent weight $\mathrm{W}_{0}^{\prime \prime}$.

(Nomenclature listing continues on next page.)

*In the case of a cylindrical tank, the equivalent weights $\mathrm{W}_{0}$ and $\mathrm{W}_{0}^{\prime \prime}$ and the corresponding forces and moments apply to the entire tank; whereas, in the case of a rectangular tank, these quantities apply to the particular width used in computing $W$. This could be the total width or a unit width. 
6.1

$\mathrm{P}_{0}, \mathrm{P}_{1}$

$\mathrm{P}_{0}^{\prime \prime}$

Q

$\mathbf{R}$

$\mathrm{S}$

$T$

$\mathrm{t}$

$\dot{u}_{0}$

W

$\mathrm{W}_{\text {o }}$

$\mathrm{W}_{0}^{\prime \prime}$

$W_{1}$

$\overline{\mathrm{y}}_{0,} \overline{\mathrm{y}}_{1}$

$\mathrm{y}_{\text {st }}$

$\theta_{\mathrm{h}}$

$\rho$

$\phi_{\text {on }}$

$\omega_{\mathrm{n}}$

\section{INTRODUCTION}

Impulsive and convective forces, respectively.

Modified $\mathbf{P}_{0}$ value corresponding to equivalent weight $W_{0}^{m}$.

A multiplier in the expression for $d_{\text {max. }}$.

Radius of cylindrical tank.

Ordinate to velocity spectrum.

Period of vibration.

Time for which seismic deflection is evaluated.

Maximum horizontal acceleration of the ground during an earthquake.

Total weight of fluid in a cylindrical tank. Weight of fluid in a specified width of a rectangular container (width measured normal to the length, $l$ ).

Equivalent weight of fluid to produce the impulsive force $P_{0}$ on the tank wall ( $W_{0}$ is assumed to be fastened rigidly to the tank walls at height $h_{0}$ above the tank bottom).

Gross equivalent weight to produce the impulsive force $\mathrm{P}_{0}^{\prime \prime}$ on the tank wall ( $\mathrm{W}_{0}$ plus tank weight and tributary weight of the support structure). In the case of a slender tank with $\mathrm{h}>1.5 \mathrm{l}$ or $\mathrm{h}>1.5 \mathrm{R}, \mathrm{W}_{0}^{n}$ also includes the weight of constrained water. (The corresponding forces, arms, and moments are designated $\mathrm{P}_{0}^{n}, \mathrm{~h}_{0}^{n}$, and $\mathrm{M}_{0}^{n}$, respectively.)

Equivalent oscillating weight to produce the convective force $P_{1}$ on tank wall ( $W_{1}$ is assumed to be fastened to the tank walls by springs at height $h_{1}$ above the tank bottom).

Maximum displacement of $W_{0}$ and $W_{1}$.

Static deflection due to a unit horizontal force.

Angular amplitude of free oscillations at the fluid surface (see Fig. F.7), based on the assumption of a plane water surface.

Mass density of fluid.

Amplitude ratio for the $n$th mode, defined as the maximum displacement of $W_{0}$ when $W_{0}$ and $W_{1}$ act as a two-degree-of-freedom system in free vibration, with the maximum displacement of $W_{1}$ assumed to be unity.

Circular frequency of free vibration for the $\mathrm{n}$ th mode.

\subsection{INTRODUCTION}

The horizontal acceleration of a fluid container generates horizontal hydrodynamic forces acting outward on one side of the tank and inward on the opposite side. A resultant force, $P$, is created which tends to translate the tank horizontally. This force, which is the sum of the dynamic fluid forces acting on each side of the tank, is numerically equal to the horizontal shear on a section just above the bottom of the tank. The force $\mathrm{P}$ acts on the tank at some distance above the bottom and creates a bending moment, $M$, at a section just above the bottom. This moment is resisted by a vertical couple consisting of compressive fiber stresses in the tank wall on the side that resists outward forces and tensile stresses in the wall on the opposite side.

Dynamic fluid forces are also generated on the bottom of the tank. These forces are equivalent to a vertical couple that is additive to the bending moment previously described and combine with the bending moment to create the overturning moment acting on the supporting structure. For convenience the overturning moment is computed by increasing the vertical arm of the force $P$ to allow for the vertical couple acting on the tank bottom, instead of adding this couple separately to the previously computed bending moment.

The shear and bending moment are of structural interest in their effect on the tank walls and attachment to the supports. The shear and overturning moment have a similar importance in their influence on the supporting structure. The method presented in this chapter evaluates these quantities and provides an estimate of the maximum vertical displacement of the water surface. 


\subsection{GENERAL APPROACH}

The mathematically precise procedure for determining seismically induced fluid pressures developed in a tank is very complex. Consequently the approach presented in this chapter ${ }^{6.1}$ is based on simplifications that involve some approximation; how ever, the results are sufficiently accurate for engineering use. The method applies to flat-bottomed, vertically oriented tanks of uniform rectangular or circular section (see Appendix $\mathrm{F}$ for derivations). Nomenclature is given at the beginning of this chapter, and a summary of formulas is given in Sec. 6.3.

When a tank containing fluid of weight $W$ is accelerated in a horizontal direction, a certain portion of the fluid acts as if it were a solid mass of weight $\mathrm{W}_{0}$ in rigid contact with the walls. Assuming that the tank moves as a rigid body, with the bottom and walls undergoing the same acceleration, the mass then exerts a maximum horizontal force directly proportional to the maximum acceleration of the tank bottom. This force is identified as an impulsive force, $P_{0}$. The acceleration also induces oscillations of the fluid, contributing additional dynamic pressures on the walls and bottom, in which a certain portion of the fluid, of weight $\mathrm{W}_{1}$, responds as if it were a solid oscillating mass flexibly connected to the walls. Again assuming that the tank itself behaves as a rigid body, the maximum amplitude, $A_{1}$, of the horizontal excursions of the mass relative to the walls determines both the maximum vertical displacement, $d_{\max }$, of the water surface (slosh height) and the horizontal force exerted on the walls. This force is defined as a convective force, $P_{1}$, since it involves fluid motion.

These considerations lead to the idealization shown in Fig. 6.1, in which the tank in (a) is replaced with the unsprung and sprung masses represented by weights $W_{0}$ and $W_{1}$, respectively, in (b). Accelerations of the tank induce the impulsive forces $P_{0}$ and the convective forces $P_{1}$ shown in (c).

The dimensions $h_{0}$ and $h_{1}$ locate the resultant forces $F_{0}$ and $P_{1}$ and determine the moment at the tank bottom. As previously stated, the overturning moment is computed by increasing these vertical arms to allow for the moment of the dynamic fluid forces acting on the bottom. Consequently each $\mathrm{arm}, \mathrm{h}_{0}$ and $h_{1}$, has two distinct numerical values, the smaller value being used to evaluate the bending moment on a plane just above the bottom and the larger value being used for determining the overturning moment on a plane just below the bottom. The smaller value does not account for the dynamic fluid pressures on the bottom. For identification purposes in the formulas of Sec. 6.3, this case is designated by the term EBP (excluding bottom pressure), whereas the larger value is distinguished by the term IBP (including bottom pressure).

The weight of the tank and the effective weight of the supporting structure are usually small compared to the weight of the fluid. They are conveniently accounted for by increasing $\mathrm{W}_{0}$ to obtain a modified weight, $\mathrm{W}_{0}^{n}$, with corresponding force, $\mathrm{P}_{0}^{\prime \prime}$, arms, $\mathrm{h}_{0}^{\prime \prime}$, and moments, $\mathrm{M}_{0}^{\prime \prime}$.

\subsection{FORMULAS FOR TANKS SUPPORTED ON THE GROUND}

The equations given below for impulsive and convective forces and their related quantities for both rectangular and cylindrical tanks have been developed by Housner. ${ }^{6.1}$ They are restated here in simplified forms and in order of the calculation steps listed in Sec. 6.4. Curves representing these equations graphically are presented in Sec. 6.8.

In the case of a cylindrical tank, the equivalent weights $W_{0}$ and $W_{1}$ and the corresponding forces and moments given by the equations apply to the entire tank; whereas, in the case of a rectangular tank, these quantities apply to the particular width that was used in computing the fluid weight $\mathrm{W}$. This would usually be either the total width or a unit width.

Any dimensionally consistent system of units may be used. In the examples presented, foot-kip-second units are used. 
6.3 FORMULAS FOR TANKS SUPPORTED ON THE GROUND

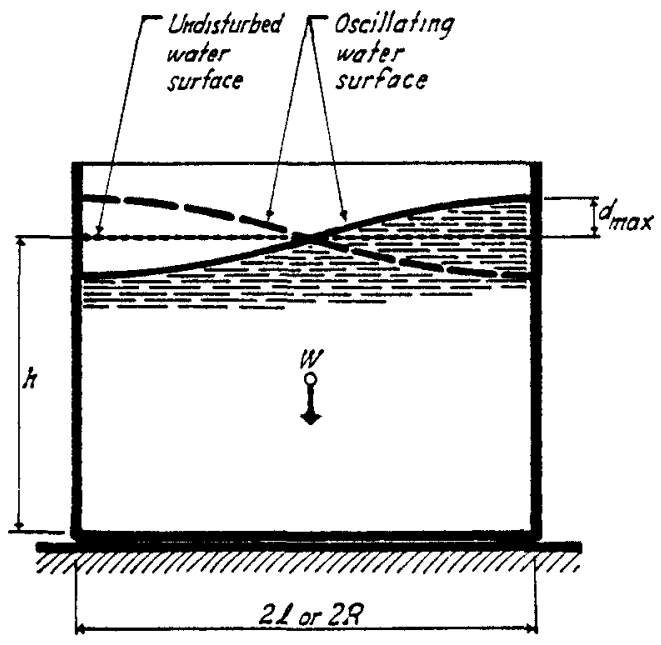

(a)

\section{Eluid Motion \\ in Tank}

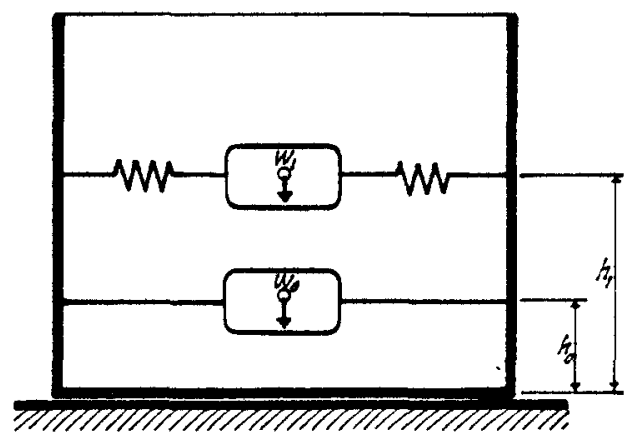

(b)

Dynamic

Model

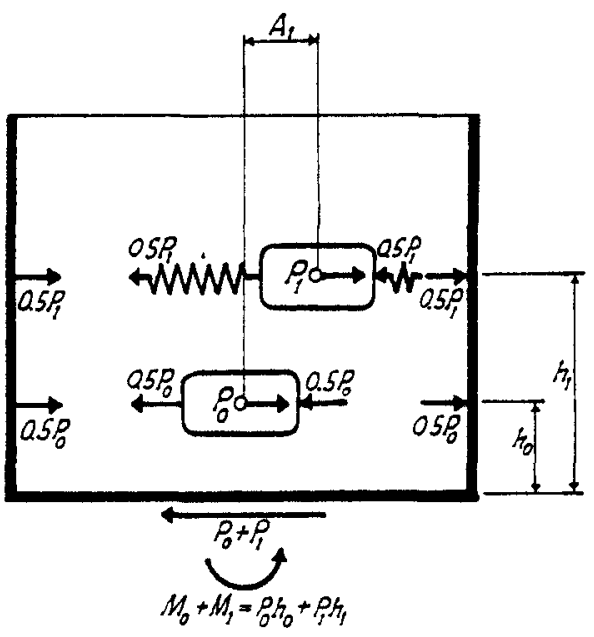

(c)

Dynamic Equilibrium of Horizontal Forces

Fig. 6.1-Dynamic model for fluid container supported on the ground. (a) Fluid motion in tank. (b) Dynamı model. (c) Dynamic equilibrium of horizontal forces. 
A tabulation cross - referencing the equation numbers in this chapter with corresponding equations in Appendix F and Ref. 6.1 is presented in Sec. F.6.

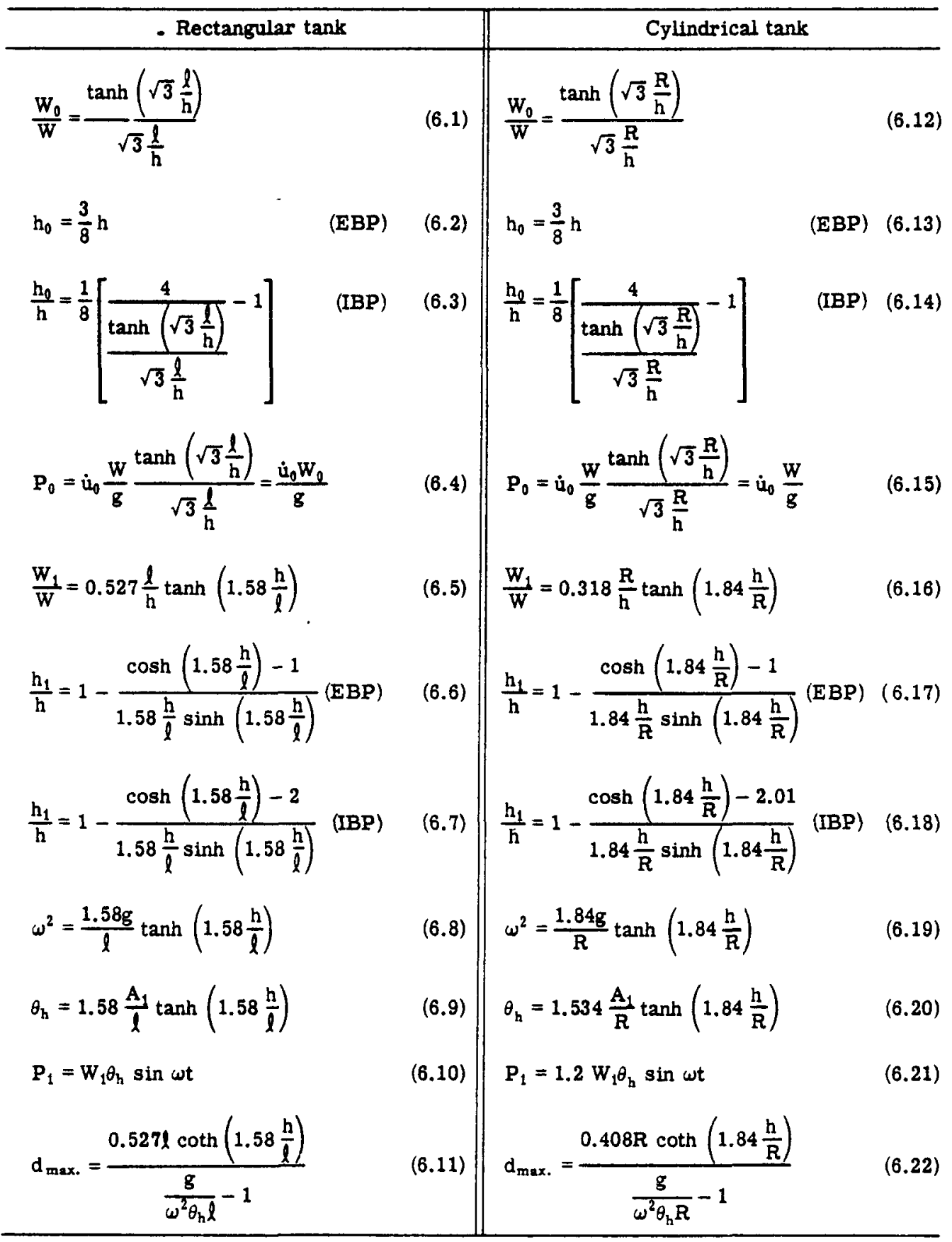

\subsection{TANKS SUPPORTED ON THE GROUND ( $h / l$ or $h / R \leq 1.5)$}

When a tank is sitting on its foundation at ground level, the motion of both the foundation and the tank is essentially that of the ground. Therefore the weight $W_{0}$ 
in the dynamic model of (b) of Fig. 6.1 responds as a rigid body (Sec. 5.3) undergoing a maximum acceleration $\dot{\mathrm{u}}_{0}$, equal to the maximum ground acceleration of the earthquake. The force $P_{0}[(c)$ of Fig. 6.1$]$ is obtained as the product $W_{0} \dot{\mathbf{u}}_{0} / g$.

The weight $\mathrm{W}_{1}$, being flexibly supported, responds as a single-degree-of -freedom system, to which the considerations of Sec. 5.4 apply. Equation 5.4 is applicable, the resulting value of $y_{\max }$. being equal to the maximum amplitude, $A_{1}$, of the oscillations of $W_{1}$ relative to the tank walls. The force $P_{1}$ can be computed either as indicated in step 4 of Sec. 5.4 or by Eqs. 6.10 or 6.21. The total horizontal shear at the bottom of the tank is the sum of $P_{0}$ and $P_{1}$.

When a tank is supported on the ground, with $h \leq 1.5 l$ or $h \leq 1.5 \mathrm{R}$, the procedure for calculating the forces and water-surface displacement caused by an earthquake is as follows:

(1) Calculate $W_{0}$ and the two $h_{0}$ values, one excluding the fluid pressure on the bottom and the other including the fluid pressure on the bottom. Height $h_{0}=$ $3 / 8 \mathrm{~h}$ when the effect of fluid pressure on the bottom is ignored.

(2) From the above value of $\mathrm{W}_{0}$ and the tank weight, obtain the gross equivalent weight $\mathrm{W}_{0}^{\prime \prime}$ and the corresponding $\mathrm{h}_{0}^{\prime \prime}$ values.

(3) Obtain the impulsive force, $P_{0}^{\prime \prime}$, from $W_{0}^{\prime \prime}$, determining the maximum seismic horizontal acceleration, $\dot{\mathrm{u}}_{0}$, from a spectrum curve such as Fig. 1.21 for $\mathbf{T}=0$ or from a tabulation such as Table 1.2.

(4) Determine the impulsive bending moment at the base of the tank and the impulsive overturning moment using the $\mathrm{h}_{0}^{\|}$values in step 2 .

(5) Calculate $W_{1}$ and the two $h_{1}$ values, one excluding the dynamic fluid pressure on the bottom and the other including the dynamic fluid pressure on the bottom.

(6) Obtain the natural frequency, $\omega$, and the period of vibration, $T$, from which the quantity $S$ may be obtained for the appropriate damping from a spectrum such as that shown in Fig. 1.19.

(7) Using $S$, compute the maximum amplitude, $A_{1}$, of the displacement; the angle of free oscillation, $\theta_{h}$, at the water surface; and the convective force, $P_{1}$.

(8) Compute the maximum water-surface displacement, $d_{\max }$ (above its original level) from the values of $\omega$ and $\theta_{\mathrm{h}}$; and the maximum bending moment, over turning moment, and shear at the base of the tank.

The example given below illustrates the application of this procedure in detall.

\section{Example 1}

A cylindrical tank $26 \mathrm{ft}$ in diameter and containing $15 \mathrm{ft}$ of water is supported on the ground. Assume its response to be based on the spectrum of Fig. 1.19, with $1 / 2 \%$ critical damping. Determine impulsive and convective forces and moments and displacement of the water surface.

\section{Solution}

Impulsive force

From Eq. 6.12

$$
\begin{aligned}
& \frac{\mathrm{W}_{0}}{\mathrm{~W}}=\frac{\tanh \left(\sqrt{3} \frac{\mathrm{R}}{\mathrm{h}}\right)}{\sqrt{3} \frac{\mathrm{R}}{\mathrm{h}}}=\frac{\tanh \left(\sqrt{3} \frac{13}{15}\right)}{\sqrt{3} \frac{13}{15}}=0.602 \\
& \mathrm{~W}=\pi\left(13^{2}\right)(15) \frac{(62.4)}{1000}=496 \mathrm{kips}, \mathrm{W}_{0}=0.602(496)=298.5 \mathrm{kips}
\end{aligned}
$$


For simplicity, assume the 21-kip tank weight to be acting at the center of gravity of $\mathrm{W}_{0}$. The gross value of $\mathrm{W}_{0}$ is

$$
\mathrm{W}_{0}^{\pi}=298.5+21=319.5 \mathrm{kips}
$$

Using Eq. 6.13

$$
\begin{aligned}
h_{0}=h_{0}^{n} & =\frac{3}{8} h \\
& =\frac{3}{8}(15)=5.63 \mathrm{ft} \quad(E B P)
\end{aligned}
$$

From Eq. 6.14

$$
\begin{aligned}
\mathrm{h}_{0}=\mathrm{h}_{0}^{\prime \prime} & =\frac{\mathrm{h}}{8}\left[\frac{\frac{4}{\tanh \left(\sqrt{3} \frac{\mathrm{R}}{\mathrm{h}}\right)}}{\sqrt{3} \frac{\mathrm{R}}{\mathrm{h}}}-1\right] \\
& =\frac{15}{8}\left(\frac{4}{0.602}-1\right)=10.6 \mathrm{ft} \quad \text { (IBP) } \\
\dot{\mathrm{u}}_{0} & \left.=10.6 \mathrm{ft} / \mathrm{sec}^{2}=0.33 \mathrm{~g} \text { (see Fig. } 1.21 \text { for } \mathrm{T}=0\right)
\end{aligned}
$$

From Eq. 6.15, using $\mathrm{W}_{0}^{\prime \prime}$ instead of $\mathrm{W}_{0}$

$$
\begin{aligned}
\mathrm{P}_{0}^{n} & =\frac{\dot{\mathrm{u}}_{0}}{\mathrm{~g}} \mathrm{~W}_{0}^{n} \\
& =0.33(319.5)=105.4 \mathrm{kips} \\
\mathrm{M}_{0}^{n} & =105.4(5.63)=594 \mathrm{kip}-\mathrm{ft} \quad(\mathrm{EBP}) \\
\mathrm{M}_{0}^{n} & =105.4(10.6)=1120 \mathrm{kip}-\mathrm{ft} \quad \text { (IBP) }
\end{aligned}
$$

\section{Convective force}

From Eq. 6.16

$$
\begin{aligned}
W_{1} & =W(0.318) \frac{R}{h} \tanh \left(1.84 \frac{h}{R}\right) \\
& =496(0.318) \frac{13}{15} \tanh \left(1.84 \frac{15}{13}\right)=133 \mathrm{kips}
\end{aligned}
$$

From Eq. 6.17

$$
\begin{aligned}
\frac{h_{1}}{h} & =1-\frac{\cosh \left(1.84 \frac{h}{R}\right)-1}{1.84 \frac{h}{R} \sinh \left(1.84 \frac{h}{R}\right)} \\
& =1-\frac{\cosh \left(1.84 \frac{15}{13}\right)-1}{1.84 \frac{15}{13} \sinh \left(1.84 \frac{15}{13}\right)}=0.63 \\
h_{1} & =0.63(15)=9.45 \mathrm{ft} \quad \text { (EBP) }
\end{aligned}
$$


6.4 TANKS SUPPORTED ON THE GROUND

Using Eq. 6.18

$$
\begin{aligned}
\frac{\mathrm{h}_{1}}{\mathrm{~h}} & =1-\frac{\cosh \left(1.84 \frac{\mathrm{h}}{\mathrm{R}}\right)-2.01}{1.84 \frac{\mathrm{h}}{\mathrm{R}} \sinh \left(1.84 \frac{\mathrm{h}}{\mathrm{R}}\right)} \\
& =1-\frac{\cosh \left(1.84 \frac{15}{13}\right)-2.01}{1.84 \frac{15}{13} \sinh \left(1.84 \frac{15}{13}\right)}=0.746 \\
\mathrm{~h}_{1} & =0.746(15)=11.2 \mathrm{ft} \quad \text { (IBP) }
\end{aligned}
$$

Using Eq. 6.19

$$
\begin{aligned}
& \omega^{2}=\frac{1.84 \mathrm{~g}}{\mathrm{R}} \tanh \left(1.84 \frac{\mathrm{h}}{\mathrm{R}}\right) \\
& \omega^{2}=\frac{(1.84)(32.2)}{13} \tanh \left(1.84 \frac{15}{13}\right)=4.44 \\
& \omega=2.11 \\
& \mathrm{~T}=\frac{2 \pi}{\omega}=\frac{2 \pi}{2.11}=2.98 \mathrm{sec} \\
& \mathrm{S}=2.6(\text { Fig. } 1.19 \mathrm{using} 1 / 2 \% \text { critical damping) } \\
& \mathrm{y}_{\max .}=\mathrm{A}_{1} \frac{\mathrm{S}}{\omega}=\frac{2.6}{2.11}=1.23 \mathrm{ft} \text { (see Eq. } 5.4 \text { ) }
\end{aligned}
$$

From Eq. 6.20

$$
\begin{aligned}
\theta_{\mathrm{h}} & =1.534 \frac{\mathrm{A}_{1}}{\mathrm{R}} \tanh \left(1.84 \frac{\mathrm{h}}{\mathrm{R}}\right) \\
& =1.534 \frac{1.23}{13} \tanh \left(1.84 \frac{15}{13}\right)=0.141
\end{aligned}
$$

From Eq. 6.21

$$
\begin{aligned}
\mathrm{P}_{1} & =1.2 \mathrm{~W}_{1} \theta_{\mathrm{h}} \sin \omega \mathrm{t} \\
& =1.2(133)(0.141) \sin \omega \mathrm{t}
\end{aligned}
$$

Maximum $P_{1}=22.5$ kips (setting $\sin \omega t=1$ )

$$
\begin{array}{ll}
\mathrm{M}_{1}=22.5(9.45)=212 \mathrm{kip}-\mathrm{ft} & (\mathrm{EBP}) \\
\mathrm{M}_{1}=22.5(11.2)=252 \mathrm{kip}-\mathrm{ft} & (\mathrm{IBP})
\end{array}
$$


Displacement of water surface

Using Eq. 6.22

$$
\begin{aligned}
\mathrm{d}_{\text {max. }} & =\frac{0.408 \mathrm{R} \operatorname{coth}\left(1.84 \frac{\mathrm{h}}{\mathrm{R}}\right)}{\frac{\mathrm{g}}{\omega^{2} \theta_{\mathrm{h}} \mathrm{R}}-1} \\
& =\frac{0.408(13) \operatorname{coth}\left(1.84 \frac{15}{13}\right)}{\frac{32.2}{4.44(0.141) 13}-1}=1.84 \mathrm{ft}
\end{aligned}
$$

Maximum bending moment on the tank at a section just above the bottom:

$$
\mathrm{M}_{0}^{\prime \prime}+\mathrm{M}_{1}=594+212=806 \mathrm{kip}-\mathrm{ft} \quad(\mathrm{EBP})
$$

Maximum overturning moment:

$$
M_{0}^{\prime \prime}+M_{1}=1120+252=1372 \text { kip }-\mathrm{ft} \quad(\mathrm{IBP})
$$

Maximum shear at base $=\mathrm{P}_{0}^{\mu}+\mathrm{P}_{1}=105.4+22.5=127.9$ kips

Summary

The ground acceleration of $0.33 \mathrm{~g}$ generates a total impulsive force of 105 kips. This results in a maximum bending moment of $594 \mathrm{kip}-\mathrm{ft}$ on a section of the tank just above the base and a maximum overturning moment of $1120 \mathrm{kip}-\mathrm{ft}$. It also generates a maximum convective force of 23 kips acting on the tank wall, which results in a maximum bending moment of $212 \mathrm{kip}-\mathrm{ft}$ on the tank wall and a maximum overturning moment of $252 \mathrm{kip}-\mathrm{ft}$. This force causes the fluid to oscillate with a period of $2.98 \mathrm{sec}$, the water surface rising $1.84 \mathrm{ft}$ above its undisturbed level. Thus the total bending moment on the tank is $806 \mathrm{kip}-$ $\mathrm{ft}$, the total overturning moment is $1372 \mathrm{kip}-\mathrm{ft}$, and the maximum horizontal shear at the base is 128 kips. This shear corresponds to a seismic coefficient of $0.25 \mathrm{~g}$.

\subsection{PROCEDURE FOR SLENDER TANKS SUPPORTED ON THE GROUND} (h/l or $h / R>1.5)$

In a rectangular tank where the depth of the fluid exceeds three-fourths of the dis tance, $2 l$, between walls or in a circular tank where the depth exceeds three-fourths of the diameter, the entire mass of fluid below this depth tends to respond as a rigid body as far as impulsive pressures are concerned (see Sec. 5.3).

For purposes of evaluating the impulsive force, $\mathrm{P}_{0}$, the container can be regarded as a tank with a fictitious bottom at a datum $1.5 \mathrm{l}$ or $1.5 \mathrm{R}$ below the fluid surface and supported on a solid mass extending from the fictitious bottom to the actual bottom. The procedure of Sec. 6.4 is applied to the portion above the datum to determine unsprung weight $W_{0}$ and levels $h_{0}$ above the datum. The action of the lower portion is represented by the actual weight below this level, located at its center of gravity. This actual weight and $W_{0}$ are combined into a single weight $W_{0}^{\prime \prime}$ at an arm $h_{0}^{\prime \prime}$ above the actual bottom of the tank, with $W_{0}^{n}$ generating the impulsive force $P_{0}^{n}$.

The concept of dividing the tank into upper and lower zones does not apply in the case of equivalent weight $W_{1}$ and related quantities. These continue to be a function of the full depth of water. The following example illustrates the procedure in detail and demonstrates the uses of Figs. 6.6 to 6.15 in the solution (see Sec. 6.8). 


\section{Example 2}

A cylindrical tank $26 \mathrm{ft}$ in diameter and containing $30 \mathrm{ft}$ of water is supported on the ground. Determine seismic forces and moments on the tank and displacement of water surface using Figs. 6.6 to 6.15. Base response on the spectrum of Fig. 1.19, using $0.5 \%$ critical damping.

$\underline{\text { Solution }}$

Since in this case $h / R=30 / 13=2.3>1.5$, only the upper portion of water with a depth of $1.5 \mathrm{R}=19.5 \mathrm{ft}$ is considered to be in fluid motion, and the water in the lower $10.5 \mathrm{ft}$ is assumed to move as a completely constrained fluid in calculating the impulsive force. This is shown in (a) of Fig. 6.2. The calculation of convective forces 1 s based on the full depth of water (Table 6.1). This assumption gives the following data:

Impulsive force

$$
\begin{aligned}
& R=13 \mathrm{ft}, \mathrm{h}=19.5 \mathrm{ft}, \mathrm{R} / \mathrm{h}=0.667 \\
& W=\pi(169)(19.5)\left(\frac{62.4}{1000}\right)=646 \mathrm{kips}
\end{aligned}
$$

Convective force

$$
\begin{aligned}
& \mathrm{R}=13 \mathrm{ft}, \mathrm{h}=30 \mathrm{ft}, \mathrm{R} / \mathrm{h}=0.433 \\
& \mathrm{~W}=\pi(169)(30)\left(\frac{62.4}{1000}\right)=993 \mathrm{kips} \\
& \omega=2.14 \\
& \mathrm{~T}=\frac{2 \pi}{2.14}=2.94 \mathrm{sec}, \mathrm{S}=2.6 \mathrm{ft} / \mathrm{sec} \text { (from Fig. 1.19) } \\
& \left.\mathrm{y}_{\text {max. }}=\mathrm{A}_{1} \frac{\mathrm{S}}{\omega}=\frac{2.6}{2.14}=1.21 \mathrm{ft} \text { (see Eq. } 5.4\right) \\
& \theta_{\mathrm{h}}=\frac{1.534 \mathrm{~A}_{1}}{\mathrm{R}} \text { (from above), } \theta_{\mathrm{h}}=\frac{1.534(1.21)}{13}=0.143
\end{aligned}
$$

From Eq. 6.21

$$
P_{1}=1.2(139)(0.143) \sin \omega t=23.9 \sin \omega t
$$

Maximum $P_{1}=23.9$ kips

From Eq. 6.37 (see Sec. 6.8)

$$
\begin{aligned}
& d_{\text {max. }}=\frac{Q}{g \omega^{2} \theta_{\mathrm{n}} R-1} \\
& d_{\max .}=\frac{5.3}{\frac{32.2}{4.56(0.143)(13)}-1}=1.89 \mathrm{ft}
\end{aligned}
$$




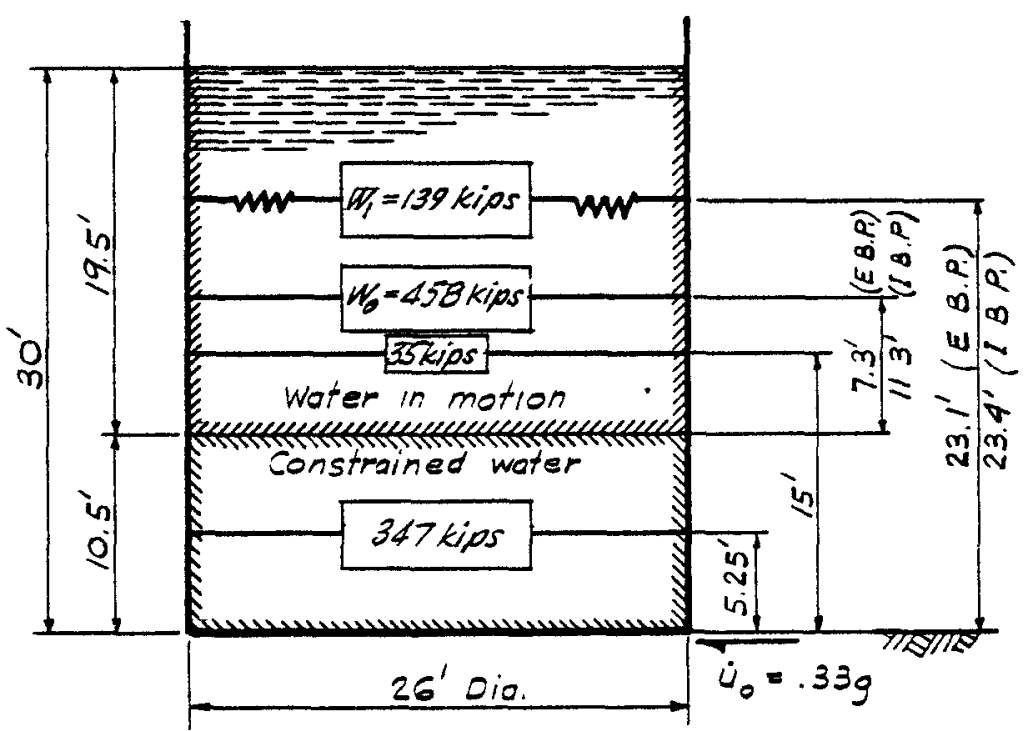

(a)

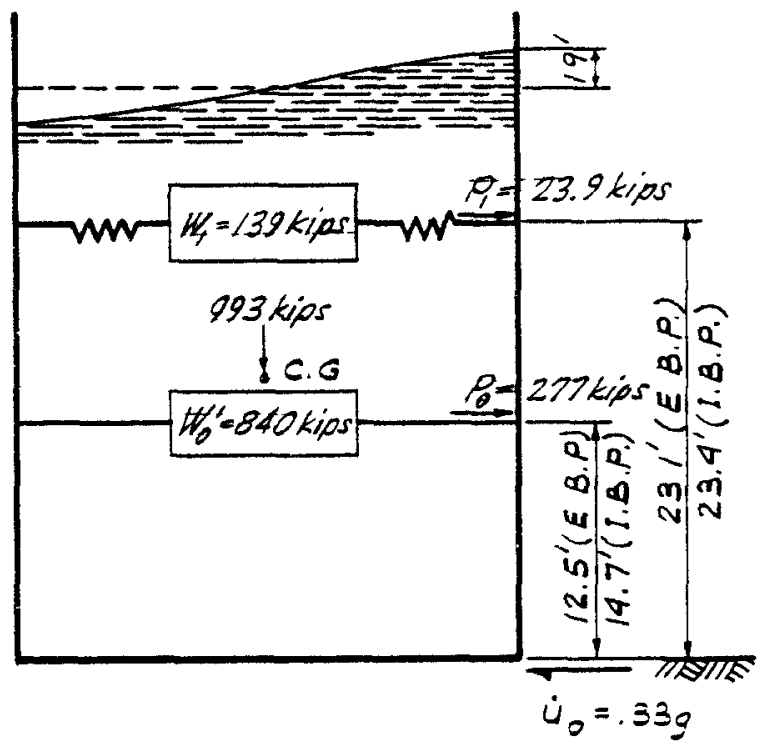

(b)

Fig. 6.2-Slender ground-supported water tank. 
PROCEDURE FOR SLENDER TANKS SUPPORTED ON THE GROUND

Table 6.1-CALCULATION OF CONVECTIVE FORCES

\begin{tabular}{|c|c|c|c|}
\hline $\begin{array}{c}\text { Figure } \\
\text { or } \\
\text { equation }\end{array}$ & $\begin{array}{c}\text { Value of } \\
\text { parameter }\end{array}$ & \multicolumn{2}{|l|}{ Calculation } \\
\hline Fig. 6.6 & $\frac{W_{0}}{W}=0.71$ & $W_{0}=0.71(646)=458 \mathrm{kups}$ & \\
\hline Eq. 6.13 & $\mathrm{~h}_{0}=\frac{3}{8} \mathrm{~h}$ & $\mathrm{~h}_{0}=\frac{3}{8}(19.5)=7.31 \mathrm{ft}$ & (EBP) \\
\hline Fig. 6.7 & $\frac{h_{0}}{h}=0.58$ & $h_{0}=0.58(19.5)=11.3 \mathrm{ft}$ & (IBP) \\
\hline Fig. 6.12 & $\frac{W_{1}}{W}=0.14$ & $W_{1}=0.14(993)=139 \mathrm{kips}$ & \\
\hline Fig. 6.13 & $\frac{h_{1}}{h}=0.77$ & $h_{1}=0.77(30)=23.1 \mathrm{ft}$ & (EBP) \\
\hline Fig. 6.14 & $\frac{h_{1}}{h}=0.78$ & $h_{1}=0.78(30)=23.4 \mathrm{ft}$ & (IBP) \\
\hline \multirow[t]{2}{*}{ Fig. 6.15} & $\frac{R \theta_{h}}{A_{1}}=1.534$ & \multicolumn{2}{|c|}{$\omega^{2}=\frac{38.6(1.534)}{13}=\begin{array}{l}4.56 \text { (multiplier } \\
\text { from Sec. } 6.8)\end{array}$} \\
\hline & & \multicolumn{2}{|c|}{$Q^{*}=\frac{0.626(13)}{1.534}=\begin{array}{l}5.3 \text { (multiplier } \\
\text { from Sec. } 6.8 \text { ) }\end{array}$} \\
\hline
\end{tabular}

*See Sec. 6.8 for definition of $Q$.

Weight of constrained water $=\pi(169)(10.5)(62.4)=347$ kips.

The following procedure shows ho ' ${ }_{n}^{\prime \prime}$ and its location $h_{0}^{n}$ are obtained: Assuming the steel weight of 35 kips to be concenus ded at half the water depth, for simplicity, then from (a) of Fig. 6.2,

$$
\begin{aligned}
& \mathrm{W}_{0}^{\prime \prime}=458+347+35=840 \text { kips } \\
& \mathrm{h}_{0}^{n}=\frac{458(7.31+10.5)+347(5.25)+35(15)}{840}=12.5 \mathrm{ft} \quad \text { (EBP) } \\
& \mathrm{h}_{0}^{n}=\frac{458(11.3+10.5)+347(5.25)+35(15)}{840}=14.7 \mathrm{ft} \quad \text { (IBP) } \\
& \left.\dot{\mathrm{u}}_{0}=\frac{10.6}{32.2} \mathrm{~g}=0.33 \mathrm{~g} \text { (see Fig. } 1.21 \text { for } \mathrm{T}=0\right)
\end{aligned}
$$

From Eq. 6.15 the impulsive force due to $W_{0}^{\prime \prime}$ is

$$
\mathrm{P}_{0}=\frac{\dot{\mathrm{u}}_{0}}{\mathrm{~g}} \mathrm{~W}_{0}^{N}=0.33(840)=277 \mathrm{kips}
$$

Maximum bending moment on a section of the tank just above the base:

$$
\begin{aligned}
& \mathrm{M}_{0}^{n}=277(12.5)=3460 \mathrm{kip}-\mathrm{ft} \quad(\mathrm{EBP}) \\
& \mathrm{M}_{1}=23.9(23.1)=552 \mathrm{kip}-\mathrm{ft} \quad(\mathrm{EBP}) \\
& \mathrm{M}_{0}^{n}+\mathrm{M}_{1}=4012 \mathrm{kip}-\mathrm{ft}
\end{aligned}
$$


Maximum overturning moment on the tank:

$$
\begin{aligned}
& \mathrm{M}_{0}^{\prime \prime}=277(14.7)=4070 \mathrm{kip}-\mathrm{ft} \quad(\mathrm{IBP}) \\
& \mathrm{M}_{1}=23.9(23.4)=560 \mathrm{kip}-\mathrm{ft} \quad(\mathrm{IBP}) \\
& \mathrm{M}_{0}^{\prime \prime}+\mathrm{M}_{1}=4630 \mathrm{kip}-\mathrm{ft}
\end{aligned}
$$

Maximum shear at base $=\mathrm{P}_{0}^{\phi}+\mathrm{P}_{1}=277+23.9=300.9$ kips. These numerical re sults are shown in (b) of Fig. 6.2.

\section{Summary}

The ground acceleration of $0.33 \mathrm{~g}$ generates a total impulsive force of $277 \mathrm{kips}$, which results in a maximum bending moment of $3460 \mathrm{kip}-\mathrm{ft}$ on the tank wall and a maximum overturning moment of $4070 \mathrm{kip}-\mathrm{ft}$. It also generates a maximum convective force of 23.9 kips, which produces a maximum bending moment of $552 \mathrm{kip}-\mathrm{ft}$ and a maximum overturning moment of $560 \mathrm{kip}-\mathrm{ft}$. This convective force causes the fluid to oscillate with a period of $2.94 \mathrm{sec}$. The water surface rises above its original level by $1.9 \mathrm{ft}$. Thus the total bending moment is $4012 \mathrm{kip}-\mathrm{ft}$, the total overturning moment is 4630 kip-ft, and the maximum horizontal shear at the base is $301 \mathrm{kips}$. This shear is equivalent to a seismic coefficient of about $0.29 \mathrm{~g}$.

\subsection{PROCEDURE FOR ELEVATED TANKS}

In the case of the ground-supported tanks previously considered, the weight $W_{0}$ (or Wo $_{0}^{\prime}$ ) was assumed to be rigidly coupled to the ground through the tank walls, undergoing a maximum horizontal acceleration equal to that of the ground. When the tank is mounted on an elevated supporting structure, the coupling to the ground is no longer rigid, and the flexibility of the supporting structure must be considered. The resulting model (Fig. 6.3) is a two-degree-of-freedom system, to which the equations in Sec. 5.5 apply. The fictitious springs joining $W_{1}$ to the tank walls in Fig. 6,1 have been replaced with a single hypothetical column of the same stiffness, $k_{1}$, forming a direct coupling between $W_{1}$ and $W_{0}$. The weight $W_{0}$ is connected to the ground through a similar hypothetical column representing the support structure and having the same spring constant, $\mathrm{k}_{0}$.

The properties $W_{0}, W_{1}, h_{0}, h_{1}$, and $\omega$ are independent of the support conditions and are obtained from the equations of Sec. 6.3 or the curves of Sec. 6.8. The value of $\omega$ so calculated determines the spring constant, $\mathrm{k}_{1}$, of the two-mass system, defined as the horizontal shear developed in the hypothetical column joining $W_{0}$ and $W_{1}$ when $W_{1}$ is translated horizontally through a unit distance with $W_{0}$ restrained against translation. The value of $k_{1}$ is conveniently found by transposing Eq. 5.5 and expressing $T$ in terms of $\omega$, resulting in the following equation:

$$
k_{1}=\frac{\omega^{2} W_{1}}{g}
$$

Spring constant $\mathrm{k}_{0}$ is defined as the horizontal shear in the hypothetical column joining $W_{0}$ to the ground when $W_{0}$ is translated horizontally through a unit distance with $W_{1}$ restrained against translation. In the case of a support structure consisting of a diagonally braced tower, $\mathrm{k}_{0}$ can be obtained by computing the horizontal deflection of $\mathrm{W}_{0}$ under a given static horizontal force acting through that point, using the well-known method of virtual work. (See, for example, Ref. 6.2, Sec. 10, page 19; Ref. 6.3, Sec. 28, page 37; or Ref. 6.4; Sec. 7-2, page 175.) Frequencies, periods of vibrating mode shapes, and maxi- 


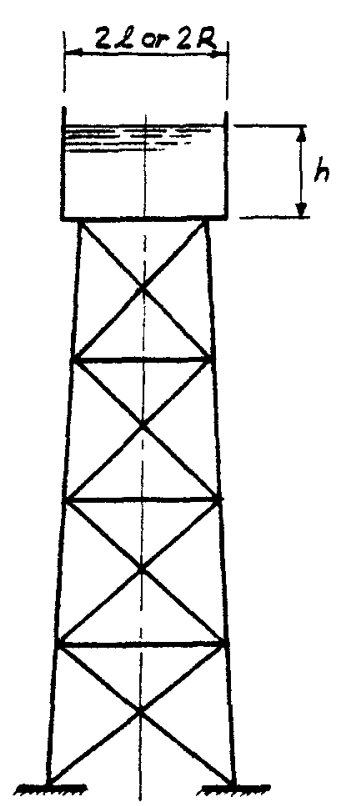

(a)

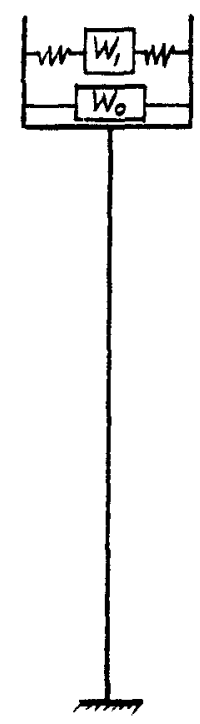

(b)

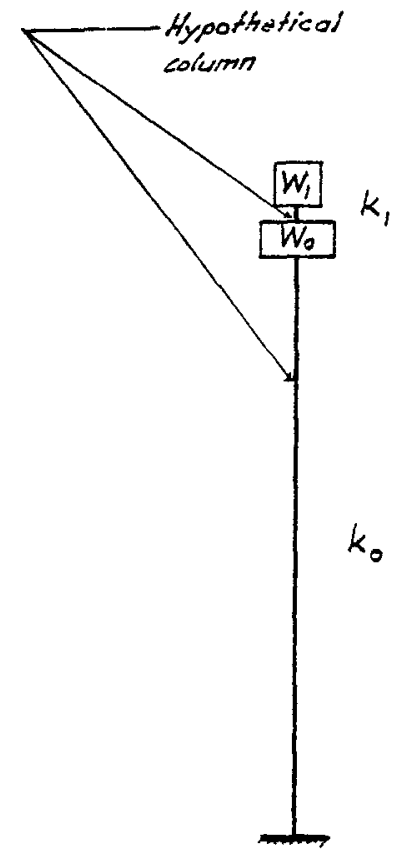

(c)

Fig. 6.3-Dynamic models for elevated fluid container.

mum deflections of the system can be found from Eqs. 5.7 to 5.16 if the following quantities are used:

$$
\begin{aligned}
& \mathrm{m}_{\mathrm{a}}=\frac{\mathrm{W}_{0}}{\mathrm{~g}} \\
& \mathrm{~m}_{\mathrm{b}}=\frac{\mathrm{W}_{1}}{\mathrm{~g}} \\
& \mathrm{k}_{\mathrm{a} \mathrm{a}}=\mathrm{k}_{0}-\mathrm{k}_{1} \\
& \mathrm{k}_{\mathrm{bb}}=\mathrm{k}_{1} \\
& \mathrm{k}_{\mathrm{ab}}=\mathrm{k}_{\mathrm{ba}}=\mathrm{k}_{1}
\end{aligned}
$$

It should be noted that, as in the case of ground-supported tanks, the weight $W_{0}^{\prime \prime}$ replaces $W_{0}$ in the calculations when the tank weight or that of the support structure is taken into account.

Quantities to be determined are obtained by summing the contributions of the two modes. For each mode the amplitude $A_{1}$ (maximum deflection of $W_{1}$ relative to $W_{0}$ ) used in calculating the maximum angle of free oscillation, $\theta_{\mathrm{h}}$, of the water surface is the algebraic difference of the maximum horizontal deflections. $\vec{y}$, of the two masses.

In computing the maximum vertical displacement, $d_{\text {max. }}$, of the water surface, contributed by the second mode, the following expressions should be used rather than Eqs. 6.11 or 6.22:

For rectangular tanks

$$
d_{\max .}=\theta_{\mathrm{h}} l
$$


For cylindrical tanks

$$
\mathrm{d}_{\max .}=\theta_{\mathrm{h}} \mathrm{R}
$$

The damping associated with sloshing action is quite low, possibly in the range of $0.5 \%$ critical, whereas that associated with the motion of the supporting structure may be considerably larger. Usually the first mode involves sloshing almost entirely, whereas the second mode is primarily motion of the supporting structure. Consequently it is reasonable to use $0.5 \%$ critical damping for the first mode and a value for the second mode appropriate to the type of structure involved (see Sec. $5.2 \mathrm{C}$ for suggested values).

The procedure for calculating $W_{0}, W_{1}, h_{0}, h_{1}$, and $\omega^{2}$ is identical with that used for ground-supported tanks. The additional calculations necessary to complete the analysis are summarized as follows:

(1) Calculate the spring constant $k_{1}$ from Eq. 6.23, and compute spring constant $k_{0}$ from a deflection analysis of the supporting structure.

(2) Evaluate $m$ and $k$ values from Eqs. 6.24 to 6.28 and substitute the resulting quantities in Eqs. 5.7 to 5.10 to obtain natural frequencies, $\omega$, periods of vibration, $T$, and amplitude ratios, $\phi$, for the first and second modes. From the $T$ values, using the assumed damping factors, obtain $S$ values from an earthquake velocity spectrum, such as that given in Fig. 1.19.

(3) Determine the maximum deflection of $W_{0}$ and $W_{1}$ for each mode, using Eqs. 5.11 to 5.16 .

(4) For each of the two modes calculate the horizontal forces, F (see Eqs. 5.17 and 5.18 ), induced in the structure; maxinum displacement, $A_{1}$; maximum angle of free oscillations, $\theta_{h}$, of the fluid surface; and maximum vertical displacement, $\mathrm{d}_{\max .}$, of the fluid surface.

(5) Combine values for the two modes so as to maximize values of $F$ and $d_{\max }$.

The procedure is illustrated in detail in the following example.

Example 3

The tank described in Example 1 (Sec. 6.4) is supported on a steel tower, as shown in Fig. 6.4. Determine maximum deflection, seismic shear on the tower, and dis-

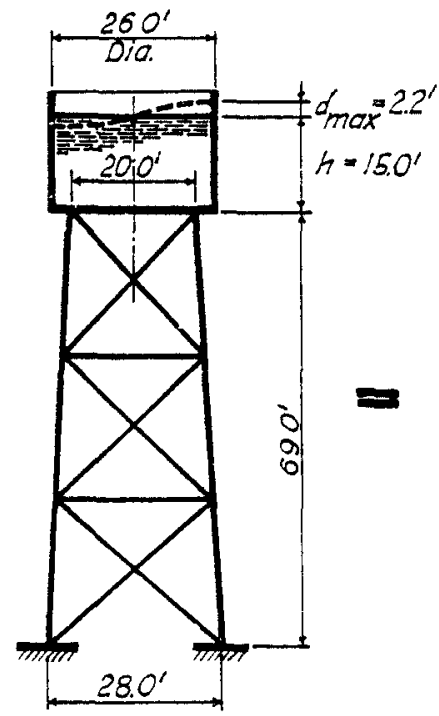

(a)

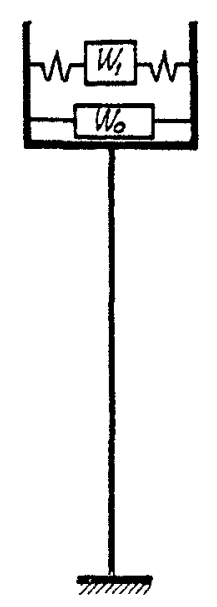

(b)

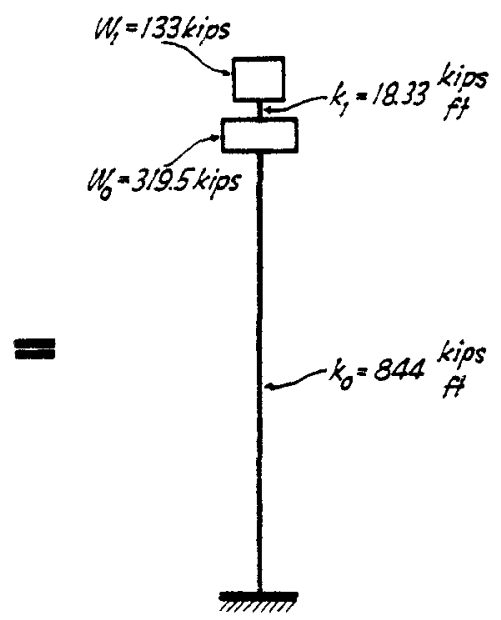

(c)

Fig. 6.4-Elevated water tank. 
placement of the water surface. Response is to be based on the spectrum of Fig. 1.19, using $0.5 \%$ critical damping for the first mode and $2 \%$ critical damping for the second mode. A deflection analysis of the tower indicates that a horizontal force of 844 kips applied through the centroid of the unsprung weight, $W_{0}^{n}$, would cause a horizontal deflection of $1 \mathrm{ft}$ at that point.

Solution

\section{From Example 1}

$$
\mathrm{W}_{0}^{n}=319.5 \mathrm{kips}, \mathrm{W}_{1}=133 \mathrm{kips}, \omega^{2}=4.44
$$

In this example the value of $\mathrm{W}_{0}^{\prime \prime}$ is assumed to include the total weight of the tank, contents, and tributary weight of the tower framing acting at $h_{0}=10.6 \mathrm{ft}$ above the tank bottom.

\section{Mode shapes}

From Eq. 6.23

$$
\begin{aligned}
& \mathrm{k}_{1}=\frac{\mathrm{W}_{1}}{\mathrm{~g}} \omega^{2}=\frac{133}{32.2}(4.44)=18.33 \mathrm{kips} / \mathrm{ft} \\
& \mathrm{k}_{0}=844 \mathrm{kips} / \mathrm{ft}
\end{aligned}
$$

From Eqs. 6.24 through 6.28

$$
\begin{aligned}
& \mathrm{m}_{\mathrm{a}}=\frac{\mathrm{W}_{0}^{\prime \prime}}{\mathrm{g}}=\frac{319.5}{32.2}=9.94 \mathrm{kip} \mathrm{sec}^{2} \mathrm{ft}^{-1}
\end{aligned}
$$

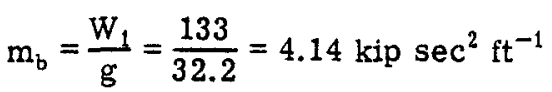

$$
\begin{aligned}
& k_{22}=k_{0}+k_{1}=844+18.33=862.33 \mathrm{kips} / \mathrm{ft} \\
& \mathrm{k}_{\mathrm{bb}}=\mathrm{k}_{\mathrm{1}}=18.33 \mathrm{kips} / \mathrm{ft} \\
& \mathrm{k}_{\mathrm{ab}}=\mathrm{k}_{\mathrm{b}_{2}}=\mathrm{k}_{1}=18.33 \mathrm{kips} / \mathrm{ft}
\end{aligned}
$$

Using Eq. 5.7

$$
\begin{aligned}
& \omega_{\mathrm{n}}^{2}=0.5\left[\frac{\mathrm{k}_{\mathrm{aa}}}{\mathrm{m}_{\mathrm{a}}}+\frac{\mathrm{k}_{\mathrm{bb}}}{\mathrm{m}_{\mathrm{b}}} \pm \sqrt{\left.\left(\frac{\mathrm{k}_{\mathrm{ab}}}{\mathrm{m}_{\mathrm{b}}}-\frac{\mathrm{k}_{\mathrm{bb}}}{\mathrm{m}_{\mathrm{b}}}\right)^{2}+4 \frac{\mathrm{k}_{\mathrm{ab}}}{\mathrm{m}_{\mathrm{a}}} \frac{\mathrm{k}_{\mathrm{ba}}}{\mathrm{m}_{\mathrm{b}}}\right]}\right. \\
& \omega_{\mathrm{n}}^{2}=0.5\left[\frac{862.33}{9.94}+\frac{18.33}{4.14} \pm \sqrt{\left(\frac{862.33}{9.94}-\frac{18.33}{4.14}\right)^{2}+4 \frac{18.33}{9.94} \frac{18.33}{4.14}}\right]
\end{aligned}
$$

Solving

$$
\begin{aligned}
& \omega_{1}^{2}=4.35, \omega_{1}=2.09, \mathrm{~T}_{1}=\frac{2 \pi}{\omega_{1}}=3.00 \mathrm{sec} \\
& \omega_{2}^{2}=87.007, \omega_{2}=9.33, \mathrm{~T}_{2}=\frac{2 \pi}{\omega_{2}}=0.673 \mathrm{sec}
\end{aligned}
$$


Using Eq. 5.9

$$
\phi_{a n}=\phi_{o n}=\frac{-\frac{k_{a b}}{m_{a}}}{\frac{k_{2 a}}{m_{a}}-\omega_{a}^{2}}=\frac{-\frac{18.33}{9.94}}{\frac{862.33}{9.94}-\omega_{n}^{2}}
$$

substituting values of $\omega_{1}^{2}$ and $\omega_{2}^{2}$

$$
\begin{aligned}
& \phi_{21}=\phi_{01}=0.0224 \\
& \phi_{22}=\phi_{02}=-18.70
\end{aligned}
$$

Maximum response

From Eqs. 5.15 and 5.16

$$
\begin{aligned}
& \mathrm{K}_{1}=\frac{\mathrm{m}_{\mathrm{a}} \phi_{\mathrm{a} 1}+\mathrm{m}_{\mathrm{b}}}{\mathrm{m}_{\mathrm{a}} \phi_{\mathrm{a} 1}^{2}+\mathrm{m}_{\mathrm{b}}}=\frac{9.94(0.0224)+4.14}{9.94(0.0224)^{2}+4.14}=1.053 \\
& \mathrm{~K}_{2}=\frac{\mathrm{m}_{\mathrm{a}} \phi_{\mathrm{a} 2}+\mathrm{m}_{\mathrm{b}}}{\mathrm{m}_{\mathrm{a}} \phi_{22}^{2}+\mathrm{m}_{\mathrm{b}}}=\frac{9.94(-18.70)+4.14}{9.94(-18.70)^{2}+4.14}=-0.05223
\end{aligned}
$$

From Fig. 1.19

$$
\begin{aligned}
& \mathrm{S}_{1}=2.6 \mathrm{ft} / \mathrm{sec} \text { using } \mathrm{T}_{1}=3.00 \mathrm{sec} \text { and } 0.5 \% \mathrm{critical} \text { damping } \\
& \mathrm{S}_{2}=1.93 \mathrm{ft} / \mathrm{sec} \text { using } \mathrm{T}_{2}=0.673 \mathrm{sec} \text { and } 2 \% \text { critical damping }
\end{aligned}
$$

Using Eqs. 5.11 through 5.14

For the first mode

$$
\begin{aligned}
& \overline{\mathrm{y}}_{\mathrm{b} 1}=\overline{\mathrm{y}}_{11}=\frac{\mathrm{K}_{1} \mathrm{~S}_{1}}{\omega_{1}}=\frac{1.05(2.6)}{2.09}=1.2094 \mathrm{ft}=\text { deflection of } \mathrm{W}_{1} \\
& \overline{\mathrm{y}}_{\mathrm{z} 1}=\overline{\mathrm{y}}_{01}=\overline{\mathrm{y}}_{\mathrm{b} 1} \cdot \phi_{\mathrm{a} 1}=1.31(0.0224)=0.0293 \mathrm{ft}=\text { deflection of } \mathrm{W}_{0}^{n}
\end{aligned}
$$

For the second moc.

$$
\begin{aligned}
& \bar{y}_{b 2}=\bar{y}_{12}=\frac{K_{2} S_{2}}{\omega^{2}}=\frac{-0.05223(1.93)}{9.33}=-0.0108 \mathrm{ft}=\text { deflection of } W_{1} \\
& \bar{y}_{12}=\bar{y}_{02}=\bar{y}_{b 2} \cdot \phi_{a 2}=-0.0108(-18.70)=0.2020 \mathrm{ft}=\text { deflection of } W_{0}^{\prime \prime}
\end{aligned}
$$

Maximum seismic forces and shears

Using Eqs. 5.17 and 5.18

For the first mode

$$
\begin{aligned}
F_{b 1}=F_{11}=k_{b b} \bar{y}_{b 1}+k_{b a} \bar{y}_{a 1}=18.33(1.3094)+(-18.33)(0.0293) & =23.46 \text { kips } \\
F_{a 1}=F_{01}=k_{a b} \bar{y}_{b 1}+k_{2 a} \bar{y}_{a 1}=-18.33(1.3094)+862.3 \sim(0.0293) & =1.26 \mathrm{kips} \\
\text { Tower horizontal shear } & =24.72 \mathrm{kips}
\end{aligned}
$$


For the second mode

$$
\begin{aligned}
F_{b 2}=F_{12}=k_{b b} \vec{y}_{b 2}+k_{b a} \vec{y}_{\mathrm{a} 2}=18.33(-0.0108)+(-18.33)(0.2020) & =-3.90 \mathrm{kips} \\
F_{\mathrm{a} 2}=F_{02}=k_{\mathrm{ab}} \overline{\mathrm{y}}_{\mathrm{b} 2}+k_{\mathrm{a} a} \overline{\mathrm{y}}_{\mathrm{a} 2}=18.33(-0.0108)+(862.33)(0.2020) & =174.39 \mathrm{kips} \\
\quad \text { Tower horizontal shear } & =170.49 \mathrm{kips} \\
\text { Maximum tower horizontal shear }=24.72+170.49 & =195.21 \mathrm{kips}
\end{aligned}
$$

Maximum water-surface displacement

Using Eq. 6.20

$$
\theta_{\mathrm{h}}=1.534 \frac{\mathrm{A}_{\ln }}{\mathrm{R}} \tanh \left(1.84 \frac{\mathrm{h}}{\mathrm{R}}\right)
$$

where $A_{1 \mathrm{n}}=\bar{y}_{b n}-\bar{y}_{2 n}$ *

For the first mode

$$
\begin{aligned}
& A_{11}=1.3094-0.0293=1.2801 \mathrm{ft} \\
& \theta_{\mathrm{h}}=1.534 \frac{1.2801}{13} \tanh \left(1.84 \frac{15}{13}\right)=0.147
\end{aligned}
$$

Using Eq. 6.22

$$
\mathrm{d}_{\max .}=\frac{0.408 \mathrm{R} \operatorname{coth}\left(1.84 \frac{\mathrm{h}}{\mathrm{R}}\right)}{\frac{\mathrm{g}}{\omega^{2} \theta_{\mathrm{h}} \mathrm{R}}-1}=\frac{0.408(13) \operatorname{coth}\left(1.84 \frac{15}{13}\right)}{\frac{32.2}{4.35(0.147)(13)}-1}=1.90 \mathrm{ft}
$$

For the second mode

$$
\begin{aligned}
& A_{11}=-0.0108-0.2020=-0.2128 \mathrm{ft} \\
& \theta_{h}=1.534\left(\frac{-0.2128}{13}\right) \tanh \left(1.84 \frac{15}{13}\right)=-0.024
\end{aligned}
$$

Using Eq. 6.30

$$
\mathrm{d}_{\text {max. }}=\theta_{\mathrm{h}} \cdot \mathrm{R}=-0.024(13)=-0.31 \mathrm{ft}
$$

Maximum displacement $=1.90-0.31=1.59 \mathrm{ft}$

The equivalent system for this tank-tower structure consists of the 319.5-kip equivalent dead weight of water and steel and the 133 -kip equivalent oscillating weight of water, having individual spring constants of 844 and $18.3 \mathrm{kips} / \mathrm{ft}$ of lateral deflection, respectively. The system vibrates with computed periods of vibration of 3.00 and $0.673 \mathrm{sec}$ for the two principal modes. The maximum seismic shear at the base of the tower, obtained from combining the two mode shapes, is 195 kips. The maximum water-surface displacement is $2.2 \mathrm{ft}$ above the undisturbed level. The contribution of the second mode to the total displacement is much lower than that of the first mode (see Fig. 6.5). 


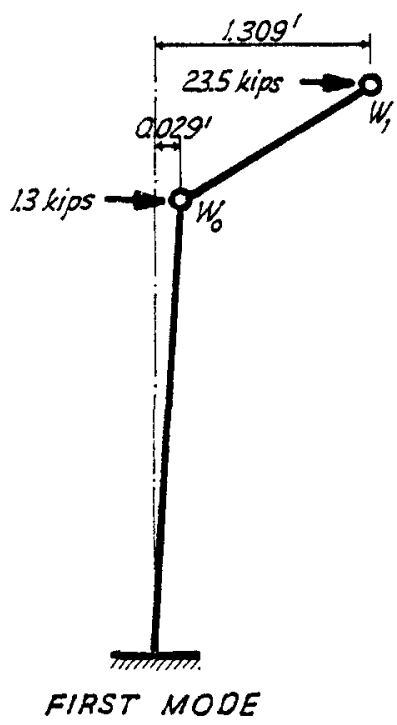

(a)

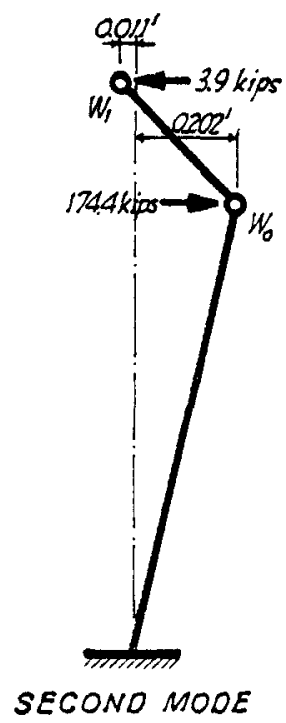

(b)

Fig. 6.5-Elevated water tank showing mode shapes and inertia forces.

This example is a further illustration of the large amount of strength required to maintain elastic response of a structure with low damping. The shear at the base of the tower is equivalent to that resulting from a seismic coefficient of about $0.38 \mathrm{~g}$.

The analysis for elevated tanks in this chapter assumes that the response of the tower is elastic under earthquake ground motion; in this case, having a maximum acceleration of $33 \% \mathrm{~g}$. Consequently the tower properties were selected to match this assumption; thus stresses are within the yield point under the $38 \% \mathrm{~g}$ static horizontal force representing the effect of the earthquake. Diagonals are upset rods varying in diameter from 2 in. in the top panel to $2 \frac{3}{8}$ in. in the bottom panel. Legs are 10 -in. pipe; struts are double-channel members, one with the web vertical the other with the web horizontal, ranging in size from 5 to $7 \mathrm{in}$. This water tower is much heavier and stiffer than a conventional water tower designed for $10 \% \mathrm{~g}$. A $10 \% \mathrm{~g}$ design might survive a $33 \% \mathrm{~g}$ earthquake through energy absorption due to overstress. However, its response to an earthquake of $33 \% \mathrm{~g}$ could not be estimated using the procedures for elevated tanks described in this chapter, and a limit-design approach, as discussed in Chap. 5, would be needed.

Measurements of the vibration characteristics of water towers have been attempted. Reference 6.5 , page 75 et seq., contains results of such an investigation.

\subsection{SPECIAL CONSIDERATIONS IN DESIGNING SEISMIC-RESISTANT FLUID CONTAINERS}

A ring girder or its equivalent at the top of a circular steel tank is required to provide stability against excessive distortion due to the lateral forces generated by the accelerated fluid. Suificient freeboard should be provided to prevent wave action from damaging the roof when the tank is full unless the roof is considered expendable, in which case, protective framing is needed for critical piping within the tank. Damage to floating roots can be anticipated when sloshing becomes severe.

Observations of the behavior of circular steel tanks supported directly on the ground indicate that a primary cause of damage during earthquakes is the lack of sufficient re- 
sistance against uplift. ${ }^{6.6}$ This is especially true for thin-walled tanks with large heightto-diameter ratios. Because of insufficient uplift resistance, the tilting (overturning) moment created by the impulsive force of the contained fluid generates a large vertical compressive force on the side opposite the uplifted portion. This often causes buckling of the tank wall and forces the base angle at the junction of the wall and tank bottom into the soil.

Prevention of uplift makes the entire tank perimeter effective in resisting the tilting moment. This alleviates the severe local bending stresses at the junction of the wall and bottom on the uplifted side and relieves compressive stresses on the side opposite the uplifted portion. Use of a continuous concrete perimeter footing tends to minimize damage from overturning moments.

The weight of the contained fluid in steel tanks can be effectively utilized to resist uplift from the overturning moment if the bottom of the tank is adequately stiffened for this purpose. This can be accomplished through internal stiffeners, such as tees, laid on the bottom and extending radially inward from the tank walls, with the stem welded to the bottom and to the tank wall. Length of the stiffeners is established so that, with uplift impending, the tributary weight of the water above will supply a downward reaction at the wall which exceeds the computed net uplift force. The intent of this scheme is to limit the separation of the tank wall from the foundation to a negligible amount so that a horizontal section through the tank at the base remains essentially plane under seismic loading.

The weight of the fluid can also be utilized through friction to resist the horizontal forces generated by the earthquake. Sliding of the tank is unlikely unless the coefficient of friction between the tank bottom and the subgrade is unusually low.

In the case of reservoirs or very large tanks, the period of the sloshing motion may be very long, perhaps $30 \mathrm{sec}$ or more. This is beyond the range of the spectra presently available, which is limited to values of $3 \mathrm{sec}$ or less (Fig. 1.19, for example). This long period indicates that the sloshing amplitude is affected strongly by the ground vibrations that occur some time after the start of strong ground motions. Accelerograms of severe earthquakes indicate diminishing ground vibrations after the initial stage of strong ground motion, this initial stage being considerably shorter than $30 \mathrm{sec}$. Under these circumstances a reduction in the spectral values is appropriate. A rational estimate of this reduction cannot be provided; however, a value of $50 \%$ appears to be reasonable when the period of the sloshing motion is about $30 \mathrm{sec}$.

Possible trouble spots in reservoirs are potential damage to the roof due to sloshing and damage to embankments from settlement, sliding, or erosion from sloshing. Leakage is a possibility in reinforced-concrete reservoirs through wall and bottom joints if these joints lack sufficient flexibility to accommodate relative motion across the separations.

Seismic damage to elevated tanks is usually identified with the supporting tower rather than with the tank shell itself. The seismic performance of elevated tanks designed for wind only is poor, often resulting in their complete collapse in major earthquakes. Tower-bracing and tower-base details of elevated tanks are also frequently damaged when designed using a seismic coefficient of the order of $0.10 \mathrm{~g}$, indicating that the forces used in the design were too low to prevent overstress. In theory, elevated tank shells with small height-to-diameter ratios transmit smaller seismic forces into the tower than shells with large height-to-diameter ratios. This is due to the dynamics of the fluid motion.

Inconsistent margins of safety can result when the conventional working stress approach, based on the elastic limit, is used in the design of elevated tank towers without considering conditions at impending failure. Investigation of the collapse condition is needed to determine whether energy absorption through inelastic stretch of the diagonals can occur without prior failure of the legs, struts or connections, anchor-bolt stretch, or footing uplift. The limit-design approach (see Chap. 5) is useful in such an evaluation. 
When inelastic stretch induces large lateral displacements, the effect of the displacements on the vertical riser extending from the bottom of the tank to the ground must be considered, especially if the riser is laterally stayed to the tower at each bracing level. Elimination of the stays at certain levels and use of flexible connections at the top and bottom may be necessary to avoid dangerous overstress in the riser.

\subsection{CURVES FOR TANKS SUPPORTED ON THE GROUND}

For expediency in analysis, curves are presented in this section. These curves, which are based on the equations of Sec. 6.3 and the correlation of desired quantities to the parameter $l / h$ or $R / h$, are listed in Table 6.2 .

Table $6.2-$ CURVES FOR GROUND-SUPPORTED TANKS

\begin{tabular}{|c|c|c|c|}
\hline \multicolumn{2}{|c|}{ Rectangular tank } & \multicolumn{2}{|c|}{ Cylindrical tank } \\
\hline Figure & & Figure & \\
\hline No. & Curve & No. & Curve \\
\hline 6.6 & $\mathrm{w}_{0} / \mathrm{W}$ vs. $\ell / \mathrm{h}$ & 6.6 & $\mathrm{~W}_{0} / \mathrm{W}$ vs. $\mathrm{R} / \mathrm{h}$ \\
\hline 6.7 & $h_{0} / h$ vs. $l / h($ IBP $)$ & 6.7 & $h_{0} / h$ vs. $R / h($ IBP) \\
\hline 6.8 & $\mathrm{~W}_{1} / \mathrm{W}$ vs. $\ell / \mathrm{h}$ & 6.12 & $\mathrm{~W}_{1} / \mathrm{W}$ vs. $\mathrm{R} / \mathrm{h}$ \\
\hline 6.9 & $h_{1} / h$ vs. $l / h(E B P)$ & 6.13 & $h_{1} / h$ vs. $R / h(E B P)$ \\
\hline 6.10 & $h_{1} / h$ vs. $\ell / h($ IBP) & 6.14 & $h_{1} / h$ vs. $R / h(\mathrm{BBP})$ \\
\hline 6.11 & $\ell \dot{\theta}_{\mathrm{h}} / \mathrm{A}_{1}$ vs. $\ell / \mathrm{h}$ & 6.15 & $\mathrm{R} \theta_{\mathrm{h}} / \mathrm{A}_{1}$ vs. $\mathrm{R} / \mathrm{h}$ \\
\hline
\end{tabular}

\section{Multipliers}

Figures 6.11 and 6.15 can be used to simplify the calculations of $\omega^{2}$ and $d_{\max }$ for rectangular and cylindrical tanks, respectively, by using the multipliers derived from the following formulas repeated from Sec. 6.3.

\begin{tabular}{cc||cc}
\hline Rectangular tanks & $\begin{array}{c}\text { Equation } \\
\text { No. }\end{array}$ & Cylindrical tanks & $\begin{array}{c}\text { Equation } \\
\text { No. }\end{array}$ \\
\hline$\frac{\ell \theta_{\mathrm{h}}}{\mathrm{A}_{1}}=1.58 \tanh \left(1.58 \frac{\mathrm{h}}{\mathrm{l}}\right)$ & $(6.9)$ & $\frac{\mathrm{R} \theta_{\mathrm{h}}}{\mathrm{A}_{1}}=1.534 \tanh \left(1.84 \frac{\mathrm{h}}{\mathrm{R}}\right)$ & $(6.20)$ \\
$\omega^{2}=\frac{\sqrt{\frac{5}{2}}}{\ell} \tanh \left(1.58 \frac{\mathrm{h}}{\ell}\right)$ & $(6.8)$ & $\omega^{2}=\frac{\sqrt{\frac{27}{8}}}{\mathrm{R}} \tanh \left(1.84 \frac{\mathrm{h}}{\mathrm{R}}\right)$
\end{tabular}

Defining $Q$ as follows:

For rectangular tanks

$$
Q=0.5271 \operatorname{coth}\left(1.58 \frac{h}{l}\right)
$$

For cylindrical tanks

$$
Q=0.408 R \operatorname{coth}\left(1.84 \frac{h}{R}\right)
$$




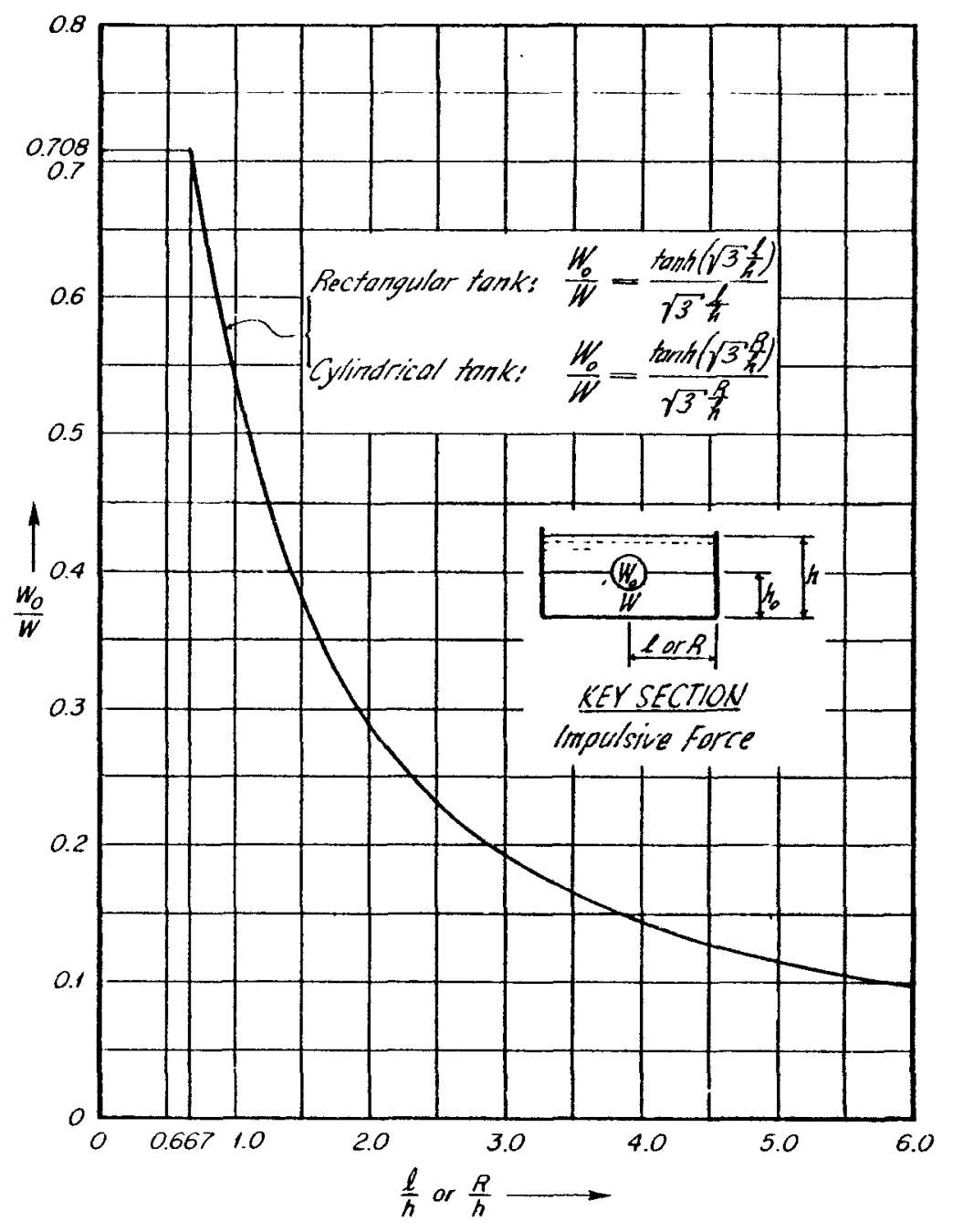

Fig. 6.6-Rectangular tank, $W_{0} / W_{\mathrm{vs}} l / \mathrm{h}$; cylindrical tank, $\mathrm{W}_{0} / \mathrm{W}$ vs. $\mathrm{R} / \mathrm{h}$.

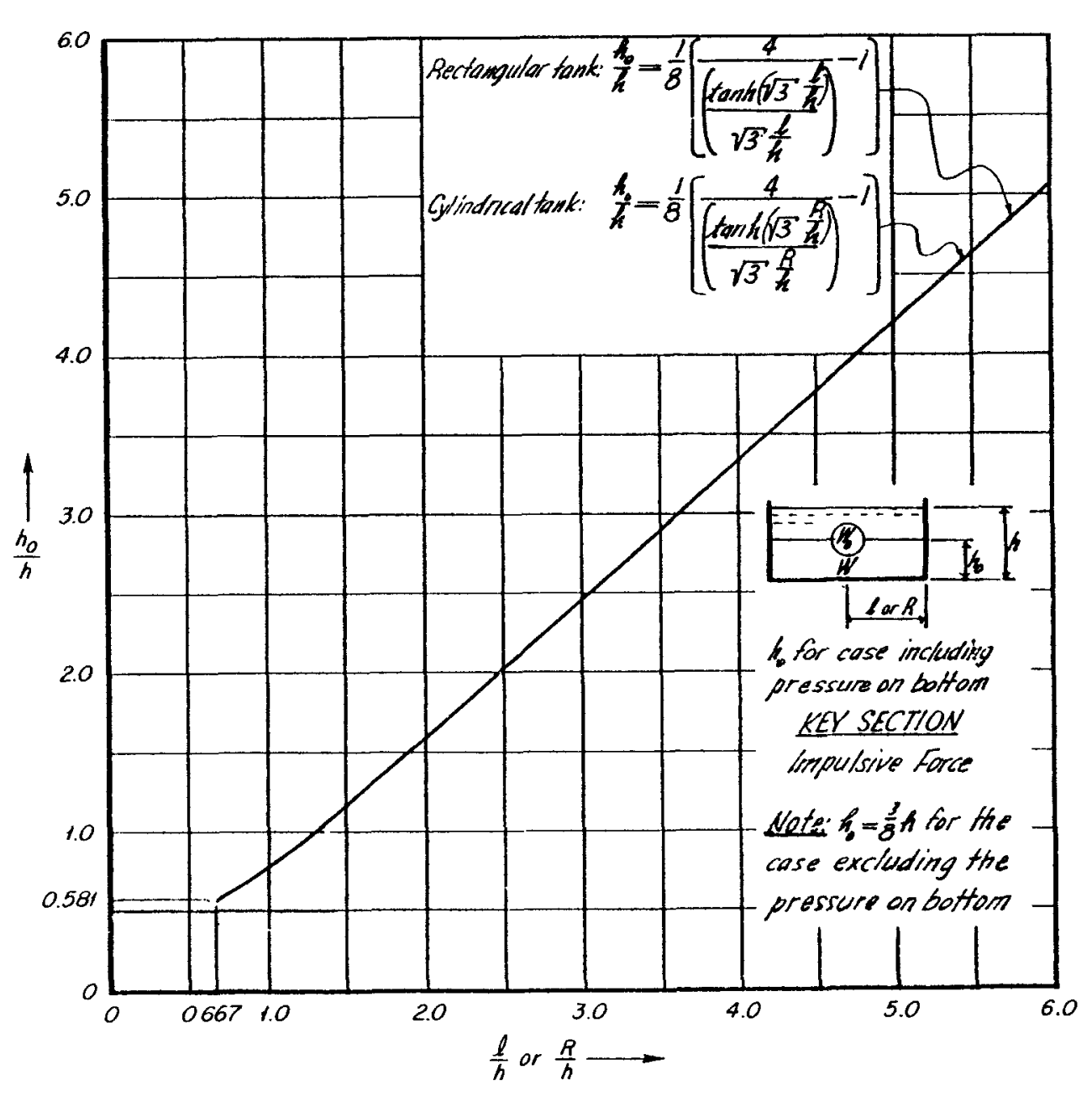

Fig. 6.7-Rectangular tank, $h_{0} /$ h vs. $\ell / h$; cylindrical tank, $h_{0} / h$ vs. $R / h$. 


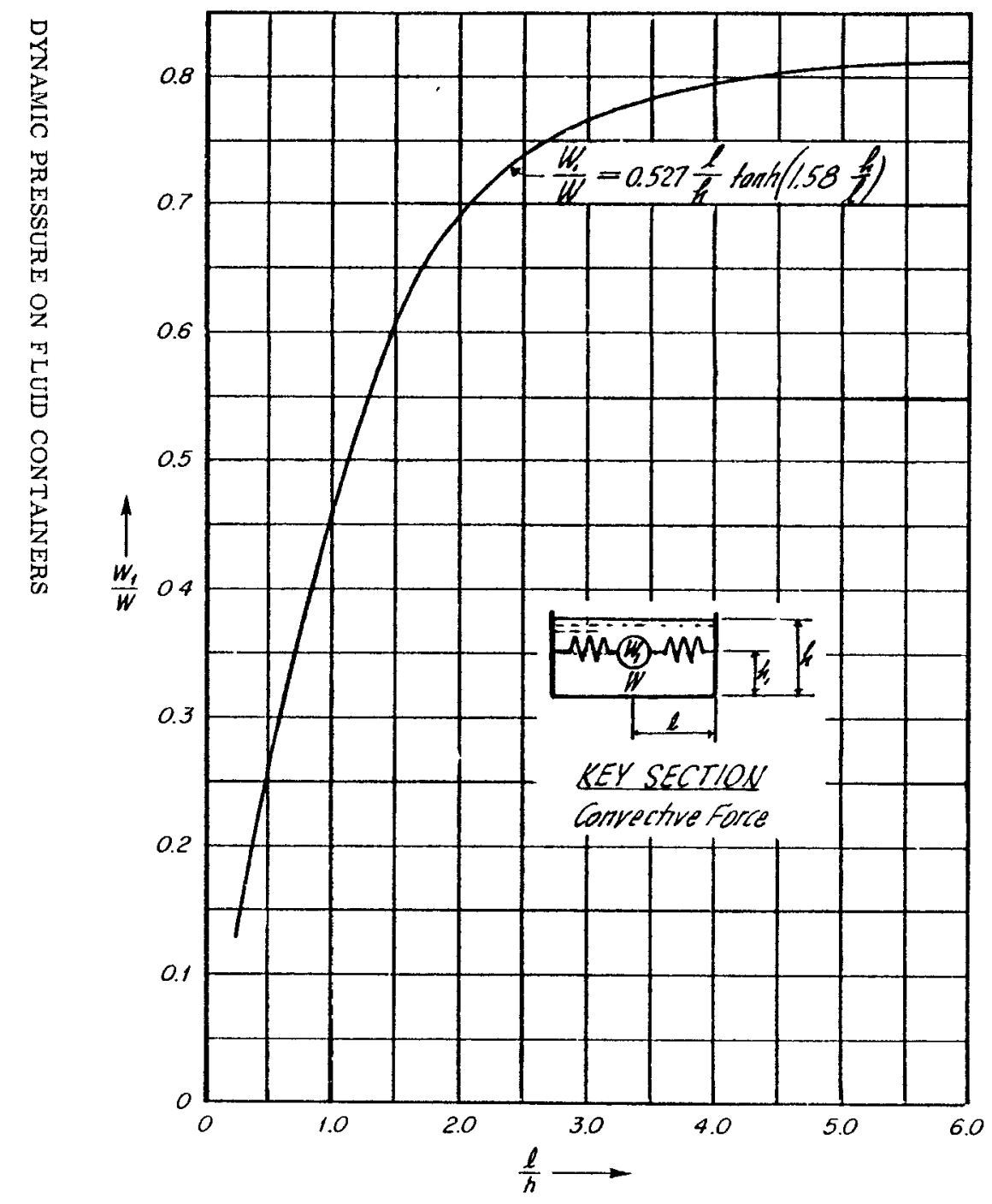

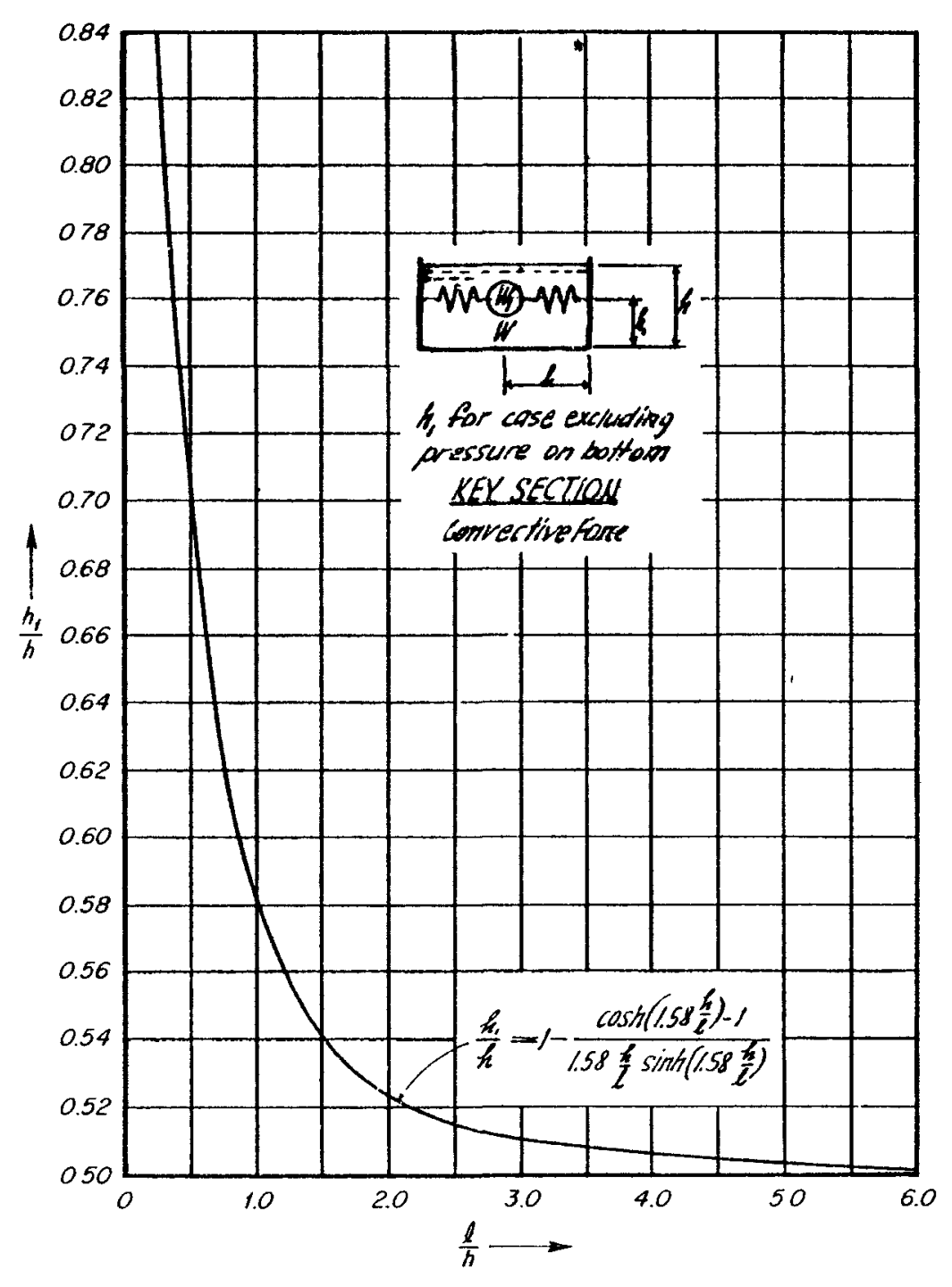

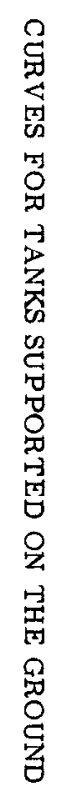

Fig. 6.9-Rectangular tank, $h_{1} / h$ vs. $\ell / h$, excluding bottom pressure. 


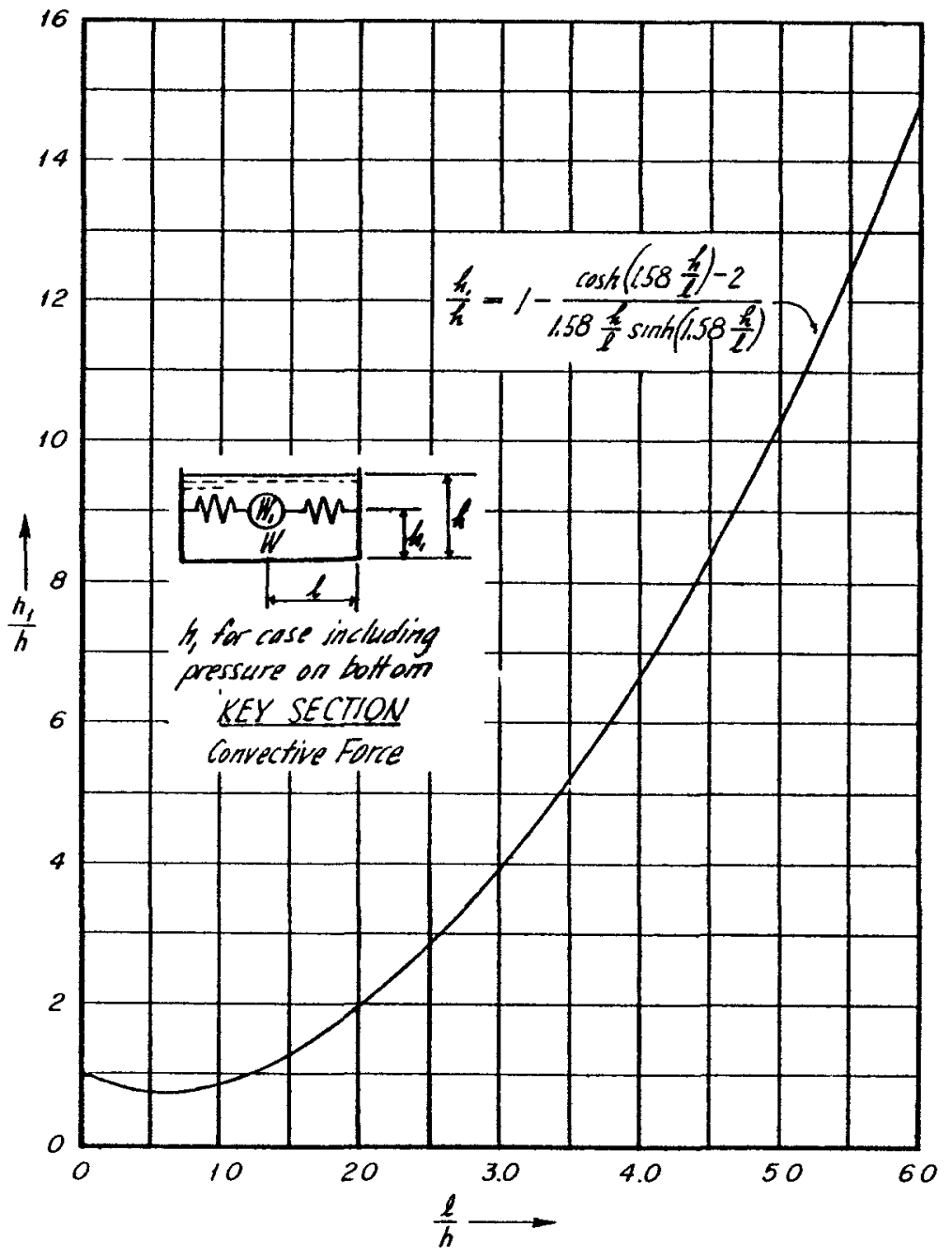

Fig. $6.10-$ Rectangular tank, $h_{1} / h$ vs. $l / h$, including bottom pressure.

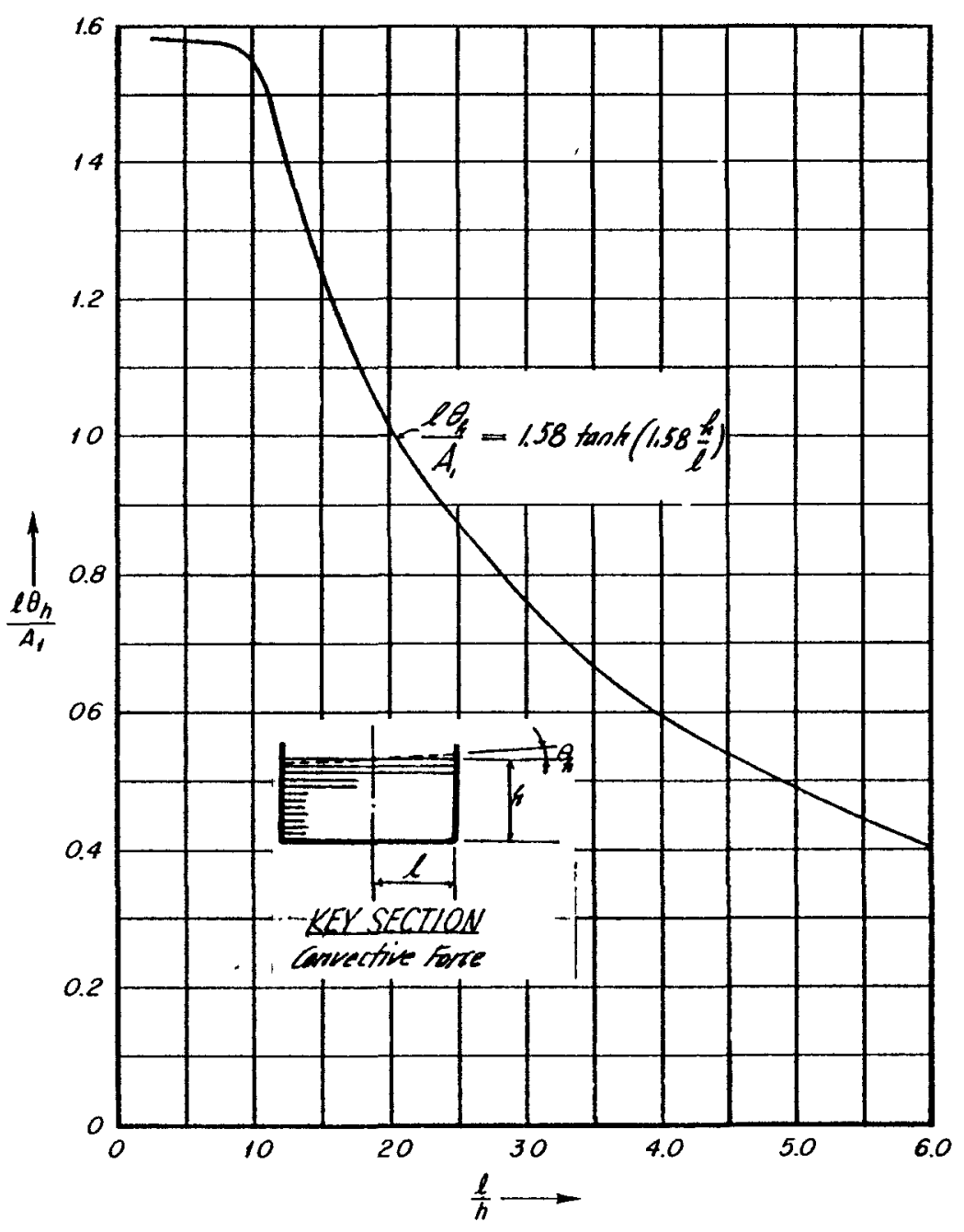

Fig. 6.11-Rectangular tank, $\ell \theta_{\mathrm{h}} / \mathrm{A}_{1} \mathrm{vs.} \ell / \mathrm{h}$. 


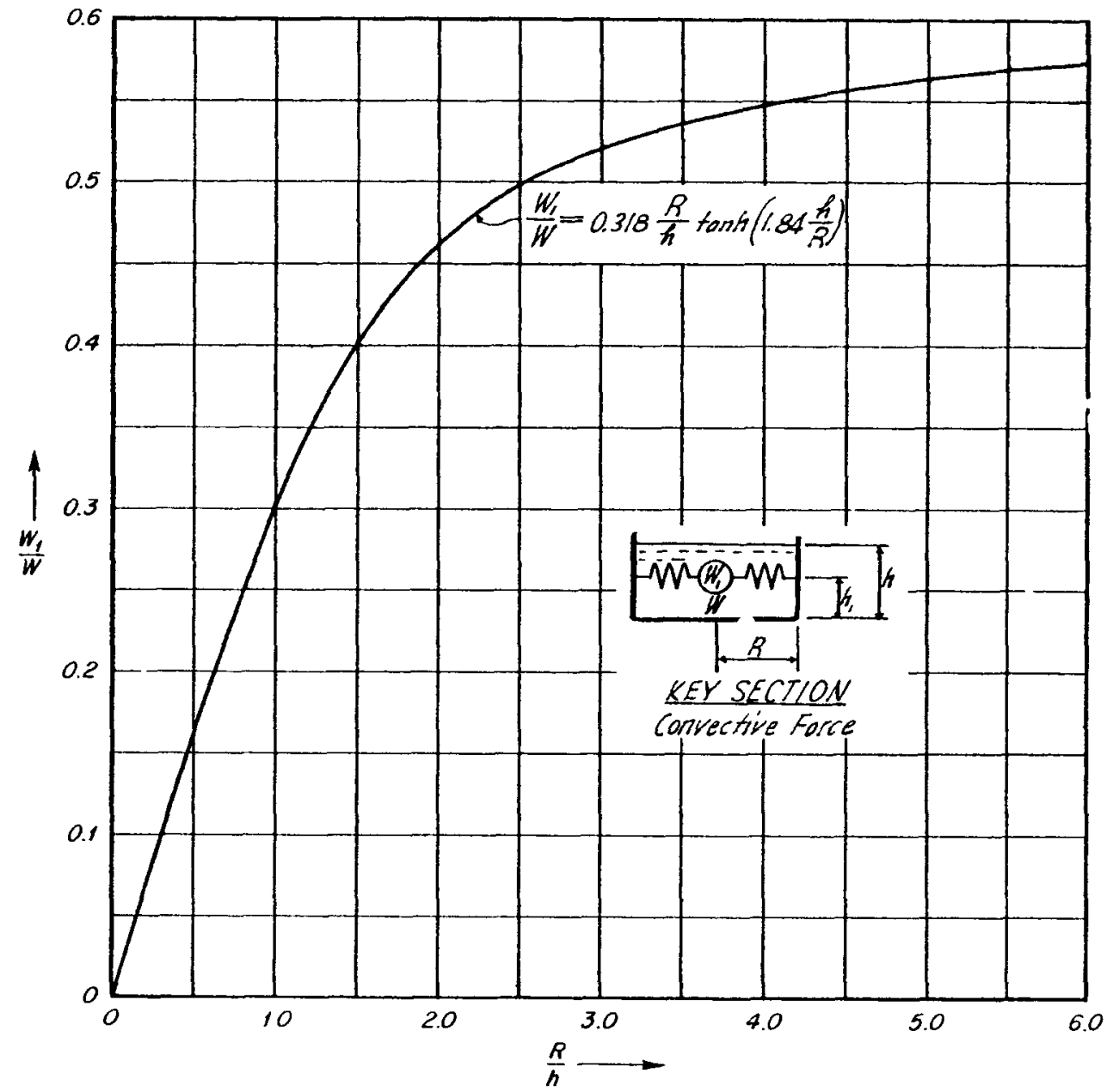

Fig. 6.12-Cylindrical tank, $W_{1} / W$ vs. $R / h$.

Fig. 6.13-Cylindrical tank, $h_{1} / h$ vs. $R / h$, excluding bottom pressure.

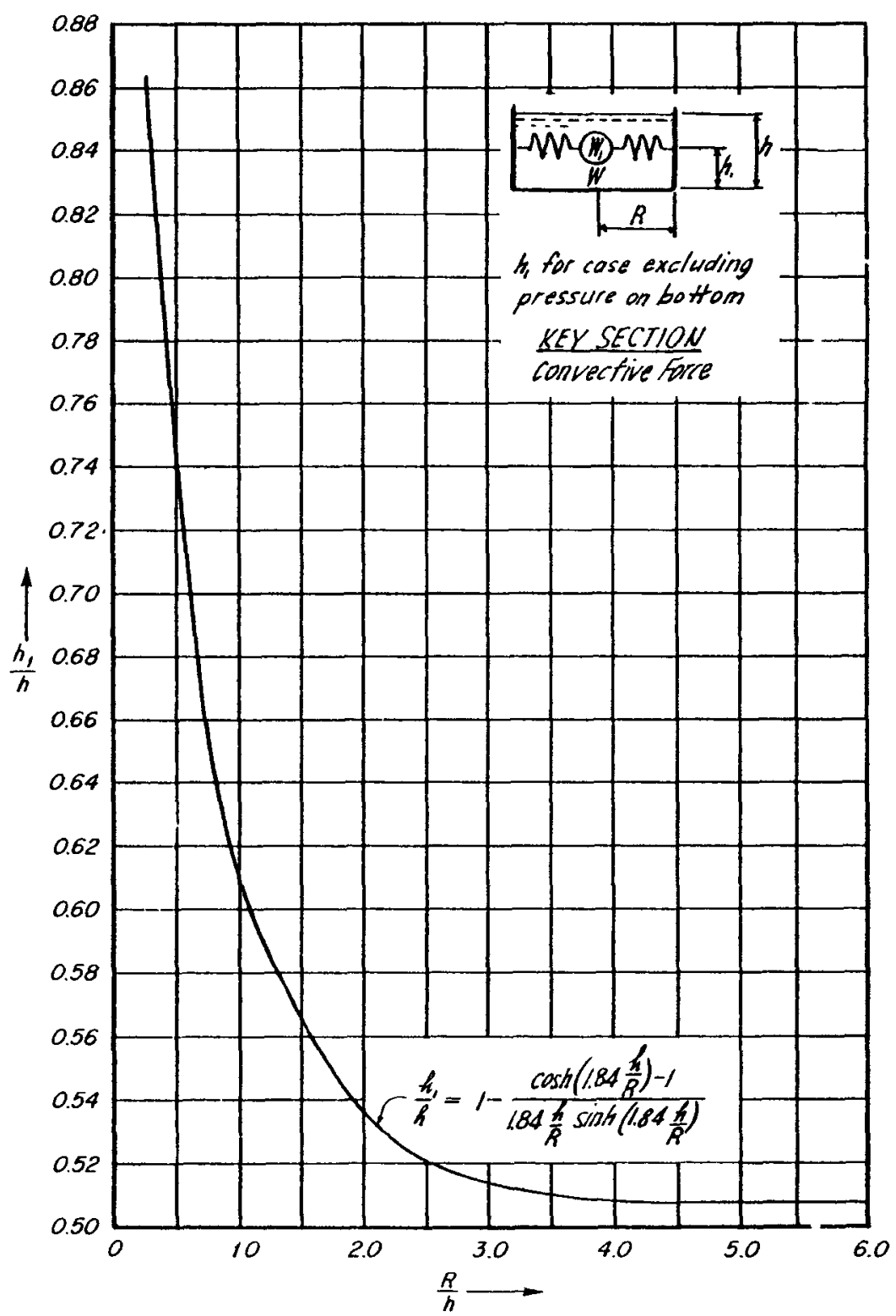




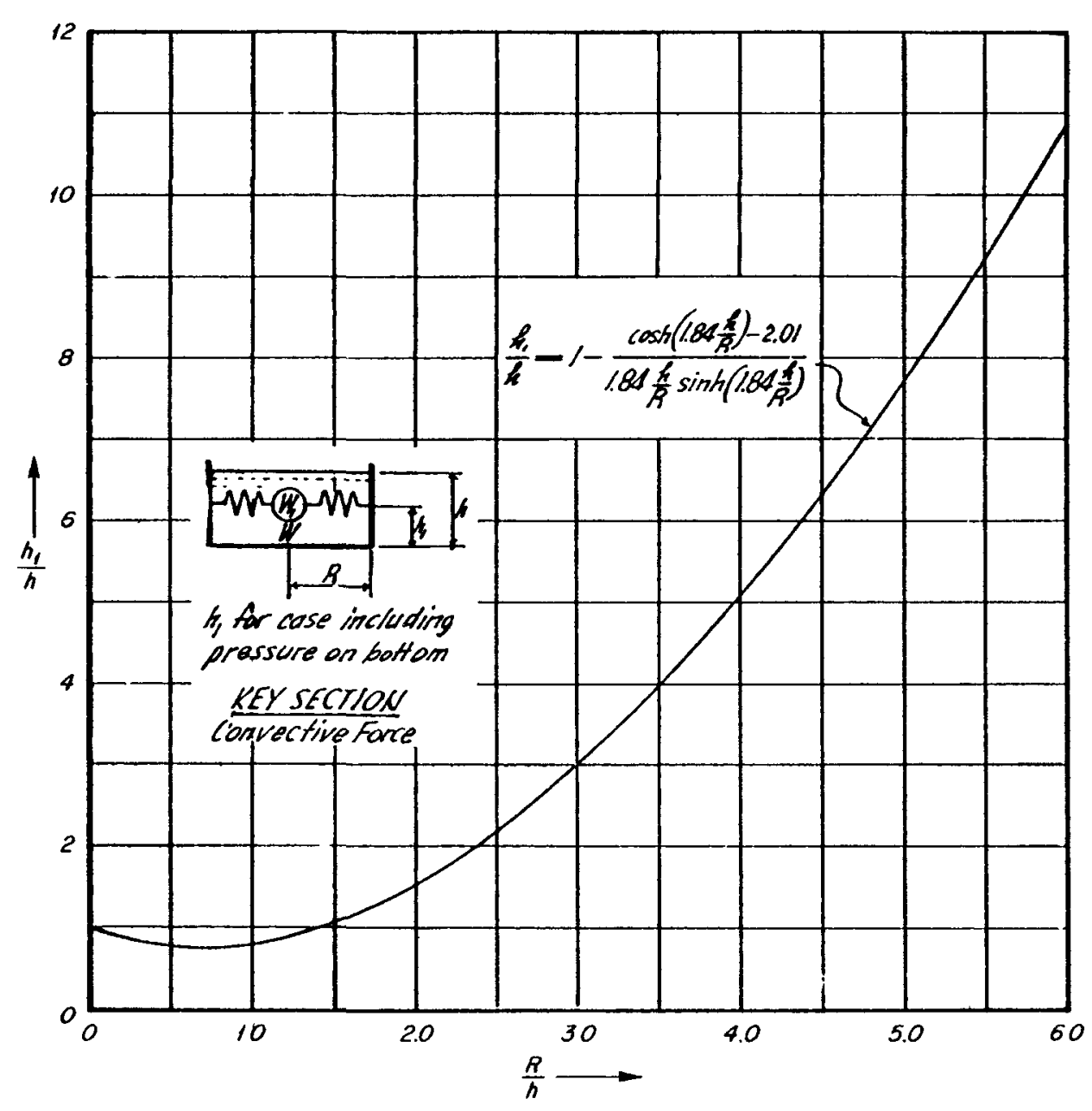

Fig. 6.14-Cylindrical tank, $h_{1} / h$ vs. $R / h$, including bottom pressure.

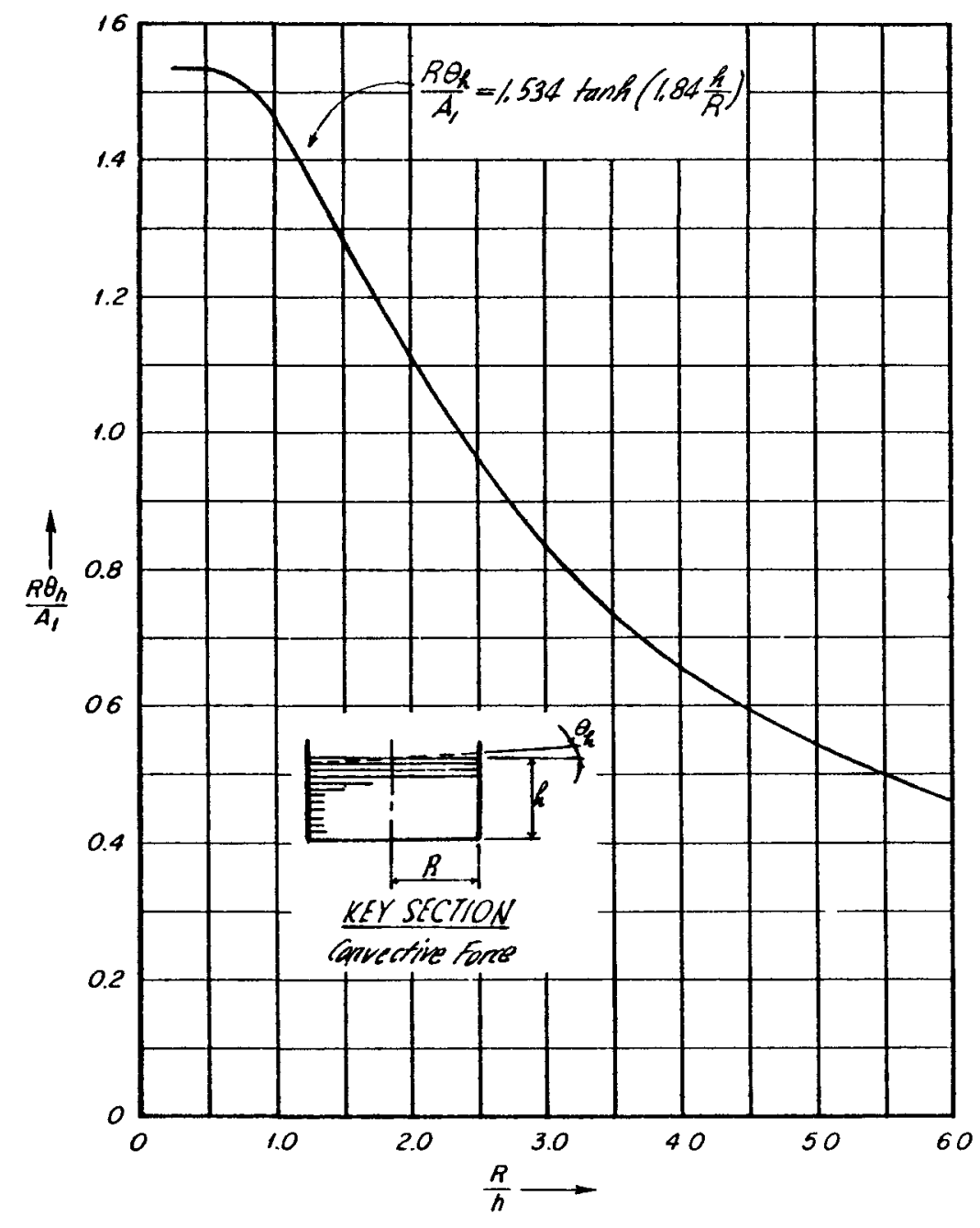

Fig. 6.15-Cylindrical tank, $R \theta_{\mathrm{h}} / \mathrm{A}_{1}$ vs. $\mathrm{R} / \mathrm{h}$. 
Equations 6.11 and 6.22 can be written as

For rectangular tanks

$$
\mathrm{d}_{\max .}=\frac{\mathrm{Q}}{\frac{\mathrm{g}}{\omega^{2} \theta_{\mathrm{h}} l}-1}
$$

For cylindrical tanks

$$
d_{\max .}=\frac{Q}{\frac{g}{\omega^{2} \theta_{h} R}-1}
$$

From the above formulas, the following expressions for $\omega^{2}$ and $Q$ are obtained:

For rectangular tanks

$$
\begin{aligned}
& \omega^{2}=\frac{g}{\ell}\left(\frac{l \theta_{h}}{A_{1}}\right) \\
& Q=\frac{0.8331}{\left(\frac{l \theta_{h}}{A_{1}}\right)}
\end{aligned}
$$

For cylindrical tanks

$$
\begin{aligned}
& \omega^{2}=\frac{1.2 g}{R}\left(\frac{R \theta_{h}}{A_{1}}\right) \\
& Q=\frac{0.629 R}{\left(\frac{R \theta_{h}}{A_{1}}\right)}
\end{aligned}
$$

Hence $\omega^{2}$ can be obtained by multiplying the value of $l \theta_{h} / A_{1}$ or $R \theta_{h} / A_{1}$ from Fig. 6.11 or 6.15 by $32.2 / l$ and $38.6 / R$, respectively, where $l$ and $R$ are in feet. Similarly the factor $Q$, used in obtaining $d_{\text {max }}$, from Eqs. 6.31 and 6.32, can be found by dividing the value of $0.833 l$ or $0.626 R$, respectively, by $l \theta_{h} / A_{1}$ or $R \theta_{h} / A_{1}$ from Fig. 6.11 or 6.15.

\section{REFERENCES}

6.1 G. W. Housner, Dynamic Pressures on Accelerated Fluid Containers, Bull. Sejsmol. Soc. Am., 47(1): January 1957.

6.2 L. C. Maugh, Statically Indeterminate Structures, John Wiley \& Sons, Inc., New York, 1946.

6.3 L. E. Grinter, Theory of Modern Steel Structures, Vol. II, The Macmillan Company, New York, 1949.

6.4 H. Sutherland and H. L. Bowman, Structural Theory, 4th ed., John Wiley \& Sons, Inc., New York, 1950.

6.5 U. S. Department of Commerce, Coast and Geodetic Survey. Earthquake Investigations in California, 1934-1935, Special Publication No. 201, U. S. Government Printing Office, Washington, D. C., 1936 .

6.6 K. V. Steinbrugge and D. F. Moran, An Engineering Study of the Southern California Earthquake of July 21, 1952, and Its Aftershocks, Bull. Seismol. Soc. Am., 44(2B): Part 2 (April 1954). 


\section{Chapter 7}

\section{REACTOR HAZARDS AND THEIR DEPENDENCE ON EARTHQUAKES .}

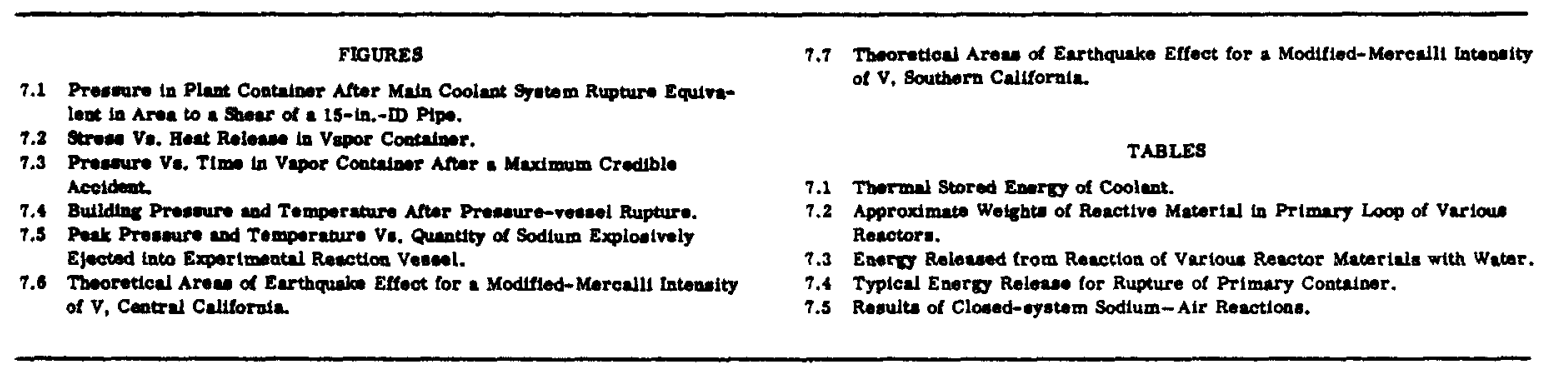

\subsection{GENERAL CONSIDERATIONS FOR REACTOR SAFETY}

The worst accident that knowledgeable persons would judge as having a small but recognizable probability of occurrence has been established as the basis for evaluating the relative safety of reactors. The fundamental criterion for the siting of the reactor, the design of its containment, and the administrative operating procedures is the "maximum credible accident." For the purpose of this report, the following terms (listed in decreasing order of severity) will be used.

Maximum Conceivable Accident. This accident involves the release of all or almost all available energy. In this case the mechanis $m$ for triggering the accident cannot be postulated, and the accident model is purely hypothetical.

Maximum Credible Accident. This accident is that which might occur with a finite probability and is triggered by understandable mechanisms. Most reactors are designed to contain a postulated maximum credible accident.

Maximum Probable Accident. This accident is that which might occur with a fairly high probability. The mechanisms for triggering it are well understood and include human error. It is guarded against by administrative control, protective instrumentation, and appropriate design provisions.

In judging the safety of a new reactor and its site, it is necessary to evaluate and minimize all the factors that may increase the possibility of uncontrolled release of radioactivity. In the past decade, progress in the design and operation of reactors has served to reduce the probability of accidents from many sources; thus, currently, a major earthquake assumes relatively greater importance as a possible cause of accidents. It is possible to design reactors, often without excessive cost increases (particu- 
larly in the more compact plants), which will not incur damage of a hazardous nature during the worst postulated earthquake (the magnitude of earth motions being held in manageable upper limits by limits to which strength of rock formations can resist energy accumulations).

The basic problem is that the prompt physiological and ultimate genetic effects of radiation on the human require that his exposure, as well as contamination of his environment, be minimized. The need for containment of reactors, therefore, is primarily dependent on the amount of fission products existing in the reactor core, the proximity of the reactor to human habitation, and the extent to which the maximum credible accident and subsequent events could disperse the fission products.

Although from the governmental point of view on public safety the deciding factor regarding the potential damage to a nuclear facility may be the possibility of escape of radioactive material from the site boundary as a result of earthquakes, another stringent criterion is imposed by the facility operator. He ordinarily requires a maximum utilization of the reactor, so almost no physical or functional damage is acceptable. Self-imposed design and operating standards are often more exacting than governmental requirements. In choosing reactor sites to be consistent with these criteria relative to earthquake occurrence, a qualitative judgment can be made, although it is impractical to assign exact probabilities to the chain of many unlikely events that would result in the final radiation hazard.

Factors that tend to increase the potential radiation hazard of a plant include:

The power level and length of the fuel loading cycle that determine the fissionproduct inventory

The speed of control action and the inherent nuclear factors that alter reactivity relating to the magnitude of a possible power excursion

Core design, insofar as it decreases the following:

a. Neutron lifetime, which partly determines the rate at which power can increase

b. Thermal capacity

c. Rate at which heat can be transferred out of the core

High operating pressures and temperatures

Factors that tend to decrease the hazard include:

The degree of containment of possible releases of fission products

Selection of heat-resistant, nonflammable, nontoxic materials that do not become activated under irradiation

Protective instrumentation

Blast protection

Administrative controls for all operating conditions and standardized procedures for all nonoperating conditions

Emergency systems, such as stand-by electrical power supply, supplementary cooling, dousing, or spray systems

Use of reactor systems with small amounts of stored energy

Factors that determine the suitability of a site for the location of a specific reactor include:

$\begin{array}{ll}\text { Population density } & \text { Seismicity } \\ \text { Meteorology } & \text { Geology } \\ \text { Hydrology } & \text { Exclusion radius }\end{array}$

Many other factors are also involved; therefore, when it is desired to build a specific reactor type on a given site, each reactor complex should be studied separately and all pertinent factors evaluated. 


\subsection{EARTHQUAKES AS CAUSES OF REACTOR FAILURES}

\subsection{EARTHQUAKES AS CAUSES OF REACTOR FAILURES}

A. Accident Initiation

During the past 10 years, considerable sophistication has developed in the analysis of the maximum credible accidents to which reactor complexes may be subject. There is beginning to evolve a body of pertinent literature firmly based on experimentation. Where the maximum credible accident is primarily nuclear in character, actual transient tests on several types of reactors have been conducted. Notable in this respect have been the SPERT, BORAX, KEWB, EBR-1, and Godiva experiments encompassing kinetic behavior over a wide range of operating variables. These programs have already delineated safe areas of operation of many reactor-core configurations, and the continuing programs will include additional core types. Other research includes (1) transient heat-transfer considerations, such as heat fluxes at which vapor blanketing of the fuel element in liquid-cooled reactors occurs with concurrent decrease in heat transfer and subsequent melting; (2) conditions under which molten reactor materials explosively react with water; (3) the resistance of pressure vessels and containment structures to internal explosions; and (4) fission-product-release studies under simulated accident conditions.

The reason for the nonnuclear safety studies lies in the fact that the initiating mech anism for fission-product release is not necessarily a nuclear excursion. The accident may be due to chemical, thermodynamic, or mechanical causes. Severe damage from earthquakes or sudden release of energy stored in pressured systems fall in this category. (Heterogeneous, water-cooled reactors, with their relatively large amounts of stored energy, will probably represent the most prevalent class of reactors in the United States in the near future; therefore, discussion will be based on this type, although most considerations apply to all reactor types). Very large fission-product releases occur only if the fuel-element cladding melts or is otherwise destroyed (exposing irradiated fuel) as a result of the initiating mechanism. However, a certain amount of radioactivity may be available in many systems, external to the fuel elements, as a result of prolonged radiation; this may be significant to safety on a localized, plant-only basis after an initiating incident.

Early speculation on the causes of reactor accidents focused on human actions as having the highest probability of precipitating a disaster. Human actions can be controlled to a certain extent, and plant design provides safety features to prevent accident initiation due to human error. As human error is minimized as a probable instigator of severe reactor accidents, earthquakes take a more important role in deliberations regarding safety. In fact, in identifying a credible event that could precipitate the release of large quantities of fission products to the atmosphere, hazards analyses could single out the severe earthquake (even though the maximum credible accident may not involve an earthquake at all). This is true for reactors under construction as well as for older plants, in which improvements in design have eliminated earlier causes for concern.

B. Power Increase

Increases in reactor power, which accompany increases in fission density, may be caused by maloperation of nuclear controls. Heat-transfer requirements for reactors cause them to be operated with a small safety factor for heat removal. A power increase by a factor of 2 or 3 is generally sufficient to produce melting of fuel elements. Normally, overpower safety-trip levels are set between 110 and $125 \%$ of maximum rated power and rarely above $150 \%$. This trip level is primarily to combat brief surges, and melting under sustauned power increases is prevented by additional controls. The many automatic protective devices and instruments and the improved mechanical design of control rods have largely eliminated the possibility of a power excursion with sufficient energy release to exceed the fuel-element heat capacity in the normal reactor environ- 
ment. However, seismic motions might cause erroneously low signals from the powermeasuring instrumentation (unless such equipment is installed to resist any lateral displacement that might prevent normal operation of controls) or earthquake damage might bind control rods and prevent their further insertion when they are needed to forestall an excessive power increase.

A power increase can also occur in a reactor with a large negative-temperature coefficient of reactivity if the core temperature is lowered by the addition of a volume of cold water, as in the startup of a loop that has been shut down for a considerable period. It is not inconceivable that seismic disturbances could rupture pipes or vessels and trigger this type of accident, although the possibility is remote in a well-designed reactor.

\section{Loss of Flow}

Fuel-element integrity is dependent on the continuity of coolant flow in power reactors, flow being generally of the forced-circulation type. Normally a stand-by pump is also available with an emergency power source to produce at least the coolant flow required for removal of the afterheat from fission-product decay in a shut-down reactor. Large centrifugal pumps and, in particular, the shaft connections to their motive power are sensitive to the misalignments that may be produced by earthquake-induced ground movement. Similariy, if the valves and flow-control instrumentation are at all vibration sensitive, an earthquake may be the initiating event to trigger flow reductions.

Some reactor designs, where high power density is not an overriding requirement, permit naturai-convection circulation of the coolant so that complete loss of pumping power will not necessarily result in melting. It is doubtful that economic power reactors can be designed in this manner; rather, they will be dependent on continuity of forced flow, and seismic considerations will continue to be pertinent.

\section{Loss of Coolant}

The credible major accident for most types of reactors is currently taken to be the loss of coolant from the core. In the case of water-cooled reactors utilizing highpressure vessels, pumps, piping, and heat exchangers, it is certainly conceivable that fractures of the primary loop envelope could occur. Such'fractures would probably occur in areas of fatigued or radiation-embrittled materials, and an earthquake may precipitate such failure.

It appears less probable, but still within the realm of credibility, that physical displacement between points of support may tear open a heavy-duty primary loop. Long, poorly supported runs of piping may be oscillated at frequencies close to resonance, inducing swaying sufficient to rupture junctions. There is, in general, an additional hazard where the unpressurized emergency water supply is involved. This secondary supply, when excited by earth waves, may be subject to earthquake damage. Reservoirs elevated on flexible supports can be subjected to large dynamic forces, which in the past in nonnuclear installations have sometimes resulted in collapse of the tower.

In swimming-pool type research reactors, which are of less concern than power reactors due to the smaller fission-product inventory associated with lower powers, the fuel elements are contained in a free pool of water. In many cases the pool structure is erected above ground to allow free access to experimental beam facilities at the side of the pool. In this case also a severe earthquake is an easily imagined natural event that may fracture the concrete and cause the coolant to drain from the pool, allowing the fuel elements to melt if high burnup levels have been reached.

Loss of coolant is the most probable mechanism whereby a severe earthquake can initiate a maximum credible incident. Loss of flow appears as the second most likely event of severe consequence to be triggered by an earthquake. Both effects may eventually cause the cladding to melt and release fission products. 


\subsection{ENERGY SOURCES AND RELEASE MECHANISMS}

The stored energy of the reactor coolant (particularly in power reactors of the pressurized-water type) ordinarily is the largest source of energy that might be released during a maximum credible accident. Other energy sources may be chemical or nuclear.

The energy released in nuclear excursions or the sudden loss of core-cooling capability, besides being a factor in any mechanical damage, may lead to larger problems of safety due to melting of the fuel elements. Fission products would be released from these elements at the same time that temperature and vapor pressure of the remaining coolant would be increasing. The resulting forces might breach the primary containing envelopes (if loss of coolant through such a breach had not already occurred), creating a leakage path to the plant environment for the fission products. Release of stored energy might thereafter breach the outermost containment envelopes (however, these envelopes are ordinarily designed to resist the maximum forces that could possibly be generated by the release of stored energy from all sources) and tend to spread radioactivity beyond the immediate plant. The extent to which seismic disturbances could initiate or aggravate any tendency to fission-product release should be evaluated in any particular plant.

Phenomena that may increase the magnitude of the total energy release are:

Chemical explosions (metal-water reactions) resulting from oxidation of the molten fuel or cladding

Coolant fires involving alkali metals or organic material

Reassembly of the molten fuel in a more reactive and supercritical configuration

Explosive combination of the hydrogen liberated by the metal-water reaction with oxygen in the air confined in the containment vessel

These factors are generally much smaller than the thermodynamic stored-energy release.

In addition to the amount of energy release, the rate at which the release impinges on suceessive envelopes is important. Shock or transient pressure loadings may occur, and, unless the nature of the release mechanisms is well understood, these may not have been included in the design criteria of the envelopes.

If all containment envelopes should be breached, the energy liberated in the accident could be assumed to propel a cloud of released fission products to some altitude above the site, where it may be dispersed by prevailing winds. Diffusion from an elevated source may, in some instances, produce more severe biological damage than an equivalent ground source, although the reverse is normally true.

\section{A. Nuclear Energy Sources}

Various mechanisms have been postulated by which the power level of a reactor may be increased. Fissionable-material inventory of the reactor core may be increased, poisons may be withdrawn, or the neutron leakage from the core may be decreased. These can occur, for example, due to rapid removal of control rods, dropping a fuel plate subassembly into the core, sudden addition of moderator to an undermoderated assembly, or instantaneous removal of an experiment detrimental to reactivity. It is conceivable that such events could be caused by earthquakes (although this is unlikely), and consideration of the possibility may be necessary in the hazards analysis of particular reactors. There are, however, certain inherent phenomena that may operate to return a reactor to a noncritical condition before any excursion occurs, even in the event of an earthquake. These operate independently of any designed safety mechanisms. Increase of neutron leakage, decrease of moderator density, generation of bubble voids due to increased temperature, and thermal expansion of the core itself are examples. It is even possible that eventual melting of the fuel elements may result in dispersion to a 
subcritical configuration (the reverse also being possible). These are typical of the factors that deserve study in evaluating the effect of earthquakes on reactors.

The rate of increase of reactor power is governed by the excess reactivity of the core and the neutron lifetime (time from generation of a neutron to its subsequent participation in fission). In thermal reactors (those in which most fissions are caused by neutrons at low velocities in thermal equilibrium with their environment), energy can be dissipated rapidly enough (due to relatively long lifetimes) so that a rate of energy release approaching that of an explosion is difficult to achieve. From this standpoint, thermal reactors are relatively insusceptible to earthquake-induced malfunctions that would tend to increase the reactor power level rapidly and, therefore, lead to hazardous situations. In fast reactors, however, the neutron lifetime is extremely short (of the order of microseconds or less). With a slight increase of reactivity, the rate of increase in power is very rapid. Inadvertent, rapid control-rod withdrawal or other earthquake-induced malfunctions could add to excess reactivity, and it is possible for a fast-reactor core to quickly experience a sufficient number of fissions for a very large quantity of energy to be released. A maximum conceivable accident, which involves the melting of the fuel elements and the collapse of the molten core upon itself under the acceleration of gravity, has been postulated for fast reactors. This may produce a molten, supercritical mass outside the influence of control mechanisms. Analysis of this type of accident in a typical fast-power reactor suggests that not more than the energy equivalent of several hundred pounds of TNT will be liberated before the mass disassembles itself because of heat and vaporization.

It should be noted that there is a wide range of possible reactor types intermediate between fast and thermal systems. In addition, it is possible that a thermal reactor under adverse conditions could experience a rapid energy release greater than that in a well-designed fast reactor.

\section{B. Stored Energy}

In certain reactor plants large volumes of gaseous or liquid coolants at high pressures may be the major source of energy susceptible to release as a result of earthquakes. Table 7.1 gives examples of stored energy for various reactors. Long-term stress existing in the pressurized primary coolant system may cause rupture if seismic vibrations or relative displacement of components should be superimposed. The escaping coolant may enlarge the rupture and perhaps create and eject missiles at a velocity sufficient to reach and pierce other envelopes that are otherwise adequately designed to contain the plant and any accidents and assure public safety. The energy release itself

Table 7.1 - THERMAL STORED ENERGY OF COOLANT

\begin{tabular}{|c|c|c|}
\hline $\begin{array}{l}\text { Reactor } \\
\text { system }\end{array}$ & $\begin{array}{l}\text { Thermal } \\
\text { energy, }{ }^{*} 10^{6} \mathrm{Btu}\end{array}$ & Reference \\
\hline SM-1 & 2 & 7.1 \\
\hline \multicolumn{3}{|l|}{ Shippingport } \\
\hline PWR & 77 & 7.2 \\
\hline EBWR† & 9 & 7.3 \\
\hline SRE $\ddagger$ & 14 & 7.4 \\
\hline EBR-2‡ & 154 & 7.5 \\
\hline HRT & 2 & 7.6 \\
\hline
\end{tabular}

*Primary coolant enthalpy referred to $70^{\circ} \mathrm{F}, 1 \mathrm{~atm}$. †Fluid and steam in pressure vessel, plus $10 \mathrm{wt} . \%$ steam estimated for external circuit.

$\ddagger$ Thermal energy only, does not include oxidation. 
will, in a tightly contained plant, raise the pressure of the gas within the shell. Since a failure of the primary loop envelope is a conceivable accident, the minimum pressure specification for the shell is often calculated (irrespective of earthquake occurrence) on the assumption that all the released energy goes into raising the temperature and pressure of the contents of the shell and that thermodynamic equilibrium is achieved. Stored thermal energy may be added to that from the other sources to evaluate the total loads on any container or the altitude to which a cloud of released fission products might be raised if the outer container is grossly breached. The distribution of downwind fallout and direct radiation is dependent on this height. [In comparison with the amounts of energy from other sources, thermal energy is often the greatest, and it becomes the controlling factor in the design of missile, blast, and containment shields (see Table 7.1)]. It is hardly conceivable that all thermal energy can be released, but a major uncertainty in hazards calculations lies in the fraction of energy which is likely to be released. A considerable amount of research is now under way to reduce this uncertainty.

C. Chemical Energy Sources

Mechanical damage from violent earthquakes that do not of themselves cause a maximum reactor accident may result in bringing together reactor materials that normally are kept separated (because of their mutually reactive nature). The subsequent reaction and release of energy may in turn trigger additional damage, leading to serious consequences. Possible dislocations due to earthquakes should therefore be studied in hazards analyses of particular plants. The total amounts of chemically reactive materials present in the core of typical power reactors are listed in Table 7.2.

Table 7.2-APPROXIMATE WEIGHTS OF REACTIVE MATERIAL IN PRIMARY LOOP OF VARIOUS REACTORS

\begin{tabular}{lllll}
\hline & \multicolumn{4}{c}{ Reactive material in primary loop, tons } \\
\cline { 2 - 5 } Reactor & $\mathrm{U}$ & $\mathrm{Zr}$ & $\mathrm{Na}$ & Graphite \\
\hline SM-1 & 0.027 & 0 & 0 & 0 \\
Shippingport & & & & \\
$\quad$ PWR & 14 & 16 & 0 & 0 \\
EBWR-1 & 6.3 & 1.8 & 0 & 0 \\
SRE & 2.5 & 1 & 27.0 & 45 \\
ORNL GCR-2 & 0 & 0 & 0 & 1120 \\
HRT & 0 & 0.2 & 0 & 0 \\
EBR-2 & 31.5 & 0 & 316 & 0 \\
\hline
\end{tabular}

For analysis of water-cooled reactor plants, the amounts of energy per unit mass which may be released from the reaction of various reactor materials with water are listed in Table 7.3 together with the additional energy from the oxidation of the liberated hydrogen. A series of early experiments aimed at evaluating the energy release in metal - water reactions was conducted by Higgins ${ }^{7.8}$ in which various metals and alloys were melted and dropped into a pool of water. Early experiments derected little oxidation of the metal, presumably because of poor dispersion. When the metal was later dispersed into fine particles, violent and nearly complete oxidation reactions resulted.

The fraction of reactive metal which might oxidize rapidly in any reactor incident remains one of the principal uncertainties in hazards evaluation. Additional research is under way to reduce this uncertainty. However, under specific and perhaps unlikely conditions, nearly complete reaction can occur. Table 7.4 shows the wide variation in degree of reaction assumed by several reactor designers. 
Table 7.3-ENERGY RELEASED FROM REACTION OF VARIOUS REACTOR MATERLALS WITH WATER

\begin{tabular}{|c|c|c|c|c|c|c|}
\hline \multirow[b]{2}{*}{ Element } & \multirow[b]{2}{*}{$\begin{array}{l}\text { Moles } \\
\text { per kg }\end{array}$} & \multirow[b]{2}{*}{$\begin{array}{l}\text { Oxide } \\
\text { product }\end{array}$} & \multicolumn{4}{|c|}{ Energy release, $\times 10^{3}$} \\
\hline & & & $\begin{array}{l}\text { Btu* per } \\
\text { mole of } \\
\text { oxide }\end{array}$ & $\begin{array}{l}\text { Btu per } \\
\mathrm{kg} \text { of } \\
\text { oxide }\end{array}$ & $\begin{array}{c}\text { Btu from } \\
\text { hydrogen } \\
\text { recombination }\end{array}$ & $\begin{array}{l}\text { Total } \\
\text { Btut }\end{array}$ \\
\hline $\mathrm{Al}$ & 37 & $\mathrm{Al}_{2} \mathrm{O}_{3}$ & 1.54 & 28.6 & 8.50 & 37.10 \\
\hline $\mathrm{Zr}$ & 11 & $\mathrm{ZrO}_{2}$ & 0.71 & 7.84 & 2.52 & 10.36 \\
\hline $\mathrm{U}$ & 42 & $\mathrm{UO}_{2}$ & 1.03 & 1.07 & 0.96 & 2.03 \\
\hline $\mathrm{Na}$ & 43 & $\mathrm{Na}_{2} \mathrm{O}$ & 0.39 & 2.16 & 9.87 & 12.03 \\
\hline
\end{tabular}

* Free energies and enthalpy. $7 . ?$

† Metal-water reaction plus hydrogen explosion.

Table 7.4-TYPICAL ENERGY RELEASE FOR RUPTURE OF PRIMARY CONTAINER

\begin{tabular}{|c|c|c|c|c|c|c|}
\hline \multirow[b]{3}{*}{ Reactor system } & \multirow{2}{*}{\multicolumn{3}{|c|}{ Energy release, $10^{6} \mathrm{Btu}$}} & \multicolumn{2}{|c|}{$\begin{array}{c}\text { Extent of } \\
\text { chemical reaction }\end{array}$} & \multirow[b]{3}{*}{ Reference } \\
\hline & & & & \multirow[b]{2}{*}{ Metal, $\%$} & \multirow{2}{*}{$\begin{array}{c}\text { Hydrogen } \\
\text { recombination }\end{array}$} & \\
\hline & Nuclear & Chemical & Thermal & & & \\
\hline$S M-1$ & 1 & 0 & 7.4 & 0 & 0 & 7.9 \\
\hline Shippingport PWR & & 4.5 & & 10 & $\begin{array}{l}2.25 \times 10^{6} \\
\text { Btu }\end{array}$ & 7.10 \\
\hline EBWR & 0.1 & 3.2 & & 25 & Yes & 7.3 \\
\hline $\mathrm{EBR}-2$ & 0.6 & 5.2 & 13 & 4 & 0 & 7.5 \\
\hline HRT & & 2 & 7.5 & $100^{\circ} \mathrm{Zr}$ & & 7.11 \\
\hline \multicolumn{7}{|l|}{ Plutonium Recycle } \\
\hline Test Reactor & 3.5 & 7 & & $\begin{array}{l}12 \% \mathrm{Zr} \\
20 \% \mathrm{Pu}-\end{array}$ & Yes & 7.12 \\
\hline
\end{tabular}

In fast - and intermediate-reactor designs, such as EBR-1 and EBR-2 and the sodium graphite reactors, high-temperature liquid sodium or sodium-potassium alloys are used as primary as well as secondary coolants. These working fluids are pyrophoric and will react with air or water, liberating heat as well as sodium hydroxide smoke by the reactions

$$
\begin{aligned}
& 4 \mathrm{Na}+\mathrm{O}_{2}=2 \mathrm{Na}_{2} \mathrm{O}+99.2 \mathrm{kcal} / \mathrm{mole} \\
& 2 \mathrm{Na}+2 \mathrm{H}_{2} \mathrm{O}=2 \mathrm{NaOH}+\mathrm{H}_{2}+101.9 \mathrm{kcal} / \mathrm{mole}
\end{aligned}
$$

The free hydrogen, triggered by the heat of the oxidizing reaction, combines with any oxygen present:

$$
2 \mathrm{H}_{2}+\mathrm{O}_{2}=2 \mathrm{H}_{2} \mathrm{O}+57.8 \mathrm{kcal} / \mathrm{mole}
$$

Because the normal atmosphere contains oxygen, it is apparent that any mechanical damage or dislocation of barriers isolating the coolants from the air could have serious consequences. Since earthquakes are conceivable causes of such damage, the analysis of seismic resistance may be particularly important in this type of system.

Sodium also reacts rapidly with concrete. Because of the common occurrence of concrete in reactor construction and its susceptibility to seismic damage and dislocation, it becomes another reason for the study of earthquake resistance. When concrete sur- 
faces are potentially liable to contact with alkali metals, a protective covering should be interposed. Actually little is known about the parameters that limit these reaction rates, although some empirical data exists.

Hines et al. ${ }^{7.13}$ have concluded that the highest pressure to expect for closed-system sodium - air reactions, regardless of the amount of sodium or the size of the reactor housing, is 40 psig. Decrease of available oxygen within the containment to below the atmospheric norm of 21 vol.\% was demonstrated to have little effect on maximum pressure. Significant results of Hines et al. ${ }^{7.13}$ are reproduced in Table 7.5. As for metalwater reactions, the degree of dispersion is important. High pressures result from finer dispersions, but these are improbable under actual reactor conditions.

Table 7.5-RESULTS OF CLOSED-SYSTEM SODIUM-AIR REACTIONS*

\begin{tabular}{|c|c|c|c|c|c|c|c|c|c|}
\hline \multirow{2}{*}{$\begin{array}{l}\text { Initial } \mathrm{O}_{2} \\
\text { content, } \\
\text { vol. } \%\end{array}$} & \multirow{2}{*}{$\begin{array}{c}\text { Maximum } \\
\text { pressure, } \\
\text { psig }\end{array}$} & \multirow{2}{*}{$\begin{array}{c}\text { Time to } \\
\text { maximum } \\
\text { pressure, sec }\end{array}$} & \multicolumn{7}{|c|}{$\mathrm{O}_{2}$ remaining after ignition, vol.\% } \\
\hline & & & $\begin{array}{l}5-10 \\
\text { sec }\end{array}$ & $\begin{array}{c}5-15 \\
\text { sec }\end{array}$ & $\begin{array}{c}10-15 \\
\text { sec }\end{array}$ & $\begin{array}{c}15-25 \\
\sec \end{array}$ & $\begin{array}{c}25-35 \\
\text { sec }\end{array}$ & $\begin{array}{c}1 \\
\min \end{array}$ & $\begin{array}{c}10 \\
\text { min }\end{array}$ \\
\hline 21.0 & 38 & 6 & 17.5 & & 0.35 & & & & 1 \\
\hline 10.5 & 34 & 10 & & 10.2 & & 1.5 & 1.0 & 0.1 & \\
\hline 5.3 & 26 & 21 & & 5.4 & & 4.7 & 4.3 & & 1 \\
\hline 0.6 & 8 & 8 & & 0.6 & & 0.6 & 0.2 & 0.2 & \\
\hline
\end{tabular}

*These data (from Hines et al., Detroit Edison Company, Ref. 7.13) are included to emphasize the unlikelihood of any metal oxidation reaction (whether or not it is earthquake initiated) proceeding to near completion in a restricted atmosphere; however, it can easily be seen that the extent to which the atmosphere is actually restricted can depend upon the severity of an earthquake and the subsequent damage.

\section{Contamination Release}

In the majority of $U$. S. reactors, there are three barriers between fission products and the environment. The first barrier is the fuel-element cladding; the second is the primary loop; and the third is the containment vessel, which serves primarily as a safety feature and secondarily as shelter for the plant. The effect of energy releases on these barriers must be analyzed to evaluate the potential hazard of the plant. If only one of these barriers survives an accident essentially intact, the reactor probably does not become a hazard to the health and safety of the public beyond the radius of possible direct radiation effects.

Seismic disturbances may affect all these barriers directly or indirectly.

(1) Primary barrier (fuel-element cladding)

a. Direct rupture by earthquake motion is unlikely for metallic fuel elements. Rupture of brittle ceramic elements or thin metal seals on ceramic elements is possible, but the fraction of fission products released through such fractures would probably be small.

b. Indirect effects causing melting of this barrier during power surges, produced by malfunction of control rods or by excessive temperatures due to loss of coolant flow, might be initiated by seismic disturbances.

(2) Secondary barrier (envelope of primary coolant system)

a. Internal pressures may arise from coolant vaporization due to power surges, reduced flow, or amount of coolant and exceed the strength of the vessel and appurtenances. Metal-water reactions following fuel melting may add to this energy input.

b. Direct rupture of the secondary barrier by seismic damage is probably the most likely accident to be initiated by an earthquake. In plants with high- 
pressure coolants, such as water-cooled power reactors, the primary system is massive and complex. Supports of all components must allow for differential (or otherwise restrained) thermal expansion to permit movement while resisting oscillations caused by earth motions. Fatigue, radiation embrittlement, and ill-considered modifications will make the plant more subject to vibration damage with age.

This damage may take the form of:

Rupture of vessels and piping due to relative motion of plant components or to impulsive loading

Damage to instrument penetrations (e.g., thermocouple wells, control-rod entries, electrical circuity)

External damage by falling objects such as shielding walls, cranes, or other elevated structures

(3) Tertiary barrier (containment vessel)

Internal pressure surges created by plant failure of seismic origin may rupture the container or, more likely, increase the leakage rate of fission products through any existing openings. This leak rate, as well as direct radiation, is considered when siting the reactor and dictating a suitable radius of exclusion. However, in assessing potential hazards, it is difficult to predict the leakage rates from a large vessel. Precipitation of the maximum credible incident by an earthquake may lead to some predicted overpressure and to release of fission products, but it will not necessarily create a unique hazard unless the leakage through the final barrier constituted by the containment vessel is increased. Several possibilities exist for producing this increase. For instance, gross underestimates of the pressures created (due to primary vessel rupture) would permit this increase, as would failure of vessel seals at the foundation or around penetrations due to earth motion. However, direct damage of containers by destructive resonance caused by earth motion is unlikely because the fundamental frequencies of such structures do not normally fall in the critical range of earthquake-response spectra and because they are geometrically simple and ruggedly constructed. In addition, missile damage by fragmentation of the primary loop, resulting in penetration, is a possible mode of damage. Damage due to falling objects, such as an exhaust stack toppled by the earth motion, is also possible. As discussed above, seismic vibrations may be significant in contributing to rupture stresses in the primary system and hence to missile generation. A considerable degree of conservatism is justified in guarding against missiles until more is known about the phenomenon.

For tertiary shell, possible lines of defense against missiles include:

Blast attenuation shields to degrade shock waves

Hold-down devices to restrain large closures that may be blown free (in particular, the pressure-vessel plug) and control-rod drive mechanisms

Shadow shields and concrete linings around vulnerable components

Choice of alloys not subject to brittle fracture at the operating temperature of the primary system

Dual purposes may be achieved by using the massive biological shielding as a shock barrier. Shock waves should be attenuated to prevent secondary missile production by spallation of the concrete surface.

In determining the ability of the tertiary shell to resist missiles, model studies conducted by Zabel, ${ }^{7.14}$ in which drill-steel rods were projected at flat plates (roughly simulating such phenomena as control-rod ejection), showed that mild steel of thickness $\mathrm{T}$ is penetrated if

$$
e=16,000 T^{2}+1500 T
$$


where $e$ is the kinetic energy per unit diameter of rod in foot-pounds per inch and $\mathrm{T}$ is in inches. The following parametric variations were noted:

If the support of the plate is remote from the point of contact, e increases but not by more than a factor of 3 .

If a missile is deformed because its diameter or its yield strength is too small, e is greater than indicated by the equation. Energies for penetration at other than normal incidence are also greater than indicated.

For steels other than mild steel,

$$
\frac{\Delta \mathrm{e}}{\mathrm{e}} \simeq \frac{\Delta \sigma_{u}}{\sigma_{u}}
$$

where $\sigma_{u}$ is the ultimate tensile strength of mild steel.

Penetration for semistatic conditions requires approximately half the energy indicated by the formula.

Cylindrical rods with conical tips require greater specific kinetic energy to achieve penetration to full diameter, but acutely pointed rods can produce small perforations at appreciably lower energy than that required for penetration by flat-ended rods.

In reference to concrete spallation, the same experimenter has estimated that if an energy release of $10^{9}$ calories occurs in a cubical reactor $6 \mathrm{ft}$ on a side within $1 \mathrm{msec}$, surface fragment ejection may occur from a 10 -ft-thick solid-concrete biological shield. The energy input will produce such a condition if it occurs within the time required for a compression wave to traverse the medium. If the pressure builds up slowly, massive portions of the surrounding material may be accelerated, but this can be prevented by adequate venting.

\subsection{TYPICAL MAXIMUM CREDIBLE ACCIDENTS}

A series of maximum credible accidents is described here for the basic reactor types now in operation in the United States. Because there is no typical accident covering all reactors, the most representative of each group was considered and its maximum credible accident was taken as representative of the whole group. The following reactors were chosen:

$\begin{array}{ll}\text { Pressurized-water reactors } & \text { PWR, SM-1 } \\ \text { Boiling-water reactors } & \text { EBWR } \\ \text { Organic-moderated reactors } & \text { OMR } \\ \text { Tank type reactors } & \text { NASA }\end{array}$

The purpose of detailed examination of these maximum credible accidents is to underline the event that an earthquake may trigger or find already existing at the plant. As stated previously, it is remotely possible to envisage the latter case as aftershock tremors that hit a plant where a maximum credible accident has occurred.

In the case of water reactors, it should be understood that the structural vulner ability (of reactor containment) created by the maximum credible accident will, gener ally treated, ordinarily last for only a relatively short period of time. The maximum internal pressure generated by the release of stored energy and imposed on the system will decrease with decreasing temperature within the containment structure as the heat is dissipated through the containment vessel to the atmosphere, into the massive equipment of the plant, or by spray cooling from a stand-by water system. The pressure differential between the containment vessel and the atmosphere will subside, gradually reducing susceptibility to further damage to containment in the event of further shocks. The reactor is still vulnerable to earthquake damage (from the standpoint of public hazards) to the degree that the containment vessel encloses a cloud of gaseous fission 
products, but the reduced stored energy present after the heat losses reduces the possibility that an earthquake will rupture the containment. There remains the possibility that the maximum credible accident may have created minor structural inadequacies that could be greatly aggravated by aftershocks later. Thus an earthquake may both initiate the maximum credible accident and trigger further damage later in water reactors, even though major internal pressures have subsided. The possibility of similar effects of earthquakes on other than water systems should also be taken into account when seismic studies are made.

Usually the maximum credible accident is evaluated on the basis of the reactor plant itself, independent of the external structure. The degree of containment (i.e., the design pressure and leaktightness of the vessel) is in turn based on the accident. The potential leak rate can be used to estimate the escape of radioactivity to the atmosphere, based on the amount and type of fission products freed from the core, the internal driving pressure available, and the number and size of any existing leak paths. A considerable amount of research is being sponsored by the U. S. Atomic Energy Commission to give quantitative definition to these three items.

\section{A. Shippingport Pressurized-water Reactor}

The Shippingport Pressurized-water Reactor (PWR) basically consists of a reactor heat source through which primary coolant (water) is circulated and steam generators where the heat picked up by the primary coolant is used to generate steam. The primary coolant, at $538^{\circ} \mathrm{F}$ and $2000 \mathrm{psig}$, circulates in four separate loops with one steam gener ator per loop.

There is about $145,000 \mathrm{lb}$ of primary coolant at $534 \mathrm{Btu} / \mathrm{lb}$ of stored energy. The total heat energy contained in the primary coolant is about $78 \times 10^{6}$ Btu. When the primary coolant system ruptures, high-pressure water flashes to steam, and about $65 \times 10^{6}$ Btu is liberated into the plant container. This corresponds to about $69,000 \mathrm{Mw}-\mathrm{sec}$.

The following set of assumptions establishes the maximum case, i.e., a rupture of the primary coolant system, which gives the maximum pressure rise in the plant container.

The postulated conditions are:

(1) Instantaneous equilibrium flash of the primary coolant, leaving any unvaporized coolant in contact with hot metal surfaces at the temperature corresponding to the resulting plant-container pressure

(2) Continued boiling of the unvaporized coolant by heat transfer from the hot metal surface with which the coolant is in contact

(3) All the hot metal surface remaining in contact with the primary coolant as long as any remains unvaporized in the system

(4) Instantaneous condensation of the vaporized coolant on the plant-container shell and other cool objects located therein

(5) In addition to the above, the assumption that one boiler is ruptured on the secondary side

Based on these assumptions, the worst case was calculated, and the plant container was designed for $52.8 \mathrm{psig}$ and $280^{\circ} \mathrm{F}$.

A metal-water reaction and burning of hydrogen resulting from this reaction was considered as a consequence of the loss of coolant. These reactions would liberate additionally about $4.5 \times 10^{6} \mathrm{Btu}$, corresponding to an added 2-psig pressure rise in the vapor container. However, because it takes a certain time for the fuel elements to heat up to the melting temperature and react with water, the pressure rise resulting from the chemical reactions would occur well past the peak pressure, which is attained almost instantaneously. Thus the chemical reaction has no effect on the peak pressure. The pressure-time relation in the plant container is illustrated in Fig. 7.1. 


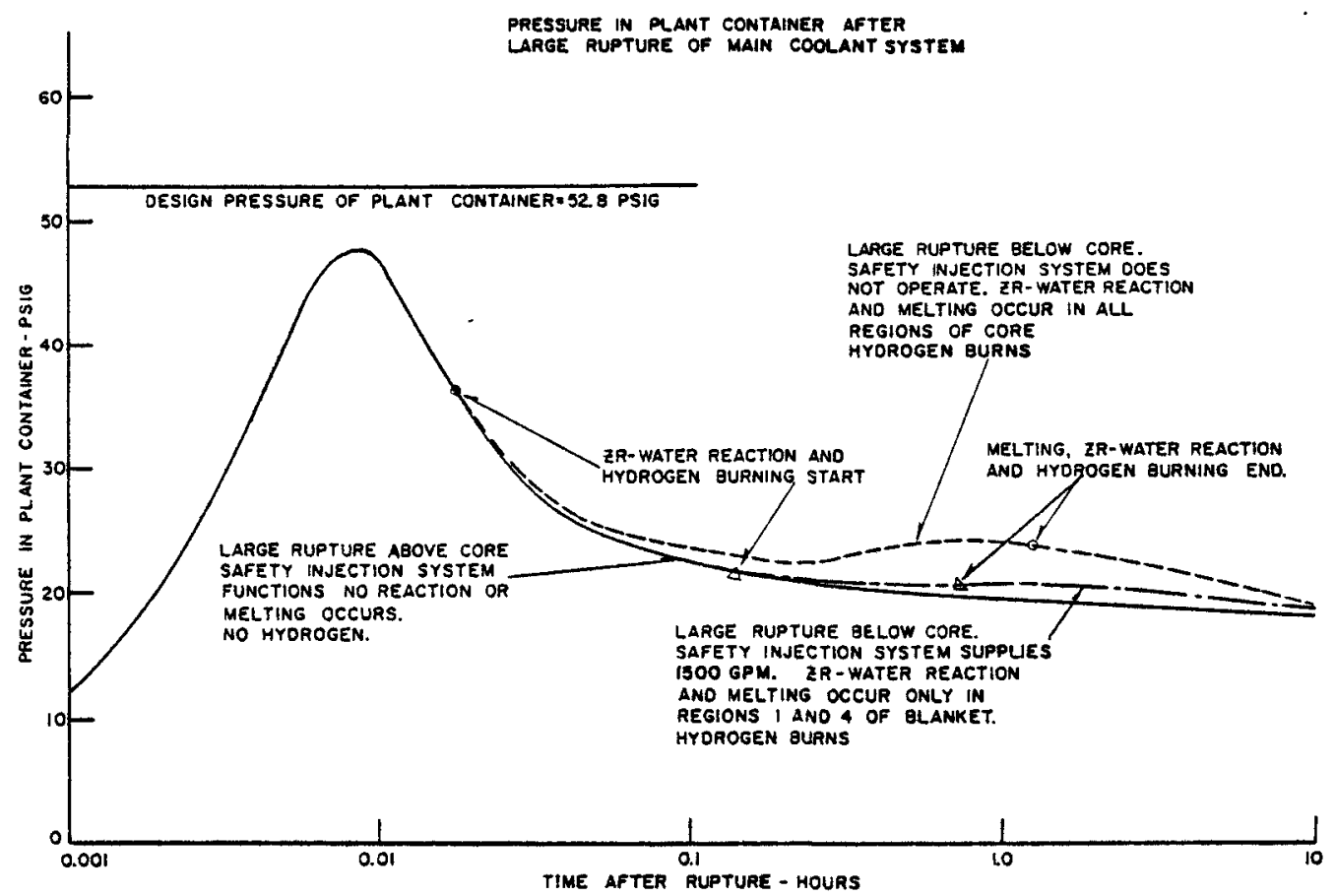

Fig. 7.1- Pressure in plant container after main coolant system rupture equivalent in area to a shear of a 15-1n.-ID pipe.

B. Stationary Medium Power Plant No. 1

The Stationary Medium Power Plant No. 1 (SM-1), also a pressurized-water reactor, is similar to the Shippingport Pressurized-water Reactor, although it operates at a lower temperature $\left(450^{\circ} \mathrm{F}\right)$ and pressure $(1200 \mathrm{psig})$ than the PWR. There is $5 \times 10^{6}$ Btu stored at heat energy in the primary and secondary water systems when the reactor is operat ing at steady state.

The maximum credible accident postulates a set of operating conditions in which both the primary and secondary water systems are allowed to reach saturation temperature at 1500 psig and rupture the system. The energy released in flashing water is $7.4 \times 10^{6}$ Btu. The vapor container was designed to contain $9.5 \times 10^{6}$ Btu without exceeding $80 \%$ of the yield point of the containing material. Under such conditions the internal pressure would be 90 to 95 psig.

The maximum credible accident releases only $7.4 \times 10^{6} \mathrm{Btu}$, which corresponds to 65 psig pressure and only $56 \%$ of minimum yield strength. Figure 7.2 shows stress vs. heat release in the vapor container. The vapor container is provided with water sprays to quickly reduce the overpressure after an accident. Figure 7.3 shows the pressuretime curve in a vapor container after a maximum credible accident.

\section{Experimental Boiling-water Reactor}

Water boils in the Experimental Boiling-water Reactor (EBWR) core at $600 \mathrm{psig}$, $489^{\circ} \mathrm{F}$. At the rated power conditions, $60,000 \mathrm{lb}$ of steam is generated per hour. Water enters the core $5.2^{\circ} \mathrm{F}$ below saturation temperature at a rate of $3.86 \times 10^{6} \mathrm{lb} / \mathrm{hr}$.

The maximum credible accident is a nonnuclear accident. The plant container (vapor shell) was designed accordingly. It will withstand a sustained overpressure of 15 psig. No leaks were detected when the plant container was tested at 18 psig. 


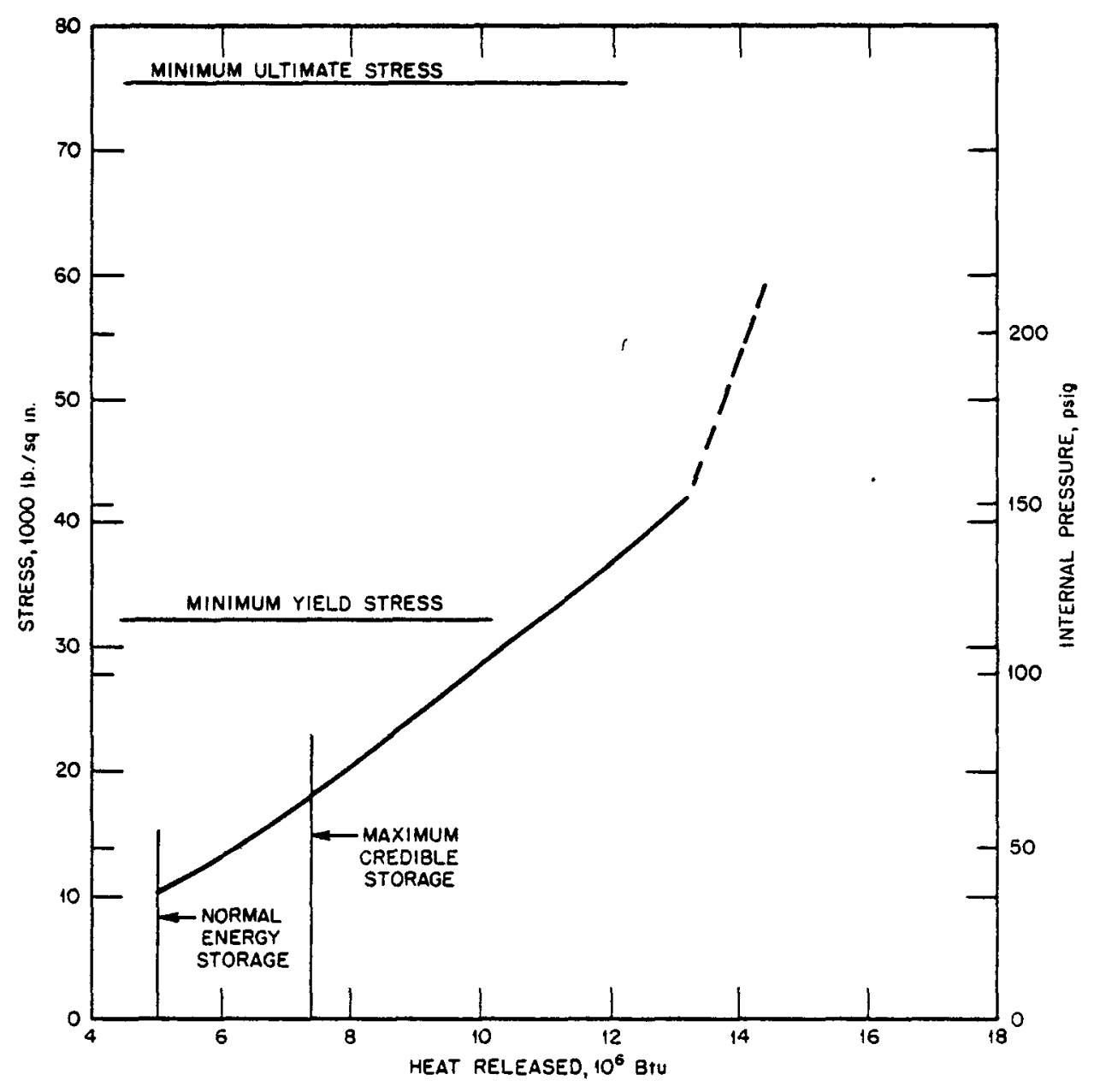

Fig. 7.2- Stress vs. heat release in vapor container.

Calculations made for a nonnuclear-energy release indicate that, if all the water in the reactor flashed from $600^{\circ} \mathrm{F}$ into the plant container at an ambient temperature of $90^{\circ} \mathrm{F}$, the resulting pressure and temperature would be 9.8 psig and $178^{\circ} \mathrm{F}$. Expulsion of the coolant can be brought about by a break in the inlet line. Another way is to assume that, if some of the fuel elements for some unknown reason were to melt and react chemically with water in the core, the pressure in the reactor vessel would rise to the point where the vessel would fail.

Calculations indicate that breaking of the vessel would require an energy release of $1.9 \times 10^{9} \mathrm{ft}-\mathrm{lb}$. This energy is equivalent to the energy released when $10 \%$ of the metal in the core reacts with water. If, then, water from a broken reactor vessel flashes and hydrogen liberated in the metal-water reaction burns, the temperature and pressure in the plant container would reach $187^{\circ} \mathrm{F}$ and $12 \mathrm{psig}$. The plant is equipped with a water-spray system that is actuated following such an accident. Figure 7.4 shows that the temperature and pressure would be brought down by water sprays to $125^{\circ} \mathrm{F}$ and 3.2 psig within $15 \mathrm{~min}$.

\section{Experimental Breeder Reactor No. 2}

The primary cooling system in Experimental Breeder Reactor No. 2 (EBR-2) is liquid sodium entering the core at $700^{\circ} \mathrm{F}$ and leaving at $900^{\circ} \mathrm{F}$. The primary coolant sys- 


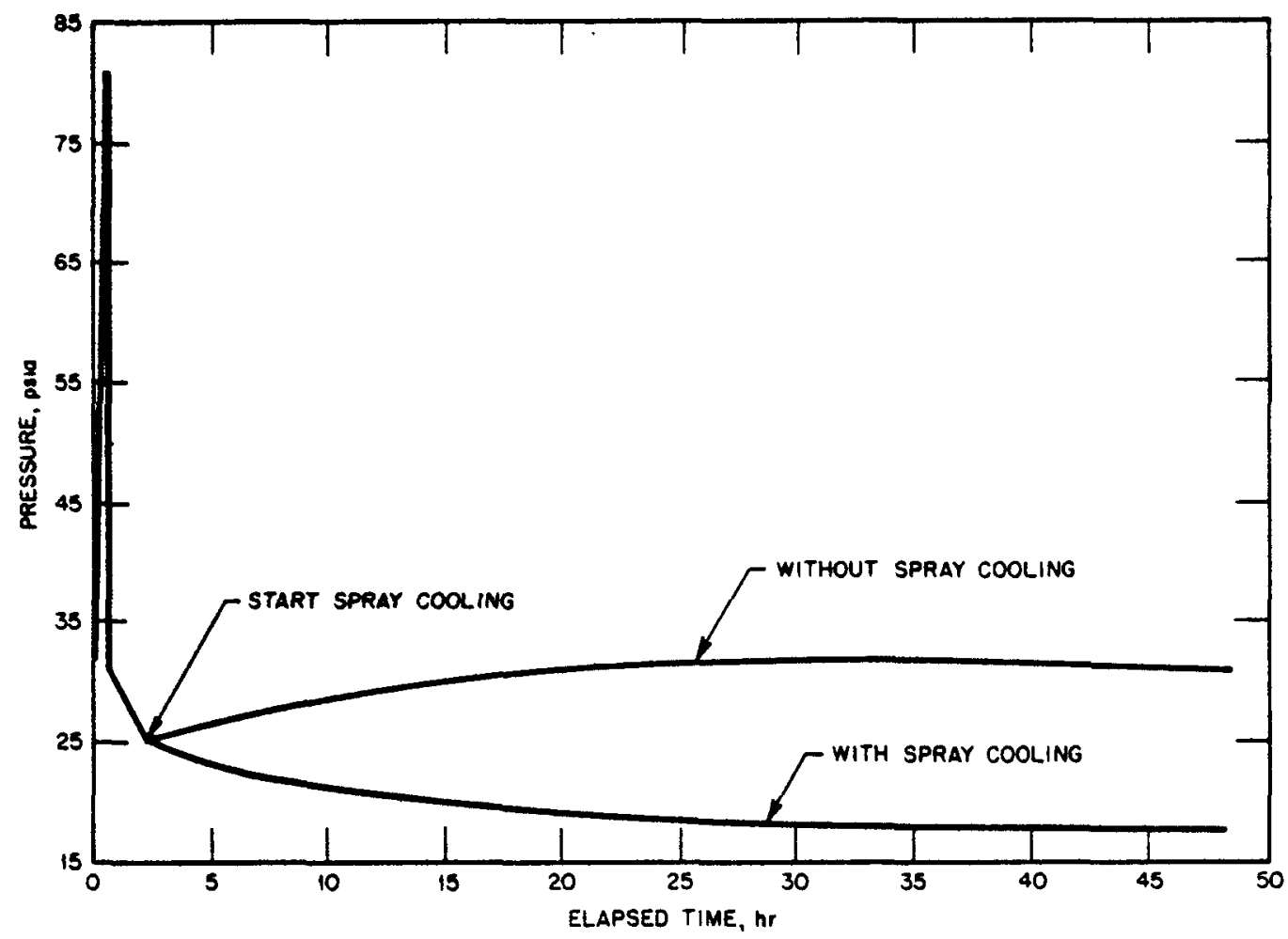

Fig. 7.3- Pressure vs. time in vapor container after a maximum credible accident.

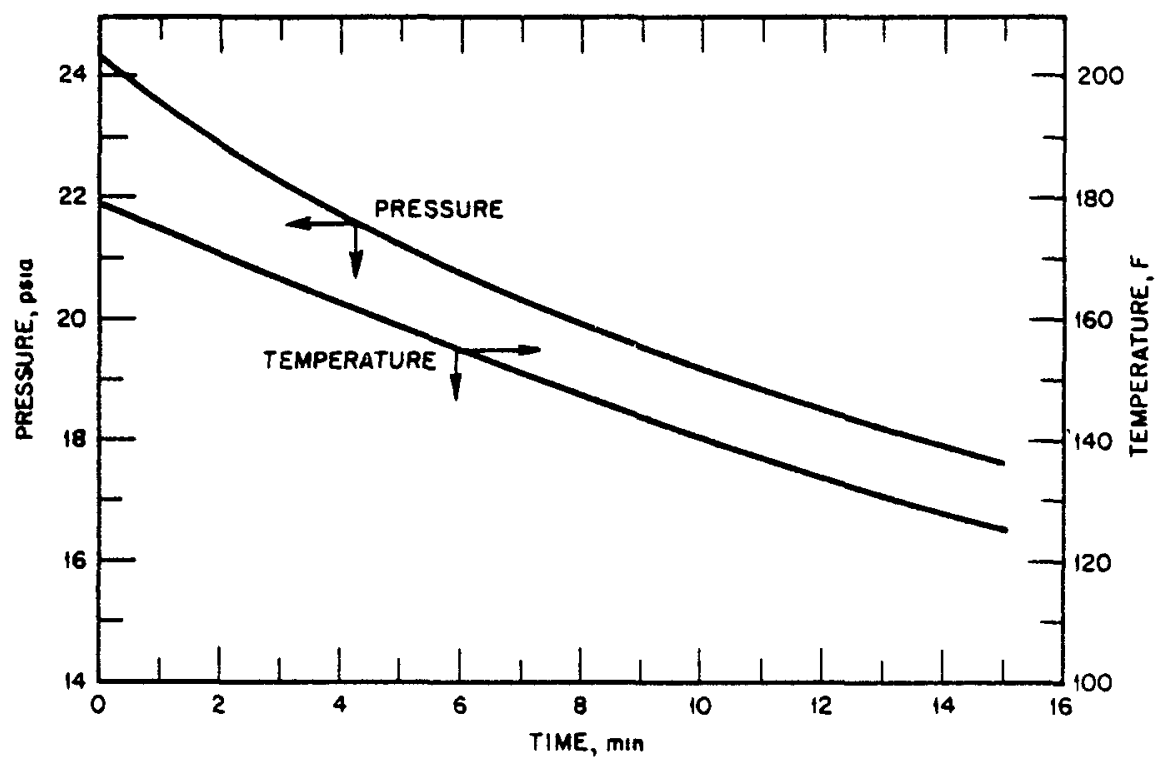

Fig. 7.4- Building pressure and temperature after pressure-vessel rupture. 
tem has a capacity of 86,000 gal. The heat from the primary coolant is exchanged with a secondary coolant that is also liquid sodium in a temperature range of 610 to $880^{\circ} \mathrm{F}$. The secondary coolant is circulated through a steam generator raising $248,000 \mathrm{lb} / \mathrm{hr}$ of steam at $850^{\circ} \mathrm{F}$ and $1300 \mathrm{psig}$.

The steam plant is in a separate building from the reactor building. Rupture of the steam system presents no danger of fission-product release. The primary coolant, however, erupting from a breached reactor in the form of jet dispersing in the air, could cause a chemical reaction between sodium and oxygen in air. Such an occurrence is considered to be the maximum credible accident. Figure 7.5 shows peak pressures in the reactor building in relation to the amount of sodium reacted.

A probable condition for the chemical reaction to occur in a violent manner is that the sodium be finely dispersed in air. The mechanism for such a dispersion may be a nuclear excursion followed by a breach of the reactor vessel and a stream of sodium jetting out through a small orifice, as postulated in the preceding paragraph. A realistic estimate of energy, inherently available in the reactor to disperse the sodium, puts an upper limit of $3000 \mathrm{lb}$ on the amount of sodium to be dispersed. A complete reaction of this amount would raise the pressure in the reactor building shell to $25 \mathrm{psig}$. Based on this calculation, the building was designed for an overpressure of 25 psig. Calculations indicate that a pressure of $24 \mathrm{psig}$ at $1200^{\circ} \mathrm{F}$ would induce a stress of $15,000 \mathrm{psi}$ in the shell. Such a high temperature would, of course, never be reached, and the shell would have the same strength from room temperature to $650^{\circ} \mathrm{F}$.

E. Organic-moderated Reactor Experiment

The Organic-moderatêd Reactor Experiment (OMRE) uses an organic medium as moderator, reflector, and coolant. The heat is removed from the coolant in an air-heat exchanger. The organic medium is diphenyl, which enters the core at $500^{\circ} \mathrm{F}$ and leaves at $700^{\circ} \mathrm{F}$ under a pressure of $300 \mathrm{psig.}$

At room temperature, diphenyl is solid, and its inelting temperature is $152^{\circ} \mathrm{F}$. The flammability characteristics of the diphenyl indicate that it presents the greatest hazard at the highest temperature. With a serious rupture in the reactor vessel or heat-transfer loop, the liquid diphenyl probably would be sprayed into the atmosphere as fine droplets and partially flash into vapor. Ambient temperature will cause the dispersed vapor to condense and solidify as fine smoke or dust, causing a continued fire hazard.

The loss of pressure in the reactor, however, would make it scram, and an emergency cooling system would adequately remove decay heat in the core. Large-scale melting of fuel elements is not considered possible. The loss of coolant is, therefore, the most serious accident that can happen in the OMRE. It is clearly a nonnuclear accident, although different from loss-of-coolant accidents in pressurized-water or boilingwater reactors.

\section{F. NASA Engineering Test Reactor}

The reactor consists of a 9 - by 32 -ft vertical, cylindrical, stainless-steel-clad pressure tank surrounded by concrete shielding mounted in a pool of water $70 \mathrm{ft}$ in diameter and $25 \mathrm{ft}$ deep. The coolant water enters the side of the pressure vessel and flows upward in the outer annulus and downward through the fuel elements. Water enters the reactor vessel at $160 \mathrm{psia}$ and $159^{\circ} \mathrm{F}$ and leaves at $120 \mathrm{psia}$ and $187^{\circ} \mathrm{F}$. Saturation temperature of the coolant is $341^{\circ} \mathrm{F}$ at outlet pressure. A secondary cooling system dumps the reactor heat load into a cooling tower.

The maximum credible accident is postulated as an excursion leading to core disassembly and a chemical reaction resulting from molten fuel elements. The energies released in this type of accident are estimated to be equivalent to $400 \mathrm{lb}$ of TNT exploded at the center of the core. Such an explosion would rupture the pressure vessel 


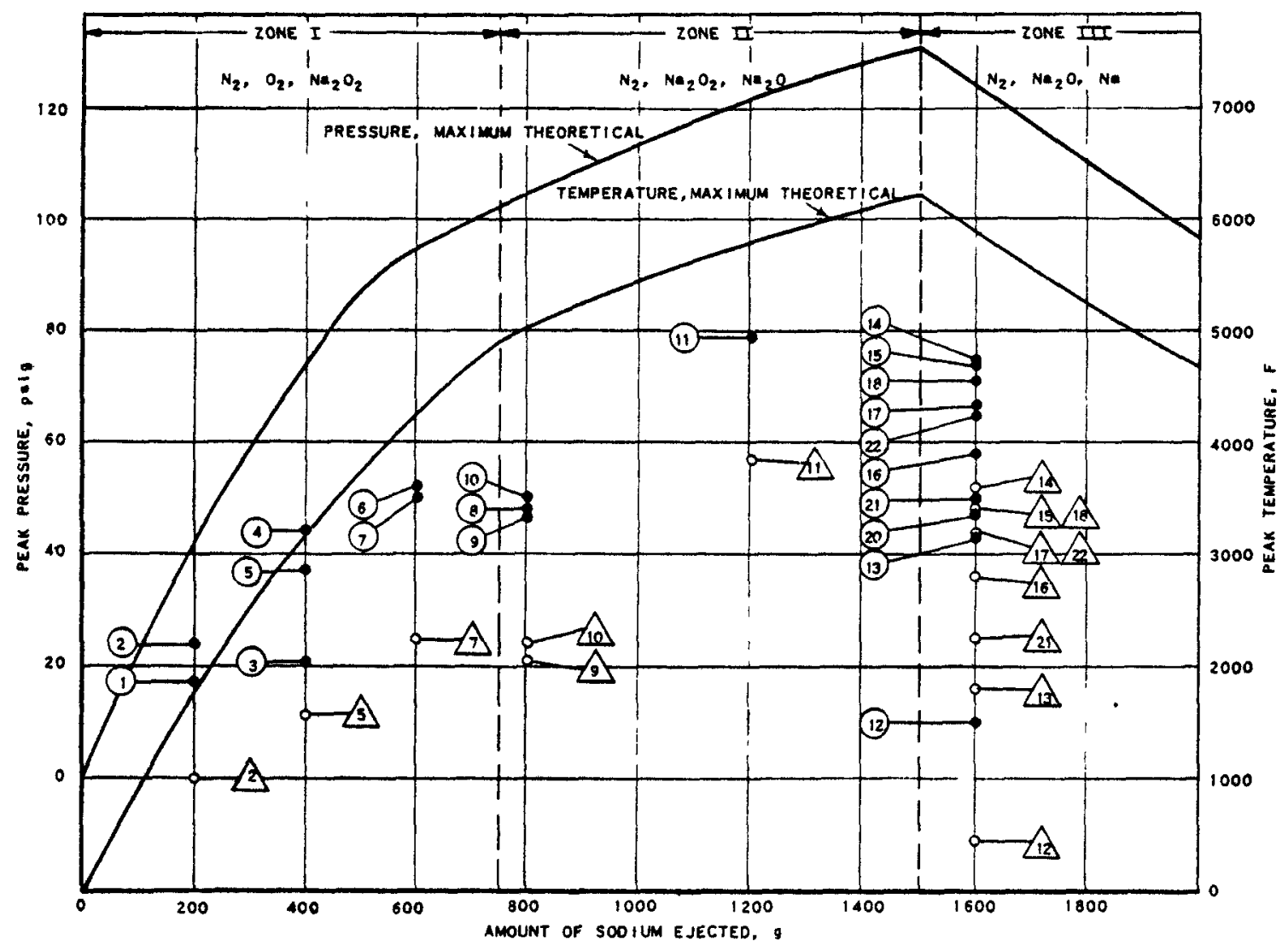

NOTES:

1. CURVES INOICATE MAXIMUM POSSIBLE PEAK PRESSURES AND TEMPERATURES BASED ON:

(a) 1OOK REACTION OF SODIUM OR OXYGEN; WHICHEVER IS LIMITING.

(O) INSTANTANEOUS REACTION (WHICH IMPLIES NO HEAT LOSS. OR, PERFECT DISTRIBU. TION, INFINITE PARTICLE VELOCITY, AND INFINITESIMAL PARTICLE SIZE OF THE SODIUMI.

(e) THE FOLLOWING AVERAGE SPECIFIC HEATS ARE ASSUMED:

$C_{y}\left(N_{2}\right)=4.82+3.3 \times 10^{-4} t-4.7 \times 10^{-\theta} t_{t}^{2} \mathrm{cs} / / \mathrm{mol} 0^{\circ} \mathrm{C}$

$\mathrm{C}_{7}\left(\mathrm{Na}_{2} \mathrm{O}_{2}\right)=0.31 \mathrm{Ca} / \mathrm{g}^{\circ} \mathrm{C}$

$\mathrm{C}_{p}\left(\mathrm{Na}_{2} \mathrm{O}\right)=0.31 \mathrm{Ca} / \mathrm{g}^{\circ} \mathrm{C}$

$C_{p}(\mathrm{Na})=0.31 \mathrm{Ca}=\mathrm{g}^{\circ} \mathrm{C}$

2. EXPERIMENTAL DATA ARE INDICATED AS FOLLOWS:

(A) EXPERIMENTAL PEAK PRESSURE (MEASURED),

(A) RUN A.

A EXPERIMENTAL PEAK temperature (CALCULATED FROM MEASURED PEAK PRESSURE), RUM A.

Fig. 7.5-Peak pressure and temperature vs. quantity of sodium explosively ejected into experimental reaction vessel. 
and crush the concrete, but the integrity of the 100-ft-diameter containment shell around and above the water pool would be maintained. The equilibrium overpressure from such an explosion would be about 2 psi, and the vapor container is designed for a steady load of 5 psi. All solids, liquids, and gases present inside would be cortained.

\subsection{EARTHQUAKES AND POWER-DISTRIBUTION NETWORKS}

The area affected by an earthquake of a given magnitude is difficult to predict due to the nonhomogeneity of the earth's structure and the source shape. An isopleth, connecting points of equal intensity during an earthquake, is therefore complex in form.

An approximation ${ }^{7.6}$ gives radii of isoseismals of Modified-Mercalli intensities near the epicenters of earthquakes of varying Richter magnitude. The following table is an adaptation of this information showing radii of areas which will experience an intensity of Modified-Mercalli $V$ or greater from earthquakes of several magnitudes, assuming there is a homogeneous crustal structure.

$\begin{array}{cc}\begin{array}{c}\text { Magnitude } \\ \text { (Richter) }\end{array} & \begin{array}{c}\text { Radius of area within } \\ \text { Modified-Mercalli V } \\ \text { isoseismal, miles }\end{array} \\ 5 & 12 \\ 6 & 37 \\ 7 & 62 \\ 8 & 120\end{array}$

These data are realistic in that they roughly correspond to average intensities vs. distance from the epicenters for average southern California earthquakes. Intensity $V$ on the Modified-Mercalli scale is described as "a few instances of cracked plaster; unstable objects overturned. Disturbance of poles, trees and other tall objects sometimes noticed." In general, seismic disturbances creating intensities of less than ModifiedMercalli $V$ will produce no physical damage to sound structures.

Figure 7.6 shows the location of existing power plants in the San Francisco area. Superimposed upon this are circles enclosing areas expected to experience intensities of Modified-Mercalli $\mathrm{V}$ or greater from earthquakes of larger magnitudes centered at San Francisco.

Current production reactors are protected by seismometers set to initiate automatic shutdown at Modified-Mercalli $V$, and power reactors might follow this practice. An earthquake of magnitude 6 (Richter) would therefore shut down all local (Bay Area) power plants if these were protected by the same earthquake criteria as current production reactors. The power-distribution network would then have to be fed from stations as far away as Sacramento, Fort Bragg, and Moss Landing if these plants had been able to operate through the severe electrical transient introduced by the shutdown of the Bay Area plants. An earthquake of magnitude 8 (Richter) would produce intensities above Modified-Mercalli $\mathrm{V}$ even at the three above-mentioned plants. This would leave the San Francisco area dependent on such power as could be imported from Morro Bay, the Eureka-Arcata area, and the hydroelectric plants along the western slope of the Sierras.

Figure 7.7 shows the location of existing power plants in the Los Angeles area. The power-plant data are based on Federal Power Commission Map Series M-49, Principal Electric Utility Generating Stations and Transmission Lines, 1957.

Conventional process equipment is normally protected with commercial seismic switches that are activated by shocks from explosions or earthquakes of intensity VIII or greater on the Modified-Mercalli scale. Modified-Mercalli VIII is defined as "damage slight in specially designed structures; considerable in ordinary substantial 


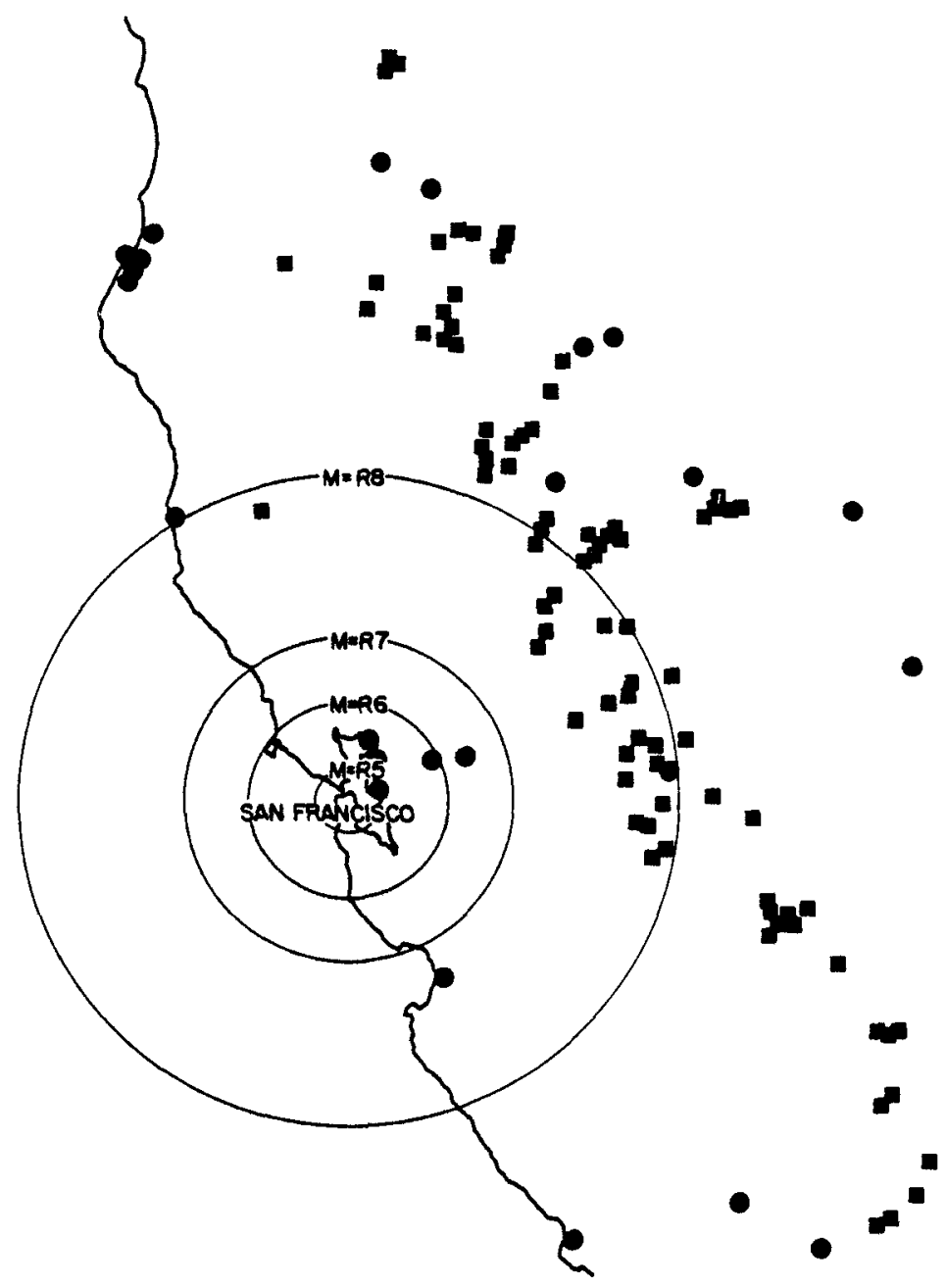

Fig. 7.6- Theoretical areas of earthquake effect for a Modified-Mercalli intensity of $\mathrm{V}$, central California. •, fossil-fuel fired; $\mathbf{w}$, hydroelectric.

buildings with partial collapse; great in poorly built structures." This would imply little interference with the functions of a power plant where designs have taken into account the effects of earthquakes. As nuclear fuels begin to assume an increasing share of energy pl oduction, reactors should be designed to equal or improve the reliability of fossil-fuel plants. Reactor systems and structures should therefore be designed with sufficient resistance to seismic shock so that, consistent with protection now given conventional equipment, operation need not be terminated for the safety of the plant on seismic disturbances of less than Modified-Mercalli VIII.

\subsection{SEISMOLOGY AND THE NEW REACTOR PROJECT}

Seismology should enter the initial site consideration for a new reactor project. If the project is national in scope, there may be freedom to select a seismically quiescent area, although strategic planning, isolation from large centers of population, and availability of power and cooling water will probably override this consideration. Usually the site-selection area is limited to the vicinity of the operator's existing facilities; thus the 


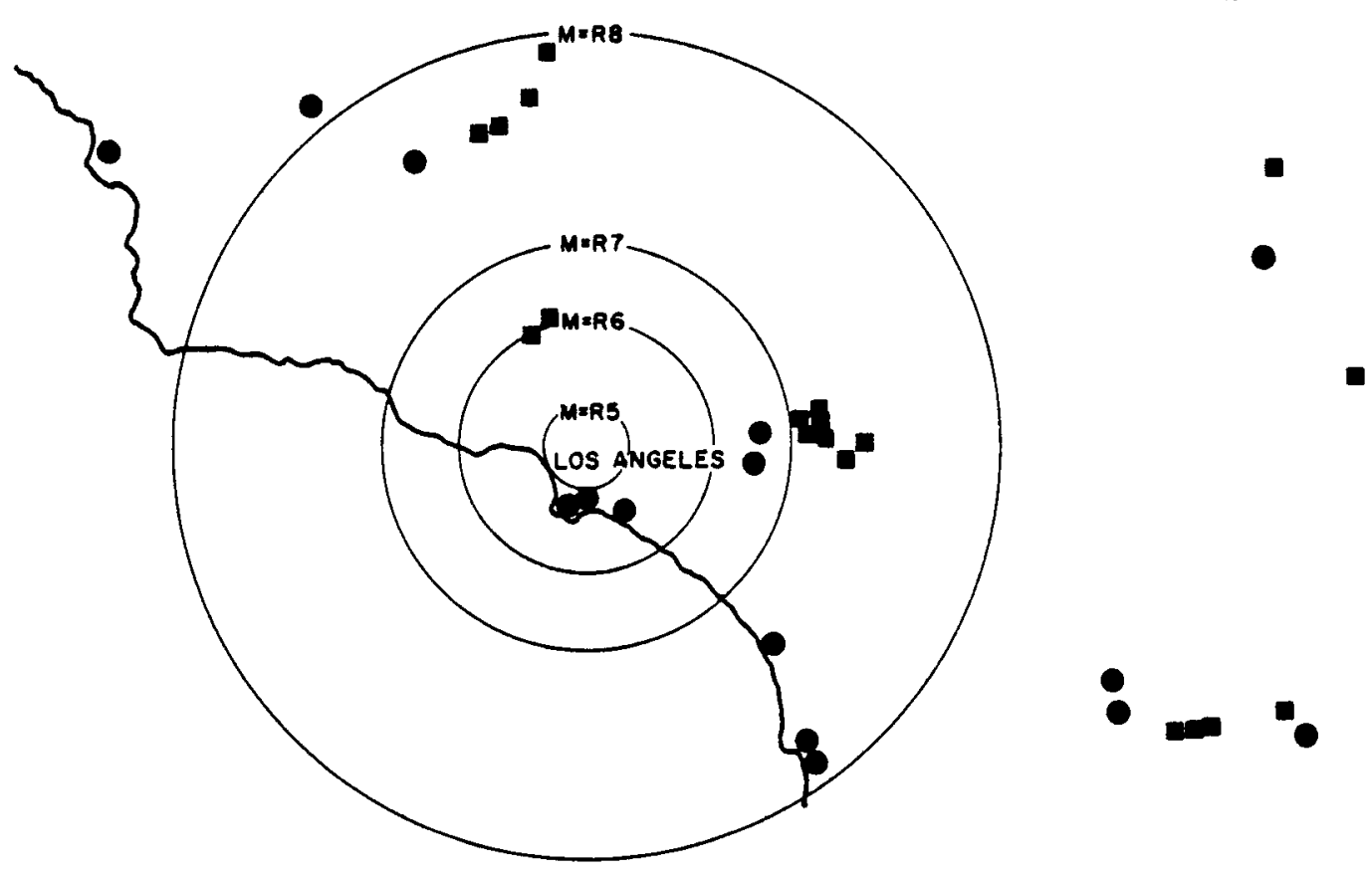

Fig. 7.7 - Theoretical areas of earthquake effect for a Modified-Mercalli intensity of V, southern California. •, fossil-fuel fired; $\mathbf{m}$, hydroelectric.

exact site selection can be related only to distance from known faults and construction on the most suitable ground structure available.

The following procedures are suggested to those planning a new reactor to assure that the potential hazard from earthquakes has been adequately considered.

(1) Geological and seismological consultation regarding reactor siting for maximum displacement from known faults and optimum ground structure

(2) Selection of a seismic safety factor appropriate to the seismicity of the area

(3) Incorporation of this safety factor into the engineering design of critical plant components, particularly:

a. Reactor, pressure vessels, and primary loop supports

b. Control-rod mounting structure

c. Emergency cooling-system reservoirs and piping

d. Overall study of building complex to ensure accommodation or prevention of relative motion between sensitively coupled units

e. Containment structure and its penetrations

(4) Analysis of the effects of the maximum credible earthquake on the reactor's operating safety

(5) Provision in operating procedures of measures to be taken in the event of a severe earthquake, including inspections to be made after the event

(6) Establishment of routine inspections to ascertain whether aging or modifications have affected the plant's susceptibility to earthquakes

\subsection{OPERATING PRACTICES PERTINENT TO EARTHQUAKES}

Since no area of the United States can be guaranteed against the occurrence of a severe earthquake, all reactor operating manuals should provide for appropriate action 
to be taken during and following the event. The typical earthquake, which begins without warning and lasts only $1 / 2 \mathrm{~min}$ or so, leaves little time for operator judgment or manual preparation for trouble; therefore the operator must rely heavily on automatic instrumentation for protection. However, if the operator is alert, he may have time to initiate a manual scram. Since panic and confusion have been known to accompany and follow severe earth motion, the situation should be anticipated by written procedures, and operators should be drilled in these procedures to prepare for the eventuality of malfunction of automatic protection devices.

Reactors of an experimental nature, when there is no strong incentive to keep them continuously in operation, should probably be shut down either manually or automatically during seisms. However, it is desirable that large power reactors continue in service as long as practical. The most severe seismic shocks occur within a few tenths of a second after the initial shocks. Consequently, automatic controls of large power reactors should be designed to relieve the operator of the need to make quick decisions to shut down manually or to continue on the line.

If the earthquake is very violent, circumstances other than seismic or manual scram, such as high temperature and coolant loss, may shut down the plant. Lateral bracing and securing of relay racks, instrument panels, activity measuring and monitoring equipment, etc., should be designed to reduce the possibility of spurious scrams due to minor circuitry damage during seisms. Regular plant-safety inspections should be conducted at least twice a year and should include attention to such features.

\section{A. Continued Operation During an Earthquake}

To the uninitiated, the concept of reactor operation during a severe earthquake may appear to be daring. However, operators of well-designed power plants, chemical plants, and other large complex installations have been, in many instances, unaware of earthquakes of medium intensity which caused considerable alarm in the immediate vicinity. For instance, in the San Francisco earthquake of March 1957, with a magnitude of 5.2 (Richter), the only recorded effect on the Pacific Gas and Electric system in the vicinity was the opening of a circuit breaker in one plant, presumably by inertia forces due to the response of the panel supports to the earthquake stimulus. In the Olympia, Wash., earthquake of 1949 , the shock was felt (estimated Modjfied-Mercalli intensity of VI) at the Hanford Atomic Power Operations site, but the only noticeable effect was the erratic behavior of power-level galvanometers.

It is conceivable that panic on the part of members of the operating crew could lead to reactor incidents not directly related to earthquake damage, but in which an operator error plays the major role. In this connection, education of the operators to acquaint them with the nature, probable maximum intensity and duration of earthquakes, and the expected response of the reactor system to earthquake stimuli should be of value in an emergency. Periodic earthquake drills might serve well to condition the crew to perform automatically such special tasks as might be deemed necessary during a severe earthquake.

Frequently earthquake damage is caused by fires, explosions, or flooding brought about by escaping gas or fluids from ruptured or otherwise damaged piping systems. This risk can be greatly reduced by the strategic location of shock-operated valves. These are available either as inertially activated ball check valves or as solenoid, air, or spring-activated valves triggered by shock switches. Each reactor installation should be carefully studied to ensure maximum utilization of this protection. Lines carrying explosive, pyrophoric, combustıble, toxic, or radioactive fluids should, where possible, be so protected. Manifolds of high-pressure bottled gases, often used about reactors for various purposes, should be strengthened and braced to prevent overturn or rupture of connecting lines. 
Fire-fighting equipment should be of such type and located so that earthquake damage to the surrounding environment does not interfere with its accessibility or operability. Small fires around oil storage tanks, for instance, have resulted in major disasters because the fire-fighting equipment was buried under debris or was of such a type that the failure of utilities rendered it useless.

B. Programmed Shutdown

In the operation of high-power-level, high-temperature plants of a complex nature, a total scram is resorted to primarily to terminate fast and potentially dangerous transients originating in or near the reactor. It is obvious that the nuisance of low-intensity seismic scrams would be great in an area of frequent earthquakes of disturbing but not damaging intensity. An earthquake alarm on the anunciator panel, activated at an intensity of Modified-Mercalli V, would serve to warn the operator of possible greater shocks to be anticipated. A second seismic switch, set to signal at Modified-Mercalli VII, could be employed to initiate an orderly shutdown with all controls being driven in the direction of reduced reactivity. A third switch, set at Modified-Mercalli VIII (an intensity rarely exceeded in earthquake history), would complete the shutdown on a scram basis should the shocks build up to a threatened total-damage earthquake. (The entire system must, of course, be designed to adequately withstand the sequence of shocks up to the total shutdown condition). An evaluation of the specific plant complex is necessary to determine the proper location of seismic sensors and the response characteristics of their mountings, which will determine the threshold intensities at which these circuits are activated. In all probability the data on which a choice is made will of necessity contain arbitrary elements.

\section{RE FERENCES}

7.1 Alco Products, Inc., Phase III Design Analysis for Army Package Power Reactor, Vol. 1, Design Analysis, USAEC Report APAE-10, August 1957.

7.2 Westinghouse Electric Corporation, Description of the Shippingport Atomic Power Station, USAEC Report WAPD-PWR-970, June 1957.

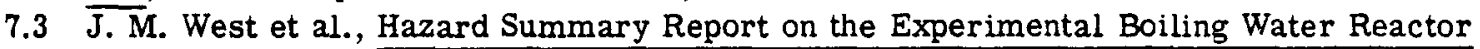
(EBWR), USAEC Report ANL-5781, Argonne National Laboratory, November 1957.

7.4 Nucleonics, 15(12): facing 36-40 (1957).

7.5 L. J. Koch et al., Experimental Breeder Reactor II (EBR-II); Hazard Summary Report, USAEC Report ANL-5719, Argonne National Laboratory, May 1957.

7.6 Division of Reactor Development, Experimental Power and Test Reactors, A Technical and Pictorial Summary, USAEC Report TID-4562, November 1956.

7.7 B. Lustman, Zirconium - Water Reactions, USAEC Report WAPD-137, Westinghouse Electric Corporation, March 1957.

7.8 H. M. Higgins, A Study of the Reaction of Metals and Water, USAEC Report AECD-3664, Aerojet General Corporation, August 1955.

7.9 S. S. Rosen (Ed.), Hazard Summary Report for the Army Power Reactor SM-1, USAEC Report APAE -2, Alco Products, Inc., May 1960.

7.10 Westinghouse Electric Corporation, PWR Hazards Summary Report, USAEC Report WAPD-SC-541, September 1957.

7.11 M. W. Rosenthal, Hazard to HRT Containment Cell from Zirconium - Water Reaction or

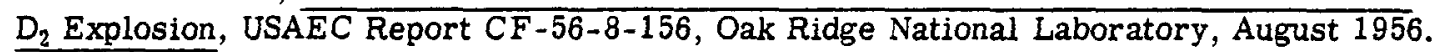

7.12 N. G. Wittenbrock, Plutonium Recycle Test Reactor Preliminary Safeguards Analysis, USAEC Report HW-48800(Rev.), Hanford Atomic Products Operation, June 1958.

7.13 E. Hines et al., How Strong Must Reactor Housing Be To Contain Na-Air Reactions?, Nucleonics, 14(10): 36 (1956). 


\section{REFERENCES}

7.14 N. R. Zabel, Containment of Fragments from a Runaway Reactor, Technical Report No. 1, Stanford Research Institute, April 1958.

\section{ADDITIONAL REFERENCE MATERIAL}

Division of Civilian Application, Theoretical Possibilities and Consequences of Major Acc1dents in Large Nuclear Power Plants, USAEC Report WASH-740, March 1957.

Earthquakes in Kern County, Callfornia, During 1952, Bulletin 171, State of California, Department of Natural Resources, Division of Mines, San Francisco, 1955. 


\section{Chapter 8}

\section{PROTECTION SYSTEMS}

\begin{tabular}{lll}
\hline & FTGURES & \\
8.1 Power Poake Aftor Startup Aceldent for Normal Vs. Extended & 8.3 & Starter Pondulum Used by U S. Coast and Geodetic Survey \\
Delay from Scrum Signal to Rod Motion Beginning. SM-1. & 3.4 Seismic Scram Swnteh Used by Aerojet-General Nucleonics. \\
\hline 2 Simplified Control-rod Syatem During Esrthquake. & \\
\hline
\end{tabular}

\subsection{INTRODUCTION}

The survival of a nuclear reactor plant during an earthquake requires that buildings, foundations, and system components be designed according to effective earthquakeresistant practices. These practices are covered elsewhere in this manual. This chapter assumes that the plant is capable of survival during a major earthquake without me chanical damage, and it is concerned with reactor equipment, processes, and procedures that might require special attention in severe earthquakes.

Of prime importance is the reactor automatic control system, on which heavy dependence must be placed during seismic activity since the onset of an earthquake is sudden and its duration is brief, allowing little time for manual emergency measures or operator judgment.

\subsection{REACTOR CONTROL}

A. Inherent Mechanisms

Natural effects, arising from changes in the nuclear, physical, chemical, or geometrical properties of a reactor, which accompany increasing temperature and/or power level, are of fundamental importance to reactor control. If these changes reduce the ratio of the neutron population at the end of a neutron cycle, or generation, to that at the beginning, a tendency toward self-stabilization exists. Depending on the reactor type, sensitivity to such natural effects may be large or small and either positive or negative in effect upon power level. The overall coefficient may be a complex function of several reactor parameters and may change sign over the range of operating conditions in complex cores.

Decrease in density of metals and liquids as temperature increases usually implies a tendency to reduce neutron population. Since incipient excursions may generally be regarded as increasing temperature, this effect may tend toward self-stabilization. However, as an example, in boiling-water reactors, steam bubbles generated in the coolant produce effects that may be negative, zero, or positive, depending on the specific reactor design. 
Neutron-generating and -absorbing properties of reactor materials are functions of temperature, and stabilizing effects exist (of secondary magnitude compared to other mechanisms). One of these is the effect of changing absorption cross section which is approximately proportional to the reciprocal of the temperature. This effect reduces the neutron population as the cross section increases. The Doppler effect is related to this mechanism; for a reactor containing $\mathrm{U}^{238}$, the absorption cross section reaches extremely high values for those of the neutron population having certain energy levels, producing the so-called resonance peaks corresponding to these resonance energy levels. The net effect is an increase in the resonance capture of neutrons by $\mathrm{U}^{238}$, which usually acts to reduce neutron population (and hence the tendency to excursion) as the reactor temperature rises.

Geometrical distortion of core structures as a result of earthquake shocks might cause some of the naturally occurring effects to be changed in significance; however, the extent and direction of the change are difficult to estimate. It can be seen that some factors inherent in the nature of the fission chain reaction can produce self-stabilizing effects. However, the actual effect is peculiar to the individual reactor and cannot be relied on for safety purposes in the event of a seism. The extent to which these are dependent upon earthquakes is not completely known but is believed to be small.

\section{B. Contrived Mechanisms}

Because inherent natural shutdown effects cannot always be accurately predicted and may be inadequate to curb reactor excursions or to maintain any particular power level, practical reactor control is usually accomplished by the insertion or removal of strongly neutron-absorbing material (in the form of rods) in the reactor core. These materials depress the neutron population in their immediate vicinity, restrict the tendency to excursion, and ensure a reasonable rate of rise to any desired power level.

Control rods are usually mechanically driven, utilizing electric motors acting either through mechanical, hydraulic, or magnetic drives. Some reactors, such as the PWR or HRE, have the drive motor inside the pressure shell, whereas other reactors (SM-1, EBWR, MTR, and ETR) utilize an external location operating through pressure seals. It is in the functional and structural integrity of control mechanisms under earthquakes that the major safety reliance should be placed. Of course, it is also necessary that the measuring and other devices (which, in turn, control rod movement) be secure during seisms.

Under normal conditions control rods may be either manually operated or servo driven in response to signals from radiation detectors as the neutron flux (and reactor power) fluctuates about a desired power level. In cases where rapid shutdown is necessary (such as severe seisms), scram mechanisms are employed which disengage the rod from its drive unit, permitting free fall of the rods into the reactor core (sometimes aided by initial spring load), or the rods can be driven in rapidly by a stand-by source of power aside from the normal drive mechanism. These mechanisms must be designed to assure operation during seismic shock, and they must be used early enough to prevent destructive excursions. Scrams can be initiated by any condition considered a precursor to unsafe operation, the most significant conditions being excess reactor power and an abnormally fast period (a measure of the rate of power increase). Control circuit instrumentation responding to these parameters must remain operative at least up to the point at which other properly designed portions of the reactor system would have been significantly damaged regardless of control system operation.

An additional control mechanism is generally provided in all reactors and could be used in severe seisms. For example, some reactors utilizing liquid fuel or moderator can be chemically poisoned by the addition of a strong neutron-absorbing material, usually boric acid, to the solution stream. This, as indicated, could be resorted to when all normal control mechanisms have failed and an uncontrolled power excursion is imminent. 
A similar effect can be obtained in gas-cooled reactors by the release of boron-containing steel balls that fill reactor voids and reduce reactivity to less than unity.

\subsection{SEISMIC SENSITIVITY OF CONTROL-ROD TYPES}

\section{A. Freely Falling Rods}

In a typical reactor, scram is accomplished by interrupting the current to the mag nets by which the rods are suspended so that the rods are free to fall in their guide tubes. These guide tubes can initially be considered frictionless. Suppose a scram is initiated during an earthquake that is causing the entire reactor structure to vibrate in the vertical direction with a period on the order of 0.1 or $0.2 \mathrm{sec}$ and with acceleration varying ac cordingly $( \pm 0.1 \mathrm{~g}$, which is typical of strong-motion earthquakes as recorded by vertical component seismometers). Lateral forces will be of secondary importance (except as noted in Sec. 8.3E) with respect to rod-drop time. When the current breaks, the control rod, along with the reactor, will have either upward, downward, or zero velocity with respect to the earth's mass as a whole. Since the magnitude of the vertical ground displacement in typical strong-motion quakes has rarely been known to exceed $\pm 2 \mathrm{~cm}$, the effect of any change in total travel on the rod-drop time is insignificant. The effects of initial velocity of the rod at the time the magnet releases may be more significant. Suppose that at release the rod has an upward velocity of $0.3 \mathrm{ft} / \mathrm{sec}$, which is not unreasonable in strong quakes. The rod, once free, must continue upward until this velocity is reversed, which causes a theoretical delay of

$$
\frac{2 \mathrm{v}}{\mathrm{g}}=\frac{2(0.3)}{32.2}=0.02 \mathrm{sec}
$$

Since the individual motions and reversals of the core and the control rods imposed by earthquakes are erratic both in time and magnitude, a detailed analysis of all probable sequences of events in this initial split second appears unrewarding. However, as a worst case assumption, one can assume a delay in the beginning of the free-fall drop cycle on the order of $0.02 \mathrm{sec}$. A similar delay at the end of the cycle could conceivably occur, although it would be of little significance since, by this time, the reactivity will be reduced far below unity.

This possible delay of $\pm 0.02 \mathrm{sec}$ is small, but it represents a significant fraction of the normal delay in a typical reactor scram. In the SM-1, for instance, extending the delay after initiation of scram signal to $0.070 \mathrm{sec}$ rather than the normal $0.050 \mathrm{sec}$ (plus the normally somewhat larger actual drop time) during the postulated startup accident is estimated ${ }^{8.1}$ to cause the reactor power transient to peak at $187 \mathrm{Mw}$ rather than at $97 \mathrm{Mw}$ (Fig. 8.1). This discussion assumes no amplification of the vertical component of the earthquake-induced ground motion. Should the reactor supports (such as grid or pressure vessel) have earthquake-sensitive spring characteristics and small damping in the vertical direction, this motion may be magnified with corresponding increase in the ef fects described above. This should be an object of special study in assuring adequate and automatic control during seisms.

\section{B. Friction Damped Rods}

In most reactors employing gravity-actuated scram systems, the effects of friction significantly affect rod-drop time. This friction is derived from metal-to-metal rubbing, fluid drag, shaft seals, etc. Lateral seismic forces on the rod can increase the first type of friction. The rod remains partly coupled to the reactor through friction forces so that the up-and-down motion of the reactor during an earthquake results in alternate increases and decreases in the acceleration of the rod relative to the reactor according to the velocity dependence of these friction forces. Since the period of these oscillations 


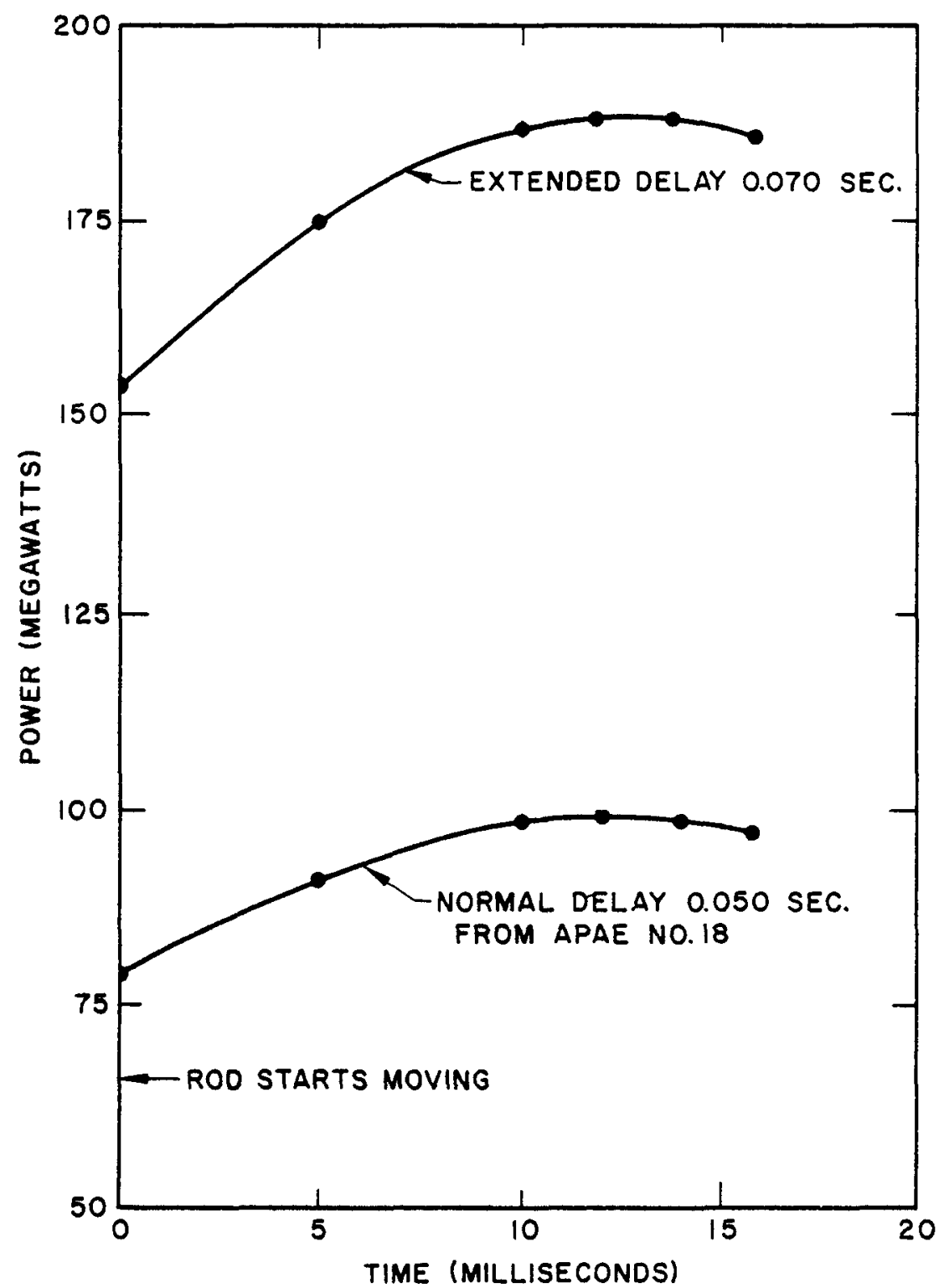

Fig. 8.1- Power peaks after startup accident for normal vs, extended delay from scram signal to rod motion beginning, SM-1.

can be expected to be on the order of $0.1 \mathrm{sec}$, compared to an approximate rod-drop time of $0.5 \mathrm{sec}$, the overall effect of these perturbations should largely cancel out. However, the significance of the possible initial delay, as explained here, remains unchanged.

C. Mechanically Driven Rods

Reactors that employ mechanically driven scram systems should be least affected by an earthquake. The energy sources used for scram, whether an electrical network, hydraulic accumulator, or rotating flywheel, are capable of exerting many times the necessary forces for rod insertion; thus the effects of a vertical acceleration of $0.1 \mathrm{~g}$ from strong earthquakes would be negligible. This advantage, of course, holds only 
so long as everything is in good working order, and such systems should be carefully designed for use in areas of high seismic activity. Components should be simple, rugged, closely coupled, and mounted on a highly earthquake-resistant foundation integ ral with the reactor itself.

Mechanically driven scram systems have the advantage in that the rods are still connected to the drive mechanism so that gravity alone is not relied upon to hold them in after a scram. This, although not significant with respect to expected earthquake accelerations (always much less than $1 \mathrm{~g}$ ), would prevent expulsion of the rods from the core by escaping coolant, possibly as the result of earthquake damage in the pressure vessel complex.

D. Controlled Drop Rods

In certain large reactors, such as the gas-cooled low-enrichment type, the weight of the control rod and the length of travel are such that free fall cannot ordinarily be permitted during a scram. In these cases the rod velocity is limited by energy dissipation, usually in the form of an eddy-current brake, independent of external power sources. In principle, this system appears to be satisfactory for application in areas of high seismic activity. However, study is necessary in each individual case to determine whether the magnitude of a hypothetical earthquake emergency might override the ordinary need to prevent internal damage to the reactor due to free fall. If wire ropes and pulleys are used, care should be taken to prevent fouling of the cables due to lateral whip or tension slackening during an earthquake. Very careful design is required to ensure that false position signals (a possible contributor to a chain of events leading to an excursion) do not arise as the result of lateral whip or slack in the cables during an earthquake. It is suggested that a limit switch arrangement be employed where possible in areas of strong seismic activity.

E. Control-rod Whip During an Earthquake

Consider a control rod, shown schematically in Fig. 8.2, a moment after release during an earthquake. Assume that the reactor is being accelerated to the left at a rate $\mathrm{g}^{\prime}$ due to the earthquake, that the rod is rigid, and that its density does not vary along its length.

If the center of mass of the rod is within a reactor core channel or other rigid guide, the effect of the lateral acceleration will be to develop small friction forces between the rod and guide. Since the lateral acceleration $\mathrm{g}^{\prime}$ will probably not exceed $10 \mathrm{ft} / \mathrm{sec}^{2}$ even in a very strong earthquake, these forces will generally be small, depending on the friction coefficient and the mass of the rod: For instance, in the SM-I the rod weighs $72 \mathrm{lb}$. Assuming a friction coefficient of 0.1 , the retarding friction force will be

$$
\frac{72}{32.2} \times 10 \times 0.1=2.2 \mathrm{lb}
$$

This is not a constant retarding force. Actually, acceleration can reverse direction several times during the rod fall, varying from zero to $\pm 10 \mathrm{ft} / \mathrm{sec}^{2}$ (max.); thus the rod could rub alternately on opposite sides of the guide tube as it descends. This effect should be negligible in a well-designed system. Using the SM-1 again as an example, the effect of friction, built-in water drag, and inertia of rotating parts reduce the effective rod vertical acceleration ${ }^{8.2}$ to $0.43 \mathrm{~g}$. The earthquake-induced friction (probably less than $2 \mathrm{lb}$, as estimated above) is a small fraction of the total retarding force.

Referring again to Fig. 8.2, a different situation arises if the center of mass of the rod is outside the guide tube or reactor. In this case the rod, with the greater fraction of its mass outside the guide, will pivot about $R_{1}$, and the resulting reactions at $R_{1}$ and $R_{2}$ 
can become large due to the lever action of the whipping rod. When the sum of these reactions, multiplied by the coefficient of friction, exceeds the weight of the rod, it will not fall under the influence of gravity. In fact, in the case of cylindrical rods, a rotary motion may develop so that this retarding effect is continuous, and rod entry may be delayed for the duration of the earthquake, which may be minutes. Square or keyed rods are therefore preferable, although, if cylindrical rods are well guided over their full length of stroke, the difference should be negligible.

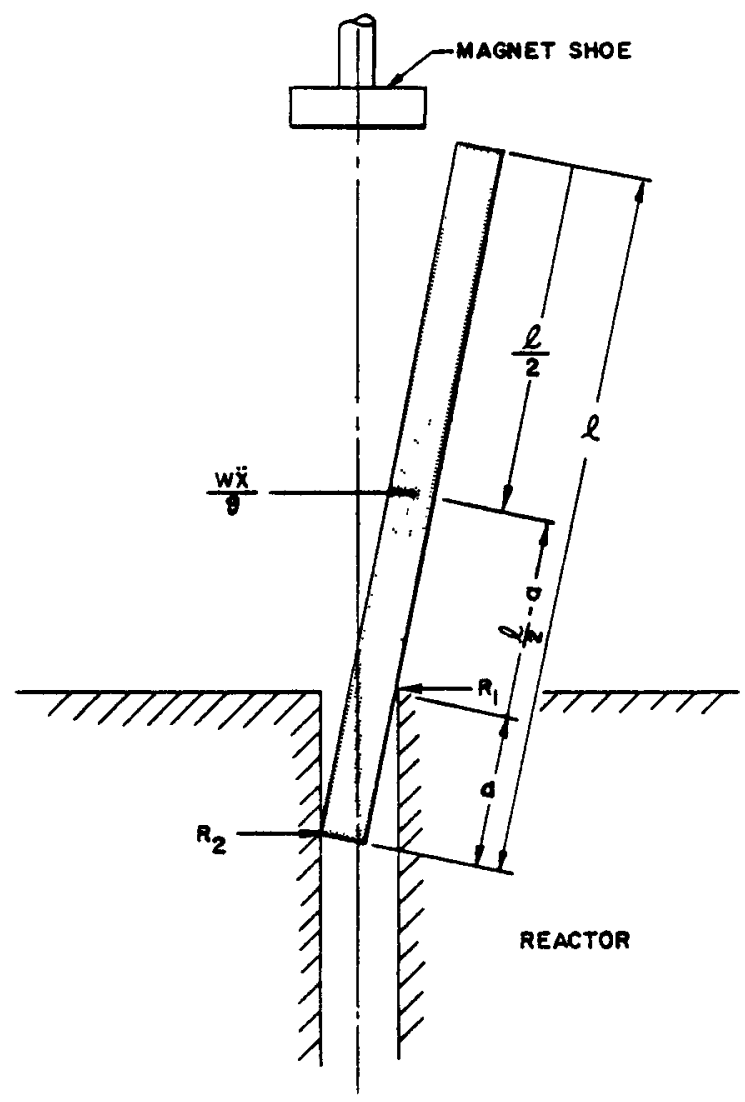

Fig. 8.2-Simplified control-rod system during earthquake.

With reference to Fig. 8.2, a condition under which rod jamming could occur is simply derived as follows:

For acceleration $\ddot{x}$ to the left, the summation of horizontal forces is

$$
R_{1}=\frac{w \ddot{x}}{g}+R_{2}
$$

where $w$ equals the weight of the rod.

The summation of moments about $R_{1}$ yields

$$
R_{2} a=\frac{w \ddot{x}}{g}\left(\frac{l}{2}-a\right)
$$

or

$$
R_{2}=\frac{w \ddot{x}}{g}\left(\frac{l}{2 a}-1\right)
$$


Substituting Eq. 8.2 into Eq. 8.1 yields

$$
R_{1}=\frac{w \ddot{x} \ell}{2 a g}
$$

In order for the rod not to jam, $\mu\left(R_{1}+R_{2}\right)<w$, where $\mu$ is the coefficient of friction.

Thus

$$
\mu \frac{\mathrm{w} \ddot{x}}{\mathrm{~g}}\left[\frac{\ell}{2 \mathrm{a}}+\frac{\ell}{2 \mathrm{a}}-1\right]=\frac{\mu \mathrm{w} \ddot{x}}{\mathrm{~g}}\left[\frac{\ell}{\mathrm{a}}-1\right]<\mathrm{w}
$$

or

$$
\frac{\ell}{a}<1+\frac{g}{\mu \ddot{x}}
$$

or

$$
\left[1+\frac{g}{\mu \ddot{x}}\right]^{-1}<\frac{a}{l}
$$

As an example, let

$$
\begin{aligned}
& \ell=10 \mathrm{ft}=120 \mathrm{in} . \\
& g=32.2 \mathrm{ft} \mathrm{sec}^{-2} \\
& \mu=0.1 \\
& \ddot{x}=10 \mathrm{ft} \mathrm{sec}-2 \\
& \frac{\ell}{\mathrm{a}}<1+\frac{32.2}{(0.1)(10)}=33.2 \\
& a>\frac{\ell}{33.2}=\frac{120}{33.2}=3.61 \mathrm{in} .
\end{aligned}
$$

This simplified example serves to illustrate the need for care in designing rods and rod guides, although only in extreme cases could jamming occur without actual mechanical misalignment or distortion of the guides and rods.

\subsection{REACTOR-CONTROL INSTRUMENTATION}

A. Startup

At startup the neutron flux may be very low, and the sensing element may be measuring as few as one or two neutrons per second. In this range, only counting-rate meters, which consist of pulse chambers, ampiifiers, and counting circuits or scalers, are used. Pulse chambers respond to individual nuclear reactions involving neutrons and consist of two common types, i.e., chambers filled with boron trifluoride gas and fission chambers coated inside with $\mathrm{U}^{235}$.

Counting-rate meters will usually reach their limit of usefulness at about $10^{-6}$ of full power, which corresponds in the average case to criticality. Above this range, logarithmic, counting - rate $(\log -n)$ circuitry is employed. The detector for this circuit usually consists of an ionization chamber, which measures total ionization for a given flux rather than counting individual pulses and which is small and mechanically rugged. These chambers cover several decades of neutron density (say, $10^{-6}$ to 1.5 full power). Although considerable overlap is provided to permit safe transfer from one counting range to 
another, both ranges of instruments should receive study from the seismic standpoint. A scram circuit can always be actuated when the neutron flux reaches a dangerous level, regardless of what power range is then current.

B. Intermediate Power Range

From $10^{-4}$ to full power, when the reactor is subject to wide variations in power level, gamma radiation from fission-product decay can mask the neutron flux observed from an ionization chamber such as described above. In the steady state the contribution of fission-product gammas is negligible; but, in the intermediate region, additional ion chambers are needed to separate the effects of neutron flux and gamma flux. These chambers, although more complicated, are constructed along the same lines as lower range equipment and should be no more earthquake sensitive.

C. Full Power

For normal operation at full power, neutron level indicators are used to operate servo- or automatic-control mechanisms. Conventional instrumentation, calibrated to read power level as indicated by coolant flow rate and temperature rise, is usually employed in this range in addition to nuclear instrumentation.

\section{Seismic Sensitivity}

The reactor-control complex (i.e., sensing elements, amplifiers, and other electronic gear) is sufficiently rugged to survive strong seismic accelerations in its own right. With proper attention to lateral bracing of relay racks, cabinets, wiring details, gas supply lines, etc., there should be no trouble in this respect during earthquakes. Ionization chambers are commercially available which have been shock and vibration tested for military use to much more stringent specifications than would appear necessary for seismic resistance. Damage to circuitry and components from falling objects or shifting masses appears to be the principal threat. Exposed wiring is particularly vulnerable to this type of damage.

Because of the fail-safe criteria to which reactor-control circuitry are designed, the effects of practically all imaginable earthquake damage to the control system should result in automatic reactor shutdown. However, jamming of the control rod itself is still a possibility to be considered, and one which would require the execution of emergency or last-ditch measures. For this reason, the emergency shut-down mechanism for power reactors in areas of seismic risk should be examined critically with respect to the possibility that it, too, might be rendered inoperable by extreme seismic damage.

Reactors are often equipped with horizontal instrument thimbles in which fission and ion chambers are located for radiation measurement. These thimbles provide a wide range of adjustment of the radial position of the chamber relative to the reactor. The usual practice is to determine empirically the position that provides a full-power reading when the reactor is shown by other measurements to be operating at the rated power. In some instances, static friction alone is relied upon to maintain this position. In areas of high seismic activity, lateral shocks might conceivably cause the chamber positions to shift, giving rise to an erroneous power-level reading. Control rods might be withdrawn, which could initiate an excursion to an abnormal power level. This shifting, although not normally a serious condition, might set the stage for further difficulty in the confusion usually accompanying severe shocks. It is recommended that positive means of locating such instruments be adopted for good earthquake-resistant reactor practice.

\section{5}

\section{SEISMOMETERS}

Seismometers, although not specifically a part of control or protection systems, may reasonably be considered for inclusion in reactors. A seismometer may be broadly 
described as any instrument which senses vibrations of the ground under its supports. The most widely used is the inertial or pendulum type, which, in its simplest form, consists of an inertial mass suspended in such a manner that it remains at rest while the earth's crust vibrates due to the passage of seismic wave trains. Three seismometers, which resolve the components into east-west, north-south, and vertical displacement recordings, are usually used to get a meaningful record of this motion.

To the reactor designer and operator, a strong-motion-sensitive, short-periodsensitive $(0.03$ to $0.10 \mathrm{sec})$ seismometer is of interest since such an instrument responds very well to strong shocks in the immediate vicinity, and its action reflects the actual local effects with respect to accelerations, period, and duration of these shocks. A complex of seismometers may be required to ensure that, in the case of strongly directional seismic waves, the reactor instrumentation is not insensitive to waves in the worst direction while registering weaker waves.

Where long-term reliability is a factor, a system that breaks electrical contacts when shocks occur is probably preferable to one that makes contact (see Sec. 8.6C). The setting, which is decided upon for tripping any protective circuitry, should always include the response characteristics of the mounting structure itself.

A trigger device to start recording seismometers, as shown in Fig. 8.3, has been standardized by the U. S. Coast and Geodetic Survey (USC\& GS). The device consists of
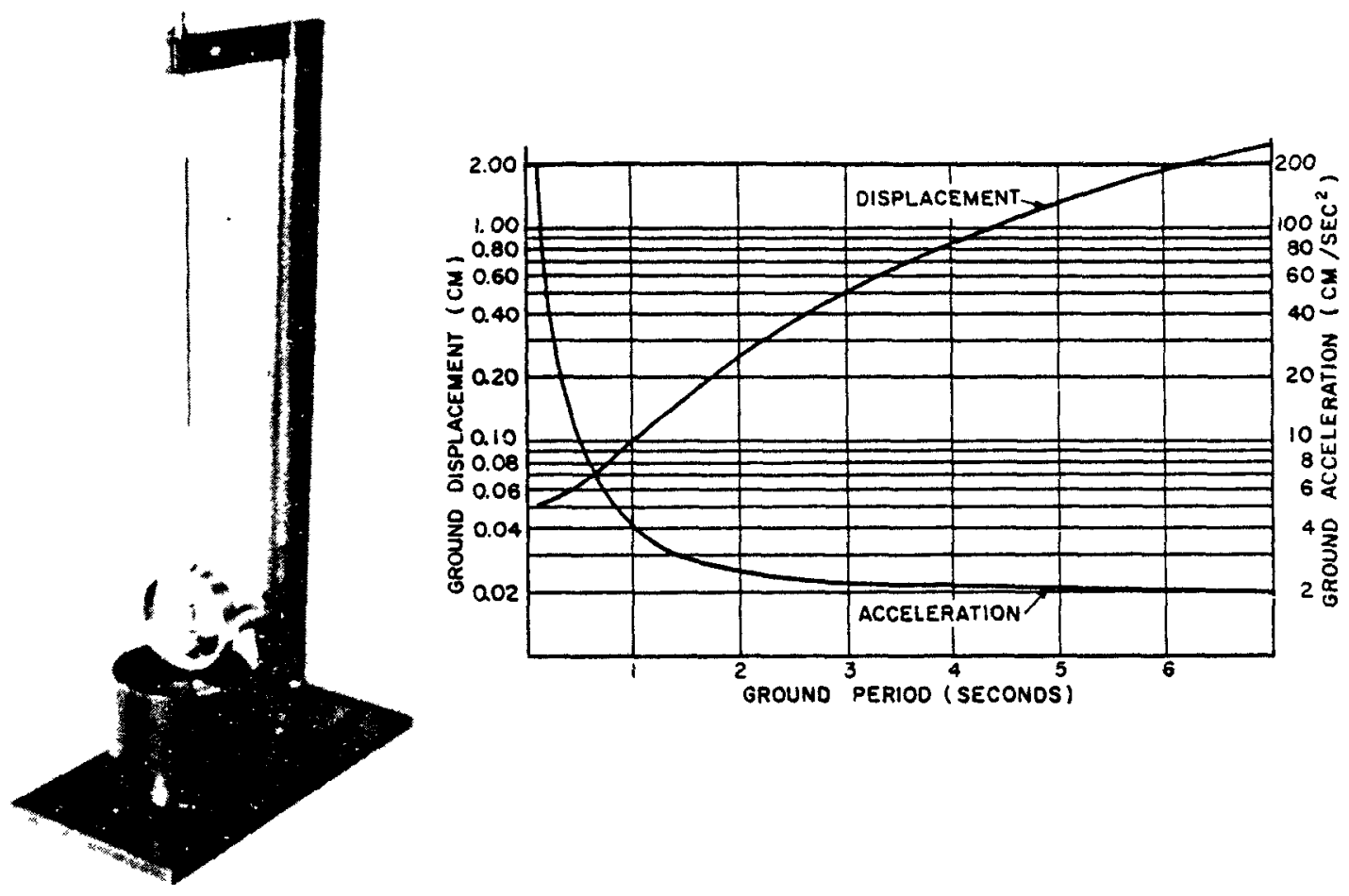

Fig. 8.3-Starter pendulum used by U. S. Coast and Geodetic Survey. (From U.S. Coast and Geodetic Survey and the Seismological Society of America.)

a swivel pendulum surrounded by a ring member with an air gap in the static state. Lateral accelerations set the pendulum swinging; and, if the amplitude is sufficiently large, contact is made with the ring, completing an electrical circuit that starts the 
recorder: (As noted in Appendix D, Sec. 3, such a device may be insensitive to vertical shock and unable to distinguish between the sources of such shocks.) A similar device is used as a seismic scram switch in several reactor systems, as described below, even though recording is not necessarily required for any reactor seismic-protection system.

\subsection{CURRENT EARTHQUAKE-PROTECTION SYSTEMS}

A. Aerojet-General Nucleonics

Aerojet-General Nucleonics equips its small research reactors with a seismic shock switch of its own design. This switch, shown in Fig. 8.4, utilizes a brass ball that com-
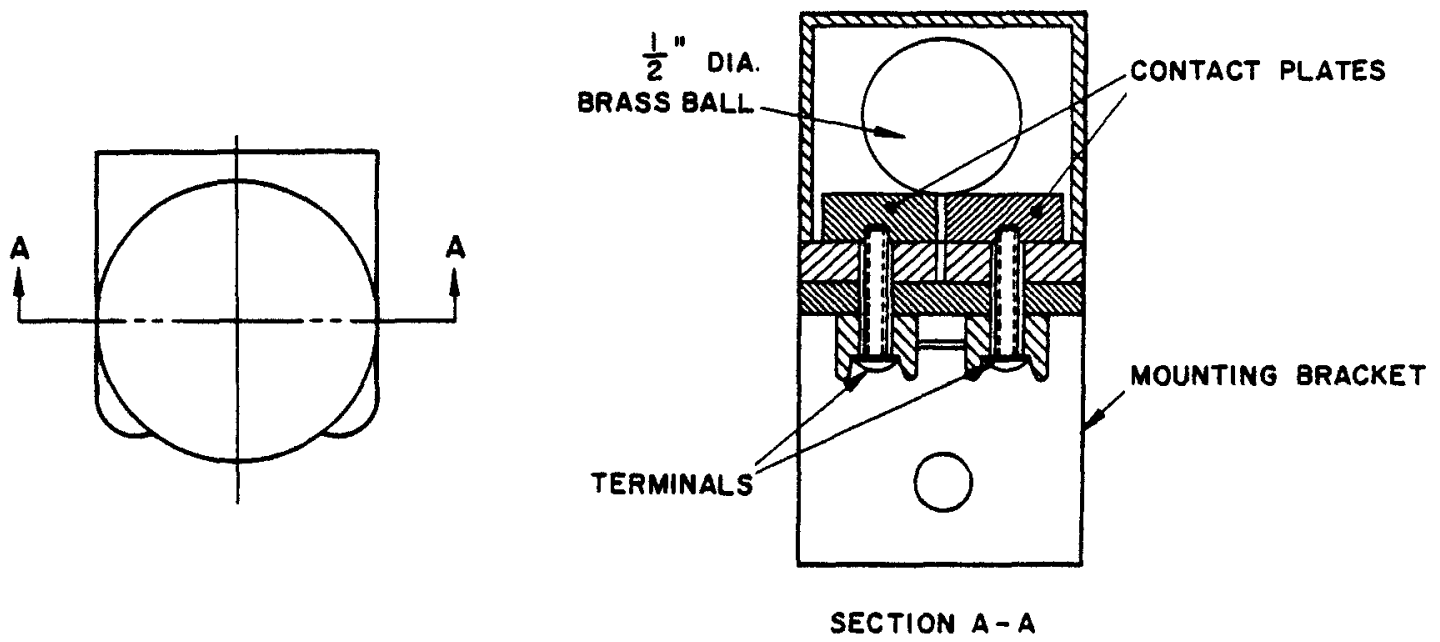

Fig. 8.4-Seismic scram switch used by Aerojet-General Nucleonics. (From Aerojet-General Nucleonics.)

pletes an electrical circuit across two terminal strips. A lateral force, corresponding to an acceleration of $0.01 / 100 \mathrm{~g}$, dislodges the ball from the shallow groove created by the edges of the terminal strips. Should the seismic force be oriented along the groove, the rolling action of the ball along the groove increases contact resistance sufficiently to interrupt the circuit and cause control-rod release. This switch is very sensitive and should be firmly mounted to the reactor foundation to prevent shutdowns from spurious sources such as passing trucks, accidental impact to the structure, or other nonseismic vibrations. Such a high degree of sensitivity may be unwelcome in power reactors if an excessive number of shutdowns result from low-level vibrations.

\section{B. General Electric Company, Vallecitos Atomic Laboratory}

At its Vallecitos Laboratory, near Oakland, Calif., the General Electric Company utilizes a pendulum type seismic switch for earthquake protection. This device is patterned closely after the standard starter switch used by the USC\&GS to actuate strongmotion accelerometers (see Sec. 8.5). A wire-supported pendulum, responsive to lateral accelerations from any direction, supports a platinum-tipped cone that swings to contact an adjustable concentric ring and complete an electric circuit. By varying the clearance the instrument can be made to initiate signals at varying degrees of earthquake intensity. 


\section{Atomics International}

The reactors operated by Atomics International in the Los Angeles area (the SRE and several experimental homogeneous reactors) are equipped with a commercial shockoperated switch, as described in Sec. 8.7. After the Tehachapi earthquake of 1952, prior to which no seismic scram device was used, the Water Boiler Neutron Source, a lowpower device that was the only reactor then operating, was equipped with a pendulum type alarm switch similar to the USC\&GS instrument described in Sec. 8.4. However, since this instrument requires the making rather than the breaking of an electric circuit (an undesirable feature in safety circuitry due to contact surface aging and interference of foreign material), it was replaced later with a commercial switch and was set to scram at Modified-Mercalli intensity VIII.

D. American-Standard, Advanced Technology Laboratories

The UTR-1, a prototype of the UTR-10 training reactor manufactured by AmericanStandard, is located in Mountain View, Calif., near San Francisco, in a seismically active region. This reactor is designed to operate at a power level of 1 watt. A commercial shock switch, as described in Sec. 8.7, is employed to scram the reactor by dropping the safety rods at an earthquake intensity of IV on the Modified-Mercalli scale.

\section{E. University of California Lawrence Radiation Laboratory}

The laboratory, located at Livermore, Calif., is equipped with two research reactors for experimental purposes. A small, aqueous, homogeneous boiling type reactor, operated at 500 watts (thermal), is equipped with a commercial shock switch for seismic protection. This switch, of the type described in Sec. 8.7, is set to drop the control rods at a shock intensity of VII on the Modified-Mercalli scale.

The 10-kw pool type reactor at this laboratory is not equipped with a seismic alarm or scram device (as of January 1959).

\section{F. Hanford Production Reactors}

All the Hanford production reactors utilize the same earthquake protective instrumentation, based on the high-intensity starter design of the USC\&GS.

For each reactor the instrumentation has, until recently, been set to trip at ModifiedMercalli II $(0.3-\mathrm{mm}$ gap) to give a warning signal and to scram the reactor at ModifiedMercalli $\mathrm{V}(2.6-\mathrm{mm}$ gap). The warning signal was given in the control room by sounding an alarm and lighting a panel on the annunciator board. This warning signal would occur well below the threshold of any physical damage. Two additional USC\&GS units are provided to trip at Modified-Mercalli $\mathrm{V}$, which is just below the threshold of minor structural damage. A coincident signal from both switches is required to scram the reactor unless one unit is bypassed for repair or maintenance, in which case activation of the switch remaining on line will initiate the shutdown. Recently the scram setting was changed to Modified-Mercalli IV, and the warning signal has been eliminated.

In addition to the above safeguards, a written operating standard instructs the reactor operator to scram the pile manually if any of the following phenomena are observed:

(1) Power-level galvanometer (light beam) spot vibration

(2) Fluctuation of flux monitor needles

(3) Swaying of overhead lights

(4) Shaking of equipment

(5) Movement of floor

The entire system may be bypassed under approved standards for as long as $5 \mathrm{~min}$ to replace relays or perform other maintenance. The operator is, however, continuously on duty. The instruments are grouped together in a single box and mounted close to the 
floor, which is a part of the main reactor foundations. The units are inspected for response during each major scheduled shutdown. Pendulum gap-spacing checks are made every six months.

G. Savannah River Production Reactors

The protection system of these reactors (as reported by the Savannah River Operations Office, U. S. Atomic Energy Commission, on Sept. 16, 1958) is exactly the same as that of the Hanford installation. For each reactor, three USC\&GS type pendulum starter switches are used, one initiates an alarm at a Modified-Mercalli intensity of II, and coincident closure of the contacts on the other two switches (set for Modified-Mercalli V) initiates a reactor scram.

This system, and others based on the pendulum switch, may occasionally produce an unjustified reactor shutdown by responding to earth waves of long period but large displacements from distant earthquakes. Seismograph starter switches in the Seattle area have responded to such waves from Alaskan earthquakes when very few humans noted the disturbance. This slight possible overconservatism and the consequences of unnecessary shutdown of a large reactor plant, particularly one supplying base-load power, must be weighed in each individual case.

\subsection{RECOMMENDED EARTHQUAKE INSTRUMENTATION}

In the adaptation of presently available seismic instrumentation to the task of reactor protection, the designer has little choice other than the on-off seismic switch concept employed in industry for protection of equipment from shock or seismic motion and by seismologists to start fast-recording mechanisms associated with strong-motion seismometers.

The on-off switch concept employs an inertial element suspended so that an electric circuit is activated (or deactivated) on receipt of a threshold impulse from any direction in the azimuthal plane. In the starter pendulum, this is accomplished directly by contact of the pendulum with a bumper ring, closing the circuit. A modification of the USC\&GS switch actuated by vertical impulses has been developed but is reported to have poor aging characteristics. Another type, available commercially, can simultaneously make or break circuits by the use of intervening mechanical elements between the inertial mass and the switchgear.

Such switches, however satisfactory they may be for their intended purposes, are limited in their usefulness for the protection of large, complex reactor installations. A switch, set for an impulse of threshold intensity, can accomplish its function only once during a given earthquake, requiring either manual reset or a quiescent period for the pendulum to come to rest after contacting the bumper ring. It is, of course, of no use in the intensity region above the threshold. Also, a single such instrument will respond as readily to a maximum impulse of a small earthquake as well as to a similar impulse at the beginning of a major earthquake. Two or more instruments are needed for an alarm at threshold intensity, set back (power reduction) at intermediate intensity and scram at damaging intensity. On the assumption that worse is to follow, scram at low intensity is, of course, a safe procedure with only one seismometer. However, it could become an expensive nuisance in the operation of complex plants.

One may ask, "Why not use existing strong-motion seismometers to monitor the earthquake continuously over the total intensity range and direct the reactor accordingly?" In fact, strong-motion seismometers are avallable with electrical output sufficient to operate a galvanometer or to impress a record on a magnetic tape. The limitation of such instruments lies in the fact that, for reasons peculiar to seismology, the instruments are constrained to unidirectional motion of the sensing element so that eastwest, north-south, and vertical components of the ground acceleration are recorded on separate instruments and are combined later to reconstruct the true record. However, 
since the reactor operator is generally more concerned with the magnitude of lateral accelerations rather than with the direction of their origin, strong-motion instruments, nondirection sensitive in the azimuthal plane, should be adequate for the task of reactor protection.

An integrated reactor-protection system could perform the following desirable functions:

(1) Continuously monitor strong seismic disturbances

(2) Signal its own failure or malfunction if live circuitry design is employed

(3) Signal alarm to annunciator panel at an intensity level indicative of a given earthquake intensity having been reached

(4) Begin power reduction at low shock intensity, driving all reactivity controls at normal speed toward reduced reactivity

(5) Override manual cancellation of power reduction as long as strong signals persist

(6) Scram when signal strength reaches proportions indicating mandatory shutdown

(7) Produce strong-motion accelerograms for comparison with other plant records to assist in the analysis of incidents

This last function might be more satisfactorily accomplished by the use of an inexpensive continuous-belt magnetic tape recorder, recording and erasing data until a hold signal indicates data of interest are being taken. The magnetic tape technique suggests the possibility of a simultaneous record of other important reactor parameters in the abnormal range during an earthquake or other transient disturbances. This would, of course, be invaluable in the reconstruction of reactor behavior after an incident, whether earthquake connected or not.

Suggested criteria for the design of a reactor plant seismometer are as follows:

(1) Period in the range of 0.03 to $0.1 \mathrm{sec}$ with critical damping

(2) Fail safe, not requiring the closing of contacts to complete an electrical circuit to initiate signals

(3) Free of mechanical or rubbing friction between elements

(4) Small hysteresis effects in comparison to driving forces

(5) Rugged and reliable, with minimum sensitivity to fouling or decrepitation

(6) Signal output proportional to intensity of seismic disturbance so that varied reactor-control response is possible if the type of reactor justifies such protection

(7) Capable of simple functional testing in the field

\section{RE FERENCES}

8.1 J. G. Gallagher and T. M. Silks, Effect of APPR-1 Control Rod Acceleration After Scram on Start-up Accident, USAEC Report APAE-Memo-97, Alco Products, Inc., April 1957.

8.2 J. L. Meem (Ed.), Initial Operation and Testing of the Army Package Power Reactor APPR-1, USAEC Report APAE-18, Alco Products, Inc., August 1957.

\section{ADDITIONAL REFERENCE MATERIAL}

Ewing, J. A., Earthquake Measurement, Tokyo Imperial University, Member Science Department No. 9,1883 .

Reid, H. F., Theory of the Seismograph, in California Earthquake of 1906, Vol. 2, 1910.

Davison, C., Manual of Seismology, 1921.

Lundsberg, H. E., Advances in Geophysics, Vol. II, Academic Press Inc., New York, 1955. Earthquakes in Kern County, California, During 1952, Bulletin 171, State of California, Department of Natural Resources, Division of Mines, San Francisco, 1955. 


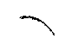

, 


\section{Appendix A}

\section{SEISMIC CONSIDERATIONS PERTINENT TO THE STATIONARY MEDIUM POWER PLANT NO. 1}

TABLE

A.1 Seismic Response of SM-1 Containment Vessel.

\section{A.1 SITE CHARACTERISTICS}

The Stationary Medium Power Plant No. 1 (SM-1), formerly the Army Package Power Reactor No. 1 (APPR-1), was conceived as a prototype to advance nuclear power design and operational technology to enable the feasible operation of successive package reactors at remote military establishments. Although the prototype is located at Fort Belvoir, Va., successive designs may be required to withstand the seismic loads of nearly any credible location, particularly locations remote from the ordinary sources of power or fuel. Considering the global scale of modern military logistics, it would be unrealistic to anticipate ideal conditions of geology and sensmicity for each possible site. Even for those sites selected after due consideration of available geological and historical seismic data, the influence of local geology is at best uncertain; assessment of seismicity is far from precise, and conservative practice should be followed. It is not possible to formulate a general rule for optimum reactor siting in a given area, and professional geological consultation should be employed.

The existing SM-1, located at Fort Belvoir, Va., in a Zone 1 area as defined in Fig. 1.10 , is used in this chapter as an illustration of seismic analysis considerations. The earthquake experience of this site is such that seismic considerations were minor in the original design. However, to illustrate the effects of seisms upon an SM-1 type reactor system, this chapter conservatively assumes that the seismicity of Zone 3 applies (as illustrated by the average response spectra of Figs. 1.19 to 1.24).

The conclusions and calculated stress levels contained in this appendix are based upon an assumed seismic environment more severe than that in which the reactor, as originally designed, was intended to operate. Therefore any indication of possible overstressing of some reactor parts does not imply inadequacy of the original design, but rather indicates only some design areas to which attention should be directed in the event that a similar plant should someday be constructed in areas subject to much more severe conditions. 


\section{A.2 BUILDING AND CONTAINMENT RESPONSE}

\section{A.2 BUILDING AND CONTAINMENT RESPONSE}

This investigation has been directed at those features of the building, containment vessel, and associated equipment (see figures in Chap. 3) which have been demonstrated from past experience to be susceptible to seismic damage or malfunction; at those features which are unique with nuclear power reactor plants, and for which a seismic history is not available; and at those features requiring a high degree of integrity to maintain biological and structural safety during seismic disturbances. No attempt has been made to perform an exhaustive analysis of every detail of the SM-1. Rather, a sampling has been selected to be representative of the seismic response. The review does not attempt to evaluate stresses other than those of seismic origin.

Structural calculations covering pertinent items are presented in Sec. A.5. These calculations further illustrate the application of some of the techniques outlined in the preceding chapters, but they are not intended as model calculations applicable to all systems. As discussed in Sec. 5.1, regardless of the method used in evaluating response, idealization and simplification are necessary to synthesize the model needed to represent the structure dynamically. Each feature investigated can be represented by models that differ in complexity and configuration, with corresponding variations in complexity of analysis and differing end results. The approaches presented do not represent the only approach possible, nor necessarily that which is most desirable. For this reason it is to be expected that the use of more refined models and more sophisticated techniques could give results that vary appreciably from those presented here. However, it must also be remembered that the varying properties of earthquakes impose a severe limitation on the rewards of extended refinements in analysis, so that the results of highly simplified solutions may be entirely adequate.

\section{A. Containment Vessel}

The containment vessel encloses the nuclear reactor, the separate steam generator, and the primary coolant piping connecting the two units, together with appurtenant equipment such as pumps, a pressurizer, and related piping. The turbine, condenser, and generator are housed in the adjacent building and are connected to the steam generator by a secondary piping system piercing the containment vessel. The spent-fuel storage pit is also exterior to the containment vessel; however, it is loaded from within the containment vessel through a small-diameter spent-fuel chute.

The principal structural component of the vessel is a vertical, cylindrical steel shell with hemispherical ends. The interior of the shell is lined with $2 \mathrm{ft}$ of concrete, which is in turn surfaced by a light steel lining. The final clear interior of the shell is $32 \mathrm{ft}$ in diameter and $52 \mathrm{ft}$ in nominal height. The shell bears upon the footing through a circumferential base ring at the level of elevation 27.33. The base ring is anchored to the footing concrete with 16 equally spaced 1-in.-diameter bolts. The exterior of the shell is enclosed within a 3-ft-thick cylindrical concrete wall extending up to the bottom of the hemispherical head. The exterior concrete cylinder and containment vessel are structurally separated by $1 \mathrm{in}$. of fiber glass insulation.

Of the $701 / 2$-ft overall height of the vessel and footings, $24 \frac{1}{2} \mathrm{ft}$, or $35 \%$ of the height, is embedded below the ground surface. More important, the center of gravity of the containment vessel, the exterior concrete cylinder, and their common footings has been determined to be within a few inches of the ground surface, so that a positive identity will exist between ground and containment vessel motion.

Two methods are appropriate to the investigation of containment vessels: (1) the spectrum method and (2) the coefficient method (in which, however, coefficients are selected with regard to the maximum acceleration of the ground motion.) The response will generally be elastic, and limit-design methods are not applicable.

The spectrum method described in Chap. 5 is well suited to the investigation of seismic behavior. In this study the containment structure is taken as a simple cantilever issuing from, 
and intimately associated with, the ground, with broad base sections of adequate strength to assure full and continued elastic response during seismic motion. The method is applied in conformity with the averaged response spectra of Figs. 1.19 to 1.24 , taking damping at $5 \%$ of critical.

Alternatively the calculations required in using the spectrum method can be avoided by using an appropriate seismic coefficient. If the containment vessel has a very short period of vibration so that it may be assumed to be a rigid body, the motion of the structure may be assumed to duplicate that of the ground. The coefficient is then selected to conform with the maximum acceleration of the ground, which, from the averaged response spectrum, is $0.33 \mathrm{~g}$. Alternately, an arbitrary coefficient could be taken from building codes; however, such coefficients would materially underestimate the seismic response.

Table A.1 is a comparative summary of seismic response calculated by the preceding methods. The following assumptions are pertinent to all calculations:

(1) The steel containment vessel is free to vibrate about the level at elevation 27.33, called the base, as a cantilever beam independent of the exterior concrete cylinder.

(2) The inner concrete liner is well bonded to the steel shell.

Tabie A.1 - SEISMIC RESPONSE OF SM-1 CONTAINMENT VESSEL*

\begin{tabular}{|c|c|c|c|c|c|}
\hline \multirow{2}{*}{\multicolumn{2}{|c|}{ Item $\dagger$}} & \multirow[b]{2}{*}{ Units } & \multicolumn{3}{|c|}{ Method } \\
\hline & & & $\begin{array}{l}\text { Coefficient } \\
\text { from } \\
\text { code } \ddagger \\
(\mathrm{C}=0.133)\end{array}$ & $\begin{array}{l}\text { Coefficient } \\
\text { from } \\
\text { spectrum } \S \\
(\mathrm{C}=0.33)\end{array}$ & $\begin{array}{l}\text { Response } \\
\text { spectrum }\end{array}$ \\
\hline \multicolumn{2}{|c|}{ Period (first mode) } & $\mathrm{Sec}$ & & & 0.049 \\
\hline \multicolumn{2}{|c|}{ Base moment } & In.-kips & $7.15 \times 10^{4}$ & $17.9 \times 10^{4}$ & $17.1 \times 10^{4}$ \\
\hline \multicolumn{2}{|c|}{ Base shear } & Kips & 238 & 596 & 451 \\
\hline \multicolumn{2}{|c|}{ Deflection ${ }^{* *}$} & In. & & & $9.25 \times 10^{-3}$ \\
\hline \multicolumn{2}{|c|}{ Concrete } & Psi & $\{-39$ & $\{-\overline{5} 6$ & $\int-5 \overline{5}$ \\
\hline \multirow{3}{*}{$f_{a}+$} & $\{$ conclese & PS1 & $\{-2+\dagger$ & $\{15+\}$ & $\{13+t$ \\
\hline & Steel & Psi & $\left\{\begin{array}{l}-390 \\
\end{array}\right.$ & $\{-560$ & $\{-550$ \\
\hline & & & $1-23+\dagger$ & $149+t$ & $130+\uparrow$ \\
\hline \multirow{2}{*}{$f_{v}$} & $\{$ Concrete & Psi & 3.7 & 9.2 & 6.9 \\
\hline & $\{$ Steel & Psi & 37 & 92 & 69 \\
\hline
\end{tabular}

* SM-1 is located in a Zone 1 earthquake region, but calculations have conservatively assumed Zone 3 conditions for illustrative purposes.

† The symbols have the following meanings: $f_{a}$ is the direct axial stress, $f_{b}$ is the flexural stress, $f_{a} \neq f_{b}$ is positive when tensile and negative when compressive, and $f_{v}$ is the average shear stress.

I Representative coefficient from current building codes.

$\$$ Coefficient selected from averaged response spectra to conform with maximum ground acceleration of $0.33 \mathrm{~g}$.

$\pi$ Averaged response spectra (Figs. 1.19 to 1.24 ).

** Deflection at level of junction of cylinder with top hemispherical head relative to base.

†† Computed from uplift using $50 \%$ of dead load.

Calculation procedures for the coefficient methods conform with those described in Sec. 5.3, Example 1, for a typical rigid-body structure.

Calculation procedures for the response spectrum method included solving for the shape of the first mode and determination of the corresponding period of vibration. The Stodola Newmark method of numerical integration was used and verified within acceptable limits using 


\section{A.2A CONTAINMENT VESSEL}

the Rayleigh method (see Sec. G.2 and Refs. 6.3 and 6.4). Both bending and shear deformations were considered.

Table A.1 demonstrates that the earthquake stresses of the SM-1 containment vessel are generally negligible, so that differences in results obtained by the three methods are of little consequence. However, if stresses should reach significant levels (for example, local stress in design details), the use of code coefficients could result in unrealistically low calculated values of stress, leading to possibly inadequate structural details.

Coefficients selected from the spectra to conform with maximum ground accelerations will yield very close approximations to base moments for this structure. However, base shears will be materially overestimated by this method. As explanation for this type of structure, the more rational response spectrum method indicates that the inertia forces inducing shear at the base are somewhat attenuated by the slight flexibility, while their resultant moment arm has been increased. Thus base moments determined by the two methods are approximately equal, whereas base shears by coefficients are high when compared to those calculated by the response spectrum method.

The stresses indicated by the response spectrum method are more of the secondary order than of the primary order. Obviously then no construction-cost penalty accrues through use of this technique. Conversely the engineering involved in the spectrum approach is appreciably more tedious, and, since results of this precision are not warranted, use of the coefficient method is recommended for this and directly comparable structures. The coefficient should be selected to conform with the maximum ground acceleration, as previously described.

Considering containment-vessel anchorage, maximum bearing stresses under the circumferential base ring are obtained with seismic-overturning additive to the full vertical load. This results in a bearing stress on the concrete of about 80 psi. Maximum anchor-bolt tensile stresses are obtained with seismic uplift reduced by $50 \%$ of the vertical load, effecting a stress of about 20,000 psi through the root of the thread, which corresponds to a tension of roughly 11 kips in each 1-in.-diameter anchor bolt. These stresses were calculated from the overturning moments obtained using the response spectrum method.

Dead-load soil-bearing values under the containment-vessel footings were found to be 5500 psf. When considered with seismic overturning, usually only maximum values are of interest, and dead load and overturning are directly additive. For this condition, (with Zone 3 conditions applied to our essentially Zone 1 design), soil-bearing values were found to increase to about 14,000 psf, indicating the necessity for foundation materials of excellent stability, a possible governing factor in the selection of remote sites or in standardizing an all-around design. Since the response spectrum method was not applied to the vapor container as a whole, including such items as the concrete outer wall and footings, the overturning moment used for the determination of soil pressures was obtained from the more convenient coefficient method, with the coefficient taken to conform with $33 \% \mathrm{~g}$.

These high soil stresses result from the compact and massive configuration of the SM-1 containment vessel, and they should be expected of other reactor containments exhibiting these compact characteristics. On the other hand, for the EBWR, with a generously scaled envelope, the soil bearings were found to be of more ordinary magnitude (Appendix B.)

The exterior location of the spent-fuel storage pit necessitated a projection of the containment footing. Experience has indicated that such irregularities in massive footings, together with shrinkage stresses, high soil stresses, and large differential loadings, may often cause major cracking of the footing or supported structure where insufficient care has been taken in design. Cracking of an unlined spent-fuel pit or one lined with brittle tile would allow percolation of contaminated water into underground courses, susceptible to infiltration into distribution systems for general consumption. Loss of water could also result in the melting of highly irradiated spent-fuel elements, which would lead to fission-product release to the environment. However, the final design of the SM-1 included the use of a stainless-steel liner in the spentfuel storage pit, a practice to be recommended in most cases. Cursory examination of the SM1 has indicated that the design of this feature is probably adequate. 
A structural separation is provided between the containment vessel and operations building. The manhole extension bridging the two buildings is supported wholly from the vessel, as is consistent with the concept of separation. The connecting element of most interest is the secondary piping system conveying steam from the generator within the containment to the turbine in the adjacent building. This piping follows a circuitous path, incorporates provision for expansion and contraction, and will absorb any relative seismic displacement between its terminal points with no difficulty.

\section{B. Primary System}

The primary system includes the reactor vessel, a steam generator, a 12-in. piping loop with two coolant pumps joining the reactor and generator, and a pressurizer connected by a 4-in. pipe. All components are enclosed within the containment vessel and all derive support from a common mass of concrete.

The pressurizer is supported on three 6-in.-diameter pipe stanchions that cantilever approximately $10 \mathrm{ft}$ from the floor. The pressurizer is anchored with one $2 \frac{1}{2}$-in.-diameter hightensile bolt extending down through each stanchion to firm embedment in the concrete base. This system of anchorage affords the pressurizer the freedom to rotate about the top of its support owing to bolt extension, as well as to translate with the top of the stanchions. However, this rotation is small, so that the system can be regarded as a single-mass system with one degree of freedom. Practically all the lateral deflection is due to the flexural deformation of the stanchions.

Results of this analysis are as follows:

(1) The effect of the pressurizer rotating about the top of the stanchions was found to be negligible.

(2) The natural period of vibration was determined to be about $0.43 \mathrm{sec}$.

(3) Maximum deflection at the top of the support was found to be about $1.3 \mathrm{in}$.

(4) The support structure and details are adequate to maintain full elastic response to ground motion of the intensity indicated by the averaged spectra. The equivalent static loading at these intensities is $72 \% \mathrm{~g}$.

The 4-in.-diameter pipe was investigated for the condition where one end of the pipe was held stationary and the other end was allowed to translate with the pressurizer. Stresses thus determined were combined with the 1200-psi internal pressure to obtain principal tensions of approximately $16 \mathrm{ksi}$. Although this value is well below the normal yield point for type 304 stainless steel, it is considered sufficiently high to warrant the conclusion that this pipe should be investigated for damage after a strong seismic shock.

The steam generator is rigidly tied to the reactor vessel through the stiff primary piping loop. As a simplification, the steam generator may be considered as mounted on a flexible support, and the reactor vessel mounting is such as to prevent translation while allowing rotation about the vessel's vertical axis. These conditions present the following possible modes of movement for analysis.

(1) The seismic activity tends to induce motion of the steam generator radial to the reactor vessel, and this motion is restrained both by the primary piping loop and by the steamgenerator support. The load carried by these load paths is determined on a relative rigidity basis.

(2) Motion of the steam generator is tangential to the reactor vessel, and the primary piping loop and vessel rotate with the steam generator, leaving only the steam-generator support available to react to the inertia loadings.

The steam-generator support is similar to that for the pressurizer. It is comprised of four 6-in.-diameter pipe stanchions cantilevering about $4 \mathrm{ft}$ from the floor. Although bolt extension allows the steam generator to rotate about the top of its support, the preceding analy sis of the pressurizer showed the effects of this freedom to be negligible; thus it sufficed to assume the properties of a single-degree-of-freedom system, as described in Sec. 5.4, Ex- 


\section{A.2C PRIMARY SHIELDING}

ample 2. Response of the steam-generator support, with motion tangential to the reactor ves sel, is as follows: The natural period of vibration for the second (tangential) mode of translation was found to be $0.20 \mathrm{sec}$, with the pipe stanchions acting as simple cantilevers fixed at the base. This resulted in an inertia load of $29 \mathrm{kips}$, or about $75 \% \mathrm{~g}$. The support structure and base details were found to be overstressed.

Overstress invalidates the spectrum analysis used, which is based on the assumption of elastic response. If the facility were located in a highly seismic area instead of its present location, uncertainty regarding the magnitude of the deflection and its effect on the connected piping in a severe earthquake could be minimized only by strengthening the supports to assure elastic response. Such strengthening would further attenuate stresses in this short-period system by decreasing the period of vibration.

If space permits, diagonal bracing could be used between stanchions. Another effective aiternative would be to tension the bolts sufficiently to provide the fixity needed for developing bending moment at the upper end of the stanchions. This second scheme would create restraint against free thermal movement of the steam generator, which might limit its desirability.

In the first mode of translation, where the steam generator is restrained radially by the primary piping, a similar analysis yields:

(1) The period of vibration for the first mode of the single-mass system, with primary piping as a spring acting with the stanchions, was $0.14 \mathrm{sec}$.

(2) The maximum inertia load was computed to be about $20 \mathrm{kips}$, or $53 \% \mathrm{~g}$.

(3) Stresses induced in the primary piping by this mode of translation, when combined with the 1200-psi internal pressure, yield a principal tensile stress of roughly $13 \mathrm{ksi}$.

The pipe stresses are probably overestimated in view of the grossly simplifying assumptions necessary to the analysis. Even if the indicated $13 \mathrm{ksi}$ should be attained, this value is again well below the yield point for type 304 stainless steel. As with the pressurizer pipe, however, special inspection after a strong shock would be warranted.

\section{Primary Shielding}

A water shield envelops the reactor vessel. Contannment for this shield is provided by two concentric steel tanks, with the inner tank housing the reactor vessel. The water shield filling the annular space between the two tanks is supplemented by seven concentric steel shielding cylinders. Anchorage for the inner tank is furnished by four 3-in.-diameter high-tensile bolts extending through floor-plate shear lugs. No direct anchorage is afforded the outer tank, although both inner and outer tanks attach to a common 2 -in. floor plate. Although the tanks are connected at their tops with a steel cover, the resulting complexity of seismic response necessitated individual analysis of each unit without direct regard to the structural properties of the other. Modifying assumptions were such that the results are believed to be representative, but possibly conservative to some extent.

Analysis of the inner tank presumed it to be a structurally isolated element cantilevering from the concrete base and furnishing lateral restraint only to the inertia loads of the enclosed reactor vessel and upper water shield. The inherent stiffness of the steel cylinder justified a rigid-body analysis, as described in Sec. 5.3, Example 1, with the lateral coefficient selected to conform with an acceleration of $0.33 \mathrm{~g}$.

Response of the outer tank was considered under two overlapping assumptions:

(1) The water in the annular space was considered a rigid mass, with the inner tank a void (see Sec. 5.3, Example 1).

(2) The tank was considered a simple fluid container filled with water, with no regard given the inner tank, shield cylinders, etc. (see Sec. 6.4, Example 1).

Assumption (1) indicated the more severe response and was selected as the basis for the subsequent detail analysis. The results are as follows:

(1) Both inner and outer tanks were found to maintain elastic response. 
(2) The inner tank anchor bolts are not effective in restraining uplift of the edge of the outer tank. This uplift extends over $85 \%$ of the outer tank periphery and is of a complex nonlinear behavior. Although the consequences of such uplift are difficult to assess, they can be avoided in future designs by a more rational distribution of anchorage, including simply the direct bolting of the outer tank to the floor.

(3) Friction of the bottom plate with the concrete floor would be just adequate to prevent translation of the tank without regard to other restraints. In addition, the anchor-bolt shear lugs would also suffice of themselves for this purpose, so that the tanks may be considered effectively secured against sliding.

\section{Turbine and Generator Support}

The turbine and generator, although housed in the operations building, are supported by concrete framing structurally separated from the building proper. This framing includes a heavy concrete slab bearing the turbine and generator at the second-floor level of the operations building. The slab is supported by six concrete columns extending down to an isolated spread footing.

Determination of the response was in conformity with the averaged spectra applied to the support as a system with one degree of freedom (see Sec. 5.4, Example 2). The period of vibration for the structure was computed as $0.05 \mathrm{sec}$, for which the corresponding loading conforms to $35 \% \mathrm{~g}$. Stresses calculated for this condition were found to be within the normal working range of values for a conventional design.

Maximum soil-bearing stresses were found to be about 1400 psf for gravity loadings and about 4000 psf for gravity loadings combined with lateral loadings. These values are nominal, considering the better classes of foundation material necessary for support of the adjacent vapor container and full elastic recovery of the soil after seismic perturbation appears probable.

Maximum deflection of the supporting slab is only of the order of $0.01 \mathrm{in}$, disregarding rotation of the footing, however. Since the minimum separation from the operations building is 1.25 in., structural isolation is maintained.

\section{E. Operations Building Framing}

The operations building is an irregular structure, principally of two stories, with simple steel framing. So-called wind connections (i.e., clip angles connecting the top and bottom beam flanges to the column) furnish the lateral resistance of the frame.

No complete system of seismic-resistant design features is immediately apparent in the plant design studied in this report. (However, such a system is reported to have been incorporated in the arctic modification to the operations building. The arctic modification is a smaller, less irregular structure that is inherently earthquake resistant. The design is for a level site, as opposed to the sloping site at Fort Belvoir, obviating the potentially troublesome condition at Fort Belvoir where first-story columns are of unequal length and carry disproportionate lateral shears. The modification is reportedly wind braced and is said to have minimal wall openings, so that material reserve strength is available from wall panels acting as vertical diaphragms.) No attempt was made to analyze the prototype structure as a whole; however, the frame investigated is considered to be a representative sampling of governing conditions in the principal members. This frame is two bays wide and two stories in height. Of the three columns supporting the second floor, one is of only $2.8 \mathrm{ft}$ effective length, and this short, stiff column was found to bear a disproportionately heavy share of the aseismic effort.

\section{(1) Analysis by Response Spectrum}

Natural periods of vibration for the first and second modes of translation were determined to be 0.29 and $0.19 \mathrm{sec}$, as determined in a manner similar to that described in Sec. 5.5C, Example 3, for two-degree-of-freedom structures. Analysis by the averaged response 


\section{A.2F SIGNIFICANCE OF OVERSTRESS}

spectra for these periods yielded equivalent lateral loadings of about 220 and $70 \% \mathrm{~g}$ through the upper and lower levels, respectively. For these loadings the following results are obtained:

a. Two of the three columns in the upper story and the short column in the lower story are stressed beyond the yield point.

b. All beams maintain full elastic response.

c. All except one of the lateral-moment connections and the base connection for the overstressed column undergo plastic deformations.

It must be recalled that a required condition for application of the response spectra is continued elastic behavior. For this case, where large-scale plasticity is prevalent, results obtained by spectra have little significance and function principally as a basis for the designer's considered judgment.

\section{(2) Analysis by Code Coefficients}

Coefficients were applied in conformity with the Uniform Building Code for Zone 3 seismicity. This provided for lateral loadings of 13.3 and $10.9 \% \mathrm{~g}$ through the upper and lower levels, respectively. It was found that all stresses were within the values assigned by code for these conditions, with the exception of the base plate, for the previously noted critical column and the second-floor beam connection to this same column. The overstress might be significant only if the facility were located in a highly seismic area instead of the present site. Had all columns been of equal length, the resulting shear distribution would have been more equitable, and seismic difficulty would be reduced.

\section{(3) Limit-design Methods}

Where dynamic analysis indicates large-scale plastic behavior, as with this frame, limitdesign methods would appear to be applicable. However, at the present time, the technology of this method has not been advanced sufficiently to account for cyclic plastic reversal as related to total energy dissipation and ultimate strengths when considered with random motions. Consequently limit-design methods must be used with caution in such cases.

\section{F. Significance of Overstress}

Most of the structural elements investigated have periods of vibration such that the horizontal accelerations induced by a strong earthquake would be a large percentage of the acceleration of gravity. For installations in regions of high seismicity, the significance of any resulting overstress must be assessed from the standpoint of the consequences of failure. Thus some overstress could probably be tolerated in those instances where failure would not involve the release of fission products (see Sec. 5.8A).

\section{G. Static Resistance of Equipment Items}

If reasonable allowances for stresses other than those of seismic origin are made, it appears that most of the overstressed equipment items can resist a static horizontal force of $0.20 \mathrm{~g}$. As stated in Sec. $4.12 \mathrm{~A}$, this static coefficient is often used in designing critical features of conventional power plants in areas of high seismicity.

\section{A.3 REACTOR SYSTEM}

In this section the SM-1 system is examined with respect to seismic vulnerability. Only those areas considered to be seismically sensitive are considered. 


\section{A. Control Rods}

No damage or malfunction of the control rods is expected for severe earthquakes. The generally acceptable fail-safe scram feature, in which the safety rods fall by gravity, is used here, with the modification that some friction is encountered in the seal bearings of the drive shaft. Misalignment of this shaft is not expected to be sufficient during an earthquake to cause significantly greater rod drop time.

In Report APAE-2 (Hazards Summary Report for the SM-1), it is stated that a major rupture of the exit coolant line may cause a temporary raising of the control rods, but the raising is found to be insufficient to create serious nuclear perturbations because of the attendant for mation of steam voids.

\section{B. Loss of Power During Earthquakes}

As with nearly all nuclear power stations, the SM-1 is provided with emergency power (in this case, a battery set).

Should a complete loss of power occur, tests have shown that the negative-temperature coefficient of reactivity of this pressurized-water system leads to power self-regulation and that natural-convection cooling is sufficient to take care of fission-product decay heat. If there is a complete loss of power, the control rods will automatically scram, all pumps will stop, and the pressurizer heater will go off. In a test the reactor power dropped from $10 \mathrm{Mw}$ to 100 watts in about $7 \mathrm{~min}$. After $10 \mathrm{~min}$ the control rods were pulled out just enough to make the reactor critical. It was verified that the reactor automatically kept itself barely critical by its negative-temperature coefficient of reactivity and that no boiling took place in the core.

\section{Loss of Heat Sink During Earthquakes}

In a simulated loss-of-heat-sink experiment, the turbine throttle valve was closed suddenly (it is presumed that the primary pump was kept operating during this test). With no scram or movement of the control rods, the reactor power automatically decreased from $10.6 \mathrm{Mw}$ to 100 watts in about $17 \mathrm{~min}$ as the small temperature rise of the coolant decreased the core reactivity. Heat loss from the primary loop lowered the temperature in about $1 \mathrm{hr}$ to a point at which the reactor became barely critical again; thereafter it regulated itself through its negative-temperature coefficient. Thus, even in the event of a major secondary loop rupture during an earthquake, there should be no serious damage to the reactor core.

\section{Transient Load Demand During Earthquakes}

During severe seismic disturbances a power station may experience either a sudden load increase or a sudden load decrease. In either event the SM-1 is capable of self-regulation, as demonstrated by the experiment described in Sec. A.3C and by a test in which the load was increased from 225 to $2050 \mathrm{kw}$ in about $75 \mathrm{sec}$ with no adjustment to the plant.

\section{E. Nuclear Perturbations}

For the SM-1 the small core size and positive positioning of the fuel elements between the upper and lower grid plates provide a sturdy assembly that is capable of withstanding strong shocks. There would be no reactivity changes due to voids so long as the pressurized-water loop is intact. In the Hazards Summary Report for the SM-1 (Report APAE-2), the nuclear excursions postulated of nonearthquake origin are not sufficient by themselves to rupture the primary loop.

\section{F. Energy Release}

As stated in Sec. A.2, main components and piping appear to be structurally capable of withstanding severe earthquakes. About the only failure that could occur during an earthquake 


\section{A.4 STANDARD OPERATING PROCEDURE WITH RESPECT TO EARTHQUAKES}

is that due to a combination of seismic forces and a brittle fracture from long-term irradiation or faulty material.

In the event of such unlikely damage, the maximum energy release will be of the order of that postulated for the maximum credible accident in the Hazards Summary Report for the SM-1 and hence can be contained in the vapor container. Metal-water reaction is not deemed likely in the SM-1.

\section{A.4 STANDARD OPERATING PROCEDURE WITH RESPECT TO EARTHQUAKES}

A written operating procedure and drills should be used to minimize the possibility of operator panic during an earthquake. Since the SM-1 appears, in general, able to withstand strong earth shocks, for remote sites such as those where SM-1 systems may be used, it may be advisable to continue operation during the seism. The standard procedures should provide instructions for this eventuality.

Usually after an earthquake, it is advisable to make a systematic check of the reactor plant for damage. In addition to visual observations, one could make a survey incorporating nondestructive tests to detect large cracks hidden from view. Instruments should be checked electrically and mechanically. Equipment and places that should be checked are indicated in the preceding analyses.

\section{A. 5 STRUCTURAL CALCULATIONS}

Various components of the SM-1 system and the sheets on which calculations appear are given below.

Item

Vapor container

Pressurizer

Steam generator

Reactor vessel and shield tank

Operations building:

Turbine-generator support

Building proper
Sheet No.

$$
1-11
$$

$12-16$

$17-19$

$20-29$

$30-34$

$35-46$ 
To Determine the natural Perioo of Vibration of the vapor Container. THe Following Assumptions Are Considered Valid:

(1) Vapor comtainer free to Vibrate about El. 27.33 independent OF BFT EXTERIOR WALL

(2) ZFT. CONC LINER ACTS IN UNISON WITH OUTER STL. SHELL.

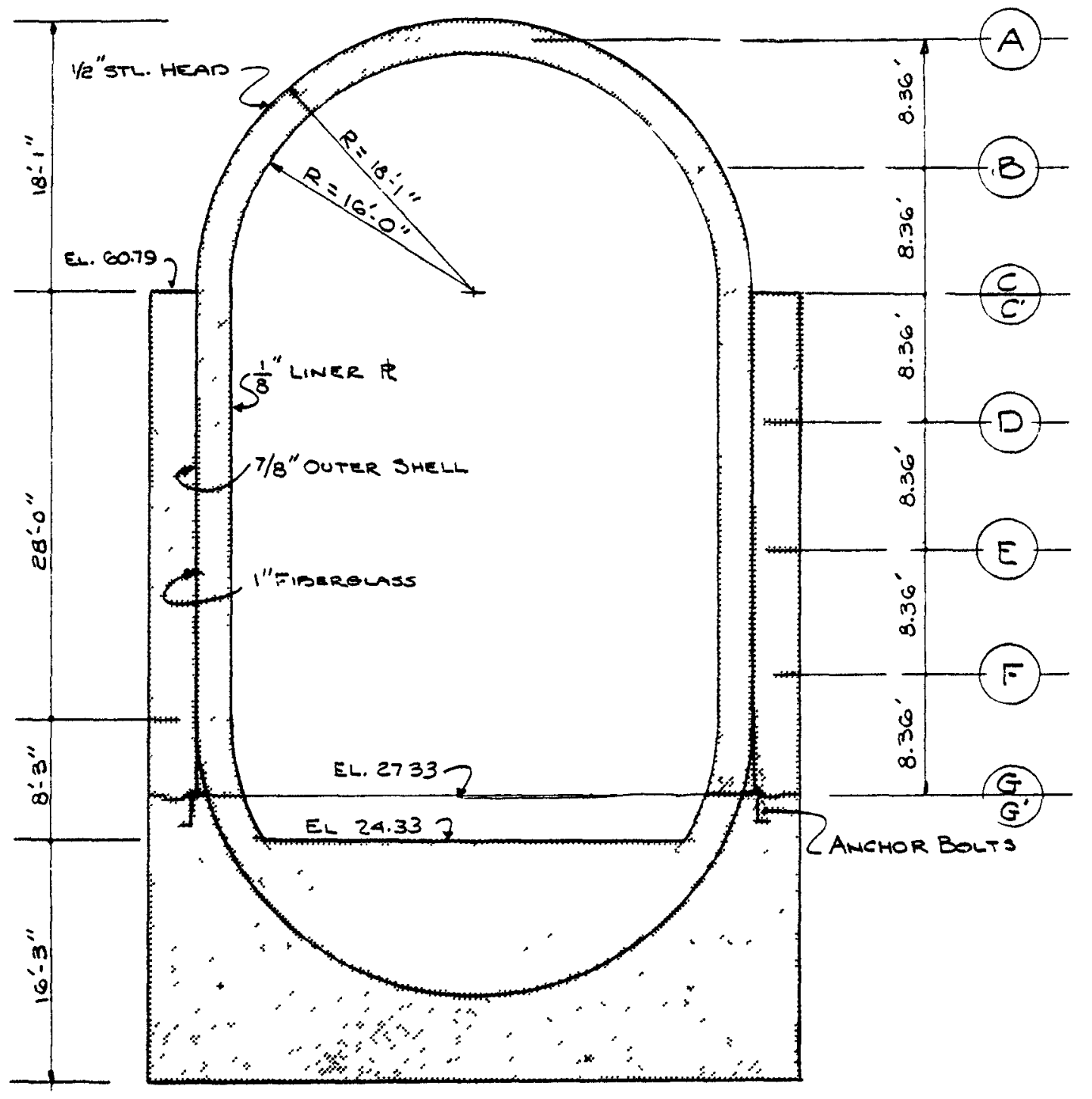

SEction throvgh Vapor CONTAINER 


\section{SECTION PROPERTIES}

\begin{tabular}{|c|c|c|c|c|c|c|c|c|}
\hline \multirow[b]{2}{*}{ SECTION } & \multicolumn{2}{|c|}{ CONGRETE } & \multicolumn{2}{|c|}{ STEEL } & \multirow{2}{*}{$\begin{array}{c}\text { Trans Rormed } \\
\text { AREA } \\
10^{2} \\
10^{4} \text { units }\end{array}$} & \multirow{2}{*}{$\begin{array}{l}\text { TRANSFORHED } \\
I \\
\text { ina } \\
10 \% \text { units }\end{array}$} & \multirow{2}{*}{$\begin{array}{c}\text { F/AE } \\
\text { LBs.-1 } \\
10^{-11} \text { units }\end{array}$} & \multirow{2}{*}{$\begin{array}{c}1 / E I \\
\left(L B S \cdot-1 N^{2}\right)^{-1} \\
1 \theta^{-16} \text { uNiTS }\end{array}$} \\
\hline & $\begin{array}{l}\text { AREA } \\
\text { 1N? } \\
10^{4} \text { LNITS }\end{array}$ & $\begin{array}{c}I \\
10^{10^{4}} \text { units }\end{array}$ & $\begin{array}{l}G-1) A_{3} \\
1 A^{4} \\
1 a^{4} \text { units }\end{array}$ & $\begin{array}{c}(n-1) I_{3} \\
1 N^{4} \text { unvits } \\
108 \text { unts }\end{array}$ & & & & \\
\hline$B$ & 3.40 & 5.29 & .54 & 1.01 & 3.94 & 6.30 & 4.23 & 5.30 \\
\hline$c$ & 3.22 & 6.61 & .61 & 1.44 & 3.83 & 3.05 & 4.35 & 4.15 \\
\hline$c^{\prime}$ & do & do & 1.07 & 2.52 & 4.29 & 9.13 & 3.36 & 3.05 \\
\hline 0 & do & do & do & do & do & do & do & do \\
\hline$\Sigma$ & do & do & do & do & do & do & do & do \\
\hline$* F$ & do & do & 1.07 & 2.52 & 4.27 & 9.13 & 3.35 & 3.55 \\
\hline$* F^{\prime}$ & 3.22 & 6.61 & 2.14 & 5.04 & 5.36 & 11.05 & $3.1:$ & 3.00 \\
\hline$* G$ & 4.41 & 8.81 & 2.09 & 4.69 & 6.50 & 13.50 & 2.56 & 2.97 \\
\hline
\end{tabular}

* values adjusted to accommodate calchlations.

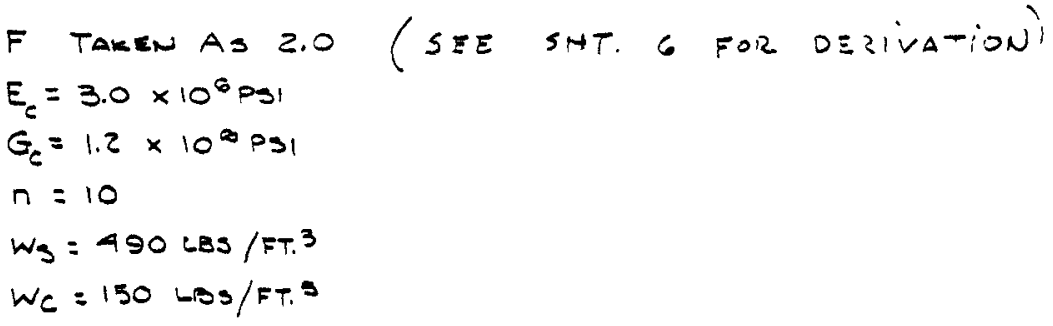


PERIOD OF VIBRATION - I ST MODE - STODOLA-NEYMMARK METHOD OF MECH. quADRATURE

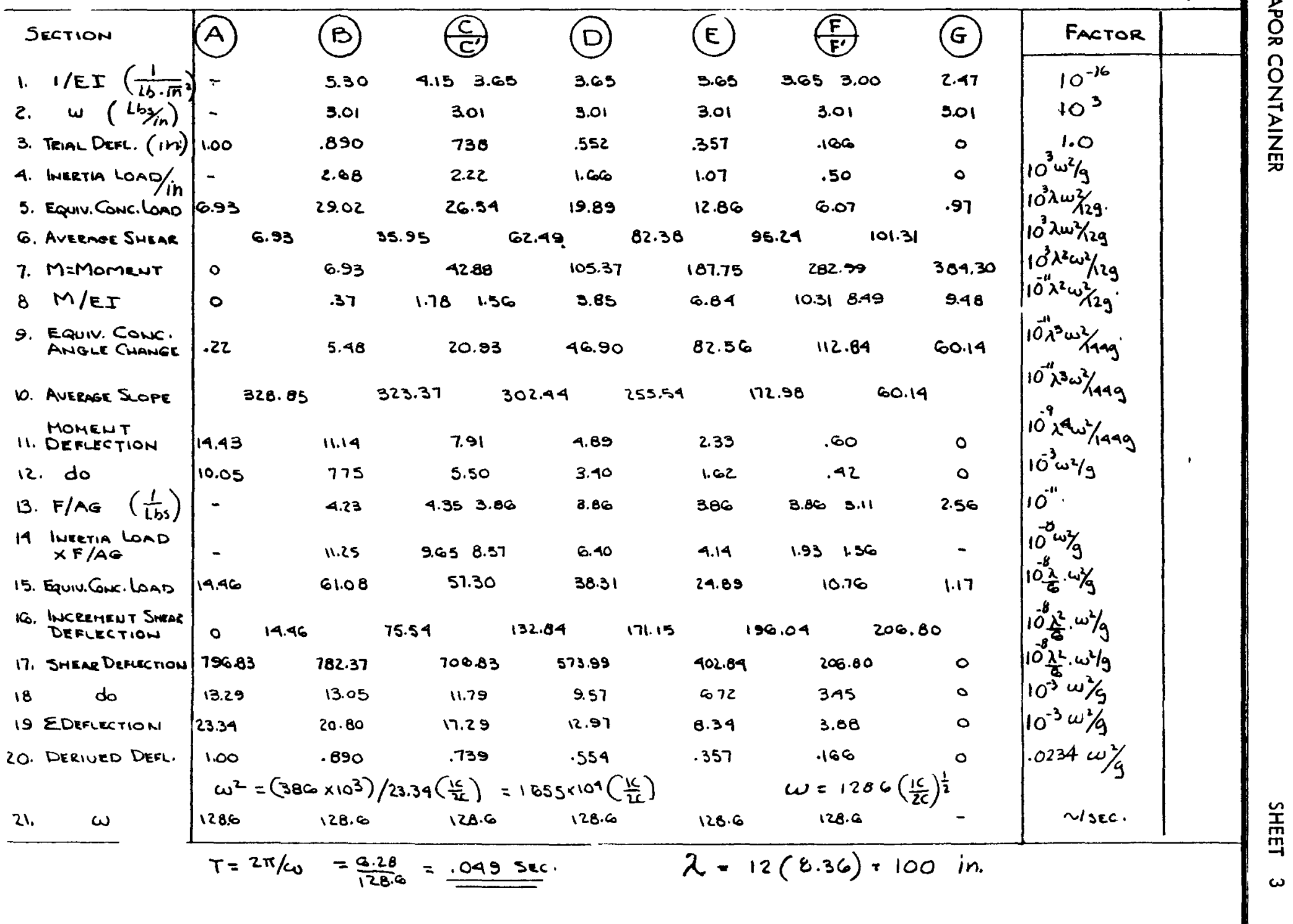




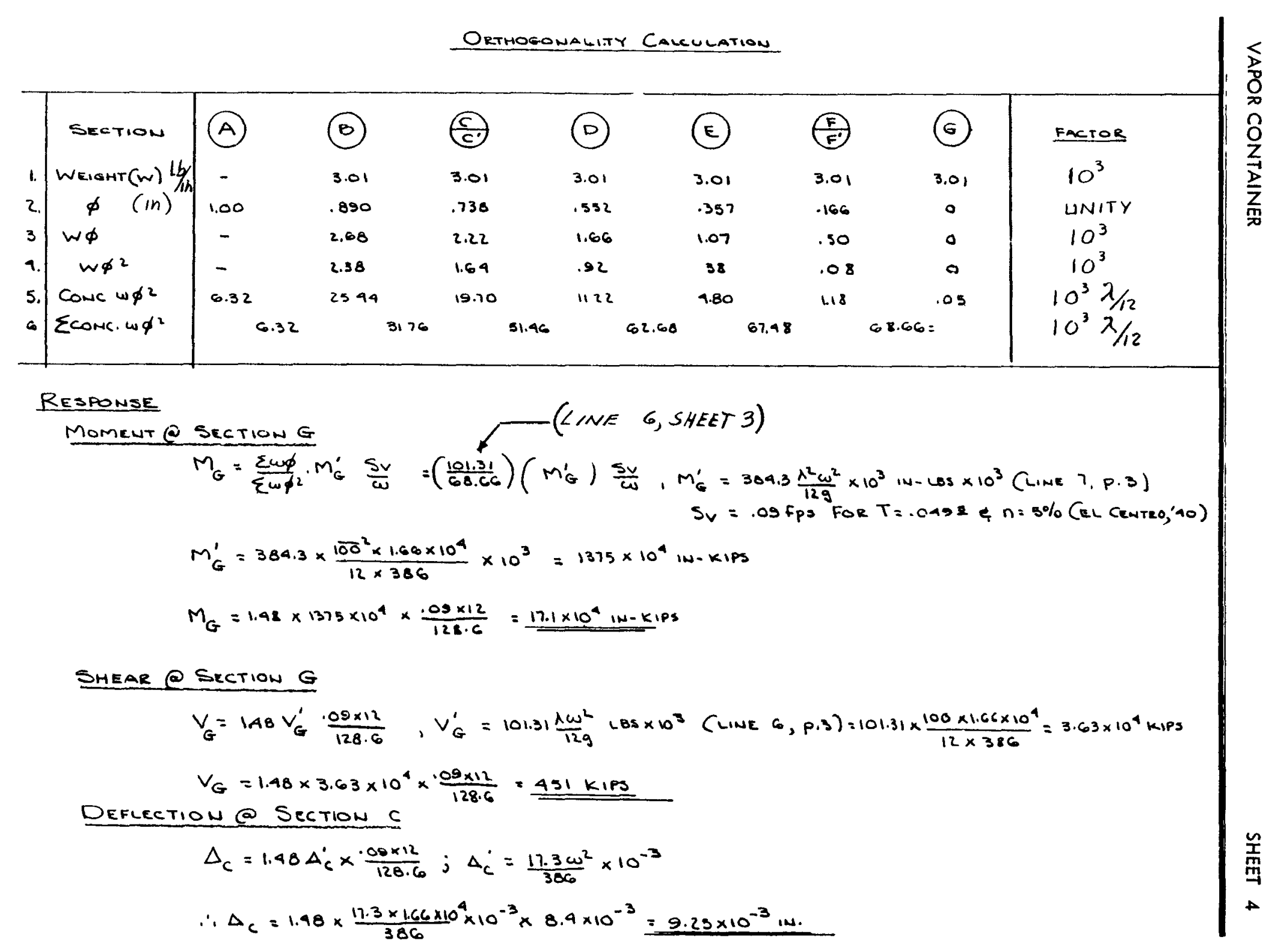


VAPOR CONTAINER

SHEET 5

CONCRETE E STEEL STRESSES

$$
\begin{aligned}
& M=171 \times 10^{4} \text { in-kips, } V=451 \text { kips, } \rho=1740 \mathrm{ki \rho s}, A_{T}-65 \times 10^{4} \mathrm{Tn}^{2} \\
& I_{T}=135 \times 10^{4} \mathrm{in}^{4}, \mu^{2}=\frac{I_{T}}{A_{T}}=208 \times 10+, e \cdot \frac{\mu}{\rho} \\
& f_{c}=\frac{p}{A_{T}}\left(1 \pm \frac{e c}{p^{2}}\right) \text { for compression } p=1790+e \cdot \frac{171}{179} \cdot 95^{\circ} \\
& \begin{array}{l}
\text { for tension } \\
\text { (use } \left.\frac{1}{2} 06\right)
\end{array} \\
& f_{c}(\operatorname{comp})=\frac{1790 \times 10^{3}}{65 \times 10^{4}}\left(1+\frac{950 \times 216}{208 \times 10^{4}}\right)=550 \text { iss es - rofec suss }
\end{aligned}
$$

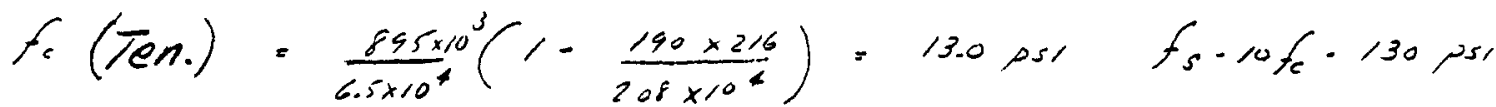

BASE RP AND ANCHOR BOL STRESSES

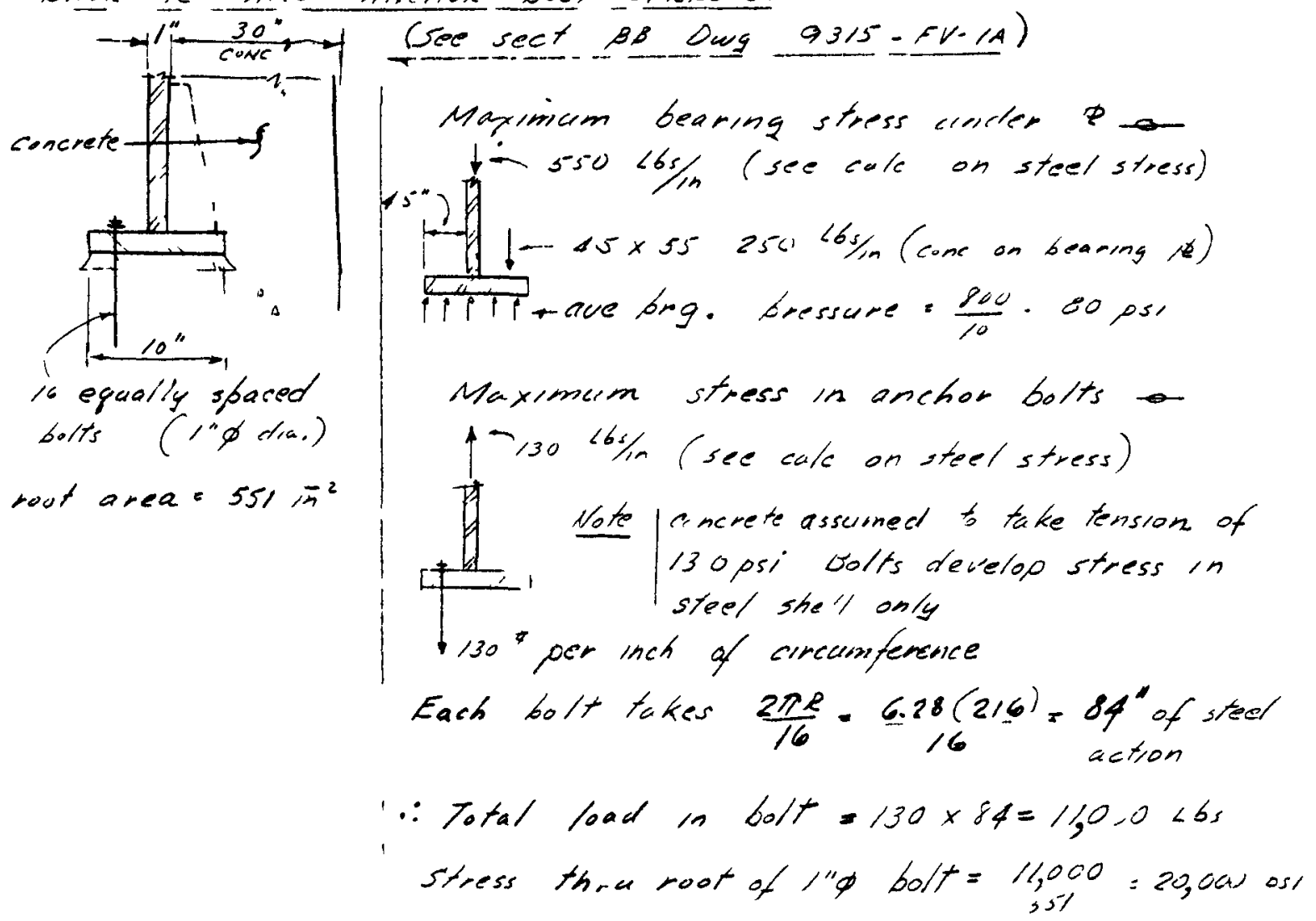

The above calculations are conservative.

261 
VAPOR CONTAINER

SHEET 6

DETERMINATION OF SHEAR DEFLECTION CONSTANT EOR A SEAM OE ThIN ANNULAR CROSS SECTION

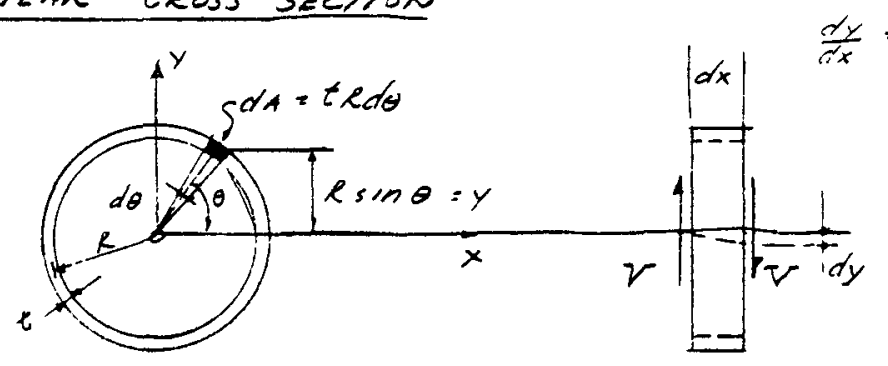

$$
\begin{aligned}
& \frac{K V}{A} \cdot \frac{V Q}{\bar{I} \sigma} \\
& \left.Q=2 \int_{0}^{\pi / 2} \operatorname{cod}(\alpha \sin \theta)=-\left(2 t R^{2}\right) \cos \theta\right]_{0}^{\frac{\pi}{2}}=2 t R^{2} \\
& \left.r \cdot 4 \int_{0}^{\frac{\pi}{2}} t R d \theta(R \sin \theta)^{2}=46 R^{3}\left(\frac{\theta}{2}-\frac{\sin 2 \theta}{4}\right)\right]_{0}^{\pi / 2}=\pi t R^{3} \\
& A=2 \pi R t \\
& \therefore \frac{K}{A}=\frac{2+R^{2}}{\pi t R^{3}(2 t)}=\frac{1}{\pi R t} \quad \because k=\frac{A}{\pi e t}=\frac{2 \pi R t}{\pi k t}=2.0 \\
& \because y=\int \frac{K V}{A G} d x=2 \int \frac{K}{A G} d x
\end{aligned}
$$

SHEAR DEFLECTION BY METHOD OF EQUIVALENT CONCENTRATED LOS.

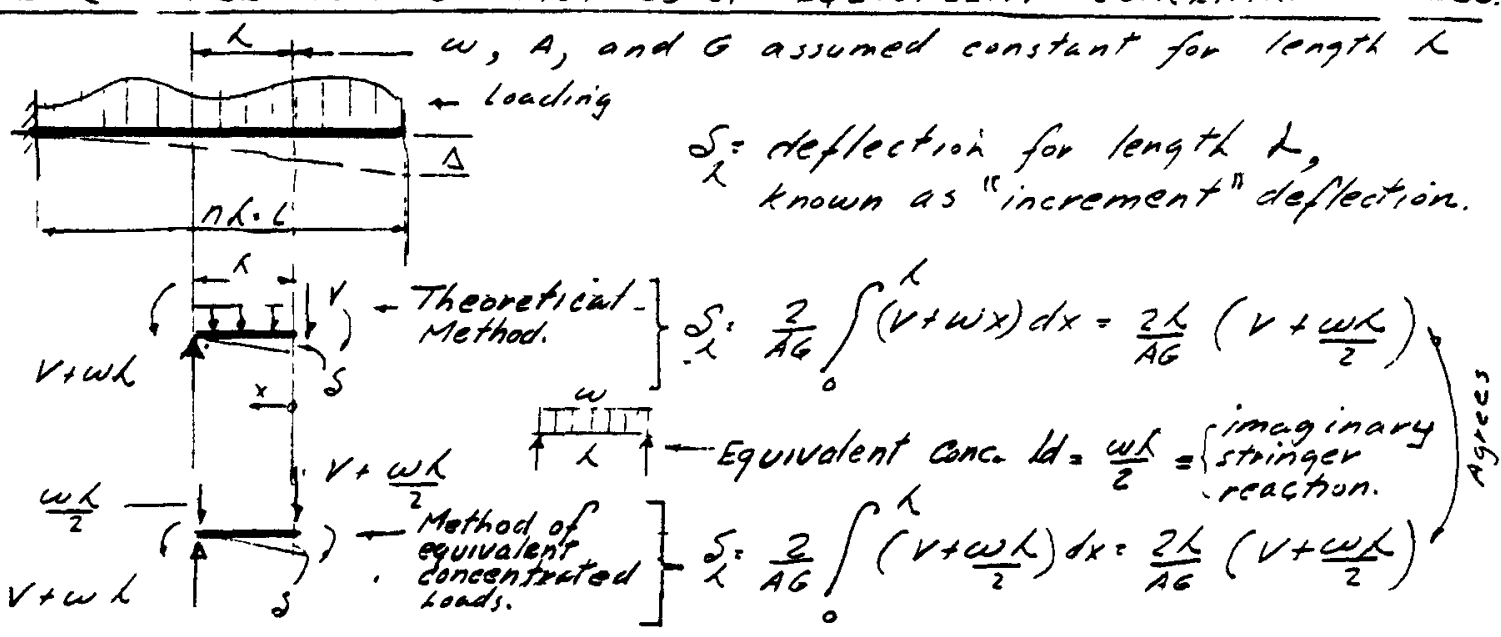

$$
\begin{aligned}
& \text { Total deflection }=\Delta=\sum S_{L}
\end{aligned}
$$

Results above shows that shear deflection is theoretically correct by using the method of equivalent concentrated loads.

262 


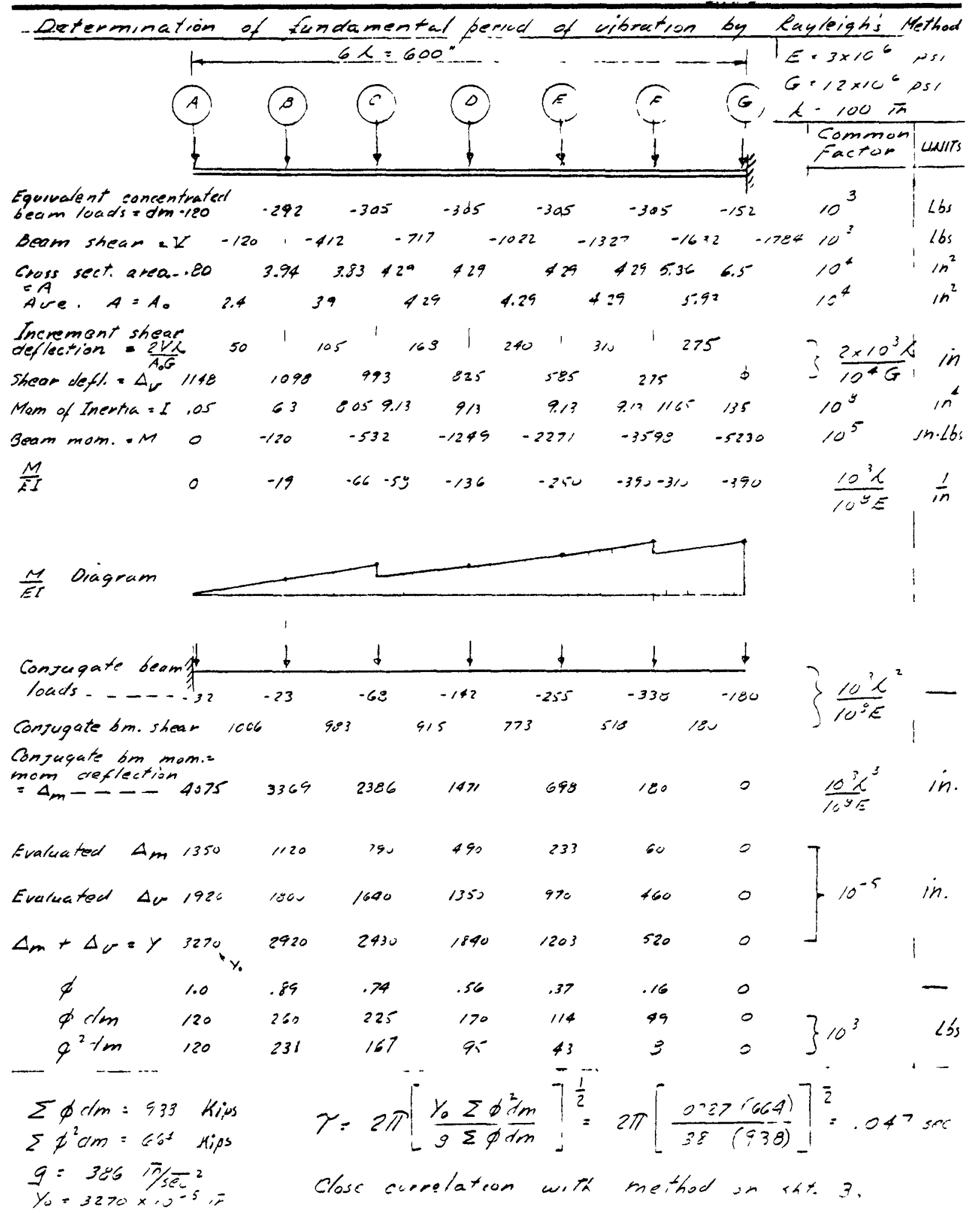


Determiniation of shear, mom deflection and stresses by values devived fom Rayleight Method.

From the average acceteration spectumen eurues, El Centw, 1910.

for $T=.0 x>$ and $5 \%$ dampirg, acceleration $=11.25 \mathrm{f} / \mathrm{fec}$

Mom.at (6) $=\frac{11.25}{32.2}\left(5230 \times 10^{4}\right)=18.2 \times 10^{4}$ in-e.ps

Shear at $(6)=\frac{11.25}{32.2}(1734)=620$ kips

Deflection at seetion (C) $=\frac{11.25}{32.2}\left(2430 \times 10^{-5}\right)=0.5 \times 10^{-3}$ inches 146 values above have an acceptable correlation with rexults of sht. 4 concrete and steal stresses af Sect. G

$M E G=18.2 \times 10^{2}$ in-kis.

re G. 620 kips

$p: 1790$ * fur compatirig comparession.

$P .895^{*} "$ "tension.

$T_{r}=13.5 \times 10^{8} \mathrm{in}^{-1}$

A. $=6.5 \times 10^{2} \overline{1 n}^{2}$

$A^{2}=\frac{I_{Y}}{A_{T}}=2.08 \times 10^{4}$

$C=\frac{18.2 \times 10^{-6}}{1790}$ (sur comp) $=102 \mathrm{i}$

e. $\frac{18.2 \times 10^{4}}{895}$ (For tension) $204 \mathrm{in}$

$f_{c}=\frac{p}{a_{r}}\left(1+\frac{e c}{p^{2}}\right)($ for com $\beta)$

$f=\frac{1790 \times 10^{3}}{6.5 \times 10^{4}}\left(1+\frac{102 \times 216}{2.08 \times 10^{4}}\right)$

$f_{c}=27.6(1+1.05)=56505$

$f_{s}$ infe: scsess

$f_{c}=\frac{P_{i}}{a_{i}}\left(1-\frac{e c}{d^{2}}\right)$ (far tension)

$f_{c}=\frac{895 \times 10^{3}}{0.5 \times 10^{4}}\left(1-\frac{204 \times 216}{2.08 \times 10^{4}}\right)$

Them Summary .... Value $\quad f_{c}=13.8(1-2.1)+15.2$ psi

\begin{tabular}{|c|c|c|}
\hline & & \\
\hline Perrod (firist move) & 0.047 & \\
\hline Base moment & $10.2 \times 10^{4}$ in-kips & Frave.) \\
\hline $\begin{array}{l}\text { Dase shear } \\
\text { Deflectron at (c) }\end{array}$ & $\begin{array}{ll}620.0 & \text { kips } \\
8.50 \times 10^{-3} \text { inches }\end{array}$ & $\begin{array}{l}f_{\text {(ave) }} \text { steet } \\
\text { (ave } 10\left(9.5^{\circ}\right)=95 \text { psi }\end{array}$ \\
\hline
\end{tabular}

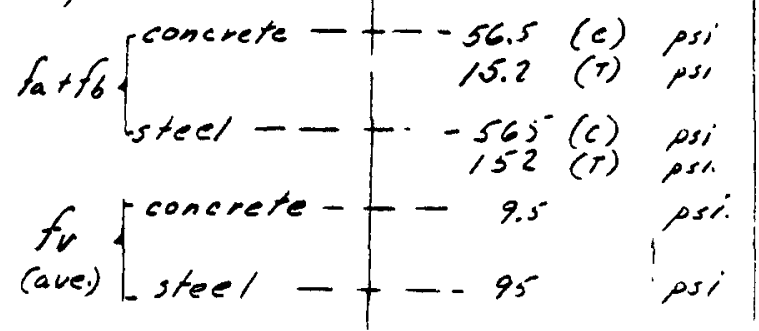


VAPOR CONTAINER (SUpplemental Calculations)

SHEET 9

1) Calculate on using averaged response spectrum

from SiT. $5, \quad A_{T}=6.5 \times 10^{4} \mathrm{in}^{2}$

from shit. 4, $r_{G}: 451$ kips

then $v_{c}=\left(451 \times 10^{3}\right)\left(6.5 \times 10^{\prime}\right)=6.9$ psi $v_{s}=10(6.9): 69$ psi

1) Calculate $M E^{\prime} V$ using static coefficients

coefficient from spectrum $=0.333$

coefficient from code $\cdot 0.133$

$0.33 \% 0.133 \cdot 2.5$

from shit. $5, \quad W=1790$ kips

from st. $), \quad L: 8.36(6)=50.16 \mathrm{ft}$.

$Y_{\text {code }}=0.1333(1790)=238 \mathrm{kips} \quad Y_{\text {spectrum }}=2.5(238): 596 \mathrm{kips}$

Mode $=238(50.16) 6=7.15 \times 10^{d}$ in -kips Al spectrum $=2.5\left(1.15 \times 10^{d}\right)=17.9 \times 10^{1}$ in-kipi

Calculate fat fob:

$$
\begin{aligned}
& e_{\text {code }}=0.1333(50.16) 6=40.1 \text { in } \\
& \text { from sot. } 5,
\end{aligned}
$$

Calculate $\mathrm{N}$ :

$v_{c}$ code $=23.8 \times 10^{4} \% .5 \times 10^{4}+3.66 p s i \quad v_{c}$ spectrum s $2.5(3.06)=9.17$ psi

$v_{s}$

$=37$

$v_{s}$

$=92$

la) Calculate fo and for fo using $50 \%$ of seismic from response spectrum.

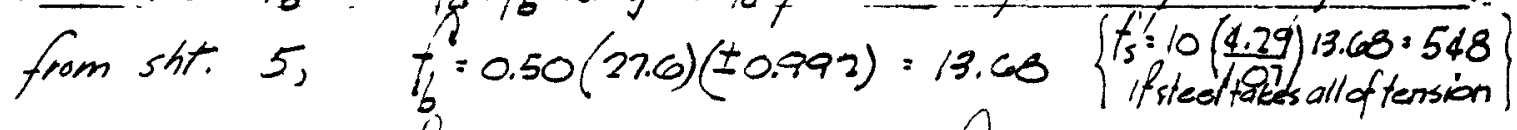
$f_{c}=27.6+13.7=41.3(c) \quad f_{s}=413$ (c)

$f_{c}=13.8-13.7=0.1$ (c) $f_{5}=1$ (c)

265 
3) Calculate soil-bearing pressures

For containment vessel only, use results from specturum method; For concrete footings and exterior concrete cylinder, use coefficient from spectrum: 20.333 -

2) Containment vesse from sbt $5, W=1790$ Kips $R: 17.1 \times 10^{4}+4.51(2.32) \times 10^{4}$

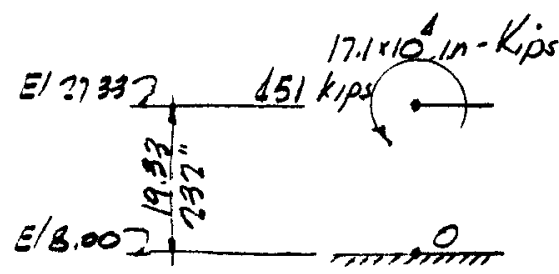

1790

$$
\text { b) Exterior cylinder }
$$

b) Exterior cylinder $A_{0}: 2037 \times 10^{2}+5341.44: 371$
$A_{1}=1693$ $W=150(371)(36.25)=2015 \mathrm{kips}$ $V=0.333(2015)=671$ $h=671(4 / 2.5)$

c) Containment vessel (lower portion)

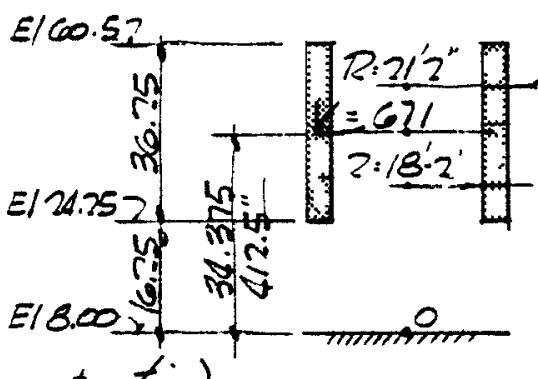

2015 $A_{0}=1466 \times 10^{2}$ $A_{1}=902-504 / 144^{\prime} 350$ $W=150(350)(3.08)=1618 \mathrm{kips}$ $V=0.333(161.8)=53.9$ $\mathbb{K}=53.9(213.5)=$

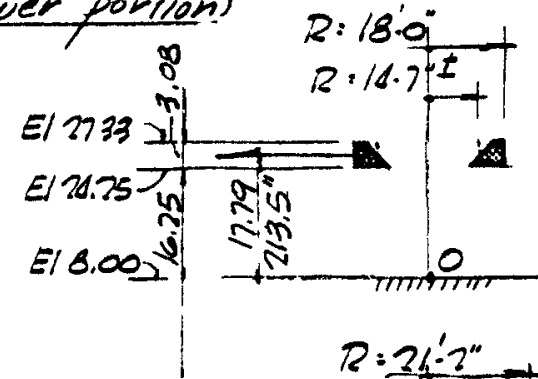

d) Base

$$
\begin{aligned}
& L_{0}=2027 / 1.44: 1409 \\
& W=150(1409) / 6.25=3430 \mathrm{kips} \\
& V=0.333(3430)=1143 \\
& M=1143(975)=
\end{aligned}
$$

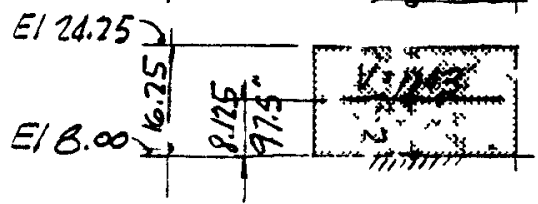

162
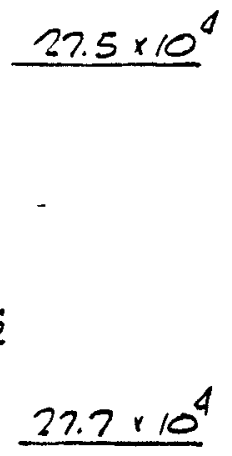

e) Shield tank:

toner tank and reador from sht. $3, w$ :

$$
\begin{aligned}
& W=23.6 \text { kips } \\
& M=23.6(\text { ic.25) } 12+0.187=
\end{aligned}
$$

Outer tank and water:

$$
\begin{aligned}
& \text { from sht. } 5, W= \\
& \mathbb{M}=94.4(16.25) / 2+0.89=
\end{aligned}
$$

$-3030$
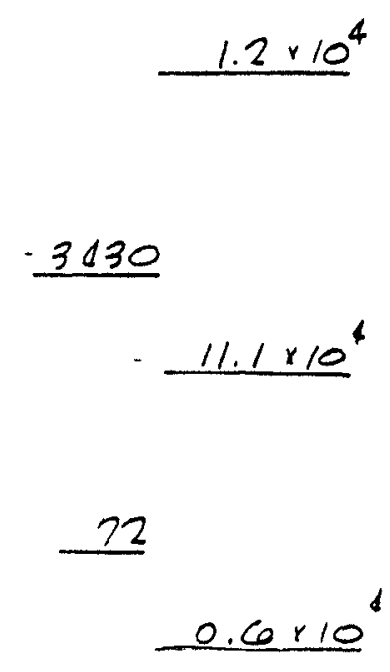

286

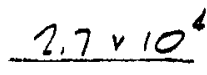


VAPOR CONTAINER (SUpplemental Calculations)

SHEET 11

3) Sout-bearina stresses (Contd)

A) Summary

$k^{q}: 7755 k i p s$

$$
\begin{aligned}
\mu & =70.8 \times 10^{8} \text { in. - kips } \\
& =59,000 \mathrm{ft}^{-k_{i j s}}
\end{aligned}
$$

g) Soil bearing
$e=59,000 / 7755=7.61$
$s / r=1.61 / 21.17=0.36$

from standard $\{=0.0030$

graf hs: $\left\{\begin{array}{l}Q \cdot 0.630(71.7): \cdot 13.32 \\ Q \cdot 1\end{array}\right.$

$$
\begin{aligned}
f & =k(R \cdot Q) \\
k & =\frac{F}{R^{3}} \cdot \frac{3}{2 d^{3}+3 p^{2} d \cdot 3 q 3}
\end{aligned}
$$

From standard graphs:

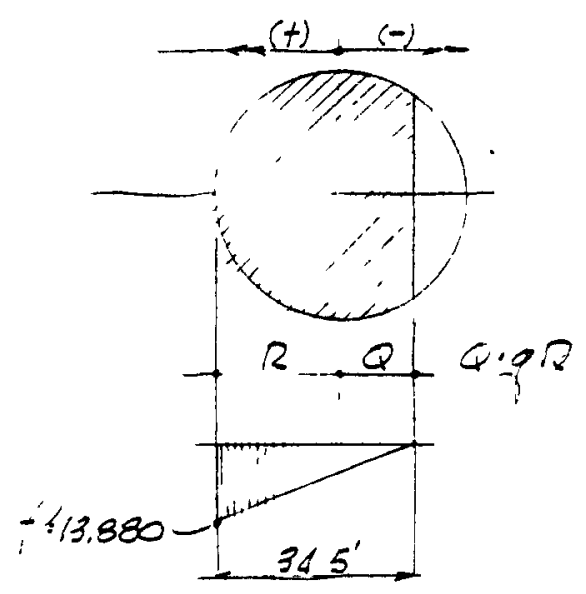

$$
\begin{aligned}
& k=\frac{F}{R}, 0.492 \cdot \frac{7755}{9480} 0.492=0.402 \\
& P=0.102(34.5) \cdot 13,880 \mathrm{Lbs} / \mathrm{ft}^{2} \mathrm{DL}+\text { Seis/1/L } \\
& f=7755 / 1009=5,500 \mathrm{kbs} / \mathrm{H}^{2} \mathrm{DL} \text { onLy }
\end{aligned}
$$

267 

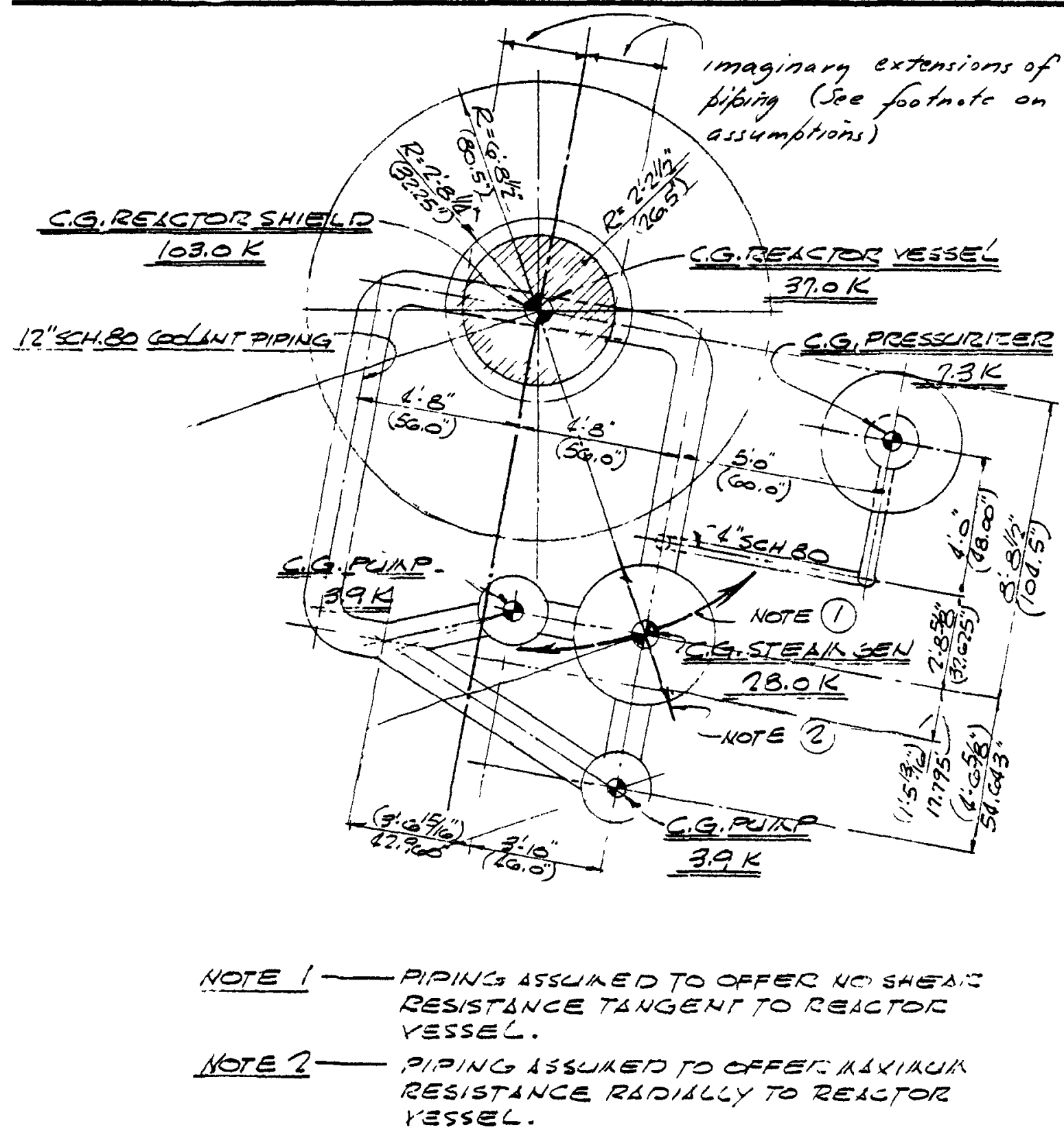

PLAN OF PIPING SYSTEM

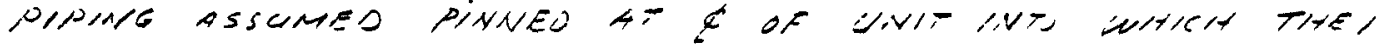

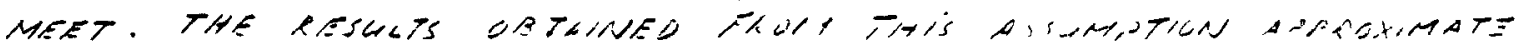
THE EFFECT OF PIPES PEING PIXEO AT ACTUM PUNTU OF CONNECTIN, NATELY, THE OUTFP SIUELL OF THE UNITS. 


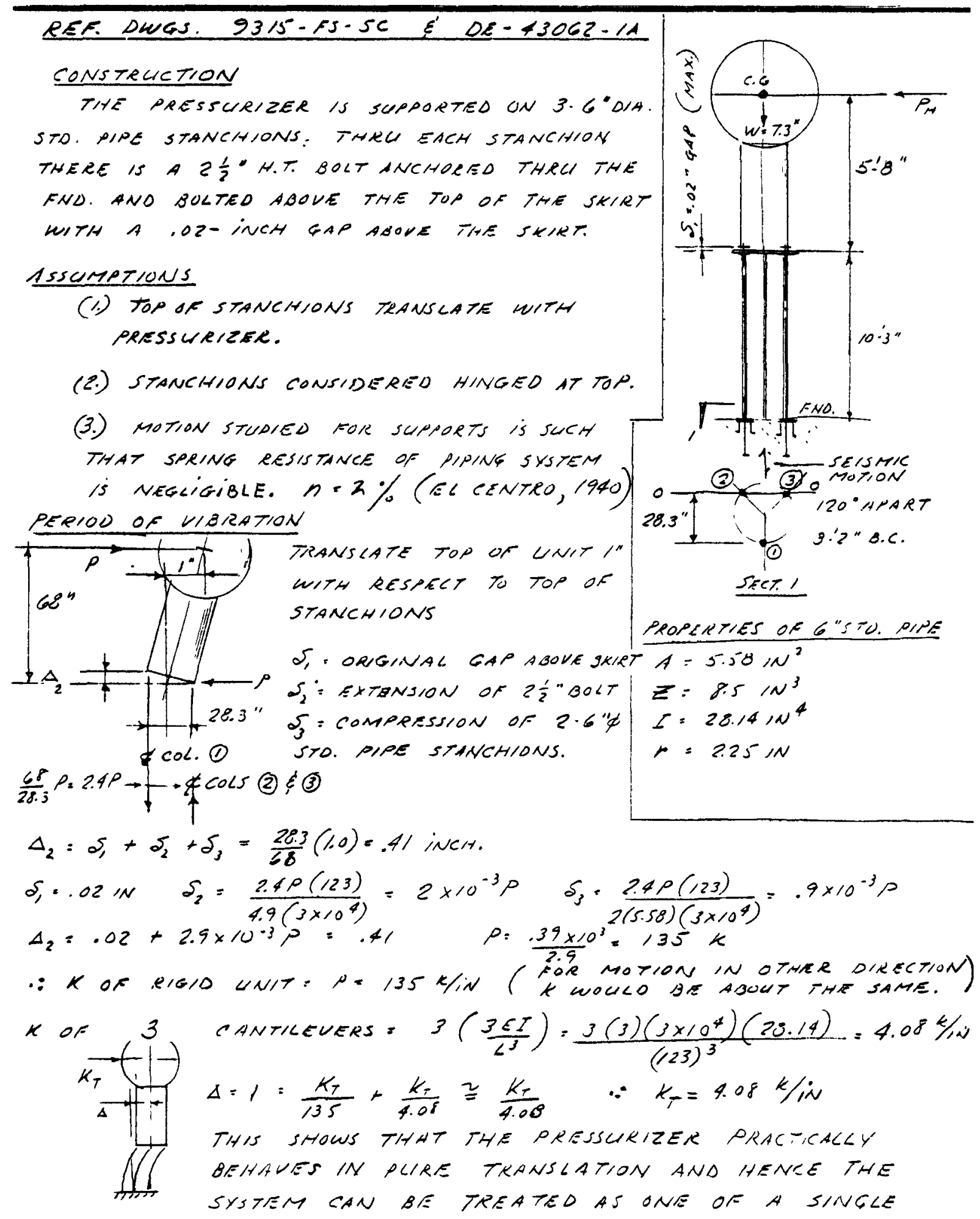




$$
\begin{aligned}
& \text { PERIOD OF VIBRATION (CONT'D) } \\
& \text { MASS WITH ONE DEGREE OF FREEDOM. } \\
& \because T .2 \pi \sqrt{\frac{M}{K_{T}}}=2 \pi \sqrt{\frac{7.3}{386(4.00)}}=\frac{6.28(2.7)}{40}=.13 \mathrm{sec} . \\
& \text { ACC. }=23 \mathrm{FT} / \mathrm{SEC}^{2} \quad \text { TNERTIA FORCE }=P_{M}=\frac{83}{32.2}(7.3)=5.2^{\mathrm{K}}=72 \% \mathrm{G} .
\end{aligned}
$$

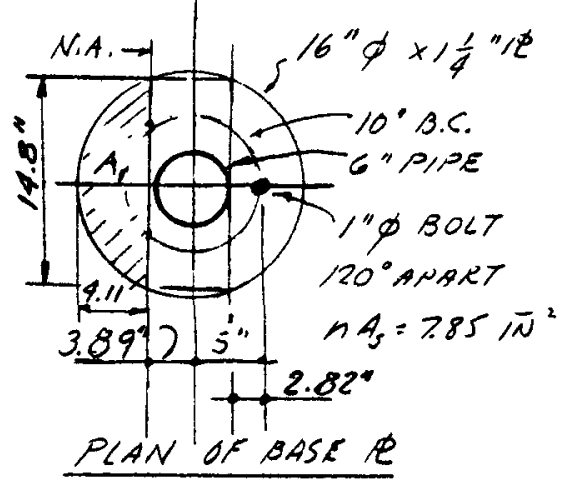

PIPE BASE TO APPROXIMATE AN AVERAGE CONDITION,

CONCLCSIONS:

PRESSURIEER ANO SWPPORT AS PRESENTLY DESIENED COULD WITHSTAND AN EARTIQUAKE OF MAGMITUDE OF EL CENTRO, 1940. SYSTEM REMAINS ELASTIC WITIA A IERIOD OF. K3 SECOND. 
Determination of stiffuess of pipe systen leading from the pressurizer

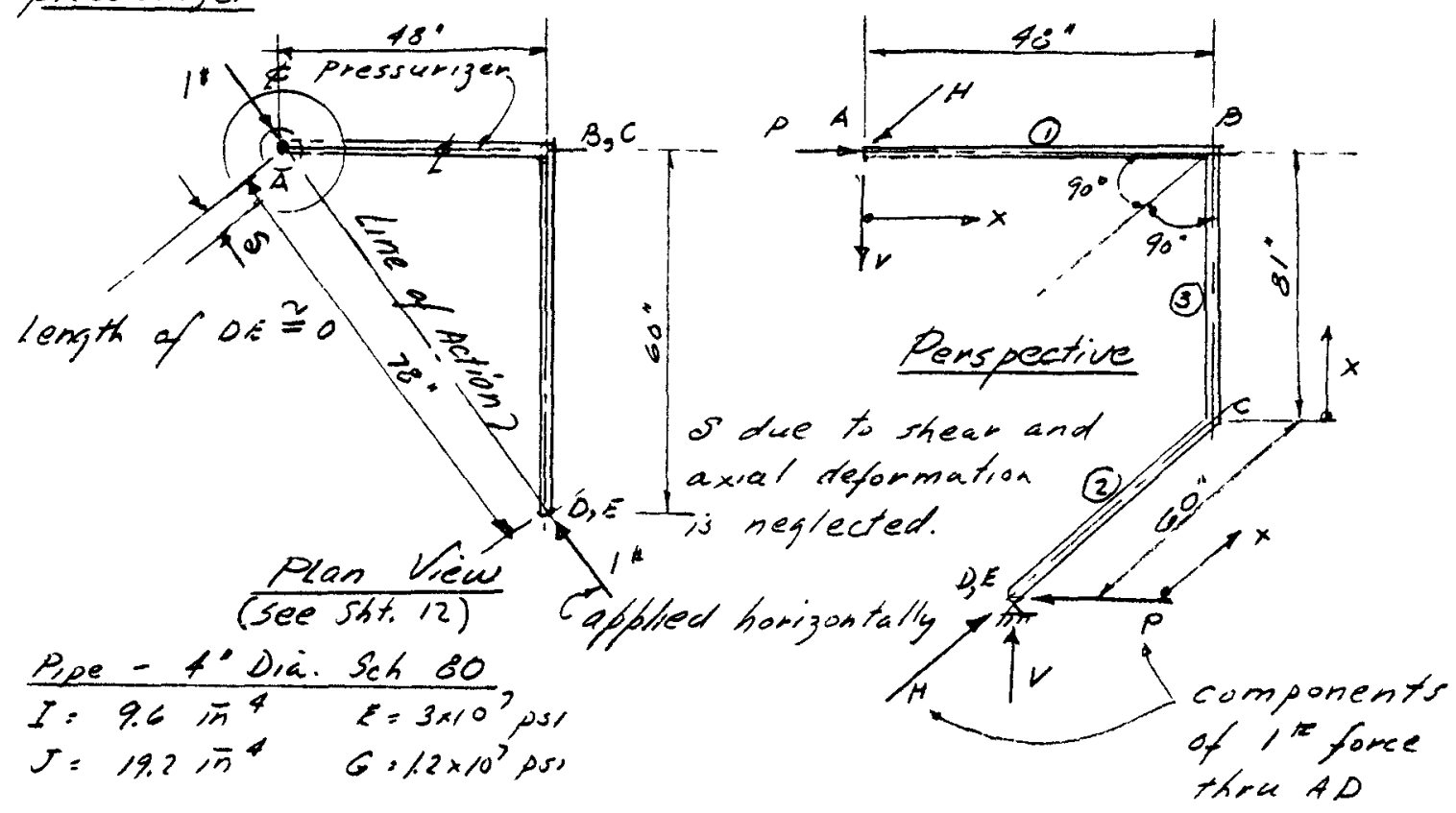

Apply, force, as shown in plan, horizontally. Finds $r=\frac{1(81)}{78}=1.05 \mathrm{Lb} . \quad H=\frac{60}{78}(1.0) . .7716 \quad p=\frac{49}{78}(1.0)=.6166$ $S=\int m^{2} \frac{d s}{E l}+\int \tau \frac{d s}{G J}=\delta_{1}+\delta_{2}+S_{S}$, where $\delta_{1}$ is conteibution of Member $A \theta$ (O) Resultant bending force $=\sqrt{.57^{2}+\overline{.05}^{2}}=1.3$ memben. torgere $=t=0$ $\left.S_{1}=\int_{0}^{10}(1.3 x)^{2} \frac{d x}{E I}=\frac{1.7 x^{3}}{3 k J}\right]_{0}^{45}=\frac{62000}{E J}$

Member oc (2)

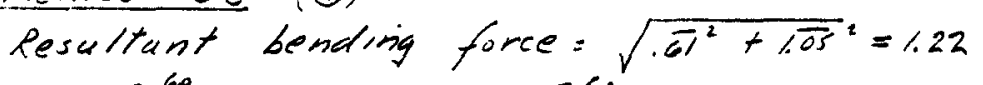
$\left.S_{2} \cdot \int_{0}^{60}(1.22 x)^{2} \frac{d x}{E I}=\frac{1.5 x^{3}}{3 E S}\right]_{0}^{60}=\frac{108000}{E I}$

Member sC (3)

m in plane $O C D=60(1.05)-77 x=63-77 x$

$m$ " " ABC $=.61 x$

resultant $m=\sqrt{4000-97 x+.60 x^{2}+.37 x^{2}}+\sqrt{1000-97 x+97 x^{2}}$

$t=.61(60)=37$ in-kips (Torgue)

$S_{3}=\frac{1}{E S} \int_{0}^{8 / 8000}\left(47 x+.97 x^{2}\right) \frac{17 x}{4}+\int_{0}^{8 \prime}(37)^{2} \frac{d x}{6 J}=\frac{180000}{67}+\frac{114000}{6 J}$

$S=S_{1}+S_{2}+S_{3}=1.7 \times 10^{-3}$ inches. $K=\frac{1}{S}=600 \mathrm{kbs} /$ inch 
PRESSURIZER

SHEET 16

Analysis of 4"Dia pipe from pressurizer

Pipe Properties slightly conservative call. for $\triangle$

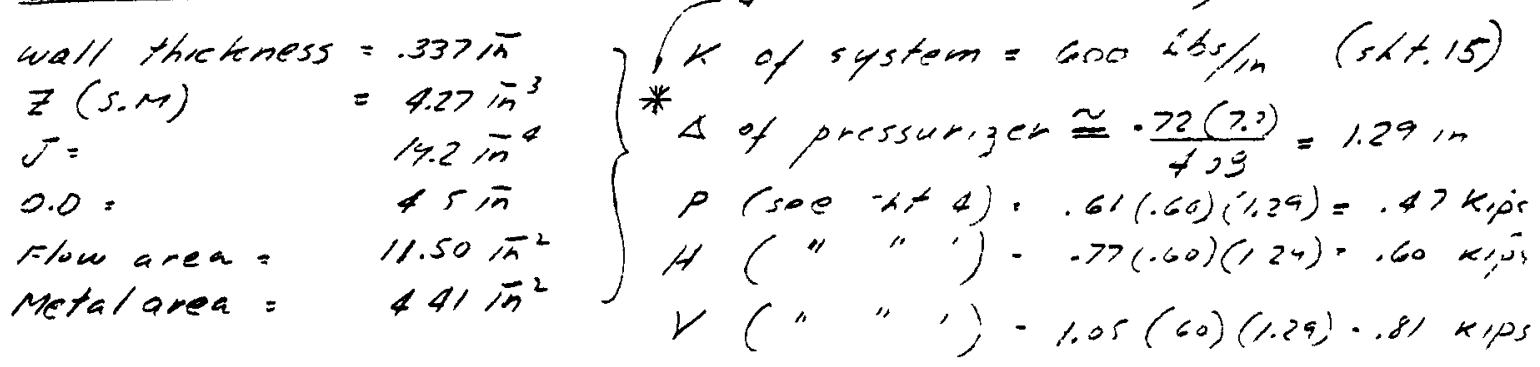

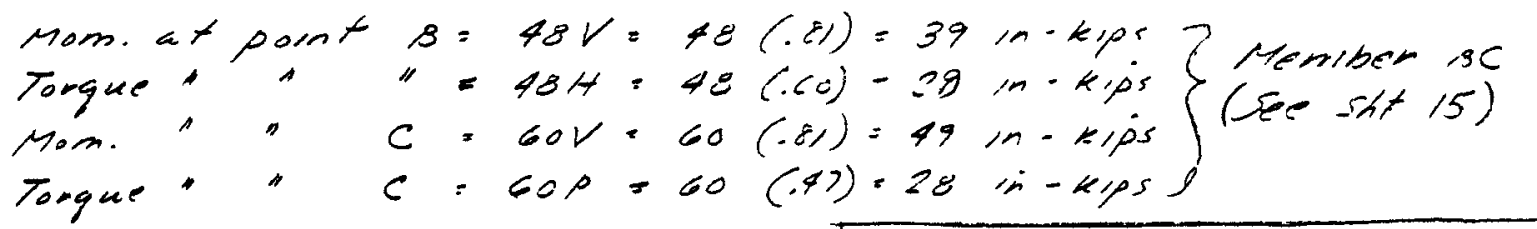

Point $C$ is critical point $\quad$ *stiffness of pipe $=k_{1}=.60$

$f_{6}=\frac{49}{4.27}=11.5 \mathrm{ks}$
$f_{5}=\frac{20(2.25)}{5}=\frac{28(225)}{19.2}=32 \mathrm{ksi}$

stiffness of stanchions $=k_{2}=408$

Laid to pipe system $=\frac{K_{1}}{k_{1}+k_{2}}\left(P_{\mu}\right)$

$P_{M}=.72(73)-5.2 \mathrm{kess}$

Load to pipe system $=\frac{i}{F .08}(5.2)$.

Line Pressure $=1.2$ ks

$f_{t}=$ hoop stress $\cong \frac{1.2(1.91)}{.337}=6.8$ isl Actuaries $1=.67 .601 .11$ in $\cong 1.29$ in

$f_{a}=$ Longitudinal stress $=\frac{1.2(11.5)}{4.41}=3.1 \mathrm{ksi}$

ling principal stresses

$$
\begin{aligned}
\text { Principal tension stress } & =\frac{1}{2}\left[\left(f_{b}+f_{a}\right)+f_{t}\right]+\sqrt{\left(\frac{\left(f_{b}+f_{a}-f_{t}\right.}{2}\right)^{2}+f_{s}^{2}} \\
& =\frac{1}{2}(11.5+3.1+6.8)+\sqrt{\left(\frac{(1.5+3.1)-6.9}{2}\right]^{2}+\frac{-1.2}{3.2}} \\
& =10.7+5.0=15.7 k 5 i
\end{aligned}
$$

Principal shear $=5.0$ est.

Conclusions:

Piping system is adequate to sustain shack equal in magnitude to El Cento, 1510 .

272 


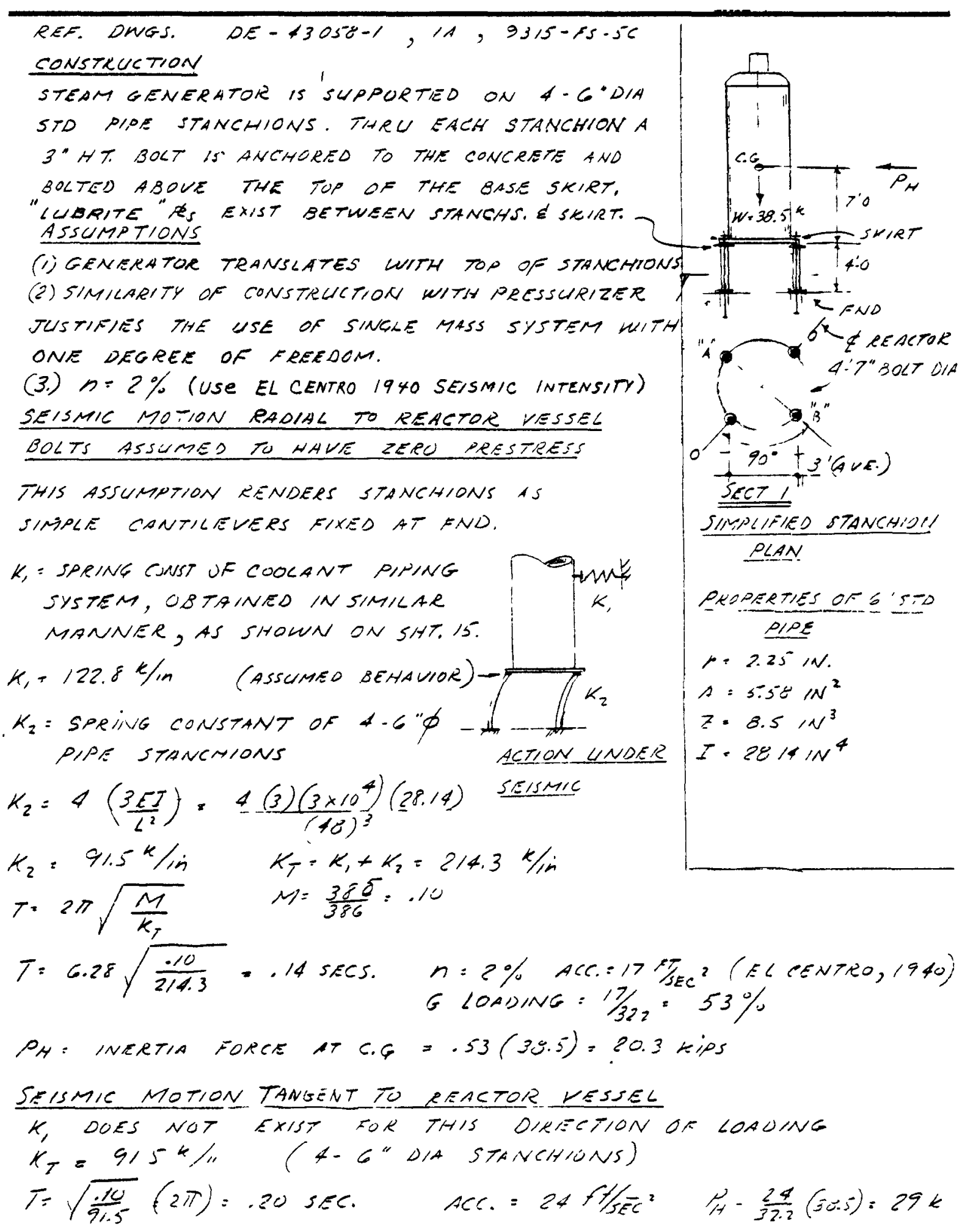




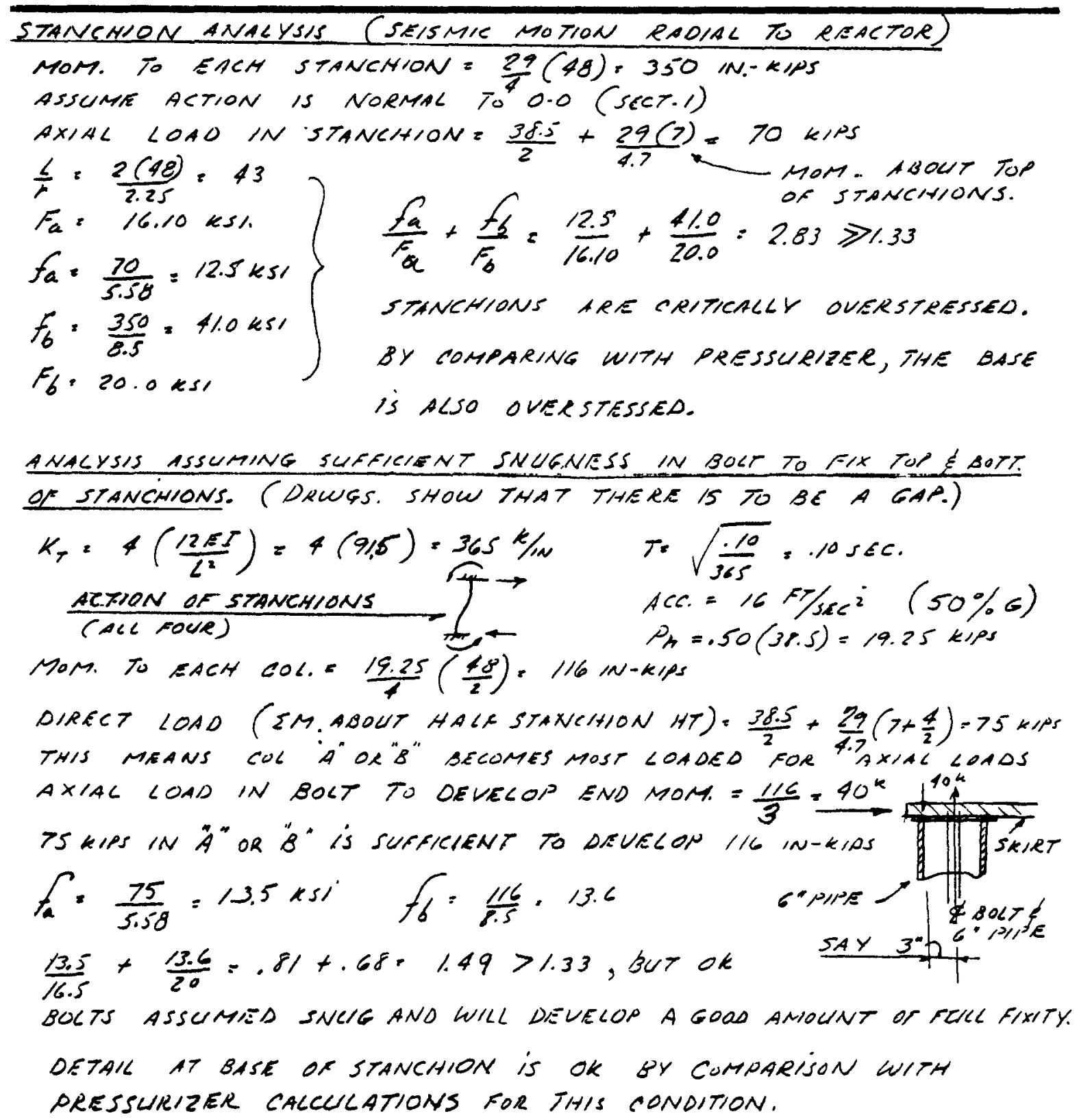




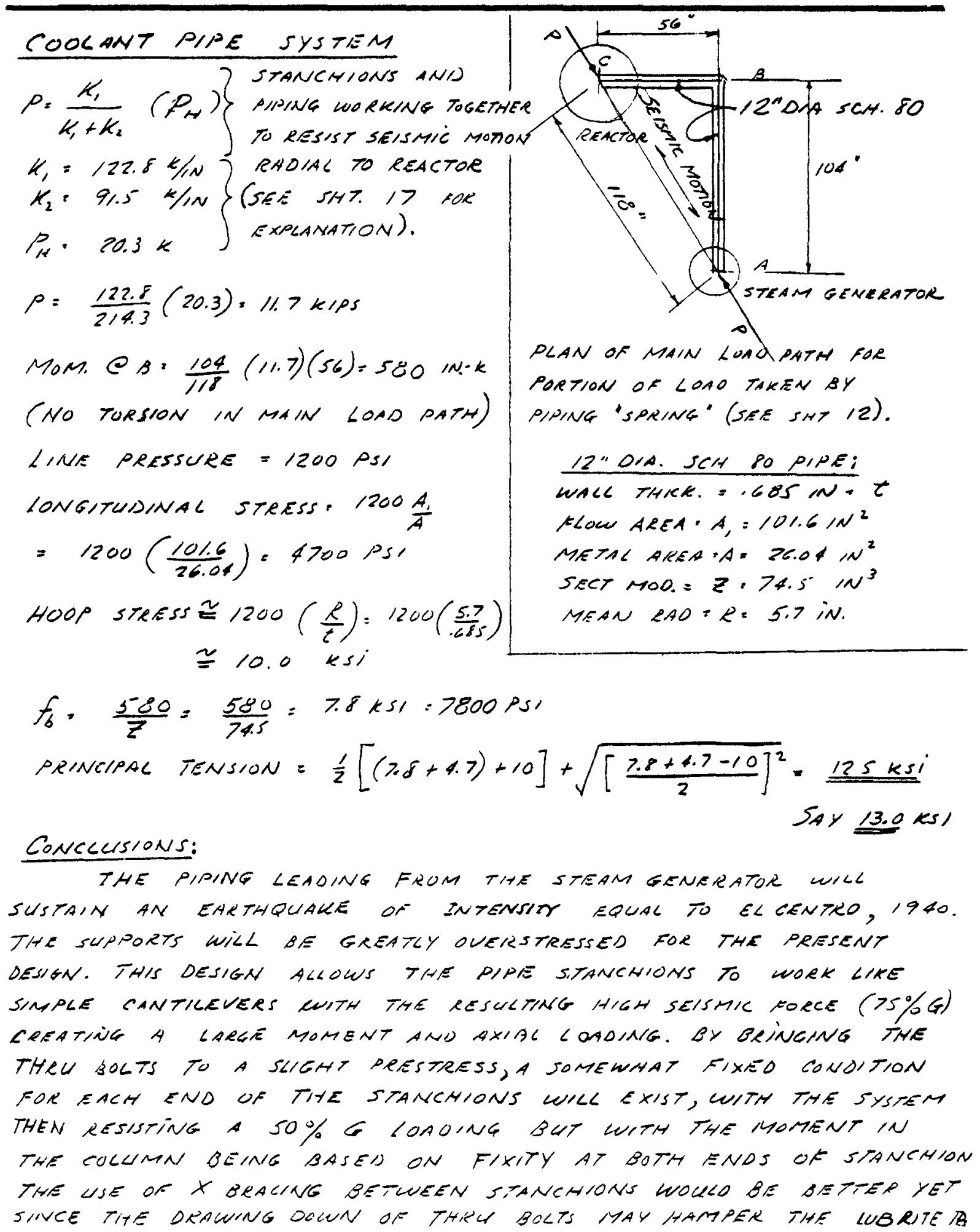


REFS: DWG R-9.40.1001, DE - 43060

Design Amalysis for 5M-1, phase III, Vol. 1 , p. $1 \mathrm{~V}-32$

Assumptious:

(a) Complete lateral load of reactor Vesarl carried BY IUNER TAUK.

(b) Maximum lateral load of Reactor Vissel = Ny, WHERE $U$ = WEIGHT OF REACTOR VESSEL \& $U$ = COEFF, Of STMTIC Friction for SteEl (USE $M=.25$ ). An EXAMINATIOH OF THE Primary CoOlant System ANd REActor ShIELD Assembly Will Reueal 2 Ways of Developina This load:

(1) By teying To Restrain The Thrust of the Pressurizer.

(2) BY BeING ACcelerated BY the motion of the INHER Shielo Tauk. It is Wot Necessary to Attempt to Eualuatr The Period of Vioration As an examination of the Cancs. For the pressurizer Win revea That THe Response of Reactor CAN Be Such As to result in a load Greater tuan Ny if it WAS RIGIDLY ATtACHEd TO THE INNER SHIEL TAMK.

(c) Water in Outer tauk Acts as Rigio Mass Subjected To Maximum Acceleration of Vapor Container base (33G.) This is on the conservative Side, As WILl be shown later, And Probably More truly Represents the actual response of the Water as the InWer Tank, SHIELDS, AND TANK COVER \& ALL Serve to REStrict the Motion of the water. 


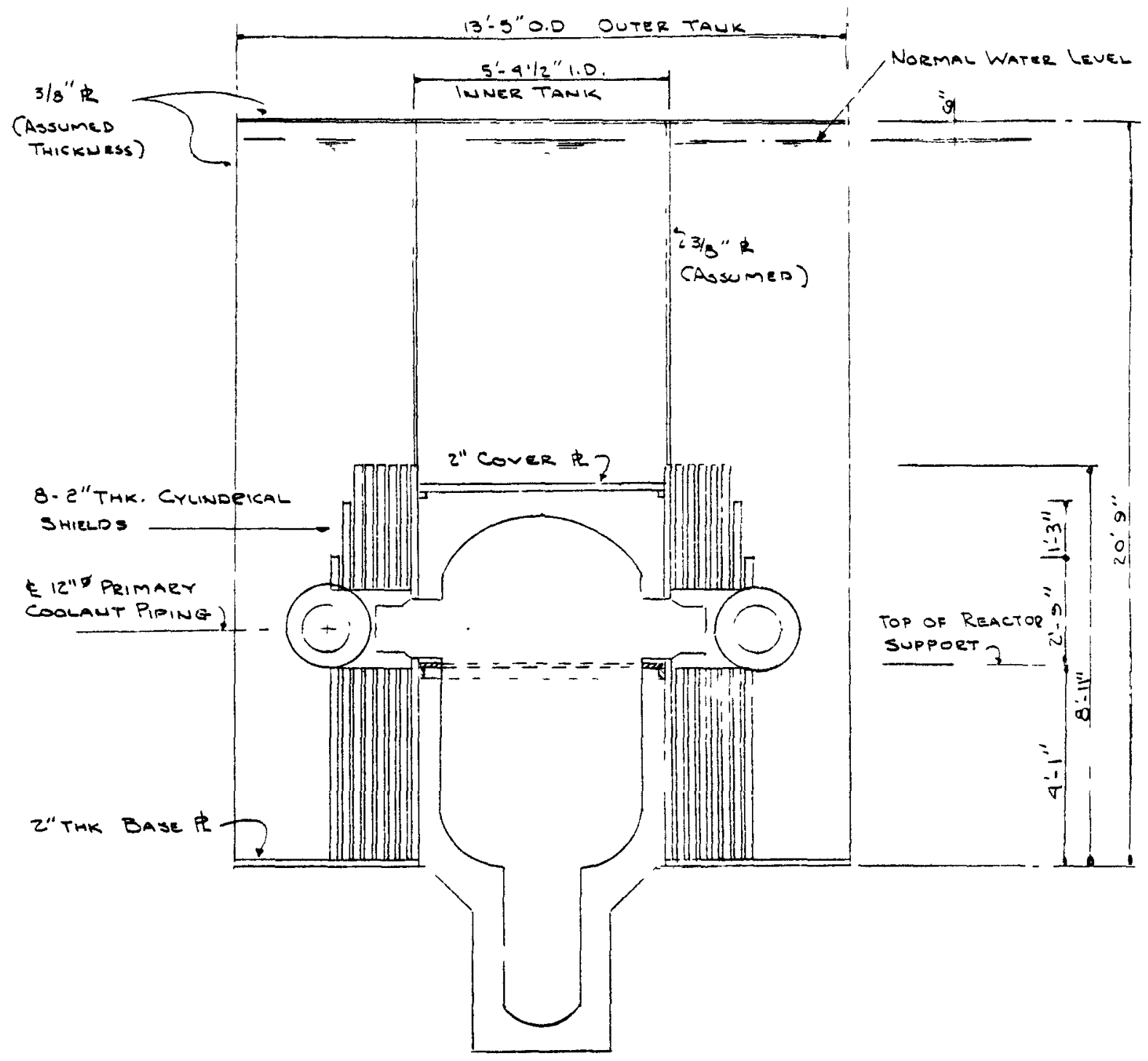


OVerturning Moment \& Shear for lnner ShIElo Tamk for .33G boaOIwa AwO WATER RIGID MASS

\begin{tabular}{|c|c|c|c|c|}
\hline ITEM & \multicolumn{2}{|c|}{ WEIEHT (LBS.) } & $P$ (INCHES) & $W \bar{Y}\left(11,-60 . \times 10^{3}\right)$ \\
\hline $\begin{array}{l}\text { UPPER WATER } \\
\text { SHIELD }\end{array}$ & $.785 \times 5.4^{2} \times 11.33 \times 62.5$ & $=16,200$ & 173 & 2840 \\
\hline 2"Cover 虫 2 & $.755 \times 5.9^{2} \times 81.6$ & $=1,900$ & 107 & 203 \\
\hline REACTOR VESSEL ${ }^{3}$ & & $=36,600$ & 37 & 1350 \\
\hline $\begin{array}{l}\text { lWHER TANK } 4 \\
\text { (ADOVE SHIELO) }\end{array}$ & $3.19 \times 5.4 \times 11.83 \times 15.3$ & $=3100$ & 178 & 550 \\
\hline ISI SMIELO RING & $3.14 \times 6.0 \times 8.93 \times 51.6$ & $=13,700$ & 53.5 & 730 \\
\hline & TOTAL & 71,500 & & $\sum 5673$ \\
\hline
\end{tabular}

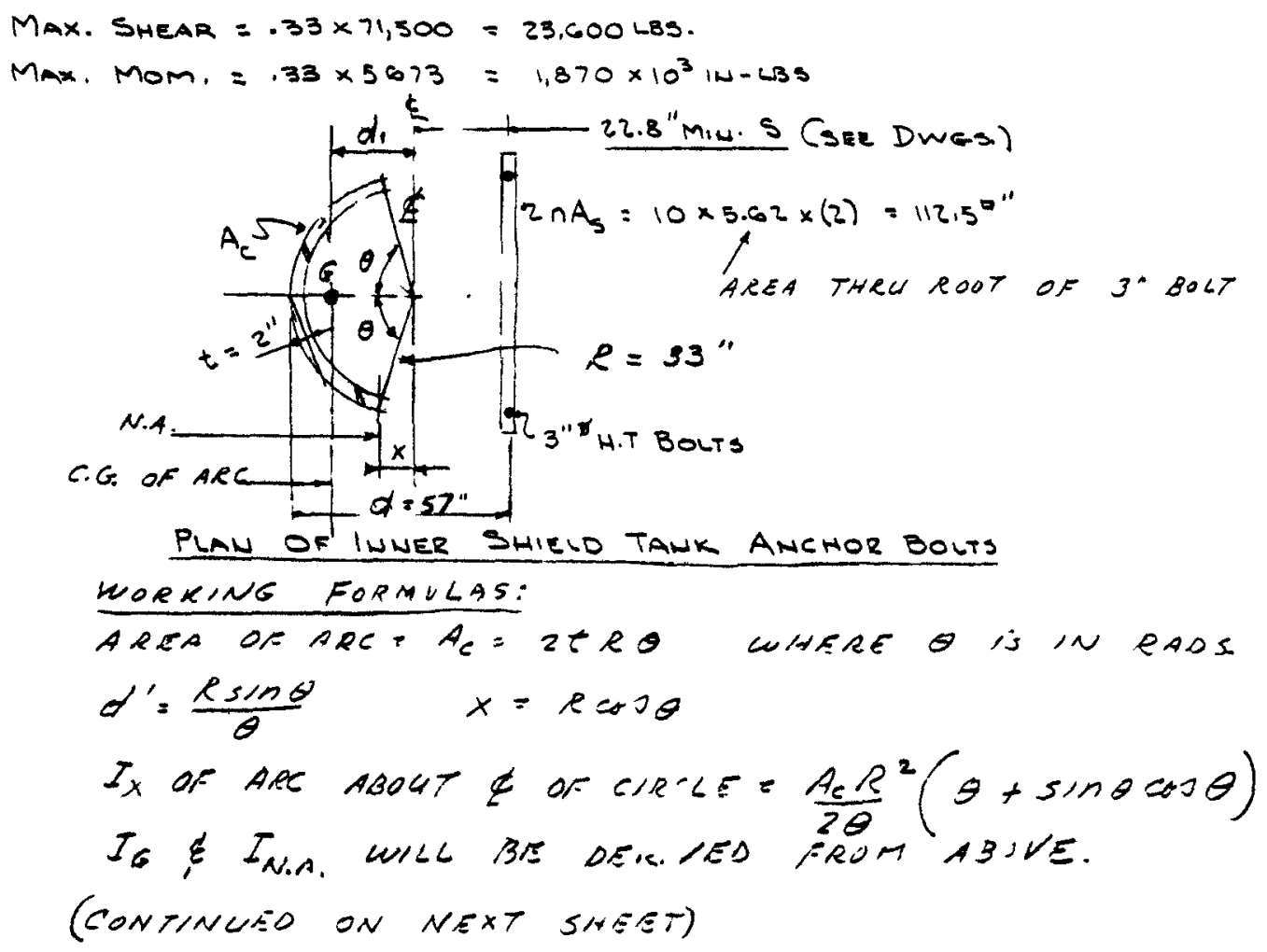

NOTES:

1. Height of Water Assumeo to be $11-4 "$ (Unable to hocate on Dwgs.).

2. THICKNESS Assumed To be $2 "$.

3. OPERATING WT. TAKEN From DWG. DE-43060-1.

4. R THICKNESS Assumed TO BE $3 / 8^{\prime \prime}$.

5. 6.0' DIM OBtained from Report (USED lusteau of Dim ON DWos.) 
REACTOR VESSEL AND SHIELD TANK

SHEET 23

INNER TANK (CONT.)

Locepton of N.A.

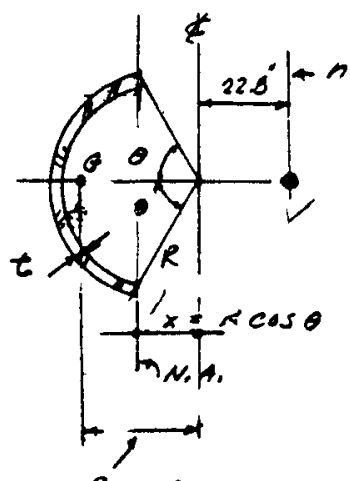

$\frac{\text { Rising }}{\theta}$

$$
\begin{aligned}
& A_{s}=112.5 \pi^{2} \\
& \text { AREA ON ARC }=2 \operatorname{CR} \theta=A_{C} \\
& \left(\frac{R_{\sin } \theta}{\theta}-x\right) A_{c}=n A_{s}(x+22.8) \\
& \begin{array}{l}
\left(\frac{e \sin \theta}{\theta}-r \cos \theta\right) 2 \operatorname{te} \theta=112.5(x+22.8) \\
2 \operatorname{tr} e^{2}(\sin \theta-\theta \cos \theta)=112.5 R \cos \theta+2600
\end{array} \\
& 2(2)(33)^{2}(\sin \theta-\theta \cos \theta)= \\
& \sin \theta-\theta \cos \theta \quad=.85 \operatorname{cov} \theta+.60 \\
& \sin \theta-(\theta+.85) \cos \theta=.60
\end{aligned}
$$

TRY $\theta=80^{\circ}=14$ RADIANS $\cos 80^{\circ}=.174 \sin 80=.984$

$$
.984-(8.25) 000\left(80^{\circ}\right)=.984-.384=.60
$$$$
.60=.60 \text { checks }
$$

AREA OF ARC $=2(2)(33)(1.4)=185 \mathrm{IN}^{2}=A_{C}$

I of ARC ABOLT $E=\frac{A_{C} e^{2}}{2 \theta}(\theta+\sin \theta \cos \theta)=\frac{185(33)^{2}}{2(1.4)}(1.4+.17)$

r" " $"=1.16 \times 10^{5}$

$I . " G=1.16 \times 10^{5}-A_{C}\left(\frac{\operatorname{lsin} \theta}{\theta}\right)^{2}=1.16 \times 10^{5}-185(.984 \times 33)^{2}$

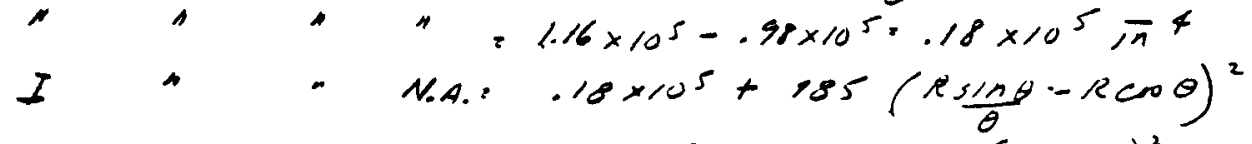

$=.18 \times 10^{5}+185(1100)(.7-.17)^{2} . .75 \times 10^{5} 1^{4}$

$I$ or $n$ As ABOUT N.A. $=112.5(22.5+x)^{2}=.90 \times 10^{5} \mathrm{in}^{4}$

SWM of LAST 2 ITEMS $=I_{T}=\sum \quad=1.65 \times 10^{5} \mathrm{in}^{4}$

$f_{c}=\frac{\mu_{c}}{I_{T}}=\frac{1.87\left(10^{6}\right)(R-x)}{1.65 \times 10^{5}}=11.2(33-5.5)=310$ Ps 1.

$f_{s}=\frac{M_{c}}{S_{1}}=11.2(22.8+x) S_{n=10.0}^{n}=112(20.3)=3200.55$

MAX. LOAD IN BOLT $=5.62(3.2)=18.0$ KIPS FOR EACH $3 " \phi$ BOLT.

279 


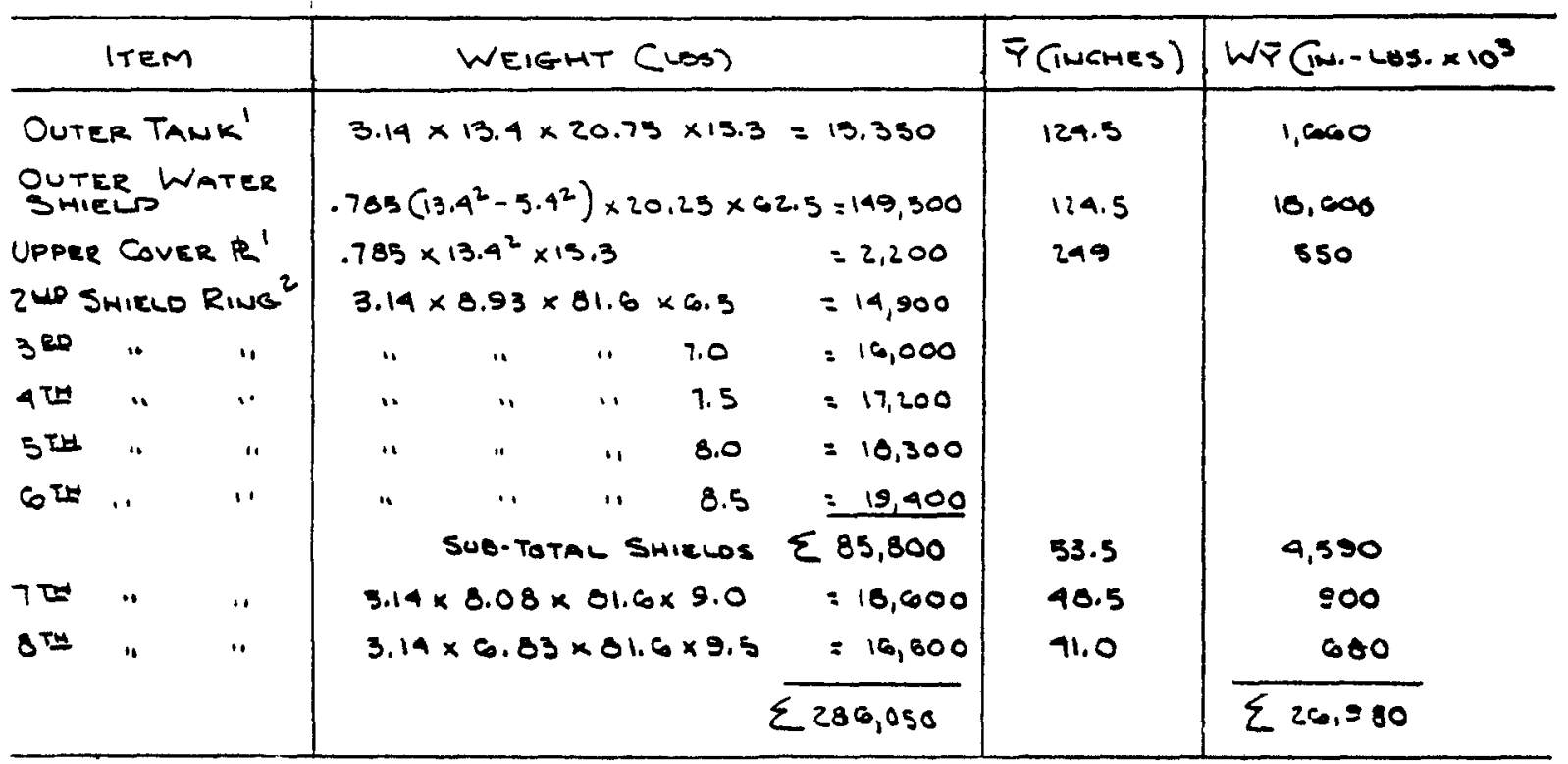

MAX. SHEAR $=286,050 \times .33=94.4 \mathrm{kIPS}$

Max. Mom. $=26,980 \times .33=8,900$ w.-kips $=740$ fT-kips.

\section{NoTES:}

1. R THickuess Assumed to OE $3 / 8 "$ ".

2. OPENINGS IN SHIELDS HEGLECTED, COMPENSMTING WITH

Omission of Collars, Tributary piping, etc. 


\section{OUTER TANK}

To Determine Rexction On Tank base, Assume unattached at INNER TANK

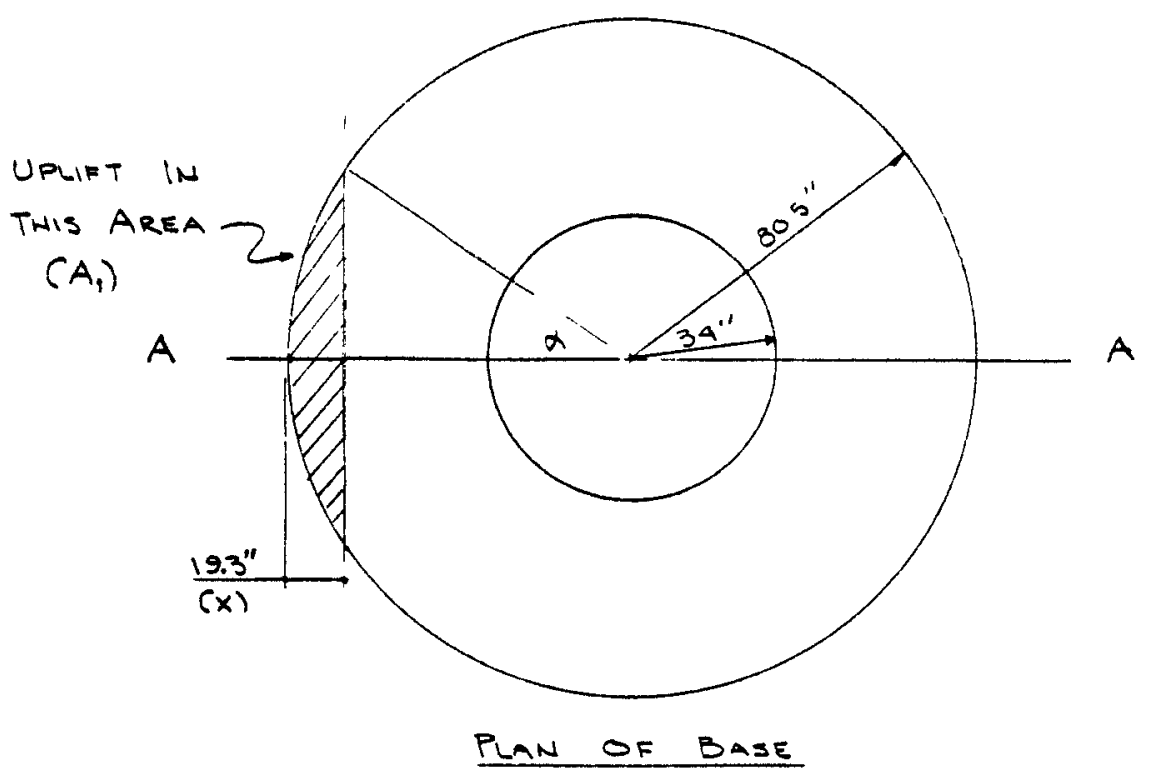

$$
\begin{aligned}
& A=3.19\left(80.5^{2}-34^{2}\right)=100,700^{\circ}, P / A=\frac{285,100}{16,700}=171 \text { PS } 1 \\
& I=\frac{3.14}{4}\left(80.5^{4}-34^{4}\right)=31.7 \times 10^{6} \\
& \frac{M C}{I}=\frac{8.870 \times 80.5}{317 \times 10^{6}} \times 10^{3}=22.5 \text { PS1, } F_{\text {MiN }}=225-17.1=5.4 P S(-) \text { UPLIRT } \\
& f_{\text {max }}=22.5+17.1=33.6051(t) \\
& \frac{5.4}{x}=\frac{4.5}{151}, x \cong 19.3^{\prime \prime}
\end{aligned}
$$




\section{OUTER TANK (CONT)}

To Approximate the max. Bottom $R$ stress in area $A_{1}$, consider a I" element along Axis aA loadeo As SHOWN BELOW, BENDING is Assumed TO OCCUR ABOUT THE BTH Shield Rine. Bearine On The Bottom is Neglected Becmust of The Congervatism or the Assumption of An isolated I"Element

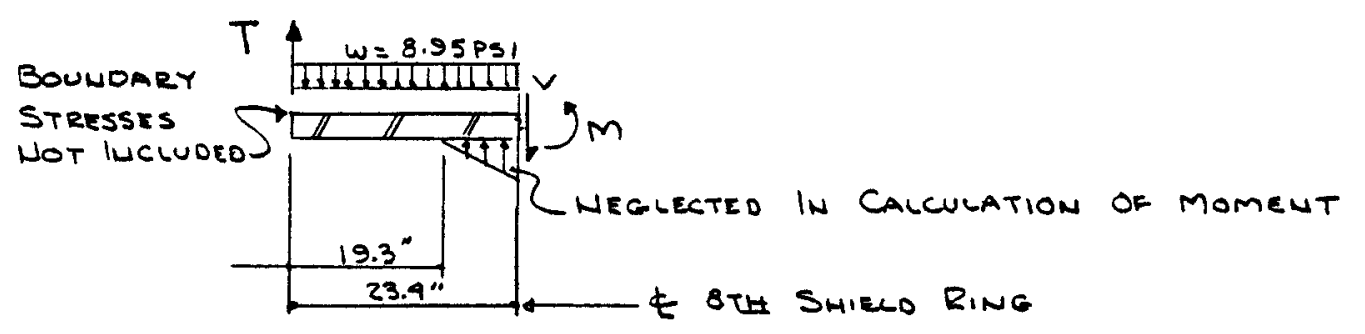

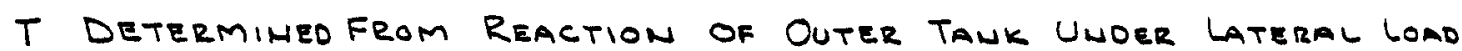

$f_{t}=P / A-\frac{M_{c}}{I}, P=W T$. OF TANK + COVER $=15,550^{*}$ (SEE SHT. 24)

M= OVERTURNING MOM. OF TANK, COVER, AND

OUTER WATER SHIELS $=20.8 \times 10^{6} \mathrm{IN-LBS} \times .33$ (SHT. 24)

$I=\pi R^{3} t=3.14 \times 80.5^{3} \times .375=61.5 \times 10^{4} 1 \mathrm{u}^{4} \quad=572^{1.4}$

$A=\pi D t=3.19 \times 161 \times .375=189.5 \mathrm{in}^{2}$

$f_{t}=\frac{15.550}{189.5}-\frac{13.20 .8 \times 80.5}{.615}=82.0 \mathrm{PS1}-900.0 \mathrm{PS} 1=818 \mathrm{PS} / \mathrm{WN}$.

$T=F_{t} A=818 \mathrm{PSI} \times 1375^{\prime \prime} \times 1^{\prime \prime}=307$

$M=.307^{k} \times 23.4^{\prime \prime}-.0895 \times \frac{\overline{23.4}^{2}}{2}=7.19^{\prime \prime K}-2.45^{\prime 1 K}=4.74^{11 K}$

$f=\frac{G M}{t^{2}}=\frac{6 \times 4.74^{11 \mathrm{~K}}}{4}=7.10 \mathrm{ks1}$

BAsE R SHEAR

TOTAL SHEAR $=23.6+99.4: 118 \mathrm{KIPS}$

TOTAL D. LOAO $=71.3+286=358$ KIPS

shear can be deVEloped:

1. D. LOAD XM. This Would Require A 4 OF $.33 \mathrm{~W} / 0 \mathrm{~F}$. SAFety.

2. Shemr luss \& A.bolts on InNer Tank tie Down (SEe Next Page) 
OUTER TAMK (CONT.)

BOTTOM \& SHEAR

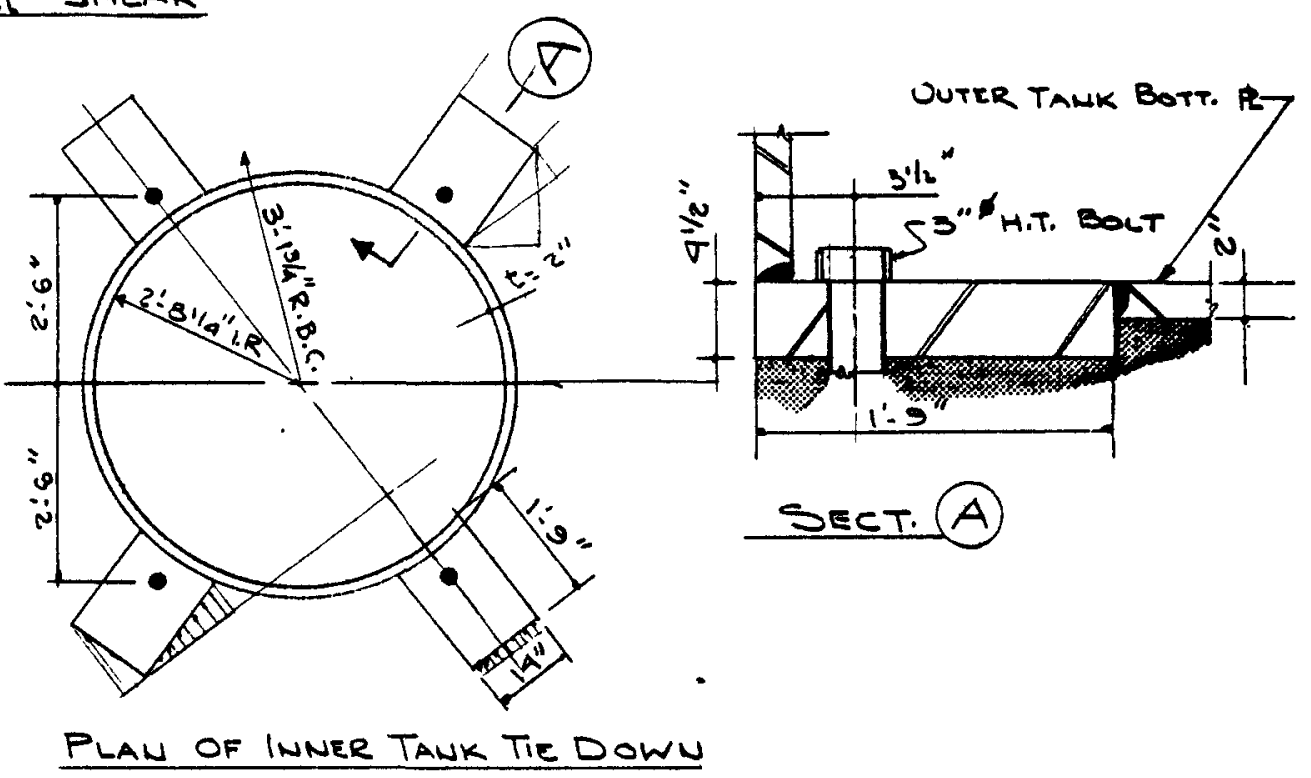

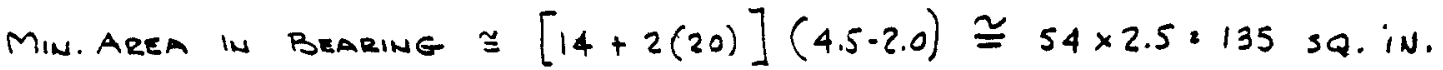
$f_{C}=\frac{17,800}{135}=870$ PSI OK

THIS Assumes All THE JHeAr is CARried BY 4.412 "THK. ths in bearing AND is conservative.

$\therefore$ shear dors not appear to be Critical, ando there Will not be Aur Reuative Movement between The Primary Shield Tauks \& Comcrete Base for THE Assumed REsponse, 
QUTER TANK

Response Assumine TANK VOID OF INNER TANK, SHIELDS,

Cover H. Reactor Vessel AND COMPLetely filled With

water to hormal level (OVertoppine of tank neclected).

$$
R=\frac{13.4^{\prime}}{2}=6.7^{\circ}, 1.5 R=10.0^{\prime}
$$

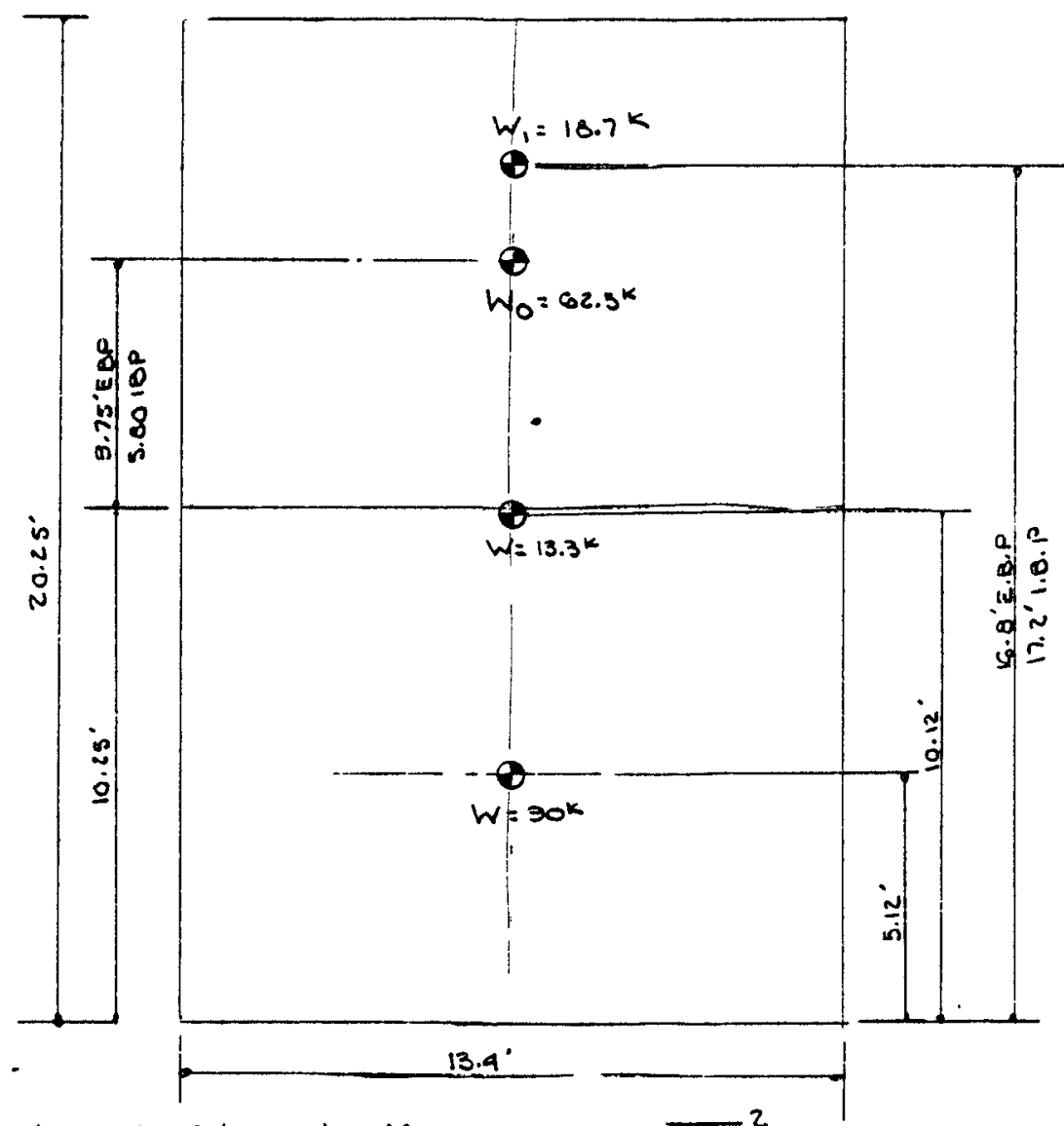

WT. OF WATER IN MOTION $=.783 \times \overline{13.4}^{2} \times 10^{\prime} \times .0624=88 \mathrm{~K}\left(d=10^{\prime}\right)$

$h_{0}=3 / 8 \mathrm{~h}=3 / 8 \times 10=3.75^{\circ}($ E.B.P.) -EXCLUDING BOTTOM PRESSLIRE.

$h_{0}=.38 \mathrm{~h}=.58 \times 10=3.8^{\circ}\left(1.8 . P^{\circ}\right)-$ inCLLLOING

$W_{0}=.71 W=.71 \times 88=62.5 \mathrm{~K}$

SONVECTIVE

$R / h=6.7 / 20.25=.33, \frac{W_{1}}{W}=.105, W_{1}=(.105) \times \frac{20.25}{10}(88)=.105(178) \cdot 18.7 \mathrm{~K} / \mathrm{ps}$ 


$$
\begin{aligned}
& h_{1} / h=.83, h_{1}=.83 \times 20.25=16.8^{\prime} \text { (E.B.P.) - EXCLUDING BOTTOM PRESSURE. } \\
& n_{1} / h=.85, h_{1}=.85 \times 20.25=17.2^{\prime}(1.0 . P)-\text { INCLUDING } " \| \\
& R_{\theta_{h} / A_{1}}=1.53, \omega^{2}=\frac{30.6}{6.7} \times 1.53=8.84, \omega=2.98 \\
& T=2 \pi / \omega=6.28 / 2.98=2.112 . S_{V}=2.6 \mathrm{Fps}, A_{1}=\frac{S_{U}}{\omega}=\frac{2.6}{2.90}=.873 \\
& \theta_{h}=\frac{1.53 \times .87}{6.7}=.2, P_{1}=1.2 W_{1} \theta_{h} \sin \omega t \\
& P_{1}=1.2 \times 18.7 \times .2 \times 1=4.5 \mathrm{~K} \\
& \text { WT. of CONStranined WMTER } \\
& =178^{k}-88^{k}=90^{k} \\
& \text { Equivalent Wo' } \\
& =62.5^{k}+13.3^{k}+90^{k}=165.8^{k}, P_{0}=.33 \times 185.8=54.5^{k} \\
& h_{0}^{\prime}=\frac{5.12^{\prime} \times 90^{k}+14.0^{\prime} \times 62.5^{k}+10.12^{\prime} \times 13.3^{k}}{165.8}=\frac{1470}{165.8}=8.87^{\prime} \text { (E.B.P.) } \\
& h_{0}^{\prime}=\frac{5.12^{\prime} \times 30^{k}+16.05^{\prime} \times 62.5^{k}+10.12^{\prime} \times 13.3^{k}}{163.8}=\frac{1505}{163.8}=9.63^{\prime}\left(18 . P_{0}\right)
\end{aligned}
$$

MAX. MOMENT ON TANK

$$
\begin{aligned}
& M_{0}=34.6^{k} \times 8.87^{\prime}=485^{1} \mathrm{~K} \\
& M_{1}=4.5^{k} \times 16.8^{\prime}=\frac{75^{k}}{561^{1 K}} \text { (THis is Less THAH THE } 372^{116} \text { useo on } \\
& \text { SHT. } 26 \text { AsSUMING Rigio Masses) }
\end{aligned}
$$

Max. OVErturnine MOM.:

$$
\begin{aligned}
& M_{0}=59.8^{k} \times 9.63^{\prime}=526^{\prime k}
\end{aligned}
$$

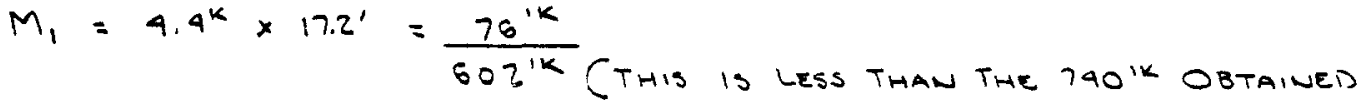

$$
\begin{aligned}
& \text { ON SHT. } 24 \text { ASSuMING RIGIO MASSES) }
\end{aligned}
$$

It Can been seen from above that the cricical condition

IS WHEN THE SHIRLD TANK \& ITS CONTENTS ARE TREATED As RIGd masses, And for this Condition the design sF the shielo Tank Appears adequate, 
TURBINE-GENERATOR SUPPORT

REF OWES. 9315-FC-10A, IIA

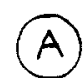

(B)

(c)

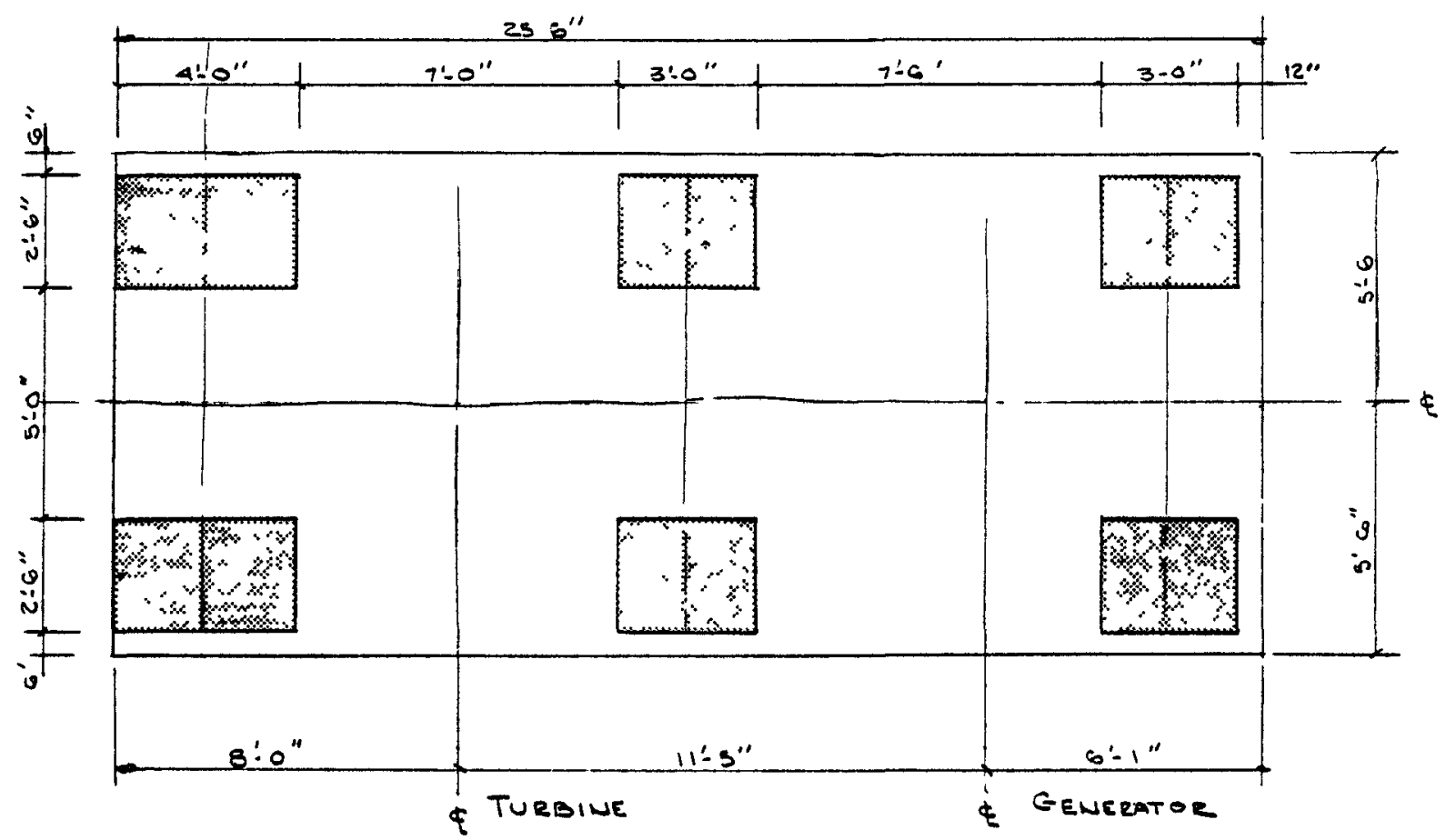

PLAN OF SUPPORT PAD

NOTE: OPEnINGS In PAO hot ShOWn; for Location And Size, See Ree DWgs. 


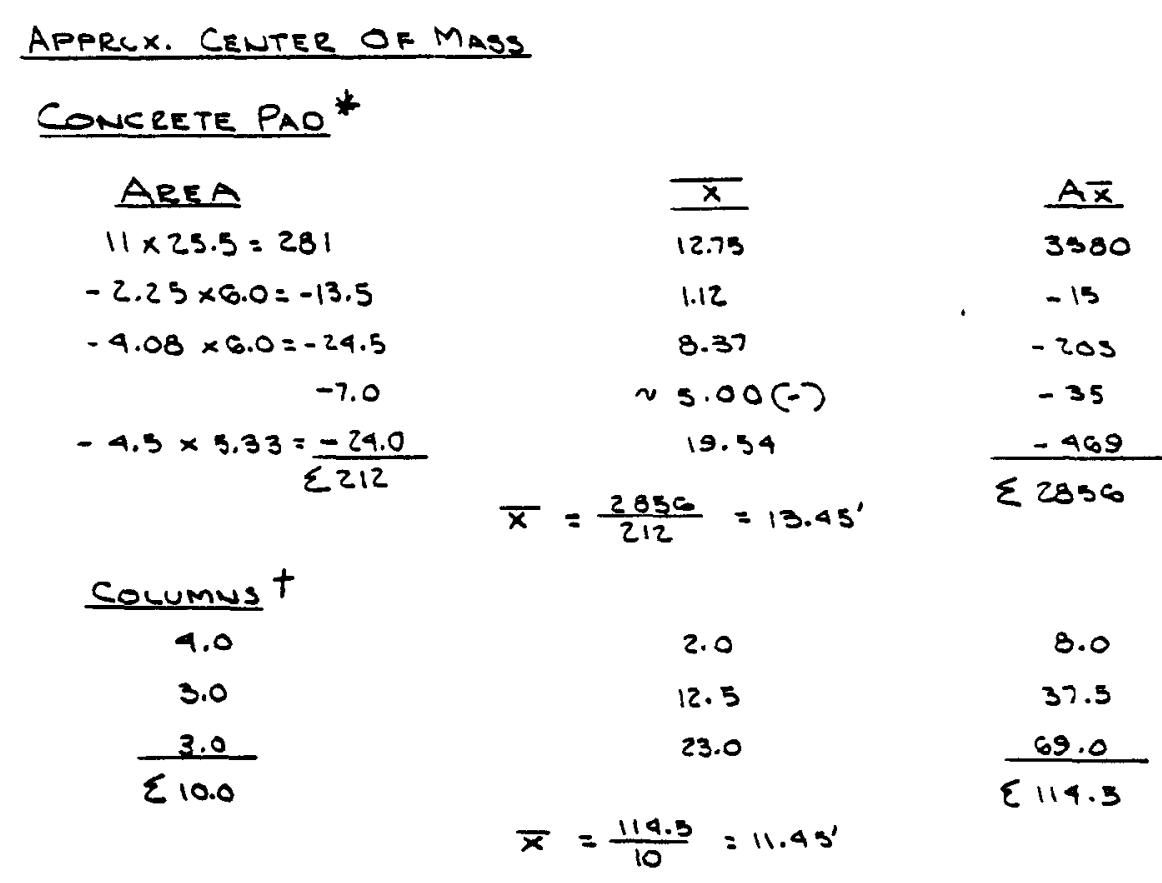

Equipt. $F$

WT (kIPS) $\bar{x} \quad W_{\bar{x}}$

\begin{tabular}{lccc} 
TURGINE & 17.1 & 8.0 & 136.5 \\
GENERATOR & 22.7 & 19.4 & 490 \\
EXCITRR & 2.0 & 24.5 & 49 \\
GEAR & 0.7 & 12.1 & 105.2 \\
\cline { 2 - 3 } & 50.5 & & 131
\end{tabular}

Senter of mass

\begin{tabular}{|c|c|c|c|}
\hline $\operatorname{ITEM}$ & $W T$ (kips) & $\bar{x}$ & $W \bar{x}$ \\
\hline Equipr. & 50.5 & & 731 \\
\hline Cowe. PAD & $212 \times 3.00 \times .15=95.5$ & 13.43 & 1285 \\
\hline const & $3.0 \times 10 \times 3.7 \times .15=27.0$ & 11.45 & 310 \\
\hline
\end{tabular}$$
\bar{x}=\frac{2339}{173.8}=13.95^{\prime}
$$

* Approx. Onlt. Col. caps \& Appendages neglected.

T 1/3 Cal. HeIGHT used.

* Equipt WTS. ODtalned from SM-I REPOrT.
} 


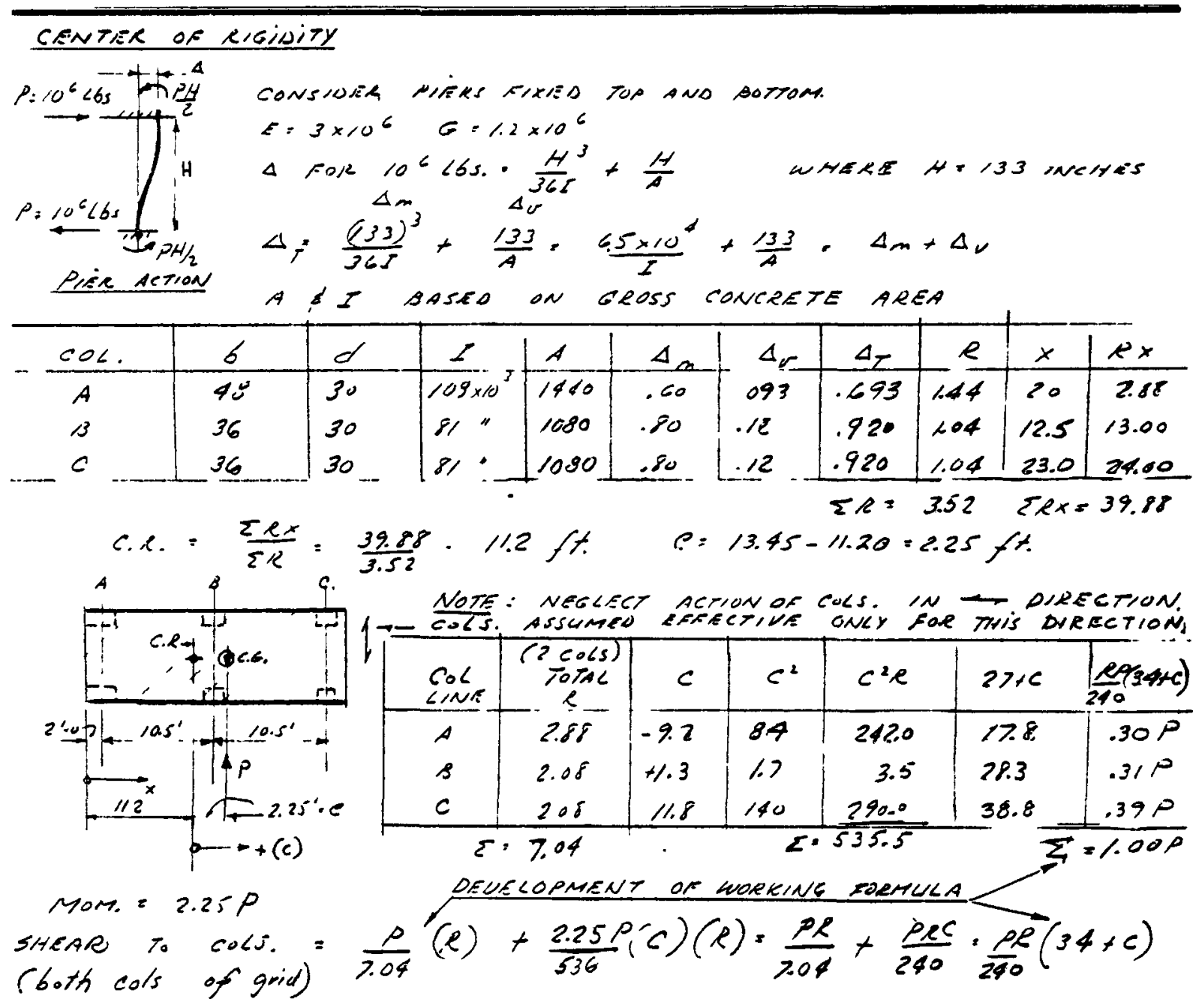

DEFLECTION OF DIAPHRAEM, NEGLECTING ROTATION, ROR A IOAD OF $10^{6} \mathrm{LBS}=\frac{1}{7.04} \cdot 142 \mathrm{INCH}$ (GEE SHT 31) $S_{S T}=$ STATIC OERL. $=\frac{173.8}{1000}(.142) \cdot .025 \mathrm{inCA}$

$\tau=2 \pi \sqrt{\frac{S_{5}}{5}}=6.28 \sqrt{\frac{.025}{386}}=6.28\left(\frac{.16}{19.5}\right) \cdot .05 \mathrm{sec}$.

For $n=5 \% \quad \gamma=.05$ sec. $a=11.3 \mathrm{Ft} / \mathrm{sec}^{2} \quad \mathrm{El}$ Centr. 40

g. $\operatorname{Los} \sin \theta=\frac{11.3}{32.0}=.35$ 


\section{Response}

Max. Moment

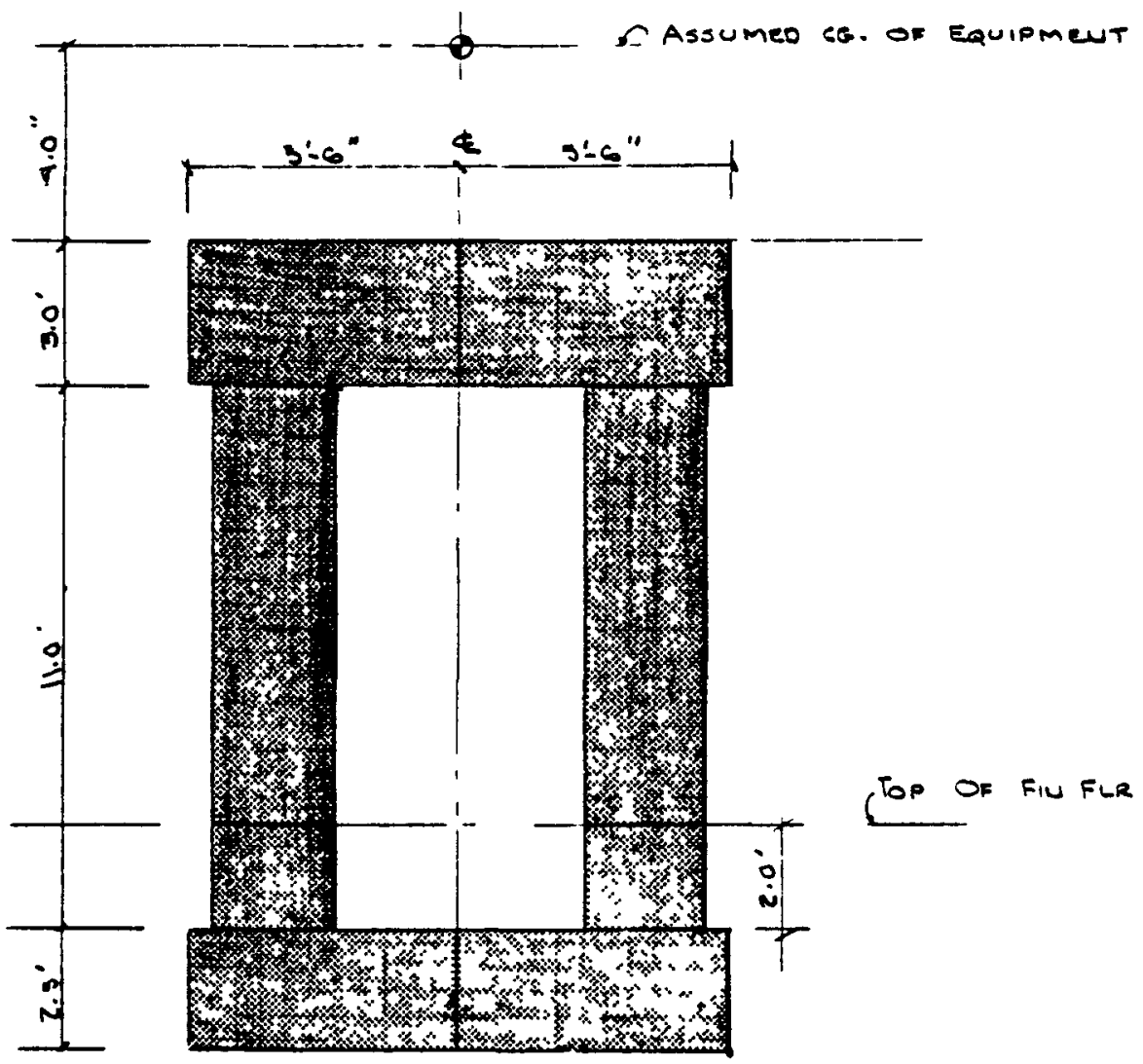

For O.T. Moment Neglect O.T. Mom of Base Aud Assume heieht of EquipmENT To BR 4.0' AoOve TOP OF PAD

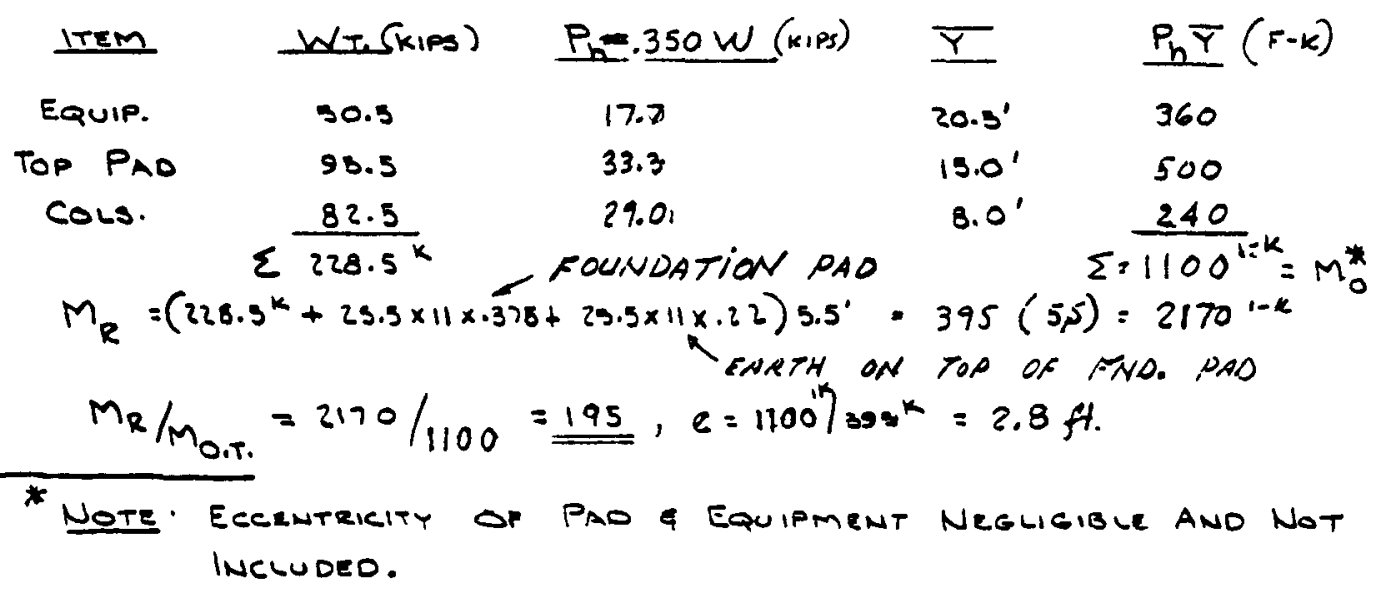


Soll Perssuer

$F=P / A\left(1 \pm \frac{60}{2}\right)=\frac{395}{25.3 \times 11.0}\left(1 \pm \frac{6 \times 2.8^{\prime}}{110}\right)$, UPLIFT

$\therefore f_{\text {mAX. }}=\frac{395}{35.5 \times 8.1}$

$(z)=3.8$ K.S.F

$255^{\prime} \times 11^{\prime}$ PAD

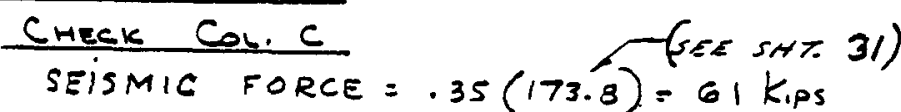

SHEAR FORCE TO EACH COL. IN LINE C= MOM. $=\frac{11}{2}(13)=71$ FT-KIPS

FOr D.LOAD, Assume 1/6 TOTAL LOMO $=228.5 / 6=38 \times$ (Conservative)

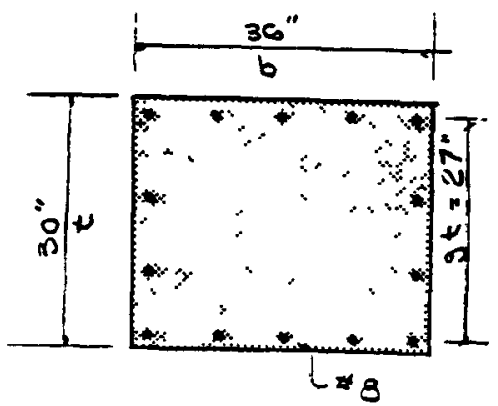

$b=13^{\prime \prime}, t=30^{\prime \prime}, g=.867, M=71^{1-k}, N=33^{k}$

$e^{\prime}=\frac{12 M}{N}=\frac{12 \times 7}{38}+1.0=22.5^{\prime \prime} ; \frac{e^{\prime}}{t}=\frac{22.5}{30}=.75$

$n p=\frac{n A_{3}}{b t}=\frac{10 \times 10 \times .79^{0 "}}{36 \times 30}=\frac{79}{1080}=.073$

Assume $11 / 2$ " COVER $\because g=\frac{30-3}{30}=.90$

FROM STANDAQD CHARTS $\frac{1000 N}{f_{C} b T} \cong .15 \quad K=.34$

$f_{c}=\frac{1000(38)}{.15(36)(30)}=230 p s 1$

$f_{3}$ (TENS10N) $=n f_{6}\left(\frac{1+9}{2 k}-1\right)=10(230)\left(\frac{1.9}{.68}-1\right)=4100251$.

$f_{5}$ (COMP.) IS LESS THAN ABOVE, BY INSPECTION.

SHEAR IS NOT CRITICA:

DEFLECTION OF DIAPHRAGM $=.35(.025)=.0087$ iNCH

G. COAONG

t use Oult Top = Bott Stre, To Accommodate Sacs. 


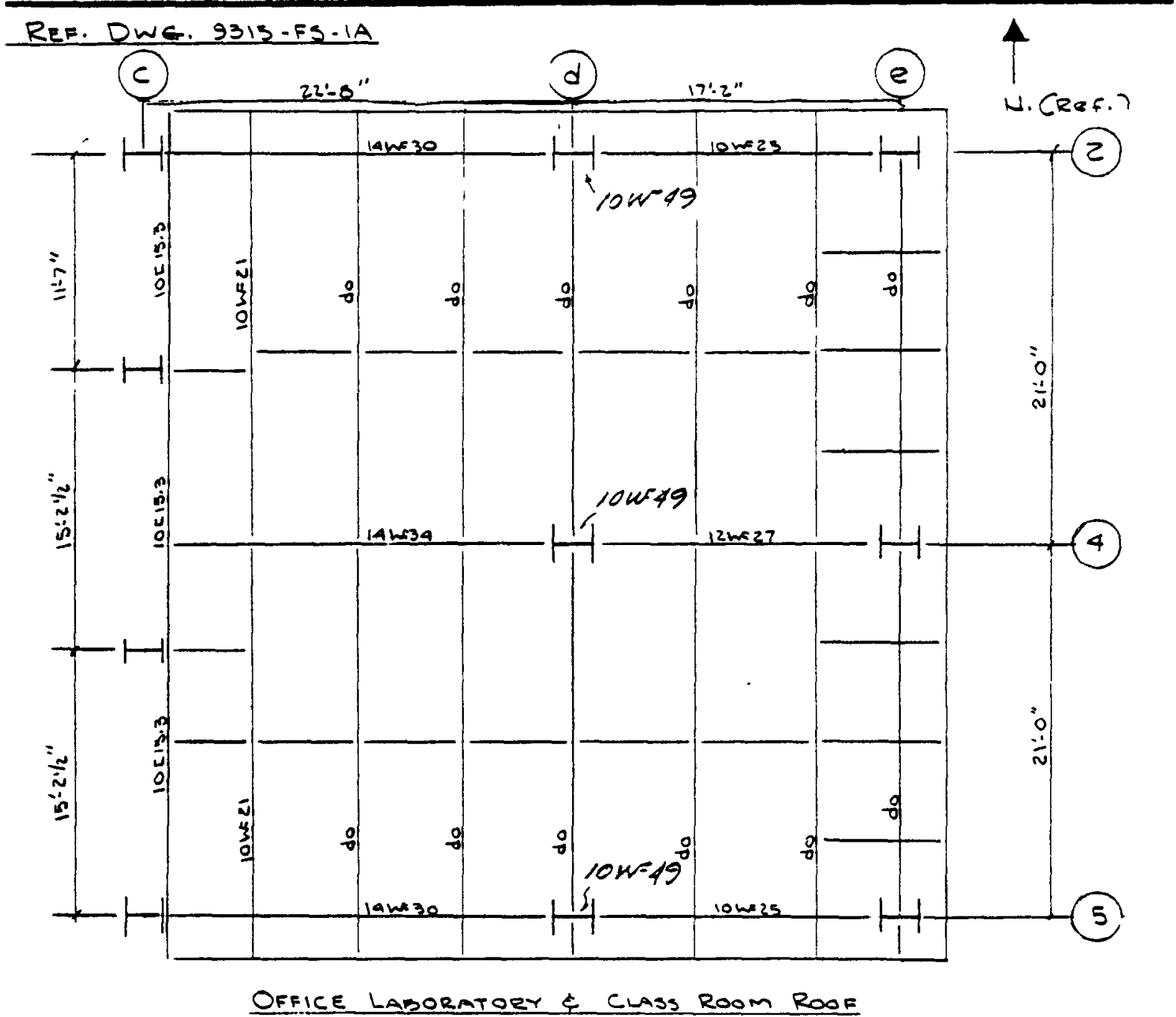

\section{Dear Lomo}

Compo. Roofina

insulation

DECKING:

2.5

Puening

3.5

13.0 LBS. $/$ FT. $^{2}$

SEISMIC N.S
Teibutaey
D. Lomb
To hiwe
(d) =
$13.0 \times 19.9 \times 46.7=12,100 \mathrm{LB} 5$ 


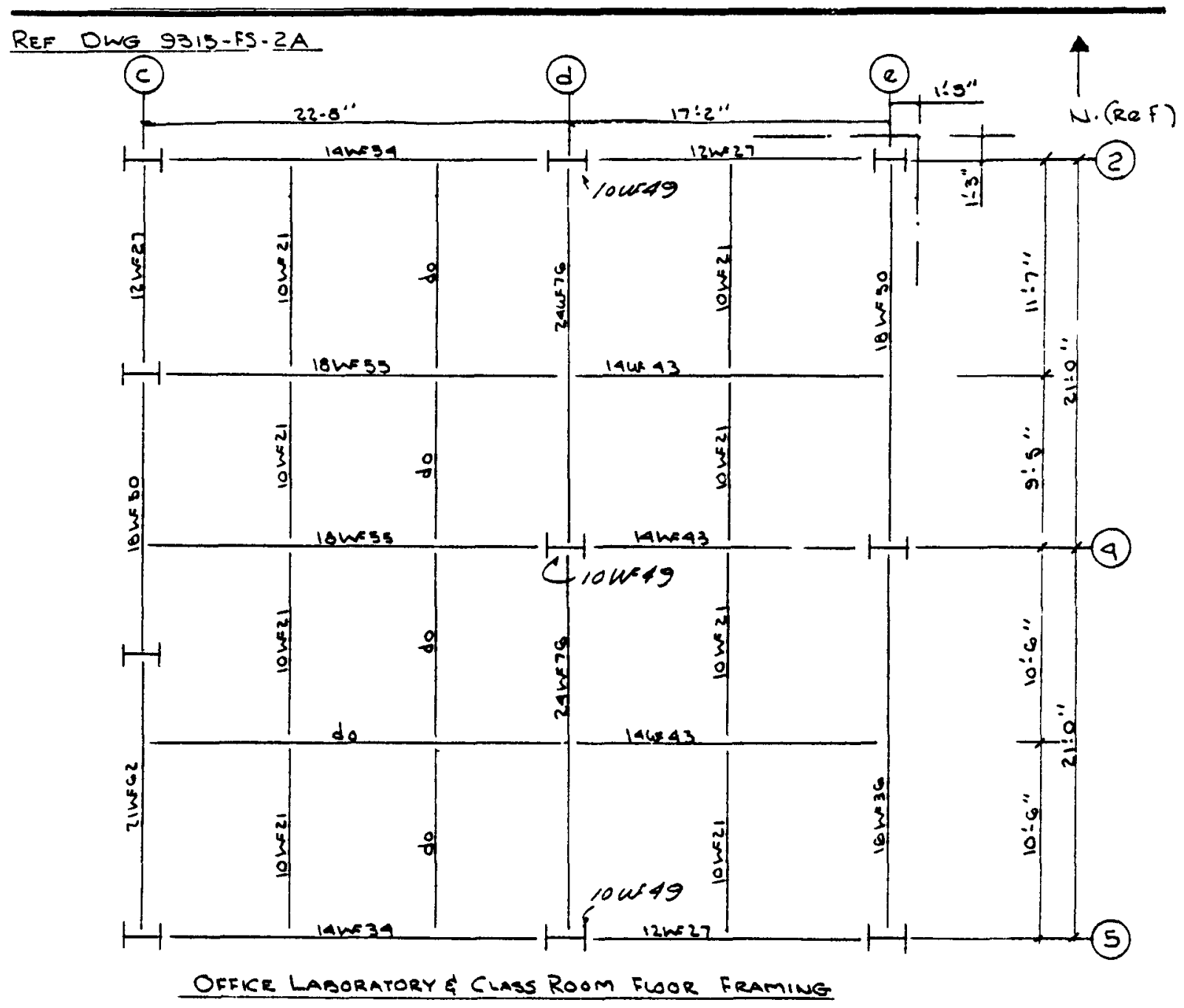

\section{Deap Lomo}

$$
\begin{aligned}
& \text { G" Slats }=75.0 \\
& \text { Framing }=7.0 \\
& \text { Partitious }=\frac{20.0}{102.0 \mathrm{ps}}
\end{aligned}
$$

SEISMIC N.S.

Tributary D. LoAd To Line (d) $=102 \times 199 \times 46.7=94,600 \mathrm{LBS}$ 


\section{Frame Constants (col line d)} Distrigution factores

MBR.

$C D$

$I / L=106.3 / 21.0=5.06$

$C B$

$I / L=93.0 / 11.9=\frac{7.82}{12.88}$

$C D I / L=106.3 / 21.0=3.06$

$D G I / L=106.3 / 21.0=3.06$

$D E I / L=93.0 / 11.9=\frac{7.82}{17.94}$

$C B \quad 4 I / L=4 \times 7.82=31.3$

$A B \quad 3 I / 6=3 \times 33.0 / 11.3=24.7$

BE $4 I / L=4 \times 2090 / 21.0=\frac{399.0}{455}$

BE $45 / L$

DE 4I/L $4 \times 7.82$

$=399.0$

EH $4 I / L$

$=31.3$

: 399.0

$\frac{0 . F .}{.30}$

.61

$E F$

$3=/ 2$

$\frac{24.7}{854}$

.28

(5)

(9)

(2)

.28

.44

EH $\quad 4 I / L$

$=399.0$

i

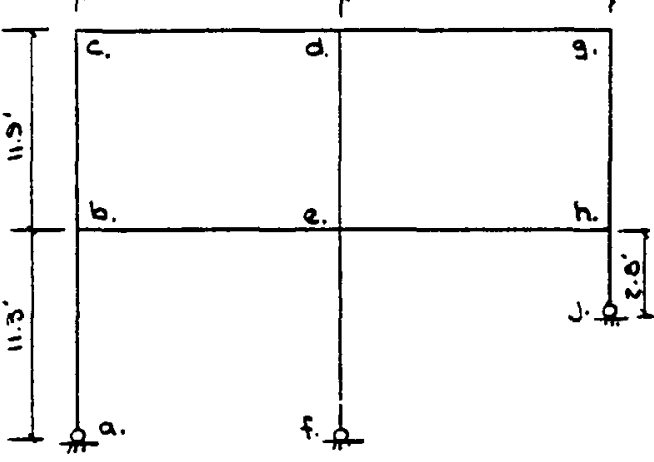

GH $4 I / L$

$=31.3 \quad .00$

HJ $3 I / L=3 x^{93 / 2.0}$

$\frac{99.7}{330} .19$

EleV. Line (d)

COL. HEIGHTS SLIGHTLY AOJUSTEO To Accommodate Cancs.

Lateral Moments $\left(Y=I^{\prime \prime}\right.$

240 Sior - GEKR $=6 \times 3.0 \times 10^{4} \times \frac{93}{11.3 \times 12^{2}} \times \frac{1}{11.9 \times 12}=820^{11 \mathrm{~K}}=60.3^{\mathrm{kK}}$

15I Stoer 3ekR $=3 \times 3 \times 10^{4} \times \frac{93}{11.3 \times 12} \times \frac{1}{11.3 \times 12}=455^{11 K}=37.91 \mathrm{~K}$

$3 E K R=3 \times 3 \times 10^{4} \times \frac{93}{2.8 \times 12} \times \frac{1}{2.8 \times 12}=7900^{116}=617^{1 K}$ 


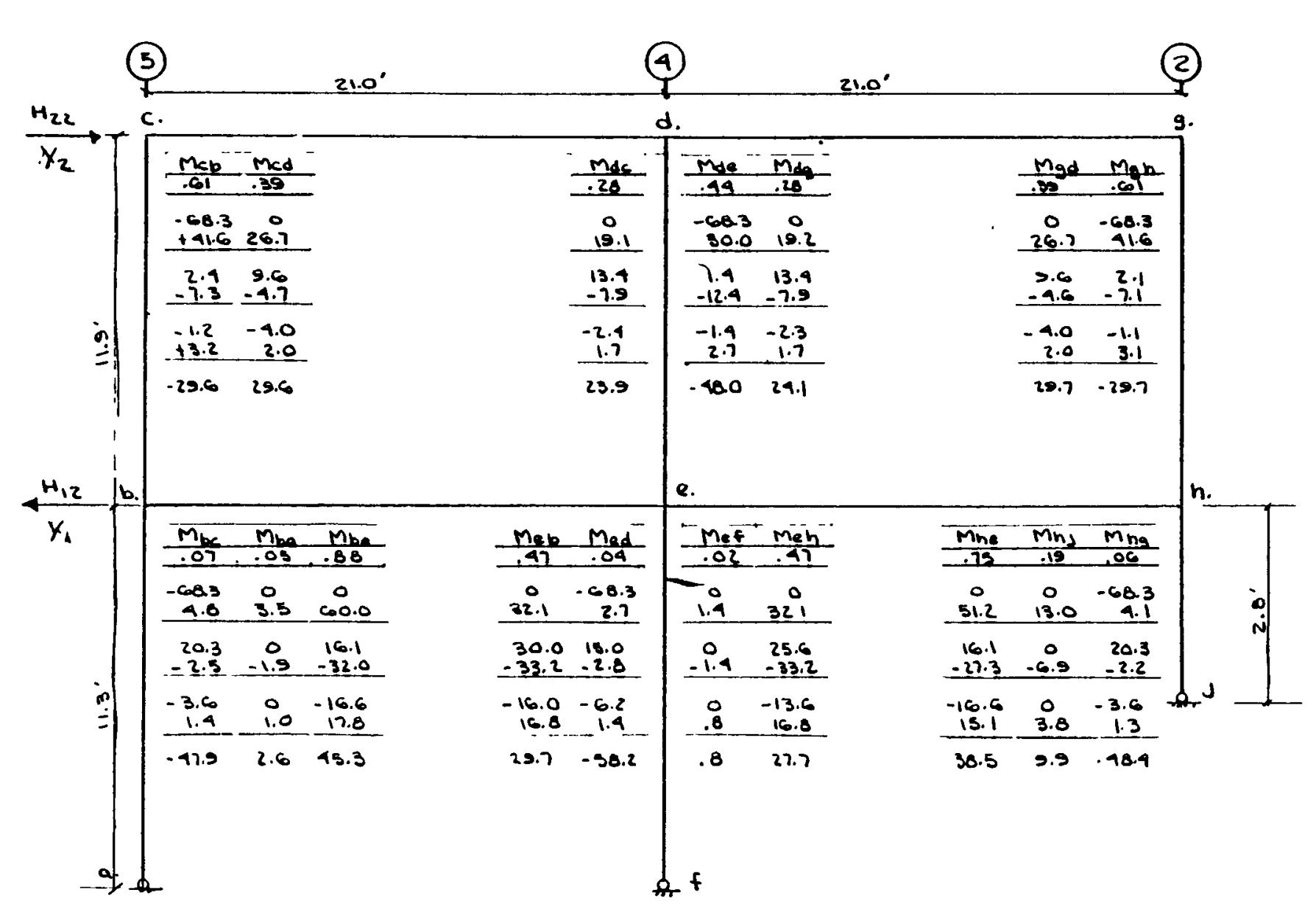

Elevation line (d)

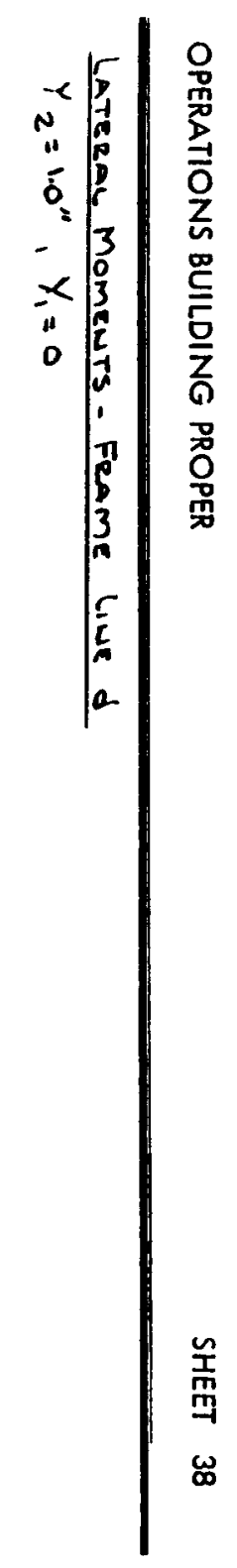



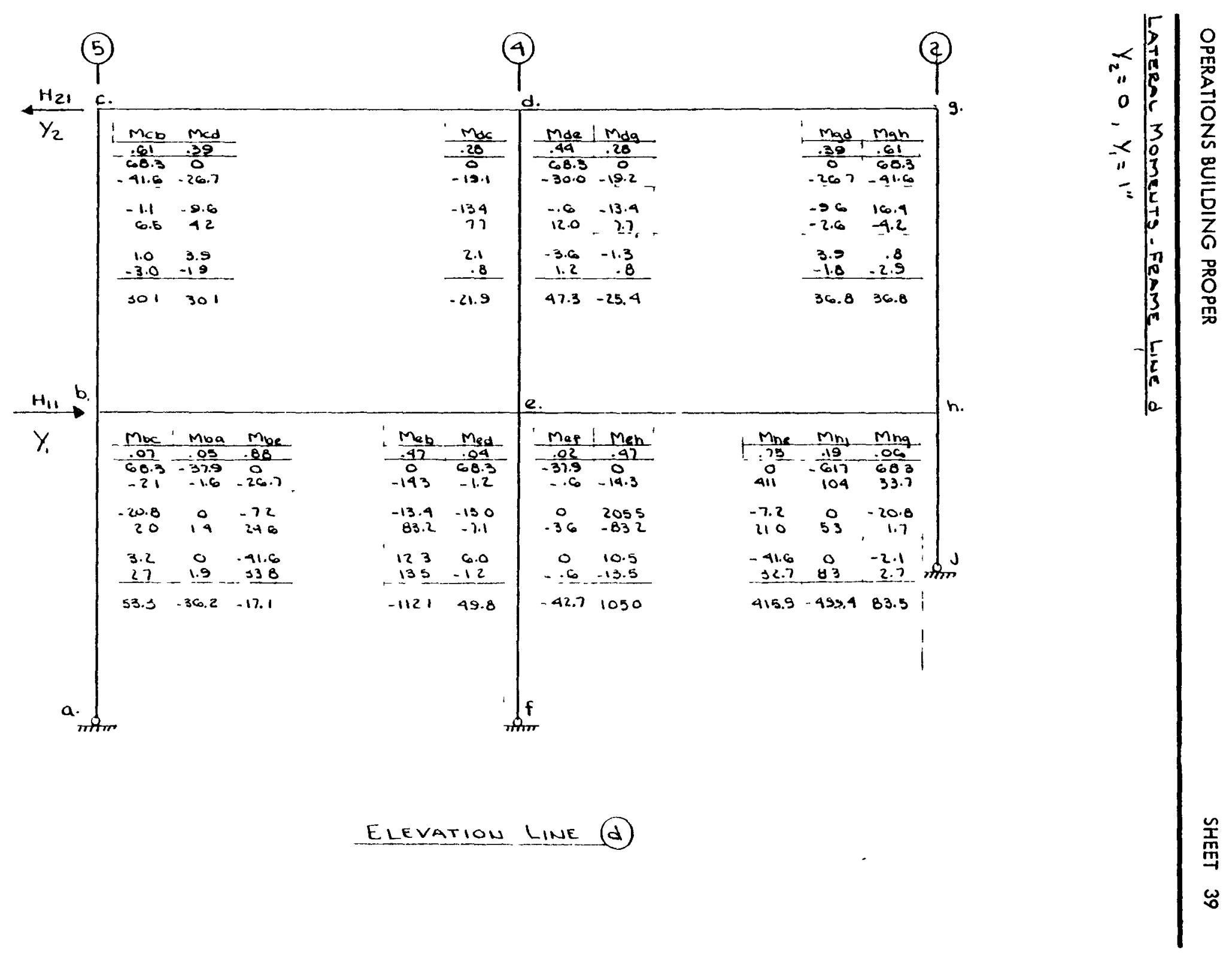

Elevation Line (d) 


\section{LATERAL MOMENT SHEARS}

Sherr Through zhe Story, $Y_{2}=1^{\prime \prime}, Y_{1}=0$

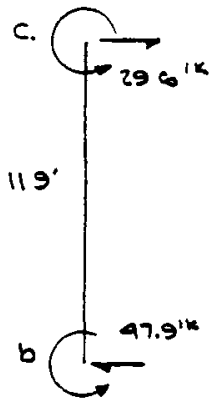

shear in

" $" \quad d e=\frac{40.0+30.2}{119}=8.94 \mathrm{k}$

". $" g h=\frac{29.7+48.4}{11.9}=6.56 \mathrm{k}$ $22.02^{k}=H_{22}$

Shene Through ist story, $Y_{2}=1^{\prime \prime}, Y_{1}=0$

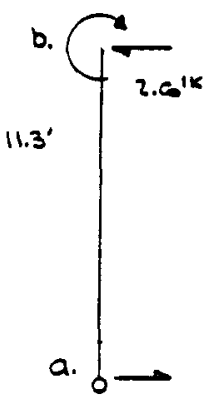

e.

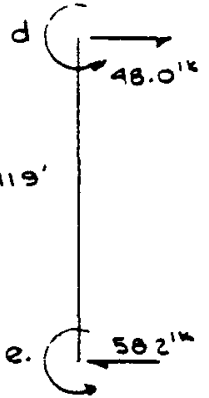

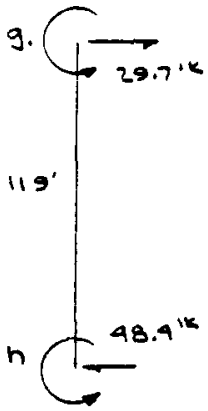


Lateral Moment SHEars

Smear Through 2 WR Store $Y_{2}=0, Y_{1}=1^{\prime \prime}$
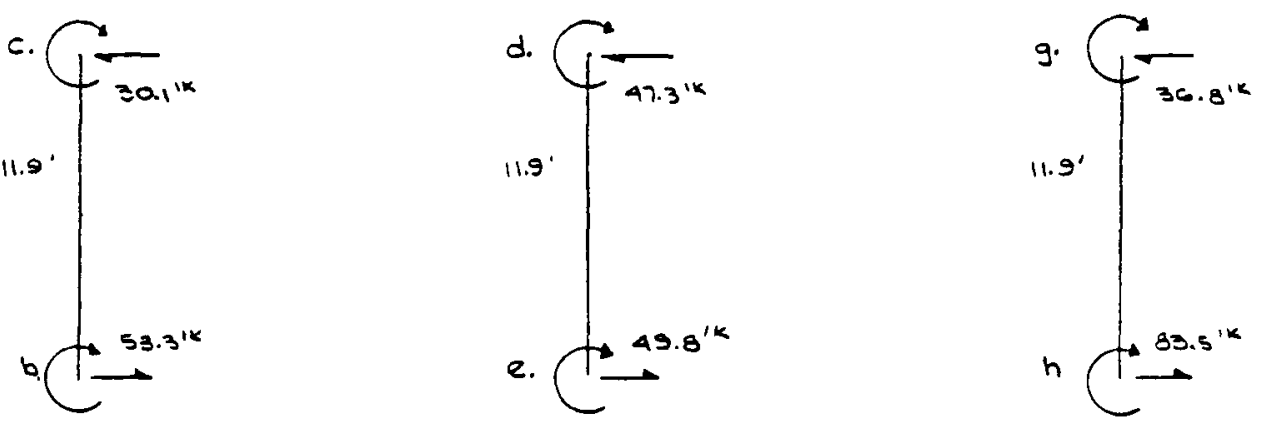

SHEAR IN MOR. CD $=\frac{30.1+33.3}{11.9}=7.0^{K}$

" $\quad$ " de $=\frac{47.3+49.8}{11.9}=8.16 \mathrm{~K}$

" $\quad " \quad g h=\frac{36.8+83.5}{11.9}=10.1 \mathrm{k}$

$25.26 \cong 25.86=H_{21}\left(H_{21}=H_{12}\right) \quad \checkmark$

Shear Through II S tore $y_{2}=0, Y_{1}=1^{\prime \prime}$

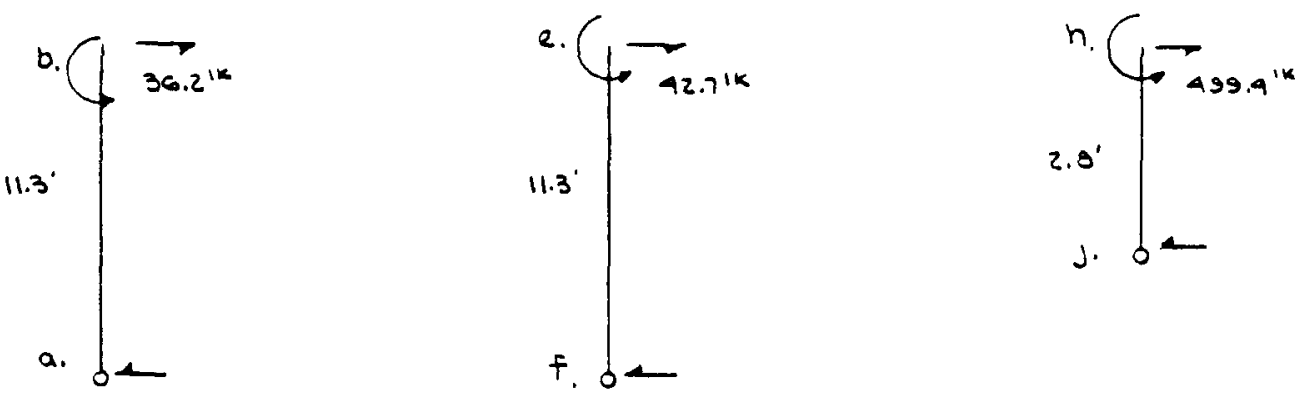

SHEAR IN MBR. $a b=36.2 / 11.3=3.2 \mathrm{~K}$

$$
\begin{aligned}
& \text { " } " \text { " ef }=42.7 / 11.3=3.8^{k} \\
& \therefore J^{h}=959.4 / 2.8=\frac{177 k}{184 k} \\
& \therefore H_{11}=184+23=209 \% 11
\end{aligned}
$$


OPERATIONS BUILDING PROPER

SHEET 42

Periods of Vibration, Mode Shapes, Participation Factors

$$
\begin{aligned}
& k_{a b}=209 \mathrm{k} / " k_{b 6}=22.02 \mathrm{k} / " k_{a b}=k_{b a}=-25.86 \mathrm{k} / \mathrm{N} \\
& m_{a}=0.245 \mathrm{ksec}^{2} / \mathrm{in} . \quad m_{b}=0.0313 \mathrm{ksec}^{2} / \mathrm{in} \text {. } \\
& \frac{k_{00}}{m_{a}}=853.06 \cdot \quad \frac{k_{b b}}{m_{b}}=703.51 \quad \frac{k_{a b}}{m_{a}}=-105.51 \quad \frac{k_{b b}}{m_{b}}=-826.20 \\
& w_{n}^{2}=0.5\left[\frac{k_{a b}}{m_{a}}+\frac{k_{b b}}{m_{b}} \mp \sqrt{\left(\frac{k_{a b}}{m_{a}}-\frac{k_{b b}}{m_{b}}\right)^{2}+4 \frac{k_{a b}}{m_{a}} \frac{k_{b a}}{m_{b}}}\right] \\
& =0.5\left[859.06+703.51 \mp \sqrt{(853.06-703.51)^{2}+4(-105.51)(-826.20)}\right] \\
& w_{n}^{2}=0.5[1556.587609 .15] \\
& \omega_{1}^{2}=473.72 ; \omega_{1}=21.8 ; T_{1}=0.29 \mathrm{sec} . \\
& \omega_{2}^{2}=1082.87 ; \omega_{2}=32.9 ; T_{2}=0.19 \text { sec. } \\
& \phi_{a n}=\frac{-\frac{k_{a b}}{m_{a}}}{\frac{k_{a q}}{m_{a}}-\omega_{n}^{2}}=\frac{+105.5}{853.1-\omega_{n}^{2}} \\
& \phi_{a_{1}}=0.279 \\
& \phi_{a 2}=-0.459 \\
& K_{n}=\frac{m_{0} \phi_{a n}+m_{b}}{m_{0} \phi_{a n}^{2}+m_{b}}=\frac{0.245 \phi_{a n}+0.0313}{0.245 \phi_{a n}^{2}+0.0313} \\
& K_{1}=1.978 \\
& K_{2}=-0.979
\end{aligned}
$$

Response For $2 \%$ damping, from Fig.119 of Cha, $S,=1.12$ ft/ser, $\int_{2}=0.7$

$$
\begin{aligned}
& \bar{y}_{b 1}=\frac{k_{1} S_{1}}{\omega_{1}}=\frac{1.978(1.12 \times 12)}{21.8}=+1.219^{\prime \prime} ; \bar{y}_{62}=\frac{k_{2} S_{2}}{\omega_{2}}=\frac{(-0.979)(0.7 \times 12)}{32.9}=-0.250^{\prime \prime} \\
& \bar{y}_{a 1}=\bar{y}_{b 1} \phi_{a z}=\quad+0.340^{\prime \prime}, \bar{y}_{a 2}=\bar{y}_{b 2} \phi_{a 2}=\quad+0.1147^{\circ} \\
& F_{b 1}=m_{b} \omega_{1}^{2} \bar{y}_{b 1}=18.07 \mathrm{k} \quad F_{b 2}=m_{b} \omega_{2}^{2} \bar{y}_{b 2}=-8.47 \mathrm{k} \\
& F_{a 1}=m_{a \omega_{1}}^{2} \bar{y}_{a 1}=39.46 \mathrm{k} \quad F_{a 2}=m_{a} \omega_{2}^{2} \bar{y}_{a 2}=+30.47 \mathrm{k}
\end{aligned}
$$

298 


\section{SEISMiC MOMEnTS}

\section{USE L.A. BLDG. CODE REGMís.}

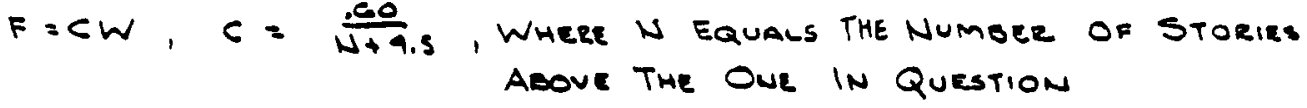

Foe Roor $C=.135, F=12,100 \mathrm{LBs} \times 133=16010 \mathrm{L80}$.

zul Floor C. .109, F $=94,600 \times .109=10,300$ cos.

Esmear Adove zUl FloDr $=1610 \mathrm{LOS}$

$$
22.0 Y_{2}-23.3 Y_{1}=1.61
$$

E SHEMR BELOW ZWe FLOOR: 11,910 LBS

$$
\begin{aligned}
& -23.5 Y_{2}+209 Y_{1}=11.91 \\
& 100 Y_{1}=13.76, Y_{1}=.0765 ", Y_{2}=.1611
\end{aligned}
$$

\section{SEISMIC MOMENTS}

$M_{c d}=M_{c b}$
$M_{d c}$
$M_{d a}$
$M_{g d}=M_{g h}$
$M_{b c}$
$M_{b a}$
$M_{b e}$
$M_{e b}$
$M_{e d}$
$M_{e f}$
$M_{c h}$
$M_{h e}$
$M_{h j}$
$M_{n g}$
$M_{d g}$

$=-23.6 \times .161+30.1 \times .0765$
$=23.9 \times .161-21.9 \times .0763$
$=\quad-40.0 \times .161+47.3 \times .0765$
$=\quad 29.7 \times .161-36.8 \times .0765$
$=\quad-47.9 \times .161+53.3 \times .0765$
$=\quad 2.6 \times .161-36.2 \times .0763$
$=\quad 45.3 \times .161-17.1 \times .0765$
$=\quad 29.7 \times .161-112.1 \times .0705$
$=\quad-38.2 \times .161+49.8 \times .0765$
$=\quad 8 \times .161-42.7 \times .0765$
$=\quad 27.7 \times .161+105 \times .0765$
$=38.5 \times .161+415.9 \times .0765$
$=\quad 9.9 \times .161-499.4 \times .0765$
$=48.9 \times .161+835 \times .0765$
$=\quad 24.1 \times .161-29.4 \times .0765$

$$
\begin{aligned}
& \frac{\text { Fr.-kiPS }}{2.46} \\
& 2.17 \\
& -4.12 \\
& 1.97 \\
& -3.63 \\
& -2.33 \\
& -5.90 \\
& -3.80 \\
& -5.56 \\
& -3.26 \\
& 12.50 \\
& 38.00 \\
& -36.50 \\
& -1.40 \\
& 1.99
\end{aligned}
$$


COLumn D. LOAO AND Selismic Stresses

\begin{tabular}{|c|c|c|c|c|c|c|}
\hline \multirow{2}{*}{ Columa* } & \multicolumn{3}{|c|}{ ELEvation $45.0^{+}$} & \multicolumn{3}{|c|}{ ELEVATION 45- } \\
\hline & $\begin{array}{c}p t \\
\text { Skips) }\end{array}$ & 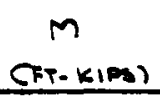 & $\begin{array}{c}P / A+M / s \\
(P S B)\end{array}$ & $\begin{array}{c}P \\
\text { Ckips) }\end{array}$ & $\begin{array}{c}M \\
(F T-k+p s)\end{array}$ & $\begin{array}{l}P / A+M / s \\
\text { CPSi) }\end{array}$ \\
\hline$d_{2}$ & 3.2 & 1.48 & 1180 & 27.5 & 36.5 & 23,410 \\
\hline$d a$ & 5.4 & 5.36 & 39600 & 43.1 & 3.26 & 3100 \\
\hline$d_{5}$ & 3.2 & 3.03 & 2560 & 27.5 & 2.33 & 3410 \\
\hline
\end{tabular}

Alu Colums lo we 49, $A=19.4$ " SYr $=18.0 \mathrm{in}^{3}$.

t Column D. Lomds Odtained from Tributary Arras.

\section{Moment COnUEction Stzesses \\ REF. DWGS 9315 - F5 - IA 2A}

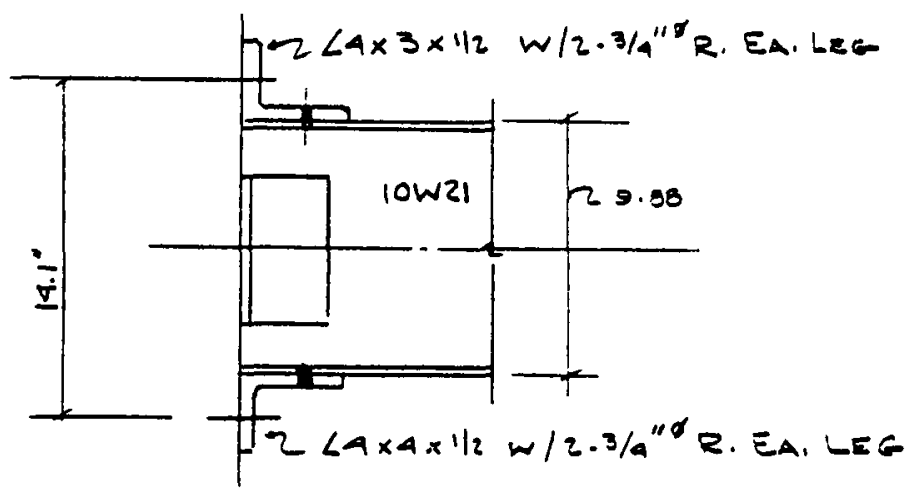

TyPICAL ROOF Framing Mom. Conn.

Max. Mom. $=$ MCd $=2.96^{1 \mathrm{~K}}$

Max. Shear in RIVETS $=\frac{2.46 \times 12}{(2) \times .44 \times 9.89}=3.4 \mathrm{KS}$ (TEUSION IN RIVETS OK

Dending in Clip ls (Assume $b=8 "$ )

$T=2.46 \times 12^{4} / 14.1^{\prime \prime}=2.1^{k}, e \cong 1^{\prime \prime} \quad \therefore M=2.1^{11 \mathrm{~K}}$

$$
F=\frac{6 \times 2.1}{8 \times 5^{2}}=6.3 \times 51 \text { OK }
$$




\section{MOMENT CONHECTION Stresses (CONT.)}

REF. DWG. 9313 -FS.2A

Max. Mom. $=M_{h e}=38.0^{1 k}$

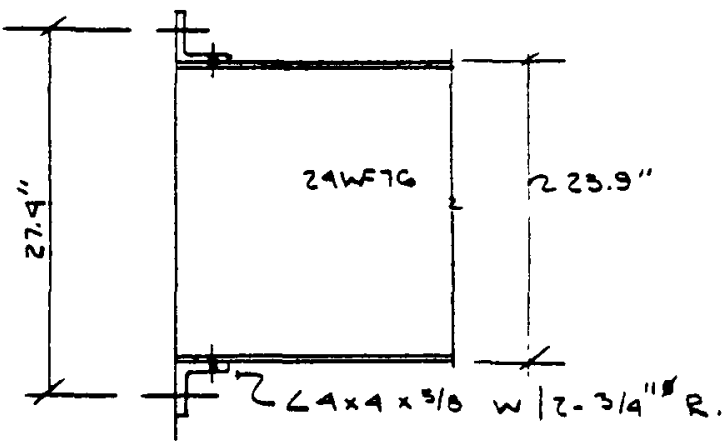

Typ, 2Ne Floor Framing MOM. CONN.

Max. Shear in Rivets

$=\frac{38.0 \times 12}{2 \times .99 \times 23.9}=21.7 \mathrm{kSI}>13.0 \times 1.33$ (TENS10N oK BY (NSP.)

Bending In $L$ (Assume $b=3^{\prime \prime}$ )

$$
\begin{aligned}
& T=38.0 \times 12 / 27.4=10.6^{*}, e \cong 1^{\prime \prime} \\
& F_{b}=\frac{6 \times 16.6}{8 \times .625^{2}}=32.0 \mathrm{ks} \mathrm{H}_{1 \mathrm{GH}} \\
& \text { SAr } b_{e+f_{1}}=6^{\prime \prime}, f_{b}=42.6 \mathrm{ks}
\end{aligned}
$$

From Agove it Appeares that CONH.he is critical

Other CONu. For zUL floOr OK BY lnsp. 
OPERATIONS BUILDING PROPER

SHEET 46

Col. Base Conn.

REF. DWT. 9315-F5-3A

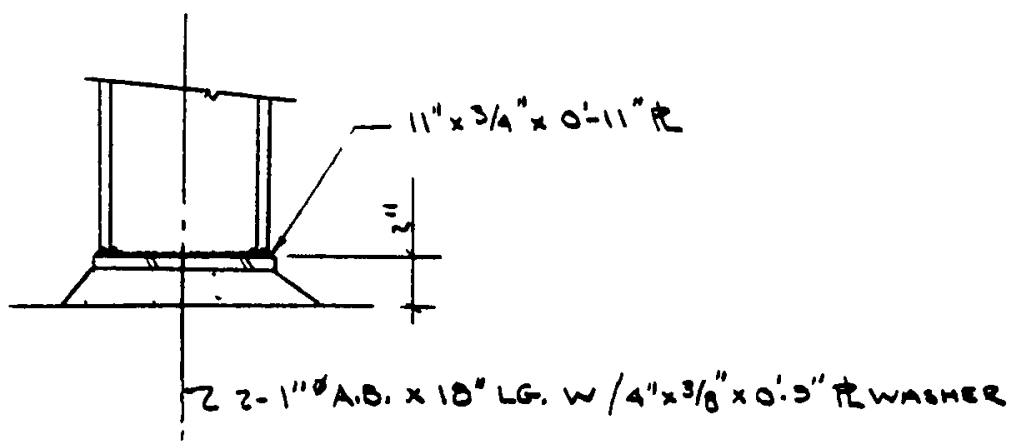

Sol .dz BAsE DETAIL

SHEAR $=36.5 / 2.8=13.0^{\mathrm{K}}>2 \times 2.5 \times 1.33$ (CODE Allownec)

Above $k$ POOR CONN. For Carrying smear As Bolts Are placed in Bending.

302 


\section{Appendix B}

\section{SEISMIC CONSIDERATIONS PERTINENT TO THE EXPERIMENTAL BOILING-WATER REACTOR}

TABLE

B.1 Sersmic Response of the EBWR Containment Vessel.

\section{B.1 SITE CHARACTERISTICS}

The Experimental Boiling-water Reactor (EBWR) was built to further the under standing of the boiling-water reactor concept through experimental operation, with the size of the facility being selected as a minimum suitable for extrapolation to the commercial ratings of succeeding large central-station units. Thus it may be considered characteristic of a number of future commercial installations, except for size. As with the SM-1, a study of the earthquake-resistant facets of the EBWR must presume any location pertinent to possible power demand, and economic and political considerations may dictate a site in seismically active areas. In actual practice, geological consultation should be employed for each prospective site.

Figure 1.10 places the present site in Zone 1, a zone of minor earthquake damage, thus minimizing the need for providing special antiseismic features in the original design of the EBWR. To provide a conservatively based study, the seismicity of Zone 3 has been adopted here, as represented by the averaged response spectra of Figs. 1.19 to 1.24. Structural calculations are given in Sec. B.5.

The conclusions and calculated stress levels contained in this appendix are based upon an assumed seismic environment more severe than that in which the reactor, as originally designed, was intended to operate. Therefore any indication of possible overstressing of some reactor parts does not imply inadequacy of the original design but rather indicates only some design areas to which attention should be directed in the event a similar plant should someday be constructed in areas subject to such more severe conditions.

\section{B.2 BUILDING AND CONTAINMENT RESPONSE}

As with the SM-1, an exhaustive analysis of all power-plant elements has not been attempted; however, a sampling of representative conditions has been studied, using care in selecting those components potentially subject to seismic damage. No attempt has been made to evaluate stresses of nonseismic origin. Calculations made in arriving 
at conclusions stated in the following paragraphs are included in Sec. B.5. However, these are not intended as model calculations to be applied to earthquake analysis of all reactors.

\section{A. Containment Vessel}

The turbine, generator, condenser, associated equipment and piping, fuel-transfer operations, and spent-fuel storage are wholly contained within the containment vessel.

The containment vessel is a vertical, cylindrical steel shell having a diameter of $80 \mathrm{ft}$ and an overall height of $119 \mathrm{ft}$ and a hemispherical top closure and an ellipsoidal bottom (see figures in Chap. 3). Below the main floor level, the shell is lined with $2 \mathrm{ft}$ of concrete. Above the main floor level, the concrete lining is reduced to $1 \mathrm{ft}$; and, at a height of $26 \mathrm{ft}$ above the main floor, it is enclosed by an irregular, truss-supported concrete ceiling. The upper portions of the concrete liner are separated from the steel shell by a varying thickness of Flexcell insulation board.

Of the $123 \mathrm{ft}$ overall height of the vessel and footings, about $60 \mathrm{ft}$, or $49 \%$ of the height, is embedded below the ground surface. The center of gravity of the containment vessel, footings, and enclosed structure and equipment has been determined to be approximately $23 \mathrm{ft}$ below the surface, so that, even more so than with the SM-1, a positive identity will exist between the ground and containment-vessel motion.

Determination of the maximum response of the containment vessel was predicated upon the following assumptions:

(1) The steel shell is free to vibrate about the 727.00 - $\mathrm{ft}$ level of elevation independently of the inner concrete liner. For reference, the level of the main floor, at about mid-height of the containment vessel, is at elevation 730.00. The exterior ground surface is at elevation 729.00 .

(2) The inner concrete liner is free to vibrate above the main floor level (elevation 730.00 ) independently of the steel shell.

(3) Below the 724.00-ft level of elevation. the steel shell acts in unison with the concrete liner in consideration of their intimate contact; however, actual bonding is minimized by a coating of bituminous paint.

Above the main floor level, the steel shell and the concrete liner have been structurally separated to minimize the effects of differential-thermal-dimensional change of the shell relative to the liner. This situation differs from that of the SM-1 with respect to the shell and inner liner. However, the outer concrete wall of the SM-1 was structurally separated from the enclosed shell and liner in recognition of this differential expansion.

The natural periods of vibration, first modes, were calculated to be 0.076 and 0.056 sec for the steel shell and concrete liner, respectively. From these periods applied in conjunction with the averaged response spectra, the deflections at the level of the top of the concrete liner (elevation 754.00 ) were determined as $0.011 \mathrm{in}$. for both the shell and the liner; thus maximum deflection of the shell relative to the liner is only $0.011 \pm 0.011$ in., or of the order of 0.02 in. Assumptions (1) and (2) are seen to be substantiated when they are considered with the more than 1 in. of Flexcell separation.

Although the periods of the EBWR shell and liner are respectively, 55 and $15 \%$, longer than the period of the SM-1 containment vessel $(0.049 \mathrm{sec})$, they are still relatively inconsequential in regard to the extreme response experienced by less rigid structures of longer period. Thus the arguments favoring the coefficient method of analysis for the SM-1, with the coefficient conforming with the maximum ground acceleration $(\sim 1 / 3 \mathrm{~g})$, are applicable here. The analysis has been performed by this coefficient method, and the results are presented in Table B.1, with the qualification that bending moments are a close approximation to the actual, and shears are somewhat overestimated. 
Table B.1-SEISMIC RESPONSE OF THE EBWR CONTAINMENT VESSEL*

(Zone 3 Conditions Are Assumed, Although the EBWR Is Essentially a Zone 1 Design)

\begin{tabular}{|c|c|c|c|c|}
\hline & & & \multicolumn{2}{|c|}{ Section } \\
\hline \multicolumn{2}{|c|}{ Item $\dagger$} & & $\begin{array}{c}\text { Main floor } \\
\text { (elevation } 730.00 \mathrm{ft} \text { ) }\end{array}$ & $\begin{array}{l}\text { Lower bend line } t \\
\text { (elevation } 69300 \mathrm{ft} \text { ) }\end{array}$ \\
\hline Moment & $\left\{\begin{array}{l}\text { Concrete } \\
\text { Steel }\end{array}\right.$ & $\begin{array}{l}\text { In -kıps } \\
\text { In.-kıps }\end{array}$ & $\begin{array}{l}23.1 \times 10^{4} \\
628 \times 10^{4}\end{array}$ & $1572 \times 10^{4 \pi}$ \\
\hline \multirow{3}{*}{$f_{a} \neq f_{b}$} & Concrete & Ps1 & -114 & -187 \\
\hline & $\{$ Steel & Psi & $\begin{array}{l}-12 \S \\
-368\end{array}$ & $\begin{array}{l}2 \S \\
-1870\end{array}$ \\
\hline & - & & $24 \S$ & $17 \S$ \\
\hline Shear & $\left\{\begin{array}{l}\text { Concrete } \\
\text { Steel }\end{array}\right.$ & $\begin{array}{l}\text { Klps } \\
\text { Kips }\end{array}$ & $\begin{array}{l}922 \\
144\end{array}$ & 3680 \\
\hline \multirow{2}{*}{$f_{v}$} & Concrete & Psi & 28 & 41 \\
\hline & $\{$ Steel & Psi & 76 & 410 \\
\hline
\end{tabular}

* Coefficient selected from averaged response spectra to conform with maximum ground acceleration of $0.33 \mathrm{~g}$.

TThe symbols have the following meanings $f_{a}$ is the direct axial stress, $f_{b}$ is the

flexural stress, $f_{a} \pm f_{b}$ is positive when tensile and negative when compressive, and $f_{v}$ is the average shear stress.

†Maximum stresses occur at junction of steel cylinder with lower ellipsoidal head.

$\$$ Computed from upluft reduced by $50 \%$ of dead load.

TTotal moment on composite section.

Maximum containment-vessel stresses are of the same order of magnitude as those of the SM-1.

Seismic overturning is resisted by two reacting soll-stress couples. The first is the usual vertical couple generated immediately under the footing. The second is the consequence of passive soll pressures acting in a horizontal direction upon the vertical projection of the containment vessel in a manner similar to the behavior of a "flagpole" footing. Although it is not possible to exactly describe the distribution of overturning moment to the two reacting couples, some reasonable limits can be established. The least values of soll-bearing stress result when rotation is about a horizontal axis in the plane of the footing-foundation interface. For this condition the distribution is about 60 to 40 between footing and passive pressure couples. Maximum credible values of sollbearing stress result from rotation about an axis one-third the embedded depth above the footing-foundation interface, yielding a distribution of about 80 to 20. This more severe latter condition was assumed to prevall, and soll-bearing stresses were calculated to be 4200 psf for a vertical load and approximately 8300 psf for a vertical load combined with seismic overturning.

Unlike the SM-1, the spent-fuel storage pit of the EBWR is housed within the reactor containment. Fracture of the pit would permit seepage of contaminated water only to the interior of the containment vessel and would not result in the possible degradation of subterranean water supplies.

However, it is recommended that fuel pits of future installations be lined with stainless steel to avold the risk of water loss through cracked concrete since undetected water loss here could lead to melting of highly ir radiated fuel assemblies, with consequent release of fission products.

The containment vessel is structurally isolated from the adjacent service building by a continuous separation. The alr lock bridging the two structures is supported entirely from the steel shell, thus maintaining the required isolation. The footings of the 
service building are generally of massive construction; and, in the area of the filled excavation adjacent to the containment vessel, they extend down to undisturbed soil, founding at the same level as the vessel footings. The diverse nature of the footings for the entire reactor complex (e.g., continuous footings, spread footings, and mat footings), together with varying soil-bearing stresses, indicates possible differential settlement, with the least desirable effect being the closing of the structural separation.

As discussed further in Sec. B.2D, the service building is of a type sometimes deficient in seismic resistance. Closing of the separation, with subsequent impact be tween the masses of containment vessel and service building during seismic motion, would increase the possibility of damage to this structure. The containment vessel has sufficient reserve strength so as to be little affected.

\section{B. Equipment and Supports}

The reactor core is enclosed in a vessel having a diameter of $7 \mathrm{ft}$ and an overall height of about $31 \mathrm{ft}$, including the extensions of the control-rod thimbles. The upper end of the vessel is closed with an indexing plug and shield assembly that allows selective access to the vessel's interior for fuel handling. The lower end has an ellipsoidal closure.

The dry weight of the pressurizer, together with the items of internal equipment, is approximately 120 kips. The pressurizer vessel is supported by four pairs of brackets arranged symmetrically about the circumference, adjacent to the upper end of the vessel. Each bracket bears on a cylindrical $C$ spring, which in turn bears on the support structure framing. A mounting stud with a cotter-pinned nut at each end passes through each bracket, $C$ spring, and the support framing. This arrangement effectively prevents translation of the vessel's upper end, while allowing the springs to roll with thermal expansion.

Translation of the lower end of the vessel is prevented, in a manner similar to that shown in Fig. 4.3, by four sway-bracing lugs restrained by parallel plate yokes welded to the shield form. This arrangement permits vertical thermal expansion of the vessel, as well as expansion in a radial direction.

The support system is well conceived and, assuming adequate design, should effectively restrain the vessel during seismic disturbances.

The main condenser, suspended in a horizontal position directly below and parallel to the turbine, is a 5300 -sq ft single-pass, divided water box, surface type unit with operating and flooded weights of 81 and $141 \mathrm{kips,}$, respectively. Under normal conditions the condenser is supported from the turbine exhaust flange by a structural weld joining the flange to the condenser neck.

The analysis was that for a rigid body subjected to an acceleration of $33 \% \mathrm{~g}$. Direct shear across the joining weld was found to be $190 \mathrm{lb}$ per linear inch. A torsional shear may be induced by the eccentricity of the condenser mass with the supporting weld. This was not expected to be of major magnitude and was not investigated. Axial stress from vertical loading was determined to be $580 \mathrm{lb}$ per linear inch. Bending across the exhaust flange and condenser neck was calculated to be 4200 in.-kips. This bending induced a load of about $1080 \mathrm{lb}$ per linear inch. When the maximum axial load of $1660 \mathrm{lb}$ per linear inch was combined with the shearing stress, a principal stress load of approximately $1700 \mathrm{lb}$ per linear inch was obtained. The thickness of joined material is probably adequate since even $1 / 4$-in. plate would be stressed to, roughly, only 7000 psi, a generally acceptable value.

The turbine and generator are mounted to a common base secured to the main floor with eight $1 \frac{1}{2}$-in. -diameter and eight 1 -in.-diameter anchor bolts.

When an acceleration of $33 \% \mathrm{~g}$ was applied to the combined operating weights of the generator, turbine, and condenser, a base shear of 84 kips was obtained. The anchorage is adequate for this shear within the normal working limits prescribed by building codes. 
The air ejectors, located in the 3-in. reactor feedwater line, are supported from the condenser floor by two reinforced-concrete pedestals approximately $3 \mathrm{ft}$ in height. Calculations indicate that the pedestals are of sufficient strength to maintain full elastic response when the ejectors are subjected to an acceleration of $33 \% \mathrm{~g}$.

The vacuum tank, a 5 -ft-diameter by $81 / 2-\mathrm{ft}$-high vertical steel cylinder, is closed by ellipsoidal heads. Four integral angle legs support the tank 3 ft from the floor. Each leg has a simple base plate anchored with a $3 / 4$-in.-diameter bolt.

The operating weight of the vacuum tank was not known. This necessitated the assumption that the tank was filled with water, yielding a weight of 13 kips. The vibration period of the tank as a single-mass system was determined to be $0.31 \mathrm{sec}$ (Sec. 5.4, Example 2). When the response spectrum is entered with this period, a maximum acceleration of $78 \% \mathrm{~g}$ is obtained, inducing a base shear of about $10 \mathrm{kips}$. Results of this analysis (with Zone 3 conditions applied to an essentially Zone 1 design) indicate that:

(1) Supporting angle legs are stressed in bending beyond their ultimate strengths.

(2) Maximum uplift is 13.3 kips per leg, far in excess of the capacity of $a 3 / 4$-in. anchor bolt.

As discussed for similar behavior of the SM-1 operations building (Appendix A), the response spectrum method loses significance when the structure passes into the plastic range and best serves as a basis for the considered judgment of the designer. Since the supports meet usual code requirements, they are probably adequate, with some allow ance for permanent deformations. If such deformation should occur, the affected structural units should be replaced and the assembly realigned to prevent progressive damage from future strong shocks; hence, postseismic inspection of this unit should be made.

The uncertainty in regard to aseismic adequacy could be avoided by using adequate diagonal bracing. Such bracing would effectively stiffen the presently flexible supports so that the vacuum tank and supports would qualify as a rigid-mass system, with reduction of seismic response from 0.78 to $0.33 \mathrm{~g}$. Since the base shear would then be reduced to only 0.33 ( $13.0 \mathrm{kips})=4.3 \mathrm{kips}$, only nominal bracing would be required to maintain elastic response. Alternately, use of sections stiffer than the present leg angles would also strengthen the structure and attenuate response.

\section{Piping Stresses}

The steam-dryer emergency cooler is an item that may cause high piping stress during seismic disturbances. This unit, installed in the main steam system between the reactor and the turbine, is a 36-in.-diameter by 72 -in.-long cylindrical vessel with ellipsoidal heads at each end. It is suspended below the main floor with two 1 -in. diameter $U$ bolts in such a manner as to provide no restraint to lateral translation of the vessel.

Considering motion of the dryer normal to its longitudinal axis, the reacting force is furnished by the 6-in.-diameter steam lines between the reactor and turbine. These lines were considered to be equivalent to a simple beam, with the inertia forces of the dryer applied as a concentrated load between the quarter and third points of the span. Considerable simplification was necessary to arrive at the dynamic model. Results of the investigation of the simplified system yielded, as a first approximation, a fundamental period of vibration of about $1 \mathrm{sec}$. Maximum acceleration of the dryer from the averaged response spectrum was determined to be $40 \% \mathrm{~g}$, inducing an inertia load of about 4 kips. Bending stresses in the pipe were approximately $40 \mathrm{ksi}$. When the bending stresses were combined with internal pressure stresses of $3 \mathrm{ksi}$, they yielded $43 \mathrm{ksi}$, a value in excess of the yield point for the carbon-steel material. Further, this is probably an understatement of the true maximum total stress because the simplified solution disregarded complex eccentricities inducing torsional and shearing effects. This area should be rigorously inspected after severe earthquakes. 
The above stresses resulted from applying Zone 3 conditions to an essentially Zone 1 design, and the indicated adverse conditions could be readily avoided in future installations located in highly seismic areas by the following:

(1) Provision for direct and positive restraint of lateral translation of the vessel (see Fig. 4.2)

(2) Piping runs of flexibility sufficient to accommodate the minor residual translations of the vessel without inducement of major stresses

\section{Service Building}

Investigation of the service building was limited to that portion of the building above the main floor level. This portion is of simple steel framing, with brick-faced unreinforced-concrete-tile filler walls and with precast lightweight-concrete roof decking, a type of structure long recognized as being deficient in resistance to seismic motion. These features would require considerable modification if the facility were to be located in strongly seismic areas instead of at its present site. Below and including the main floor, the structure is of steel and reinforced concrete, and it is not sensitive to seismic disturbances.

Unreinforced-concrete-tile filler walls have a poor seismic history. Such walls, when subjected to direct lateral loading, undergo large-scale cracking and nonrecoverable deformations. Considering inertia loadings normal to the plane of a wall, induced moments may be of sufficient magnitude to cause physical separation of masonry units over the surface stressed in tension. When the inertia loadings are reversed, the opposing surface may also experience tensile failure, with the result that bonding between masonry units is rendered ineffective. Considering participation of the walls as vertical shear elements reacting to shearing loads in the plane of the wall, major tensile effects may be induced along panel boundaries and the edges of openings or other discontinuities. The inertia loadings normal to, and the shear loadings in the plane of, a wall may be experienced in phase, so that the effects become directly additive. Openings in walls should be placed and designed so as to prevent any disproportionate distribution of loads and consequent magnification of seismic effects.

The roof diaphragm is a folded plate comprised of discrete concrete deck elements in the horizontal surfaces and of unreinforced-concrete tile through the vertical clerestory surface. The seismic resistance of this assembly is dependent upon positive attachment of the precast units to the structural steel. If the attachments are assumed to be inadequate, the concrete deck elements, in reacting to lateral loads, may slip into bearing; although the horizontal surfaces and the diaphragm could be said to have remained intact, there is the possibility of inelastic deflections sufficient to permit cracking of the supported walls.

In an existing building, initially effective response could be lost through excessive deflections or outright failure, so that the response would change accordingly. The progressive changes in response, particularly in the case of cyclic loading, are not ordinarily amenable to rational analysis. The previously described methods of studying structural response are generally inapplicable in such cases:

(1) The averaged response-spectrum method is dependent upon continued elastic behavior. Treatment as a rigid body is also inapplicable for this reason.

(2) Limit-design techniques are still incomplete. The energy dissipation associated with failing masonry or with repeated plastic reversals has not as yet been sufficiently described for working applications.

(3) The empirical methods recommended by building codes apply to normal aseismic construction and to response short of any gross failure.

In analyzing the Service Building, the coefficient method was used; localized plastic deformation and other energy losses were assumed to damp the seismic response to a 
lateral load of $0.133 \mathrm{~g}$ in the conservatively assumed Zone 3 environment. So long as stresses due to this load are less than 1.33 times normal working stresses, the use of code coefficients is considered tenable.

Results of the analysis are as follows. If the interior transverse shear walls are conservatively assumed to have falled and the lateral seismic load is applied transversely to the bullding, the roof diaphragm spans between end walls and maximum shears of $650 \mathrm{lb}$ per lineal foot occur. The jogged end walls may experience some localized marginal fallures, but load transter between offset portions of the walls will probably result in the offset portions remaining intact. The front wall, interior portal, and rear wall can function as longitudinal shear walls; a shearing stress of 85 psi is indicated in the slender unreinforced-masonry piers of the interior portal, which are therefore susceptible to fallure. Because of its many openings, the front wall experiences shears of $100 \mathrm{psi}$, which is beyond the structural capacity of unreinforced masonry. Despite redistribution of loads to the rear wall, it is presumed that the rear wall will remain intact, partly as a result of the appreciable energy absorption that accompanies the possible fallure of other shear walls.

Remedial measures for use with this type of minor bullding in areas of high seismicity could include: eliminating the offsets in end walls; minimizing the size of wall openings to provide piers and spandrels of adequate size; reinforcing and grouting of concrete tiles and mechanical anchoring of veneers; casting welding inserts integrally with roof elements for anchoring to frame; providing studs or dowels for shear transter from roof diaphragms to shear walls; and providing anchor studs between masonry walls and steel columns at jambs and corners.

\section{E. Significance of Overstress}

Most of the structural elements investigated have periods of vibration such that the horizontal accelerations induced by a strong earthquake would be a large percentage of the acceleration of gravity. In considering installations in regions of high seismicity, the significance of any resulting overstress must be assessed from the standpoint of the consequences of fallure. Thus some overstress could probably be tolerated in those instances where fallure would not involve the release of fission products (Sec. $5.8 \mathrm{~A}$ ).

\section{F. Static Resistance of Equipment Items}

In making reasonable allowances for stresses other than those of seismic origin, it appears that most of the overstressed equipment items can resist a static horizontal force of $0.20 \mathrm{~g}$. As stated in Sec. $4.12 \mathrm{~A}$, this static coefficient is often used in designing critical features of conventional power plants in areas of high seismicity.

\section{B.3 REACTOR SYSTEM}

\section{A. Nuclear Yerturbations}

During an earthquake a bolling-water reactor is subject to liquid oscillations and hydrostatic pressure changes that may create or collapse steam voids in the core. A simple analysis of the forces involved indicated, however, that the change in void volume was a fraction of $1 \%$; thus it is believed that seismic effects are negligible in this respect. Furthermore, the EBWR reactor-transfer-function curves, ${ }^{3.1}$ obtained from sinusoidal variations of reactivity input, show that the seismic periods involved are probably not signuficant as a factor tending toward power magnufication.

In partial support of the theory that the EBWR is relatively insensitive to vibratory motions, one may cite the turbine-biade fallure experienced by the EBWR. ${ }^{3.1, B .2}$ This mechanical fallure created strong vibrations in the reactor building with no noticeable effect on reactor stability; however, direct comparison with seismic shocks should not be made because of the difference in vibration frequencies. 
At some very high power density, instability may be expected in a boiling-water reactor. ${ }^{\mathrm{B}} \cdot 3$ To date the EBWR has been operated at approximately over three times its design power rating of $20 \mathrm{Mw}^{3.4}$ and has proved itself stable. It may be possible to predict the effects of seismic perturbations by including that factor in a dynamic analysis such as that given by E. S. Beckjord, ${ }^{\mathrm{B} .5}$ and as pointed out by J. A. DeShong, Jr. ${ }^{\mathrm{B} \cdot 6}$

\section{B. Control Rods}

In the EBWR control-rod design, when the rods are released from the drive nut, initial downward acceleration is imparted by a spring-loaded mechanism which, together with gravity force, permits a scram in $0.5 \mathrm{sec}$. Under the normal operating pressure of $600 \mathrm{psig}$, the aid of pressure shortens the average scram time to $0.35 \mathrm{sec}$.

The operating parts of the control-rod-drive mechanism are outside the reactor pressure vessel. A solenoid-operated roller latch connects the control-rod shaft with the screw nut, resulting in a latch release upon interruption of the electrical current. Friction is kept small by means of a breakdown labyrinth seal. At a radial bushing clearance of 0.008 in., the seal leakage is about $200 \mathrm{~cm}^{3} / \mathrm{min}$.

\section{Core Structure}

In Fig. 3.15, the entire core assembly is affixed to the bottom grid plate, which in turn is bolted to machined pads in the bottom head of the reactor pressure vessel by means of 1 -in. stainless steel $T$ bolts. For this cantilever type core support, seismic stresses on the bolts were found to be quite low.

For natural-circulation boiling the vertically aligned fuel assemblies have a locating fitting that fits into holes in the bottom grid plate. With forced-circulation operation the lower end is modified to accept a hold-down assembly to withstand the expulsion force of the pump pressure. Springs in the top end fitting provide lateral stability; thus the fuel assemblies bear against one another and against the upper guide structure.

Fuel plates are thick enough to withstand loads that might be reasonably expected.

Taking these factors into consideration, one is led to conclude that the EBWR core structure appears to be adequate for seismic shocks. The upper portion of the core can be made more rigid by bracing with radial spokes, if such a device does not interfere with operations.

\section{Loss of Power}

In line with nuclear-power-plant safety practices, the EBWR is provided with emergency power supply, which consists of a battery source with a motor-generator set plus a diesel-generator set. Hence continuous plant power is assured during severe earthquakes.

\section{E. Failure of Steam System}

Since this is a direct-cycle boiling-water reactor, failure of the steam system implies primary loop rupture or malfunction of the equipment and valves. Numerous safety precautions installed in the EBWR will scram the reactor as a result of signals caused by a rise in the activity level in the building due to steam release, low water level in the reactor, low' ..ie: temperature, closing of the turbine trip-throttle valve, etc.

If turbine failure should occur and eject flying fragments, the concrete-lined vapor container will not be breached since it is specifically designed for such a possibility.

\section{F. Transient Load Demand}

Normally about $5 \%$ of the steam is bypassed so that usual variations in power demand can be met, ${ }^{8.7}$ but a load increase greater than that amount automatically closes 
the pressure-regulating valves. Unless the reactor power level is adjusted by the operator, the turbine-governor-valve opening increases and brings about a gradual decrease in system pressure. If this pressure-change rate exceeds a set limit, automatic scram takes place. Below this rate the operator has the choice of meeting the load demand by adjusting the control rods or of shutting down the reactor.

If seismic damage to the power network area should decrease the load demand, the pressure-control valves are set to open from the resulting pressure rise. If this rate of pressure increase exceeds a set value or if the pressure level exceeds 625 psig, the reactor automatically scrams. The relief valve is set to open at $700 \mathrm{psi}$ and dump the steam to the condenser. Two more pressure-relief valves are set to open at 725 and 750 psig, with reactor scram taking place when any of the three relief valves are opened.

Therefore it is concluded that transient power demands, which may be expected during earthquakes, can be accommodated by the power plant.

\section{G. Energy Release}

Although the maximum credible accident (involving the release of steam and the reaction of zirconium with water) is considered to be quite unlikely even for severe earthquakes, it has been used as a basis for designing the EBWR vapor container and blast and missile shields. Therefore, with the closing of the normal vent system, widespread release of fission products is very unlikely.

\section{H. Emergency Shutdown and Cooling System}

As a backup safety feature in the unlikely event of control-rod failure, a low - and high-pressure boric acid injection system is provided to poison the core.

Emergency cooling water is supplied from the overhead 15,000-gal water tank, which also feeds the sprinkler system devised to condense steam released in an accident. This overhead tank was found to be adequately attached to the reactor building roof to withstand severe earthquakes.

\section{Fuel-transfer System}

The fuel-transfer carriage was found to be seismically stable. EBWR fuel assemblies are not expected to swing with a large amplitude during the fuel-assembly lifting from or to the core. No damage is expected to result from seismic effects on the fueltransfer system. Section B.2A covers the spent-fuel storage pit.

\section{B.4 STANDARD OPERATING PROCEDURE}

To avoid the panic and confusion that may follow strong earth tremors, it is suggested that earthquake-emergency procedures be established and practiced.

In the case of the present EBWR, the decision on a course of action during earth shocks could be considered optional; but, looking ahead to future boiling-water reactor plants, it may be advisable to operate at moderate power, judging from the text of Sec. 3.3C. In that case the reactor could be instrumented to decrease power on a graduated scale, taking its signals from a seismometer (see Sec. 8.7).

Should an earthquake occur during some phase of fuel loading or unloading, the question of continuing the operation could well depend on the phase of operation one has reached. This should be outlined in a standard operating procedures manual.

For any power system a postearthquake examination of the facilities and equipment is recommended after strong seismic shocks. Those points outlined in this appendix should be reviewed. Obvious damages will clearly be discernible, but care will be necessary to detect hidden flaws. Stretched bolts, cracks in concrete, etc. may be noted if one consciously searches for them. A health physics survey of the area may indicate possible radiation leakage after earthquakes. 


\section{B.5 STRUCTURAL CALCULATIONS}

\section{B.5 STRUCTURAL CALCULATIONS}

Various components of the EBWR system and the sheets on which calculations appear are given below.

\begin{tabular}{lc}
\multicolumn{1}{c}{ Item } & Sheet No. \\
Vapor container & $1-8$ \\
Condenser and turbine support & $9-10$ \\
Air-ejector support & 11 \\
Vacuum-tank support & 12 \\
Steam dryer & $13-14$ \\
Service building & $15-29$
\end{tabular}

\section{REFERENCES}

B.1 J. A. DeShong, Jr., Power Transfer Functions of the EBWR Obtained Using a Sinusoidal Reactivity Driving Function, USAEC Report ANL-5798, Argonne National Laboratory, January 1958.

B.2 Nucleonics, 16(6): 25 (1958).

B.3 Nucleonics, 15 (7) (1957).

B.4 Nucleonics, $\overline{16}(1)$ and $16(4)$ (1958).

B.5 E. S. Beckjord, Dyanamic Analysis of Natural Circulation Bolling Water Power Reactors, USAEC Report ANL-5799, Argonne National Laboratory, March 1958.

B.6 J. A. DeShong, Jr., Upping EBWR's Power, Nucleonics, 16(6): $68-72$ (1958).

B.7 J. M. West et al., Hazard Summary Report on the Experimental Boiling Water Reactor (EBWR), USAEC Report ANL-5781, p. 116, Argonne National Laboratory, November 1957. 
Perioos of VIBration. InNER AND OUTER SHELLS

EL. 7920 (Inside R)?

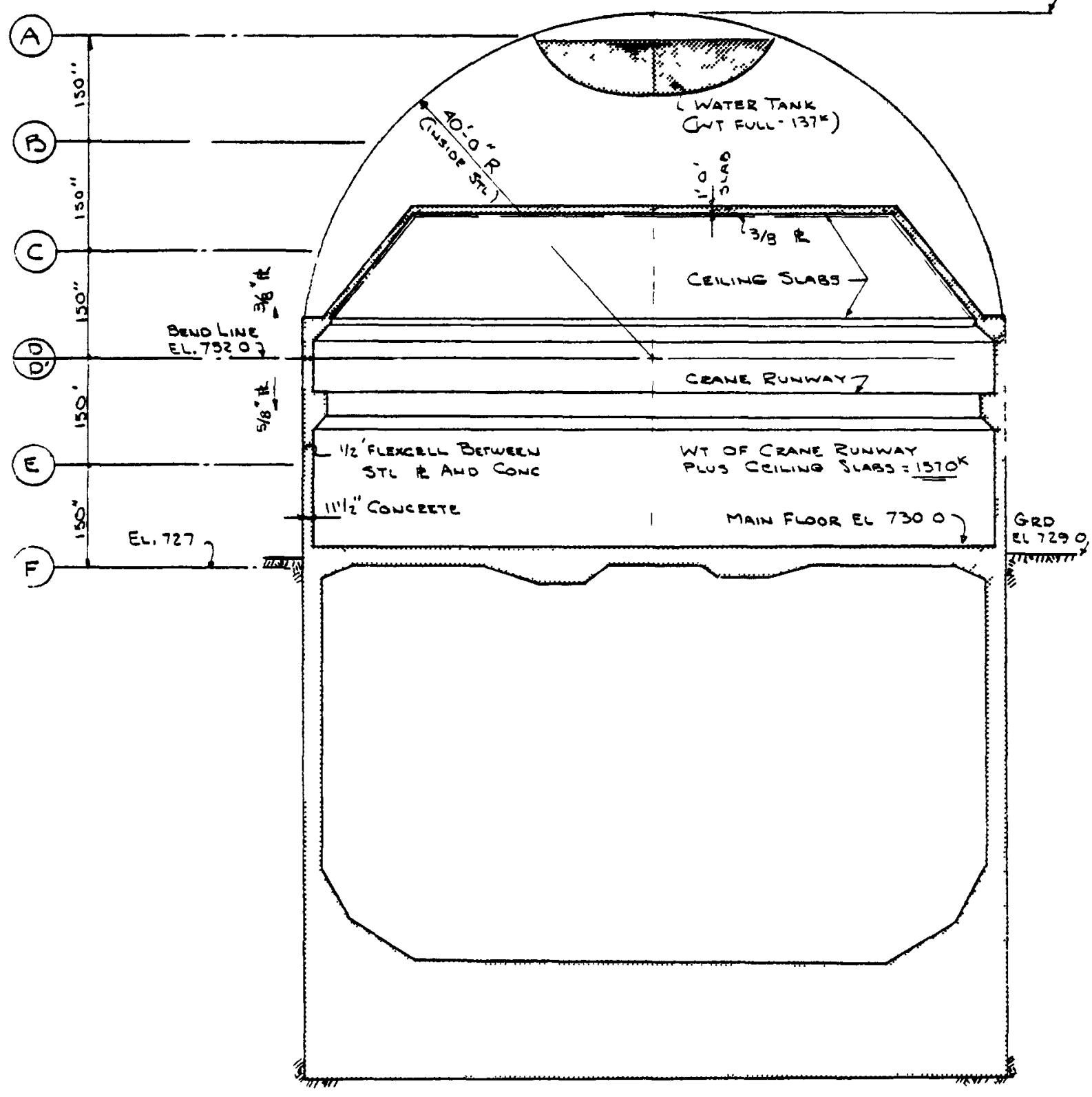


In Determing the natural period of Vibration of The

Vapor Contminer, The folowing Assumptions are Made:

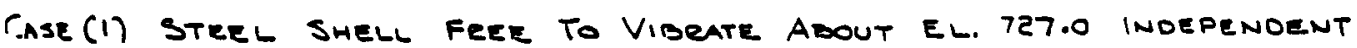

OF I:0" CONCRETE INUER SHELL

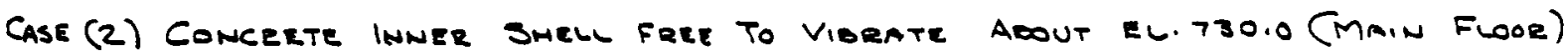
INDEPEHDENT OF OUTER STERL SMELL WITH THE WEIGHT OF

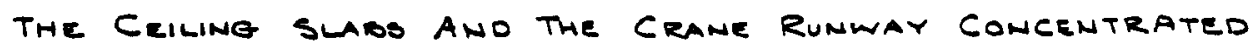

AT EL. 736

\section{Case 1}

SEction Propertics. STREL SMELL

\begin{tabular}{|c|c|c|c|c|c|}
\hline SECTION & $\begin{array}{l}\text { AREA } \\
1 N^{2} \\
10^{3} \text { UNITS }\end{array}$ & $\begin{array}{c}\text { Mom. OF INERTIN } \\
I^{1 N^{4}} \\
10^{8}{ }_{\text {UNITS }}\end{array}$ & $\begin{array}{c}F / A G \\
\angle b S^{-1} \\
10^{-10} \text { WNITS } \\
\end{array}$ & $\begin{array}{l}1 / E I \\
\left(L b_{S}-I N^{2}\right)^{-1} \\
10^{-15} \text { LINITS }\end{array}$ & $\begin{array}{c}w \\
\mathrm{Lbs} / \mathrm{in} \\
10^{2} \text { UNITS }\end{array}$ \\
\hline A & .384 & .512 & 4.35 & 6.30 & $1.09^{*}$ \\
\hline$B$ & .902 & 6.31 & 1.85 & .530 & 2.56 \\
\hline$c$ & 1.07 & 1.09 & 1.56 & .300 & 3.04 \\
\hline$D$ & 1.13 & 1.30 & 1.48 & .257 & 3.21 \\
\hline$D^{\prime}$ & 1.80 & 2.17 & .885 & .154 & 3.34 \\
\hline$E$ & 1.00 & 2.17 & .885 & .154 & 5.34 \\
\hline$F$ & 1.88 & 2.17 & .885 & .154 & 3.34 \\
\hline
\end{tabular}

$F=2.0, E_{S}=30 \times 10^{\circ} \mathrm{ps}, w_{S}=490 * 1 \mathrm{R}^{3}$.

* Conc. load or $137^{k}$ not included here (Water tank + Water) 
PERIOD OF VISRRATION - I SI MODE - STODOLA-NEWMARK METHOD

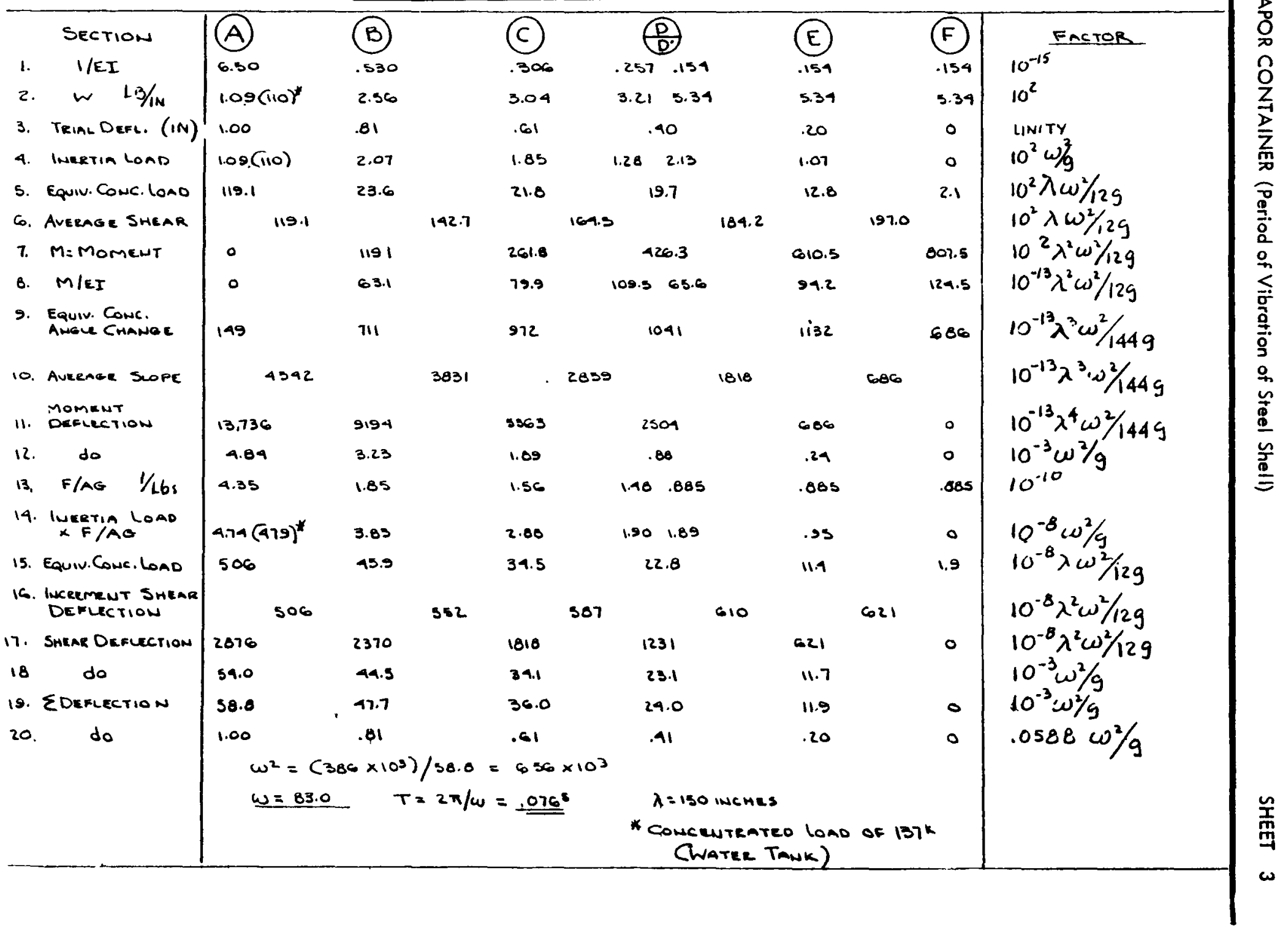




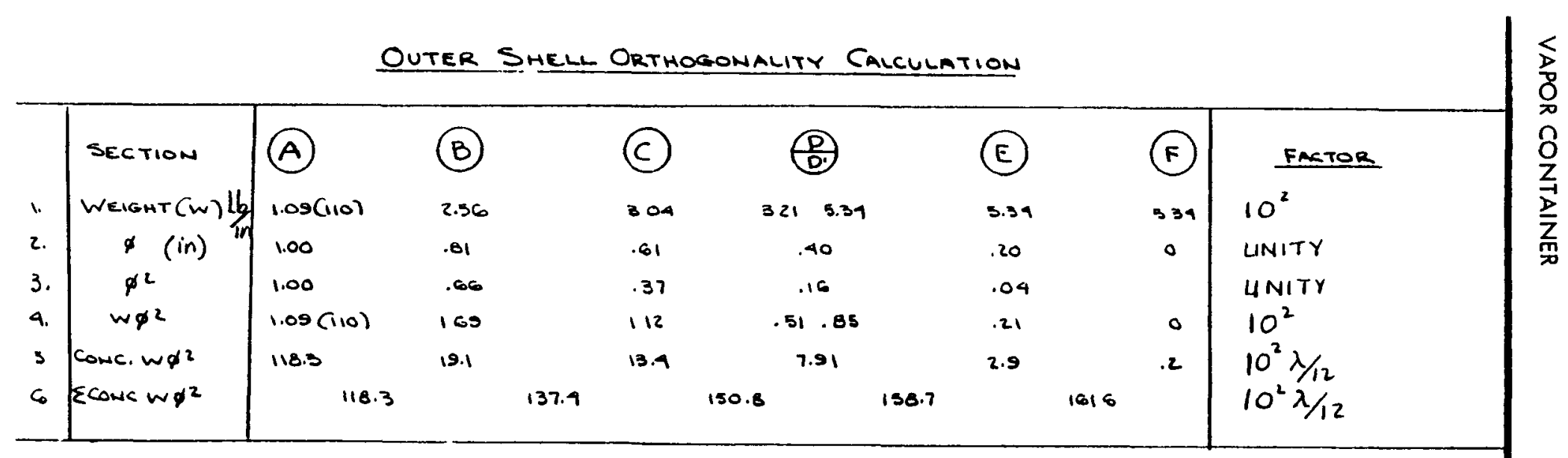

$\varepsilon w \phi^{2}=161.6, \varepsilon w \phi=197$ (FROM SHT. 3, LiNe 6)

$\Delta_{D}=\frac{\sum w \phi}{\sum \omega \phi^{2}} \cdot \phi_{D} \cdot \frac{S_{v}}{\omega}, \phi_{D}=.90$ (FROM SHT. 3, WwE 3)

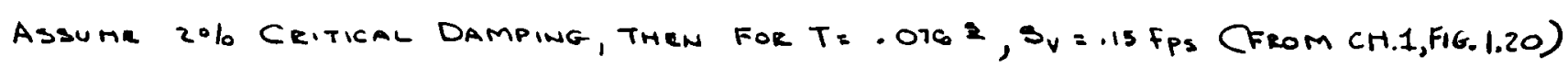

$\therefore$ DEFLECTION@EL.759Y $\left(\frac{197}{161.6}\right)(.40)\left(\frac{.05 \times 12}{85}\right)=.011 \mathrm{INCH}$ 


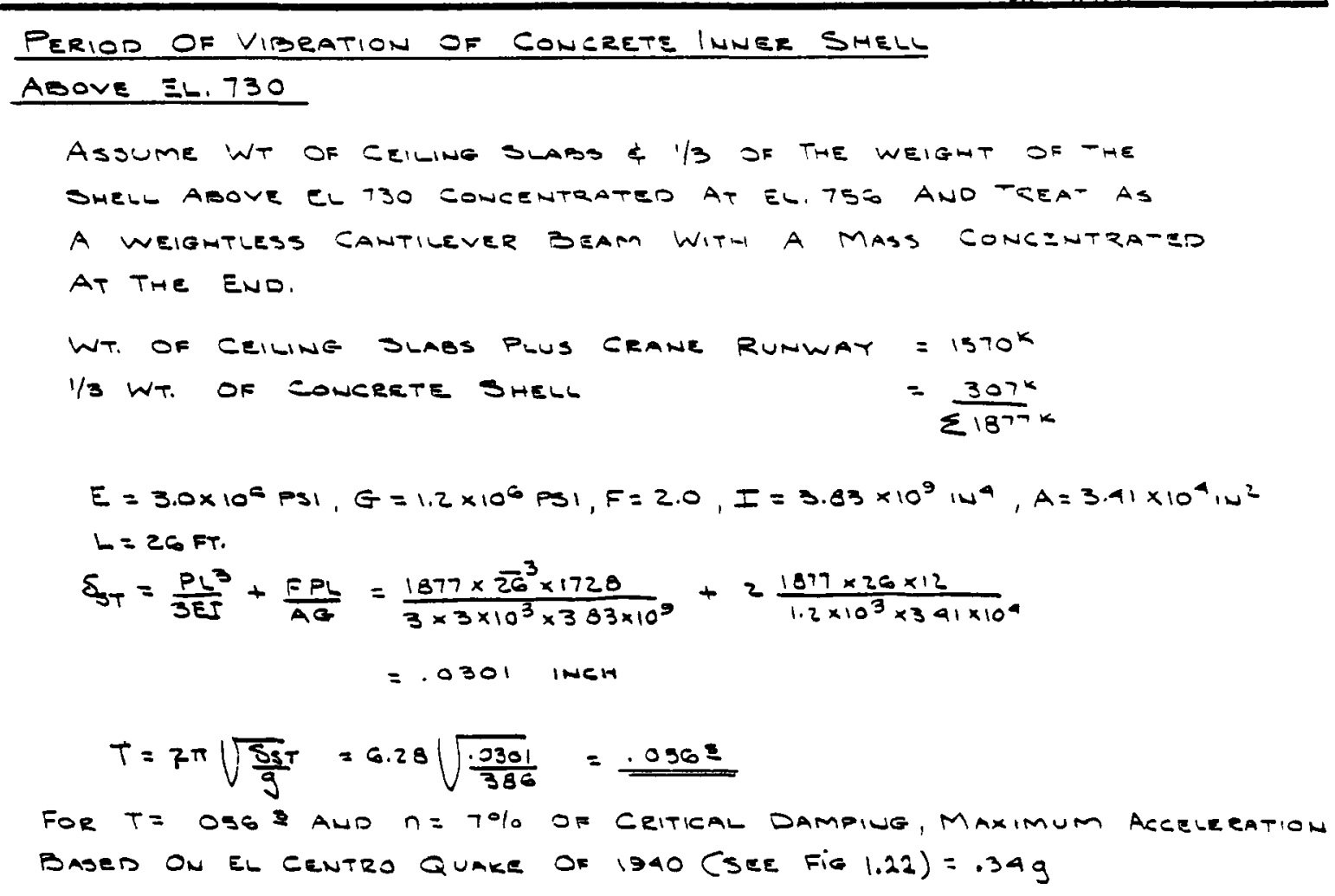

PEFlection AT EL 754 OF CONCRETE InNER SHELL

$$
\begin{aligned}
& \Delta_{b} \text { (uniform LOAD) }=(34) \frac{311 \times 10^{3} \times \overline{26}^{4} \times \bar{z}^{4}}{8 \times 3.0 \times 10^{6} \times 383 \times 10^{9}}=.109 \times 10^{-3} \\
& \left.\Delta_{b} \text { CCOncentrated Lomo }\right)=(.34) \frac{1.57 \times 10^{6} \times 26^{3} \times 12^{3}}{3 \times 3 \times 10^{6} \times 3.83 \times 10^{9}}=469 \times 10^{-3} \\
& \Delta=C . " \quad)=(.94)(2) \frac{1.57 \times 10^{6} \times 26 \times 12}{3.41 \times 10^{4} \times 1.2 \times 10^{6}}=8.13 \times 10^{-9} \\
& \Delta_{s} \text { C Unirorm Lono) }=(34)(2) \frac{3.11 \times 10^{3} \times \overline{26}^{2} \times 7^{2}}{2 \times 3.41 \times 1.2 \times 10^{10}}=\frac{2.52 \times 10^{-3}}{8.0111064} \\
& w=3.11 \times 10^{3} \mathrm{LOS} / \mathrm{WN}, P=1.37 \times 100 \mathrm{LOS} \quad \overline{\varepsilon .0111 \mathrm{NCH}}
\end{aligned}
$$

minimum separation between SteEl and Concrete shells above Main floor is .5" a Calculatious indicate that smells are frer to vibrate independently of One Anothre Above The

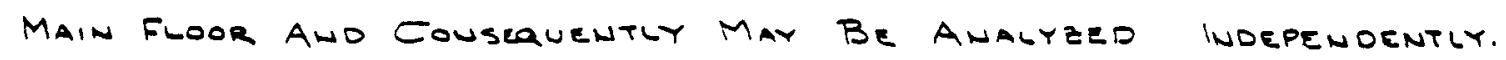


VAPOR CONTAINER (Supplemental Calculations)

SHEET 6

1.- Determine moms. Es hears AT El. 730 \& EL 693.

$\varepsilon 1.780$

$\underline{E} \leq 693$

Steel $V: \frac{1}{3} 432$

$=181.0$ Kips

$V=\frac{1}{3} 11039 \cdot 3600 \mathrm{kips}$

$1 x \cdot \frac{1}{3} 16 / 45-144(730.00 \cdot 1.0828 .92)$

$A=\frac{1}{3} 392902 \cdot 130930$ frt. km

$=5382-155$

$: 157.2 \times 10^{\circ}$ in -kip

$=5227$ ft-kips

$=6.38 \times 10^{\circ} \mathrm{in}-\mathrm{kips}$

Cons. $V: \frac{1}{3} 2706 \quad: 922$ kips

$$
\begin{aligned}
\text { A. } & =\frac{1}{3} 600001 \cdot 922(1.08) \\
= & 20220-1000 \\
= & 19220 \text { ft. kips } \quad=13.1 \times 10^{d} \text { in -kips }
\end{aligned}
$$

3.- Determine flt 6 \& tot El 730

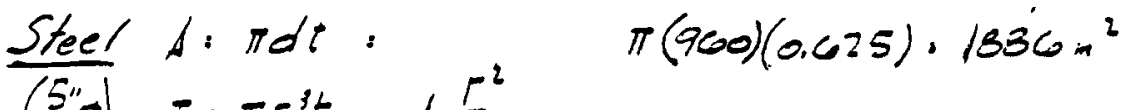

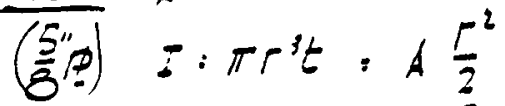

$$
\begin{aligned}
& s \cdot \pi r^{2}=1 \frac{r}{2}=1886(480) \frac{1}{2} \cdot 45.3 \times 10^{4} \mathrm{in}^{3} \\
& f_{a}+f_{b}=\frac{132}{1886}+\frac{6.28}{15.3}=229+139=368 \mathrm{~m}^{2} \quad f_{0} \frac{1}{3} 229: 76.3 \mathrm{k} / \mathrm{m}^{2} \\
& f_{a} \cdot f_{b}=\frac{d o}{2}-d o=115 \cdot 130:-24 * / m^{2}(T)
\end{aligned}
$$

Conc $1: \quad \pi(967)(110)=37300 \mathrm{kn}:$

$$
\begin{aligned}
& 5: 1 \frac{1}{2} \cdot 33800(473.5) \frac{1}{2}: 775 \times 10^{6} \mathrm{in}^{3}
\end{aligned}
$$

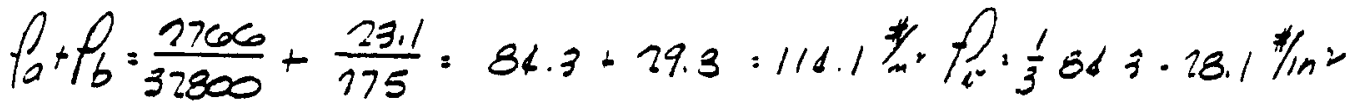

$$
\begin{aligned}
& f_{\rho} f_{b}=\frac{d o}{z}-d 0 \cdot 82.1 \cdot 29.8=12.3 \mathrm{k} / \mathrm{m}^{2}(\mathrm{c})
\end{aligned}
$$

318 
VAPOR CONTAINER (Supplemental Calculations)

SHEET 7

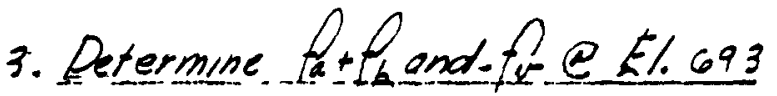

Areas . Steel

- $1886(10) \cdot 18860$

Conc. $-\pi d t=\pi(936) 24: 10000\} 89400$

I. Steed $\cdot 4 \frac{F^{\prime}}{2}=18800(180)^{2} \frac{1}{2}=217 \times 10^{\prime}$

Concrete.

$=70600(468)^{2} \frac{1}{2} \cdot \frac{774}{1191 \times 10^{7}}$

$S \cdot$ Composite $\left(1191 \times 10^{3}\right) / 180 \quad: 2480 \times 10^{4} \mathrm{in}^{3}$

$f_{a}+f_{b} \cdot \frac{11039}{89500}+\frac{157.2}{2680} \cdot 1233+63.4$

Conc. Steel

$f_{a} \cdot \rho_{b} \cdot \frac{d o}{2}-$ do $=61.7 \cdot 03.1$

$186.7 \mathrm{~m}^{2} \quad 1867 \mathrm{~m} / \mathrm{n}^{3}$

$f_{0} \cdot \frac{1}{3}(123.3)$

$-1.7(1) \quad-17(1)$

$41.1 \quad 411$

4. Determine Soul-beuring Values

Overturning mom restrained by: 1) Base moment

8) Passive Soil-bearing couple

Determine stiffness of passive soil couple for notation about norma axis at 1/3 height.

Soil stiffness taken as proportional to depth-

Effective width of cylinder taken as $\frac{\pi D}{4}$

$$
\begin{aligned}
& " 2 I_{a} ":(y-a)^{2} y_{l} d x \\
& \text { "Ia" } \frac{\pi}{4} 0 /\left(y_{0}^{2} \cdot 2 a y+a^{2}\right) y^{d} y
\end{aligned}
$$

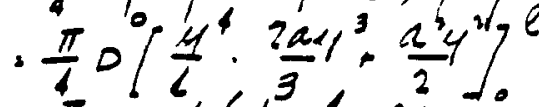

$$
\begin{aligned}
& =\frac{\pi}{4} D l^{4}\left(\frac{1}{4} \cdot \frac{1}{9} \cdot \frac{2}{9}\right) \\
& =\frac{\pi}{114} D L^{4}
\end{aligned}
$$

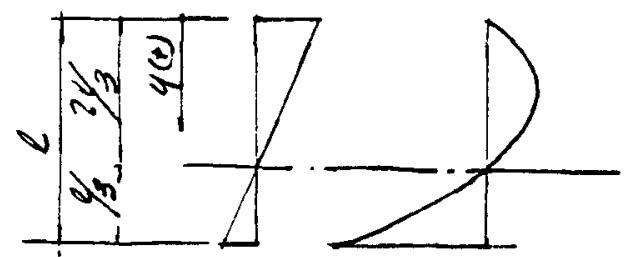

Stiffness. "et where $E: 2 l$

$$
\text { : } \frac{2}{l}: \varepsilon \frac{\pi}{164} D L^{3}
$$

319 
VAPOR CONTAINER (Supplemental Calculations)

SHEET 8

$E F$ (circular area): $E \frac{\pi}{64} 0^{4}$

cancel $\pi 0 / 4$

Passive Sori Stiffness: $\frac{1}{36} l^{3} \frac{\pi}{4} \not \phi / \frac{1}{9} l^{3}: \frac{(60)^{3}}{9}: 24 \quad 15.5 \%$

Base Stiffness : $\frac{1}{16} D^{3} \frac{\pi}{4} \phi \quad \frac{1}{4} D^{3}: \frac{800^{3}}{4} \cdot 128 \quad 84.2 \%$

Determine stiffness of passive soil couple for rotation about axis is plane of footing foundation interface

solving (i) for $a \cdot \ell$,

$$
\text { "I" }=\frac{\pi}{4 B} D l^{4}
$$

$E I \cdot E \frac{\pi}{43} D L^{3}$

Passive Soil Stiffness: $\frac{1}{12} l^{3} \frac{\pi}{4} D \quad \frac{1}{3} l^{3}: \frac{(60)^{3}}{3}=72 \quad 36 \%$

Base stiffness $\quad=\frac{1}{16} D^{3} \frac{\pi}{4} D \quad \frac{1}{4} D^{3}={\frac{(B O)^{3}}{4}}_{\Sigma}=\frac{128}{200} \quad 61 \%$

- Take $80 \%$ of overturning moment to base couple Determine soil pressure:

$$
\begin{aligned}
& P=21145 \quad \not 1=0.80\left(\frac{1}{3}\right) 767410=205000 \\
& A=\pi R^{2} \cdot \quad \pi(40)^{2}=5030 \\
& S=\pi R^{3} \frac{1}{4}: A R \frac{1}{4}=10 A=50300 \\
& f_{a}=\frac{21165}{5030}=4200 \\
& f_{b}=\frac{205000}{50300}=\frac{4080}{8280} \text { psf. }
\end{aligned}
$$

320 
Main Condenser (Ref. OWg. 19.662-702)

OPERATING $W_{T}=80.7 \mathrm{~K}$

FLOODED WT. $=141^{K}$

uSE $.33 G$ for lateral lond

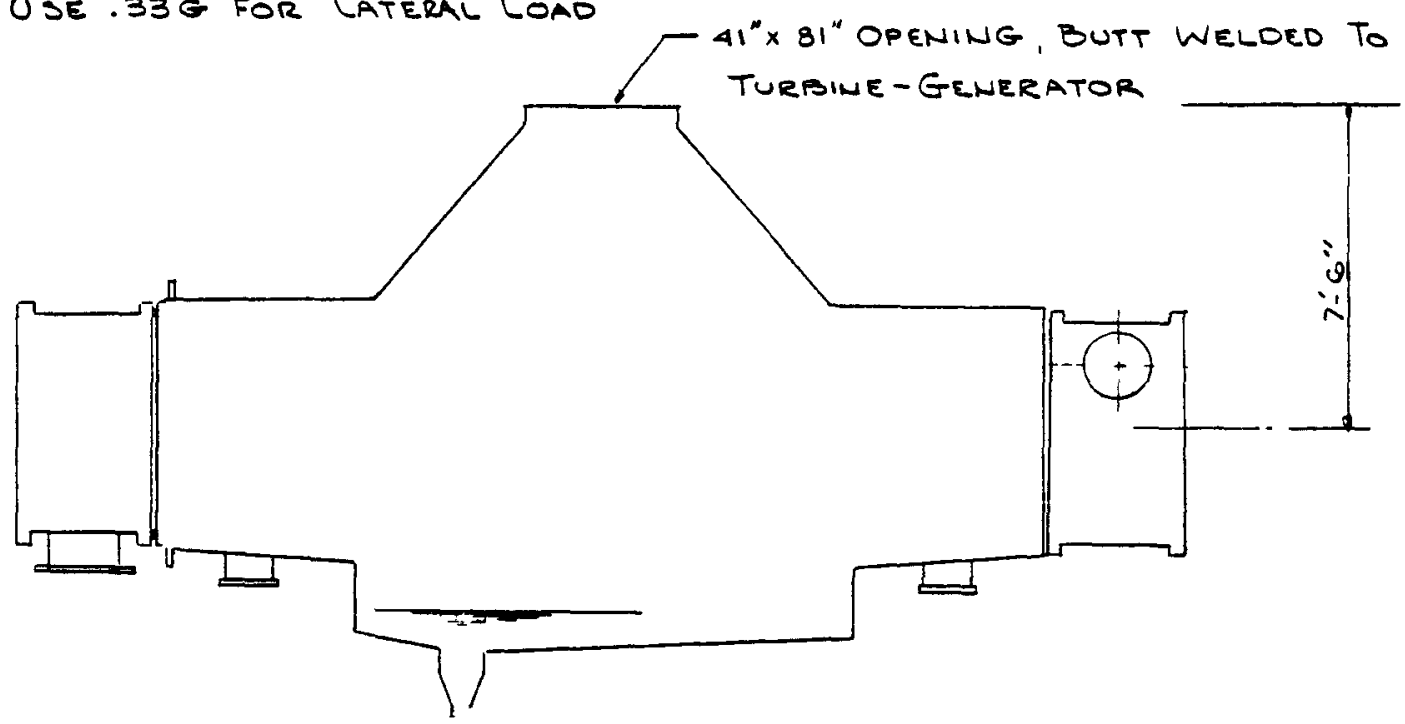

Max. LATERAL LOAd $=.33 \times 191=46.5^{k}$

Shear ter lineal INGh of Weld $=\frac{46,500}{2 \times 41+2 \times 01}=191 \mathrm{LBS} / \mathrm{in}$.

$P / A=191 / .33=580 \mathrm{LBS} / \mathrm{WN}^{2}$

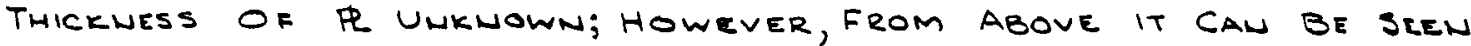
That the Direct stezsses Are Negligible,

Minimum $s$ BAsed On $t^{\prime \prime}$ 中 THICKNESS:

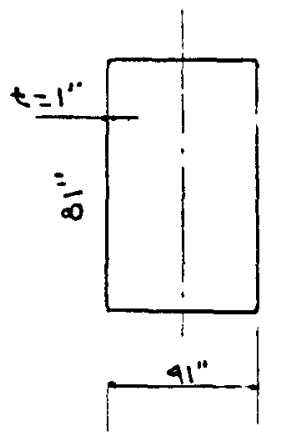

$$
\begin{aligned}
I=(2) 81 t \times \overline{20.5}^{2} & =60,000 t \\
\text { (2) } \frac{\pi_{1}^{3}}{12} t & =\frac{11,500 t}{79,500 t} \quad S=\frac{79,500 t}{20.5}=3,000 t
\end{aligned}
$$

MAx. MOM. $=7.5^{\circ} \times 46.5^{k} \times 12=4180^{\prime K}$

$f=\frac{4,180}{3,800 t}=\frac{1.08}{t}$

Assume $t=1 / 4^{\prime \prime} \therefore f=4.32 \mathrm{kSI}$ (NeGlect Direct Stresses)

Eccentricity About the Vertical axis through the c.g. Of the Support Will produce Torsion; However, There Does hot Appear to be Enovgh eccentricity Present to excero Capacity of joint. 


\section{MAIN CONENSER AND TURbINE SUPPORT}

FLOODEO WT OF CONDENSER $=141^{\mathrm{K}}$

WT. OF TURDINE \& GENERATOR $=\frac{114^{k}}{255^{k}}$

$P_{H}=.33 \times 255=84^{k}$

$8-11 / 2^{11 \sigma}$ A.B. G000 FOR $48 \mathrm{~K}$

$8-1$ - A.B. . " " $\quad \frac{27 k}{75 k}$

$75^{k}<89$ (12\% OVER L.A. BLDG COOE Allowable)

If operating Wt. Of condenser used (81.0k)

THEN $P_{H}=64^{k}<75^{k}$

In View of the Above, it is Believeo that the Auchormate is Adequate. 
AIR EJECTOR

(REF. DWGS. M-30 \& M.44)

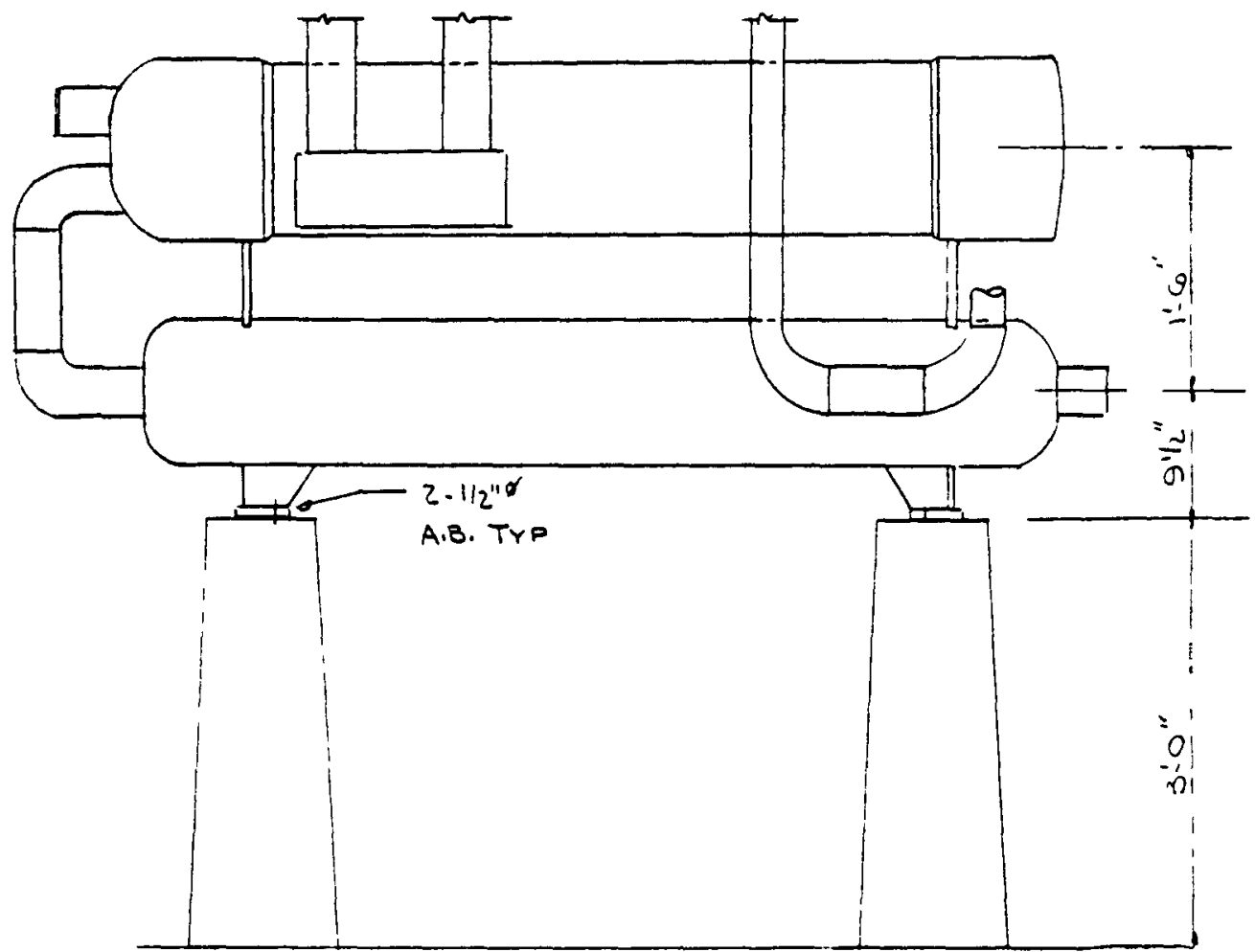

TOTAL LISTED ORY WEIEHT $=2.4^{K}$

Assume ADditional soo for OPErating CONDITION

$$
\therefore W_{T}=2.9^{k}
$$

Max. Shear to top of pedestals $=29 \times .33=.96^{\circ}$ (USE $C=.33 g$ )

SHEAR/BOLT $=.96 / 4=240 *$ (750 133 (L.A. BLOG CODE)

MAX. O.T. MOM. PER PEDESTAL

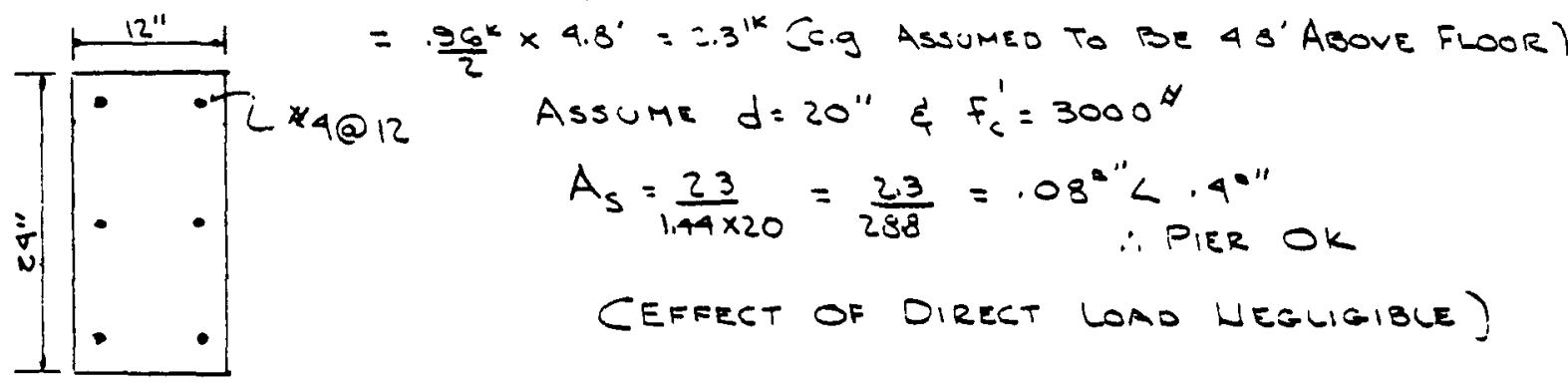

PLAN OF PIER 


\section{VACUUM TANK}

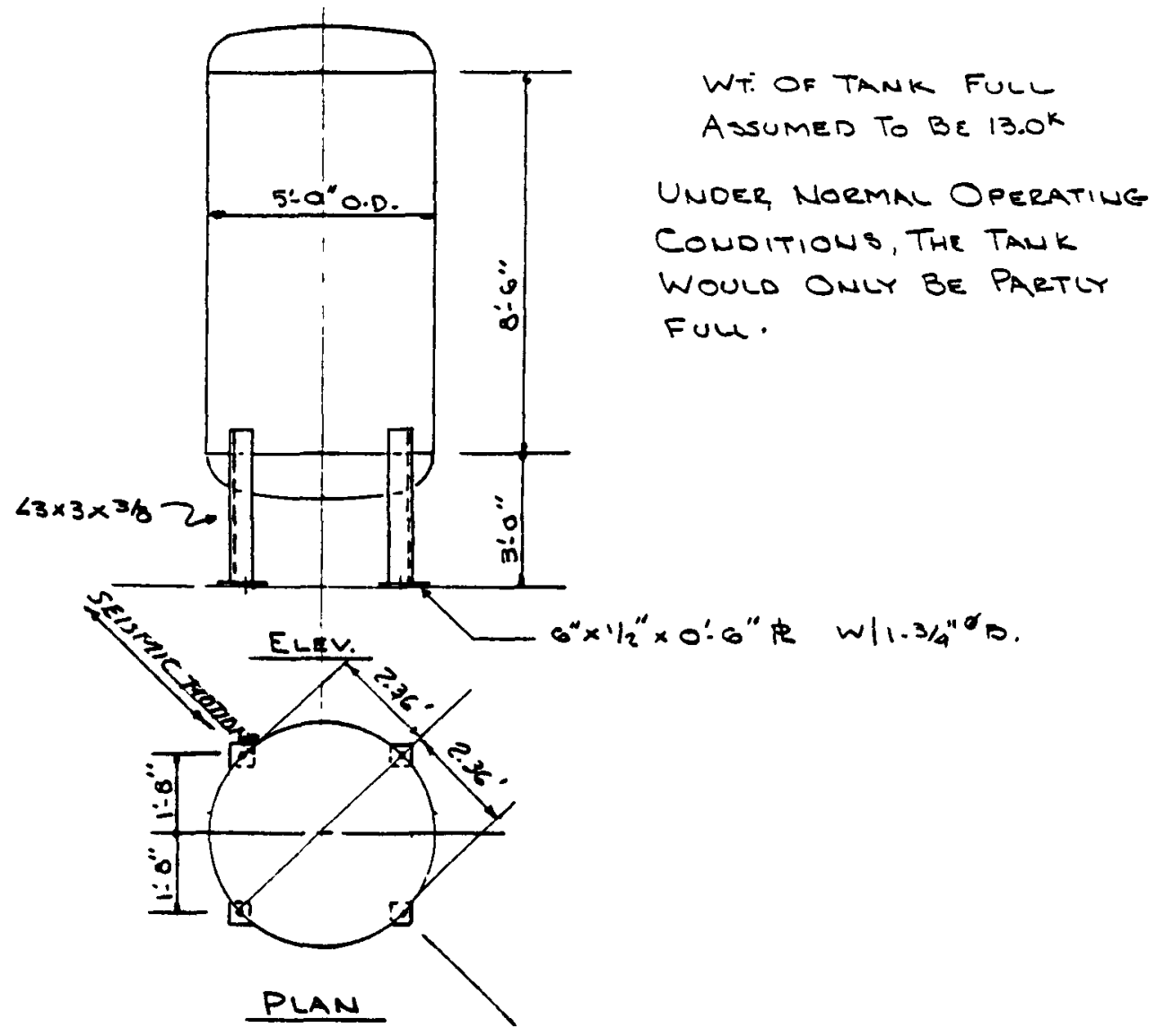

Static Deflestion for a $13.0^{K}$ lateral loado

$=\frac{13.0^{*} \times 27 \times 1728}{4 \times 3 \times 3 \times 10^{4} \times 1.8}=\frac{60.5}{69.8}=.935^{\prime \prime}$

Period of Vibration, treating tank as An Infinitely Rigid Body Awo VEGLCTING ANY ROCKING, $=2 \pi \sqrt{\frac{.935}{386}}=.31$ SEC.

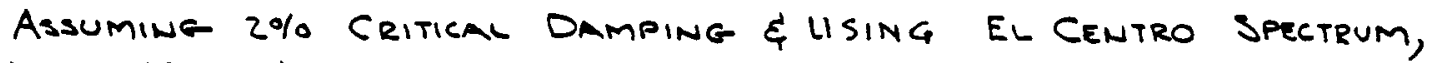
1940. MAX. Acceleration = 23 fps 2

$\therefore P_{H}=\frac{25}{32.2} \times 13.0^{k}=10.1 \mathrm{~K} ; P / A=\frac{2}{3}\left(\frac{13}{4}\right)=2.2 \mathrm{~K}$

MAX. UPLIFT $=\frac{10.1^{k} \times 7.25^{\prime}}{2 \times 2.36^{\prime}}-2.2^{k}=13.5^{k}-2.2^{K}=13.3^{k}$

Unable To Develop This LOMO WITH 3/4" FB. 


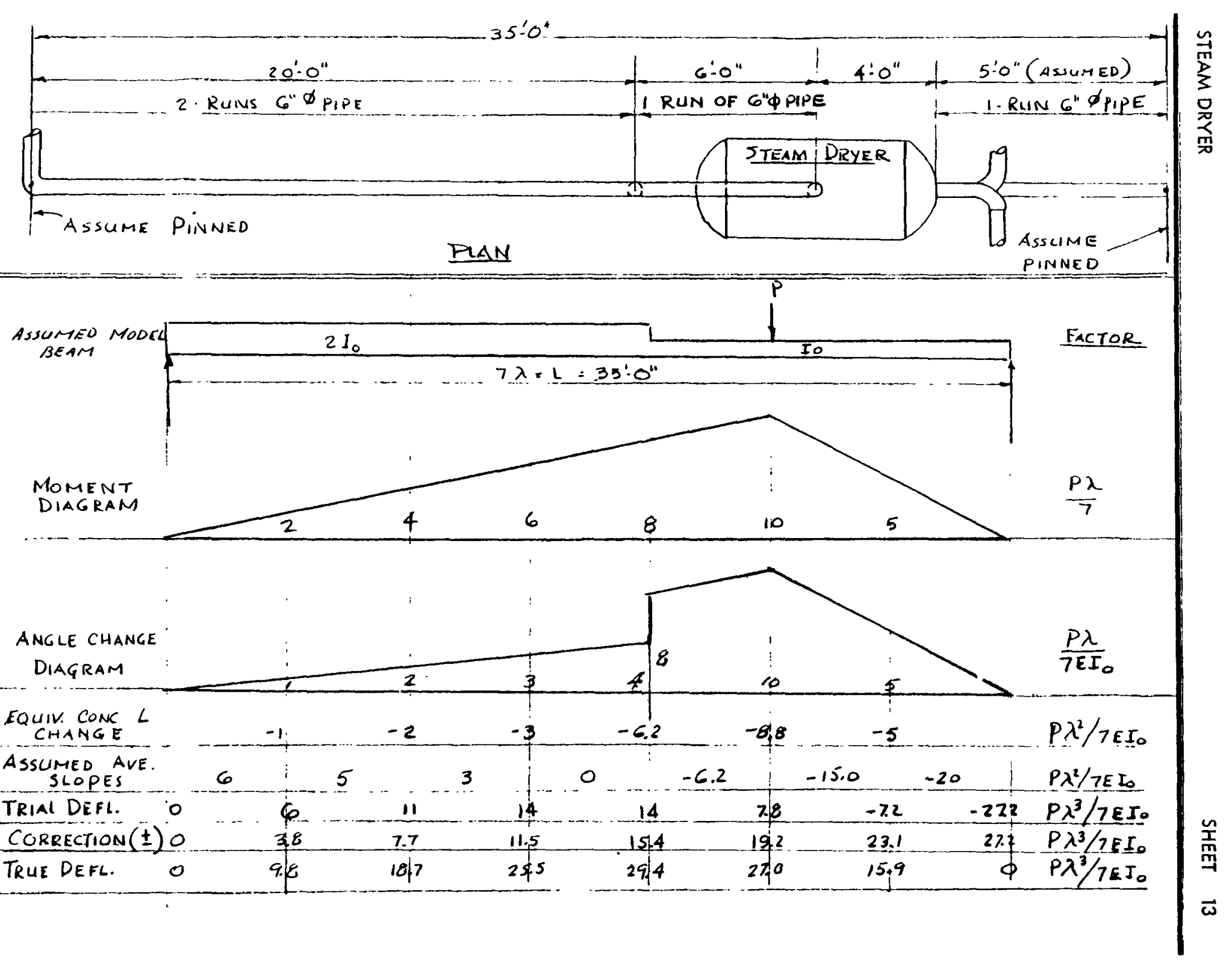


DEFLECTION OF MODEL BEAM AT LOAD $P$

is $27.0 P \lambda^{3} / 7 E I_{0}$

Assume $S C H .40$ PIPE, $\therefore I_{0}=28.14 \mathrm{in}^{4}, S=8.50 \mathrm{in}^{3}$

WT, OF DEYER FULL OF WATER $=9.7 \mathrm{~K}$

StATIK DEfLEction a FOr A HORIzONTAL LOAO = 9.7K

$$
\begin{aligned}
& =27.0 \times 5^{3} \times 1728 / 7 \times 3 \times 10^{4} \times 28.14 \\
& =302 / 390=.986 P=9.55^{11}
\end{aligned}
$$

$\therefore$ A First ApProximation for the FundMmEnTAL PERIOD of laternl Oscillation for the Assumed model beam is $T=2 \pi \sqrt{\frac{S_{87}}{9}}=6.28 \sqrt{\frac{955}{386}}=0.99 \mathrm{sec}$

USING THE EL CENTro SPECTRUM for 1990 \& Assumina $2 \%$ Ceitical Damping, Mnx. Acceleration $=13.0 \mathrm{Fps}^{2}$

$\therefore \quad P_{H}=\frac{13}{32.2} \times 9.7 \mathrm{~K}=3.92 \mathrm{~K}$, Max. MOM. $=\frac{10}{7} \times 3.92 \times 3=28.0^{1 \mathrm{~K}}$

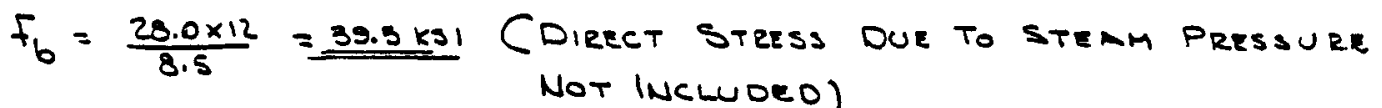
$f_{t}=P \frac{A_{0}}{A_{s}}=600 P 31 \times \frac{28.9^{\circ \prime}}{5.38}=3100$ PS1

$f_{b}+f_{t}=30.5+3.1=42.6 \mathrm{ksI}$ 


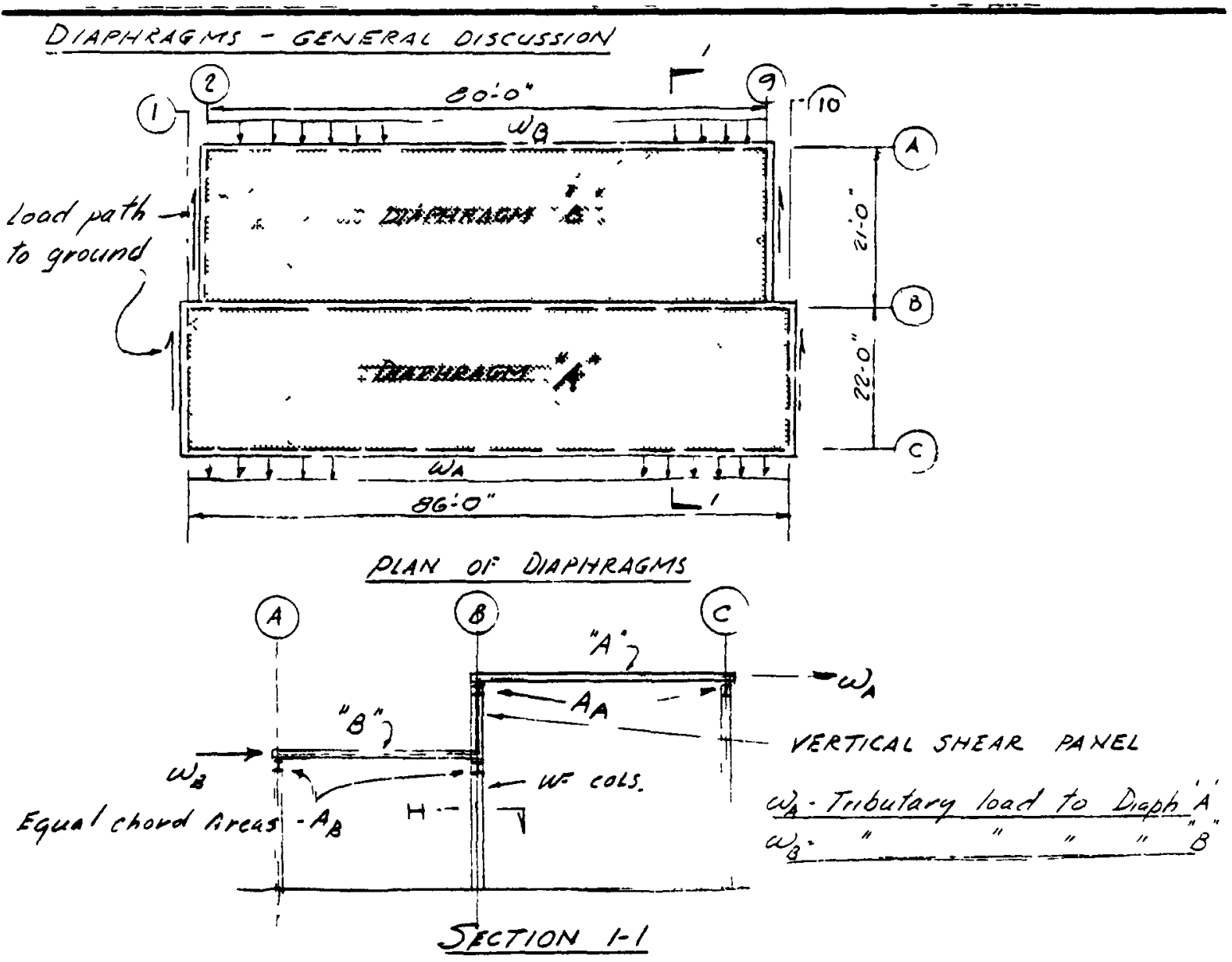

The diaphragms consist of precast units connected together in a questionable manner. However, it can be assumed that the lateral stiffness is of sufficient magnitude that the culumns on line (B) will not partake in interaction between the two lovels This would be especially true when the lateral loads, $\omega_{n}$ and $\omega_{\beta}$, are in the same direction, since both draphragms are obout equally loaded and of similur stimensions and of equal strexith. the verfical shear banel at line (e) serves separate functions for transverse \&' Iongitudivar seismic loads for transwerse loads, it will act along curlt the wede flange chords in resisting the moment of the diaphragms, as these diaphragens act separately fir longetudinat seismic, it will serve to transfer the shear to the grou.. thre the system of shear walls 
SERVICE BUILDING

SHEET 16

For the commonly assumed case of the resisting moment furnished solely by the diaphragm chords, free bodies are obtained

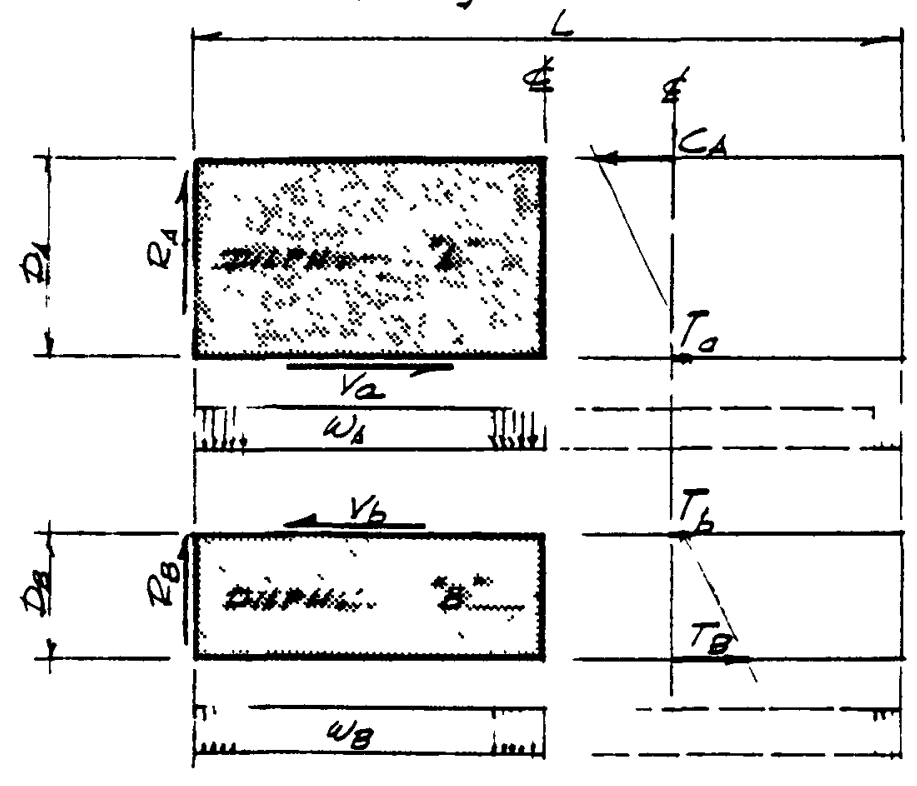

$$
\begin{aligned}
& W_{A}=W_{A} L \\
& W_{B}=w_{B} c \\
& V_{a}+T_{a}=C_{A}
\end{aligned}
$$

Fr equal axial deform,

$$
\begin{aligned}
& T_{a}=\frac{A_{A}}{A B} T_{b} \\
& T_{b}=\frac{A B}{A_{A}} T_{a} \\
& r_{b}-T_{b}=T_{B} \\
& r_{a}=V_{b}-\left[\begin{array}{l}
\text { shear in } \\
\text { vert panel }
\end{array}\right.
\end{aligned}
$$

1) Where the diaphragms are free fo delos independently, no interdiopnrogm load trans fer ceders, the, free bodies indicate the complete force system, and, consequently, the conditions of statics ore seen to be sufficient It may then be concluded that, for this case, each horizontal diaphragm resists only the loadings direly trite tory thereto, and no rather complications need be consideredvalues for chord stresses may be obtained from

$$
\begin{aligned}
C_{A} & =\frac{\omega_{A} L^{2}}{8 D_{A}} \\
T_{a}+T_{b} & =C_{A}-T_{B} \\
T_{a} & =\left(\frac{A_{A}+A_{B}}{A_{A}}\right)\left(C_{A}-T_{B}\right)
\end{aligned}
$$$$
T_{B}=\frac{\omega_{g} L^{2}}{8 D_{B}}
$$$$
T_{b}=\left(\frac{A_{A}+A_{B}}{A_{B}}\right)\left(C_{A}-T_{B}\right)-(2)
$$

for $A_{A}=A_{B}=A$ equation (2) becomes

$$
T_{a}=T_{b}=2\left(C_{A}-T_{B}\right)
$$

328 
ROOFDIAPHR: TRANSVERSE LOADING

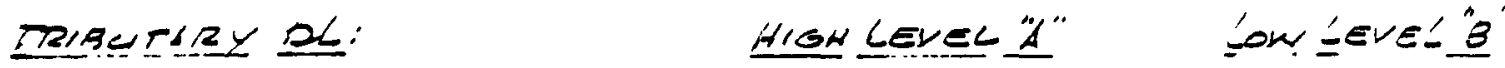

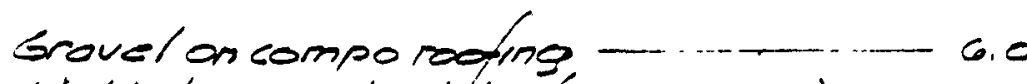

lightwr. concrete slabs (owrwne 3 33) 25.0

steel froming

Suspended ceiling

Block portitions

WALL-LWE

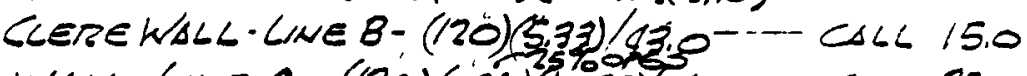

WALL - LNE C - (120) $(0.75)(10.33) / 2(22,0)$ CSLC 3.5.0

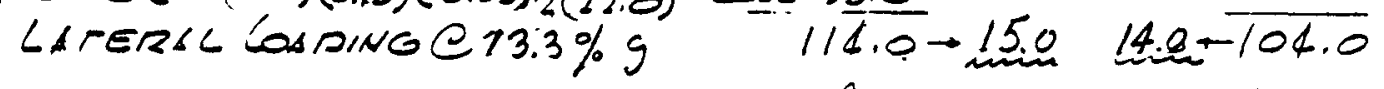

Note: Assume opproximotely $60 \%$ of the block sortitions of the lower roof level oreo derive lateral support from the low ievel diophragm " $\theta$ ".

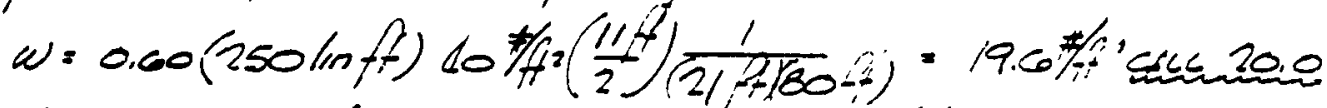

Assume all of the block pantition's sithe higher roof level orea of erwe lateroi support from the high level diophrogm "A".

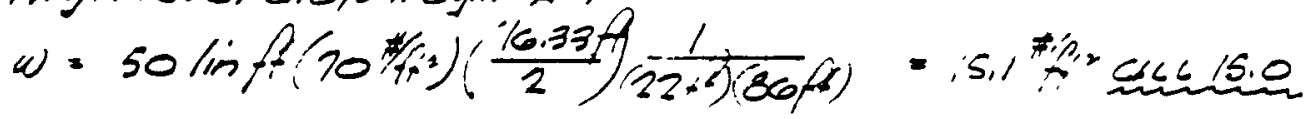

\section{LOSDING DISTRIBUTION}

Since diafhragins act independent (this wocid be true for monolithic diopiragms connected by fitexible colemns), then disiribution is by tributary orees, ond,

$$
\begin{aligned}
& \omega_{A}=15.0(27,0) \cdot 330 \neq \\
& \omega_{B}=14.9(21.0) \cdot 290 \% \\
& \left.\begin{array}{l}
W_{A}=330(86.0): 28,000^{\#} \\
W_{B}=290(80.0): 23,000^{\#}
\end{array}\right\} 51,000
\end{aligned}
$$




\section{Dibphragams - Transveresa loadna (Contá)}

DETSIL GHECK:

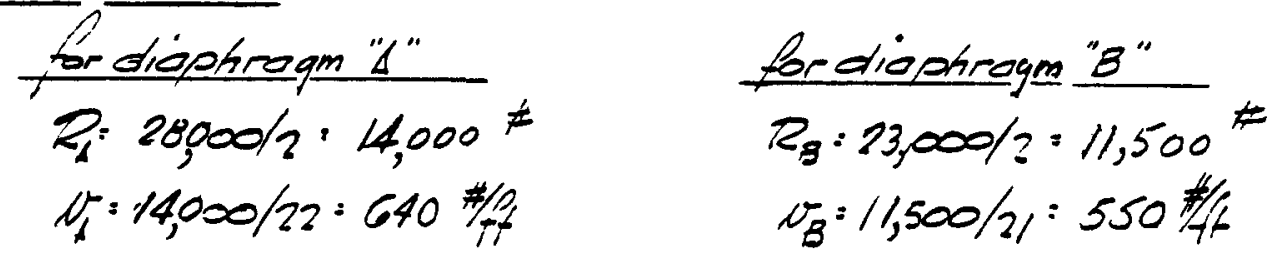

For the ossumed construction condition orno positwe atfachments o-precost slobs to stee: toming, the vorious discrete = v shrogm elemenits will slio into besring, ond the dio ohrogm will remoin intact. However, excessuve inelostic vie'́lections will bermíl crocking oripported walls.

Fr the possistecons-ruction sondition o- a positile

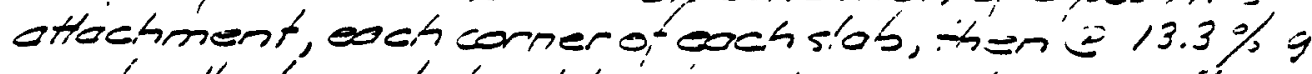
equi attachment should no- ne stress=e' to more fhon ills normal volues. Six atteciments ivaibice, or, $H_{A}=14,000 / 6=2300$ * $\quad H_{B}=11,500 / 6=1900$

As these volwes ore relotwe'y small, well-vesianed modera's atfochments will be odequote to maintoin in terity ódiophrogm.

$$
\begin{aligned}
& M_{4}=28.0(86) / 8 \cdot 300^{1 K} \quad M_{\theta}=230(80) / 8=230^{1-k} \\
& C_{B}=T_{A}=300 / 220^{\circ} / 3.6 \mathrm{~K} \quad C_{B}=T_{B}=230 / 210^{\circ} 11.0 \mathrm{~K} \\
& \bar{a}=C_{a}=z_{1}^{\prime}(3.6-11.0) \cdot 5.2 \mathrm{k}=\bar{i}_{b}=C_{b}=\left(E_{g}-(3)\right)
\end{aligned}
$$

Direci lines o, steel -́raming assum= chors stresses. splice lood's moy induce slos-ic bending of cilip. 
SERVICE BUILDING

SHEET 19

RoOF DIAHRAGM- LONGITUDINAL LORMNG

TK'BCTARY DOL.

HIES LEVEL 'A

From. transverse loads

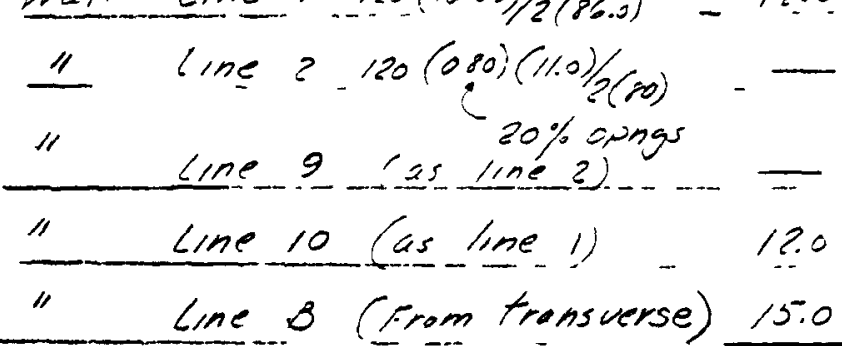

loads $013.3 \% \sum_{G} \cdot \frac{103.0}{136}$
LON LE ESL

690

-

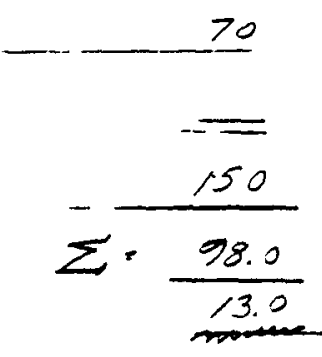

DETAIL CHECK: (FOR ROOF CALLS., ASSUME WALL B INEFFECTIVE (IN GATING SHEAR LOAD TO THE GROUND.)

for diaphragm " $A$ "

$\omega_{4}=13.6(86.0)=11501 \mathrm{bs} / \mathrm{ft}$

$W_{A}=1150(22.0)+26,000 \mathrm{lbs}$

* $r_{A}=$ Rear line $c$ - 25,00u lbs

$v_{A}=24500 / 860=280 \mathrm{~kb} / \mathrm{ft}$ for diaphragm ' $\beta$ "

$\omega_{B}=13.0(800)-104 \mathrm{~s} \mathrm{lbs} / \mathrm{st}$

$r_{B}=1040(210) \cdot 22,00065$

* $V_{B}=40-i n e A-23,000$ lb ir

$\sigma_{B} \cdot 23000 / 30=290 \mathrm{Lbs} / \mathrm{th}$

$V_{A}+r_{B}=W_{A}+W_{B}$

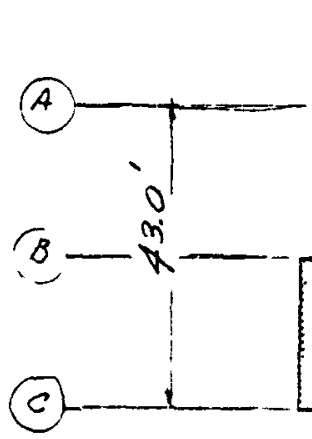

(c)

.

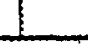

$D, a, b t . " A$

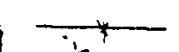

$\frac{\hat{s}}{i_{n}} \times N_{B}=22,000 \mathrm{lbs}$

$V_{A}=25,000 \mathrm{lbs}$

LONGITUDINAL LOADING

331 
SERVICE BUILDING

SHEET 20

LONCITUDINAL SEISMIC (CONT'O)

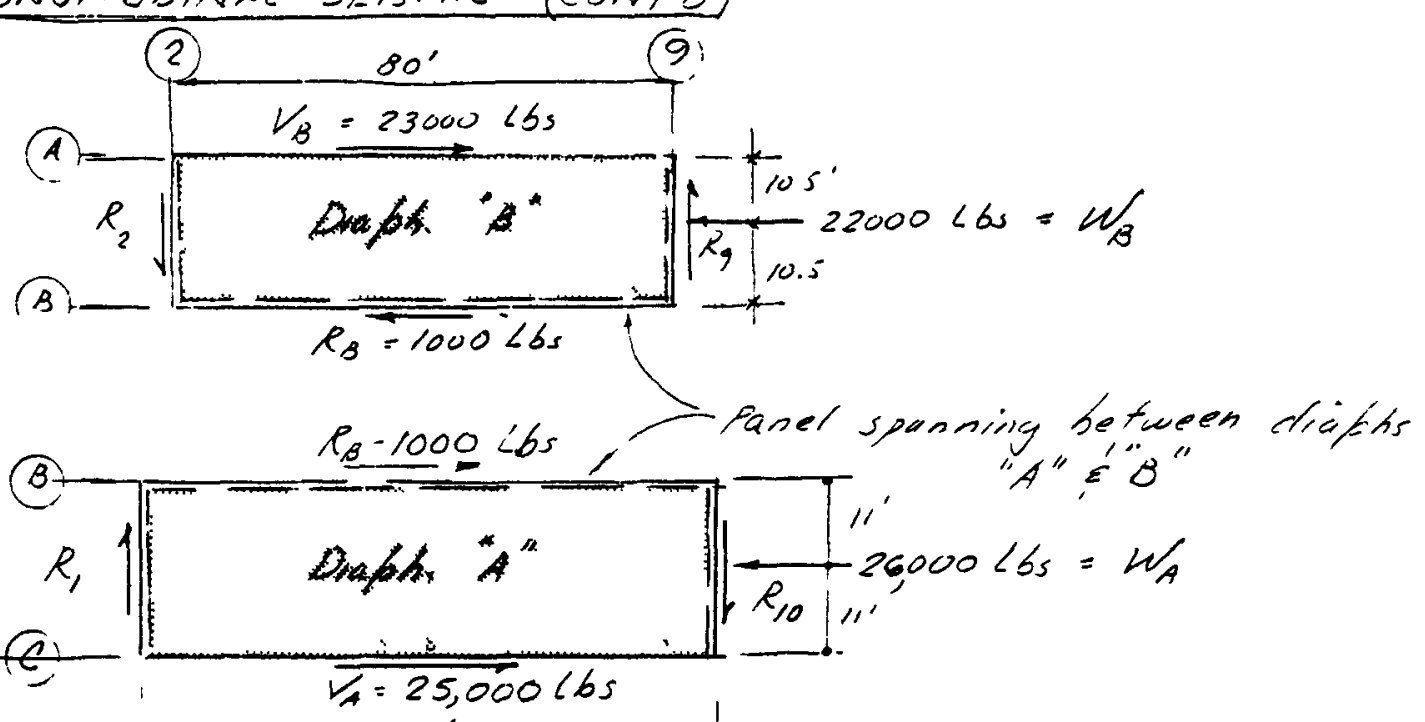

(e)

(1) FREL-BODY DIRGS. (10)

$$
\begin{aligned}
& r_{2}=R_{9}=\frac{23,000(21)-22,000(10.5)}{80.0}=6000-2900=3100 \mathrm{Lbs} \\
& r_{2}=r_{9}=3100 / 21.0=150 \mathrm{Lbs} / \mathrm{ft} . \\
& R_{1}=r_{10}=\frac{25,000(22)-26,000(11)}{86.0}=6400-3300=3100 \mathrm{Lbs} \\
& r_{1}=v_{10}=3100 / 22.0=140 \mathrm{Ls} / \mathrm{ft} .
\end{aligned}
$$

ROOF DIAPA - SUMAIAYY

1) Transverse lateral anll govern shearsterses e $640 \mathrm{lbs} / \mathrm{ft}$, is ofposed to 290 bs/ft mbminlongitudinut leading.

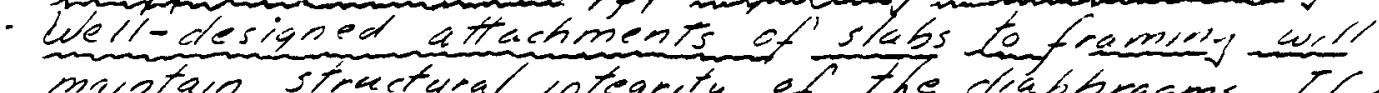

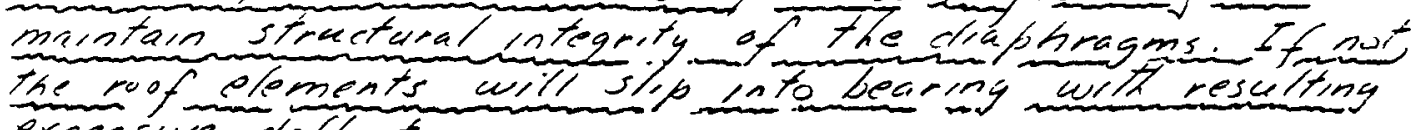
excessive deflections.

2) Adeyaate chords arefuenished by lines of steel froming,

332

$v$ 


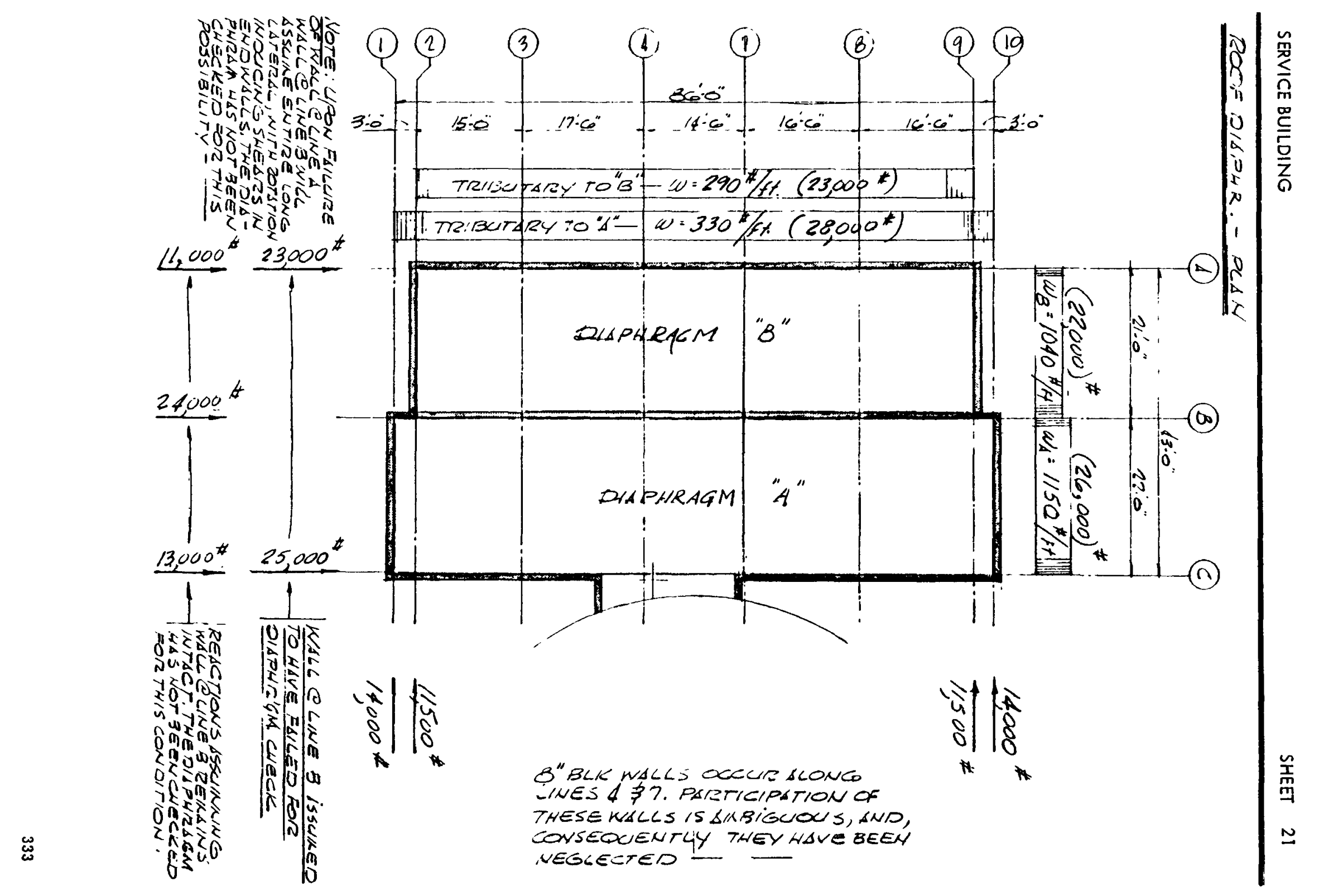


IKAIN FLOOR DISPWRS'M PLSN

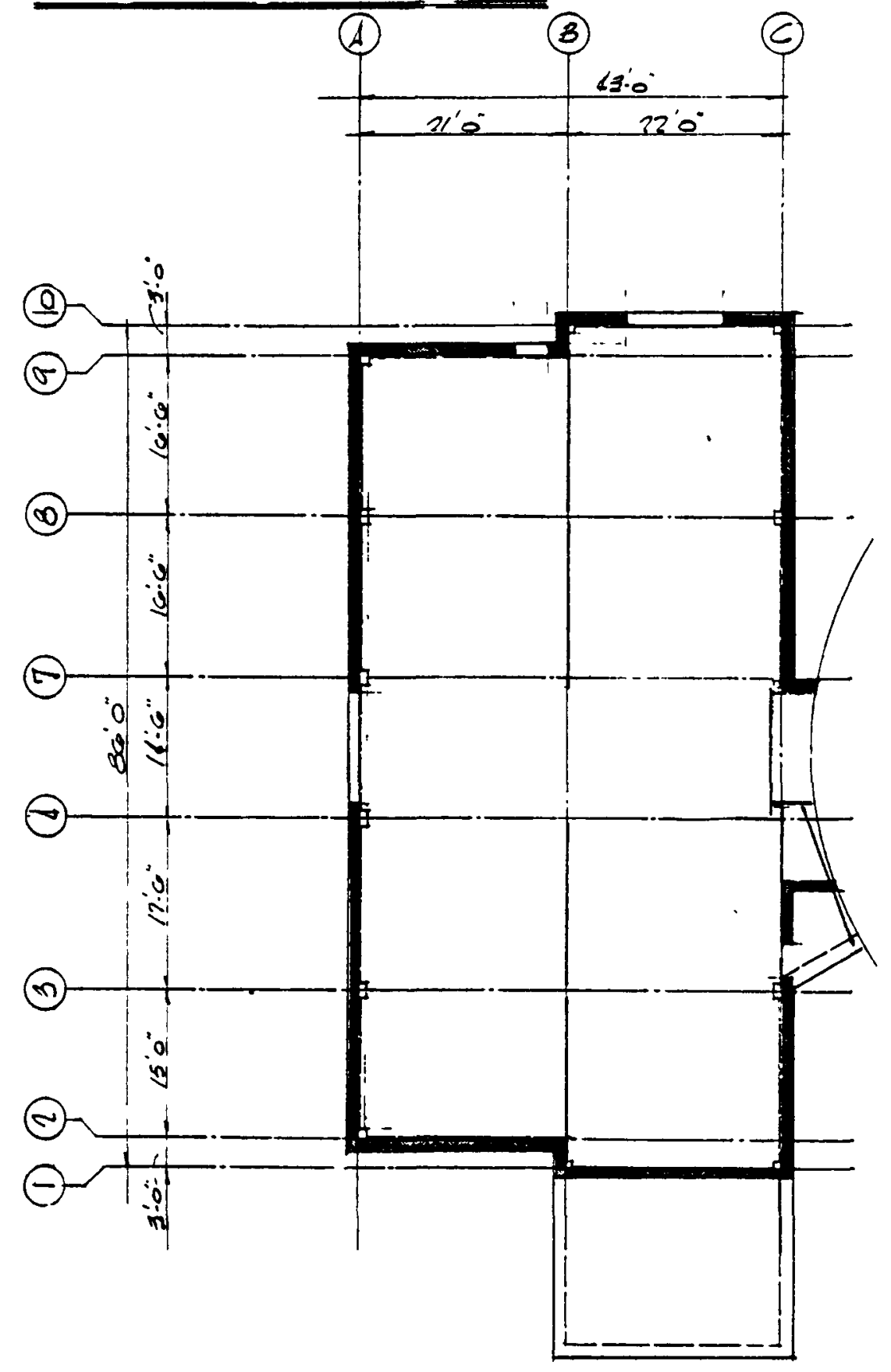

prophragm is o 6"-8" concrete steb with primors steel froming along oll chords. Bosement shear walls of 1.4 "concrete enciose" four sides. Cateral suster? adequate without detal cheet - 
N/ALC LNE 3

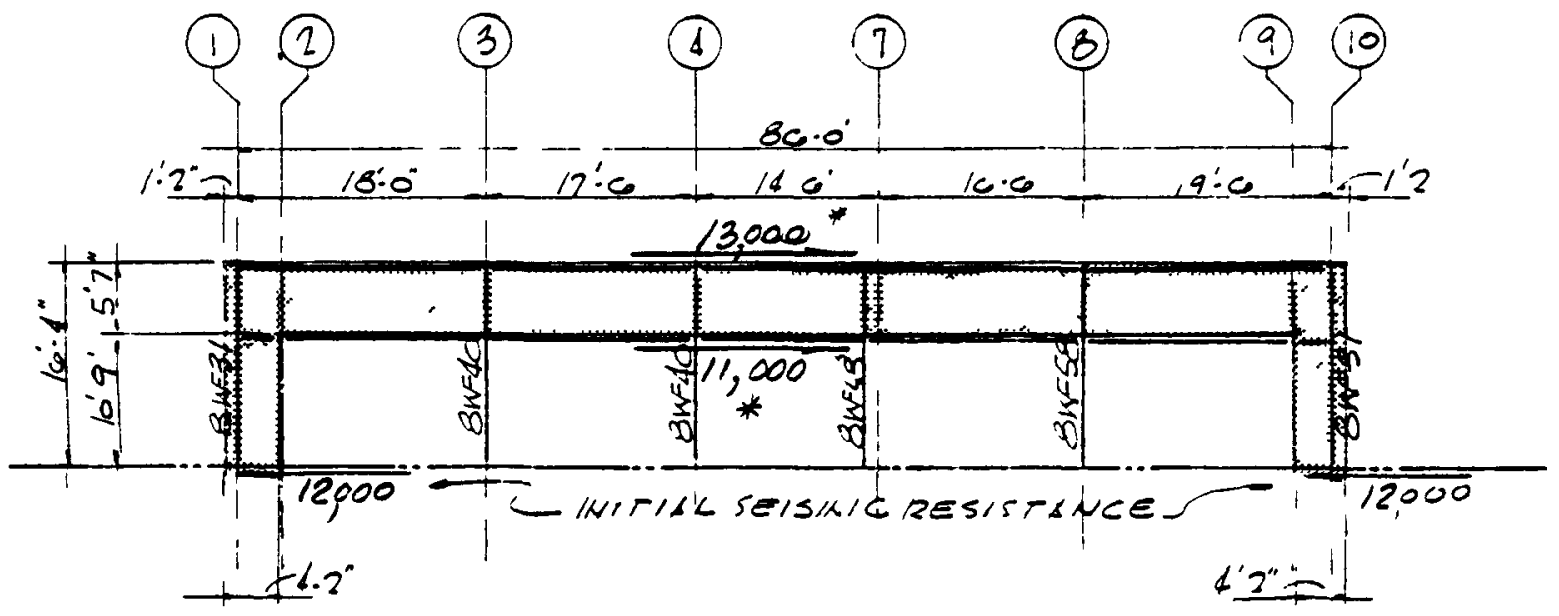

*ivcli des wat. of brick sPAndrel

GHECK ENP DIERS

$\left.M=12.0(1075)=130.0^{\prime \prime} 5.800^{\prime}=0\right)^{2} \cdot 6: 3330 \mathrm{in}^{3}$

$F_{6}=130(11000) / 3330=470^{\circ}$ in igrossarea

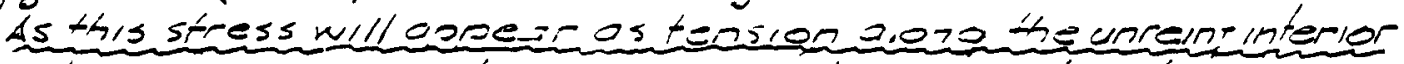

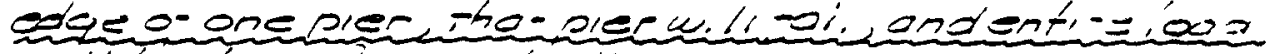

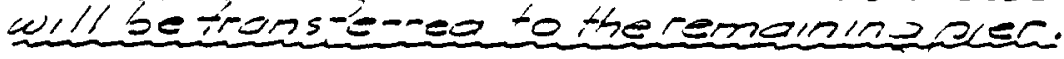

Correc- pier llomenit to $k=$ (2) $130.0: 260$ 'c

sect on properies of .

resisting 'ension

Tak= $=10 \quad 10 \cdot \frac{874}{210(355)} \cdot 0345 \quad$ B"*

$\dot{c}=, \overline{0,00+0.060}-0215: 0190$ kd: $174^{\circ} \mathrm{jd}=29.7^{\prime \prime}$

fe. $\frac{2(260)(12,000)}{207(2,0)(174)}=570 \mathrm{Hin}^{2}$ $F_{c}=210(1 / / 3)=320 \mathrm{in}^{2}(\Delta \Delta \text { cir } Y)^{-t}$ Pessibie Cano jilis

$$
(\operatorname{con},-0)
$$

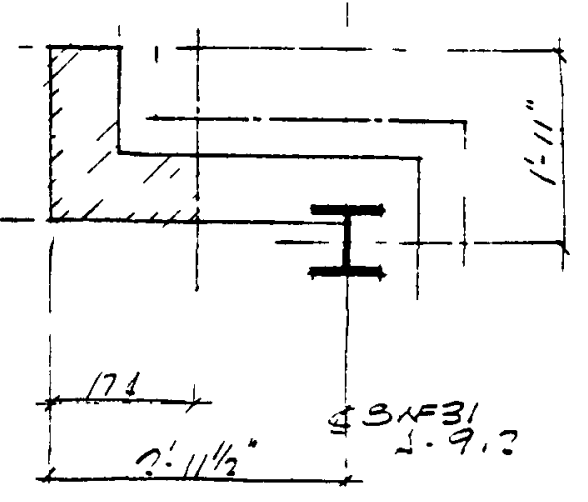


Entire sheor 15 ,ributory bo onesier, $v=24,000$ \#

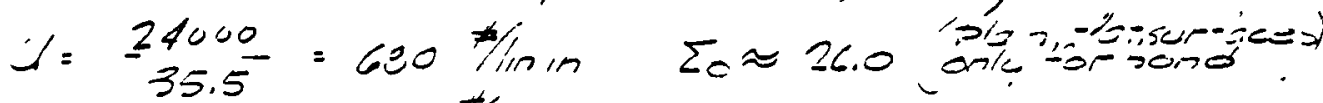

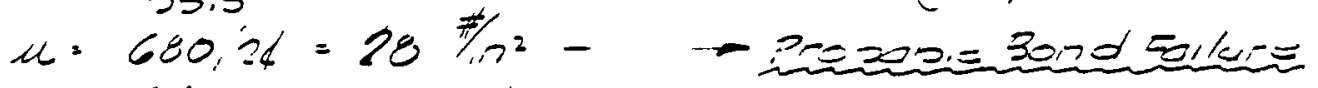
if: $\frac{24000}{8(35.5)}=85.1 / 2-$ - -

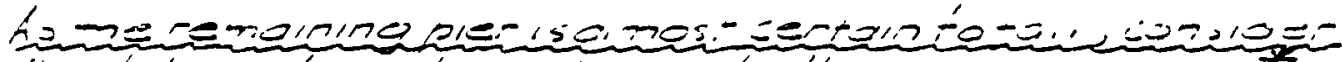

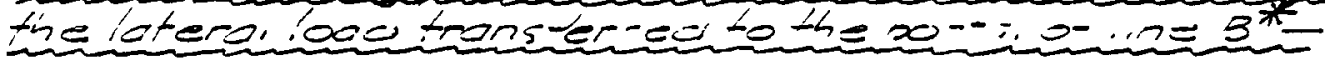

in the following rabuiar soiution, the unsurport $=d$ coumn

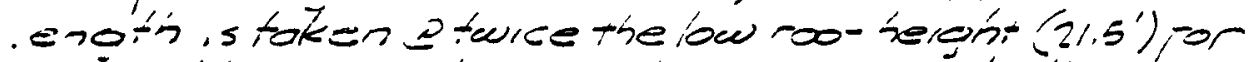
allowcible comp. Stresses to con-orm with the cose, or

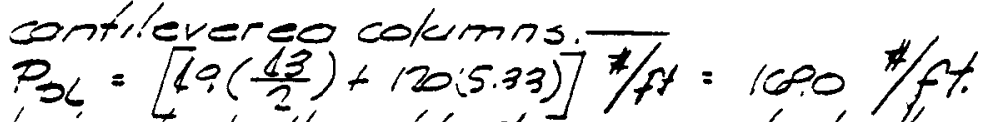

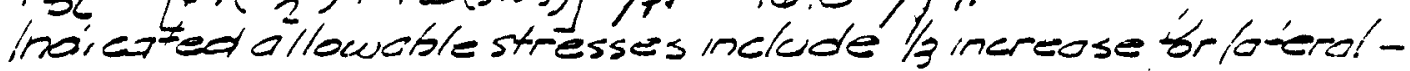

\begin{tabular}{|c|c|c|c|c|c|c|c|c|}
\hline Line & Col. & $I_{y y}$ & $v((6))$ & $x(1 \cdot k)$ & $S_{Y y}$ & $=8$ & $f_{b} /=$ & \\
\hline 1 & $S K=31$ & 37.0 & 2900 & 31 & 9.2 & 20.0 & 2.0 & \\
\hline 3 & $8 K=60$ & 69.0 & 3800 & 41 & izi & 1 & 2.0 & \\
\hline 4 & $8 k=10$ & 49.0 & 3000 & 41 & 2.1 & ! & 2.0 & \\
\hline 7 & $\sigma k=18$ & 60.9 & 4700 & 50 & 5.0 & & 2.0 & \\
\hline 8 & $B k=58$ & 74.9 & 5800 & 62 & 8.2 & & 2.0 & \\
\hline 10 & Ox=31 & 37.0 & 2900 & 31 & 7.2 & & 2.0 & \\
\hline Line & Col. & $T L$ & $P_{D L}$ & $A$ & Ir & $F_{4}$ & $F_{A}$ & $\sum H / F$ \\
\hline 1 & $8 k=31$ & 9.58 & 16.2 & 9.12 & 198.3 & 10.8 & 0.16 & 2.16 \\
\hline 3 & $8 x=10$ & 17.75 & 30.0 & 11.76 & 120.7 & 11.0 & 0.23. & 2.23 \\
\hline 4 & $8 k=40$ & 16.00 & 27.1 & 11.76 & 120.7 & 11.0 & $02:$ & 2.21 \\
\hline 7 & $B W=18$ & 15.00 & 25.3 & 1411 & 124.2 & 11.4 & 0.10 & 2.16 \\
\hline$b$ & $8 k=58$ & 18.00 & 30.4 & 17.00 & 1330 & 11.6 & 0.15 & 2.15 \\
\hline 10 & $8 k=31$ & 10.33 & 17.5 & 9.12 & 128.3 & 108 & 0.13 & 2.18 \\
\hline
\end{tabular}

Considering bending only, oase sheor to develor yield stress of 42,000 orisny, $8 w=40)=3950$. Corresinondina iateral"detlection = 1.92 " (See wollo-line A for conciuding remorks).

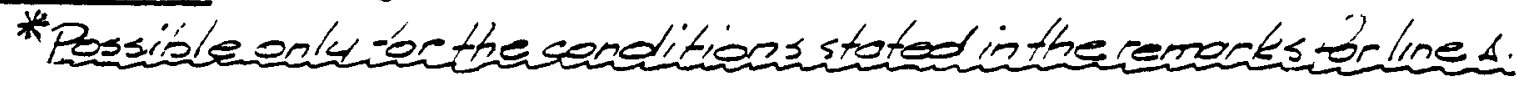


WALL LNUEA

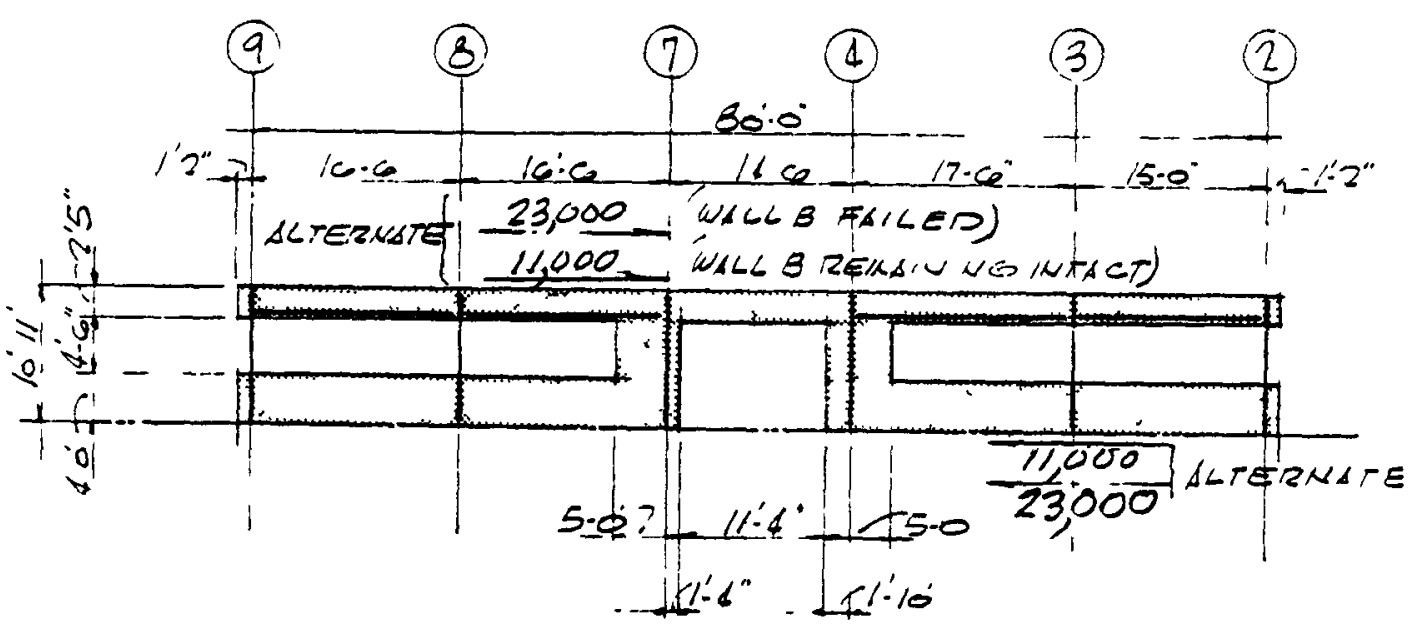

LOADING TRANSFER FROK WALL

The colcubtions or wall b indicate a orogressue julure or end piers and possiple lood transier to the limber hame or line B. if however, the roo, diophragm mointoins structurol integrity,

1) The limber frome will ossume nobod; insteos: the bad of woll $\theta$ will be shored by the walls orlines $A$ \& $C$

1) If wall A fils (as willse demonstrated), the entire seismic efori, will se resisted by wollc, with resultino torsional sheors to the end walls.

3) Limber frome willossume locd only f Woll of line c foils, and it will be shown thathis wall is odequote, br, Zll lonoitudinal seismic.

It though the fbilures will probobly progress in the indicated order, it is iniorabable that such a degree of destrectron will be attoined, considering the major magnitude of energy odsorption esvolved- 


\section{SHECK PIERS}

The masonry spandre' appears ineffective os a device to fix the uprer ends of the piers, and, consequentle, this spondrel willbe neqlected. -

Then, os for the woll ofline $B$, one of the two prens will hove on unicinforced edge stressed in tension with accomponying failure, and the remaining pier will ussume the entire woll lood. -

Cheek this pier, for the condition of failure of wall a. $V=23,000^{*} x=23.0(4.5)=10 \mathrm{f}^{1-k}$

Taken=20 np: $\frac{187.4}{8.0(38.0)}=0.60$ $k: \quad \sqrt{1.30+0.36}-0.60 \cdot 0.65$ $k d \cdot 21.7^{\prime \prime} / d .29 .8^{\prime \prime}$ $I_{c}=\frac{.(104)(12,000)}{29.8(8.0) 24.7}=430 \% / 1 n^{2}$ $F_{c}=260^{-}(1 / 1 / 3): 320 \% 1 /(6.1 . c 1 r y)$

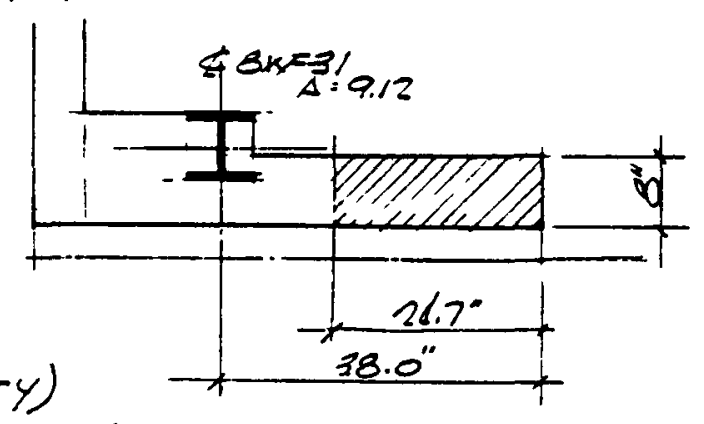

\section{Bossible compressive bilure}

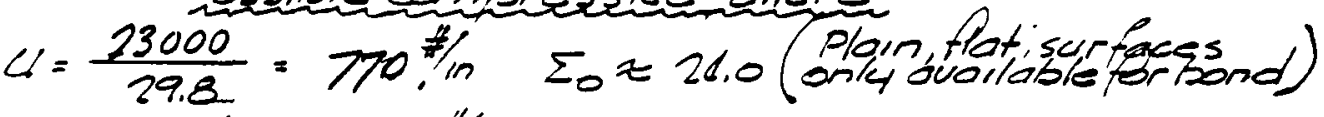

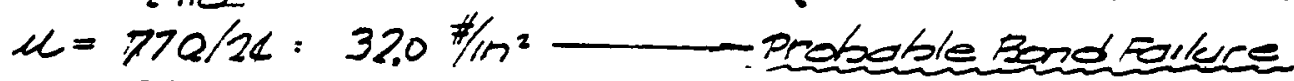
$v=\frac{23000}{B(29.8)}=97.0 \% / \mathrm{n}^{2} \ldots$. Sertoin Sheor foilure Easidering bilure ofwall t check walleline ctor:

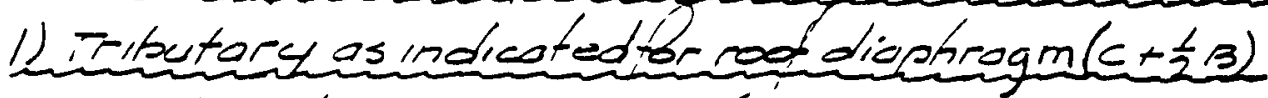
2) Full longitudinol seismic $(\Delta+\beta+c)$ 
$K A L L-L N E C$

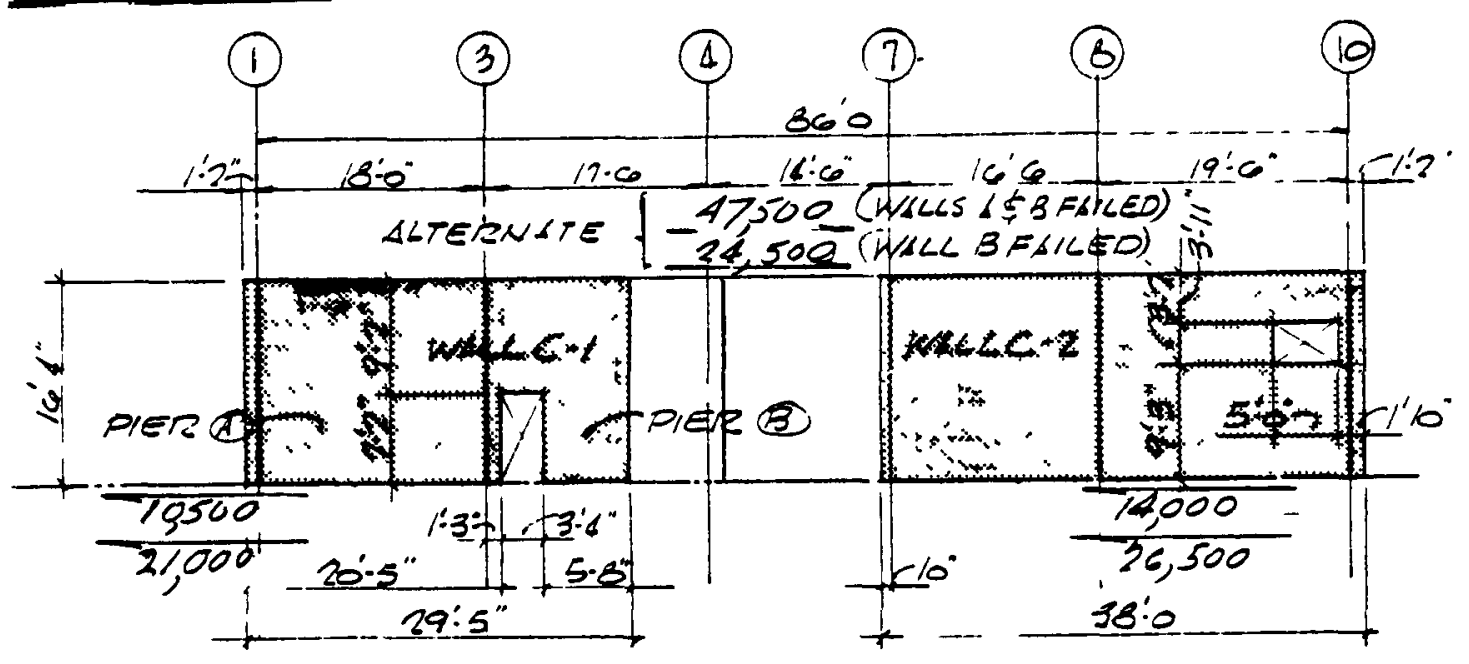

GHECK FOR CONPITION OFWLLB ESILEO

$W / L L C-1:$

Cowsidering lack of adequate tensilt reinfórcing along one edge of pier (G), consider ine; -estive-

As stesl-foming will-érnish boundory requirements opierd, shearing and bond stresses will govern.

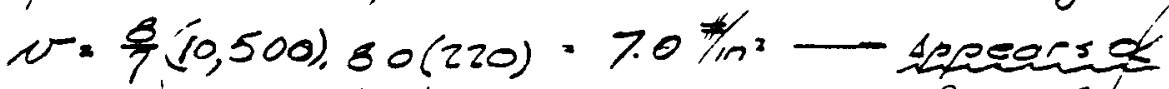

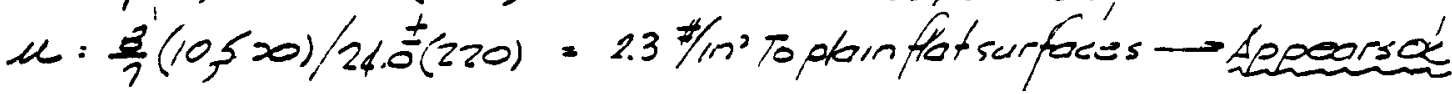

$W / L C=2:$

steel framing will tünis n boundory requirements -

$v=\frac{\theta}{7}(14,000), 18.0(602)=4.401 / n^{2}-\cdots$

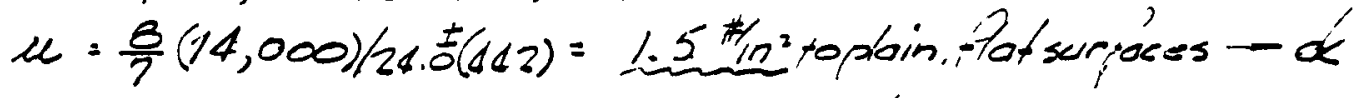

CHECK FOR CWUTION OF SOTH WALCS $\triangle$ E 3 FLILEO WALLC-I:

$v=7.0(21.0 / 10.5)=13.4-v k \quad v=4.4(26.5 / 14.0)=8.7 \ldots$

$\mu=2.3$ (do) $\cdot 4.5$-ok $\mu=1.5$ (do) $=2.9-k$ Asenerger dissipationwill prevent this All lood forn developing vullis Ewith nossible minor cracsing - 
WALLS-LINES I Eै

(A)

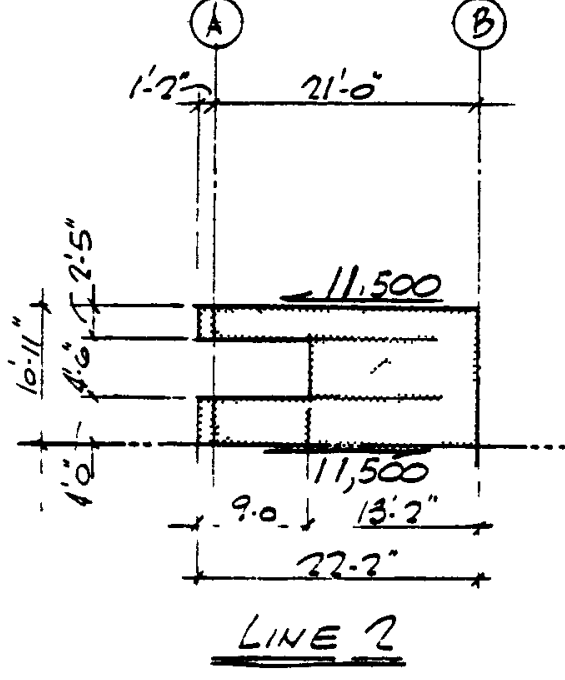

Masopry, spandrel appears ine recive, br pier plxity; toks moment is that or $45^{\prime}$ cantilever and cheek'tensile, compressive, isheorstresses-

$K=11500(4.5) / 2=630,000 \mathrm{in}-\mathrm{lbs}$.

$S=8.0(158)^{2 / 6}: 33300 \mathrm{in}^{3}$

$\frac{1}{t}=\frac{1}{c} \cdot 630,000$ 3330n: $19.0 \mathrm{H} / \mathrm{in}^{2}$

$\left.v=\frac{\theta}{7}(11,500) / 8.0^{\prime} / 56.0\right)=10.67 / 1^{2}$

$N=\frac{8}{7}(14,000) / 30(275)=7.3 \mathrm{k} / \mathrm{in}^{2}$

sliqht cracking possible as shear acts in confunction with tensiun.

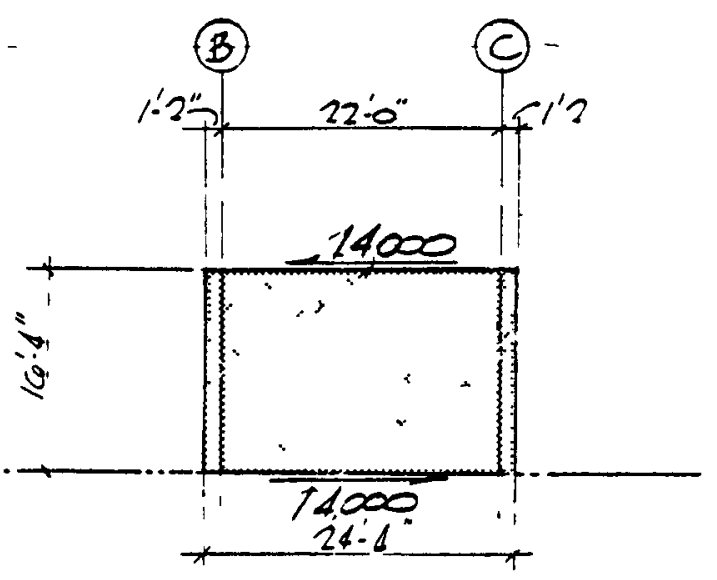

As steol Loming will fünisí boundors requirements of pier, shearing and bonostressewillgovern -

$$
65 .
$$


WALLS- CWES $9 \pm 10$

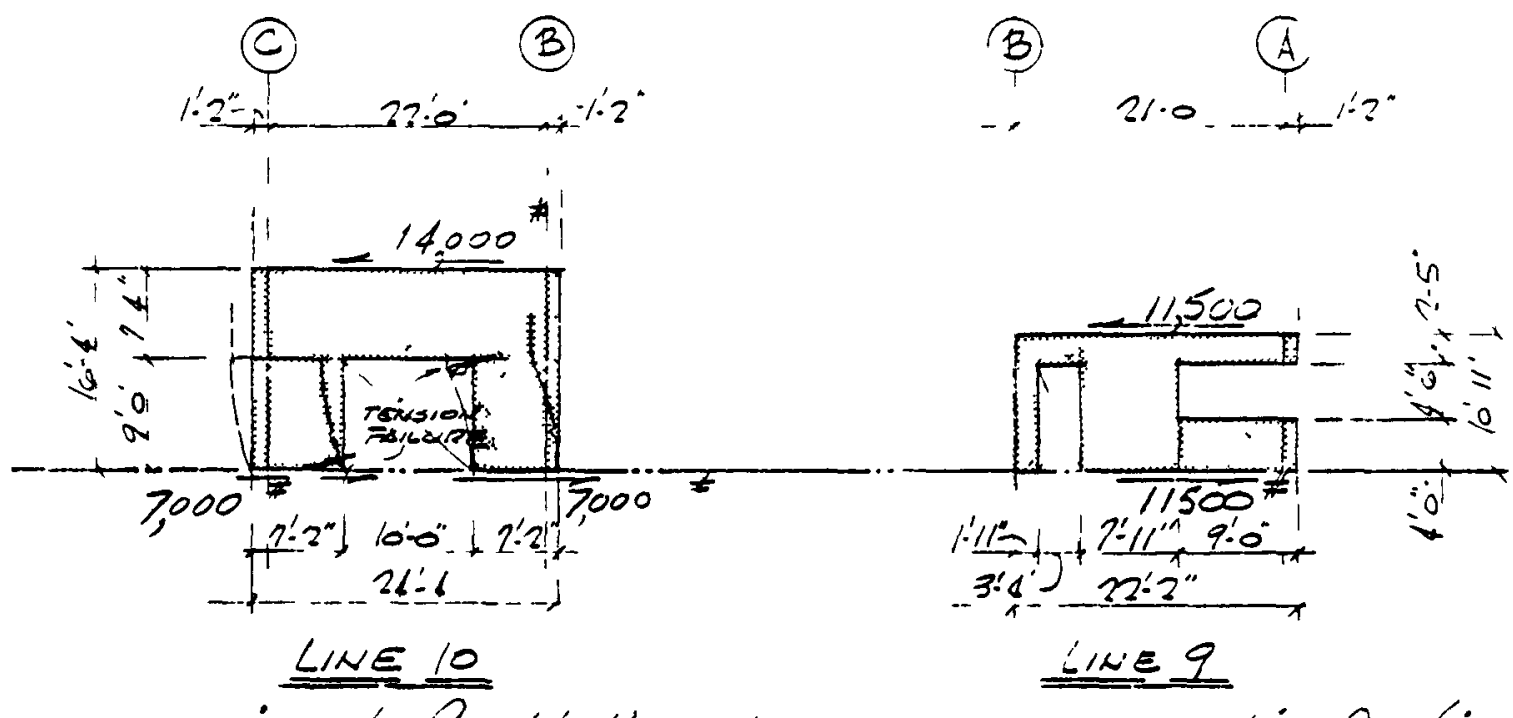

ussume pierstof fxed both ends. Kasonrey spondrel inefective vilure intension edooredses willinduce a condilion winere eneplerconticuers from the sponoirel pind the oitherpier from the foundotion wall-

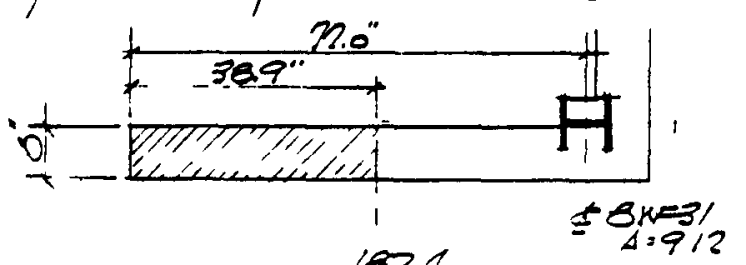

.xten.20 pp: $\frac{182.4}{8.0(22.0)}=0.317$ ón piertiwity, rien, $K=11.50(\mathrm{l})=52.0 \mathrm{ft}-\mathrm{K}$ $S=80(950), 6 \cdot 12000 \mathrm{in}^{3}$ fticic. 52 i2000/12000 $=52$ in - Excessive ortension $w=\frac{8}{7}(11.50018095 .0)=17.5 \mathrm{in}^{2}$

- - Possible cracking as shear

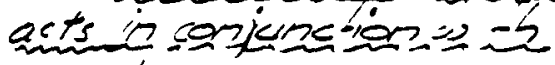
tension.

$k \cdot \sqrt{0.636+0.100}-0.317 \cdot 0.540$ kd: 38.9 fd: 590

$K=70(9.0): 63.0^{1-k}$ $\tau_{c}=\frac{2(63.0)(12.000)}{59.0(80) 38.9}: 04.0 \mathrm{~m}^{2}$

$=\bar{c}_{c}=260^{-}(4 / 3): 370^{-1 / 1 n^{2}}$

$\left.\omega=7,000 / 26.0(720)=4.107 / 10^{2}\right\}$ wallwill bescocked bet,

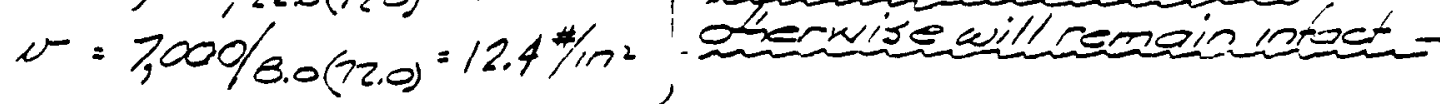




\title{
Appendix C
}

\section{EARTHQUAKE EXPERIENCE IN UTILITIES AND INDUSTRIAL PLANTS}

\author{
FIGURES \\ C.1 Example of Instrument Behavior During an Earthquake. \\ $\begin{array}{lll}\text { C.1 Example of Instrument Behavior During an Earthquake. } & \text { C.t Tranaformers Damaged by an Earthquake. } \\ \text { C.2 Demaged Oll-etorage Tank. } & \text { C.5 Tranaformers Damaged by an Earthqualce. }\end{array}$ \\ Tehachapt, Callf., Earthquake, July $21,1952$.

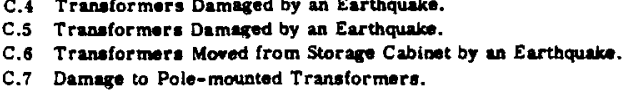

\section{C.1 INTRODUCTION}

The following discussion deals primarily with fossil-fuel and hydroelectric power plants and oil refineries on the West Coast. The former category is chosen because of the direct comparison that may be made between such plants and the conventional parts of nuclear power stations. Petroleum refineries are included because of their functional similarity to certain nuclear installations and because this type of plant seems to have suffered more damage from earthquakes than any other on the West Coast.

Much of the data in this section was furnished through the courtesy of the following organizations:

California Edison Company

Pacific Fire Rating Bureau

Pacific Gas and Electric Company

Southern California Gas Company

\section{C.2 STEAM-ELECTRIC POWER STATIONS}

\section{A. Plant 1}

Plant 1 , built in 1910 , consists of two sections. The first section is of reinforced concrete; the second section is a light-steel frame with reinforced-concrete sidewalls and end filler walls. The building columns, walls, and principal machinery foundations were on piles, but the floors were of mat construction poured directly on backfill. All walls were finished with stucco plaster over the concrete surfaces.

After the March 1933 earthquake, there was apparent uneven settlement of the two buildings. The floor in the turbine room settled, causing severe cracking at the adjacent walls. Settlement of the floor around one boiler caused bad sagging of an adjacent roof panel and loosened the firing aisle windows that leaned in beyond the walls. The floor in the transformer house settled as much as $1 \frac{1}{4}$ in., and lesser settlement was noted in the 
machine shop floor. Severe settlement of the blacksmith and carpenter shops resuited in these buildings pulling away from the main building about $1 \frac{1}{2}$ in. Severe cracking of masonry walls occurred at wall junctions and construction joints and to a lesser degree in other areas. The entire wall of the generator room moved slighly in a southerly direction. A water standpipe $36 \mathrm{ft}$ in diameter and $100 \mathrm{ft}$ in height stretched its anchor bolts from $1 \frac{1}{16}$ in. to 2 in. All the anchor bolts were stretched, which indicated a gyratory motion of the tank. A considerable amount of breakage occurred in cast-iron pipes buried in the ground around the installation. Transformer oil piping lines were broken at welded and brazed joints.

\section{B. Plants 2 and 3}

Plants 2 and 3 , built about 1925, are extensions to Plant 1. Both plants are supported on 40-ft piles on 30-in. centers. The plant foundation consists of a heavy concrete mat on these piles, with pyramidal facing for concentrated loads. Building frames are integral with internal structures, resulting in a strong, probably well-damped, complex. These two plants survived the 1933 earthquake without serious damage. Minor damage to oil and water lines resulted in recommendations that these lines be run above ground for ease of inspection and repair. It is interesting to note that, in the 25 years following the 1933 earthquake, these plants have undergone about 24 ft of vertical subsidence with necessary adjustments in equipment and interconnections being made as the settling occurred. (This subsidence has not resulted directly from any earthquake but is thought to be a result of the removal of offshore oil deposits and the support they have afforded for coastal regions).

\section{Plant 4}

Plant 4 was severely damaged in the 1933 earthquake. This damage is described in a letter from an eyewitness, H. C. Vander Heyden of the Southern California Gas Company, formerly known as the Los Angeles Gas and Electric Corporation. Excerpts from the letter are as follows:

In the Long Beach earthquake of 1933, the Seal Beach power plant of the Los Angeles Gas and Electric Corporation was extensively damaged. The plant was designed and constructed by Dwight $P$. Robinson and Company of Chicago for the Los Angeles Gas and Electric Corporation and was completed in May, 1925 at a cost of approximately $\$ 6,000,000$, or about $\$ 85$ per kilowatt based on 70,000-kilowatt capacity. It is located in the City of Seal Beach on the south side of the inlet to Alamitos Bay which is about six miles southeast of the City of Long Beach and about 30 miles from the business center of Los Angeles.

The building and equipment foundation, operating floors, and the water tunnels are heavy reinforced concrete. The buildings are structural steel frame, and the interior and exterior walls were non-reinforced brick, constructed as filler walls only. The two 35,000-kilowatt generating units were located on a mezzanine operating floor in the open-type turbo room and were supported on structural steel columns and girders approximately $25 \mathrm{ft}$ above the main floor. The stack was of reinforced concrete, $375 \mathrm{ft}$ high, $25 \mathrm{ft}$ across the top, and it was supported above the boiler room floor on steel columns and girders; it provided natural draft for the six boiler settings. The electrical building was four stories high.

The soil at the site was coarse gravel with scattered rock formations capable of supporting foundation loads of 3500 psi when contained. The concrete structures under high tide level were ringed with continuous steel sheet pling, and the screen intake house had steel piling under the foundation as a water cutoff. There was no visible evidence of fissures or subsidence in the ground in the plant area.

The morning after the earthquake, the station looked to be in shambles. The majority of the brick walls had fallen either in or out of the buildings. The glass in the remaining windows was broken, the piping connections to the domestic water supply tank were broken and had dropped approximately 30,000 gallons of water on the roof. The structural girders, columns and braces supporting the turbine mezzanine floor were buckled, and rivets were sheared and popped; the structural frame supporting the stack was also bent, with many rivets sheared and popped. All of the 
reinforced-concrete work, as well as the mechanical equipment except one turbine generator, all the piping and the boilers, and the electrical equipment with the exception of the transformers, remained in operating condition. In fact, one turbine kept running until the operators pulled the fire from under the boilers.

The top one-third of the concrete stack was severely cracked and spalled. The main transformers, which were mounted on wheeled trucks for easy change-out, had been tipped over against the compartment walls, severing the electrical connections, which killed the electrical output from the station. This damage all happened in a period of about 30 seconds; subsequent shocks caused additional bricks to fall without further damage.

The rebuilding of the station was started within one week after March 10, and the principle corrections made were:

The stack was cut down $177 \mathrm{ft}$ and forced draft fans installed.

The brick walls were replaced with reinforced brick, doweled into the floors, and tied into the steel frame of the building.

The cast-iron fittings and valves on the overhead domestic water tank were replaced with steel.

The steel columns and girders under the turbine floor were repaired and reinforced with additional heavy structural braces.

The steel braces and girders under the reduced stack ( 700 tons of weight removed) were repaired.

The main transformers were placed on larger and heavier constructed trucks.

The cost of rebuilding was approximately $\$ 300,000$. As noted above, the original cost was about $\$ 85$ per kilowatt, in contrast to similar stations being built at that time, costing from $\$ 100$ to $\$ 110$ per kilowatt. It was evident that the majority of the saving was in the wall construction.

It was the opinion of the investigating committee that the station would have withstood this earthquake with a minimum of damage and expense if the brick walls had been designed of reinforced concrete and properly tied to the steel frame, if the stack had been supported by a concrete foundation at ground level and not carried on steel columns, and if the turbine supporting floor had been properly designed of heavier construction.

Of interest to instrumentation engineers is the chart, Fig. C.1, which was taken from the No. 2 exciter voltage recorder. This instrument, obviously only slightly damped, is a good example of the erratic readings that might be expected from reactor instrumentation, as mentioned in Chap. 8.

\section{Plants 5 and 6}

In the Arvin-Tehachapi, Calif, , earthquake of July 21, 1952, two power-producing plants suffered minor to moderate damage. A detailed account of this damage is given below.

The Kern Steam Plant, near Bakersfield [175,000 kw(e)] was finished in 1948. It is of steel-frame construction with concrete walls. Structural damage to the building was slight, consisting of minor spalling of concrete and separation of the bond between a steel column and concrete wall at one point.

Two oil-storage tanks were damaged, principally because of rotation of the floating roofs, damaging seais and breaking access ladders. About 500 barrels of oil were spilled (see Fig. C.2).

The thrust bearing on the No. 2 house turbine was damaged, and there was one failure of the boiler feed pumps, apparently due to loss of suction.

The small damage in this plant may be attributed to the fact that the structures were all designed for lateral accelerations of $20 \% \mathrm{~g}$. The damage to the storage tanks, result ing from rotation of the floating roofs through an angle of $15^{\circ}$, indicates the need for improved design of these items in seismically active areas.

The Midway Plant, near the community of Buttonwillow, suffered broken windows and cracked partitions. A 10,000-gal elevated water tower collapsed. A small hydroelectric plant (Kern Canyon Hydro) suffered no damage to the powerhouse or equipment, but a landslide 3 miles upstream badly damaged the diversion dam and gate-control equipment (Fig. C.3). 
NOTE: AT FIRST SHOCX RECORDING ARM MEETS OBSTRUCTION AT BOTH ENOS OF SWING, ON SOME SUBSEQUENT SHOCXS MEETS OBSTRUCTION ON INNER SWING ONLY

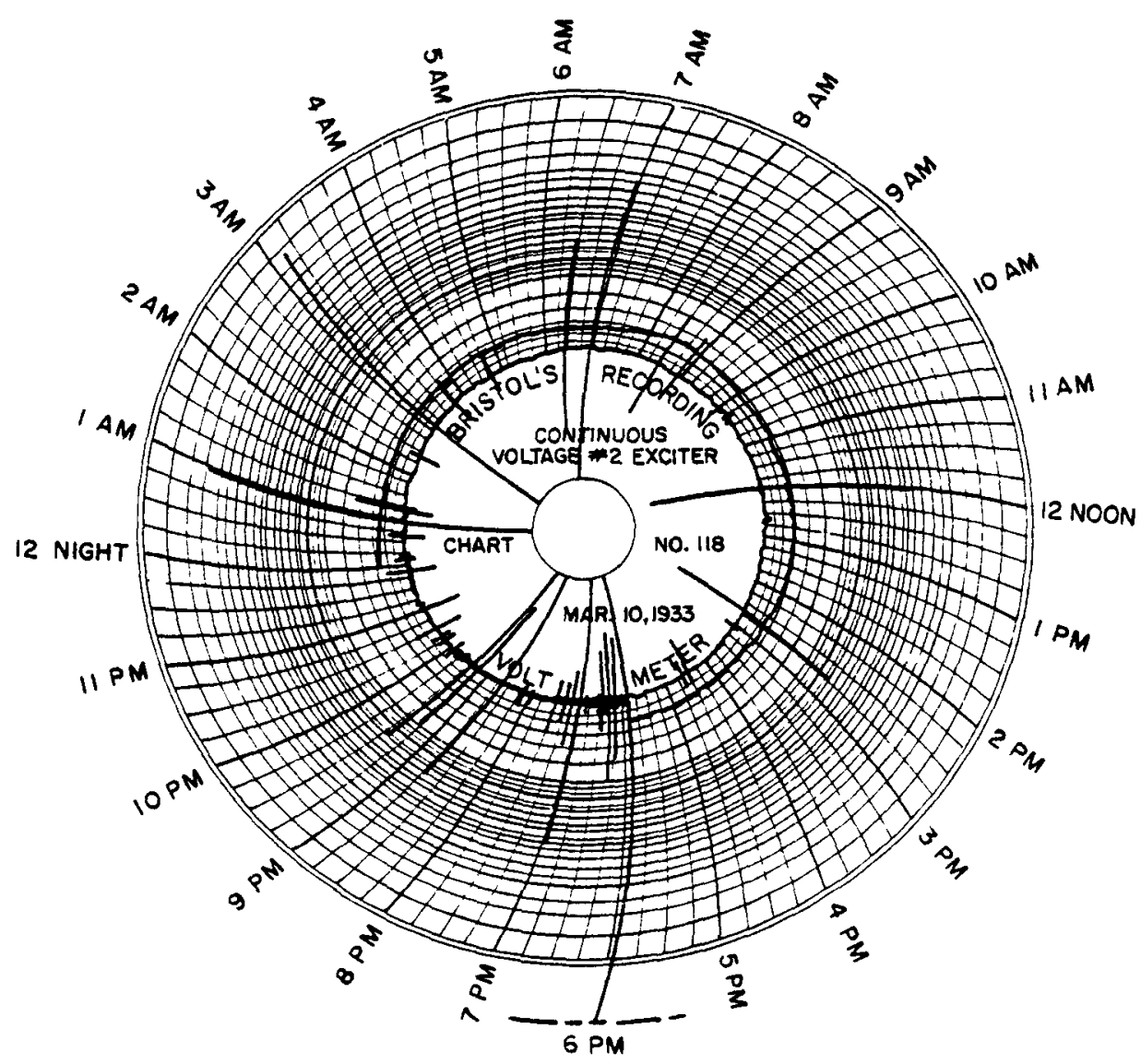

Fig. C.1-Example of instrument behavior during an earthquake. (Southern California Gas and Electric Company, formerly the Los Angeles Gas and Electric Corporation, Seal Beach Electric Plant.)

The power-distribution system had a great many minor troubles. A great deal of entanglement or wrapping of adjacent wires occurred on power-line spans, particularly where the lines were installed slack for gauging reasons. Fortunately there were few burn-downs since the wires were automatically deenergized by protective equipment before shorts due to wrapping occurred. The greatest damage to the distribution system resulted from transformers falling from platform mountings, tipping over on rails, or being displaced on supports. Figures C. 4 to C.6 are indicative of this type of damage. A total of 846 transformers were affected, 100 of which were scrapped because of age or damage; 246 suffered minor or no damage; and the remaining 500 needed moderate to extensive repairs. Of the pole-mounted transformers, those on single poles fared best because they were attached to hangers. On those installations where the transformers were set without attachment on a platform between two or more poles, toppling, rolling, and falling off were greatly in evidence (Fig. C.7). 


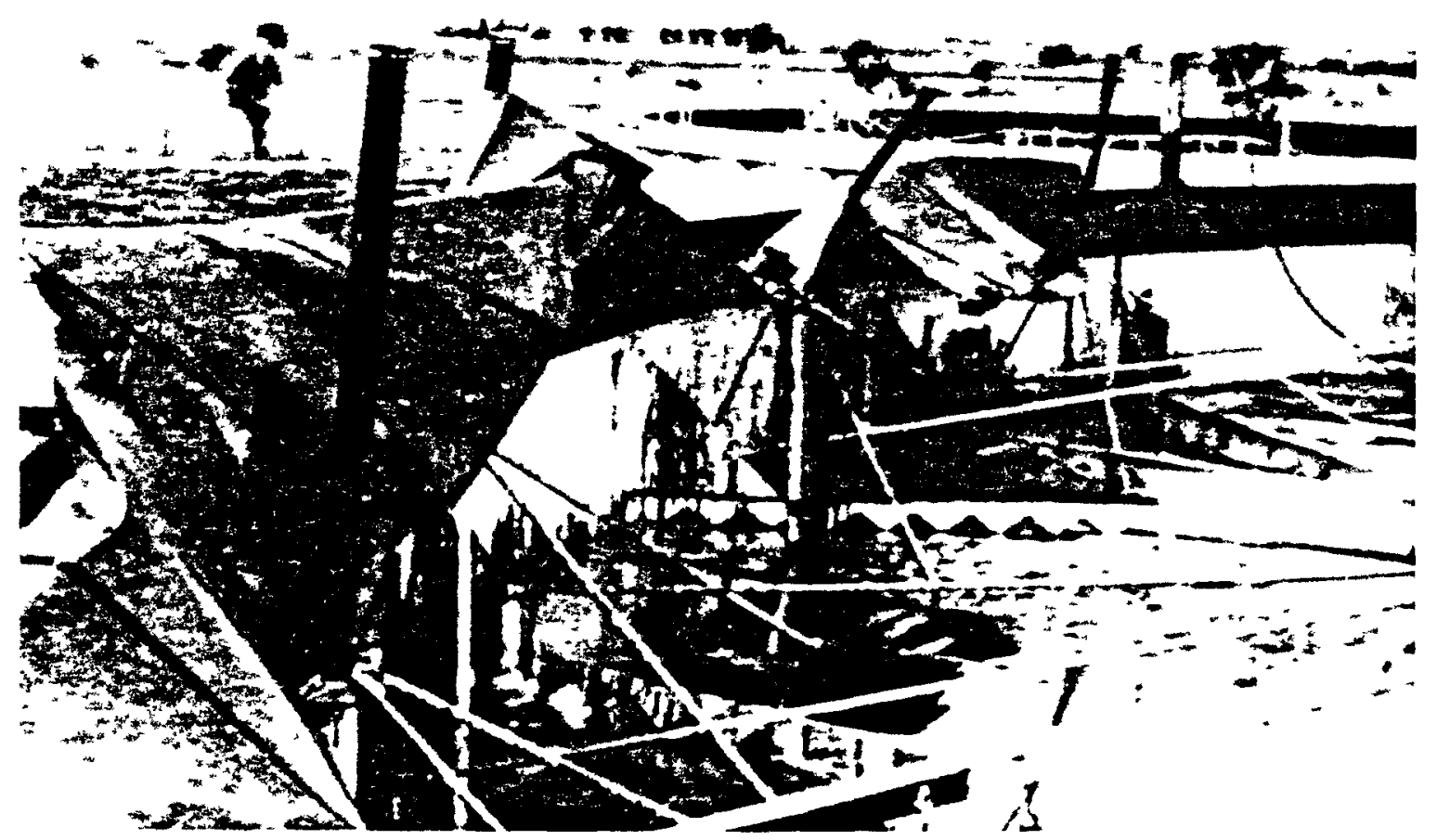

Fig. C.2-Damage oil-storage tank. (Pacific Gas and Electric Company.)

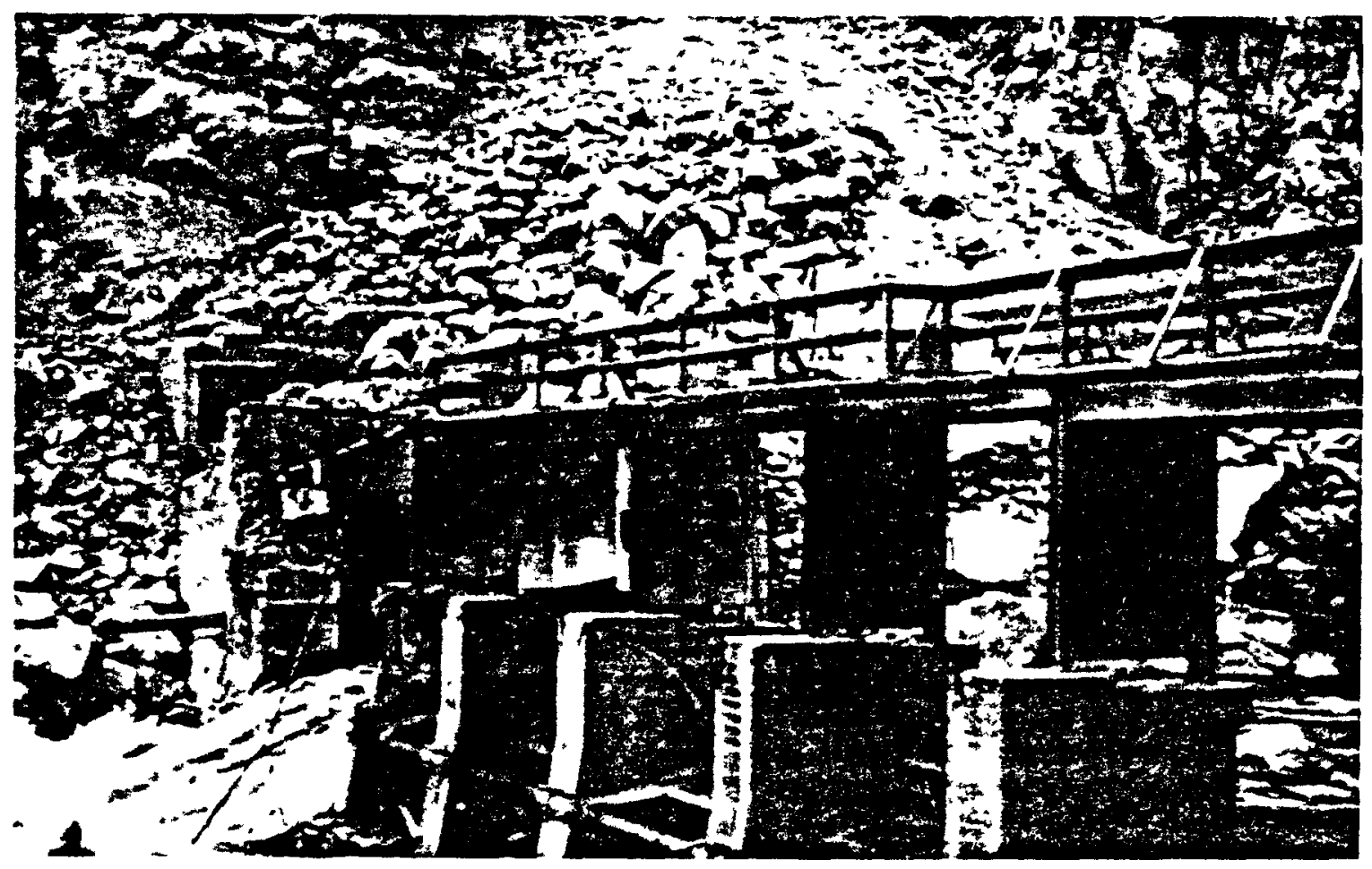

Fig. C.3-Damage to diversion dam caused by a landslide following Arvin-Tehachapi, Cahf., earthquake, July 21, 1952. (Pacific Gas and Electric Company.) 


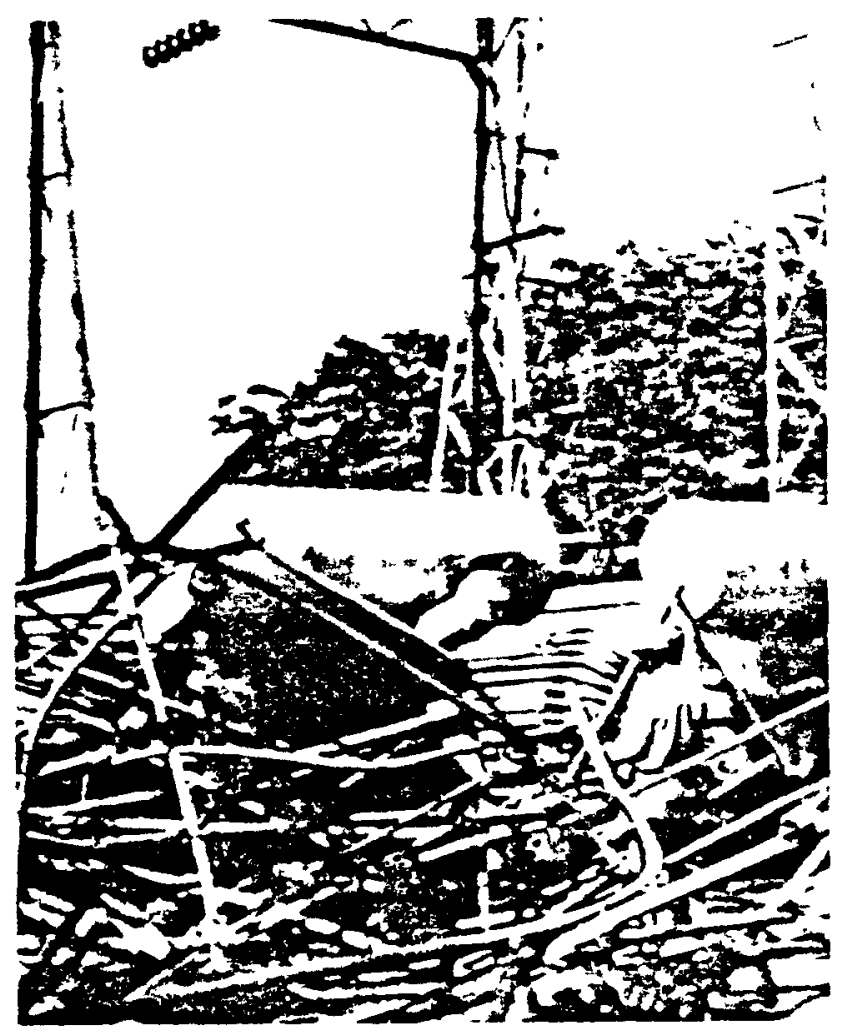

Fig. C.4-Transformers damaged by an earthquake. (Pacific Gas and Electric Company.)

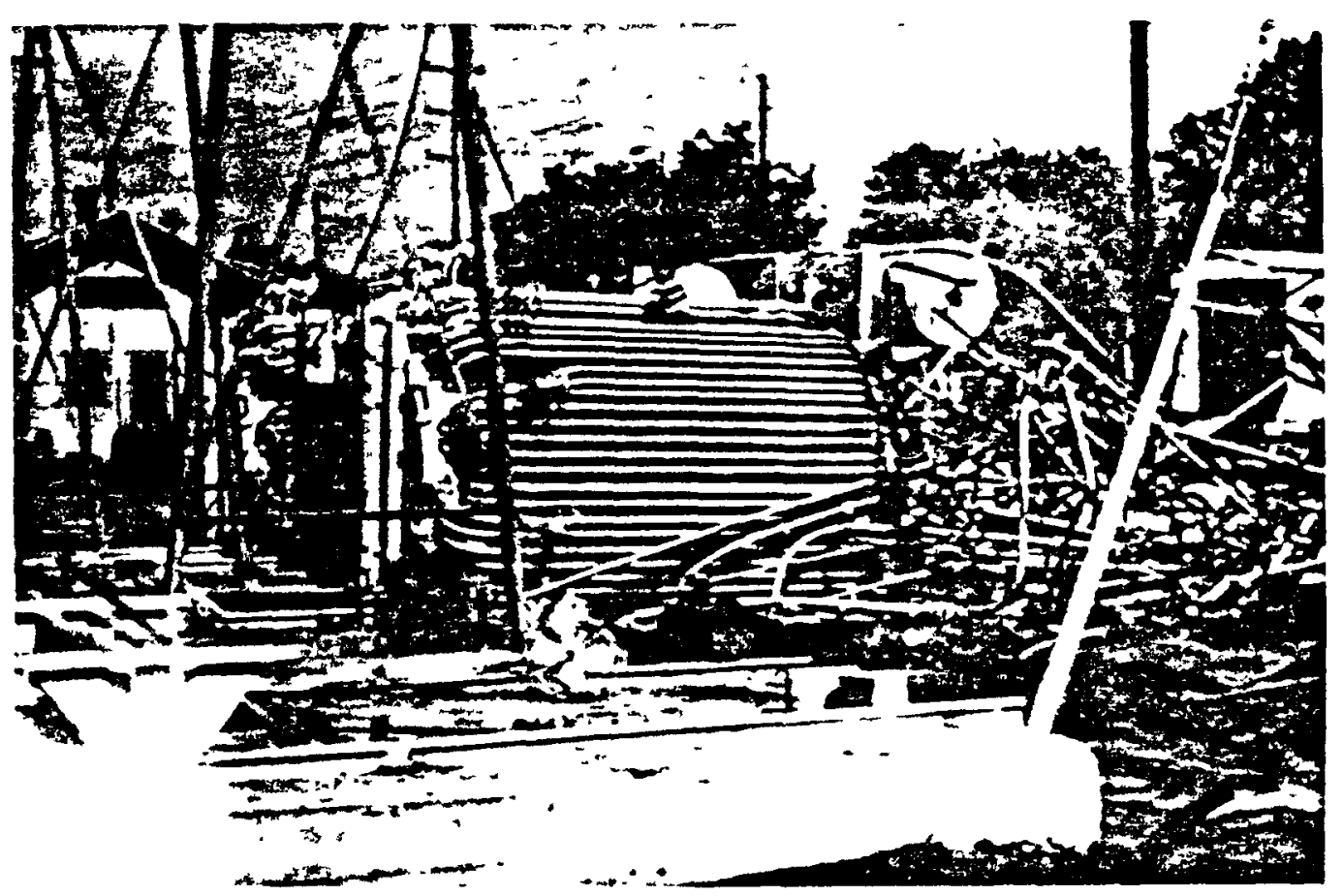

Fig. C.5 - Transformers damaged by an earthquake. (Pacific Gas and Electric Company.) 


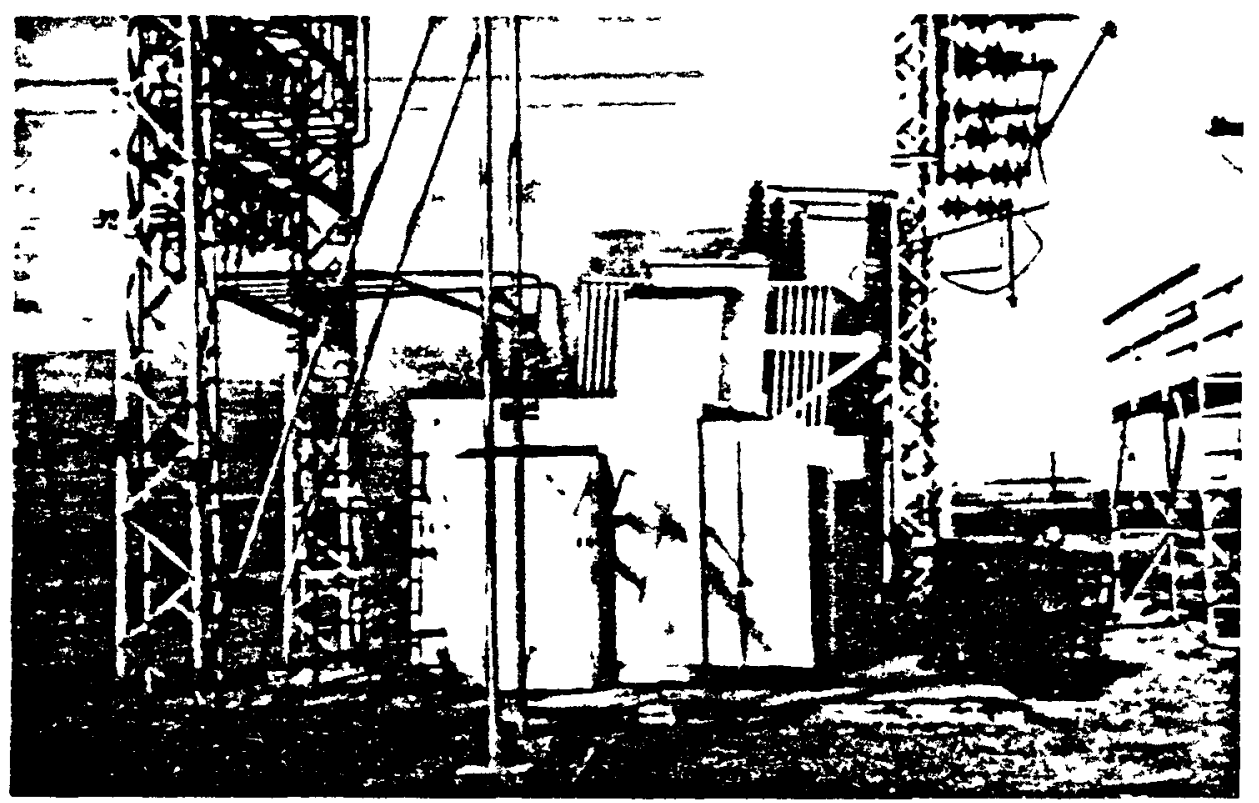

Fig. C.6- Transformer moved from storage cabinet by an earthquake. (Pacific Gas and Electric Company.)

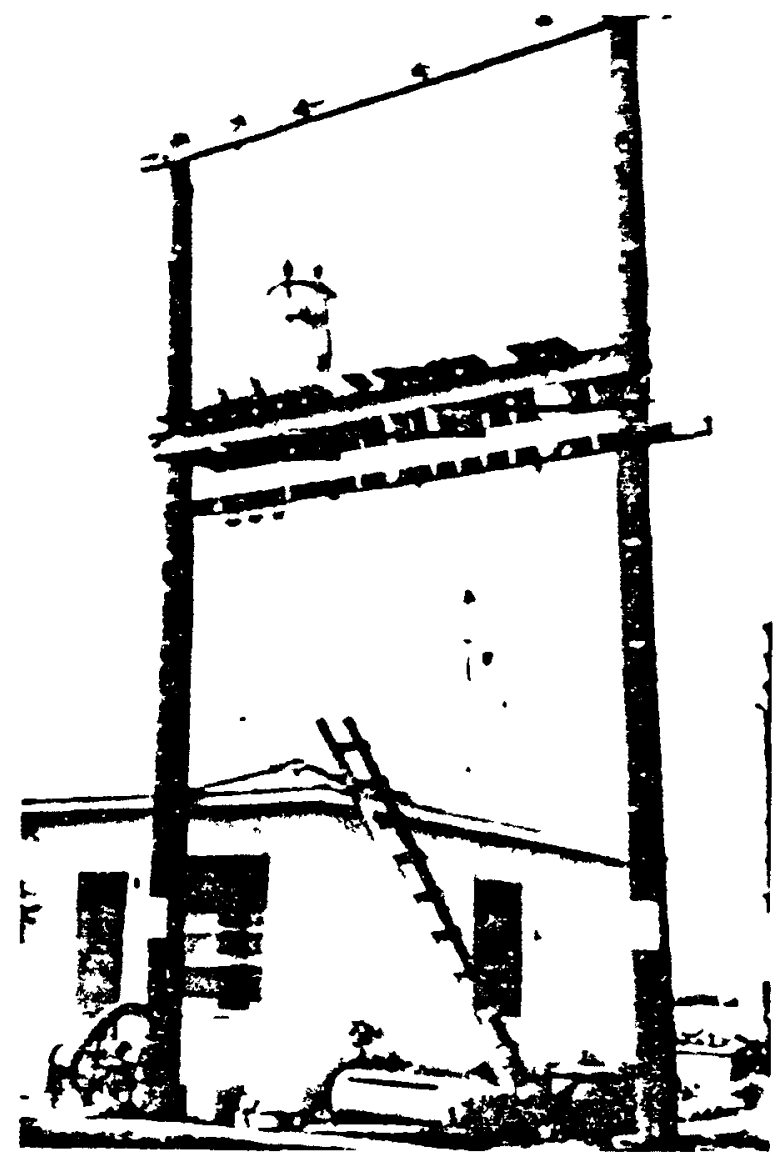

Fig. C.7-Damage to pole-mounted transformers. (Pacific Gas and Electric Company.) 


\section{C.3 OIL REFINERIES}

In this category, damage is reported according to the following classification of equipment and component types rather than being described separately for the many plants involved.

(1) Storage tanks on the ground. The usual pattern of damage to large cylindrical storage vessels is: Vertical settlement $1 / 2$ to 8 in. Shell rupture Roof distortion Piping rupture Steam leakage

(2) Spherical storage tanks, column supported. In the 1952 earthquake, two nearly full 2500-barrei pressure storage tanks fell because of column-support failure. The escaping butane ignited, and the resulting fire destroyed three adjacent tanks and contents.

(3) Horizontal vessels on concrete pads. No distortions or ruptures in tanks of this type have been reported, although, as a worst case, two $12-\mathrm{ft}$-diameter by 120 -ft-long gasoline tanks, supported on piers with only one end anchored, were damaged. The floating end of one tank moved $10 \frac{1}{2}$ in., and the corresponding end of the second tank fell off the pier, swinging $10 \mathrm{ft}$ away and coming to rest on the ground. Numerous cases of cracked concrete piers have occurred, particularly when the direction of the shock was parallel to the axis of the vessel.

(4) Elevated storage tanks on structural supports. Many such tanks, designed for wind load alone, were destroyed in the 1933 and 1952 earthquakes. Tanks of this type designed for earthquake resistance have survived even in heavily shocked areas.

(5) Small cylindrical storage tanks. In both the 1933 and 1952 earthquakes, this type container proved to be quite vulnerable. Many cases are reported involving tanks of a wide variety of sizes, materials, and plate gauges in which lateral movement, collapse, and rupture occurred. Breakage of piping, usually by shearing resulting from lack of flexibility, was frequent.

(6) Boiler plants. At one large refinery, seven 750 -hp Stirling boilers were installed in a steel-frame and corrugated-iron building. Five of the boilers were braced with horizontal buckstays. In the 1933 earthquake all seven boilers were damaged, but those with buckstays remained in alignment, whereas the two unstayed boilers were badly damaged and shifted sufficiently to damage the support to the stack.

Other minor damage to boiler installations in petroleum plants have been reported. The most serious damage required realignment of several boilers at Huntington Beach. The damage most frequently reported is that of shattered brickwork in fireboxes, sagging floors, and shifting of brickwork in control houses.

(7) Vessels and mechanical equipment. There have been very few cases of actual shifting or relocation of such equipment. However, numerous cases have been reported in which tall vessels, such as distillation columns, have tipped and anchor bolts have elongated. Many of these cases show evidence of a gyratory motion in which the vessel rolls around the base ring. Although severe cases of anchor-bolt elongation have occurred, no vessels have been reported as having actually broken free and fallen over.

In one case, at least, the housing of a Kinney oil pump was cracked. Other pumps have settled, causing fractures of connecting piping (usually cast-iron), and one oil company reports shifting of heavy pumps and motors sufficient to distort steel connecting piping. These units appear to have been employed in pipeline or dock loading installations. 
REFERENCES

\section{REFERENCES}

C.1. 1952 Earthquakes in Kern County, California, 113 pp., Structural Engineers Association of Northern California, San Francisco, 1956.

C.2. World Conference on Earthquake Engineering, Earthquake Engineering Research Institute and Department of Engıneering, Unıversity of California, Berkeley, June 1956.

C.3. Engineering News Record, June 22, 1933.

C.4. Earthquakes in Kern County, California, During 1952, Bulletin 171, State of California, Department of Natural Resources, Division of Mines, San Francisco, 1955. 


\section{Appendix D}

\section{EARTHQUAKE EXPERIENCE IN EXISTING REACTOR PLANTS}

\section{D.1 INTRODUCTION}

Because of the relative infrequency of severe earthquakes and the newness of the atomic age, so far as is known, no reactor operators in this country have as yet been faced with a significant seismic emergency. Minor shocks have caused shutdown of lowpower training reactors equipped with very sensitive seismic scram devices, and there have been some activations of seismic warning systems in other reactors.

This appendix is an account of the earthquake experiences of some reactor operators in seismically active areas.

\section{D.2 AEROJET-GENERAL NUCLEONICS ${ }^{\text {D. } 1}$}

This company, operating an AGN-201 training reactor and a pool type research reactor at San Ramon, Calif., has had at least two earthquake-connected scrams. These were the result of minor earthquakes, probably less than a Modified-Mercalli intensity of III, which were instrumentally recorded but not felt. No reactors were in operation during the March 1957 earthquake centered near San Francisco.

\section{D.3 GENERAL ELECTRIC COMPANY, VALLECITOS ATOMIC LABORATORY ${ }^{\text {D. } 2}$}

At the Vallecitos Atomic Laboratory, Vallecitos, Calif., General Electric operates the Vallecitos Boiling-water Reactor (VBWR), the General Electric Test Reactor (GETR), and a small research or training reactor. According to General Electric's records, several earth tremors have been experienced at Vallecitos since 1958. The intensities at Vallecitos have varied from Modified-Mercalli $\mathrm{I}$ to $\mathrm{V}$ and resulted from earthquakes varying from Richter magnitude 4.7 to 6.3 and Modified-Mercalli VI to VII at the source. Most intensities at Vallecitos were about Modified-Mercalli IV. Several scrams have been experienced since the seismic detectors are set with a gap of $0.6 \mathrm{~mm}$, which is estimated to be approximately equivalent to a local intensity of Modified-Mercalli III. In all these disturbances, no damage to the system was observed. In addition, in January 1958, a series of apparent seismic trips were experienced, but these have since been attributed to settling of the control building. (The oil-damped pendulum seismic detector used, such as described in Chap. 8, cannot distinguish between settling and seismlc tremors). 


\section{D.4 ATOMICS INTERNATIONAL}

As of July 1958 no locally feit earthquakes had occurred while any of the several reactors were in operation. Earthquake-induced trips had occurred during nonoperative periods, and one scram on the North American Aviation Water-boiler Neutron Source $[A E-6$ (WBNS)] was experienced from this source, but the operators were not able to correlate it with any specific earthquake.

\section{D.5 AMERICAN-STANDARD, ADVANCED TECHNOLOGY LABORATORIES}

The 1-watt University Training Reactor (UTR-1), a prototype of a training reactor marketed by the Advanced Technology Laboratories of the American Radiator \& Standard Sanitary Corporation, was put in service in June 1958, and has operated intermittently. Shortly after the UTR-1 was put in service, a mild earthquake occurred in the Santa Clara Valley (approximately Richter 4). The reactor was not in operation at the time, and, according to a company spokesman, the seismic switch did not trip.

\section{6 HANFORD WORKS}

Since the earliest operation at Hanford in 1943, there has been only one earthquake of note. This was the Seattle (or Olympic Peninsula) earthquake of 1949 , with a Richter magnitude of 7.1. The intensity was estimated as Modified-Mercalli VI at Richland, Wash., and it was thought to be slightly less severe (about Modified-Mercalli V) in the reactor area. The galvanometer spots were reported to have oscillated moderately. This was the extent of the activity observed.

Since the installation of the seismoscope system, there has been only one seismic event of sufficient intensity to activate the Modified-Mercalli II warning circuits. This warning signal was attributed to the West Yellowstone earthquake on Aug. 17, 1959, and the intensity registered at Hanford was approximately Modified-Mercalli II to III. In the past 10 years there has been an additional 15 to 20 temblors below Modified-Mercalli II.

The local geological group has measured water-well level fluctuations, presumably from compression of aquifers by seismic waves, and has observed 14 abrupt perturbations. Four of these disturbances were correlated with earthquakes in the northwestern United States, and some were correlated with events as distant as Assam and Israel. Although these measurements are of scientific interest, they are not an index of local frequency or intensity. The Blue Mountain and Walla Walla faults are close enough to contribute to some of the noted activity, and the Ringgold formation to the east of the Columbia River lowlands on which the site is located is evidence of past seismic activity.

\section{7 SAVANNAH RIVER PRODUCTION REACTORS}

This site reports that, although there have been several earthquakes in the area since 1958 (varying from Modified-Mercalli I to IV in nearby localities), the reactor alarm system, which is set at Modified-Mercalli II, has not tripped. None of these tremors were reported at the plant site, and no noticeable effects were seen.

The seismicity of this region is difficult to define since the area generally is considered to be quiescent. However, the Charleston, S. C., earthquake of 1886 was one of the most severe ever known to have occurred in the United States.

\section{REFERENCES}

D.1 Robert Geckler, Aerojet-General Nucleonics, personal communication.

D.2 R. D. Bennett, Manager, Vallecitos Atomic Laboratory, personal communication, 1958.

D. 3 J. W. Burch, USAEC, Aiken, S. C., personal communication, 1963. 


\section{Appendix E}

\section{MATRIX FORMAT FOR ANALYSIS OF TRANSIENT RESPONSE OF LINEAR UNDAMPED SYSTEMS}

FIGURE

E.1 Sumplifled Model of Steam Generator

\section{E.1 GENERAL}

In the analysis of the response to forced input motion of a multidegree-of-freedom system, the computational effort may be systematized by the use of matrices in the solution of the equations of motion. Furthermore, the usefulness of matrices need not be restricted to the determination of periods and mode shapes but may be extended to obtain the total solution, as will be shown. The theory and derivation of equations are presented first, followed by a detailed numerical example. A basic treatment of the subject can be found in Ref. E.1.

\section{E.2 DERIVATION OF EQUATIONS}

For the case of forced transient motion, Lagrange's equations take the form

$$
\frac{\mathrm{d}}{\mathrm{dt}}\left(\frac{\partial T}{\partial \dot{\mathrm{q}}_{\mathrm{i}}}\right)+\frac{\partial \mathrm{U}}{\partial \mathrm{q}_{\mathrm{i}}}=Q_{\mathrm{i}}(\mathrm{t})
$$

$$
\text { where } \begin{aligned}
T & =\text { kinetic energy } \\
U & =\text { potential energy } \\
t & =\text { time } \\
q_{i} & =i t h \text { generalized coordinate } \\
Q_{i} & =i t h \text { generalized force }
\end{aligned}
$$

The generalized force $Q_{1}(t)$ may be an active force in the usual sense or a force generated by inertia forces resulting from forced input motions. Equation E.1 can be written

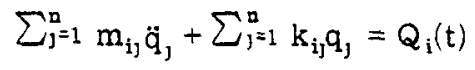




\section{E.2 DERTVATION OF EQUATIONS}

In matrix notation the set of $n$ equations can be written

$$
M \ddot{q}+\mathrm{Kq}=\mathrm{f}
$$

where

$$
\begin{aligned}
& \text { Mass matrix } M=\left[m_{i_{j}}\right] \\
& \text { Stiffness matrix } K=\left[k_{i j}\right] \\
& \text { Coordinate vector } q=\left[\begin{array}{l}
q_{1} \\
q_{2} \\
\ldots .
\end{array}\right] \\
& \text { Force vector } f=\left[\begin{array}{c}
Q_{1}(t) \\
Q_{2}(t) \\
\ldots
\end{array}\right]
\end{aligned}
$$

Let $\phi_{\mathrm{r}}$ be the eigenvector corresponding to the $\mathrm{r}$ th frequency $\omega_{\mathrm{r}}$ of the homogeneous equation

$$
M \ddot{q}+K q=0
$$

thus

$$
-\omega_{\mathrm{r}}^{2} \mathrm{M} \phi_{\mathrm{r}}+\mathrm{K} \phi_{\mathrm{r}}=0
$$

The expanded form for the eigenvector is

$$
\phi_{\mathrm{r}}=\left[\begin{array}{c}
\phi_{1}^{(\mathrm{r})} \\
\phi_{2}^{(r)} \\
\cdots
\end{array}\right]
$$

Let the matrix formed of the eigenvectors $\phi_{\mathrm{r}}$ be

$$
\Phi=\left[\phi_{1} \phi_{2} \ldots\right]=\left[\begin{array}{ccc}
\phi_{1}^{(1)} & \phi_{1}^{(2)} & \ldots \\
\phi_{2}^{(1)} & \phi_{2}^{(2)} & \ldots \\
\ldots & \ldots & \ldots
\end{array}\right]
$$

Let the time coefficients $c_{r}(t)$ for the contribution of each mode to the response be taken as a vector

$$
c(t)=\left[\begin{array}{c}
c_{1}(t) \\
c_{2}(t) \\
\ldots .
\end{array}\right]
$$

The solution is then taken in the matrix form

$$
q=\Phi c
$$


With this substituted into Eq. E.3

$$
\mathrm{M} \Phi \ddot{\mathrm{c}}+\mathrm{K} \Phi \mathrm{c}=\mathrm{f}
$$

Then premultiply by the transpose $\Phi^{\mathrm{T}}$ of the eigenvector matrix

$$
\Phi^{\mathrm{T}} \mathbf{M} \Phi \ddot{\mathbf{c}}+\Phi^{\mathrm{T}} \mathbf{K} \Phi \mathbf{c}=\Phi^{\mathrm{T}} \mathrm{f}
$$

However, owing to the orthogonality relations for the normal modes

$$
\begin{aligned}
& \phi_{\mathrm{r}}^{\mathrm{T}} \mathrm{M} \phi_{\mathrm{s}}=\sum_{\mathrm{i}} \sum_{\mathrm{j}} \mathrm{m}_{\mathrm{ij}} \phi_{\mathrm{i}}^{(\mathrm{r})} \phi_{\mathrm{j}}^{(\mathrm{s})}=0 \text { for } \mathrm{r} \neq \mathrm{s} \\
& \phi_{\mathrm{r}}^{\mathrm{T}} \mathrm{K} \phi_{\mathrm{s}}=\sum_{\mathrm{i}} \Sigma_{\mathrm{j}} \mathrm{k}_{\mathrm{ij}} \phi_{\mathrm{i}}^{(\mathrm{r})} \phi_{\mathrm{j}}^{(\mathrm{s})}=0 \text { for } \mathrm{r} \neq \mathrm{s}
\end{aligned}
$$

both $\Phi^{\mathrm{T}} \mathrm{M} \Phi$ and $\Phi^{\mathrm{T}} \mathrm{K} \Phi$ are diagonal matrices. Thus

$$
\begin{aligned}
\Phi^{\mathrm{T}} M \Phi=\left[\bar{M}_{\mathrm{r}}\right] & \text { where } \bar{M}_{\mathrm{r}}=\phi_{\mathrm{r}}^{\mathrm{T}} \mathrm{M} \phi_{\mathrm{r}} \\
\Phi^{\mathrm{T}} \mathrm{K} \Phi=\left[\overline{\mathrm{K}}_{\mathrm{r}}\right] & \text { where } \overline{\mathrm{K}}_{\mathrm{r}}=\phi_{\mathrm{r}}^{\mathrm{T}} \mathrm{K} \phi_{\mathrm{r}}
\end{aligned}
$$

Bars are used to indicate that $\overline{\mathrm{M}}_{\mathrm{r}}$ and $\overline{\mathrm{K}}_{\mathrm{r}}$ are scalars, whereas the diagonal lines on the brackets denote diagonal matrices. However, it can be shown that

$$
\omega_{\mathrm{r}}^{2}=\frac{\phi_{\mathrm{r}}^{\mathrm{T}} \mathrm{K} \phi_{\mathrm{r}}}{\phi_{\mathrm{r}}^{\mathrm{T}} \mathrm{M} \phi_{\mathrm{r}}}
$$

so that

$$
\Phi^{\mathrm{T}} \mathrm{K \Phi}=\left[\overline{\mathrm{K}}_{\mathrm{r}}\right]=\left[\overline{\mathrm{M}}_{\mathrm{r}}\right]\left[\omega_{\mathrm{r}}^{2}\right]
$$

Equation E.11 can then be written

$$
\Phi^{T} M \Phi \ddot{c}+\left\langle\Phi^{T} M \Phi\right)\left[\omega_{r}^{2}\right] c=\Phi^{T} f
$$

Premultiply by the inverse matrix $\left(\Phi^{\mathrm{T}} \mathrm{M} \Phi\right)^{-1}$ (which is easily calculated since $\Phi^{\mathrm{T}} \mathrm{M} \Phi$ is diagonal)

$$
\ddot{c}+\left[\omega_{\mathrm{r}}^{2}\right] c=\left(\Phi^{\mathrm{T}} \mathrm{M} \Phi\right)^{-1} \Phi^{\mathrm{T}} \mathfrak{f}
$$

or

$$
\ddot{c}+\left[\omega_{r}^{2}\right] c=\left[\frac{1}{\bar{M}_{r}}\right] \Phi^{T_{f}}
$$

In this form the equations have been decoupled. The equation for the $r$ th mode coefficient is

$$
\ddot{c}_{r}+\omega_{r}^{2} c_{r}=\frac{1}{\phi_{r}^{T} M \phi_{r}} \sum_{j=1}^{n} \phi_{j}^{(r)} Q_{j}
$$

With zero initial conditions the solution for the $r$ th mode coefficient is

$$
c_{r}(t)=\frac{1}{\omega_{r}\left(\phi_{r}^{T} M \phi_{r}\right)} \sum_{j=1}^{n} \phi_{j}^{(r)} \int_{0}^{t} Q_{j}(\tau) \sin \omega_{r}(t-\tau) d \tau
$$




\section{E.2 DERIVATION OF EQUATIONS}

Let the integral be called the impulse loading

$$
l_{j}^{(r)}(t)=\ell_{\jmath r}(t)=\int_{0}^{t} Q_{j}(\tau) \sin \omega_{s}(t-\tau) d \tau
$$

and the matrix composed of these elements be called L, i.e.,

$$
L=\left[l_{13}\right]=\left[\begin{array}{ccc}
l_{11}(t) & l_{12}(t) & \ldots \\
l_{21}(t) & \ldots & \ldots \\
\ldots & \ldots & \ldots
\end{array}\right]
$$

The matrix format of all equations (Eq. E.22) then is

$$
c=\left[\left(\omega_{r} \bar{M}_{r}\right)^{-1}\right] \Phi^{T} L
$$

The expanded form for a two-degree system is

$$
\left[\begin{array}{l}
c_{1} \\
c_{2}
\end{array}\right]=\left[\begin{array}{ll}
\left(\omega_{1} \bar{M}_{1}\right)^{-1} & 0 \\
0 & \left(\omega_{2} \bar{M}_{2}\right)^{-1}
\end{array}\right]\left[\begin{array}{ll}
\phi_{1}^{(1)} & \phi_{2}^{(1)} \\
\phi_{1}^{(2)} & \phi_{2}^{(2)}
\end{array}\right]\left[\begin{array}{ll}
l_{11} & l_{12} \\
l_{21} & l_{22}
\end{array}\right]
$$

or

$$
\left[\begin{array}{l}
c_{1} \\
c_{2}
\end{array}\right]=\left[\begin{array}{ll}
\frac{1}{\omega_{1} \sqrt[M_{1}]{1}} & 0 \\
0 & \frac{1}{\omega_{2} \bar{M}_{2}}
\end{array}\right]\left[\begin{array}{ll}
\phi_{1}^{(1)} & \phi_{2}^{(1)} \\
\phi_{1}^{(2)} & \phi_{2}^{(2)}
\end{array}\right]\left[\begin{array}{l}
\int_{0}^{t} Q_{1}(\tau) \sin \omega_{1}(t-\tau) d \tau \int_{0}^{t} Q_{1}(\tau) \sin \omega_{2}(t-\tau) d \tau \\
\int_{0}^{t} Q_{2}(\tau) \sin \omega_{2}(t-\tau) d \tau \int_{0}^{t} Q_{2}(\tau) \sin \omega_{2}(t-\tau) d \tau
\end{array}\right]
$$

A conservative procedure in earthquake analyses is the replacement of the integrals by their maximum value and the elimination of signs in all mode shapes, thereby resulting in an upper-limit calculation. With an input ground acceleration, the $Q_{j}$ will be products of mass and acceleration terms.

From Eqs. E.9 and E.25, the complete solution is

$$
q=\Phi\left[\left(\omega_{\mathrm{r}} \bar{M}_{\mathrm{r}}\right)^{-1}\right] \Phi^{\mathrm{T}} \mathrm{L}
$$

\section{E.3 CALCULATION OF NONDOMINANT FREQUENCIES AND MODES}

In the application of the theory developed above, it is necessary to find the eigenvalues for the vibration equation

$$
M \ddot{q}+K q=0
$$

where $M$ is the mass matrix, $q$ is the coordinate vector, and $K$ is the stiffness matrix.

Thus, if

$$
q=e^{i \omega t} \phi
$$

then

$$
q=-\omega^{2} e^{3 \omega t} \phi=-\omega^{2} q
$$


and

$$
-\omega^{2} \mathrm{M} \phi+\mathrm{K} \phi=0
$$

or

$$
\left(-\omega^{2} \mathrm{M}+\mathrm{K}\right) \phi=0
$$

This equation has nontrivial solutions only if the determinant

$$
\left|-\omega^{2} \mathbf{M}+\mathbf{K}\right|=0
$$

This determinant vanishes only for particular values, $\omega_{r}^{2}$, of $\omega^{2}$. For each eigenvalue $\omega_{r}^{2}$ there is a corresponding eigenvector $\phi_{\mathrm{r}}$.

The solution of Eq. E.34 for the eigenvalues is difficult for cases involving many degrees of freedom. However, Eq. E.32 can be modified as follows:

$$
\begin{aligned}
\omega^{2} \mathrm{M} \phi & =\mathrm{K} \phi \\
\mathrm{M} \phi & =\frac{1}{\omega^{2}} \mathrm{~K} \phi \\
\mathrm{K}^{-1} \mathrm{M} \phi & =\frac{1}{\omega^{2}} \mathrm{~K}^{-1} \mathrm{~K} \phi=\frac{1}{\omega^{2}} \phi
\end{aligned}
$$

$K^{-1}$ is the inverse of the stiffness matrix $K$ and is commonly known as an influence matrix. By using an iterative technique on

$$
K^{-1} M_{\phi}=\frac{1}{\omega^{2}} \phi
$$

the eigenvalues can be found.

With a sequence of trial vectors $\phi$, this technque finds the highest value of $1 / \omega^{2}$, and thus the lowest eigenvalue belonging to the matrix $(M)$, together with the corresponding eigenvector. Unless an exact eigenvector for a higher mode is accidently chosen, the process always converges to the highest value of $1 / \omega^{2}$.

The other values of $1 / \omega^{2}$ can be found by the scheme presented below. Let the eigenvalues be arranged as follows:

$$
\omega_{1}^{2}<\omega_{2}^{2}<\omega_{3}^{2}<\ldots \omega_{\mathrm{a}}^{2}
$$

so that

$$
\frac{1}{\omega_{0}^{2}}<\ldots<\frac{1}{\omega_{3}^{2}}<\frac{1}{\omega_{2}^{2}}<\frac{1}{\omega_{1}^{2}}
$$

After finding $1 / \omega_{1}^{2}$ and the corresponding eigenvector $\phi_{1}$, construct a new matrix $B$ as follows:

$$
B=K^{-1} M-\left(\frac{1}{\omega_{1}^{2}}\right) \frac{\phi_{1} \phi_{1}^{\top} M}{\phi_{1}^{\top} M \phi_{1}}
$$

where $M$ is the mass matrix and $\phi_{1}^{\top}$ is the transpose of $\phi_{1}$, that is, $\phi_{1}$ converted from column to row form.

By using the iterative technique with trial vectors on $B$, the process converges to the elgenvalue $1 / \omega_{2}^{2}$ with the eigenvector $\phi_{2}$. 


\section{E. 3}

To get the next eigenvalue, construct a new matrix

$$
C=B-\left(\frac{1}{\omega_{2}^{2}}\right) \frac{\phi_{2} \phi_{2}^{\mathrm{T}} \mathrm{M}}{\phi_{2}^{\mathrm{T}} \mathrm{M} \phi_{2}}
$$

and continue the process until all eigenvalues are found.

Matrices B, C, etc., have the property that they take the former highest value of $1 / \omega^{2}$ and replace it by zero without changing the other eigenvalues or eigenvectors. Thus each time the highest eigenvalue is removed, and the iterative process converges to the next highest eigenvalue. That the matrices have this property may be seen as follows:

Postmultiply Eq. E.10 by some eigenvector $\phi_{s}$ of $K^{-1} \mathrm{M}$

$$
\mathrm{B} \phi_{\mathrm{s}}=\mathrm{K}^{-1} \mathrm{M} \phi_{s}-\frac{1}{\omega_{1}^{2}} \frac{\phi_{1} \phi_{1}^{\mathrm{T}} \mathrm{M} \phi_{s}}{\phi_{1}^{\mathrm{T}} \mathrm{M} \phi_{1}}
$$

If

$$
\phi_{\mathrm{s}}=\phi_{1}
$$

then

$$
\mathrm{B} \phi_{1}=K^{-1} \mathrm{M} \phi_{1}-\frac{1}{\omega_{1}^{2}} \frac{\phi_{1} \phi_{1}^{\top} \mathrm{M}}{\phi_{1}^{\top} \mathrm{M} \phi_{1}} \phi_{1}=K^{-1} \mathrm{M} \phi_{1}-\frac{1}{\omega_{1}^{2}} \phi_{1} \frac{\phi_{1}^{\top} \mathrm{M} \phi_{1}}{\phi_{1}^{\top} \mathrm{M} \phi_{1}}
$$

or

$$
\mathrm{B} \phi_{1}=K^{-1} \mathrm{M} \phi_{1}-\frac{1}{\omega_{1}^{2}} \phi_{1}
$$

but

$$
K^{1} M \phi_{1}=\frac{1}{\omega_{1}^{2}} \phi_{1}
$$

so

$$
\mathrm{B} \phi_{1}=\left(\frac{1}{\omega_{1}^{2}}-\frac{1}{\omega_{1}^{2}}\right) \phi_{1}=0 \phi_{1}
$$

Thus the eigenvalue of $B$ corresponding to $\phi_{1}$ is zero.

In the general case, when

$$
\phi_{\mathrm{s}} \neq \phi_{1}
$$

Equation E.40 can be written

$$
\mathrm{B} \phi_{\mathrm{s}}=\mathrm{K}^{-1} \mathrm{M} \phi_{\mathrm{s}}-\frac{1}{\omega_{1}^{2}} \phi_{1} \frac{\phi_{1}^{\mathrm{T}} \mathrm{M} \phi_{\mathrm{s}}}{\phi_{1}^{\mathrm{T}} \mathrm{M} \phi_{1}}
$$

However, if both $\mathrm{K}$ and $\mathrm{M}$ are symmetric, i.e.,

$$
\mathrm{k}_{\mathrm{ij}}=\mathrm{k}_{\mathrm{ji}}
$$




$$
m_{i j}=m_{j i}
$$

(which will occur for all conservative vibrating systems), the orthogonality condition is

$$
\phi_{\mathrm{r}}^{\mathrm{T}} \mathrm{M} \phi_{\mathrm{s}}=0 \quad \mathrm{r} \neq \mathrm{s}
$$

Thus

$$
\phi_{1}^{\mathrm{T}} \mathrm{M} \phi_{\mathrm{s}}=0
$$

and Eq. E.44 becomes

$$
\mathrm{B} \phi_{\mathrm{s}}=\mathrm{K}^{-1} \mathrm{M} \phi_{\mathrm{s}}
$$

and, with the exception of a zero eigenvalue for $\phi_{1}$, the eigenvalues for $B$ are the same as those for $\mathrm{K}^{-1} \mathrm{M}$.

Notice that $C$ can be written as

$$
\mathrm{C}=\mathrm{B}-\frac{1}{\left(\omega_{2}^{2}\right)} \frac{\phi_{2} \phi_{2}^{\mathrm{T}} \mathrm{M}}{\phi_{2}^{\mathrm{T}} \mathrm{M} \phi_{2}}=\mathrm{K}^{-1} \mathrm{M}-\frac{1}{\omega_{1}^{2}} \frac{\phi_{1} \phi_{1}^{\mathrm{T}} \mathrm{M}}{\phi_{1}^{\mathrm{T}} \mathrm{M} \phi_{1}}-\frac{1}{\omega_{2}^{2}} \frac{\phi_{2} \phi_{2}^{\mathrm{T}} \mathrm{M}}{\phi_{2}^{\mathrm{T}} \mathrm{M} \phi_{2}}
$$

Thus, in general, the nth reduced matrix can be written

$$
\mathrm{N}=K^{-1} \mathrm{M}-\sum_{\mathrm{r}=1}^{\mathrm{n}} \frac{1}{\omega_{\mathrm{r}}^{2}} \frac{\phi_{\mathrm{r}} \phi_{\mathrm{r}}^{\mathrm{T}} \mathrm{M}}{\phi_{\mathrm{r}}^{\mathrm{T}} \mathrm{M} \phi_{\mathrm{r}}}
$$

Notice that $\phi_{\mathrm{r}}$ is the $\mathrm{r}$ th eigenvector and not the $\mathrm{r}$ th element of some vector.

\section{E.4 SIMPLE NUMERICAL EXAMPLE}

As an illustration of the application of the foregoing material, the periods, mode shapes, and response of a simplified model of a typical steam generator are calculated below. The input motion is assumed to be equivalent to that exhibited by the El Centro, Calif., earthquake of 1940 , and the simplifying assumptions are:

Linear relations between deflections and forces

No attached piping

Mass of support column neglected

This simplified model is shown in Fig. E.1, and it is assumed that two modes of vibration are present. The two modes consist in the rotation about the center of mass (angle $\theta$ ) and in the lateral displacement $(y)$ at the point where the column is attached to the cylindrical mass.

From Fig. E.1

$$
z=x+y+e \theta
$$

where $\mathrm{x}=$ input shock motion

$y=$ lateral deflection of column

$\theta=$ rotation of mass

$z=$ absolute motion of mass center

$e=$ distance from the column connection to the center of mass 


\section{E.4 SIMPLE NUMERICAL EXAMPLE}

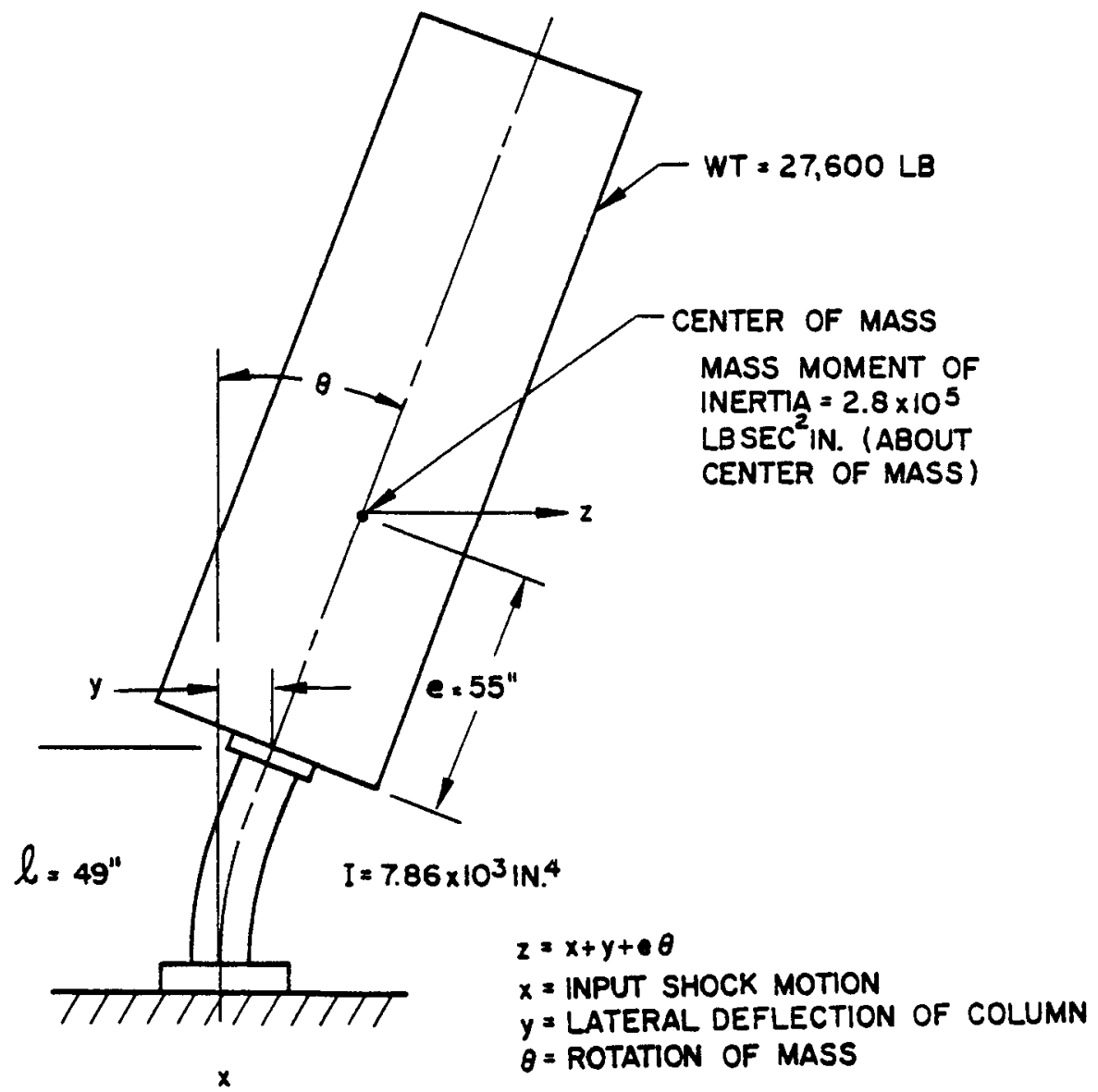

Fig. E.1-Simplified model of steam generator.

Let $\mathrm{T}$ be the kinetic energy, $\mathrm{J}$ the mass moment of inertıa about the mass center, and $\mathrm{M}$ the total mass so that $\mathrm{E} .2$

$$
T=\frac{1}{2} M \dot{z}^{2}+\frac{1}{2} J \dot{\theta}^{2}
$$

Since $\dot{z}=\dot{x}+\dot{y}+e \dot{\theta}$ from Eq. E.51, then

$$
\mathrm{T}=\frac{1}{2}[\dot{\mathrm{x}}+\dot{\mathrm{y}}+\mathrm{e} \dot{\theta}]^{2}+\frac{1}{2} J \dot{\theta}^{2}
$$

In the present case Lagrange's equation can be written

$$
\frac{d}{d t}\left(\frac{\partial T}{\partial \dot{q}_{k}}\right)=Q_{k}
$$

where $Q_{k}$ is the generalized force, including that resulting from the potential energy of deformation. 
The spring motion in terms of the forces applied to the spring can be written

$$
\begin{aligned}
& y=i_{11} P+i_{12} C \\
& \theta=i_{21} P+i_{22} C
\end{aligned}
$$

where $P$ is the lateral force, $C$ is the couple, and i is the influence coefficient. In the present case $\mathrm{y}$ and $\theta$ are the generalized coordinates, whereas $\mathrm{P}$ and $\mathrm{C}$ are the generalized forces. The generalized ' $D$ 'Alembert inertia force is

$$
Q_{k}=-\frac{d}{d t}\left(\frac{\partial T}{\partial \dot{q}_{k}}\right)
$$

so that

$$
\frac{\mathrm{d}}{\mathrm{dt}}\left(\frac{\partial \mathrm{T}}{\partial \dot{\mathrm{y}}}\right)=\mathbf{M}(\ddot{\mathbf{x}}+\ddot{\mathrm{y}}+\mathrm{e} \ddot{\theta})
$$

and

$$
\frac{\mathrm{d}}{\mathrm{dt}}\left(\frac{\partial T}{\partial \dot{\theta}}\right)=\operatorname{Me}(\ddot{x}+\ddot{y}+e \ddot{\theta})+J \ddot{\theta}
$$

Substituting the generalized inertia forces for $P$ and $C$ in Eqs. E.52 and E.53,

$$
\begin{aligned}
& -y=i_{11} M(\ddot{x}+\ddot{y}+e \ddot{\theta})+i_{12}[M e(\ddot{x}+\ddot{y}+e \ddot{\theta})+J \ddot{\theta}] \\
& -\theta=1_{21} M(\ddot{x}+\ddot{y}+e \ddot{\theta})+i_{22}[M e(\ddot{x}+\ddot{y}+e \ddot{\theta})+J \ddot{\theta}]
\end{aligned}
$$

Equations E.54 and E.55 can be written in matrix form as

$$
\left[\begin{array}{ll}
i_{11} & i_{12} \\
i_{21} & 1_{22}
\end{array}\right]\left[\begin{array}{ll}
M & M e \\
M e & M e^{2}+J
\end{array}\right]\left[\begin{array}{l}
\ddot{y} \\
\ddot{\theta}
\end{array}\right]+\left[\begin{array}{l}
y \\
\theta
\end{array}\right]=-\ddot{x}\left[\begin{array}{ll}
i_{11} & 1_{12} \\
i_{21} & i_{22}
\end{array}\right]\left[\begin{array}{l}
M \\
M e
\end{array}\right]
$$

Assume for this example

$$
\begin{aligned}
\mathrm{J} & =2.33 \times 10^{4} \mathrm{ft}-\mathrm{lb} \mathrm{sec} \\
\mathrm{I} & =0.379 \mathrm{ft}^{4} \\
\mathrm{M} & =27,600 \mathrm{lb}=857 \frac{\mathrm{lb} \mathrm{sec}^{2}}{\mathrm{ft}} \\
\ell & =49 \text { in. }=4.08 \mathrm{ft} \\
E & =30.0 \times 10^{6} \mathrm{lb}-\mathrm{in} .^{-2}=4.32 \times 10^{9} \mathrm{lb}-\mathrm{ft}^{-2} \\
e & =55 \text { in. }=4.58 \mathrm{ft}
\end{aligned}
$$

The influence coefficients can be calculated

$$
\begin{aligned}
& \mathrm{i}_{11}=\frac{\ell^{3}}{3 E \mathrm{EI}}=13.9 \times 10^{-9} \mathrm{ft}-\mathrm{lb}^{-1} \\
& \mathrm{i}_{12}=\mathrm{i}_{21}=\frac{\ell^{2}}{2 \mathrm{EI}}=5.09 \times 10^{-9} 16^{-1} \\
& \mathrm{i}_{22}=\frac{\ell}{\mathrm{EI}}=2.49 \times 10^{-9}(\mathrm{lb}-\mathrm{ft})^{-1}
\end{aligned}
$$




\section{E.4 SIMPLE NUMERICAL EXAMPLE}

so that the influence matrix is

$$
\left[i_{\text {ij }}\right]=10^{-8}\left[\begin{array}{cc}
13.9 & 5.09 \\
5.09 & 2.49
\end{array}\right]
$$

The mass matrix is

$$
\begin{aligned}
{\left[\mathrm{m}_{\mathrm{tj}}\right] } & =\left[\begin{array}{ll}
\mathrm{M} & \mathrm{Me} \\
\mathrm{Me} & \mathrm{Me}^{2}+\mathrm{J}
\end{array}\right] \\
\mathrm{M} & =857 \times 10^{3} \\
\mathrm{Me} & =857 \times \frac{55}{12}=3.93 \times 10^{3} \\
\mathrm{Me}^{2}+\mathrm{J} & =(3.93 \times 4.58)(10)^{3}+23,300=41.3 \times 10^{3}
\end{aligned}
$$

Thus

$$
\mathrm{m}_{\mathrm{i},}=10^{3}\left[\begin{array}{cc}
0.857 & 3.93 \\
3.93 & 41.3
\end{array}\right]
$$

and

$$
\left[\begin{array}{l}
\mathrm{M} \\
\mathrm{Me}
\end{array}\right]=10^{3}\left[\begin{array}{l}
0.857 \\
3.93
\end{array}\right]
$$

Substituting in Eq. E.56

$$
10^{-9}\left[\begin{array}{cc}
13.9 & 5.09 \\
5.09 & 2.49
\end{array}\right] 10^{3}\left[\begin{array}{cc}
0.857 & 3.93 \\
3.93 & 41.3
\end{array}\right]\left[\begin{array}{l}
\ddot{y} \\
\ddot{\theta}
\end{array}\right]+\left[\begin{array}{l}
y \\
\theta
\end{array}\right]=-x\left(10^{-9}\right)\left[\begin{array}{cc}
13.9 & 5.09 \\
5.09 & 2.49
\end{array}\right] 10^{3}\left[\begin{array}{l}
0.857 \\
3.93
\end{array}\right]
$$

which reduces to

$$
10^{-6}\left[\begin{array}{ll}
31.9 & 265 \\
14.1 & 123
\end{array}\right]\left[\begin{array}{l}
\ddot{y} \\
\ddot{\theta}
\end{array}\right]+\left[\begin{array}{l}
\mathrm{y} \\
\theta
\end{array}\right]=-10^{-6} \ddot{\mathrm{x}}\left[\begin{array}{l}
31.9 \\
14.1
\end{array}\right]
$$

Equation E.57 is now in the form

$$
K^{-1} M \ddot{q}+q=K^{-1} f
$$

where $K^{-1}$ is the influence matrix which is the inverse of the stiffness matrix $K$. The homogeneous equation

$$
\mathrm{K}^{-1} \mathrm{Mq}+\mathrm{q}=0
$$

is now used to calculate frequencies and vibration mode shapes. The iteration formula for calculating the lowest frequency and its corresponding mode shape is

$$
\mathrm{K}^{-1} \mathrm{M} \phi=\lambda \phi \quad \text { where } \lambda=\omega^{-2}
$$


The trial mode shape is normalized each time so that its maximum amplitude is unity

$$
10^{-8} \mathrm{~K}^{-1} \mathrm{M}=\left[\begin{array}{ll}
31.9 & 265 \\
14.1 & 123
\end{array}\right] \quad 10^{-6} \mathrm{~K}^{-1} \mathrm{M} \phi=\frac{10^{6}}{\omega^{2}} \phi
$$

Let first trial vector be $\phi=\left[\begin{array}{l}1 \\ 1\end{array}\right]$

$$
\begin{aligned}
& {\left[\begin{array}{ll}
31.9 & 265 \\
14.1 & 123
\end{array}\right]\left[\begin{array}{l}
1 \\
1
\end{array}\right]=\left[\begin{array}{l}
297 \\
137
\end{array}\right]=297\left[\begin{array}{l}
1.00 \\
0.46
\end{array}\right]} \\
& {\left[\begin{array}{ll}
31.9 & 265 \\
14.1 & 123
\end{array}\right]\left[\begin{array}{l}
1.00 \\
0.46
\end{array}\right]=\left[\begin{array}{r}
154 \\
71
\end{array}\right]=154\left[\begin{array}{l}
1.000 \\
0.461
\end{array}\right]} \\
& {\left[\begin{array}{ll}
31.9 & 265 \\
14.1 & 123
\end{array}\right]\left[\begin{array}{l}
1.000 \\
0.461
\end{array}\right]=\left[\begin{array}{r}
154.1 \\
70.8
\end{array}\right]=154.1\left[\begin{array}{l}
1.000 \\
0.459
\end{array}\right]} \\
& {\left[\begin{array}{ll}
31.9 & 265 \\
14.1 & 123
\end{array}\right]\left[\begin{array}{l}
1.000 \\
0.459
\end{array}\right]=\left[\begin{array}{r}
153.5 \\
70.6
\end{array}\right]=153.5\left[\begin{array}{l}
1.000 \\
0.460
\end{array}\right]} \\
& {\left[\begin{array}{ll}
31.9 & 265 \\
14.1 & 123
\end{array}\right]\left[\begin{array}{l}
1.000 \\
0.460
\end{array}\right]=\left[\begin{array}{r}
153.8 \\
70.7
\end{array}\right]=153.8\left[\begin{array}{l}
1.000 \\
0.460
\end{array}\right]}
\end{aligned}
$$

Thus

$$
\begin{aligned}
& \frac{10^{6}}{\omega_{1}^{2}}=153.8 \quad \phi_{1}=\left[\begin{array}{l}
1.000 \\
0.460
\end{array}\right] \\
& \omega_{1}^{2}=6502 \quad \omega_{1}=80.6 \mathrm{rad} \mathrm{sec}^{-1} \\
& \phi_{1}^{\mathrm{T}} \mathrm{M}=10^{3}\left[\begin{array}{ll}
1.000 & 0.460
\end{array}\right]\left[\begin{array}{cc}
0.857 & 3.93 \\
3.93 & 41.3
\end{array}\right] \\
& \phi_{1}^{\mathrm{T}} \mathrm{M}=10^{3}\left[\begin{array}{ll}
2.665 & 22.93
\end{array}\right] \\
& \phi_{1}^{\mathrm{T}} \mathrm{M} \phi=10^{3}\left[\begin{array}{ll}
2.665 & 22.93
\end{array}\right]\left[\begin{array}{l}
1.000 \\
0.460
\end{array}\right]=13.21 \times 10^{3} \\
& \phi_{1} \phi_{1}^{\mathrm{T}} \mathrm{M}=10^{3}\left[\begin{array}{ll}
2.665 & 22.93 \\
1.226 & 10.55
\end{array}\right]
\end{aligned}
$$

Now

$$
\begin{aligned}
10^{8} \mathrm{~B} & =10^{6} \mathrm{~K}^{-1} \mathrm{M}-\frac{10^{6}}{\omega_{1}^{2}} \frac{\phi_{1} \phi_{1}^{\mathrm{T}} \mathrm{M}}{\phi_{1}^{\mathrm{T}} \mathrm{M} \phi_{1}} \\
10^{6} \mathrm{~B} & =\left[\begin{array}{ll}
31.9 & 265 \\
14.1 & 123
\end{array}\right]-\frac{153.8}{13.21 \times 10^{3}} 10^{3}\left[\begin{array}{ll}
2.665 & 22.93 \\
1.226 & 10.55
\end{array}\right]
\end{aligned}
$$


E.4 SIMPLE NUMERICAL EXAMPLE

$$
\begin{aligned}
10^{6} \mathrm{~B} & =\left[\begin{array}{ll}
31.9 & 265 \\
14.1 & 123
\end{array}\right]-\left[\begin{array}{ll}
31.0 & 266.9 \\
14.3 & 122.8
\end{array}\right] \\
10^{6} \mathrm{~B} & =\left[\begin{array}{rr}
0.9 & -1.9 \\
-0.2 & 0.2
\end{array}\right]
\end{aligned}
$$

Iteration for second mode $\phi_{2}$

$$
\begin{aligned}
& {\left[\begin{array}{rr}
0.9 & -1.9 \\
-0.2 & 0.2
\end{array}\right]\left[\begin{array}{r}
1 \\
-1
\end{array}\right]=\left[\begin{array}{r}
2.8 \\
-0.4
\end{array}\right]=2.8\left[\begin{array}{r}
1.0 \\
-0.1
\end{array}\right]} \\
& {\left[\begin{array}{rr}
0.9 & -1.9 \\
-0.2 & 0.2
\end{array}\right]\left[\begin{array}{r}
1.0 \\
-0.1
\end{array}\right]=\left[\begin{array}{c}
1.9 \\
-0.22
\end{array}\right]=1.09\left[\begin{array}{r}
1.00 \\
-0.22
\end{array}\right]} \\
& {\left[\begin{array}{rr}
0.9 & -1.9 \\
-0.2 & 0.2
\end{array}\right]\left[\begin{array}{r}
1.00 \\
-0.22
\end{array}\right]=\left[\begin{array}{r}
1.32 \\
-0.24
\end{array}\right]=1.32\left[\begin{array}{r}
1.00 \\
-0.18
\end{array}\right]} \\
& {\left[\begin{array}{rr}
0.9 & -1.9 \\
-0.2 & 0.2
\end{array}\right]\left[\begin{array}{r}
1.00 \\
-0.18
\end{array}\right]=\left[\begin{array}{r}
1.24 \\
-0.24
\end{array}\right]=1.24\left[\begin{array}{r}
1.00 \\
-0.19
\end{array}\right]}
\end{aligned}
$$

Thus

$$
\begin{aligned}
& \frac{10^{6}}{\omega_{2}^{2}}=1.24 \quad \phi_{2}=\left[\begin{array}{r}
1.00 \\
-0.19
\end{array}\right] \\
& \omega_{2}^{2}=0.806 \times 10^{6} \quad \omega_{2}=897 \mathrm{rad} \mathrm{sec}^{-1}
\end{aligned}
$$

The computed value of $\phi_{2}$ is not very accurate, as can be seen from

$$
\begin{aligned}
& \phi_{1}^{\mathrm{T}} \mathrm{M} \phi_{2}=10^{3}\left[\begin{array}{ll}
2.665 & 22.93
\end{array}\right]\left[\begin{array}{c}
1.000 \\
-0.19
\end{array}\right] \\
& \phi_{1}^{\mathrm{T}} \mathrm{M} \phi_{2}=10^{3}(2.665-4.357)=-1.692 \times 10^{3}
\end{aligned}
$$

when the value should be zero. The trouble is in the loss of accuracy arising in computing matrix $B$. The accurate value for the second mode for this two-coordinate problem is most easily found directly from the orthogonality relation used above as a check. It is found that

$$
\phi_{2}=\left[\begin{array}{r}
1.000 \\
-0.116
\end{array}\right]
$$

obtaining accurate values for nondominant modes can often be difficult for large order systems. 


$$
\begin{aligned}
\phi_{2}^{\mathrm{T}} \mathrm{M} & =\left[\begin{array}{ll}
1.000 & -0.116
\end{array}\right]\left[\begin{array}{ll}
0.857 & 3.93 \\
3.93 & 41.3
\end{array}\right]\left(10^{3}\right)=\left[\begin{array}{ll}
0.411 & -0.861
\end{array}\right]\left(10^{3}\right) \\
\phi_{2}^{\mathrm{T}} \mathrm{M} \phi_{2} & =\left(10^{3}\right)\left[\begin{array}{ll}
0.411 & -0.861
\end{array}\right]\left[\begin{array}{r}
1.000 \\
-0.116
\end{array}\right]=511.0 \\
\Phi^{\mathrm{T}} \mathrm{M} \Phi & =\left[\begin{array}{l}
\bar{M}_{\mathrm{r}} \\
]
\end{array}=\left[\begin{array}{rr}
13,210 & 0 \\
0 & 511
\end{array}\right]\right. \\
{\left[\omega_{\mathrm{r}}^{2}\right] } & =\left[\begin{array}{rr}
6502 & 0 \\
0 & 870,000
\end{array}\right]
\end{aligned}
$$

To get Eq. E.56 in the right form, premultiply by the inverse of the influence matrix which is the stiffness matrix $\left[k_{i j}\right]$

$$
\left[\mathrm{m}_{\mathrm{i},}\right]\left[\begin{array}{l}
\ddot{y} \\
\ddot{\theta}
\end{array}\right]+\left[\begin{array}{l}
\mathbf{k}_{\mathrm{i},}
\end{array}\right]\left[\begin{array}{l}
\mathrm{y} \\
\theta
\end{array}\right]=-\ddot{\mathrm{x}}\left[\begin{array}{l}
\mathrm{M} \\
\mathrm{Me}
\end{array}\right]
$$

Thus

$$
\begin{aligned}
\mathrm{f} & =\left[\begin{array}{l}
Q_{1} \\
Q_{2}
\end{array}\right]=\left[\begin{array}{l}
-\mathrm{M} \ddot{x} \\
-\mathrm{Me}
\end{array}\right]=\left[\begin{array}{l}
-857 \\
-3930
\end{array}\right] \ddot{\mathrm{x}} \\
\Phi & =\left[\begin{array}{ll}
\phi_{1}^{(1)} & \phi_{1}^{(2)} \\
\phi_{2}^{(1)} & \phi_{2}^{(2)}
\end{array}\right]=\left[\begin{array}{cc}
1 & 1 \\
0.461 & -0.112
\end{array}\right] \\
\Phi^{\mathrm{T}} \mathrm{f} & =\left[\begin{array}{ll}
1 & 0.461 \\
1 & -0.112
\end{array}\right]\left[\begin{array}{l}
-857 \\
-3930
\end{array}\right] \ddot{x}=\left[\begin{array}{l}
-2670 \\
-417
\end{array}\right] \ddot{\mathrm{x}} \\
\left(\Phi^{\mathrm{T}} \mathrm{M} \Phi\right)^{-1} & =\left[\begin{array}{ll}
\frac{1}{13,490} & 0 \\
0 & \frac{1}{509}
\end{array}\right]=\left[\begin{array}{ll}
0.0000741 & 0 \\
0 & 0.00197
\end{array}\right] \\
\left(\Phi^{\mathrm{T}} \mathrm{M} \Phi\right)^{-1} \Phi^{\mathrm{T} f} & =\left[\begin{array}{ll}
0.0000741 & 0 \\
0 & 0.00197
\end{array}\right]\left[\begin{array}{l}
-2670 \\
-417
\end{array}\right]=\left[\begin{array}{l}
-0.198 \\
-0.822
\end{array}\right]
\end{aligned}
$$

Therefore

$$
\ddot{c}+\left[\omega_{r}^{2}\right] c=\left(\Phi^{\mathrm{T}} \mathrm{M} \Phi\right)^{-1} \Phi^{\mathrm{T}} \mathrm{f}
$$

becomes

$$
\left[\begin{array}{l}
\ddot{c}_{1} \\
\ddot{c}_{2}
\end{array}\right]+\left[\begin{array}{ll}
6370 & 0 \\
0 & 870,000
\end{array}\right]\left[\begin{array}{l}
c_{1} \\
c_{2}
\end{array}\right]=\left[\begin{array}{l}
-0.198 \\
-0.822
\end{array}\right] \ddot{x}
$$




\section{REFERENCES}

and

$$
\begin{aligned}
& c_{1}=\frac{1}{79.8} \int_{0}^{t}-0.198 \ddot{x}(\tau) \sin 79.8(t-\tau) d \tau \\
& c_{2}=\frac{1}{932} \int_{0}^{t}-0.822 \ddot{x}(\tau) \sin 932(t-\tau) d \tau
\end{aligned}
$$

then

$$
\begin{aligned}
& y=c_{1} \phi_{1}^{(1)}+c_{2} \phi_{1}^{(2)} \\
& \theta=c_{2} \phi_{2}^{(1)}+c_{2} \phi_{2}^{(2)}
\end{aligned}
$$

or

$$
y=\frac{-0.198}{79.8} \int_{0}^{t} \ddot{x}(\tau) \sin 79.8(t-\tau) d \tau-\frac{0.822}{932} \int_{0}^{t} \ddot{x}(\tau) \sin 932(t-\tau) d \tau
$$

and

$$
\theta=\frac{(0.461)(-0.198)}{79.8} \int_{0}^{t} \ddot{x}(\tau) \sin 79.8(t-\tau) d \tau+\frac{(0.112)(0.822)}{932} \int_{0}^{t} \ddot{x}(\tau) \sin 932(t-\tau) d \tau
$$

The values under the integrals can be determined from the detailed velocity-spectrum curves (Fig. 1.20).

For the first mode the period is $1 / 12.7$ or $0.079 \mathrm{sec}$, and the second mode is $1 / 149$ or $0.0067 \mathrm{sec}$.

From the curves, assuming $2 \%$ critical damping, the responses for the two modes are

$$
s_{1}=0.18 \mathrm{ft} / \mathrm{sec} \quad s_{2}=0.02 \mathrm{ft} / \mathrm{sec}
$$

Ignoring signs for maximum response

$$
\begin{aligned}
& \mathrm{y} \leq 0.0025(0.18)+0.00088(0.02) \approx 0.00047 \mathrm{ft}=0.0056 \mathrm{in} . \\
& \theta \leq 0.00021+0.000002 \approx 0.000212=0.0025 \mathrm{radian}
\end{aligned}
$$

Thus the maximum response at the center of mass will be

$$
y+e \theta=0.144 \text { in. }
$$

\section{REFERENCES}

E.1. H. Goldstein, Classical Mechanics, Addison-Wesley Publishing Company, Inc., Reading, Mass., 1950.

E.2. S. P. Timoshenko, Vibration Problems in Engineering, 2nd ed., p. 205, D. Van Nostrand Company, Inc., Princeton, N. J., 1937. 


\section{Appendix F}

\section{DYNAMIC ANALYSIS OF FLUIDS IN CONTAINERS SUBJECTED TO ACCELERATION}

\section{F.1 INTRODUCTION}

Because of the importance of fluid containers in nuclear reactor installations, a detailed presentation of a workable method for predicting the dynamic behavior of the fluids is given here. This presentation amplifies that given in a previous publication ${ }^{\mathrm{F}}{ }^{1}$ and corrects errors that appeared in some of the expressions in the original work.

The analysis treats, by an approximate method, the hydrodynamic pressures de veloped when a fluid container is subjected to horizontal accelerations. Simplified for mulas are given for containers having twofold symmetry, and the specific cases of a rectangular and a circular cylindrical container are treated in detail.

The more exact analyses show that the pressures can be separated into impulsive and convective parts. The impulsive pressures are not impulses in the usual sense but are associated with inertial forces produced by accelerations of the walls of the container and are directly proportional to these accelerations. The convective pressures are those produced by the oscillations of the fluid and are therefore the consequences of the impulsive pressures. In the following analysis the impulsive and convective pressures are examined separately, the fluid being assumed incompressible and the fluid displacements small.

\section{F.2 IMPULSIVE PRESSURES}

Consider a container with vertical side walls and a horizontal bottom that is symmetrical with respect to the vertical $x-y$ and $z-y$ planes, which are perpendicular to each other (Fig. F.1). Let the walls of the container be given an impulsive acceleration $\dot{\mathrm{u}}_{0}$ in the $\mathrm{x}$ direction. This will generate fluid acceleration $\dot{\mathrm{u}}, \dot{\mathrm{v}}$ in the $\mathrm{x}, \mathrm{y}$ directions, and it may also generate an acceleration component $\dot{w}$ in the $z$ direction. For a rectangular tank $\dot{w}$ is obviously zero, and Jacobsen ${ }^{F}{ }^{2}$ (1949) showed that for a cylindrical tank $\dot{w}$ is zero also. In the following discussion it will be assumed that the ratio of $\dot{w}$ to $i$ is either 


\section{F.2 IMPULSTVE PRESSURES}

exactly zero or at least so small that $\dot{w}$ can be neglected. Physically this is equivalent to having the fluid restrained by thin vertical membranes, spaced $\mathrm{dz}$ apart, which force the fluid motion to take place in the $x-y$ plane only. It is then sufficient to consider the impulsive pressures generated in a lamina of fluid.

Consider a lamina of fluid of unit thickness in the $x-y$ plane (Fig. F.1), and let the walls be given a horizontal acceleration $\dot{u}$. The initial effect of this acceleration is to impart a horizontal acceleration to the fluid and also a vertical component of acceleration. This action of the fluid is similar to that which would result if the horizontal component, $u$, of fluid velocity were independent of the y coordinate; that is, Imagine the fluid to be constrained by thin, massless, vertical membranes free to move in the $\mathbf{x}$ direction, and let the membranes be originally spaced a distance $\mathrm{dx}$ apart. When the walls of the container are given an acceleration, the membranes will be accelerated with the fluid, and the fluid will also be squeezed vertically with respect to the membranes. The relation between the vertical velocity, $v$, and the horizontal velocity, $u$, can be determined from a mass balance on the lamina shown in Fig. F.2, where $p$ is the dynamic impulsive pressure generated by the acceleration $\dot{\mathrm{u}}_{0}$.

Thus

$$
v d x+u(h-y)=\left(u+\frac{\partial u}{\partial x} d x\right)(h-y)
$$

or

$$
v=(h-y) \frac{\partial u}{\partial x}
$$

Differentiating Eq. F.1 with respect to time,

$$
\dot{v}=(h-y) \frac{\partial \dot{u}}{\partial x}
$$

The equation of motion in the vertical direction, considering only forces arising from accelerations of the fluid, can be derived by applying Newton's law to a differential element of fluid, as shown in Fig. F.3, where $p$ represents the impulsive pressure. The net force on the element in the $y$ direction is $(-\partial p / \partial y) d x d y$. Denoting fluid density as $\rho$, the mass of the elements is $\rho \mathrm{dx} d \mathrm{y}$, and the acceleration is $\mathrm{dv} / \mathrm{dt}$. Thus

$$
-\frac{\partial p}{\partial y} d x d y=\rho d x d y \frac{d v}{d t}
$$

or

$$
\frac{\partial p}{\partial y}=-\rho \frac{d v}{d t}=-\rho\left(\frac{\partial v}{\partial t}+\frac{\partial v}{\partial x} \frac{d x}{d t}+\frac{\partial v}{\partial y} \frac{d y}{d t}\right)
$$

Now $d x / d t$ and $d y / d t$ are $u$ and $v$, respectively. Furthermore, since the fluid displace ments were assumed to be small, the velocities, and hence the $x$ and $y$ derivatives of the velocities, are also small. Thus the second and third terms on the right-hand side of Eq. F.3 are of higher order than the first term and can be assumed to be negligible, so that Eq. F.3 becomes

$$
\frac{\partial p}{\partial y}=-\rho \frac{\partial v}{\partial t}
$$




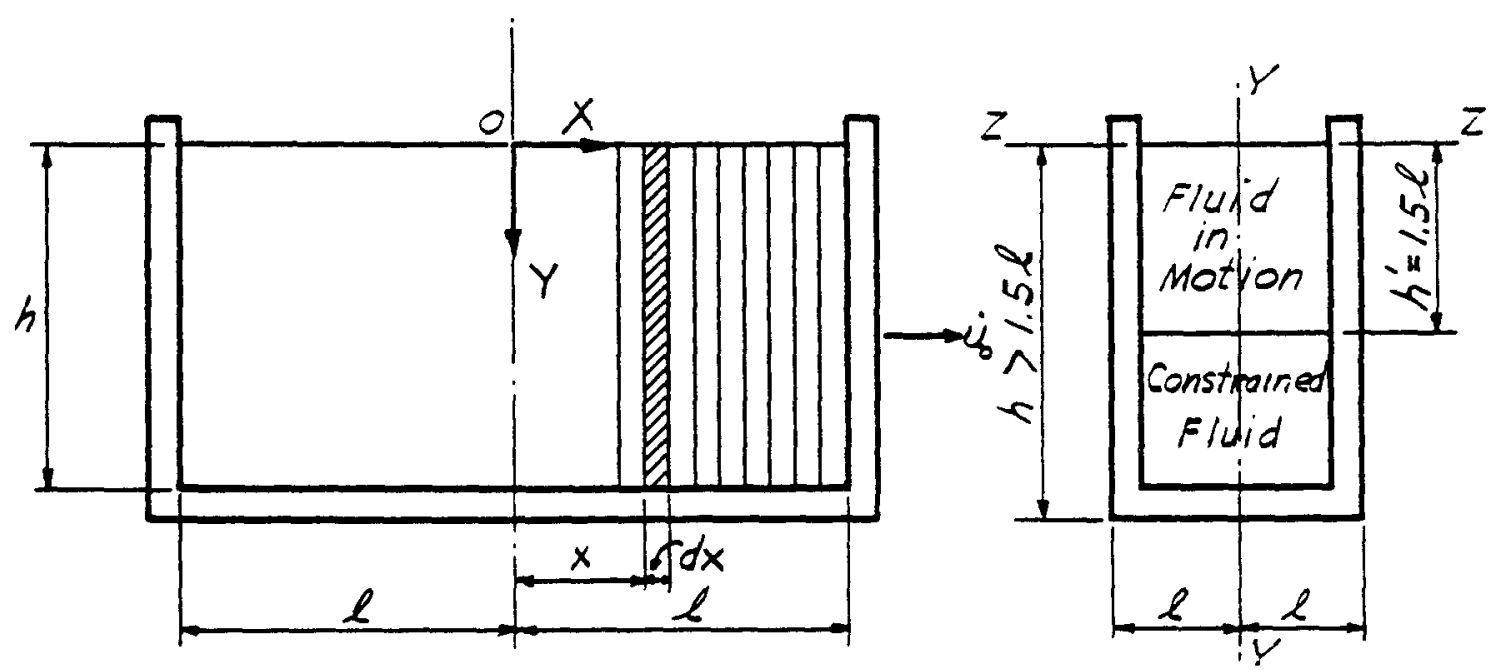

Figure F.1.
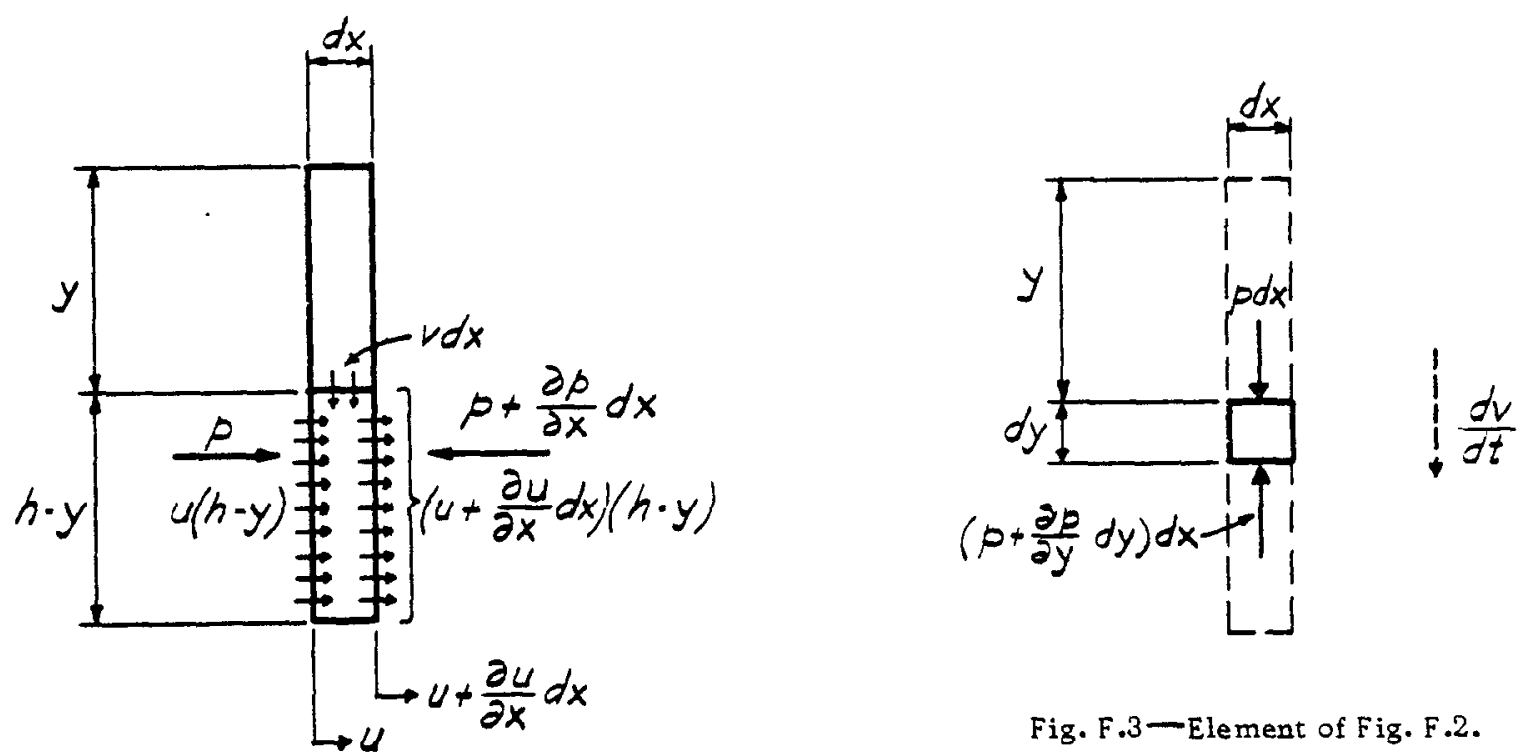

Fig. F.2-Element of Fig. F.1.

Fig. F.3-Element of Fig. F.2. 
The total horizontal force on one membrane is

$$
P=\int_{0}^{h} p d y
$$

Using Eq. F.2 in Eq. F.4 and integrating from zero to y, with the conditions that $\left.p\right|_{y=0}=0$ and $\dot{\mathrm{u}} \neq \dot{\mathrm{u}}(\mathrm{y})$,

$$
p=-\rho \frac{\partial \dot{u}}{\partial x} \int_{0}^{y}\left(h-y^{\prime}\right) d y^{\prime}=-\rho h^{2}\left[\frac{y}{h}-\frac{1}{2}\left(\frac{y}{h}\right)^{2}\right] \frac{\partial \dot{u}}{\partial x}
$$

The primes under the integral are used simply to denote a dummy variable of integration. Substituting Eq. F.6 in Eq. F.5,

$$
P=-\rho h^{2} \frac{\partial \dot{u}}{\partial x} \int_{0}^{h}\left[\frac{y}{h}-\frac{1}{2}\left(\frac{y}{h}\right)^{2}\right] d y=-\frac{1}{3} \rho h^{3} \frac{\partial \dot{u}}{\partial x}
$$

The equation of motion in the $\mathrm{x}$ direction can be determined by applying Newton's law to the element of fluid shown in Fig. F.2. Neglecting the higher order terms, as before, which arise from the total time derivative of $u$, the result can be written

$$
\frac{\partial \mathbf{P}}{\partial \mathbf{x}}=-\rho h \dot{u}
$$

Substituting P from Eq. F.7 into Eq. F.8,

$$
\frac{\partial^{2} \dot{u}}{\partial x^{2}}-\frac{3}{h^{2}} \dot{u}=0
$$

Considering $\dot{\mathrm{u}}$ to be a dependent variable which is a function only of $\mathrm{x}, \mathrm{Eq} . \mathrm{F} .9$ can be written as a total differential equation whose solution is ${ }^{F \cdot 3}$

$$
\dot{\mathrm{u}}=\mathrm{C}_{1} \cosh \sqrt{3} \frac{\mathrm{x}}{\mathrm{h}}+\mathrm{C}_{2} \sinh \sqrt{3} \frac{\mathrm{x}}{\mathrm{h}}
$$

Equations F.6 and F.10 determine the fluid pressures, and they are strictly applicable only when the surface is horizontal, as was assumed in the derivation of Eq. F.1. However, if consideration is restricted to small displacements of fluid, the equations can be used even when the surface of the fluid has been excited into motion; that is, Eq. F.6 gives the impulsive pressures, $p(t)$, corresponding to arbitrary acceleration, $\dot{u}_{0}(t)$.

If the container is slender, having $h>1.5 l$, somewhat better results are obtained by applying Eqs. F.6 and F.7 to the upper portion, $h^{\prime}=1.5 l$, of the fluid only and consider ing the fluid below this point to move as though it were completely constrained [see part (a) of Fig. F.1 and Ref. F.1]. It can be imagined that a fixed rigid membrane separates the upper and lower portions of fluid at the plane $y=h^{\prime}$, so that the preceding equations apply to the upper portion of fluid if $h$ is replaced by $h^{\prime}$. The equation of motion in the horizontal direction for the constrained fluid below the vertical depth $h^{\prime}$ can be derived by the method used to obtain Eq. F.4. Assuming a known acceleration $\dot{\mathrm{u}}_{0}$, Newton's law applied to a differential element gives

$$
\frac{\partial p}{\partial x}=-\rho \dot{u}_{0}
$$

Integrating Eq. F.11 with the condition that from symmetry $\left.p\right|_{x=0}=0$,

$$
\mathrm{p}=-\rho \dot{\mathbf{u}}_{0} \mathrm{x}
$$


The moment exerted on the horizontal membrane by the constrained fluid is, using Eq. F.12,

$$
\mathbf{M}_{\mathrm{c}}=\int_{\mathrm{l}} \mathrm{px} \mathrm{dx}=-\frac{2}{3} \rho \dot{\mathrm{u}}_{0} \ell^{3}
$$

The moment exerted on the imaginary horizontal membrane by the fludd above, if Eqs. F. 6 and F.10 are solved using the appropriate boundary conditions, can be shown to be approximately equal to the value from Eq. F. 12 for $h^{\prime}=1.5 l^{1}$. This implies that the generation of fluid velocity is restricted essentially to the fluid in the upper part of the slender container.

\section{F.3 CONVECTIVE PRESSURES}

When the walls of a fluid container are subjected to accelerations, the fluid itself is excited into oscillations, and this motion produces pressures on the walls and floor of the container. To examine the first mode of vibration of the fluid, consider constraints to be provided by horizontal, rigid membranes free to rotate as shown in Fig. F.4. Let $\mathrm{u}, \mathrm{v}, \mathrm{w}$ be the $\mathrm{x}, \mathrm{y}, \mathrm{z}$ components of fluid velocity, and let the motion be constrained as follows:

(a) All fluid in the element shown in Figs. F.4 and F.5 moves with uniform u $\left[u=f_{1}(x, y)\right]$.

(b) All fluid in the same element moves with uniform $v\left[v=f_{2}(x, y)\right]$.

Consider a mass balance on this element with the motion described by (a) and (b). Referring to Fig. F.5, the net flow into the element in the horizontal direction is

$$
-2 \frac{\partial}{\partial x}(u b) d x d y
$$

The net flow into the element in the vertical direction is

$$
-2 b \frac{\partial v}{\partial y} d x d y
$$

Since the fluid is incompressible, the volume $2 \mathrm{~b} d x d y$ remains constant. Hence

$$
-2 \frac{\partial}{\partial x}(u b) d x d y-2 b \frac{\partial v}{\partial y} d x d y=0
$$

or

$$
\frac{\partial}{\partial x}(u b)=-b \frac{\partial v}{\partial y}
$$

Constraint (b) can be described by the following equation as a function of $\mathrm{x}$ and the derivative of angle of oscillation $\theta$ :

$$
v=x \dot{\theta}
$$

Equation F.15 states that the vertical velocity of a fluid particle is the same as that of the point on the membrane with which it is in contact, which is true only if $\theta$ is small (see Fig. F.4). 
F.3 CONVECTIVE PRESSURES
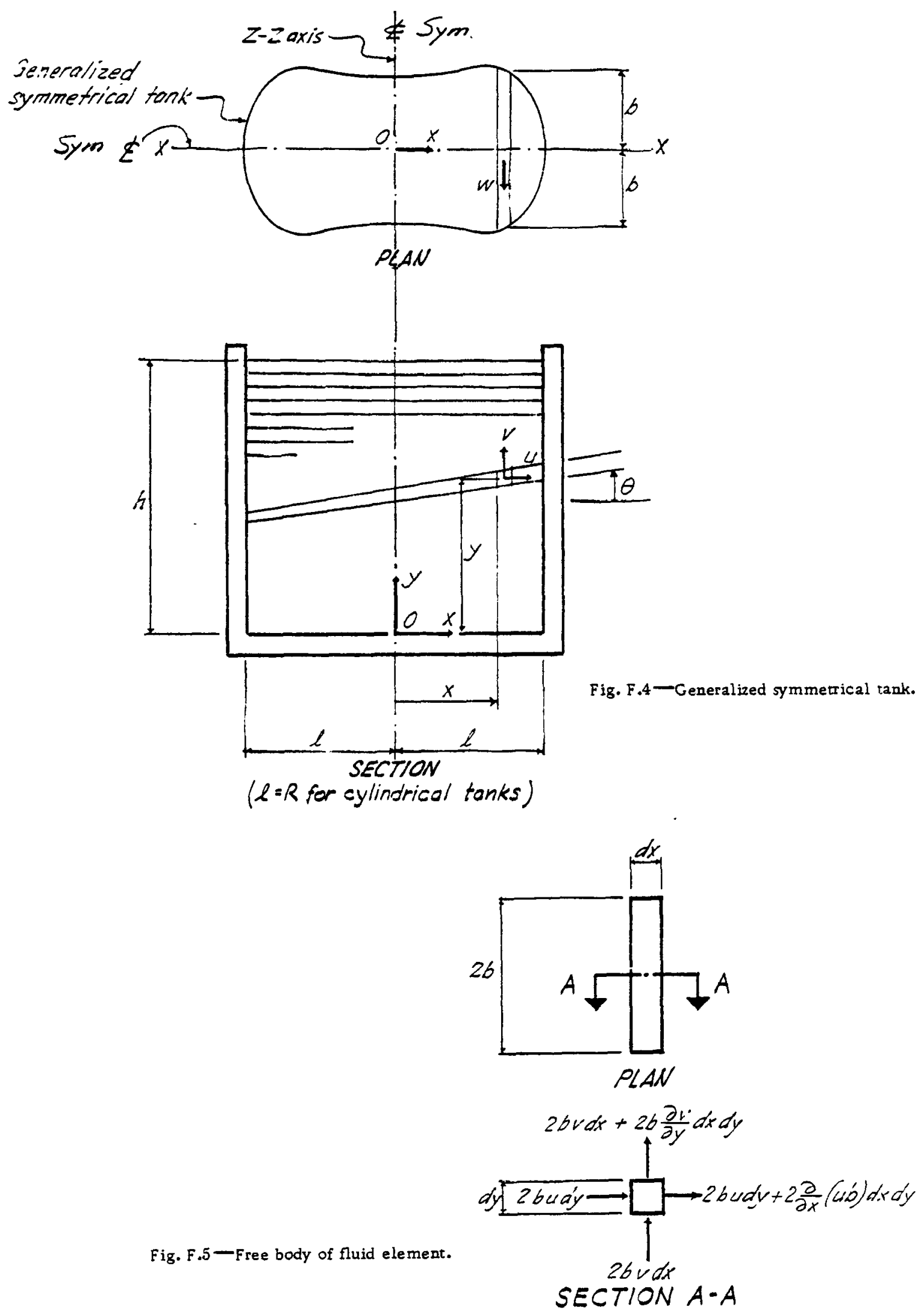
The usual equation of continuity can be derived from a mass balance on a differential element of volume, $d x d y d z$. Summing the net volume flows into the element in the $x, y$, and $z$ directions, respectively,

$$
-\frac{\partial u}{\partial x} d x d y d z-\frac{\partial v}{\partial y} d y d x d z-\frac{\partial w}{\partial z} d z d x d y=0
$$

or

$$
\frac{\partial w}{\partial \mathbf{z}}=-\left(\frac{\partial \mathbf{u}}{\partial \mathbf{x}}+\frac{\partial v}{\partial \mathbf{y}}\right)
$$

Thus, with Eqs. F.15 and F.16, Eq. F.14 states that the fluid in the element of Fig. F.5 moves with velocities $u$ and $v$ that are independent of $z$. It should be noted that $\theta$ is a function of $y$ and $t$ but not of $x$. Therefore, at a particular time, the rotation of a membrane is a function only of its vertical position.

The boundary conditions on the fluid motion are as follows:

$$
\begin{aligned}
& u=0 \text { at } x= \pm l \\
& w=0 \text { at } z=0 \\
& \theta=0 \text { at } y=0 \\
& \theta=\theta_{h} \text { at } y=h
\end{aligned}
$$

Equation F.17 states that the outermost fluid element, like that shown in Fig. F.5, has zero horizontal velocity; Eq. F.18 results from a consideration of symmetry; Eq. F.19 is required by the zero vertical velocity of the fluid at the floor of the container.

In a manner similar to that of the preceding section, the appropriate equations of motion could be written for the particular shape of container under consideration. A general solution, applicable to any prismatic tank having twofold symmetry, can be deduced as follows.

Substituting Eq. F.15 in Eq. F.14 and integrating from $-\ell$ to $x$, using Eq. F.17,

$$
\mathrm{u}=-\frac{1}{\mathrm{~b}} \frac{\partial \dot{\theta}}{\partial \mathrm{y}} \int_{-1}^{x} \mathrm{~b}\left(\mathrm{x}^{\prime}\right) \mathrm{x}^{\prime} d \mathbf{x}^{\prime}
$$

where $x^{\prime}$ is the dummy variable for integration between limits zero and $x$. Differentiating Eq. F.21 with respect to $x$,

$$
\frac{\partial u}{\partial x}=\frac{b^{\prime}}{b^{2}} \frac{\partial \dot{\theta}}{\partial y} \int_{-l}^{x} b\left(x^{\prime}\right) x^{\prime} d x^{\prime}-x \frac{\partial \dot{\theta}}{\partial y}
$$

where $b^{\prime}=d b / d x$. Substituting Eq. F.22 and $\partial v / \partial y$ from Eq. F.15 into Eq. F.16,

$$
\frac{\partial w}{\partial z}=-\frac{b^{\prime}}{b^{2}} \frac{\partial \dot{\theta}}{\partial y} \int_{-l}^{x} b x^{\prime} d x^{\prime}
$$

Integrating Eq. F.23 from 0 to z, using Eq. F.18,

$$
w=-z \frac{b^{\prime}}{b^{2}} \frac{\partial \dot{\theta}}{\partial y} \int_{-l}^{x} b\left(x^{\prime}\right) x^{\prime} d x^{\prime}
$$




\section{F.3 CONVECTIVE PRESSURES}

The total kinetic energy is the integral over the volume of the kinetic energy of the fluid elements.

$$
T=\frac{1}{2} \rho \iiint\left(u^{2}+v^{2}+w^{2}\right) d x d y d z
$$

Substituting $u, v$, and $w$ from Eqs. F.21, F.15, and F.24 into Eq. F.25,

$$
\begin{aligned}
T & =\frac{1}{2} \rho \int_{-l}^{l} \int_{0}^{h} \int_{-b}^{b}\left\{x^{2} \dot{\theta}^{2}+\frac{1}{b^{2}}\left(\frac{\partial \dot{\theta}}{\partial y}\right)^{2}\left[\int_{-l}^{x} b\left(x^{\prime}\right) x^{\prime} d x^{\prime}\right]^{2}\left[1+z^{2}\left(\frac{b^{\prime}}{b}\right)^{2}\right]\right\} d x d y d z \\
& =\frac{1}{2} \rho \int_{0}^{h}\left[I_{z} \dot{\theta}^{2}+K\left(\frac{\partial \dot{\theta}}{\partial y}\right)^{2}\right] d y
\end{aligned}
$$

where

$$
\begin{aligned}
I_{z} & =\int_{A} x^{2} d A=\int_{-l}^{l} \int_{-b}^{b} x^{2} d x d z \\
K & =\int_{-l}^{l} \int_{-b}^{b} \frac{1}{b^{2}}\left[\int_{-l}^{x} b\left(x^{\prime}\right) x^{\prime} d x^{\prime}\right]^{2}\left[1+z^{2}\left(\frac{b^{\prime}}{b}\right)^{2}\right] d x d z \\
& =2 \int_{-l}^{l} \frac{1}{b}\left[\int_{-l}^{x} b\left(x^{\prime}\right) x^{\prime} d x^{\prime}\right]^{2}\left(1+\frac{b^{\prime 2}}{3}\right) d x
\end{aligned}
$$

The potential energy of the fluid is obtained by summing the contributions from each element of fluid in the disturbed surface, due to its average displacements from the equilibrium level. For the element of volume $\left(x \theta_{h}\right) \mathrm{dA}$, displaced an average height $(1 / 2)\left(x \theta_{h}\right)$ from the undisturbed level, the potential energy is

$$
\mathrm{dV}=\frac{1}{2} \rho \mathrm{gx}^{2} \theta_{\mathrm{h}}^{2} \mathrm{dA}
$$

and the total potential energy is

$$
V=\frac{1}{2} \rho g \theta_{\mathrm{h}}^{2} \int_{\mathrm{A}} \mathrm{x}^{2} \mathrm{dx} \mathrm{dz}=\frac{1}{2} \rho \mathrm{g} \theta_{\mathrm{h}}^{2} \mathrm{I}_{\mathrm{L}}
$$

By Hamilton's principle, ${ }^{\mathrm{F} \cdot 4}$

$$
\delta \int_{t_{1}}^{t_{2}}(T-V) d t=0
$$

Using Eqs. F.26 and F.29 in Eq. F.30,

$$
\delta \int_{\mathrm{t}_{1}}^{\mathrm{t}_{2}} \frac{1}{2} \rho\left\{\int_{0}^{\mathrm{h}}\left[\mathrm{I}_{z} \dot{\theta}^{2}+\mathrm{K}\left(\frac{\partial \dot{\theta}}{\partial \mathrm{y}}\right)^{2}\right] \mathrm{dy}-\mathrm{g} \theta_{\mathrm{h}}^{2} \mathrm{I}_{2}\right\} \mathrm{dt}=0
$$

or

$$
\int_{\mathrm{c}_{1}}^{\mathrm{c}_{\mathrm{g}}} \rho\left\{\int_{0}^{\mathrm{h}}\left[\mathrm{I}_{2} \dot{\theta} \delta \dot{\theta}+\mathrm{K}\left(\frac{\partial \dot{\theta}}{\partial \mathrm{y}}\right) \delta\left(\frac{\partial \dot{\theta}}{\partial \mathrm{y}}\right)\right] \mathrm{dy}-\mathrm{g} \theta_{\mathrm{h}} \mathrm{I}_{\mathrm{z}} \delta \theta_{\mathrm{h}}\right\} \mathrm{dt}=0
$$

Examining the second term under the integral separately,

$$
I_{2}=\rho \mathrm{K} \int_{\mathrm{t}_{1}}^{\mathrm{t}_{2}} \int_{0}^{\mathrm{h}}\left(\frac{\partial \dot{\theta}}{\partial \mathrm{y}}\right) \delta\left(\frac{\partial \dot{\theta}}{\partial \mathrm{y}}\right) \mathrm{dy} d \mathrm{t}=\rho \mathrm{K} \int_{\mathrm{t}_{1}}^{\mathrm{t}_{2}} \int_{0}^{\mathrm{h}}\left(\frac{\partial \dot{\theta}}{\partial \mathrm{y}}\right) \frac{\partial}{\partial \mathrm{y}}(\delta \dot{\theta}) \mathrm{dy} d \mathrm{t}
$$


Paqe 375 is missina from document. 
Paqe 376 is missing from document. 
Integrating Eq. F.41 from $(0, y, 0)$ to $(x, y, z)$, with the condition, from symmetry, that $p(0, y, 0)=0$,

$$
p=\rho \frac{\partial \ddot{\theta}}{\partial y}\left[\int_{0}^{x} \frac{B\left(x^{\prime}\right)}{b\left(x^{\prime}\right)} d x^{\prime}+\frac{z^{2}}{2} \frac{b^{\prime}}{b^{2}} B\right]
$$

If $\mathrm{p}$ is known, the forces and moments on the walls and floor of the container can be determined readily.

\section{F.4 RECTANGULAR CONTAINER}

For a rectangular container of unit width as shown in Fig. F.1, the boundary conditions for the impulsive pressures are $\dot{u}=\dot{u}_{0}$ at $x= \pm \ell$, for which Eq. F.10 gives

$$
\dot{u}=\dot{u}_{0} \frac{\cosh \sqrt{3} \frac{x}{h}}{\cosh \sqrt{3} \frac{l}{h}}
$$

Using Eq. F.44 in Eqs. F.6 and F.7,

$$
\begin{aligned}
& \mathrm{p}=-\rho \dot{\mathrm{u}}_{0} \mathrm{~h} \sqrt{3}\left[\frac{\mathrm{y}}{\mathrm{h}}-\frac{1}{2}\left(\frac{\mathrm{y}}{\mathrm{h}}\right)^{2}\right] \frac{\sinh \sqrt{3} \frac{\mathrm{x}}{\mathrm{h}}}{\cosh \sqrt{3} \frac{l}{\mathrm{~h}}} \\
& \mathrm{P}=-\rho \dot{\mathrm{u}}_{0} \frac{\mathrm{h}^{2}}{\sqrt{3}} \frac{\sinh \sqrt{3} \frac{\mathrm{x}}{\mathrm{h}}}{\cosh \sqrt{3} \frac{\ell}{\mathrm{h}}}
\end{aligned}
$$

The wall acceleration, $\dot{\mathrm{u}}_{0}$, thus produces an increase of wall pressure, $\mathrm{f}_{\mathrm{w}}$, on one wall $(x=-l)$ and a decrease of pressure on the opposite wall of

$$
\mathrm{p}_{\mathrm{w}}=\rho \dot{\mathrm{u}}_{0} \mathrm{~h}\left[\frac{\mathrm{y}}{\mathrm{h}}-\frac{1}{2}\left(\frac{\mathrm{y}}{\mathrm{h}}\right)^{2}\right] \sqrt{3} \tanh \sqrt{3} \frac{\ell}{\mathrm{h}}
$$

and produces a bottom pressure, $p_{b}$, on the tank bottom $(y=h)$ of

$$
\mathrm{p}_{\mathrm{b}}=-\rho \dot{\mathrm{u}}_{0} \mathrm{~h} \frac{\sqrt{3}}{2} \frac{\sinh \sqrt{3} \frac{\mathrm{x}}{\mathrm{h}}}{\cosh \sqrt{3} \frac{\mathrm{l}}{\mathrm{h}}}
$$

The total force acting on one wall is the sum of those acting on the walls at $x=-l$ and $\mathrm{x}=+l$ and is given by

$$
P=-\rho \dot{\mathbf{u}}_{0} \frac{\mathrm{h}^{2}}{\sqrt{3}} \tanh \sqrt{3} \frac{\ell}{\mathrm{h}}
$$


Note that the forces act in the same direction on both walls due to the increase of pressure on one wall and the decrease on the other wall. The distance, $\bar{y}$, at which the resultant force acts is, from Eq. F.47,

$$
\bar{y}=\frac{\int_{0}^{h} y\left[\frac{y}{h}-\frac{1}{2}\left(\frac{y}{h}\right)^{2}\right] d y}{\int_{0}^{h}\left[\frac{y}{h}-\frac{1}{2}\left(\frac{y}{h}\right)^{2}\right] d y}=\frac{5}{8} h
$$

and its distance above the bottom is

$$
h_{0}=h-\bar{y}=\frac{3}{8} h
$$

It is seen that the overall effect of the fluid on the walls of the container is the same as if an equivalent mass of the fluid, $\mathrm{m}_{0}$, were fastened rigidly to the walls of the container at a height $\left(\frac{3}{8}\right) \mathrm{h}$ above the bottom. The magnitude of $\mathrm{m}_{0}$ is, using Eq. F.49,

$$
\mathrm{m}_{0}=-\frac{2 \mathrm{P}}{\dot{\mathrm{u}}_{0}}=\frac{2}{\sqrt{3}} \rho \mathrm{h}^{2} \tanh \sqrt{3} \frac{\ell}{\mathrm{h}}=\mathrm{m} \frac{\tanh \sqrt{3} \frac{\ell}{\mathrm{h}}}{\sqrt{3} \frac{\ell}{\mathrm{h}}}
$$

where $m$ is the total mass of fluid.

The total moment (clockwise) exerted on the bottom of the tank is, using Eq. F.48,

$$
\begin{aligned}
M_{b} & =\int_{-l}^{l} x_{b} d x=-\rho \dot{u}_{0} h \frac{\sqrt{3}}{2} \frac{1}{\cosh \sqrt{3} \frac{l}{h}} \int_{-l}^{l} x \sinh \sqrt{3} \frac{x}{h} d x \\
& =-\rho \dot{u}_{0} h^{2} \ell\left[1-\frac{\tanh \sqrt{3} \frac{l}{h}}{\sqrt{3} \frac{l}{h}}\right]
\end{aligned}
$$

Including this, the correct total moment on the tank is given when the equivalent mass $m_{0}$ is at an elevation above the bottom, given by

$$
\begin{aligned}
h_{0} & =\frac{3}{8} h+\frac{M_{b}}{2 P} \\
& =\frac{3}{8} h\left[1+\frac{4}{3}\left(\frac{\sqrt{3} \frac{l}{h}}{\tanh \sqrt{3} \frac{l}{h}}-1\right)\right]
\end{aligned}
$$

In the case of free oscillations of the fluid in the fundamental mode for a rectangular tank of unit width, Eqs. F.27 and F.28 give

$$
\begin{aligned}
& I_{z}=\int_{-l}^{l} x^{2} d x=\frac{2}{3} l^{3} \\
& K=2 \int_{-l}^{l} 2\left(\int_{-l}^{x} \frac{1}{2} x^{\prime} d x^{\prime}\right)^{2} d x=\frac{1}{4} \int_{-l}^{l}\left(x^{2}-l^{2}\right)^{2} d x=\frac{4}{15} l^{5}
\end{aligned}
$$


Thus $\sqrt{\frac{I_{2}}{K}}=\sqrt{\frac{5}{2}}\left(\frac{1}{l}\right)$, and Eqs. F.38 and F.39 become

$$
\begin{aligned}
\theta & =\theta_{\mathrm{h}} \frac{\sinh \sqrt{\frac{5}{2}} \frac{\mathrm{y}}{l}}{\sinh \sqrt{\frac{5}{2}} \frac{\mathrm{h}}{l}} \sin \omega \mathrm{t} \\
\omega^{2} & =\sqrt{\frac{5}{2}} \frac{\mathrm{g}}{l} \tanh \sqrt{\frac{5}{2}} \frac{\mathrm{h}}{\ell}
\end{aligned}
$$

The velocity at any point in the fluid is, from Eqs. F.21 and F.15, given by

$$
\begin{aligned}
& u=-2 \frac{\partial \dot{\theta}}{\partial y} \int_{-l}^{x} \frac{1}{2} x^{\prime} d x^{\prime}=\frac{1}{2}\left(l^{2}-x^{2}\right) \frac{\partial \dot{\theta}}{\partial y} \\
& v=x \dot{\theta}
\end{aligned}
$$

By Eqs. F.42 and F.43,

$$
\begin{aligned}
& B=\int_{-l}^{x} \frac{1}{2} x^{\prime} d x^{\prime}=\frac{-1}{4}\left(l^{2}-x^{2}\right) \\
& \int_{0}^{x} \frac{B\left(x^{\prime}\right)}{b\left(x^{\prime}\right)} d x^{\prime}=\frac{1}{2} \int_{0}^{x}\left(l^{2}-x^{\prime 2}\right) d x=-\frac{l^{3}}{2}\left[\frac{x}{l}-\frac{1}{3}\left(\frac{x}{l}\right)^{3}\right] \\
& p=-\rho \frac{l^{3}}{2}\left[\frac{x}{l}-\frac{1}{3}\left(\frac{x}{l}\right)^{3}\right] \frac{\partial \ddot{\theta}}{\partial y}
\end{aligned}
$$

Using Eq. F.56 in Eq. F.60,

$$
\mathrm{p}=\frac{1}{2} \sqrt{\frac{5}{2}} \rho l^{2} \omega^{2} \theta_{\mathrm{h}}\left[\frac{\mathrm{x}}{\mathrm{l}}-\frac{1}{3}\left(\frac{\mathrm{x}}{l}\right)^{3}\right] \frac{\cosh \sqrt{\frac{5}{2}} \frac{\mathrm{y}}{\mathrm{l}}}{\sinh \sqrt{\frac{5}{2}} \frac{\mathrm{h}}{l}} \sin \omega \mathrm{t}
$$

The pressure exerted on the wall of the container $(x=l)$ is

$$
\mathrm{p}_{\mathrm{w}}=\rho \frac{\ell^{2}}{3} \sqrt{\frac{5}{2}} \frac{\cosh \sqrt{\frac{5}{2}} \frac{\mathrm{y}}{\ell}}{\sinh \sqrt{\frac{5}{2}} \frac{\mathrm{h}}{l}} \omega^{2} \theta_{\mathrm{h}} \sin \omega \mathrm{t}
$$

The total force on one wall $(x=l)$ is

$$
P=\int_{0}^{h} p_{w} d y=\frac{1}{3} \rho l^{3} \omega^{2} \theta_{h} \sin \omega t
$$

The total force 2P exerted on the tank by the fluid is the same as that which would be produced by an equivalent mass $m_{1}$ that is spring mounted, as shown in Fig. F.6. If $m_{1}$ oscillates with a displacement given by

$$
x_{1}=A_{1} \sin \omega t
$$




\section{F.4 RECTANGULAR CONTAINER}

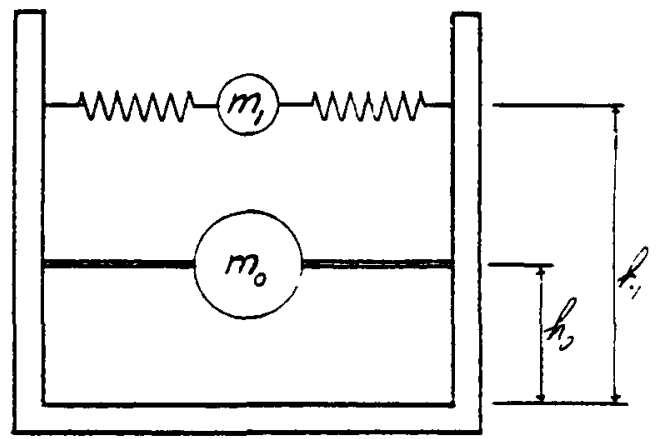

Fig. F.6-Dynamic model for fluid container supported on the ground.

the force against the tank and the kinetic energy of the mass are

$$
\begin{aligned}
& F=-m_{1} \ddot{x}_{1}=m_{1} A_{1} \omega^{2} \sin \omega t \\
& T=\frac{1}{2} m_{1} \dot{x}_{1}^{2}=\frac{1}{2} m_{1} A_{1}^{2} \omega^{2} \cos ^{2} \omega t
\end{aligned}
$$

Equating $F$ and $2 P$ from Eq. F.63 gives

$$
\mathrm{m}_{1} \mathrm{~A}_{1} \omega^{2} \sin \omega \mathrm{t}=\frac{2}{3} \rho l^{3} \omega^{2} \theta_{h} \sin \omega \mathrm{t}
$$

or

$$
\mathrm{m}_{1} \mathrm{~A}_{1}=\frac{2}{3} \rho l^{3} \theta_{\mathrm{b}}
$$

Substituting $I_{2}, K$, and $\theta$ from Eqs. F.54, F.55, and F.56 into Eq. F.26,

$$
\begin{aligned}
T= & \frac{1}{2} \rho \int_{0}^{\mathrm{h}}\left[\frac{2}{3} l^{3} \omega^{2} \theta_{\mathrm{h}}^{2} \frac{\sinh ^{2} \sqrt{\frac{5}{2}} \frac{\mathrm{y}}{l}}{\sinh ^{2} \sqrt{\frac{5}{2}} \frac{\mathrm{h}}{l}} \cos ^{2} \omega \mathrm{t}\right. \\
& \left.+\frac{4}{15} l^{5}\left(\frac{5}{2}\right) \frac{1}{l^{2}} \theta_{\mathrm{h}}^{2} \frac{\cosh ^{2} \sqrt{\frac{5}{2}} \frac{\mathrm{y}}{l}}{\sinh ^{2} \sqrt{\frac{5}{2}} \frac{\mathrm{h}}{l}} \omega^{2} \cos ^{2} \omega \mathrm{t}\right] \mathrm{dy} \\
= & \frac{1}{3} \sqrt{\frac{2}{5}} \rho l^{4} \theta_{\mathrm{h}}^{2} \omega^{2} \cos ^{2} \omega \mathrm{t} \operatorname{coth} \sqrt{\frac{5}{2}} \frac{\mathrm{h}}{l}
\end{aligned}
$$

Equating Eqs. F.66 and F.68 gives

$$
\frac{1}{2} m_{1} A_{1}^{2} \omega^{2} \cos ^{2} \omega t=\frac{1}{3} \sqrt{\frac{2}{5}} \rho l^{4} \theta_{h}^{2} \omega^{2} \cos ^{2} \omega t \operatorname{coth} \sqrt{\frac{5}{2}} \frac{h}{l}
$$


or

$$
A_{1}=\frac{2}{3} \sqrt{\frac{2}{5}} \rho l^{4} \theta_{h}^{2}\left(\frac{1}{m_{1} A_{1}}\right) \operatorname{coth} \sqrt{\frac{5}{2}} \frac{h}{l}
$$

Equations F.67 and F.69 give

$$
\begin{aligned}
\mathrm{A}_{\mathrm{t}} & =\theta_{\mathrm{h}} \frac{\ell}{\sqrt{\frac{5}{2}} \tanh \sqrt{\frac{5}{2}} \frac{\mathrm{h}}{l}} \\
\mathrm{~m}_{1} & =\frac{2}{3} \rho l^{3} \theta_{\mathrm{h}}\left(\frac{1}{\mathrm{~h} \theta_{\mathrm{h}}}\right) \sqrt{\frac{5}{2}} \frac{\mathrm{h}}{l} \tanh \sqrt{\frac{5}{2}} \frac{\mathrm{h}}{l} \\
& =\mathrm{m}\left(\frac{1}{3} \sqrt{\frac{5}{2}} \frac{\mathrm{l}}{\mathrm{h}} \tanh \sqrt{\frac{5}{2}} \frac{\mathrm{h}}{l}\right)
\end{aligned}
$$

where $\mathrm{m}$ is the total mass of the fluid.

The moment exerted about the negative $z$ axis from pressures acting on both walls of the tank is, from Eq. F.62,

$$
\begin{aligned}
M_{w} & =2 \int_{0}^{h} p_{w} y d y \\
& =\frac{2}{3} \sqrt{\frac{5}{2}} \rho l^{2} \frac{\omega^{2} \theta_{h} \sin \omega t}{\sinh \sqrt{\frac{5}{2}} \frac{h}{l}} \int_{0}^{h} y \cosh \sqrt{\frac{5}{2} \frac{y}{l} d y} \\
& =\frac{2}{3} \rho h l^{3} \omega^{2} \theta_{h} \sin \omega t\left(1-\sqrt{\frac{2}{5}} \frac{l}{h} \cosh \sqrt{\frac{5}{2}} \frac{h}{l}+\sqrt{\frac{2}{5}} \frac{l}{h} \frac{1}{\sinh \sqrt{\frac{5}{2}} \frac{h}{l}}\right)
\end{aligned}
$$

The elevation of $m_{1}$ above the bottom to produce the same moment from Eqs. F.63 and F.72 is given by the following equation. This equation does not take into account the ef fect of fluid pressure on the tank bottom.

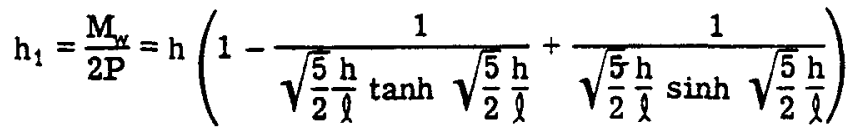

The pressure exerted on the bottom of the tank is, from Eq. F.61,

$$
\mathrm{p}_{\mathrm{b}}=\frac{1}{2} \sqrt{\frac{5}{2}} \rho l^{2} \omega^{2} \theta_{\mathrm{h}}\left[\frac{\mathrm{x}}{l}-\frac{1}{3}\left(\frac{\mathrm{x}}{\ell}\right)^{3}\right] \frac{\sin \omega \mathrm{t}}{\sinh \sqrt{\frac{5}{2}} \frac{\mathrm{h}}{\ell}}
$$

The moment about the $\mathrm{z}$ axis due to this pressure is

$$
\mathrm{M}_{\mathrm{b}}=\int_{-l}^{l} \mathrm{p}_{\mathrm{b}} \mathrm{x} d \mathrm{x}=\frac{4}{15} \sqrt{\frac{5}{2}} \rho l^{4} \omega^{2} \theta_{\mathrm{h}} \frac{\sin \omega \mathrm{t}}{\sinh \sqrt{\frac{5}{2}} \frac{\mathrm{h}}{l}}
$$


Taking into account the fluid pressure on the tank bottom, the modified value of $h_{1}$ is, from Eqs. F.73, F.63, and F.75,

$$
h_{1}=\frac{M_{w}+M_{b}}{2 P}=h\left(1-\frac{\cosh \sqrt{\frac{5}{2}} \frac{h}{l}-2}{\sqrt{\frac{5}{2}} \frac{h}{l} \sinh \sqrt{\frac{5}{2}} \frac{h}{l}}\right)
$$

The response of the system shown in Fig. F.6, when the container is subjected to arbitrary horizontal acceleration, can be computed readily. From the motion of $\mathrm{m}_{1}$, the oscillation of the fluid in the fundamental mode can be determined from Eqs. F.70 and F.71, which give the relation between $A_{1}$ and $\theta_{h}$. The actual displacement of the fluid surface can be determined from the pressure at the plane $y=h$, which is due to the weight and inertia force of the fluid above this plane. By Eq. F.61,

$$
\mathrm{p}_{\mathrm{h}}=\frac{1}{2} \sqrt{\frac{5}{2}} \rho l^{2} \omega^{2} \theta_{\mathrm{h}}\left[\frac{\mathrm{x}}{l}-\frac{1}{3}\left(\frac{\mathrm{x}}{\mathrm{l}}\right)^{3}\right] \sin \omega \mathrm{t} \operatorname{coth} \sqrt{\frac{5}{2}} \frac{\mathrm{h}}{l}
$$

Applying Newton's law to the element shown in Fig. F.7,

$$
p_{h} d x-\rho g d d x=x \ddot{\theta}_{h} \rho d d x
$$

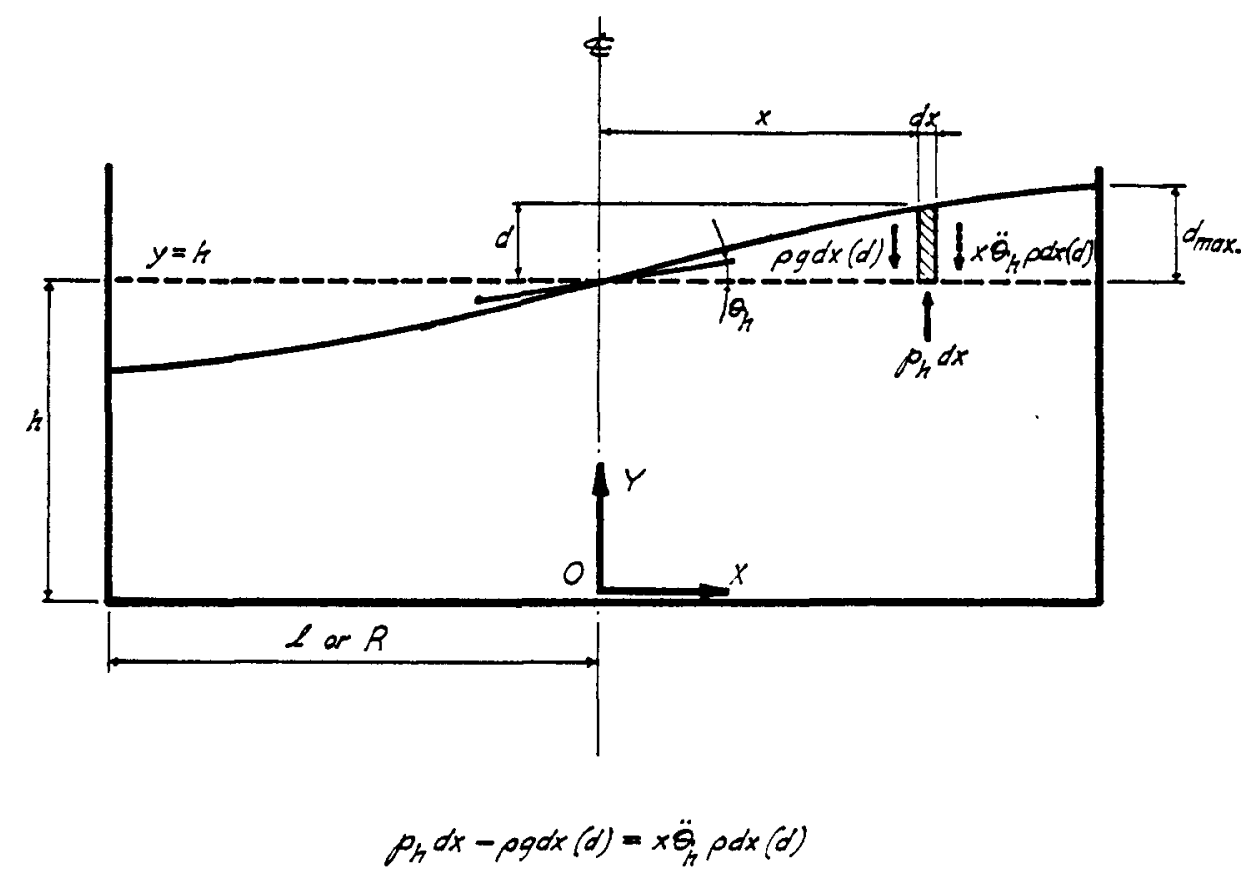

'Fig. F.7 - Displacement of oscillating fluid surface.

Hence the vertical displacement of fluid surface at any distance $\mathrm{x}$ from the center line of the tank is

$$
d=\frac{p_{h}}{\rho\left(g+x \ddot{\theta}_{h}\right)}
$$


By Eq. F.56,

$$
\ddot{\theta}_{\mathrm{h}}=-\theta_{\mathrm{b}} \omega^{2} \sin \omega \mathrm{t}
$$

Substituting Eqs. F.77 and F.78a in Eq. F.78 and setting $x=\ell$ and $\sin \omega t=1$, the maximum displacement of fluid surface for a rectangular tank is obtained.

$$
d_{\max .}=\frac{0.527 l}{\left(\frac{g}{\omega^{2} \theta_{\mathrm{h}} l}-1\right) \tanh 1.58 \frac{\mathrm{h}}{l}}
$$

It should be noted that the foregoing computation of $d_{\max }$. is based on the free vibration of the first mode. Higher modes of vibration are not considered in the analysis; hence steady-state forced vibrations of the tank at frequencies higher than the natural frequency of the first mode are handled only approximately by the foregoing analysis.

If $d_{\max }$. is to be computed for these higher frequency forced vibrations, the following equation, based on Eq. F.70, should be used instead of Eq. F.78. This gives, as an approximate value:

$$
d_{\max .}=\theta_{h} l=\frac{5}{2} A_{1} \tanh \sqrt{\frac{5}{2}} \frac{h}{l}
$$

The shortcomings of this approach can be indicated by calling attention to the fact that a free water surface cannot have a downward acceleration greater than gravity. However, the fluid, with the membranes shown in Fig. F.4, may have very large accelerations if the frequency of vibration is large. Obviously in this case the fluid pressures calculated by Eq. F.62 will not be applicable to the free surface condition.

\section{F.5 CYLINDRICAL CONTAINER}

Consider a cylindrical tank similar to that shown in Fig. F.8, subjected to horizontal acceleration $\dot{u}_{0}$, and let the fluid be constrained between fixed membranes parallel to the $x$ axis. Jacobsen ${ }^{F \cdot 2}(1949)$ has shown that an impulse $\dot{u}_{0}$ does not generate a velocity component $\dot{w}$ in the fluid; thus in this case the membranes do not actually introduce a constraint. Each slice of fluid may therefore be treated as if it were a narrow rectangular tank, and the equations of the preceding section will apply. The pressure $p_{w}$ exerted against the wall of the tank and the pressure $p_{b}$ on the bottom of the tank are, srom Eqs. F.47 and F.48, with Fig. F.8,

$$
\begin{aligned}
\mathrm{p}_{\mathrm{w}} & =-\rho \dot{\mathrm{u}}_{0} \mathrm{~h}\left[\frac{\mathrm{y}}{\mathrm{h}}-\frac{1}{2}\left(\frac{\mathrm{y}}{\mathrm{h}}\right)^{2}\right] \sqrt{3} \tanh \left(\sqrt{3} \frac{\mathrm{R}}{\mathrm{h}} \cos \phi\right) \\
\mathrm{p}_{\mathrm{b}} & =-\rho \dot{\mathrm{u}}_{0} \mathrm{~h} \frac{\sqrt{3}}{2} \frac{\sinh \sqrt{3} \frac{\mathrm{x}}{\mathrm{h}}}{\cosh \sqrt{3} \frac{\mathrm{l}}{\mathrm{h}}}
\end{aligned}
$$

The preceding expressions are not convenient for calculating the total force exerted by the fluid. The following modification of Eq. F. 79 gives very accurate values when $R / h$ is small but somewhat overestimates the pressure when $R / h$ is not small:

$$
\mathrm{p}_{\mathrm{w}}=-\rho \mathrm{u}_{0} \mathrm{~h}\left[\frac{\mathrm{y}}{\mathrm{h}}-\frac{1}{2}\left(\frac{\mathrm{y}}{\mathrm{h}}\right)^{2}\right] \sqrt{3} \cos \phi \tanh \left(\sqrt{3} \frac{\mathrm{R}}{\mathrm{h}}\right)
$$



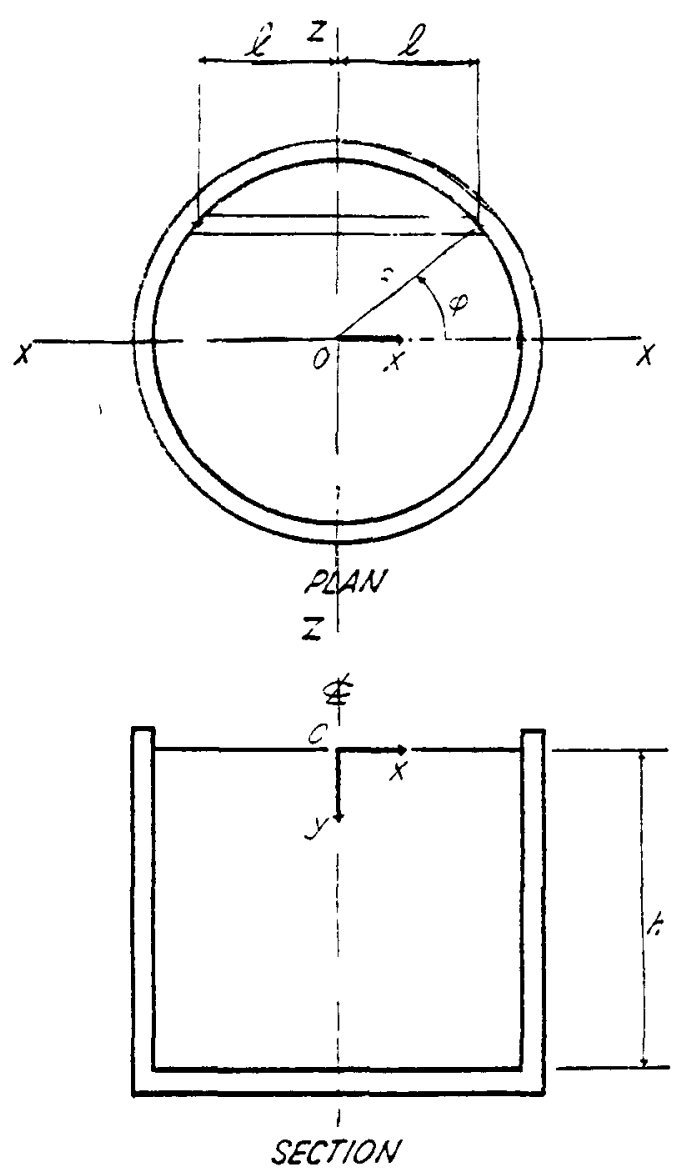

Fig. F.8-Cylındrıcal tank.

Using this expression, the resultant force exerted on the wall is

$$
P=\int_{0}^{h} \int_{0}^{2 \pi} p_{w} R \cos \phi d \phi d y
$$

Hence

$$
\begin{aligned}
P & =-\rho \dot{u}_{0} h R \sqrt{3} \tanh \left(\sqrt{3} \frac{R}{h}\right) \int_{0}^{h} \int_{0}^{2 \pi}\left[\frac{y}{h}-\frac{1}{2}\left(\frac{y}{h}\right)^{2}\right] \cos ^{2} \phi d \phi d y \\
& =-\rho \dot{u}_{0} \pi R^{2} h \frac{\tanh \left(\sqrt{3} \frac{R}{h}\right)}{\frac{\sqrt{3} R}{h}}
\end{aligned}
$$

The force exerted is the same as if an equivalent mass $m_{0}$ were moving with the tank, given by

$$
\mathrm{m}_{0}=-\frac{\mathrm{P}}{\dot{\mathrm{u}}_{0}}=\rho \pi \mathrm{R}^{2} \mathrm{~h} \frac{\tanh \left(\sqrt{3} \frac{\mathrm{R}}{\mathrm{h}}\right)}{\frac{\sqrt{3} \mathrm{R}}{\mathrm{h}}}=\mathrm{m} \frac{\tanh \left(\sqrt{3} \frac{\mathrm{R}}{\mathrm{h}}\right)}{\frac{\sqrt{3} \mathrm{R}}{\mathrm{h}}}
$$


To exert a moment equivalent to that exerted by the fluid pressure on the wall, the mass $\mathrm{m}_{0}$ should be at a height above the bottom, given by Eq. F.50,

$$
h_{0}=\frac{3}{8} h
$$

The moment exerted on the bottom of the tank due to the pressure acting on the strip shown in Fig. F.8 is, using Eq. F.80,

$$
\begin{aligned}
\mathrm{dM}_{\mathrm{b}} & =\int_{-l}^{l} \mathrm{xp}_{\mathrm{b}} \mathrm{dx} \mathrm{dz}=\frac{-\rho \dot{\mathrm{u}}_{0} \mathrm{~h} \frac{\sqrt{3}}{2} \mathrm{dz} \int_{-l}^{l}}{\cosh \sqrt{3} \frac{\ell}{\mathrm{h}}} \mathrm{sinh} \sqrt{3} \frac{\mathrm{x}}{\mathrm{h}} \mathrm{dx} \\
& =-\frac{1}{\sqrt{3}} \rho \dot{\mathrm{u}}_{0} \mathrm{~h}^{3}\left(\sqrt{3} \frac{\ell}{\mathrm{h}}-\tanh \sqrt{3} \frac{\ell}{\mathrm{h}}\right) \mathrm{d}_{\mathrm{z}}
\end{aligned}
$$

Substituting $l=R \cos \phi, z=R \sin \phi$, and $d_{z}=R \cos \phi d \phi$, and with the simplification used in Eq. F.81, Eq. F.85 becomes

$$
\mathrm{dM}_{\mathrm{b}}=-\frac{1}{\sqrt{3}} \rho \dot{\mathrm{u}}_{0} \mathrm{~h}^{3} \mathrm{R}\left(\frac{\sqrt{3} \mathrm{R}}{4}-\tanh \frac{\sqrt{3} \mathrm{R}}{\mathrm{h}}\right) \cos ^{2} \phi \mathrm{d} \phi
$$

and the total moment is given by

$$
\mathbf{M}_{\mathrm{b}}=2 \int_{\phi=0}^{\pi / 2} \mathrm{dM}_{\mathrm{b}}=-\frac{\pi}{2 \sqrt{3}} \rho \dot{\mathrm{u}}_{0} \mathrm{~h}^{3} \mathrm{R}\left(\frac{\sqrt{3} \mathrm{R}}{\mathrm{h}}-\tanh \frac{\sqrt{3} \mathrm{R}}{\mathrm{h}}\right)
$$

Including this, the height of the mass $\mathrm{m}_{0}$ above the bottom of the tank to give the correct moment is, from Eqs. F.84 and F.82,

$$
\begin{aligned}
h_{0} & =\frac{3}{8} h+\frac{M_{b}}{P} \\
& =\frac{3}{8} h\left[1+\frac{4}{3}\left(\frac{\sqrt{3} \frac{R}{h}}{\tanh \sqrt{3} \frac{R}{h}}-1\right)\right]
\end{aligned}
$$

For the free oscillations of the fluid in the fundamental mode, Eqs. F.27, F.28, F.38, and F.39 give

$$
\begin{aligned}
I_{2} & =4 \int_{0}^{R} \int_{0}^{\pi / 2} r^{3} \cos ^{2} \phi d r d \phi=\frac{\pi R^{4}}{4} \\
K & =2 \int_{\pi}^{0} \frac{1}{R \sin \phi}\left[\int_{\pi}^{\phi} R^{2} \sin \phi^{\prime} \cos \phi^{\prime} d\left(R \cos \phi^{\prime}\right)^{2}\right]\left(1+\frac{1}{3} \cot ^{2} \phi\right) d(R \cos \phi) \\
& =2 \int_{\pi}^{0} \frac{1}{R \sin \phi}\left(-\frac{1}{3} R^{3} \sin ^{3} \phi\right)^{2}\left(1+\frac{1}{3} \cot ^{2} \phi\right) d(R \cos \phi) \\
& =\frac{2 \pi}{27} R^{6}
\end{aligned}
$$




$$
\begin{aligned}
& \theta=\theta_{\mathrm{h}} \frac{\sinh \sqrt{\frac{27}{8}} \frac{\mathrm{y}}{\mathrm{R}}}{\sinh \sqrt{\frac{27}{8}} \frac{\mathrm{h}}{\mathrm{R}}} \sin \omega \mathrm{t} \\
& \omega^{2}=\frac{\mathrm{g}}{\mathrm{R}} \sqrt{\frac{27}{8}} \tanh \sqrt{\frac{27}{8}} \frac{\mathrm{h}}{\mathrm{R}}
\end{aligned}
$$

Using Eqs. F.90 and F.43,

$$
\frac{\partial \ddot{\theta}}{\partial y}=-\sqrt{\frac{27}{8}} \frac{\theta_{\mathrm{h}}}{\mathrm{R}} \omega^{2} \frac{\cosh \sqrt{\frac{27}{8}} \frac{\mathrm{y}}{\mathrm{R}}}{\sinh \sqrt{\frac{27}{8}} \frac{\mathrm{h}}{\mathrm{R}}} \sin \omega \mathrm{t}
$$

and the pressure in the fluid is given by

$$
p=\rho \frac{\partial \ddot{\theta}}{\partial y}\left[\int_{0}^{x} \frac{B\left(x^{\prime}\right)}{b\left(x^{\prime}\right)} d x^{\prime}+\frac{z^{2}}{2} \frac{b^{\prime}}{b^{2}} B\right]
$$

where

$$
\begin{aligned}
& b=\sqrt{R^{2}-x^{2}} \\
& b^{\prime}=\frac{-x}{\sqrt{R^{2}-x^{2}}} \\
& B=\int_{-R}^{x} x \sqrt{R^{2}-x^{2}} d x=-\frac{1}{3}\left(R^{2}-x^{2}\right)^{\frac{3}{2}}
\end{aligned}
$$

Using these expressions, the pressure becomes

$$
\begin{aligned}
p & =-\rho \frac{\partial \ddot{\theta}}{\partial y}\left[\frac{1}{3} \int_{0}^{x}\left(R^{2}-x^{2}\right) d x-\frac{1}{6} z^{2} x\right] \\
& =-\frac{1}{3} \rho R^{3}\left[\frac{x}{R}-\frac{1}{3}\left(\frac{x}{R}\right)^{3}-\frac{1}{2} \frac{x}{R}\left(\frac{z}{R}\right)^{2}\right] \frac{\partial \ddot{\theta}}{\partial y}
\end{aligned}
$$

Substituting Eq. F.92 into Eq. F.94,

$$
p=\sqrt{\frac{3}{8}} \rho R^{2} \theta_{h}\left[\frac{x}{R}-\frac{1}{3}\left(\frac{x}{R}\right)^{3}-\frac{1}{2} \frac{x}{R}\left(\frac{z}{R}\right)^{2}\right] \frac{\cosh \sqrt{\frac{27}{8}} \frac{y}{R}}{\sinh \sqrt{\frac{27}{8}} \frac{h}{R}} \omega^{2} \sin \omega t
$$

Using $x=R \cos \phi$ and $z=R \sin \phi$ in Eq. F.95, the pressure on the wall is

$$
\mathrm{p}_{\mathrm{w}}=\sqrt{\frac{3}{8}} \rho \mathrm{R}^{2} \theta_{\mathrm{h}}\left(1-\frac{1}{3} \cos ^{2} \phi-\frac{1}{2} \sin ^{2} \phi\right) \cos \phi \frac{\cosh \sqrt{\frac{27}{8}} \frac{\mathrm{g}}{\mathrm{R}}}{\sinh \sqrt{\frac{27}{8}} \frac{\mathrm{h}}{\mathrm{R}}} \omega^{2} \sin \omega \mathrm{t}
$$


The total horizontal force exerted on the wall is, using Eq. F.96,

$$
\begin{aligned}
P & =\int_{0}^{2 \pi} \int_{0}^{h} p_{w} R \cos \phi d \phi d y \\
& =\sqrt{\frac{3}{8}} \rho R^{3} \theta_{h} \omega^{2} \sin \omega t \int_{0}^{2 \pi} \int_{0}^{h} \frac{\cosh \sqrt{\frac{27}{8}} \frac{y}{R}}{\sinh \sqrt{\frac{27}{8}} \frac{h}{R}}\left(1-\frac{1}{3} \cos ^{2} \phi-\frac{1}{2} \sin ^{2} \phi\right) \cos ^{2} \phi d \phi d y \\
& =\frac{10 \pi}{48} \rho R^{4} \theta_{h} \omega^{2} \sin \omega t
\end{aligned}
$$

This force is the same as that produced by an equivalent mass $m_{1}$ oscillating in a horizontal plane with motion

$$
x_{1}=A_{1} \sin \omega t
$$

The force against the tank and the kinetic energy of the mass are, as for the rectangular tank,

$$
\begin{aligned}
& F=m_{1} A_{1} \omega^{2} \sin \omega t \\
& T=\frac{1}{2} m_{1} A_{1}^{2} \omega^{2} \cos ^{2} \omega t
\end{aligned}
$$

Substituting $\mathrm{I}_{2}, \mathrm{~K}$, and $\theta$ from Eqs. F.88, F.89, and F.90 into Eq. F.26, the kinetic energy of the fluid is

$$
T=\frac{\pi}{8} \sqrt{\frac{8}{27}} R^{5} \rho \theta_{h}^{2} \omega^{2} \cos \omega t \operatorname{coth} \sqrt{\frac{27}{8}} \frac{h}{R}
$$

Equating $F$ and $P$ from Eqs. F.97 and F.99 gives

$$
m_{1} A_{1}=\frac{10 \pi}{48} \rho R^{4} \theta_{h}
$$

Equating Eqs. F.100 and F.101 gives

$$
\mathrm{m}_{1} \mathrm{~A}_{1}^{2}=\frac{\pi}{4} \sqrt{\frac{8}{27}} \mathrm{R}^{5} \rho \theta_{\mathrm{h}}^{2} \operatorname{coth} \sqrt{\frac{27}{8}} \frac{\mathrm{h}}{\mathrm{R}}
$$

Equations F.102 and F.103 give

$$
\begin{aligned}
\mathrm{A}_{1} & =\frac{6}{5} \sqrt{\frac{8}{27}} \mathrm{R} \theta_{\mathrm{h}} \frac{1}{\tanh \sqrt{\frac{27}{8}} \frac{\mathrm{h}}{\mathrm{R}}}=0.653 \frac{\mathrm{R} \theta_{\mathrm{h}}}{\tanh \sqrt{\frac{27}{8}} \frac{\mathrm{h}}{\mathrm{R}}} \\
\mathrm{m}_{1} & =\frac{25 \pi}{144} \sqrt{\frac{27}{8}} \rho \mathrm{R}^{3} \tanh \sqrt{\frac{27}{8}} \frac{\mathrm{h}}{\mathrm{R}}=\frac{25}{144} \sqrt{\frac{27}{8}} \mathrm{~m} \frac{\mathrm{R}}{\mathrm{h}} \tanh \sqrt{\frac{27}{8}} \frac{\mathrm{h}}{\mathrm{R}} \\
& =0.318 \frac{\mathrm{mR}}{\mathrm{h}} \tanh \sqrt{\frac{27}{8}} \frac{\mathrm{h}}{\mathrm{R}}
\end{aligned}
$$

where $m$ is the total mass of fluid in the tank. 
The moment exerted in a clockwise direction about the floor of the tank, due to the pressure on the walls, is, using Eq. F.96,

$$
\begin{aligned}
& \mathbf{M}_{\mathrm{w}}=\int_{0}^{2 \pi} \int_{0}^{\mathrm{h}} \mathrm{yp} \mathrm{w} \cos \phi \mathrm{R} \mathrm{d} \phi \mathrm{dy} \\
& =\sqrt{\frac{3}{8}} \rho \mathrm{R}^{3} \theta_{\mathrm{h}} \omega^{2} \sin \omega \mathrm{t} \int_{0}^{2 \pi} \int_{0}^{\mathrm{h}} \mathrm{y} \frac{\cosh \sqrt{\frac{27}{8}} \frac{\mathrm{y}}{\mathrm{R}}}{\sinh \sqrt{\frac{27}{8}} \frac{\mathrm{h}}{\mathrm{R}}}\left(1-\frac{1}{3} \cos ^{2} \theta-\frac{1}{2} \sin ^{2} \phi\right) \cos ^{2} \phi d \phi d y \\
& =\frac{10 \pi}{48} \sqrt{\frac{8}{27}} \rho R^{5} \theta_{h} \omega^{2} \sin \omega t\left(\sqrt{\frac{27}{8}} \frac{h}{R}-\frac{1}{\tanh \sqrt{\frac{27}{8}} \frac{h}{R}}+\frac{1}{\sinh \sqrt{\frac{27}{8}} \frac{h}{R}}\right)
\end{aligned}
$$

The elevation of $m_{1}$ above the bottom of the tank to produce the same moment from Eqs. F.97 and F.106 is given by the following equation. This equation does not take into account the effect of fluid pressure on the tank bottom.

$$
\mathrm{h}_{1}=\frac{\mathrm{M}_{\mathrm{w}}}{\mathrm{P}}=\mathrm{h}\left(1-\frac{1}{\sqrt{\frac{27}{8} \frac{\mathrm{h}}{\mathrm{R}} \tanh \sqrt{\frac{27}{8}} \frac{\mathrm{h}}{\mathrm{R}}}}+\frac{1}{\sqrt{\frac{27}{8} \frac{\mathrm{h}}{\mathrm{R}} \sinh \sqrt{\frac{27}{8}} \frac{\mathrm{h}}{\mathrm{R}}}}\right)
$$

The pressure exerted on the bottom of the tank is, from Eq. F.95,

$$
\mathrm{p}_{\mathrm{b}}=\sqrt{\frac{3}{8}} \rho \mathrm{R}^{2} \theta_{\mathrm{b}}\left[\frac{\mathrm{x}}{\mathrm{R}}-\frac{1}{3}\left(\frac{\mathrm{x}}{\mathrm{R}}\right)^{3}-\frac{1}{2} \frac{\mathrm{x}}{\mathrm{R}}\left(\frac{\mathrm{z}}{\mathrm{R}}\right)^{2}\right] \frac{\omega^{2} \sin \omega \mathrm{t}}{\sinh \sqrt{\frac{27}{8}} \frac{\mathrm{h}}{\mathrm{R}}}
$$

This exerts a clockwise moment about the bottom of the tank given by

$$
\begin{aligned}
M_{b}= & \int_{A} p_{b} x d A=\int_{0}^{R} \int_{0}^{2 \pi} p_{b} r^{2} \cos \phi d r d \phi \\
= & \sqrt{\frac{3}{8}} \rho R^{2} \theta_{h} \frac{\omega^{2} \sin \omega t}{\sinh \sqrt{\frac{27}{8}} \frac{h}{R}} \int_{0}^{R} \int_{0}^{2 \pi}\left(\frac{r^{3}}{R} \cos \phi-\frac{1}{3} \frac{r^{5}}{R^{3}} \cos ^{3} \phi\right. \\
& \left.-\frac{1}{2} \frac{r^{5}}{R^{3}} \cos \phi \sin ^{2} \phi\right) \cos \phi d r d \phi=\frac{9 \pi}{48} \sqrt{\frac{3}{8}} \rho R^{5} \theta_{h} \frac{\omega^{2} \sin \omega t}{\sinh \sqrt{\frac{27}{8}} \frac{h}{R}}
\end{aligned}
$$

Taking into account the fluid pressure on the tank bottom, the modified value of $h_{1}$ is, from Eqs. F.107, F.97, and F.109,

$$
h_{1}=\frac{M_{w}+M_{b}}{P}=h\left(1-\frac{\cosh \sqrt{\frac{27}{8}} \frac{h}{R}+\frac{161}{80}}{\sqrt{\frac{27}{8}} \frac{h}{R} \sinh \sqrt{\frac{27}{8}} \frac{h}{R}}\right)
$$

For oscillations in the first mode, the displacement of the fluid surface can be determined from Eq. F.78,

$$
d=\frac{p_{h}}{\rho\left(g+x \ddot{\theta}_{h}\right)}
$$

Using Eqs. F.90 and F.95,

$$
\ddot{\theta}_{h}=-\theta_{h} \omega^{2} \sin \omega t
$$




$$
p_{h}=\sqrt{\frac{3}{8}} \rho R^{2} \theta_{h}\left[\frac{x}{R}-\frac{1}{3}\left(\frac{x}{R}\right)^{3}-\frac{1}{2} \frac{x}{R}\left(\frac{z}{R}\right)^{2}\right] \operatorname{coth}\left(\sqrt{\frac{27}{8}} \frac{h}{R}\right) \omega^{2} \sin \omega t
$$

In a manner similar to that used in the derivation for rectangular tanks, substituting $x=R, z=0$, and $\sin \omega t=1$ in Eq. F.113, the maximum fluid pressure at $y=h$ is

$$
\mathrm{p}_{\mathrm{h}}=\frac{0.408 \rho \mathrm{R}^{2} \omega^{2} \theta_{\mathrm{h}}}{\tanh 1.84 \frac{\mathrm{h}}{\mathrm{R}}}
$$

Substituting Eqs. F.112 and F.114 in Eq. F.111, the maximum fluid surface displacement for a cylindrical tank is

$$
\mathrm{d}_{\text {max. }}=\frac{0.408 \mathrm{R}}{\left(\frac{\mathrm{g}}{\omega^{2} \theta_{\mathrm{h}} \mathrm{R}}-1\right) \tanh 1.84 \frac{\mathrm{h}}{\mathrm{R}}}
$$

When $d_{\max }$ is computed for higher frequency forced vibrations, the following equation, based on Eq. F.104, should be used instead of Eq. F.115. This gives, as an approxumate value:

$$
d_{\max .}=\theta_{h} R=\frac{5}{6} \sqrt{\frac{27}{8}} A \tanh \frac{27}{8} \sqrt{\frac{h}{R}}
$$

For further clarification, refer to the discussion in Sec. F.4 presented in connection with Eq. F.78c.

\section{F.6 CORRESPONDING EQUATION NUMBERS}

The equations required for numerical computations in the analysis of flud containers are designated with different equation numbers in two sections of this report

\begin{tabular}{|c|c|c|c|c|c|}
\hline Chapter 6 & Appendix $\mathrm{F}$ & Reference F.1 & Chapter 6 & Appendix $F$ & Reference F.1 \\
\hline 6.1 & F.5I & 18 & 6.12 & F.83 & 34 \\
\hline 6.2 & F.50 & 17 & 6.13 & F.84 & 35 \\
\hline 6.3 & F.53 & 20 & 6.14 & $E .87$ & 36 \\
\hline 6.4 & F.49 & 16 & 6.15 & F.82 & 33 \\
\hline 6.5 & F.71 & 26 & 6.16 & F.105 & 41 \\
\hline 6.6 & F.73 & 27 & 6.17 & F.107 & $41 \mathrm{a}$ \\
\hline 6.7 & F.76 & 28 & 6.18 & F.110 & 43 \\
\hline 6.8 & F.57 & 21 & 6.19 & F.91 & 37 \\
\hline 6.9 & F.70 & 26 & 6.20 & F.104 & 41 \\
\hline 6.10 & F.63 & 24 & 6.21 & F.97 & 40 \\
\hline 6.11 & F.78b & None & 6.22 & F.115 & None \\
\hline
\end{tabular}
and in Ref. F.1. Hence for each equation there are three different numbers. For convenience in locating the derivation of each equation listed in Sec. 6.3, Chap. 6, its corresponding number in Appendix $F$ and in Ref. F.1 is given below. 
REFERENCES

\section{REFERENCES}

F.1 G. W. Housner, Dynamic Pressures on Accelerated Fluid Containers, Bull. Seismol. Soc. Am., 47(1): (1957).

F.2 L. S. Jacobsen, Impulsive Hydrodynamics of Fluid Inside a Cylindrical Tank and of a Fluid Surrounding a Cylindrical Pier, Bull. Seismol. Soc. Am., 39: 189-204 (1949).

F.3 T. Karman and M. Biot, Mathematical Methods in Engineering, p.30, McGraw-Hill Book Company, Inc., New York, 1940.

F.4 G. W. Housner and D. E. Hudson, Applied Mechanics-Dynamics, p.260, D. Van Nostrand Company, Inc., New York, 1957. 


\section{Appendix G}

\section{MISCELLANEOUS DERIVATIONS}

FIGURES

0.1 One-degree-of-freedom Syatem.

G.2 Base Acceleration Vs. Time Curve.

G.3 Dieplacement-tıme Curve for Oscillator.

\section{G.1 BEHAVIOR OF A SINGLE-DEGREE-OF-FREEDOM SYSTEM (Derivation in support} of Chap. 1, Sec. 1.3A et seq.)

The single-degree-of-freedom system shown in Fig. G.1 has a mass m supported on a weightless elastic rod whose spring constant $k$ is such that a force $-k y$ is exerted on

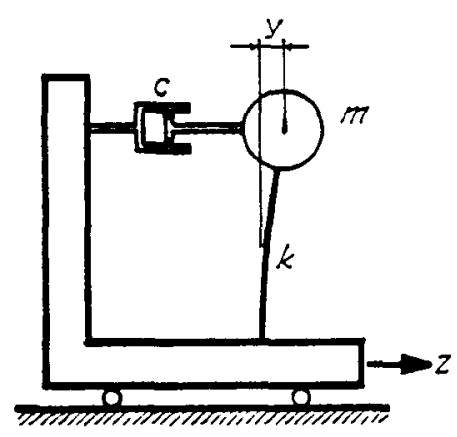

F1g. G.1-One-degree-of-freedom system.

the mass by the rod. The damping device exerts a force $-c \mathrm{dy}$ /dt, where $\mathrm{c}$ is the damping coefficient. The absolute acceleration of the mass is $(\ddot{y}+\ddot{z})$ and hence from Newton's law

$$
m(\ddot{y}+\ddot{z})=-k y-c \dot{y}
$$

or

$$
m \ddot{y}+c \dot{y}+k y=-m \ddot{z}
$$


If the equation is divided through by $\mathrm{m}$, it can be written

$$
\ddot{y}+2 \pi \dot{y}+\omega_{0}^{2} y=-\ddot{z}
$$

where $\eta=\frac{c}{2 m}=\zeta \omega_{0}$

$$
\begin{aligned}
\omega_{0} & =\sqrt{\frac{k}{m}} \\
\zeta & =\text { fraction of critical damping }
\end{aligned}
$$

The free vibrations of the system are described by the equation with $\ddot{z}$ set equal to zero:

$$
\ddot{\mathrm{y}}+2 \pi \dot{\mathrm{y}}+\omega_{0}^{2} \mathrm{y}=0
$$

This is a linear differential equation with constant coefficients, and, as is well known, its solution is

$$
y=e^{-\eta t}\left(y_{0} \cos \omega t+\frac{\dot{y}_{0}+\eta y_{0}}{\omega} \sin \omega t\right)
$$

where $\mathrm{y}_{0}$ and $\dot{\mathrm{y}}_{0}$ are the displacement and velocity at time $t=0$ and

$$
\omega=\sqrt{\omega_{0}^{2}-\eta^{2}}=\omega_{0} \sqrt{1-\zeta^{2}}
$$

As is seen from the solution, the period of vibration is

$$
T=\frac{2 \pi}{\omega}
$$

If there is no damping $(\eta=0)$, the period is

$$
\mathbf{T}=\frac{2 \pi}{\omega_{0}}
$$

If the system is at rest and if at time $t=0$ the base is given an acceleration $\ddot{z}$ that lasts for an infinitesimal time, $d t$, the base will attain a velocity increment $\ddot{z} \mathrm{dt}$. Since the mass was initially at rest, it follows that at time $t=0+d t$ the mass $m$ will have a relative velocity and displacement increments

$$
\begin{aligned}
d \dot{y}_{0} & =-\ddot{z} d t \\
y_{0} & =0
\end{aligned}
$$

Equation G.5 gives for the resulting free vibration displacement increment

$$
d y=-\frac{\ddot{z} e^{-\eta t}}{\omega} \sin \omega t d t
$$

A continuous base acceleration $\ddot{z}$ can be considered to be composed of a succession of increments $\ddot{z} \mathrm{dt}$, as shown in Fig. G.2. The response to the increment $\ddot{z}$ dt at time $\tau$ is given by Eq. G.7 if $(t-\tau)$ is written instead of $t$ :

$$
d y=-\frac{\ddot{z}}{\omega} e^{-\eta(t-\tau)} \sin \omega(t-\tau) d \tau \quad(t>\tau)
$$


The response to a continuous $\ddot{z}$ is given by summing the response produced by all the ( $\ddot{z} d t)$ 's. Hence the response at time $t$ is

$$
y=-\int_{0}^{t} \frac{\ddot{z}}{\omega} e^{-\eta(t-\tau)} \sin \omega(t-\tau) d \tau
$$

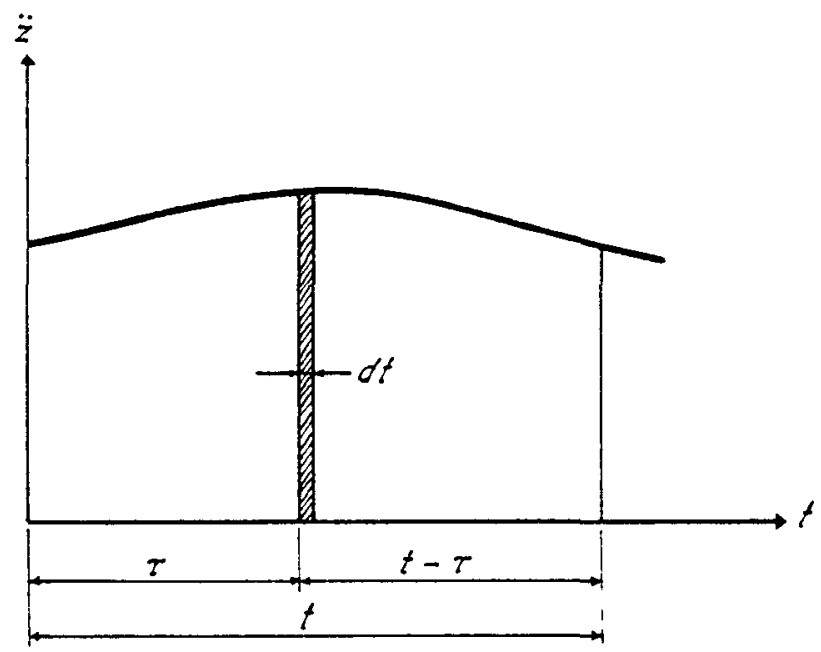

Fig. G.2-Base acceleratıon vs. tıme curve.

The velocity is given by differentiating Eq. G.9 with respect to t:

$$
\begin{aligned}
\frac{d y}{d t}= & -\int_{0}^{t} \ddot{z} e^{-\eta(t-\tau)} \cos \omega(t-\tau) d \tau \\
& +\int_{0}^{t} \frac{\eta}{\omega} \ddot{z} e^{-\eta(t-\tau)} \sin \omega(t-\tau) d \tau
\end{aligned}
$$

Equations G. 9 and G.10 can be put into convenient forms by means of the trigonometric relations

$$
\begin{aligned}
& \sin (\theta-\phi)=\sin \theta \cos \phi-\cos \theta \sin \phi \\
& \cos (\theta-\phi)=\cos \theta \cos \phi+\sin \theta \sin \phi
\end{aligned}
$$

Expanding the trigonometric terms in this manner and then combining terms give

$$
y=-\frac{1}{\omega}(A \sin \omega t-B \cos \omega t)=-\frac{1}{\omega} \sqrt{A^{2}+B^{2}} \sin (\omega t-\alpha)
$$

-

$$
\begin{aligned}
\dot{y} & =-\left(A+\frac{\eta}{\omega} B\right) \cos \omega t-\left(B-\frac{\eta}{\omega} A\right) \sin \omega t \\
& =-\sqrt{1+\frac{\eta^{2}}{\omega^{2}}} \sqrt{A^{2}+B^{2}} \cos (\omega t-\beta)
\end{aligned}
$$


where $\tan \alpha=\frac{B}{A}$

$$
\begin{aligned}
\tan \beta & =\frac{\mathrm{B}-\frac{\eta}{\omega} \mathrm{A}}{\mathrm{A}+\frac{\eta}{\omega} \mathrm{B}} \\
\mathrm{A} & =\int_{0}^{t} \ddot{z} \mathrm{e}^{-\eta(\mathrm{t}-\tau)} \cos \omega \tau \mathrm{d} \tau \\
\mathrm{B} & =\int_{0}^{t} \ddot{z} \mathrm{e}^{-\eta(t-\tau)} \sin \omega \tau \mathrm{d} \tau
\end{aligned}
$$

The absolute acceleration of $\mathrm{m}$ can be computed from Eq. G.1:

$$
\begin{aligned}
& m(\ddot{y}+\ddot{z})=-k y-c \dot{y}=-m \omega_{0}^{2}-2 m \eta \dot{y} \\
& (\ddot{y}+\ddot{z})=-\omega_{0}^{2} y-2 \eta \dot{y}
\end{aligned}
$$

Substituting from Eqs. G.11 and G.12,

$$
\begin{aligned}
\ddot{y}+\ddot{z}= & \frac{\omega_{0}^{2}}{\omega}(A \sin \omega t-B \cos \omega t)+2 \pi\left(A+\frac{\eta}{\omega} B\right) \cos \omega t \\
& +2 \eta\left(B-\frac{\eta}{\omega} A\right) \sin \omega t \\
= & \omega\left[\left(\frac{\omega_{0}^{2}}{\omega^{2}}-\frac{2 \eta^{2}}{\omega^{2}}\right) A+\frac{2 \eta B}{\omega}\right] \sin \omega t-\omega\left[\left(\frac{\omega_{0}^{2}}{\omega^{2}}-\frac{2 \eta^{2}}{\omega^{2}}\right) B-\frac{2 \eta A}{\omega}\right] \cos \omega t
\end{aligned}
$$

From Eq. G.5a this can be written

$$
\ddot{y}+\ddot{z}=\omega\left[\left(1-\frac{\eta^{2}}{\omega^{2}}\right) A+\frac{2 \eta B}{\omega}\right] \sin \omega t-\omega\left[\left(1-\frac{\eta^{2}}{\omega^{2}}\right) B-\frac{2 \eta A}{\omega}\right] \cos \omega t
$$

Combining terms reduces this to

$$
\ddot{y}+\ddot{z}=\omega\left(1+\frac{\eta^{2}}{\omega^{2}}\right) \sqrt{A^{2}+B^{2}} \sin (\omega t-\gamma)
$$

where $\tan \gamma=\frac{\left(1-\frac{\eta^{2}}{\omega^{2}}\right) B-\frac{2 \eta \mathrm{A}}{\omega}}{\left(1-\frac{\eta^{2}}{\omega^{2}}\right) \mathrm{A}+\frac{2 \eta \mathrm{B}}{\omega}}$

The response of the system is thus described by the following equations:

$$
\begin{aligned}
& y=-\frac{1}{\omega} \sqrt{A^{2}+B^{2}} \sin (\omega t-\alpha) \\
& \dot{y}=-\sqrt{1+\frac{\eta^{2}}{\omega^{2}}} \sqrt{A^{2}+B^{2}} \cos (\omega t-\beta) \\
& (\ddot{y}+\ddot{z})=\omega\left(1+\frac{\eta^{2}}{\omega^{2}}\right) \sqrt{A^{2}+B^{2}} \sin (\omega t-\gamma)
\end{aligned}
$$


These equations can be put into an alternate form by means of Eq. G.5a and the following relation:

$$
\frac{1}{2}\left(A^{2}+B^{2}\right)\left(1+\frac{\eta^{2}}{\omega^{2}}\right)=\epsilon
$$

With these equations there is obtained

$$
\begin{aligned}
& y=-\frac{1}{\omega_{0}} \sqrt{2 \epsilon} \sin (\omega t-\alpha) \\
& \dot{y}=-\sqrt{2 \epsilon} \cos (\omega t-\beta) \\
& \ddot{y}+\ddot{z}=\omega_{0} \sqrt{2 \epsilon} \sin (\omega t-\gamma)
\end{aligned}
$$

For moderate amounts of damping, $\omega_{0}$ and $\omega$ have practically the same value and

$$
\sqrt{1+\frac{\eta^{2}}{\omega^{2}}} \approx 1
$$

When the displacement is calculated from a recorded strong earthquake ground motion, its variation with time is found to be as indicated in Fig. G.3.

The potential energy of the system is

$$
V=\frac{1}{2} k y^{2}=\frac{1}{2} k\left[\sqrt{\frac{m}{k}} \sqrt{2 \epsilon} \sin (\omega t-\alpha)\right]^{2}
$$

or

$$
V=m \epsilon \sin ^{2}(\omega t-\alpha)
$$

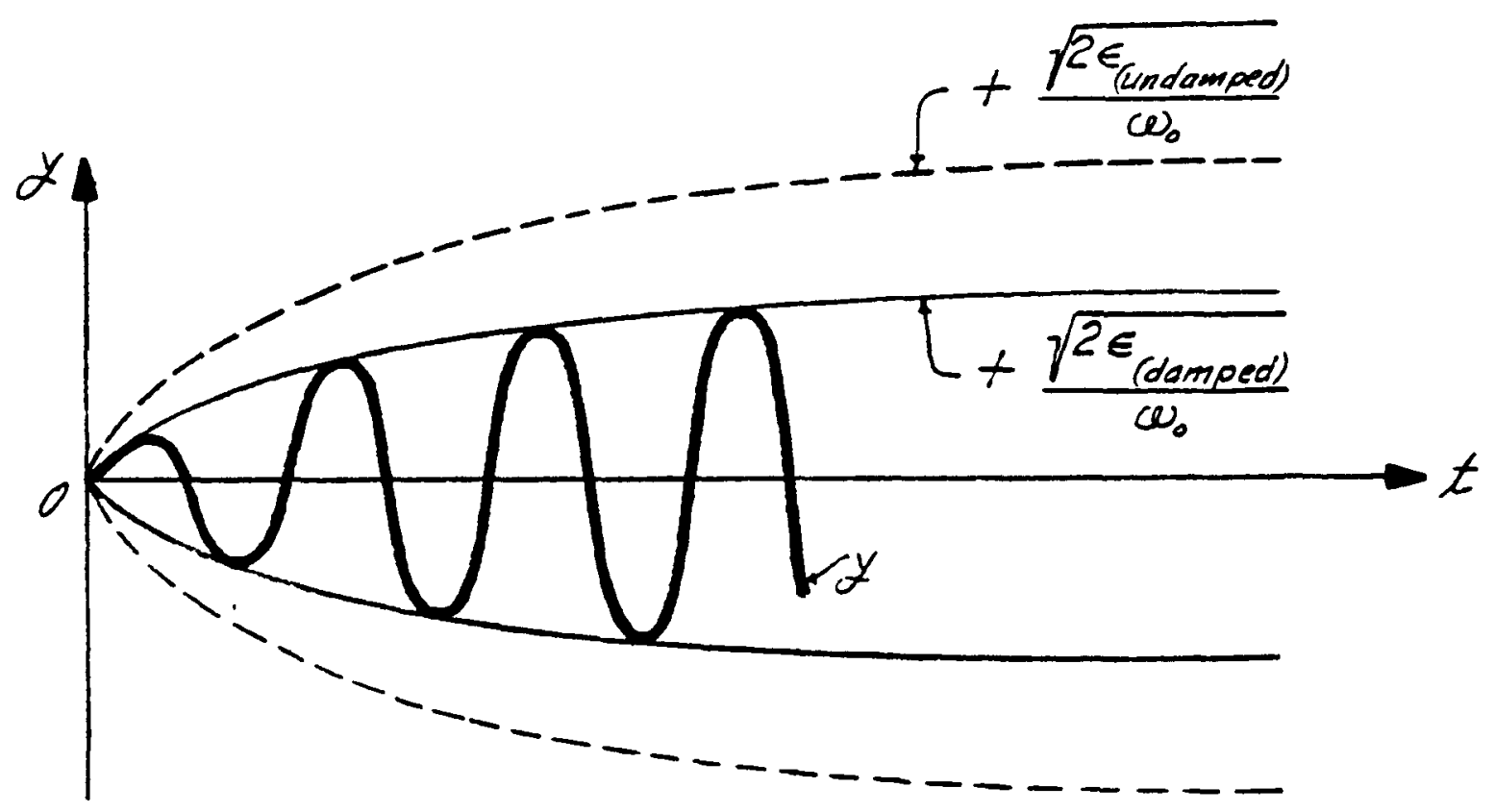

Fig. G.3-Displacement-tıme curve for oscillator. 


\section{G.2 PERIODS OF VIBRATION AND MODE SHAPES}

The relative kinetic energy of the system is

$$
K E=\frac{1}{2} m \dot{y}^{2}=\frac{1}{2} m[\sqrt{2 \epsilon} \cos (\omega t-\beta)]^{2}
$$

or

$$
\mathrm{KE}=\mathrm{m} \epsilon \cos ^{2}(\omega \mathrm{t}-\beta)
$$

The sum of the potential and the kinetic energy is

$$
V+K E=m \epsilon[1+\sin (\beta-\alpha) \sin (2 \omega t-\alpha-\beta)]
$$

For earthquake ground motions it is found that $\mathrm{A}$ and $\mathrm{B}$ are approximately equal; hence $\alpha$ and $\beta$ have practically the same value, and therefore $\sin (\beta-\alpha)$ is small compared to unity. The total energy is thus closely given by

$$
\mathrm{m} \epsilon=\mathrm{V}+\mathrm{KE}=\frac{\mathrm{m}}{2}\left(\mathrm{~A}^{2}+\mathrm{B}^{2}\right)
$$

\section{G.2 PERIODS OF VIBRATION AND MODE SHAPES (Derivation in support of Chap. 5, Sec. 5.3)}

Much of the work in applying the spectrum method to elastic systems involves determining mode shapes and vibration periods. Simple, explicit solutions are available for one-and two-degree-of-freedom systems; but more elaborate procedures become necessary in the case of more complex structures, if modes higher than the first are to be considered. Often only the first mode is important, and in this event a convenient approximate solution can be obtained by using Rayleigh's principle. ${ }^{\text {C.1 }}$

In a conservative system (one without damping) performing simple harmonic oscillations, the sum of the kinetic and potential energy is constant at all times. Consequentiy the maximum kinetic energy of a vibration mode when passing through the rest position is equal to the maximum potential energy of the vibration mode in the extreme position. This property can be used to calculate the approximate frequency of vibration if an approximate mode shape, $\phi$, is known. The first vibration mode for an elastic body, such as that for a beam, is discussed below as an example.

From Eq. 1.23, using $n=1$, the undamped vibration for the $n$th mode can be described by the following equation:

$$
y_{1}=C_{1} \phi_{1}(x) \sin \omega_{1} t
$$

where $\mathrm{y}_{1}=$ the displacement component at any point, $\mathrm{x}$, supplied by the first mode

$\mathrm{C}_{1}=$ the amplitude coefficient for the first mode

$\phi_{1}(x)=$ the first mode shape

$\omega_{1}=$ the circular frequency of the first mode

$\mathrm{t}=$ time

The maximum absolute value of $y_{n}$, occurring when the sine term has its maximum value of unity is

$$
\bar{y}_{n}=C_{n} \phi_{n}(x)
$$

so that, returning to general notation, Eq. G.19 can be more simply written as

$$
y_{n}=\bar{y}_{n} \sin \omega_{n} t
$$


By successive differentiations of Eq. G.21 with respect to time, the velocity and acceleration are obtained in terms of $\bar{y}_{n}$ as

$$
\begin{aligned}
& \dot{y}_{n}=\omega_{n} \bar{y}_{n} \cos \omega t \\
& \ddot{y}_{n}=-\omega_{n}^{2} \bar{y}_{n} \sin \omega t
\end{aligned}
$$

Maximum values, $\overline{\dot{y}}_{n}$ and $\overline{\ddot{y}}_{n}$, occurring when the trigonometric terms are unity, are given by

$$
\begin{aligned}
& \overline{\dot{y}}=\omega_{\mathrm{a}} \overline{\mathrm{y}}_{\mathrm{n}} \\
& \overline{\mathrm{y}}_{\mathrm{n}}=-\omega_{\mathrm{n}}^{2} \overline{\mathrm{y}}_{\mathrm{n}}
\end{aligned}
$$

The maximum kinetic energy, $\mathrm{KE}$, of the $\mathrm{n}$ th mode can be found by summing the products of mass per unit length times maximum velocity squared throughout the beam length. This leads to the following expressions:

$$
\mathrm{KE}=0.5 \int_{0}^{l} \mathrm{~m}_{l} \overline{\mathrm{y}}_{\mathrm{a}}^{2} \mathrm{dx}
$$

where $m_{l}$ is the mass per unit length of the beam. Substituting from Eq. G.24,

$$
\mathrm{KE}=0.5 \omega_{\mathrm{n}}^{2} \int_{0}^{l} \mathrm{~m}_{\ell} \overline{\mathrm{y}}_{\mathrm{n}}^{2} \mathrm{dx}
$$

The maximum inertia force acting on a unit length of the vibrating structure varies linearly with displacement from its maximum value of $-m_{\ell} \overline{\vec{y}}_{l}$ at maximum displacement to zero as the displacement passes through zero. The maximum potential energy per unit length stored in the structure occurs at maximum displacement and is the product of the average inertia force times the maximum displacement, so that the total maximum potential energy stored in the entire structure is

$$
\mathrm{PE}=0.5 \int_{0}^{\ell}\left(-\mathrm{m}_{l} \overline{\mathrm{y}}_{1}\right) \overline{\mathrm{y}}_{1} \mathrm{dx}
$$

Equating kinetic and potential energies from Eqs. G.26 and G.28 and solving for $\omega_{\mathrm{n}}^{2}$ :

$$
\omega_{1}^{2}=\frac{\int_{l,}^{i} q \bar{y}_{1} d x}{\int_{l,}^{x} m_{\ell} \bar{y}_{1}^{2} d x}
$$

where

$$
q=-m_{l} \bar{y}_{1}
$$

It is useful to note that $q$ is numerically equal to the force that would just hold the struc ture in a static displacement, $\bar{y}_{1}$.

Equation G.29 will give an exact solution for the fundamental period only if the inertia load $q$ and the deflection $y_{1}$ based on $q$ have a constant ratio at all points along the structure. However, approximate results can be attained for the first mode by using Rayleigh's method, which utilizes an approximate deflection curve satisfying the boundary conditions, instead of the exact curve.

In one approach utilizing Rayleigh's method, the load $q$ is assumed to be propor tional to $m_{l}$, implying a uniform acceleration $\bar{y}$ of the whole structure, and the resulting deflections are computed. If the acceleration is some fraction, $j$, of gravity, $q$ becomes

$$
q=m_{\ell}(j g)=j w
$$

where $\mathrm{w}$ is the weight per unit length of beam. 
Defining $y$ as the static deflection at any point $x$, due to the lateral load $j w$, and replacing $\bar{y}_{1}$ with $y$, Eq. G.29 becomes

$$
\omega_{1}^{2}=j g \frac{\int_{0}^{l} w y d x}{\int_{0}^{l} w y^{2} d x}
$$

Since

$$
\begin{aligned}
& T_{1}=\frac{2 \pi}{\omega_{1}} \\
& T_{1}=2 \pi\left(\frac{\int_{0}^{l} w y^{2} d x}{j g \int_{0}^{l} w y d x}\right)^{1 / 2}
\end{aligned}
$$

The factor $j$ is often taken as unity, and the resulting deflection curve is that of the structure loaded laterally by its own weight, sometimes called the one-g deflection curve. If it is not convenient to evaluate the integrals, the structure can be divided into segments, and summations can be carried out.

When a structure can be represented by a series of lumped masses, $W_{1}, W_{2}, W_{3}$, without violating the assumptions implied in deriving Eq. G.34, the fundamental period is given by

$$
\mathrm{T}_{1}=2 \pi\left(\frac{\Sigma_{0}^{l} \mathrm{Wy}^{2}}{\mathrm{jg} \Sigma_{0}^{l} \mathrm{Wy}}\right)^{1 / 2}
$$

The $y$ values in Eqs. G.34 and G.35 can include components due to flexure, shear, or deflection and rotation of supports.

An alternative approach, often used in applying Rayleigh's method to flexural vibrations of beams, consists in assuming a shape of the deflection curve and expressing the potential energy in terms of the second derivative of the deflection. This leads to the following expression in lieu of Eq. G.28:

$$
P E=\frac{1}{2} \int^{l} E I\left(\frac{d^{2} y}{d x^{2}}\right) d x
$$

This equation holds for variable as well as constant EI.

The following equation, corresponding to Eq. G.34, results from substituting y for $\bar{y}_{1}$ in Eq. G.27, equating the resulting expression for kinetic energy to the potential energy from Eq. G.36, and expressing $\omega_{1}$ in terms of $T_{1}$ by means of Eq. G.33:

$$
T_{1}=2 \pi\left[\frac{\int_{0}^{l} w y^{2} d x}{j g \int_{0}^{l} E I\left(\frac{d^{2} y}{d x^{2}}\right)^{2} d x}\right]^{1 / 2}
$$

Equations G.34, G.35, and G.37 are only useful for approximating the first mode and are not generally valid.

It is a much more difficult task to derive good approximations for the shapes of the higher modes. However, for many structures the higher modes contribute very little to the stress. If the structure is of the type where the higher modes are significan ${ }^{+}$they must be included in the analysis.

A method of successive approximations attributed to Stodola on page 162 of reference G.2 is convenient for determining the "exact" shape of the first mode and the corresponding period of beam vibration; this method can be greatly expedited by a numerical 
integration technique devised by Newmark. ${ }^{G .3-G .5}$ The Stodola method can also be adapted for finding higher modes by incorporating a "sweeping" or "purifying" process that eliminates the tendency of the lower modes to make the procedure nonconvergent (see references G.2, G.3, G.5, and G.6). Gossard ${ }^{\mathrm{C} .}$ presents a further modification of the Stodola method for finding higher modes. These are all tedious processes.

Various other methods are used for determining higher modes. An adaptation of a method attributed to Holzer and Myklestad, utilizing a single set of repetitive operations, provides a fairly simple solution for multistory "shear" type buildings of moderate height. ${ }^{G .8}$ The procedure can be performed using longhand calculation and can also be applied to flexural members. ${ }^{\text {G.9 }}$

Matrix algebra is another approach often used. This includes the formulation of a set of simultaneous equations involving either deflection due to unit forces (flexibility matrix) or forces due to unit deflections (stiffness matrix). Matrix algebra is then used to solve the denominator determinant of the set of simultaneous equations, which yield the natural frequencies of the system. ${ }^{C .9, G .10}$ The solution is often carried out using electronic computers (see Appendix E).

Minhinnick ${ }^{\mathrm{G.11}}$ presents a critical summary of various methods for finding mode shapes.

\section{G.3 DERIVATION OF FREQUENCY EQUATION FOR A SYSTEM WITH TWO DEGREES OF FREEDOM (Derivation in support of Chap. 5, Sec. 5.3)}

From Fig. 5.7, using the sign convention that positive forces act toward the right, the static horizontal force $H$, at levels $a$ and $b$ required to impose deflections $y_{a}$ and $y_{b}$, is

$$
\begin{aligned}
& H_{a}=k_{a a} y_{a}-\left(-k_{a b} y_{b}\right)=k_{a a} y_{a}+k_{a b} y_{b} \\
& H_{b}=\left(-k_{b a} y_{a}\right)+k_{b b} y_{b}=k_{b a} y_{a}+k_{b b} y_{b}
\end{aligned}
$$

From Newton's second law:

$$
\begin{aligned}
& \mathrm{H}_{\mathrm{a}}+\mathrm{m}_{\mathrm{a}} \ddot{\mathrm{y}}_{2}=0 \\
& \mathrm{H}_{\mathrm{b}}+\mathrm{m}_{\mathrm{b}} \ddot{\mathrm{y}}_{\mathrm{b}}=0
\end{aligned}
$$

After substitution of Eqs. G.38 into Eqs. G.39,

$$
\begin{aligned}
& m_{2} \ddot{y}_{a}+k_{a z} y_{a}+k_{a b} y_{b}=0 \\
& m_{b} \ddot{y}_{b}+k_{b a} y_{a}+k_{b b} y_{b}=0
\end{aligned}
$$

Assuming that the vibration of each mass is a simple harmonic motion with the same given frequency, $\omega$, but with different amplitudes, $A_{2}$ and $A_{b}$ :

$$
\begin{aligned}
& y_{a}=A_{2} \sin \omega t \\
& y_{b}=A_{b} \sin \omega t
\end{aligned}
$$

With Eqs. G.41 and their second derivatives substituted into Eqs. G.40 and the common term sin $\omega$ t divided out:

$$
\begin{aligned}
& \left(k_{2 a}-m_{a} \omega^{2}\right) A_{a}+k_{a b} A_{b}=0 \\
& k_{b 2} A_{a}+\left(k_{b b}-m_{b} \omega^{2}\right) A_{b}=0
\end{aligned}
$$


This set of simultaneous equations has the trivial solution

$$
A_{2}=A_{b}=0
$$

and a nontrivial solution only when the determinant of the coefficients of the A's vanishes. The determinant of the set is

$$
\left(k_{22}-m_{2} \omega^{2}\right)\left(k_{b b}-m_{b} \omega^{2}\right)-k_{a b} k_{b 2}=0
$$

or

$$
\omega^{4}-\omega^{2}\left(\frac{k_{a a}}{m_{2}}+\frac{k_{b b}}{m_{b}}\right)-\frac{k_{a b}}{m_{a}} \frac{k_{b a}}{m_{b}}+\frac{k_{a a}}{m_{a}} \frac{k_{b b}}{m_{b}}=0
$$

It should be noted that Eqs. G. 43 can be derived without considering determinants by solving each of Eqs. $G .42$ for the ratio $A_{2} / A_{b}$, yielding equations identical to Eqs. G.46. Equating these expressions gives Eqs. G.43.

The roots of this characteristic equation (G.43) are the natural vibration frequencies of the system. Solving for $\omega^{2}$,

$$
\omega_{a}^{2}=\frac{1}{2}\left[\frac{k_{a a}}{m_{a}}+\frac{k_{b b}}{m_{b}}=\sqrt{\left(\frac{k_{a a}}{m_{a}}-\frac{k_{b b}}{m_{b}}\right)^{2}-4 \frac{k_{a b}}{m_{2}} \frac{k_{b a}}{m_{b}}}\right]
$$

After the two frequencies are calculated from Eq. G.44, resubstitution of a value of $\omega$ into either of Eqs. G.42 will yield a ratio between the amplitudes $A_{a}$ and $A_{b}$. Only the ratio of the amplitudes is determined in this way; the absolute value is determined by the initial conditions imposed on the vibrating system by the forcing functions. It is also customary to normalize the amplitudes in some manner, the most common practices being (1) to make the largest amplitude have an absolute value of unity or (2) to make one of the amplitudes have a value of unity. The second normalization is used in this particular case. The amplitudes of the mode shapes are denoted by $\phi$ 's instead of A's to indicate that some sort of normalization has been used. Since there is a different mode shape associated with each frequency, the mode shape, $\phi$, requires two subscripts, the iirst indicating the coordinate and the second the associated frequency. For example, $\phi_{\mathrm{b} 2}$ is the amplitude of coordinate $\mathrm{b}$ for the second frequency (second mode). For this two-degree system, the amplitude of the $b$ coordinate is taken as unity for both frequencies, i.e.,

$$
\phi_{\mathrm{b} 1}=\phi_{\mathrm{b} 2}=1
$$

Solving both parts of Eq. G.42,

$$
\begin{aligned}
& \frac{\phi_{a n}}{\phi_{b n}}=\frac{\phi_{a n}}{1}=\frac{-\frac{k_{a b}}{m_{2}}}{\frac{k_{a 2}}{m_{2}}-\omega_{a}^{2}} \\
& \frac{\phi_{a n}}{\phi_{b n}}=\frac{\phi_{a n}}{1}=\frac{-\frac{k_{b b}}{m_{b}}+\omega_{n}^{2}}{\frac{k_{b a}}{m_{a}}}
\end{aligned}
$$

Each of these equations gives the same result, so that one can be used as a numerical check on the other in computations. 


\section{G.4 DERIVATION OF PARTICIPATION FACTOR FOR A SYSTEM WITH TWO DEGREES OF FREEDOM}

The maximum seismic deflection, $\vec{y}_{n}$, of an elastic multidegree-of -freedom system structure at any point, $x$, and for any mode, $n$, is given by Eq. 4.25:

$$
\bar{y}_{n}=K_{n} \phi_{n}(x) \frac{S_{n}}{\omega_{n}}
$$

where the participation factor, $K_{n}$ from Eq. 1.27 is expressed as

$$
\mathrm{K}_{\mathrm{n}}=\frac{\int_{0}^{l} \phi_{\mathbf{n}}(\mathbf{x}) \mathrm{dm}}{\int_{0}^{l} \phi_{\mathrm{n}}^{2}(\mathbf{x}) \mathrm{dm}}
$$

For a structure that can be idealized as a system of lumped masses, $\mathrm{m}_{1}, \mathrm{~m}_{2}, \mathrm{~m}_{3}$, without violating the assumptions implied in Eq. G.48, the participation factor is given by

$$
\mathrm{K}_{\mathrm{n}}=\frac{\Sigma_{0}^{\ell} \mathbf{m} \phi}{\Sigma_{0}^{1} \mathrm{~m} \phi^{2}}
$$

Applying Eq. G.49 to a system with two masses, $m_{a}$ and $m_{b}$, such as that shown in Fig. 5.7, results in the following expression, with the value of $\phi_{b n}$ set equal to unity:

$$
K_{n}=\frac{m_{a} \phi_{a n}+m_{b}}{m_{a} \phi_{2 n}^{2}+m_{b}}
$$

where $\mathrm{n}=1$ for the first mode and $\mathrm{n}=2$ for the second mode.

Using Eq. G.47, the maximum displacements of the two masses become, for each mode, $\mathrm{n}$,

$$
\begin{aligned}
& \bar{y}_{b n}=\frac{K_{n} S_{n}}{\omega_{n}} \\
& \bar{y}_{a n}=\frac{K_{\mathrm{p}} S_{n}}{\omega_{n}} \phi_{2 n}=\bar{y}_{b n} \phi_{a n}
\end{aligned}
$$

\section{REFERENCES}

G.1 G. Temple and W. G. Bickley, Rayleigh's Principle, Dover Publications, Inc., New York.

G.2 J. P. den Hartog, Mechanical Vibrations, 4th ed., McGraw-Hill Book Company, Inc., New York, 1956.

G.3 N. Isada, Design and Analysis of Tall Tapered Reinforced Concrete Chimneys Subjected to Earthquake, Proceedings of the 1956 World Conference on Earthquake Engineering, Earthquake Engineering Research Institute, 1956.

G.4 N. M. Newmark, Numerical Procedure for Computing Moments, Deflections, and Buckling Loads, Trans. Am. Soc. Civil Engrs., page 1161 (1943).

G.5 J. C. Houbolt and R. A. Anderson, Calculation of Uncoupled Modes and Frequencies in Bending or Torsion of Non-Uniform Beams, Natl. Advisory Comm. Aeronaut., Tech. Note No. 1522 (February 1948).

G.6 L. Beskin and R. M. Rosenberg, Higher Modes of Vibrations by a Method of Sweeping, J. Aeronaut. Sci., page 597 (November 1946). 


\section{REF ERENCES}

G.7 M. L. Gossard, An Iterative Transformation Procedure for Numerical Solution of Flutter and Similar Characteristic-Value Problems, Natl. Advisory Comm. Aeronaut., Rept. No. 1073 (1952).

G.8 M. G. Salvadori, Earthquake Stresses in Shear Buildings, a Discussion by J. A. Blume, Trans. Am. Soc. Civil Engrs., 119: 194-201 (1954).

G.9 W. T. Thomson, Mechanical Vibrations, 2nd ed., Prentice-Hall, Inc., Englewood Cliffs, N. J., 1953.

G.10 S. Sutcliffe, Natural Frequencies of Building Frames with Flexzble Girders (M.S. thesis), University of Illino1s, 1958.

G.11 I. T. Minhinnick, The Theoretical Determination of Normal Modes and Frequencies of Vibration, Rept. 36, Advisory Group for Aeronautical Research and Development, North Atlantic Treaty Organization, Palais de Chaillot, Paris 16, France.

\section{ADDITIONAL REFERENCE MATERIAL}

T. V. Karman and M. A. Biot, Mathematical Methods in Engineering, McGraw-Hill Book Company, Inc., New York, 1940.

J. W. S. Rayleigh, The Theory of Sound, Vols. I and II, 2nd ed., Dover Publications, Inc., New York.

S. Timoshenko, Vibration Problems in Engineering, 3rd ed., D. Van Nostrand Company, Inc., Princeton, N. J., 1955. 


\section{Appendix $\mathrm{H}$}

\section{SEISMIC CONSIDERATIONS PERTINENT TO THE ORNL PROPOSED GAS-COOLED REACTOR NO. 2}

\section{H.1 INTRODUCTION}

In this appendix analysis is restricted to the reactor, pressure vessel, and supportsleeve assembly since the preliminary design concept ${ }^{\mathrm{H} .1}$ is not sufficiently detailed beyond these areas to allow comprehensive evaluation of the plant as a whole. However, several comments with respect to the primary coolant loops, control and fuel rods, boron curtain, fuel-handling equipment, and biological shield are presented.

\section{H.2 GRAPHITE CORE}

The response of the graphite pile, pressure vessel, and thermal support sleeve, roughly approximated as a single-mass system, was found to be higher than $0.33 \mathrm{~g}$ when determined with minimal damping. However, when an estimated damping factor of $10 \%$ of critical was applied to account for nonrecoverable energy lost due to relative motions of core components, the response was reduced to about $0.33 \mathrm{~g}$.

\section{A. Restraint by Garter Rings}

Possible engineering approaches to the investigation of garter rings include:

(1) A static solution based on the assumption of sufficient pre-tension in the garter rings to prevent inelastic movement between blocks

(2) A pseudodynamic solution based on the assumption that the garter rungs exhibit no initial tension and that the necessary girdling force is developed by the geometrical changes incidental to inelastic movement between the blocks

(3) A dynamic solution presuming some initial girdling force, with the remainder of the necessary tension developed by movement between the blocks, assuming a constant base acceleration, and with numerical integration performed with due regard to inertia forces and energy considerations

For the pile configuration designated by the ORNL report, ${ }^{\mathrm{H} .1}$ with seven garter hoops, the required area of a single hoop section must be at least $3.72 \mathrm{sq} \mathrm{m}$. as determined by approach (1). This area was based upon a representative yield stress of 38,000 psi for stainless steel, with provision for a safety factor of 1.5. It may further be noted that it will not be possible to completely prevent the inelastic movement between blocks by initial tensioning of the garters since there will be space between blocks due to dimensional tolerances, and the outer tiers will probably bridge somewhat as the rings tighten. 
Using the ring areas calculated by approach (1) and disregarding the proposed auxiliary struts, the deflection at the top of the pile was indicated by method (2) to be of the order of 14 in. for the assumed condition of no initial garter tension. Without such pretension a slightly higher stress would be experienced by the rings, with reduction of the safety factor from 1.5 to about 1.1. This maximum deflection and the incidental stresses will not materialize, however, when the struts and reversal of the ground motion are taken into account. The significance of these members is that garters constitute fully effective restraining devices only when pre-tension can be provided and maintained. Factors complicating the provision of pre-tension in Gas-cooled Reactor No. 2 (GCR-2) include thermal expansion and possible radiation growth. (Although the ORNL report ${ }^{\mathrm{H} .1}$ antici- $^{-}$ pates negligible radiation growth in GCR -2, items such as those briefly described in Sec. H.2.F may have to be considered in other reactor systems.) The ORNL report proposes multitube girdlings to accommodate these factors.

From consideration of the foregoing arguments, restraint of the graphite pile with garter rings wculd appear to be applicable in areas exhibiting minor to moderate seismicity. For these conditions:

(1) Although the graphite pile could be expected to lurch slightly, motion would be limited by the auxiliary struts, and seismic activity would not be sufficient to disrupt the pile.

(2) Moderate seismic activity would not be expected to disrupt load centers or damage well-designed steam or coolant loops, so that no loss of heat sink would be expected. Consequently lurching of the pile would not result in emergency conditions.

\section{B. Restraint by Shear Keys}

Desirable characteristics for restraint by shear keys include:

(1) Keying should be furnished by continuous splines.

(2) Splines should run horizontally at each course level in the interface of each vertical joint.

(3) Spline material should exhibit shearing strengths of, say, five times that of graphite and should be selected with due regard to the nuclear characteristics of the reactor.

Splines so installed and supplemented by pre-tensioned garter rings will lend considerable continuity to the system, although deflections of the splined pile will probably be largely of an inelastic nature. However, with well-fitted splines, these deflections and nonrecoverable displacements are believed to be insignificant. The rigidity of the splined pile will probably be sufficient to prevent large seismic loads upon the garters.

\section{Horizontal Shear Transfer}

The horizontal shear transfer between layers of the GCR - 2 core graphite has been provided by a boss and recess type of key. Shearing loads are not high, and this arrangement appears to be satisfactory.

Provision for the positive transfer of shear from the lower course of block to the base plate through means other than simple friction is desirable. Although the coefficient of static friction between polished steel and graphite blocks is not immediately available, the coefficient for sliding friction, 0.36, may be used as an approximation. When compared with the assumed seismic coefficient of 0.33 . it is seen that the base may slide unless some keying system is employed.

\section{Uplift}

The necessity for uplift restraint mechanisms can be avoided if the pile is proportioned so that the resultant of seismic and dead loadings falls within the kern of the 
base. To satisfy this condition, for a circular base and the assumed seismic coefficient of 0.33 ,

$$
\text { i }<\frac{3}{4} D
$$

where $\mathrm{h}$ is the height of the graphite pile and $\mathrm{D}$ is its diameter. The GCR-2 reactor, with $\mathrm{h}=0.714 \mathrm{D}$, meets this requirement.

\section{E. Miscellaneous}

The bottoms of the lower course of blocks have been indicated as radiused to provide for the differential thermal expansion between the graphite and the steel base plate, which results in the separation of the graphite blocks. Although the radius accommodates this movement, it will also allow some seismic rocking, which would have to be evaluated in view of the continuity and rigidity afforded by the garters and other restraints.

\section{F. Radiation Effects on Graphite (General)}

It has previously been noted that provision was made in the GCR-2 system to accommodate any growth in the overall dimension of the graphite core components which could result frorn continued neutron irradiation and cause displacements of atoms from the crystalline lattice. This displacement and growth is the well-known Wigner effect. The amount of such growth has been found to be small for the graphite and environment of the GCR $-2, \mathrm{H}, 1$ and the appropriate design measures were taken. In general, a migration of displaced atoms continually goes on within the irradiated material. Some of the migration results in atoms moving back to equilibrium sites within the lattice, although these sites may be other than their original location. To a certain extent this return results in a healing of radiation damage, and the healing proceeds concurrently with the accumulation of more displacements and a tendency toward growth. Graphite exhibits an increase in the rate of migration (and consequently in the possibility of healing) at temperatures near $400^{\circ} \mathrm{F}$. Since the GCR-2 pile temperatures may be a minimum of $460^{\circ} \mathrm{F}$, a considerable annealing of radiation damage is to be expected; hence it is felt that graphite growth is a small problem in the GCR-2. In addition, there would exist periodic opportunities to shut down the reactor at the times of refueling and to apply a source of heat to accelerate the healing process without the concurrent accumulation of more damage, so that the significance of dimensional growth could be decreased still further if necessary. Since the trend of gas-cooled reactors is toward higher operating temperatures to achieve improved operating efficiencies, graphite growth is not likely to be a large problem in systems of this type.

It should be noted that growth is not the only phenomenon that can be exhibited by graphite under irradiation. Under some circumstances a considerable shrinkage can occur which might require special design considerations to maintain the structural and functional integrity of a graphite core both under normal operating conditions and under seismic loads. The occurrence, rate, and extent of shrinkage are sensitive functions of the following parameters: the temperature at which irradiation occurs, the types of materials used in manufacturing (which can include both natural graphite crystals and those resulting from different coking processes and several different binder materials), the manufacturing process (which includes mechanical effects such as molding or extruding), the crystal size and degree of alignment imposed by the process, the temperature and duration of furnace-curing the graphite, anisotropic shrinkage rates parallel and perpendicular to the main orientation of the crystals, the history of periodic shutdowns and annealings, the uniformity and spectral distribution of the radiation flux, and the total irradiation dose. 
With so many variables to be considered, it is impossible to generalize upon the magnitude of shrinkage effects which might be seen in specific reactors. Experimental data on many types of reactor graphite are still lacking. As an illustration of the data that are available, for a particular type of graphite being tested at Hanford Laboratories, three overall relations have been noted. These may perhaps exemplify relations broadly applicable to other graphites, although this generality is not assured. First, for temperatures up to $300^{\circ} \mathrm{C}$ growth due to irradiation occurs only over the initial lower levels of total dose; the period of growth is relatively short-lived, and before long the increase in dimensions reverses and shrinkage begins. The shrinkage continues with no limit under increasing irradiation (provided no intervening periods of pure annealing occur), so far as has been noted in the Hanford tests, and the graphite ultimately becomes smaller than its original dimensions. The total final shrinkage is therefore potentially much larger than any growth accumulated. Second, for temperatures above $300^{\circ} \mathrm{C}$ no noticeable period of growth occurs, and shrinkage begins from the earliest exposures. Third, the rate of shrinkage is considerably greater parallel to the main orientation of crystals within the piece than it is in directions perpendicular to the orientation. It should be emphasized, however, that not enough experimental data exist to ensure that these three general trends can be applied to all graphite reactor cores.

If shrinkage is permitted to accumulate unannealed, from the standpoint of seismic design, undesirable gaps, cracks, or other discontinuities could develop within a graphite core structure. Additional structural restraints and supports could therefore become necessary, and the changes in dimension could naturally complicate the problems of providing intimate and continuous support. In addition, if there is any significant spatial nonuniformity to the flux to which the graphite is subjected, nonuniform shrinkages can occur so that there could be generated, within any piece of graphite, differential shrinkages among adjacent fibers; owing to the unavoidable self-imposed internal restraints involved, these shrinkages would produce stresses analogous to those caused by thermal gradients. (Naturally, differential growth could produce similar effects; but, if the period of growth is short, shrinkage would probably predominate.) If not previously annealed, these stresses could be existing at the time of an earthquake and could modify the susceptibility of the graphite parts of the core to earthquake-induced stresses. The presence of the differential shrinkage (if there is a gradient of shrinkage over the cross section of a component) can also induce in such a core component a tendency to bow or twist and therefore to press against its neighbors or against any support devices that might have been included to provide seismic restraint for the core as a whole. Such restraints could also be intended to prevent excessive core deformation (caused by the tendency to bow), which could potentially impair the operating performance of the core (such as by binding control rods in distorted channels). The pressure of the graphite upon such structures would naturally create stresses in the supports, which could modify the susceptibility of the supports to seismic loads should they occur. In turn, the restraint imposed upon the graphite to prevent the tendency to bow would impose stresses upon the graphite (as would restraint of a tendency to dimensional change in any material), in addition to those caused by the internally generated stresses originally due to the differential shrinkage. The susceptibility of the graphite core to seismic loads would therefore be further modified. The possibility of such interdependent stress generations obviously requires careful consideration in seismic analysis whenever the particular temperature and flux characteristics, type of graphite, core geometry, and structural design indicate the existence of significant amounts of unannealed or restrained differential shrinkage.

Two more general characteristics of graphite may be briefly noted here since they can affect the stress and deformation that may be present at any given time and place within the core. At the present time not enough experimental data exist to fully define these characteristics in terms applicable to all graphite. Under some circumstances 
graphite can exhibit a tendency to creep under stress. The amount and rate of creep are functions of temperature, stress level, and type of graphite. In determining the stresses that may exist in either the graphite core or its supports at the time of an earthquake, it may be desirable to consider the self-relief that graphite may have experienced during the entire history of core life as adjacent fibers within graphite components accommodate themselves to stresses generated by differential shrinkage and by the core supports. The duration and rate of such creep and the total amount of elongation that graphite can undergo before a fracture occurs have not yet been fully determined ${ }^{\mathrm{H} .2, \mathrm{H.4}}$ by experiment, and the degree to which creep may be taken into account in stress calculation is at present uncertain. Since creep generally tends to limit the accumulations of stress, it is conservative to neglect its effect; where the stresses that can accumulate during core life are obviously within the structural capabilities of graphite, this course is the obvious and conservative one. On the other hand, where large stresses tend to accumulate as a result of differential shrinkage or other causes, the designer may choose to investigate creep as a factor influencing long-term structural stability and susceptibility to seisms. At any rate, a close investigation of the creep characteristics of the particular grade of graphite involved would be required to permit a fully confident use of creep in structural calculation.

The maximum strain that graphite can withstand (if large amounts of creep are found to be possible for a particular graphite in a particular environment) may be just as significant in structural analysis as the maximum stress accumulated. There appears to be a limit of such creep which graphite can undergo without fracture, more or less independent of the stress level involved. If large amounts of creep cause cracking of the graphite, the efficiency of any structural supports provided to resist seisms may be affected. Since overall flux gradients and shrinkage will vary considerably throughout the core volume, considerable analysis would probably be necessary to define the extent of cracking and the seismic-design measures that must be taken to maintain core stability despite cracking.

Because of the obvious complexity of the graphite shrinkage problem and the cur rent lack of experimental data, no generalized seismic recommendations can be given here. However, as an example of the pertinence of such problems to seismic analysis and reactor designs, one may cite the Experimental Gas-cooled Reactor (EGCR) being constructed at Oak Ridge National Laboratory. In this reactor the graphite core is in the form of large self-supporting columnar elements; positions of the columns are maintained, and distortion is minimized by cruciform keys and grids at the top and bottom of the columns and by circumferential bands around the core exterior. The general stress-and-strain situations just described were present in the design of the EGCR core $\mathrm{H.2}^{\mathrm{H.3}}$ and its restraints. Analyses of the EGCR seismic aspects have been published. ${ }^{H .5}$

\section{H.3 PRESSURE VESSEL AND THERMAL SUPPORT SLEEVE}

As previously mentioned, the response of the graphite pile, pressure vessel, and thermal support-sleeve system was evaluated by use of an approximate single-mass system. Preliminary study of deflections indicated that, considering the relative stiffnesses of these structural elements, over $90 \%$ of the lateral deflection was attributable to the thermal support sleeve. Further, it is estimated that about $60 \%$ of the load contributing to lateral deflection could be attributed to the mass of the graphite pile. By lumping the masses at their common center of gravity and considering the thermal support sleeve to extend to this center of gravity, it was found that this model closely duplicated the deflection characteristics of the prototype. In consideration of the predominant effect of the graphite mass, an estımated damping factor of $10 \%$ appeared to be reasonable. With this damping the response of the single-mass model was deter- 
mined to be about $0.35 \mathrm{~g}$, compared to the assumed seismic coefficient of $0.33 \mathrm{~g}$ used for investigating the reactor.

\section{A. Pressure-vessel Stresses}

Primary loading conditions in the pressure vessel include pressure, dead load, and seismic loadings. Thermal stresses will not be developed since the support sleeve attains the same temperature as the pressure vessel at their junction. Membrane stresses are determined primarily by pressure loadings. Seismic loadings have only small effects upon membrane stresses; a 50\% lateral loading increases the membrane stresses only $9.5 \%$ for a 3 -in. -thick shell. Discontinuity stresses at the support sleeve are somewhat increased by seismic loading; nevertheless, increasing the pressure-vessel plate thickness over the support sleeve adequately provides for such increased stress. It has been determined for this case that a reinforced plate thickness of 1.5 times the typical plate thickness will reduce stresses at the support sleeve to a level comparable with typical membrane conditions. The analysis disclosed no unusual or difficult conditions of stress, and the ORNL pressure vessel appears to be adequate.

\section{B. Support-sleeve Stresses}

An analysis was made for the four principal loading conditions on the sleeve: thermal, pressure, dead load, and seismic. As with the pressure vessel, the thermal support sleeve was found to be a reasonable design concept.

Thermal stresses are largest at the end of the skirt insulation. This area is sufficiently removed from the junction of the support sleeve with the pressure vessel, so that thermal stresses are not additive to pressure-induced stresses and are correctly combined with only those of dead load and seismic. These combinations were found not to govern the design. Pressure-induced stresses, caused by dilation of the vessel, were found to be the largest of the four cases studied. These stresses were determined to be localized in the area of the junction of the support and the vessel and, when combined with those of dead load, were found to govern the skirt design. The combination of these stresses with seismic loads will not govern the design because of the increased allowable stresses generally permitted under transient seismic conditions.

Maximum bearing values on concrete of about 1300 psi were obtained at the base ring plate for the combination of dead load and seismic load. Corresponding maximum anchor-bolt tensile stresses were about $2000 \mathrm{psi}$ through the root of the thread. Thus it would appear that no difficulty will be encountered in supporting and anchoring this vessel configuration to resist seismic loadings.

\section{Support-sleeve Alternates}

Two support configurations were considered as alternates to the thermal skirt: the flexible column and the roller bearing. In addition, the A-frame support exemplified by the Calder Hall Reactor was considered. Of these schemes the thermal skirt was found to be superior in rigidity, in the efficient use of material, and in simplicity of detailing, fabrication, and erection.

Pinned jounts are common to these alternate schemes at the junction of the support and the vessel. It will not generally be possible to place the pin within the surface of the vessel, nor even reasonably close to the surface. Consequently there may be varying eccentricities in the seismic load path, resulting in localized moments and discontinuity stresses in the vessel. Consideration of the flexible column arrangements resulted in an almost solid ring of columns in lieu of the simple skirt, utilizing material in an inefficient manner and requiring more complex design than the skirt. The rollerbearing support (for example, a circular concrete-bearing wall receiving the vessel through a more or less continuous ring of rollers) would require complicated design 
details to provide for the conditions of vessel dilation, thermal expansion, and vertical and lateral loading.

Irrespective of the type of support, the seismic response of the pressure-vessel system will favor the extreme left-hand side of the response spectrum. For this case the more rigid a system can be made, the less will be the seismic response, approaching the ground motion in the limit. Since the thermal sleeve method of support affords greater rigidity than the alternates, the sleeve arrangement is to be preferred for antiseismic design.

\section{System Deflections}

(1) The seismic deflection of a well-constructed, splined, and externally supported graphite pile, although principally of an inelastic nature, is thought to be negligible, and therefore no misalignment of fuel and cooling holes with their serving charge tubes is anticipated.

(2) The static deflection at the top of the pressure vessel (under an assumed $0.33-\mathrm{g}$ seismic load) was calculated to be about 0.25 in. Since the charge tubes will have about a 1 -in. clearance relative to the biological top shield, no problem of charge tube shearing or malfunction is expected.

\section{H.4 PRIMARY SYSTEM: DEFLECTION-INDUCED LEAKAGE}

Preliminary details of the primary system were insufficient to permit a full analysis; however, out-of-phase deflections of the pressure vessel, biological shield, and steam generators will possibly occur. Solution of problems of this nature would require more detailed information on the system.

\section{H.5 FUEL-ELEMENT AND CONTROL-ROD MALFUNCTION}

\section{A. Fuel-element Jamming}

Fuel-element jamming is directly related to the stability of the graphite pile. All the mechanisms by which localized failure or shufting of blocks can occur have not been completely defined; but, as an example, misalignment of vertical slots occasioned by shifting could effectively jam fuel elements. Even nominal relative displacement of upper and lower portions of the horizontal fuel-hanger slots could clamp the hangers. As previously noted, even a well-splined graphite pile should provide adequate shear transfer to the steel base plate (compatible with provision for the differential thermal expansions of steel and graphite) to minimize gross shifting of the core; the splines, of course, would have to maintain the necessary internal stability and relative positions of the core components.

\section{B. Control-rod Malfunction}

Three credible, possible seismic causes may prevent control rods from entering the graphite pile: (1) misalignment of the rod and its channel due to shifting plle; (2) swinging of a free-hanging rod; and (3) the whip-kinking of a partially inserted rod, preventing further entry. The first possibility can be discounted by adequate pile design, as aiready described. The second and third possibilities can be removed by providing rod guides over areas where the rods might be free-hanging or cantilevered at the time of seismic lateral loads.

\section{Control-rod Suspension}

The proposed GCR-2 control-rod suspension is of stainless-steel stranded cable wound on a drum driven by both electric and pneumatic motors. Under seismic loads 
cable fouling on the drum is possible, as are flexing of the cable (which may be rendered more significant because of possible radiation embrittlement of the cable) and intermittent false readings transmitted to the control system whenever cable slack develops during vertical accelerations. Design techniques are available to the engineer for resolution of these problems. For example, if a rotating drum is used, the relatively high inertia may render the system susceptible to cable fouling, but the use of a stationary drum with a rotating feed head and appropriate braking can eliminate this difficulty. Flexural failure of the cable is unlikely and can easily be accounted for by using suitable endurance limits based on any available radiation-damage data.

A slack-cable sensor may not be adequate for control of the rods, and replacing this concept with a more effective monitoring system will, of course, remove this source of concern due to seismic loads.

\section{H.6 BORON CURTAIN}

The ORNL proposed boron-pyrex curtain appears to offer no seismic design problem. In an auxiliary structure of this type, sizes and connecting details would generally be in excess of requirements dictated solely by stress.

\section{H.7 FUEL TRANSFER TO POND}

The fuel transfer to the pond is made in a coffin carried by a railed bogie traveling through a tunnel. The tunnel is not submerged, although final designs might make this provision. The bogie is subject to possible seismic overturning (as evidenced by the overturning of a railroad engine and cars during the 1906 San Francisco earthquake), but adequate design measures can easily be taken to assure satisfactory operation.

\section{H.8 TOP BIOLOGICAL SHELD IN SEISMIC INTEGRITY}

Holes through the central portion of the top biological shield are not significant in determining its integrity as a seismic diaphragm. It is immediately apparent that, should the whole central portion of the shield be removed, the remaining thick, annular diaphragm is still possessed of unusual lateral rigidity and strength.

\section{REFERENCES}

H.1 Oak Ridge National Laboratory, The ORNL Gas-cooled Reactor. Part 1: Summary Report; Parts 2-4: Plant Design, USAEC Report ORNL-2500(Pts. 1-4), April 1958.

H.2 Allis-Chalmers Manufacturing Company, Analysis of Graphite Core Structure for Experimental Gas-cooled Reactors, Study No. II-227, Nov. 15, 1960.

H.3 S. E. Moore and W. A. Shaw, EGCR Core Structural Analysis. The Effects of Fastneutron Irradiation and Bowing Characteristics of the Graphite Columns, USAEC Report CF-61-3-69, Oak Ridge National Laboratory, April 1961.

H.4 Oak Ridge National Laboratory, Gas-cooled Reactor Project, Quarterly Progress Report for Period Ending March 31, 1961, USAEC Report ORNL-3102, pp.116-124, May 1961.

H.5 F. J. Witt, D. R. Carver, and R. L. Maxwell, Effects of Seismic Vibrations on the Experimental Gas-cooled Reactor, USAEC Report ORNL-3224, Oak Ridge National Laboratory, June 22, 1962. 


\section{INDEX}

\section{A}

Acceleration, 1.1C, 1.1F

spectrum, $1.3 \mathrm{C}$

vertical, $1.3,4.11 \mathrm{~A}, 8.3 \mathrm{~A}$

Accelerogram, 1.1C

Accident, maximum credible, 7.1

Aftershock, 1.1

Alpide Belt, 2.2A, 2.3B

Allowable stresses, $4.6 \mathrm{C}$

Analysis, dynamic, 1.3, 5.1, Appendixes E, F

Aqueous Homogeneous Reactor, 3.2F, 3.4G, 8.2B

Arctic Belt, 2.2A

Arcuate structure, 1.1A, 2.2B

Army Package Power Reactor

See Stationary Medium Power Plant No. 1 Arvin-Tehachapi (Calif.) earthquake, 1.1C, 1.3C, Appendix C

Aseismic structures, cost, 4.2

Asiatic arcs, $2.2 \mathrm{~A}$

Atlantic ridge, $2.2 \mathrm{~A}$
Chamber, fission, 8.4 ionization, 8.4

pulse, 8.4

Charleston (S. C.) earthquake, 1.2B, 2.3G

Chemical explosion, 7.3C, 7.tD

Chemical fire, $7.3,7.3 B$

Chimney, 5.6A, 5.8E

Circum-Pacific Belt, 1.2A, 2.2B, 2.3A

Coefficient, influence, appendix $E$ reactivity, $8.2 \mathrm{~A}$ seismic, $4.6 \mathrm{~A}, 4.12 \mathrm{~A}$

Component spectrum, 1.3C, 5.2B

Concrete, reinforced, 4.10B, 4.11H

Concrete shield, 5.8D

Construction, precast concrete, $4.10 \mathrm{~B}$ tilt-up, 4.10B

Construction joints, $4.10 \mathrm{~B}$

Containers, fluid, 6.1 , Appendix $F$

Containment vessel, 5.3A, 5.3C, 7.3D

Coolant, fire, $7.3 \mathrm{C}, 7.4 \mathrm{D}$

Cooling, natural-convection, $7.2 \mathrm{C}$ emergency, $3.2 \mathrm{~A}, 7.2 \mathrm{C}, 7.6$

Corrective code revision, $4.10 \mathrm{~B}$

Cost, aseismic structures, 4.2

Couplings, flexible, 4.8B seismic, 1.3, 3.3E

Cross section, neutron, $8.2 \mathrm{~A}$

Crumple joints, 4.10D

Beams, horizontal, 4.6D

Blast shield, 3.2F, 7.3B, 7.3D

Boiling-water Reactor, 3.2B, 7.4C, Appendix B

Bracing, rod, 4.6D, 4.10A, 5.7B, 5.7G

Breeder Reactor, 3.2E, 3.4F, 7.4D

Building, separation, $4.4 \mathrm{H}, 4.8 \mathrm{~A}, 4.10 \mathrm{D}$

setback, 4.11D

vibration, 1.3E, $1.3 \mathrm{H}$

Building codes, $4.3,4.11$

seismic, 4.2, 4.11A

Buildings, Multistory, $4.3,4.6,4.10 \mathrm{~B}$

symmetry of, $4.4 \mathrm{G}, 5.2 \mathrm{D}$

\section{C}

Center of mass, $4.6 \mathrm{D}, 8.3 \mathrm{E}$

Center of rigidity, $4.6 \mathrm{D}$
Damage, fuel element, 7.2C, 7.3A primary loop, 3.3A, 7.3B seismic, 3.3, 4.2, 7.7, Appendixes $C, D$ Damping, 1.3B, 4.9B, 5.2C

Design, limit-stress, 1.3G, 5.7C static method of, 4.6

Diaphragm, $4.6 \mathrm{D}, 4.11 \mathrm{H}$

Differential motion, $3.3 \mathrm{E}, 4.8$

Differential settlement, $4.7 \mathrm{~B}, 7.6$

Dip, fault, $1.1 \mathrm{~A}$

Displacement spectrum, $1.3 \mathrm{C}$

Doppler effect, $8.2 \mathrm{~A}$

Ductility, 4.4C, 5.7B, 6.7

Dynamic analysis, $1.3,5.1$, Appendixes $E, F$ Dynamic forces, 1.3, 6.1, Appendixes $E, F$ 
Earth, crust, 1.1, 2.2B

mantle, 1.1

Earthquake, Arvin-Tehachapi (Calif.), 1.1C, 1.3C, Appendix C

Charleston (S. C.), 1.2B, 2.3G

classification, $1.2 \mathrm{~B}, 2.3$

depth of shock, 1.1, 1.2A

design loads, 4.11D

distribution, 1.1, 2.2

El Centro (Calif.), 1.1A, 1.3D, 4.12B

energy release, 1.1E, 2.2, 2.3A

epicenter, 1.1A

experience, Appendixes C, D

fault, 1.1A, $2.2 \mathrm{~A}$

focus, 1.1A

frequency, $1.1,1.2 \mathrm{E}, 2.3 \mathrm{~A}$

geography, 1.2A, 2.1

instrumentation, 1.1C, 7.7B, 8.4-8.7

insurance, $2.4 \mathrm{~A}, 4.2$

intensity, 1.1D, 2.3A, 7.5

Long Beach (Callf.), 1.1A, Appendix C

magnitude, 1.1E, 2.3A, 7.5

New Madrid (Mo.), 1.2A, 2.3G

probability, 1.2E

spectrum, 1.3C, 5.1

valves, $8.6 \mathrm{H}$

zoning, 1.2A, 2.4A, 4.12B

Elastic rebound, 1.1

El Centro (Calif.) earthquake, 1.1A, 1.3D, 4.12B

Elevated tanks, 1.3G, 6.6

Embrittlement, radiation, $7.2 \mathrm{D}$

Emergency cooling, 3.2A, 7.2C, 7.6

Emergency power, $3.2,7.2 \mathrm{C}, 7.2 \mathrm{D}$

Emergency shutdown, 3.1, 8.2B, 8.6

Emergency spray system, 3.2A, 7.3B

Energy absorption, structures, 5.7A

Energy, chemical, 7.3C

earthquake, release of, 1.1E, 2.2, 2.3A

stored, 3.3C, 7.3B

vibrational, 1.3E, $5.7 \mathrm{~A}$

Epicenter, 1.1A, 7.5

Exhaust stacks, 5.6A, 5.8E

Experimental Boiling-water Reactor, 3.2, 7.4C, Appendix B

Experimental Breeder Reactor, 3.2D, 3.4F, 7.4D

Explosion, chemical, 7.3C, 7.4D

hydrogen, 7.3

nuclear, $7.3 \mathrm{~A}$

steam, $7.3,7.3 \mathrm{~A}$

$\mathbf{F}$

Fast Reactor, $3.2 \mathrm{D}, 7.3 \mathrm{~A}, 7.4 \mathrm{D}, 8.2 \mathrm{~B}$

Fault, 1.1A, 2.2A

San Andreas, $1.1,1.2,2.5 \mathrm{C}$

Fault dip, 1.1A

Fault trace, $1.1 \mathrm{~A}$

Fault strike, 1.1A

Fire, chemical, $7.3,7.3 \mathrm{~B}$

coolant, 7.3C, 7.4D

Fire hazard, 7.4C, 7.4D, 7.7A

Fission chamber, 8.4

Fission process, $7.3 \mathrm{~A}$

Fission product, $3.2,7.1 \mathrm{~A}$

Flexible couplings, 4.8B

Floors, 4.6D

Fluid containers, 6.1, Appendix F

Fluid oscillation, 6.1, Appendix $\mathrm{F}$

Focus, earthquake, $1.1 \mathrm{~A}$

Forces, dynamic, 1.3, 6.1, Appendixes E, F lateral, 1.3, 4.6A, 4.11B

Foundations, 1.3I, 3.3E, 4.4E, 4.7, 4.10C, 7.6

Fragmentation, 7.3A, 7.3D

Frangible joints, $4.10 \mathrm{D}$

Fuel-element damage, 7.2 C, 7.3A

Fuel-element melting, 7.2C, 7.3A

Function, random, 1.3C, 5.1

\section{$\mathbf{G}$}

Gas-cooled Reactor, 3.2, 3.2D, 3.4E, 8.3D, Appendix $\mathrm{H}$

Geology, influence of local, 1.1, 1.1G, 1.3I, $2.4 \mathrm{~B}, 7.6$

Glass breakage, $4.10 \mathrm{E}$

Graphite, 3.2, 3.2D, Appendix $\mathrm{H}$

Graphite keying, 3.3E, Appendix $H$

Graphite moderator, 3.2D, 3.3, Appendix $\mathrm{H}$

Gravity, 1.1, 8.3A, 2.3B

Ground failure, $2.4 \mathrm{~B}$

H

Hazard, fire, 7.4C, 7.4D, 7.7A

Hazards summary report, 7.6

Hollywood Storage Company building, 1.3C

Homogeneous Reactor, 3.2, 3.2F, 3.4G, 8.2B

Horizontal beams, 4.6D

Hydrogen explosion, 7.3

I

Indian Ocean Belt, $2.2 \mathrm{~A}$

Influence coefficient, Appendix $\mathrm{E}$

Influence of local geology, 1.1, 1.1G, 1.3I, $2.4 \mathrm{~B}, 7.6$

Influence matrix, Appendixes E, G.2

Instrument thimbles, 8.4D

Instrumentation, reactor earthquake, 1.1C, $7.7 \mathrm{~B}, 8.4-8.7$

seismic, 8.5 
Insurance, earthquake, $2.4 \mathrm{~A}, 4.2$

Intensity of earthquake, 1.1D, 2.3A, 7.5

Intensity scale, Modifled-Mercalli, 1.1D

Rossi-Forel, 1.1D

Intensity spectrum, 1.3D, 5.2

Ionization chamber, 8.4

Isoseismal, $1.1 \mathrm{~F}, 7.5$

Isostasy, 1.1

\section{J}

Joints, construction, $4.10 \mathrm{~B}$

crumple, 4.10D

frangible, 4.10D

separation, 4.8A

threaded, $4.10 \mathrm{~A}$

\section{K}

Kamchatka Peninsula, 1.1B, 2.3A

Kurile Islands, $2.3 \mathrm{~A}$

\section{$\mathbf{L}$}

Lateral forces, $1.3,4.6 \mathrm{~A}, 4.11 \mathrm{~B}$

Limit-stress design, 1.3G, 5.7C

Loads, live, $4.11 \mathrm{~B}, 4.11 \mathrm{D}$

tributary, $4.6 \mathrm{D}$

wind, 4.5A, 4.11B

Long Beach (Calif.) earthquake, 1.1A, Appendix $\mathrm{C}$

Love waves, $1.1 \mathrm{C}$

\section{M}

Magnitude, earthquake, 1.1E, 2.3A, 7.5

Mantle, 1.1

Map, seismic, $1.2 \mathrm{~A}, 2.5,7.5$

Mass, center of, $4.6 \mathrm{D}, 8.3 \mathrm{E}$

Mass matrix, Appendix E

Masses, stable, 2.3F

Material properties, 4.9A

Matrix, influence, Appendixes E, G.2

Maximum credible accident, 7.1

Mediterranean-Transasiatic Circle, 1.2A, 2.2A

Melting of fuel elements, 7.2 C, 7.3A

Metal-water reaction, $7.3,7.4 \mathrm{C}$

Missile penetration, 7.3A, 7.3D

Mode, shape, 1.3B, 5.5A, Appendix E

vibration, 1.3B, 5.5A, Appendix $E$

Model, structural, 1.3, 5.1

Moderator, graphite, 3.2D, 3.3, Appendix $\mathrm{H}$

organic, $7.4,7.4 \mathrm{E}$

Modified-Mercalli intensity scale, 1.1D
Moment, overtuning, $4.11 \mathrm{E}$

Motion, differential, 3.3E, 4.8

Multidegree of freedom, 1.3B, 5.5, Appendix E

Multistory buildings, 4.3, 4.6, 4.10B

\section{$\mathbf{N}$}

Natural-convection cooling, $7.2 \mathrm{C}$

Neutron cross section, $8.2 \mathrm{~A}$

Neutron lifetime, 7.3A

New Madrid (Mo.) earthquake, 1.2A, 2.3G

Nuclear explosion, 7.3A

Oak Ridge Gas-cooled Reactor (GCR-2), 3.2D, $3.4 E$, Appendix $\mathrm{H}$

Organic-moderated Reactor, 7.4, 7.4E

Overstress of soil, 1.1G, 1.3,4.6C, 4.7 A, $4.10 \mathrm{~B}, 4.11 \mathrm{~B}$

Overtuning moment, $4.11 \mathrm{E}$

\section{$p$}

Pamir-Bakkal Belt, 2.2A

Pendulum starter, 1.1C, 8.5, 3.5B, 8.6

Period of vibration, 1.3B, 5.5A, 7.2C, 7.3D, Appendix $\mathrm{E}$

Pile oscillator, $3.3 \mathrm{C}$

Piping, Appendix $A$

Plastic strain, 1.3G, 5.7, 5.7C

Poison, reactor, $3.2,8.2 \mathrm{~B}$

Power, emergency, 3.2, 7.2C, 7.2D

Precast concrete construction, $4.10 \mathrm{~B}$

Pressure-vessel support, 3.2A, 3.2D, Appendix $\mathrm{H}$

Pressurized-water Reactor, 3.2A, 7.tC, Appendix A

Primary loop damage, 3.3A, 7.3B

Production reactor, $8.6 \mathrm{~F}, 8.6 \mathrm{G}$, Appendix D

Programmed shutdown, 7.7B, 8.7

Properties of materials, $4.9 \mathrm{~A}$

Pulse chamber, 8.4

\section{R}

Radiation embrittlement, $7.2 \mathrm{D}$

Random function, $1.3 \mathrm{C}, 5.1$

Rayleigh waves, $1.1 \mathrm{C}$

Reaction, metal-water, $7.3,7.4 \mathrm{C}$

Reactivity, 7.3A, 8.2A coefficient, $8.2 \mathrm{~A}$

Reactor, boiling water, $3.2 \mathrm{~B}, 7.4 \mathrm{C}$, Appendix $\mathrm{B}$ control, 7.3A, 8.2 
control rod, $3.2,8.2 \mathrm{~B}$

earthquake experience, Appendixes C, D Experimental Boiling Water, 3.2, 7.4C, Appendix B

Experimental Breeder, 3.2D, 3.4F, 7.4D

fast, 3.2D, 7.3A, 7.4D, 8.2B

gas cooled, 3.2, 3.2D, 3.4E, 8.3D, Appendix $\mathrm{H}$

homogeneous, $3.2,3.2 \mathrm{~F}, 3.4 \mathrm{G}, 8.2 \mathrm{~B}$

organic moderated, $7.4,7.4 \mathrm{E}$

period, $8.2 \mathrm{~B}$

poison, $3.2,8.2 \mathrm{~B}$

pressurized water, 3.2A, 7.4C, Appendix A

production, $8.6 \mathrm{~F}, 8.6 \mathrm{G}$, Appendix D

research, $3.2,7.2 \mathrm{D}$

shield, 3.2F, 5.8D, 7.3B

siting, 7.1B, 7.6, Appendix $A$

sodium cooled, 3.2C, 3.4D, 7.4D

Stationary Medium Power Plant No. 1 (SM-1), $3.2 \mathrm{~A}, 3.4 \mathrm{~A}, 7.3 \mathrm{~B}, 7.4 \mathrm{C}, 8.2 \mathrm{~B}, 8.3 \mathrm{~A}$, Appendix $A$

structures, 3.2, 4.12, Appendixes A, B

Reflector control, 8.2B

Reinforced concrete, 4.10B, 4.11H

Release of energy, 1.1E, 2.2, 2.3A

Response, structural, 1.3, 4.6, 5.1, Appendixes E, F

Resultant spectrum, 1.3C, 5.2B

Rod bracing, 4.6D, 4.10A, 5.7B, 5.7G

Rift zone, 2.2A, 2.3E, 5.7B

St. Lawrence, $2.2 \mathrm{~A}$

Rigidity, $1.3,4.9 \mathrm{C}, 5.3$

center of, $4.6 \mathrm{D}$

Rossi-Forel intensity scale, 1.1D

\section{5}

San Andreas fault, 1.1, 1.2, 2.5C

Scales, earthquake measurement, 1.1D

Modified-Mercalli, 1.1D

Rossi-Forel, 1.1D

Seismic, building code, 4.2, 4.11A

coefficient, $4.6 \mathrm{~A}, 4.12 \mathrm{~A}$

coupling, 1.3, 3.3E

damage, 3.3, 4.2, 7.7, Appendixes $C, D$

instrumentation, 8.5

map, 1.2A, 2.5, 7.5

probability, 1.2D, 1.2E

regionalization, $1.2 \mathrm{D}, 2.4$

resistance, 4.4

safety factor, $4.11,7.6$

switches, 1.1C, 7.5, 8.5, 8.6

working stresses, $4.11 \mathrm{~B}$

waves, $1.1 \mathrm{C}$

zoning, 1.2A, 2.4A, 4.12B

Seismic belts, alpide, 2.2A, 2.3B

Arctic, $2.2 \mathrm{~A}$

Circum-Pacific, $1.2 \mathrm{~A}, 2.2 \mathrm{~B}, 2.3 \mathrm{~A}$

Indian Ocean, $2.2 \mathrm{~A}$

Pamir-Baikal, 2.2A
Seismicity, 1.2, 2.4

Seismometer, 1.1C, 8.5

Separation, structural, 4.4H, 4.8A, 4.10D

Separation joints, 4.8A

Settlement, differential, 4.7B, 7.6

soil, 2.4B, 4.6C, 4.10B, 4.11H

Shear walls, $4.6 \mathrm{C}, 4.10 \mathrm{~B}, 4.11 \mathrm{H}$

Shield, blast, $3.2 \mathrm{~F}, 7.3 \mathrm{~B}, 7.3 \mathrm{D}$

reactor, $3.2 \mathrm{~F}, 5.8 \mathrm{D}, 7.3 \mathrm{~B}$

temporary reactor, $3.3 \mathrm{E}$

Shock switches, 8.5, 8.6

Shutdown, programmed, 7.7B, 8.7

Siting, reactor, 7.1B, 7.6, Appendix A

Sloshing in tanks, $6.2,6.4$

SM-1 reactor See Stationary Medium Power Plant No. 1

Soil, failure, 1.3, 2.4B, 4.11B

overstress, $1.1 \mathrm{G}, 1.3,4.6 \mathrm{C}, 4.7 \mathrm{~A}, 4.10 \mathrm{~B}$, $4.11 \mathrm{~B}$

settlement, 2.4B, 4.6C, 4.10B, 4.11H

stabilization, 4.7B

Spectrum, acceleration, $1.3 \mathrm{C}$

component, $1.3 \mathrm{C}, 5.2 \mathrm{~B}$

displacement, 1.3C

earthquake, 1.3C, 5.1

intensity, 1.3D, 5.2

resultant, 1.3C, 5.2B

velocity, $1.3 \mathrm{C}$

Stable masses, $2.3 \mathrm{~F}$

Stacks, exhaust, $5.6 \mathrm{~A}, 5.8 \mathrm{E}$

Starter pendulum, 1.1C, 8.5, 8.5B, 8.6

Static method of design, 4.6

Stationary Medium Power Plant No. 1 (SM-1), $3.2 \mathrm{~A}, 3.4 \mathrm{~A}, 7.3 \mathrm{~B}, 7.4 \mathrm{C}, 8.2 \mathrm{~B}, 8.3 \mathrm{~A}$, Appendix A

Statistical limitations, 1.2E, 2.4B

Steam explosion, 7.3, 7.3A

Strain, plastic, 1.3G, 5.7, 5.7 C

Stress, limit design, 1.3G, 5.7C

Stress reversal, 4.10, 5.7

Strike, fault, 1.1A

Structural model, 1.3, 5.1

Structural response, 1.3, 4.6, 5.1, Appendixes E, F

Structural separation, 4.4H, 4.8A, 4.10D

Structural symmetry, 4.4G, 5.2D

Structures, arcuate, 1.1A, 2.2B

asersmic, cost, 4.2

energy absorption, $5.7 \mathrm{~A}$

Supercriticality, $7.3 \mathrm{~A}$

Support, pressure vessel, $3.2 \mathrm{~A}, 3.2 \mathrm{D}$, Appendix $\mathrm{H}$

Switches, seismic, 1.1C, 7.5, 8.5, 8.6

shock, 8.5, 8.6

Symmetry of buildings, $4.4 \mathrm{G}, 5.2 \mathrm{D}$

\section{$\mathrm{T}$}

Tanks, elevated, 1.3G, 6.6 sloshing in, $6.2,6.4$ 
Tectonics, 1.1,2.2A

Temporary reactor shield, $3.3 E$

Thimbles, instrument, $8.4 \mathrm{D}$

Threaded joints, $4.10 \mathrm{~A}$

Tidal waves, $.1: 1 \mathrm{~B}$

Tilt-up construction, $4.10 \mathrm{~B}$

Trace, fault, 1.1A

Transasiatic Circle, 1.2A, 2.2A

Tributary loads, 4.6D

Trusses, 4.6D

Tsunami, 1.1B

\section{V}

Valves, earthquake, $8.6 \mathrm{H}$

Velocity, earth waves, $1.1 \mathrm{C}$

Velocity spectrum, $1.3 \mathrm{C}$

Vertical acceleration, $1.3,4.11 \mathrm{~A}, 8.3 \mathrm{~A}$

Vessel, containment, 5.3A, 5.8C, 7.3D

Vessel pressure, 3.2A, 3.3E, 5.3, 7.3A

Vibration, building, 1.3E, $1.3 \mathrm{H}$

mode, 1.3B, 5.5A, Appendix $E$

period, 1.3B, 5.5A, 7.2C, 7.3D, Appendix E
Vibrational energy, 1.3E, 5.7A

Void coefficient, $3.3 \mathrm{~B}, 8.2 \mathrm{~A}$

\section{W}

Walls, shear, $4.6 \mathrm{C}, 4.10 \mathrm{~B}, 4.11 \mathrm{H}$

Water-metal reactions, $7.3,7.4 \mathrm{C}$

Water tower, 1.3G, 6.6

Wave velocity, $1.1 \mathrm{C}$

Waves, Love, 1.1C

Rayleigh, $1.1 \mathrm{C}$

selsmic, $1.1 \mathrm{C}$

tidal, 1.1B

Wind loads, 4.5A, 4.11B

Working stresses, seismic, 4.11B

\section{$\mathbf{Z}$}

Zone, rift, 2.2A, 2.3E, 5.7B

Zoning, se1smic, $1.2 \mathrm{~A}, 2.4 \mathrm{~A}, 4.12 \mathrm{~B}$ 